
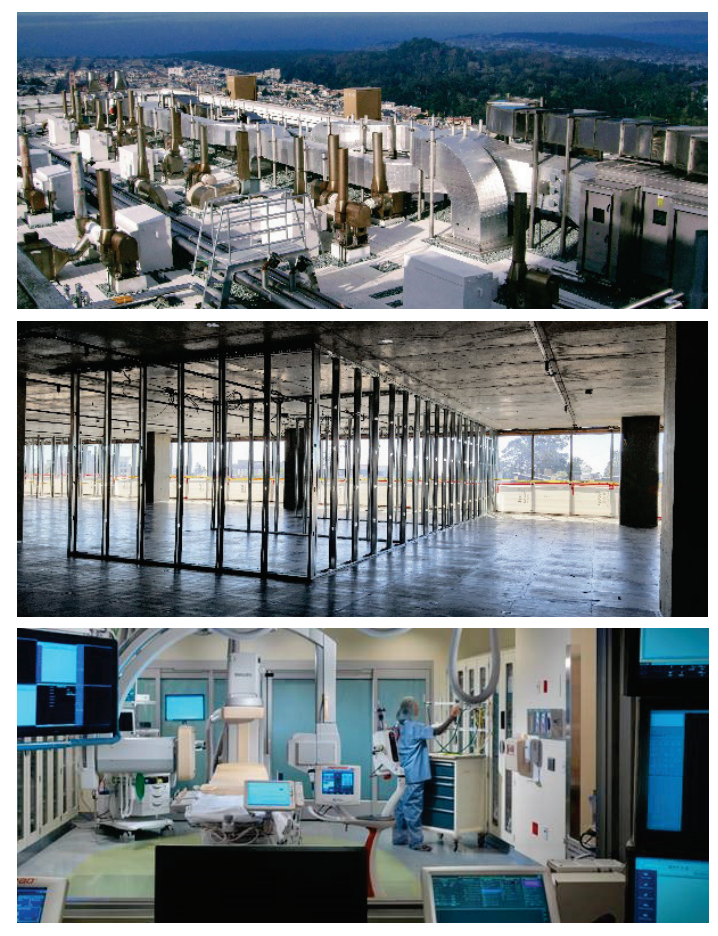

\section{Recommendations} for Improved Seismic Performance of Nonstructural Components

Applied Technology Council

This publication is available free of charge from: https://doi.org/10.6028/NIST.GCR.18-917-43

September 2018

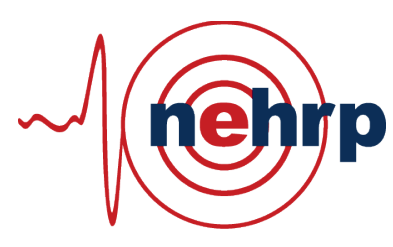

National Institute of Standards and Technology U.S. Department of Commerce 


\section{Disclaimer}

This report was prepared for the Engineering Laboratory of the National Institute of Standards and Technology (NIST) under Contract SB1341-13-CQ-0009, Task Order 14-491. The contents of this publication do not necessarily reflect the views and policies of NIST or the U.S. Government.

This report was produced by the Applied Technology Council (ATC). While endeavoring to provide practical and accurate information, the Applied Technology Council, the authors, and the reviewers assume no liability for, nor express or imply any warranty with regard to, the information contained herein. Users of information contained in this report assume all liability arising from such use.

Unless otherwise noted, photos, figures, and data presented in this report have been developed or provided by ATC staff or consultants engaged under contract to provide information as works for hire. Any similarity with other published information is coincidental. Photos and figures cited from outside sources have been reproduced in this report with permission. Any other use requires additional permission from the copyright holders.

Certain commercial software, equipment, instruments, or materials may have been used in the preparation of information contributing to this report. Identification in this report is not intended to imply recommendation or endorsement by NIST, nor is it intended to imply that such software, equipment, instruments, or materials are necessarily the best available for the purpose.

NIST policy is to use the International System of Units (metric units) in all its publications. In this report, however, information is presented in U.S. Customary Units (inch-pound), as this is the preferred system of units in the U.S. engineering industry. 
NIST GCR 18-917-43

\title{
Recommendations for Improved Seismic Performance of Nonstructural Components
}

\author{
Prepared for \\ U.S. Department of Commerce \\ Engineering Laboratory \\ National Institute of Standards and Technology \\ Gaithersburg, MD 20899-8600 \\ Applied Technology Council \\ 201 Redwood Shores Parkway, Suite 240 \\ Redwood City, CA 94065
}

This publication is available free of charge from: https://doi.org/10.6028/NIST.GCR.18-917-43

September 2018

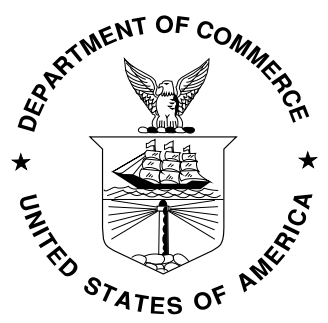

U.S. Department of Commerce Wilbur L. Ross, Jr., Secretary

National Institute of Standards and Technology Walter G. Copan, NIST Director and Under Secretary of Commerce for Standards and Technology 


\title{
Participants
}

\author{
National Institute of Standards and Technology \\ Steven L. McCabe, Research Structural Engineer and Earthquake Engineering Group Leader \\ Matthew Hoehler, Research Structural Engineer, Fire Research Division \\ Engineering Laboratory \\ www.NEHRP.gov
}

\section{Applied Technology Council}

201 Redwood Shores Parkway, Suite 240

Redwood City, California 94065

www.ATCouncil.org

\section{Program Management}

Jon A. Heintz (Program Manager)

Ayse Hortacsu (Associate Program Manager)

\section{Project Technical Committee}

Maryann Phipps (Project Director)

John Gillengerten

William T. Holmes

Bret Lizundia

Ricardo Medina

Eduardo Miranda

Robert Pekelnicky

\section{Working Group Members}

Hamidreza Anajafi

Dago de la Rosa

Athanasia Kazantzi

David Lam

Megan Leon

Matthew Namy

Dimitrios Vamvatsikos

\section{Program Committee on Seismic} Engineering

Jon A. Heintz (Chair)

Michael Cochran

James R. Harris

James Jirsa

Roberto Leon

Stephen Mahin

James O. Malley

Donald Scott

Andrew Whittaker

\section{Project Review Panel}

Robert Bachman (Chair)

Andre Filiatrault

James R. Harris

Michael Mahoney (ex officio)

Shannon Rose

Jeff Soulages

William Staehlin (ATC Board Contact)

Chris Tokas 
In 2014, the Applied Technology Council (ATC) commenced a task order project (ATC-120) under National Institute of Standards and Technology (NIST) Contract SB1341-13-CQ-0009 to improve the seismic design of nonstructural systems and components in the areas that will have the largest impact to public safety and economic welfare, with an emphasis on construction regulated by building codes. This project was conceived in direct response to recommendations provided in the NIST GCR 13-917-23, Development of NIST Measurement Science R\&D Roadmap: Earthquake Risk Reduction in Buildings, (NIST, 2013). In particular, NIST GCR 13-917-23 identified nonstructural issues as a top priority, calling for problemfocused studies in critical areas related to nonstructural design criteria. In the first phase of the ATC-120 project, a year-long study was undertaken to collect and summarize the body of available knowledge related to nonstructural components that could serve as the foundation for future investigations. The study drew from documented earthquake observations, past code development efforts related to nonstructural requirements, analytical research, and nonstructural component and system testing. This work also included a practitioners' workshop to identify the most pressing needs of the profession. This background information was used to identify and prioritize research needed to improve technical aspects of nonstructural system design. The findings and recommendations of this study are summarized in NIST GCR 17-917-44, Seismic Analysis, Design, and Installation of Nonstructural Components - Background and Recommendations for Future Work, (NIST, 2017).

The goal of this second phase of work is to improve technical aspects of nonstructural system design in the areas that will have the largest impact for public safety and economic welfare. This report summarizes the body of knowledge gathered and developed to advance the understanding of the response of nonstructural components to earthquakes. The report also makes recommendations for changes to building codes and practice.

ATC is indebted to the leadership of Maryann Phipps, who served as Project Technical Director, and to the members of the Project Technical Committee consisting of John Gillengerten, Bill Holmes, Bret Lizundia, Ricardo Medina, Eduardo Miranda, and Bob Pekelnicky, for their contributions in developing this report and the resulting recommendations. They were assisted by Working Group members including Hamidreza Anajafi, Dago De La Rosa, Nancy Kazantzi, David 
Lam, Megan Leon, Matthew Namy, and Dimitrios Vamvatsikos. The Project Review Panel, consisting of Bob Bachman (chair), Andre Filiatrault, Jim Harris, Mike Mahoney (ex officio member), Shannon Rose, Jeff Soulages, Bill Staehlin (ATC Board Contact), and Chris Tokas provided technical review and comment at key developmental stages of the project. The names and affiliations of those who contributed to this report are provided in the list of Project Participants at the end of this report. In addition, Tali Feinstein, Steve Mahin, Marlou Rodriguez, John Silva, and Jim Tauby provided valuable input.

The Applied Technology Council also gratefully acknowledges Steven L. McCabe (NIST Program Manager and Contracting Officer's Representative) and Matthew Hoehler (NIST Project Manager and Technical Point of Contact) for their input and guidance in the preparation of this report, Scott Schiff for project management support, and Carrie Perna for ATC report production services.

Jon A. Heintz

Program Manager
Ayse Hortacsu

Associate Program Manager 


\section{Table of Contents}

Preface

List of Figures...................................................................................................... xiii

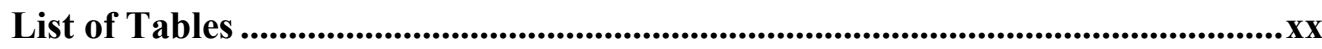

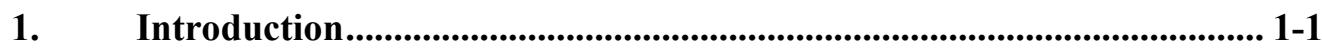

$1.1 \quad$ Project Background and Purpose ................................................. 1-1

$1.2 \quad$ Intended Audience .................................................................. 1-2

1.3 Holistic Approach to Understanding the Response of

Nonstructural Components to Earthquakes.................................. 1-2

$1.4 \quad$ Report Organization.................................................................. 1-5

2. Performance Objectives for Nonstructural Components....................... 2-1

$2.1 \quad$ Introduction.................................................................. 2-1

$2.2 \quad$ Background ........................................................................... 2-2

2.3 Development of Nonstructural Performance Objectives for

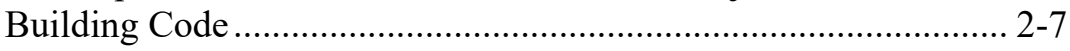

2.3.1 General................................................................. 2-7

2.3.2 Philosophy for Nonstructural Performance Objectives .... 2-9

2.4 Recommended Framework for Nonstructural Performance

Objectives ................................................................................ 2-14

2.4.1 Hazard Definition ....................................................... 2-14

2.4.2 Risks Associated with Nonstructural Damage................. 2-15

2.4.3 Nonstructural Performance Descriptions........................ 2-18

2.4.4 Recommended Performance Objectives for

Nonstructural Components ........................................... 2-18

2.5 Enhanced Nonstructural Performance Objectives ....................... 2-22

2.5.1 Strategies for Enhanced Performance............................. 2-23

2.5.2 Beyond Design...................................................... 2-28

2.5.3 Objectives for Community Resilience ............................ 2-29

2.5.4 Shelter-In-Place Objectives ........................................... 2-29

2.5.5 Damage Control Objectives.......................................... 2-30

3. Review of ASCE/SEI 7-16 Seismic Requirements for Nonstructural

Components .......................................................................................................... 3-1

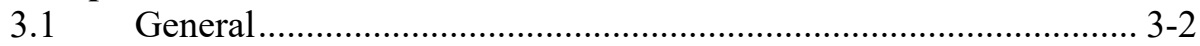

3.2 General Design Requirements ...................................................... 3-6

3.3 Seismic Demands on Nonstructural Components.......................... 3-7

3.4 Nonstructural Component Anchorage ............................................ 3-8

3.5 Architectural Components ...................................................... 3-10

3.6 Mechanical and Electrical Components..................................... 3-12 
3.6.1 Distribution Systems: Conduit, Cable Tray, Raceways,

Ducts, Piping, and Tubing....

3.6.2 Distribution Systems: Trapezes with a Combination of Systems

3.6.3 Boilers and Pressure Vessels

3.6.4 Elevator and Escalator Design Requirements

\section{Understanding the Response of Nonstructural Components to}

Earthquakes.......................................................................................................4-1

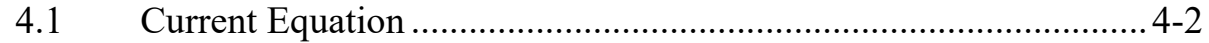

4.2 Influence of Parameters............................................................. 4-4

4.2.1 Peak Ground Acceleration, PGA ….................................. 4-4

4.2.2 Seismic Force-Resisting System ...................................... 4-7

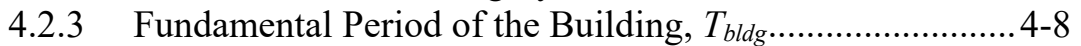

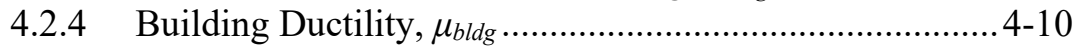

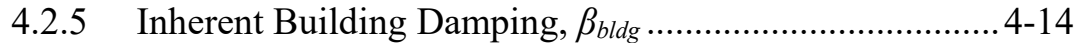

4.2.6 Building Configuration ............................................... 4-15

4.2.7 Floor and Roof Diaphragm Rigidity ............................... 4-16

4.2.8 Vertical Location of Component within the Building,

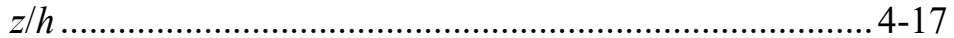

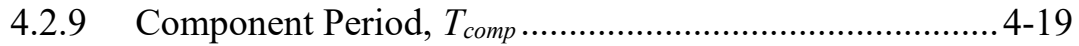

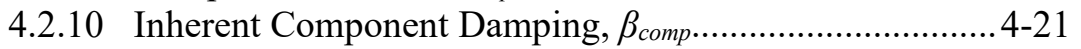

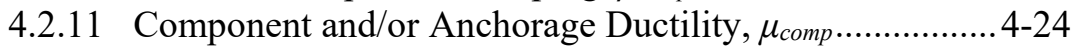

4.2.12 Component Reserve Strength Margin .............................. 4-27

4.2.13 Summary ......................................................................... 4-29

4.3 Proposed Primary Equation and Combined Effect of Multiple Parameters ............................................................................. 4-31

4.3.1 Other Recent Studies....................................................... 4-31

4.3.2 General Framework for Proposed Primary Equation ....... 4-32

4.3.3 Initial Proposed Primary Equation ..................................... 4-33

4.3.4 Refined Equation............................................................. 4-36

4.4 Proposed Minimum for Nonstructural Component Design...........4-57

4.5 Proposed Maximum for Nonstructural Component Design .......... 4-59

4.5.1 Background ................................................................. 4-59

4.5.2 Proposed Maximum .................................................... 4-60

4.6 When Building SFRS, Height, and/or Location of Component

within the Building are Not Known ............................................ 4-61

4.6.1 When Location within the Building is Not Known.......... 4-61

4.6.2 When SFRS and Height are Also Not Known ..................4-61

4.7 Use of Dynamic Analysis to Determine Nonstructural Design

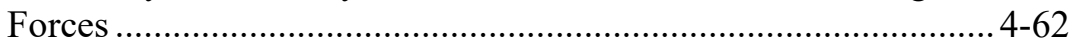

4.7.1 ASCE/SEI 7-16 Provisions ............................................. 4-62

4.7.2 Proposed Revisions .................................................. 4-62

4.8 General Comparisons between ASCE/SEI 7-16 and Proposed

Nonstructural Design Equation ..................................................4-62

4.8.1 Comparisons of Proposed Equations with

ASCE/SEI 7-16

4.9 Case Study Example Comparisons between ASCE/SEI 7-16

and Proposed Nonstructural Design Equation...............................4-70

4.9.1 Interior Wall and Partition Case Study Example .............. 4-70

4.9.2 Floor-Mounted Cabinet Case Study Example................... 4-71 
5. Ductile Design of Nonstructural Supports and Attachments................. 5-1

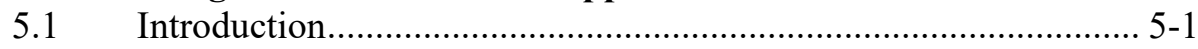

5.2 Effect of Resonance on Design................................................ 5-1

5.3 Ductile Design Philosophy .......................................................... 5-3

5.4 Elevated Vessel Design Example ............................................. 5-5

5.5 Partition Wall Design Example .................................................. 5-11

5.6 Mechanical Unit Design Example .............................................. 5-15

5.7 Piping Support Design Example.............................................. 5-18

5.8 Conclusions and Recommendations …..................................... 5-19

6. Holistic Approach to Protecting Nonstructural Components................ 6-1

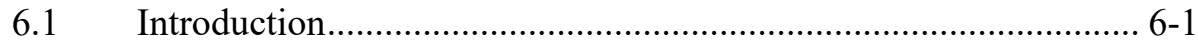

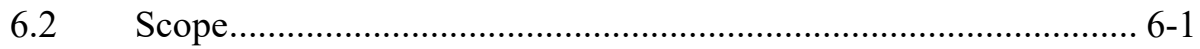

6.3 Uncertainty and Reliability ........................................................... 6-2

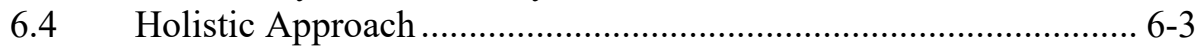

6.4.1 Assign Responsibility .................................................. 6-3

6.4.2 Select Performance Objectives ......................................... 6-4

6.4.3 Establish Structural Design Parameters ............................... 6-6

6.4.4 Select Nonstructural Components ..................................... 6-8

6.4.5 Design Nonstructural Component Restraint ...................... 6-9

6.4.6 Testing, Inspection, and Observation of Installed Components ........................................................................ 6-9

6.4.7 Additional Strategies to Increase Resilience................... 6-11

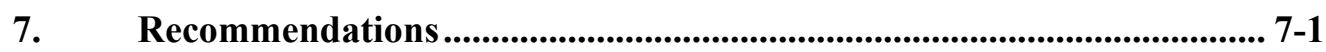

7.1 Seismic Performance Objectives for Nonstructural Components ...................................................................... 7-2

7.2 Response of Nonstructural Components in Earthquakes............... 7-3

7.3 Ductile Design of Nonstructural Supports and Attachments .......... 7-5

7.4 Review of ASCE/SEI 7-16 Seismic Requirements for Nonstructural Components ............................................................ 7-5

7.5 Additional Recommendations to Improve Nonstructural Performance ........................................................................... 7-6

\section{Appendix A: Detailed Review of ASCE/SEI 7-16 Seismic Requirements for} Nonstructural Components................................................................ A-1

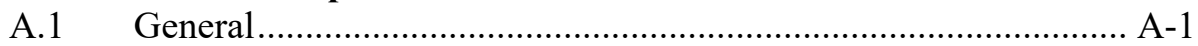

A.1.1 Scope ............................................................................ A-3

A.1.2 Seismic Design Category …......................................... A-7

A.1.3 Component Importance Factor ……............................... A-7

A.1.4 Exemptions ............................................................ A-9

A.1.5 Pre-Manufactured Modular Mechanical and Electrical Systems ............................................................... A-12

A.1.6 Application of Nonstructural Component Requirements to Nonbuilding Structures ............................................ A-12

A.1.7 Reference Documents ................................................... A-13

A.1.8 Reference Documents Using Allowable Stress

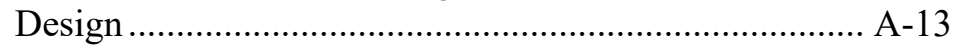

A.2 General Design Requirements ............................................. A-13 
A.2.1 Applicable Requirements for Architectural, Mechanical, and Electrical Components, Supports, and Attachments

A.2.2 Special Certification Requirements for Designated Seismic Systems

A.2.3 Consequential Damage .................................................. A-15

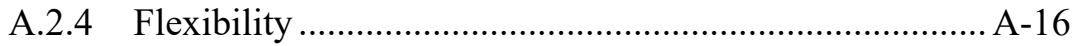

A.2.5 Testing Alternative for Seismic Capacity

Determination. A-16

A.2.6 Experience Data Alternative for Seismic Capacity

Determination.

A.2.7 Construction Documents ................................................ A-17

A.3 Seismic Demands on Nonstructural Components ........................ A-17

A.3.1 Seismic Design Force .................................................... A-17

A.3.2 Seismic Relative Displacements ................................. A-18

A.3.3 Component Period ...................................................... A-18

A.4 Nonstructural Component Anchorage .......................................... A-19

A.4.1 Design Force in the Attachment................................... A-19

A.4.2 Anchors in Concrete or Masonry ................................. A-20

A.4.3 Installation Conditions ................................................. A-21

A.4.4 Multiple Attachments .................................................. A-21

A.4.5 Power-Actuated Fasteners.......................................... A-22

A.4.6 Friction Clips........................................................... A-22

A.5 Architectural Components.................................................... A-22

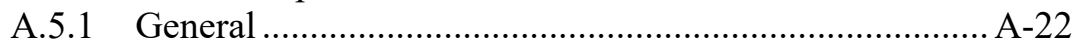

A.5.2 Forces and Displacements ......................................... A-24

A.5.3 Exterior Nonstructural Wall Elements and

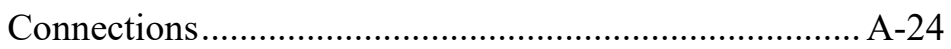

A.5.4 Glass ................................................................. A-25

A.5.5 Out-of-Plane Bending ............................................. A-25

A.5.6 Suspended Ceilings ...................................................... A-26

A.5.7 Access Floors ..................................................... A-26

A.5.8 Partitions ............................................................. A-26

A.5.9 Glass in Glazed Curtain Walls, Glazed Storefronts, and

Glazed Partitions ......................................................... A-27

A.5.10 Egress Stairs and Ramps …...................................... A-27

A.6 Mechanical and Electrical Components ................................... A-27

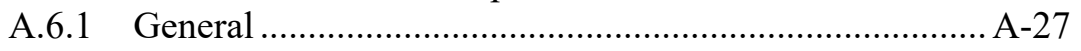

A.6.2 Mechanical Components ........................................... A-28

A.6.3 Electrical Components .............................................. A-28

A.6.4 Component Supports ................................................ A-28

A.6.5 Distribution Systems: Conduit, Cable Tray, and

Raceways..................................................................... A-30

A.6.6 Distribution Systems: Duct Systems ……....................... A-30

A.6.7 Distribution Systems: Piping and Tubing Systems ......... A-33

A.6.8 Distribution Systems: Trapezes with a Combination of

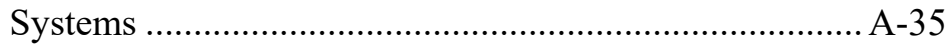

A.6.9 Utility and Service Lines............................................ A-36

A.6.10 Boilers and Pressure Vessels ....................................... A-36

A.6.11 Elevator and Escalator Design Requirements ................ A-36

A.6.12 Rooftop Solar Panels ................................................... A-37 
A.6.13 Other Mechanical and Electrical Components

A.7 Consensus Standards and Other Referenced Standards

\section{Appendix B: Studies to Support the Development of Revised Nonstructural}

Design Force Equations

B.1 Buildings, Seismic Force-Resisting Systems, and Ground

Motions

B.1.1 Instrumented Buildings and their Ground Motion

Recordings

B.1.2 Archetype Numerical Models and Selected Ground Motions

B.2 Effect of Ground Motion Intensity

B.2.1 Evaluation Based on the Response of Instrumented Buildings

B.2.2 Evaluation Based on the Response of Archetype Structures

B.3 Influence of the Building Modal Periods and Seismic Force-

Resisting System

B.3.1 Evaluation Based on the Response of Multistory Instrumented Buildings.

B.3.2 Evaluation Based on the Response of Archetype Building Models

Effect of Building Nonlinearity .....

B.4.1 Potential Amplification of Peak Component Acceleration Demands

B.4.2 Alternative Evaluation of Building Nonlinearity Based on Global Ductility

B.5 Effect of Inherent Building Viscous Damping .............................

B.6 Effect of Building Configuration ..................................................3-31

B.7 Effect of Building Floor and Roof Diaphragm Rigidity ................B-32

B.8 Incorporation of the Effect of Building Nonlinearity in the Proposed Equation ..................................................................... B-35

B.9 Studies on the Effect of Using Different Ground Motion

Record Sets

B.9.1 Role of Component Ductility for Short, Stiff, Elastic

Buildings .................................................................

B.10 Evaluation of Proposed $F_{p}$ Equation Using Archetype Models....B-42

B.10.1 Evaluation of Proposed Equation for Different Component Ductilities

B.10.2 Evaluation of Proposed $\mathrm{F}_{\mathrm{p}}$ Equation at Different Relative Heights.

Appendix C: Component Period, Damping, and Ductility Studies .................... C-1

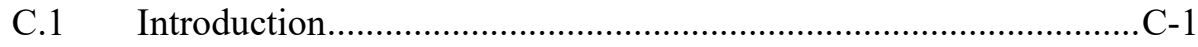

C.2 Background, Study Focus, and Methodology ............................... -1

C.2.1 Literature Review and Project Focus .................................

C.2.2 Record Selection ............................................................

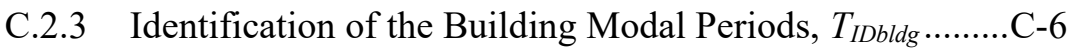

C.2.4 Normalization ...................................................................

C.3 Statistics and Fitting of PCA/PFA Data and the Effect of

Component Damping C-10 
C.3.1 Statistics of PCA/PFA ................................................. C-10

C.3.2 Fitting of PCA/PFA.....................................................

C.4 The Effect of Component Ductility ............................................. C-15

C.5 Conclusions ............................................................................. C-19

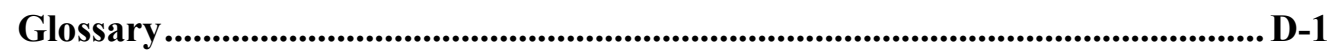

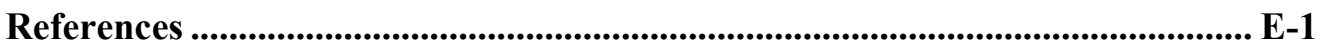

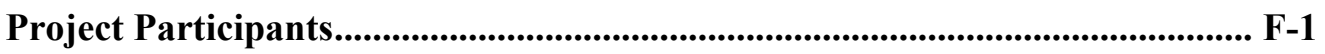




\section{List of Figures}

Figure 2-1 Performance matrix from 2015 NEHRP Provisions ..................... 2-4

Figure 4-1 The effect of ground shaking intensity on PCA and PCA/PGA in a shake table experiment as adapted from Nagae et al. (2011)... 4-5

Figure 4-2 The effect of PGA on PCA/PGA for instrumental recordings........ 4-5

Figure 4-3 Distribution of 2,224 data points from 151 fixed-base building stations used in Fathali and Lizundia (2011a) .............................. 4-6

Figure 4-4 The effect of PGA on PFA/PGA from Fathali and Lizundia (2011a)

Figure 4-5 The effect of building stiffness on PCA/PGA for instrumental recordings.

Figure 4-6 The effect of building stiffness on PCA/PGA for instrumental recordings with a normalized $\mathrm{x}$-axis

Figure 4-7 The effect of period of vibration and lateral system stiffness on PFA/PGA.

Figure 4-8 The effect of period of vibration and lateral system stiffness on PFA

Figure 4-9 The effect of building ductility and ground shaking intensity on PFA, PCA, PFA/PGA, and PCA/PGA 4-10

Figure 4-10 Effect of building nonlinearity on PCA; baseline archetype six-story steel SMRF

Figure 4-11 Effect of building nonlinearity on PCA; weak first story archetype six-story steel SMRF.....

Figure 4-12 Mean PCA/PGA ratios for the baseline and overdesigned archetype buildings and their associated building global displacement ductility values.

Figure 4-13 Effect of inherent building damping on PCA from analytical studies of a archetype six-story steel SMRF model exposed to the spectrum compatible record set at the Design Earthquake level.

Figure 4-14 Sample equation for PFA/PGA for PGA $>0.20 \mathrm{~g}$ from Fathali and Lizundia (2011a) ............................................................... 4-18

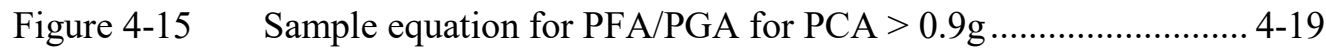


Figure 4-16 PCA/PFA versus $T_{\text {comp }}$ in Fathali and Lizundia (2011a)....

Figure 4-17 Relationship between PCA/PFA comparing spectra without and with normalization by $T_{I D b l d g}$

Figure 4-18 Inherent component damping values from Table 6.4-1 of Seismic Evaluation Procedure for Equipment in U.S. Department of Energy Facilities.

Figure 4-19 Inherent component damping values from translational modes in a cooling tower system.

Figure 4-20 Mean elastic PCA ratios between inherent component damping, $T_{\text {comp }}$, of $5 \%$ and other damping levels

Figure 4-21 PCA/PFA versus $T_{\text {comp }} / T_{\text {IDbldg }}$ for $T_{\text {comp }}=2 \%$ and $T_{\text {comp }}=5 \% \ldots .4-24$

Figure 4-22 Comparison of PCA/PFA versus $T_{\text {comp }} / T_{I D b l d g}$ for different levels of component ductility

Figure 4-23 Comparison of PCA/PFA versus $T_{\text {comp }} / T_{\text {IDbldg }}$ for different levels of component ductility

Figure 4-24 Comparison of mean response of PCA/PFA versus $T_{\text {comp }} / T_{\text {IDbldg }}$ for different levels of component ductility......

Figure 4-25 Reduction in PCA/PFA response for a component tuned to the building's fundamental period ( $\left.T_{\text {comp }}=T_{I D b l d g}\right)$ with varying levels of component ductility

Figure 4-26 Floor acceleration spectra for elastic and inelastic SDOF equipment supported by a SDOF primary structure.

Figure 4-27 Ratio of $F_{p \text {,actual }} / F_{p, p r o p o s e d}$ at the roof for a 6-story steel moment frame archetype $T_{\text {abldg }}=0.93 \mathrm{~s}$, assuming $\mu_{\text {comp }}=1.5$ and $\beta_{\text {comp }}=5 \%$ inherent component damping, where $F_{p, \text { actual }}$ is the mean of 20 spectrum-compatible ground motions ...

Figure 4-28 Ratio of $F_{p \text {,actual }} / F_{p \text {,proposed }}$ at the roof for an 8-story concrete shear wall archetype with $T_{\text {abldg }}=0.62 \mathrm{~s}$, assuming $\mu_{\text {comp }}=1.5$ and $\beta_{\text {comp }}=5 \%$ inherent component damping, where $F_{p, \text { actual }}$ is the mean of 20 spectrum-compatible ground motions

Figure 4-29 Ratio of $F_{p, \text { actual }} / F_{p, \text { proposed }}$ at the roof for a 2-story moment frame archetype and 2-story concrete shear wall archetype, assuming $\mu_{\text {comp }}=1.5$ and $\beta_{\text {comp }}=5 \%$ inherent component damping, where $F_{p \text {,actual }}$ is the mean of 20 spectrum-compatible ground motions.

Figure 4-30 The horizontal natural frequency distribution of a unit under test developed based on test data available from the California Office of Statewide Health Planning and Development OSP special seismic certification program for equipment rigidly mounted on the floor and components with spring isolators mounted on the floor...... 
Figure 4-31 Histogram of building fundamental periods for buildings studied $4-42$

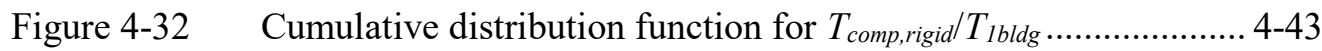

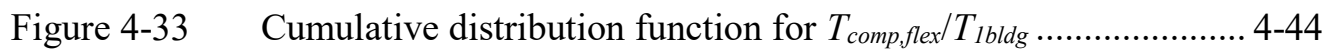

Figure 4-34 Cumulative distribution function for $T_{\text {comp,rigid }} / T_{2 b l d g}$.................... 4-44

Figure 4-35 Cumulative distribution function for $T_{\text {comp fflex }} / T_{2 b l d g} \ldots \ldots \ldots \ldots \ldots \ldots \ldots . . . . . . . .4-45$

Figure 4-36 Cumulative distribution function for $T_{\text {comp, rigid }} / T_{3 b l d g} \ldots \ldots \ldots \ldots \ldots \ldots \ldots . . . . . .4-45$

Figure 4-37 Cumulative distribution function for $T_{\text {comp fflex }} / T_{3 b l d g} \ldots \ldots \ldots \ldots \ldots \ldots \ldots . . . . . . . .4-46$

Figure 4-38 Component amplification and capping of PCA/PFA................... 4-46

Figure 4-39 Cumulative distribution function for $T_{\text {comp, rigid }} / T_{\text {bldg }(0.3 s)} \ldots \ldots \ldots \ldots \ldots . . . . .4-47$

Figure 4-40 Cumulative distribution function for $T_{\text {comp fflexible }} / T_{\text {bldg( }(0.3 s)}$............. 4-48

Figure 4-41 Mean of the simulated $F_{p, a c t u a l}$ normalized by PGA and normalized by $F_{p, p r o p o s e d}$ at the roof for a 2-story steel momentresisting frame archetype

Figure 4-42 Mean of the simulated $F_{p \text {,actual }}$ normalized by PGA and normalized by $F_{p, p r o p o s e d}$ at the roof for a 6-story steel momentresisting frame archetype

Figure 4-43 Mean of the simulated $F_{p, a c t u a l}$ normalized by PGA and normalized by $F_{p, p r o p o s e d}$ at the roof for a 2-story concrete shear wall archetype.....

Figure 4-44 Mean of the simulated $F_{p \text {,actual }}$ normalized by PGA and normalized by $F_{p, p r o p o s e d}$ at the roof for an 8-story concrete shear wall archetype....

Figure 4-45 Mean of the simulated $F_{p, \text { actual }}$ normalized by PGA and normalized by $F_{p, p r o p o s e d}$ at the roof for a 2-story steel momentresisting frame archetype

Figure 4-46 Mean of the simulated $F_{p \text {,actual }}$ normalized by PGA and normalized by $F_{p, p r o p o s e d}$ at the roof for a 6-story steel momentresisting frame archetype

Figure 4-47 Mean of the simulated $F_{p, a c t u a l}$ normalized by PGA and normalized by $F_{p, p r o p o s e d}$ at the roof for a 2-story concrete shear wall archetype....

Figure 4-48 Mean of the simulated $F_{p, a c t u a l}$ normalized by PGA and normalized by $F_{p, p r o p o s e d}$ at the roof for an 8-story concrete shear wall archetype $4-53$

Figure 4-49 Mean of the simulated $F_{p \text {,actual }}$ normalized by PGA and normalized by $F_{p, p r o p o s e d}$ at the roof and second floor for a 2-story steel moment-resisting frame archetype. 4-54 
Figure 4-50 Mean of the simulated $F_{p, \text { actual }}$ normalized by PGA and normalized by $F_{p, p r o p o s e d}$ at the roof, fifth, fourth, and third levels for a 6-story steel moment-resisting frame archetype

Figure 4-51 Mean of the simulated $F_{p, \text { actual }}$ normalized by PGA and normalized by $F_{p, p r o p o s e d}$ at the roof and second floor for a 2-story concrete shear wall archetype

Figure 4-52 Mean of the simulated $F_{p \text {,actual }}$ normalized by PGA and normalized by $F_{p, p r o p o s e d}$ at the roof and selected lower levels for an 8-story concrete shear wall archetype

Figure 5-1 The effect of building stiffness on PCA/PGA for instrumental recordings with a normalized $\mathrm{x}$-axis

Figure 5-2 Comparison of PCA/PFA with an elastic component $\mu_{\text {comp }}=1$ and a nonlinear component with $\mu_{\text {comp }}=1.5$.

Figure 5-3 Component with angle anchorage to floor

Figure 5-4 Anchorage deformations due to angle yielding.

Figure 5-5 Code-compliant design of elevated vessel support structure and anchorage

Figure 5-6 Ductile design of elevated vessel support structure and anchorage

Figure 5-7 Code-compliant partition wall with casework attached

Figure 5-8 Plan view of mechanical unit

Figure 5-9 Code-compliant design of internally-isolated mechanical unit anchorage

Figure 5-10 Code-compliant design of externally-isolated mechanical unit anchorage

Figure 5-11 Typical pipe support and seismic bracing $5-18$

Figure A-1 Seismic design process of ASCE/SEI 7-16 for nonstructural components

Figure A-2 Seismic design requirements for electrical distribution systems, applicable for SDC C, D, E, and F

Figure A-3 Seismic design requirements for duct systems, applicable for SDC C, D, E, and F

Figure A-4 Seismic design requirements for piping systems, applicable for SDC C, D, E, and F.

Figure B-1 Distribution of selected instrumented building directions in terms of number of above-grade stories; and recorded PGA ......... B-4 
Figure B-2 Estimated fundamental periods of instrumented building directions versus number of stories.............................................

Figure B-3 Plan configuration of typical archetypes.......................................

Figure B-4 5\%-damped ground response spectra...................................... 15

Figure B-5 The normalized ground motion intensity measure for different instrumented building-directions; and probability of exceeding normalized ground motion intensity measure.

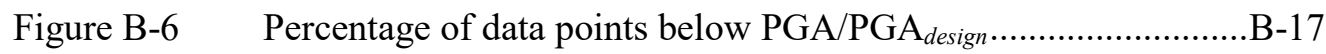

Figure B-7 PCA/PGA versus the relative height for instrumented building directions.

Figure B-8 Ground response spectra for the basic spectrum-compatible record used in this study; $G S_{a}$ is the pseudo-spectral acceleration

Figure B-9 5\%-damped roof floor response spectra for six-story SMRF archetype building, elastic components

Figure B-10 PCA and PFA response at roof level versus ground motion intensity level for six-story steel MRF archetype building.

Figure B-11 5\%-damped roof floor response spectra for eight-story RCSW archetype building, elastic components

Figure B-12 PCA and PFA response at roof level versus ground motion intensity level for eight-story RCSW archetype building

Figure B-13 5\%-Damped normalized roof spectra for the multistory buildings.

Figure B-14 Effect of building nonlinearity on PCA; baseline archetype 6-story SMRF

Figure B-15 Effect of building nonlinearity on PCA; weak first story archetype 6-story SMRF

Figure B-16 Mean PCA/PGA ratios B-28

Figure B-17 Pushover curves for archetype buildings used in this section when exposed to an inverted triangular load pattern

Figure B-18 Effect of inherent building damping on PCA from analytical studies of the archetype six-story SMRF model exposed to the spectrum-compatible record set at the DE level .....

Figure B-19 Effect of inherent building damping on PCA from analytical studies of the archetype six-story SMRF model exposed to the spectrum-compatible record set at the $0.25 \mathrm{DE}$ level. 
Figure B-20 Effect of inherent building viscous damping on PCA from analytical studies of the archetype eight-story RCSW model exposed to the spectrum-compatible record set at the DE level; and at the $0.25 \mathrm{DE}$ level

Figure B-21 Sensor arrangements in building floors

Figure B-22 Amplified PFA and PCA responses in the single-story instrumented buildings

Figure B-23 Amplified PFA and PCA responses with height due to the inplane diaphragm flexibility of the multistory buildings....

Figure B-24 Amplified PFA and PCA responses with height due to the torsional responses of the multistory buildings

Figure B-25 Comparison of the amplitude of $\gamma_{\text {flexibility }}^{\mathrm{PFA}}$ and $\gamma_{\text {torsion }}^{\mathrm{PFA}}$ for floor directions in which the sensor arrangement allows for better estimation of in-plane diaphragm flexibility effects and torsional responses simultaneously

Figure B-26 Mean of the simulated $F_{p}$ normalized by the $F_{p}$ from the proposed equation; baseline 6-story SMRF building

Figure B-27 Mean of the simulated $F_{p}$ normalized by the $F_{p}$ from the proposed equation; 6-story SMRF building with an overdesign factor of 1.5

Figure B-28 Mean of the simulated $F_{p}$ normalized by the $F_{p}$ from the proposed equation; baseline 8-story RCSW building ....

Figure B-29 Mean of the simulated $F_{p}$ normalized by the $F_{p}$ from the proposed equation; 8-story RCSW building with an overdesign factor of 1.5

Figure B-30 Mean of the simulated $F_{p}$ normalized by the $F_{p}$ from the proposed equation; 2-story SMRF building with an overdesign factor of 2.0

Figure B-31 Mean of the simulated $F_{p}$ normalized by the $F_{p}$ from the proposed equation; 2-story RCSW building with an overdesign factor of 3.0

Figure B-32 Normalized $F_{p, a c t u a l}$ for the baseline 6-story SMRF building

Figure B-33 Normalized $F_{p \text {,actual }}$ for the 6-story SMRF building with an overdesign factor of 1.5

Figure B-34 Normalized $F_{p, a c t u a l}$ for the baseline 8-story RCSW building.........

Figure B-35 Normalized $F_{p \text {,actual }}$ for the 8-story RCSW building with an overdesign factor of 1.5 B-40

Figure B-36 Normalized $F_{p, a c t u a l}$ for the baseline 2-story SMRF building B-40 
Figure B-37 Normalized $F_{p, \text { actual }}$ for the baseline 2-story RCSW building ........ B-40

Figure B-38 Mean and mean plus one standard deviation of the simulated $\left(F_{p} / \mathrm{PGA}\right)$ normalized by the $\left(F_{p} / \mathrm{PGA}_{\text {design }}\right)$ from the proposed equation

Figure B-39 Mean and mean plus one standard deviation of the simulated $F_{p}$ normalized by the $F_{p}$ from the proposed equation.

Figure B-40 Normalized $F_{p, \text { actual }}$ obtained from the 44 scaled FF records from FEMA P-695 …....................................................................

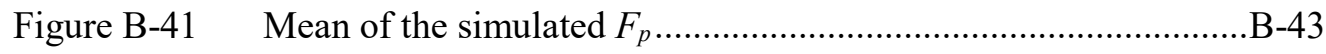

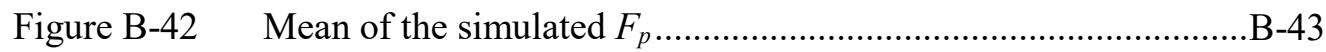

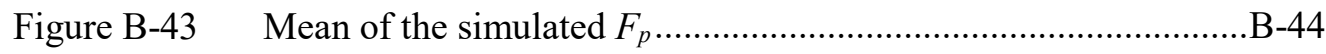

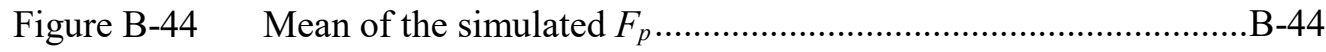

Figure B-45 Mean of the simulated $F_{p}$ normalized by the $F_{p}$ from the proposed equation ...................................................................

Figure B-46 Mean of the simulated $F_{p}$ normalized by the $F_{p}$ from the proposed equation

Figure B-47 Evaluation of $F_{p, p r o p o s e d}$ based on the responses of the 2-story SMRF building with an overdesign factor of 2.0........................ B-46

Figure B-48 Evaluation of $F_{p, p r o p o s e d}$ based on the responses of the 6-story

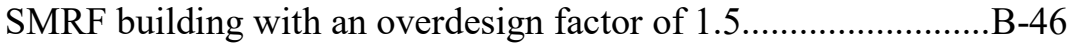

Figure B-49 Evaluation of $F_{p, p r o p o s e d}$ based on the responses of the 2-story RCSW building with an overdesign factor of $3.0 \ldots \ldots \ldots \ldots \ldots \ldots \ldots . . . . . . . . . . .46$

Figure B-50 Evaluation of $F_{p, p r o p o s e d}$ based on the responses of the 8-story RCSW building with an overdesign factor of 1.5 ........................

Figure B-51 Evaluation of $F_{p, p r o p o s e d}$ based on the responses of the 2-story and 6-story overdesigned SMRF buildings..

Figure B-52 Evaluation of $F_{p, p r o p o s e d}$ based on the responses of the 2-story and 6-story overdesigned RCSW buildings...

Figure C-1 5\% floor spectra computed for a roof recording. .C-7

Figure C-2 PCA/PFA spectra for 5\% inherent component damping for eight recorded floor motions, each associated with a particular building, direction, earthquake, and floor level

Figure C-3 The $16^{\text {th }}, 50^{\text {th }}$, and $84^{\text {th }}$ percentiles for PCA/PFA evaluated from eight recorded floor motions selected from Group 1 C-10

Figure C-4 Mean elastic PCA ratios between inherent component damping of $5 \%$ and other damping levels for Group 1 records C-11 
Figure C-5 The mean and $16^{\text {th }}, 50^{\text {th }}, 84^{\text {th }}$ percentiles for PCA/PFA

Figure C-6 Dispersion of PCA/PFA evaluated for Group 1; and Group 2 records

Figure C-7 The mean PCA/PFA, its $16^{\text {th }}, 50^{\text {th }}$, and $84^{\text {th }}$ percentiles and the fitted curves

Figure C-8 The mean strength reduction factor $R_{\mu c o m p}$ and its $16^{\text {th }}, 50^{\text {th }}$, and $84^{\text {th }}$ percentiles for $2 \%$ inherent component damping and Group 1 records for a nonlinear nonstructural component with a component ductility

Figure C-9 The mean strength reduction factor $R_{\mu c o m p}$ and its $16^{\text {th }}, 50^{\text {th }}$, and $84^{\text {th }}$ percentiles for $2 \%$ inherent component damping and Group 2 records for a nonlinear nonstructural component with a component ductility

Figure C-10 Comparison of PCA/PFA versus $T_{\text {comp }} / T_{\text {IDbldg }}$ for different levels of component ductility for Group 1 records.

Figure C-11 Comparison of PCA/PFA versus $T_{\text {comp }} / T_{\text {IDbldg }}$ for different levels of component ductility for Group 1 records.

Figure C-12 Comparison of mean response of PCA/PFA versus $T_{\text {comp }} / T_{\text {IDbldg }}$ for different levels of component ductility for Group 1 records

Figure C-13 Reduction in PCA/PFA response for a component tuned to the building's fundamental period with varying levels of component ductility for Group 1 records 


\section{List of Tables}

Table 2-1 ASCE/SEI 7-10 Table C.1.3.1b Anticipated Reliability

(Maximum Probability of Failure) for Earthquake

Table 2-2 Proposed Hazard Levels for Design of Nonstructural

Components $2-15$

Table 2-3 Expected Performance of Nonstructural Components in Code-

Designed Buildings.....

Table 2-4 Proposed Nonstructural Performance Descriptions

$2-20$

Table 2-5 Proposed Building Code Requirements for Nonstructural

Components

Table 4-1 Reduction in PCA Demands .................................................... 4-15

Table 4-2 PCA/PFA Values …….......................................................... 4-37

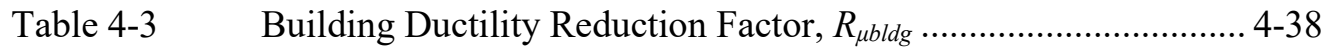

Table 4-4 Code and Modal Periods of Various Archetypes.......................... 4-40

Table 4-5 Mean Period and Beta for Buildings and Components................. 4-43

Table 4-6 Basis for PCA/PFA Values for Flexible Components at Roof and Suspended Floors ............................................................... 4-48

Table 4-7 PCA/PGA for Ground-Supported Components .......................... 4-56

Table 4-8 $\quad F_{p} / W_{p}$ for ASCE/SEI 7-16 ................................................ 4-63

Table 4-9 $\quad F_{p} / W_{p}$ for ASCE/SEI 7-16 Incorporating Minimum and Maximum ............................................................................ 4-63

Table 4-10 $\quad F_{p} / W_{p}$ for ASCE/SEI 7-16 for Anchors..................................... 4-63

Table 4-11 $\quad F_{p} / W_{p}$ for Proposed Equation .................................................... 4-64

Table 4-12 $\quad F_{p} / W_{p}$ for Proposed Equation Incorporating Minimum and Maximum....................................................................... 4-64

Table 4-13 $\quad F_{p} / W_{p}$ for Proposed Equation for Anchors ................................. 4-66

Table 4-14 $\quad F_{p} / W_{p}$ for Proposed Equation for Anchors .................................. 4-66

Table 4-15 Ratio of $F_{p} / W_{p}$ for Proposed Equation versus ASCE/SEI 7-16 .... 4-68

Table 4-16 Ratio of $F_{p} / W_{p}$ for Proposed Equation versus ASCE/SEI 7-16 for Anchors 4-68 
Table 5-1 Comparison of Design Force Values for Elevated Vessel, $a_{p}=1.0$

Table 5-2 Comparison of Design Force Values for Elevated Vessel, $a_{p}=2.5$

Table 5-3 Comparison of Design Force Values for Partition Walls, $a_{p}=1.0$

Table 5-4 Comparison of Design Force Values for Partition Walls, $a_{p}=2.5$

Table B-1 Seismic Force-resisting Systems for Instrumented BuildingEarthquake Samples Used in this Study.....

Table B-2 Characteristics of the Selected Instrumented Buildings and their Recorded Ground Motions....

Table B-3 Characteristics of Baseline Archetype Buildings ........................ B-13

Table B-4 Member Sizes for Six-story SMRF Archetype Building ............. B-13

Table B-5 Member Sizes for Two-story SMRF Archetype Building ........... B-13

Table B-6 Design Characteristics of Eight-story Special RCSW Building.

Table B-7 Design Characteristics of Special Two-story RCSW Building.... B-14

Table B-8 Code and Modal Periods of Various Archetypes ......................... B-27

Table B-9 Parameter Values of the Proposed $F_{p}$ Equation ......................... B-38

Table C-1 Group 1 Building Dataset............................................................ C-3

Table C-2 Group 2 Building Dataset....................................................... C-5

Table C-3 Constants Evaluated for the Regression Equation C-1 of PCA/PFA. C-14 


\section{Chapter 1}

\section{Introduction}

\subsection{Project Background and Purpose}

Nonstructural components and systems account for the majority of direct property losses due to earthquake damage. Although significant structural damage to modern buildings has generally been rare in moderately strong earthquakes, costly and disruptive nonstructural damage is much more widespread, and can result in additional economic losses from functionality and business interruptions.

NIST GCR 17-917-44, Seismic Analysis, Design, and Installation of Nonstructural Components - Background and Recommendations for Future Work, (NIST, 2017) summarizes a year-long study undertaken to collect and document the body of available knowledge related to the seismic performance of nonstructural components that could serve as the foundation for future investigations. The study drew from documented earthquake observations, past code development efforts related to nonstructural requirements, analytical research, and nonstructural component and system testing. The study also included a practitioners' workshop to identify the most pressing needs of the profession. This background information was used to identify and prioritize research needed to improve technical aspects of nonstructural system design. The following topics were identified as the highest priority items for advancing nonstructural design:

- Conduct a review of current code design approaches

- Develop nonstructural component and system performance objectives

- Improve implementation and enforcement of code requirements

- Clarify requirements for displacement-based design of nonstructural components and systems

Based on these recommendations and available project resources, this project was organized around three main subject areas: (1) developing performance objectives for nonstructural components that can ultimately serve as the foundation for building code requirements, and can be adapted for use when enhanced performance is desired; (2) performing a comprehensive review of all factors contributing to seismic performance of nonstructural components and systems, using the latest information from instrumented buildings, laboratory tests, and analytical studies, and proposing improved design force equations for nonstructural components, if needed; and (3) 
conducting a detailed assessment of code requirements, with a focus on improving clarity, consistency, and enforceability.

Although improvement of implementation and enforcement of code requirements across building occupancy classes is of paramount importance, it is outside the purview of this project. The goal of this project is to improve technical aspects of nonstructural system design in the areas that will have the largest impact for public safety and economic welfare. This report summarizes the body of knowledge gathered and developed to advance the understanding of the response of nonstructural components to earthquakes. The report also makes recommendations for changes to building codes and practice.

\subsection{Intended Audience}

This report is primarily intended for design professionals, building code and standards development committee members, and researchers interested in the response of nonstructural components and systems to earthquakes. Portions of the report will also be of interest to individuals in the construction industry with a vested interest in the seismic performance of buildings and manufacturers of components or systems installed in buildings designed for earthquake resistance.

\subsection{Holistic Approach to Understanding the Response of Nonstructural Components to Earthquakes}

The nonstructural universe contains a myriad of components and systems that enable buildings to function for their intended purpose. It includes architectural components that enclose buildings and create usable interior space; mechanical, electrical and plumbing systems that provide basic services needed for occupancy, and contents needed for occupants to function in the space. Variations in scale and importance of components are extreme. Nonstructural components range from a cabinet to a desktop computer; from cladding on a high-rise building to stucco on a house; or from emergency generators providing back-up power to a hospital to a residential water heater. Consequently, finding a "one size fits all" strategy for nonstructural design is a daunting undertaking.

Adding to the complexity of developing a design strategy that covers all nonstructural components is the challenge of accurately predicting the earthquake motions to which they may be subjected. The input motion for a nonstructural component is dependent on not only the ground motions at the site, but also how the ground motions are modified throughout the building to create floor response. Predicting floor response in a building given the ground shaking input at its base is dependent on many building-specific factors. If the input motion at the support of a nonstructural component is known, then the challenge of predicting its response is dependent on the details of the component itself. Where the performance objective is 
position retention, that is the state where components are secured in their place following the chosen shaking intensity, but may have sustained damage that prevents them from functioning, simple design procedures may suffice. Some essential nonstructural components can be modeled and analyzed with sufficient reliability to base a design, such as piping containing hazardous materials. However, for most nonstructural components, information required to build a detailed analytical model is unavailable, and the related effort is unwarranted in the context of most designs.

This project identified the factors that influence response and, through analytical studies and reflection on observed performance, achieved a fundamental understanding of them. With more study, it became increasingly clear that designing nonstructural components to achieve desired response is complex given the uncertainty in predicting demands, the number of factors influencing response, incomplete information about buildings in which nonstructural components reside, and a lack of detailed information about the components themselves.

Despite the complexities, uncertainties, and unknowns, simple tools are needed as a basis for design. Therefore, the project focused on developing a fundamental understanding of the factors influencing response and creating practical strategies that provide a reliable basis of design for most components. It concluded that a holistic approach is needed to integrate the many variables associated with nonstructural design and construction into a technically sound and practical implementation strategy.

The recommended approach for designing protection of nonstructural components and systems is founded on the following context and understanding:

- Design begins with identifying vulnerable nonstructural components and systems. This requires knowledge of the architectural, mechanical, electrical, plumbing, and infrastructure components and systems, as well as the installed furnishings, fixtures, and building contents.

- The next step is to identify the desired performance objectives for the building. This will require an understanding of the intended use of the building and the owner or occupant's post-earthquake needs.

- The owner or occupant's overarching performance objectives for the building need to be translated into component-specific performance objectives. For buildings in which post-earthquake functionality is required in the Design Earthquake, this requires an understanding of the components and systems that are required to maintain continuity of operations, and evaluating and establishing the level of acceptable damage.

- For new building design, an important step is to determine whether the attributes of the selected structural system are compatible with those of the nonstructural 
components. There are practical limitations to the performance that some nonstructural components can achieve. One way to address this is by explicitly designing the structure within the limitations of the nonstructural components. For example, a building may be provided with added stiffness to enable a desired cladding system to be used or a building may be base-isolated to protect contents sensitive to horizontal accelerations.

- Once it is clear which components and systems require what level of protection, design demands must be determined.

○ For "ordinary" components for which post-earthquake functionality is not required, components may be designed for minimum code requirements to satisfy the performance objectives on which ASCE/SEI 7-16 is based:

- In frequent earthquakes: No damage

- In the Design Earthquake: Position retention to protect components that could pose a safety concern

- For components requiring post-earthquake functionality or for those where damage must be limited to allow for continued occupancy, components may be designed for minimum code requirements to satisfy the following ASCE 7 performance objectives:

- In frequent earthquakes: No damage

- In the Design Earthquake: Position retention; continued functionality of required mechanical, electrical, or plumbing (MEP) components, egress, fire protection, and any other component or systems needed to maintain post-earthquake operations; and limited damage to architectural systems

- In lieu of using the minimum code prescribed demands, an engineer may elect to determine design demands based on building-specific analysis. Additional demands may also be used to satisfy specific owner or occupantdesired performance objectives.

- Components should be selected to achieve specified objectives. Special consideration must be given to components for which post-earthquake functionality or limited damage is required. For example:

- Active mechanical and electrical equipment that must remain operable after the Design Earthquake can be shake-table tested to certify operability

- Mock-ups of cladding systems can be built and tested under prescribed interstory drifts to confirm acceptable performance

- Components and systems can be analytically modeled and analyzed to assess acceptability under prescribed levels of acceleration and drift 
- Design requirements for all nonstructural components should be clearly defined, ideally by the Structural Engineer of Record (SEOR). The party responsible for design/specification for each nonstructural component and system should be identified. For delegated nonstructural designs, project specifications should clearly delineate the required design demands and associated performance. The responsible design professional should be designated to review related designs to confirm that project requirements have been satisfied.

- Component locations can be adjusted to suit nonstructural performance limitations. For example, a piece of equipment that may not be certified for the high accelerations on a roof may perform acceptably under the anticipated shaking demands near the base of a building.

- Where components form part of a larger system, all components in the system should be designed to achieve the intended performance objective.

- Components and systems must be designed and installed with consideration of other adjacent systems. Unacceptable consequences of interactions must be identified and protected against.

- Testing and inspection of installed nonstructural components and systems is needed to ensure that intended design objectives are met. For components and systems requiring post-earthquake functionality, final inspection should be conducted after all systems are installed to identify conditions where adverse interactions of adjacent components can lead to unacceptable damage.

\subsection{Report Organization}

This report is organized around the main subjects of investigation, with a culminating chapter that describes the understanding that has been gained through execution of the project.

Chapter 2 describes the process by which seismic performance objectives for nonstructural components were developed and presents a framework for nonstructural performance objectives for code design of nonstructural components and recommended considerations for enhanced performance.

Chapter 3 provides a review of ASCE/SEI 7-16 seismic requirements for nonstructural components. It contains a section by section examination of code requirements and proposes needed changes for clarity, consistency, and technical soundness.

Chapter 4 summarizes the analytical investigations undertaken to provide a fundamental understanding of the response of nonstructural components to earthquakes, and proposes new design equations for horizontal forces on nonstructural components. 
Chapter 5 presents investigations of a new design philosophy for nonstructural components, which can be used to design for more predictable nonstructural performance.

Chapter 6 synthesizes and integrates the main subjects of study into a holistic approach to the seismic protection of nonstructural components.

Chapter 7 contains recommendations for near term changes to building codes, design practice, and construction quality assurance. It also contains recommendations for additional research that will foster enhancements and improvements to the understanding of nonstructural response.

Appendix A expands on Chapter 3 and contains additional details on the current procedures for the seismic design of nonstructural components and recommendations for clarifications, enhancements, or further study. Flowcharts are provided to describe complex interrelationships between different code design requirements.

Appendix B and C provide detailed information about analytical studies that form the foundation to the findings reported in Chapter 4.

A glossary, reference section, and list of project participants are given at the end of the report. 


\section{Chapter 2}

\section{Performance Objectives for Nonstructural Components}

\subsection{Introduction}

Establishing minimum acceptable seismic risk for a building is not solely a technical issue, but a matter of public policy. An understanding of building performance, both structural and nonstructural, under a range of earthquake intensities is required to inform and guide public policy through the code development process. This chapter proposes explicit performance objectives for nonstructural components and systems subjected to seismic shaking, where possible to do so. The performance objectives are primarily intended to serve as a transparent basis for further development of nonstructural code requirements. The performance objectives for nonstructural systems and components proposed in this chapter are intended to be a starting point for community-wide discussions with the intent of arriving at a consensus set of objectives that will be affirmed through the code development process and adopted by future code and standards writers. These objectives could also be translated into explicit goals used for performance-based design of nonstructural components and systems.

Every design begins with a performance objective in mind. The vast majority of building designs consider building code compliance as the goal and the performance objectives implicit in the building code and standards referenced within it typically serve as the de facto performance objectives for the design. In performance-based design, the objectives are explicit, consisting of one or more ground motion hazard levels combined with a related description of desired performance.

Although structural performance objectives have evolved considerably over time, both qualitative and quantitative expressions of nonstructural performance have lagged behind. Presently, quantitative expressions of structural performance are in use and are the subject of ongoing development. The implicit performance objective of the building code for buildings of ordinary importance is protection of life safety, quantified as an acceptably low probability of collapse in a rare, powerful seismic event, the Risk-Targeted Maximum Considered Earthquake $\left(\mathrm{MCE}_{\mathrm{R}}\right)$. Nonstructural performance objectives, however, are described in more general terms. Section C13.1.3 of ASCE/SEI 7-16, Minimum Design Loads and Associated Criteria for Buildings and Other Structures, (ASCE, 2017a) indicates the following: 
For noncritical nonstructural components (those with a component Importance

Factor, $I_{p}$, of 1.0), the following behaviors are anticipated for shaking of different levels of intensity:

1. Minor earthquake ground motions - minimal damage; not likely to affect functionality;

2. Moderate earthquake ground motions-some damage that may affect functionality; and

3. Design earthquake ground motions-major damage but significant falling hazards are avoided likely loss of functionality.

The Design Earthquake is defined as two-thirds of the corresponding $\mathrm{MCE}_{\mathrm{R}}$ intensity. Critical nonstructural components, such as fire protection systems and stairways, are expected to remain functional after the Design Earthquake.

Some building owners or communities may desire a performance level for select nonstructural systems higher than those mandated by the building code to reduce the risk of extended loss of building use or function following an earthquake. This chapter also provides guidance to building owners and communities who elect to establish performance objectives higher than the minimum objectives prescribed by the code for select nonstructural components.

This chapter provides background for the work related to nonstructural performance objectives, lays a foundation for establishing nonstructural performance objectives, proposes a framework for nonstructural objectives, sets forth recommendations for minimum building code performance objectives, and proposes enhanced objectives and approaches to achieving them.

\subsection{Background}

Current seismic design regulations and the performance objectives on which they are based, have evolved since the first seismic regulations in the United States were introduced as a voluntary appendix to the 1927 Uniform Building Code (ICBO, 1927). The performance intent of the early U.S. earthquake design provisions was to provide reasonable protection of life by safeguarding against major failures, i.e., collapse or partial collapse.

Following the poor performance of some code-compliant hospital buildings in the 1971 San Fernando earthquake in Southern California, there was recognition that certain types of facilities should be designed to preserve their pre-earthquake functionality following a major earthquake. Facilities such as hospitals and emergency operations centers should be designed to limit property damage so that they can continue to serve the public after an earthquake. The Fourth Edition of the Recommended Lateral Force Requirements and Commentary (SEAOC, 1974), which 
formed the basis for the seismic provisions of the 1976 Uniform Building Code (ICBO, 1976), added an Importance Factor that required selected buildings to be designed for higher lateral forces. It also established more stringent detailing requirements and quality assurance for such buildings.

Commentary to the 1974 Recommended Lateral Force Requirements contains general language outlining the implicit performance expectations of the standard, noting that the provisions should result in structures that resist the following:

- Minor earthquakes without damage

- Moderate earthquakes without structural damage, but some damage to nonstructural components

- Major earthquakes with substantial structural and nonstructural damage

- Most severe earthquake ever anticipated to occur without collapse

However, the terms "minor," "moderate," "major," and "most severe earthquake ever anticipated" were not quantitatively defined in the document.

In the early 1970s the concept of probabilistic ground motion mapping was developed, allowing the level of ground shaking hazard associated with the design requirements to be quantified. ATC 3-06, Tentative Provisions for the Development of Seismic Regulations for Buildings, (ATC, 1978) introduced explicit performance objectives for nonstructural components based on the consequences of damage and included a recommendation for seismic qualification of components required for post-earthquake functionality.

In the mid-1990s, the improved ability to analyze nonlinear structural response allowed major advances in the definition of the expected performance of buildings in earthquakes to be made in FEMA 273, NEHRP Guidelines for the Seismic Rehabilitation of Buildings, (FEMA, 1997) and Vision 2000: Performance Based Seismic Engineering of Building (SEAOC, 1996). Both projects defined building performance in terms of discrete levels termed: Fully Operational (FEMA 273 defined Operational), Operational (FEMA 273 defined Immediate Occupancy), Life Safe and Near Collapse (FEMA 273 defined Collapse Prevention), each representing progressively more severe levels of damage from negligible to near total. Vision 2000 linked the discrete performance levels to quantitative seismic shaking levels at which they should be achieved for structures of different occupancy categories.

1997 Edition of NEHRP Recommended Provisions for Seismic Regulations for New Buildings and Other Structures (FEMA, 1998) updated the concept of avoiding collapse for the most severe earthquake intensities that had ever been experienced by setting a target of collapse prevention performance for structures subject to a rare shaking intensity termed Maximum Considered Earthquake (MCE) seismic hazard. 
MCE shaking was defined as having a $2 \%$ probability of exceedance in 50 years (2,475-year return period), with a cap of $150 \%$ of the median deterministic hazard at sites in regions near major active faults. Design shaking intensity (Design Earthquake) was taken as $2 / 3$ of the MCE levels based on the belief that welldesigned structures would incorporate a margin against collapse on the order of 1.5. The 2015 NEHRP Provisions (FEMA, 2015b) presented the intended performance objectives graphically, as shown in Figure 2-1.

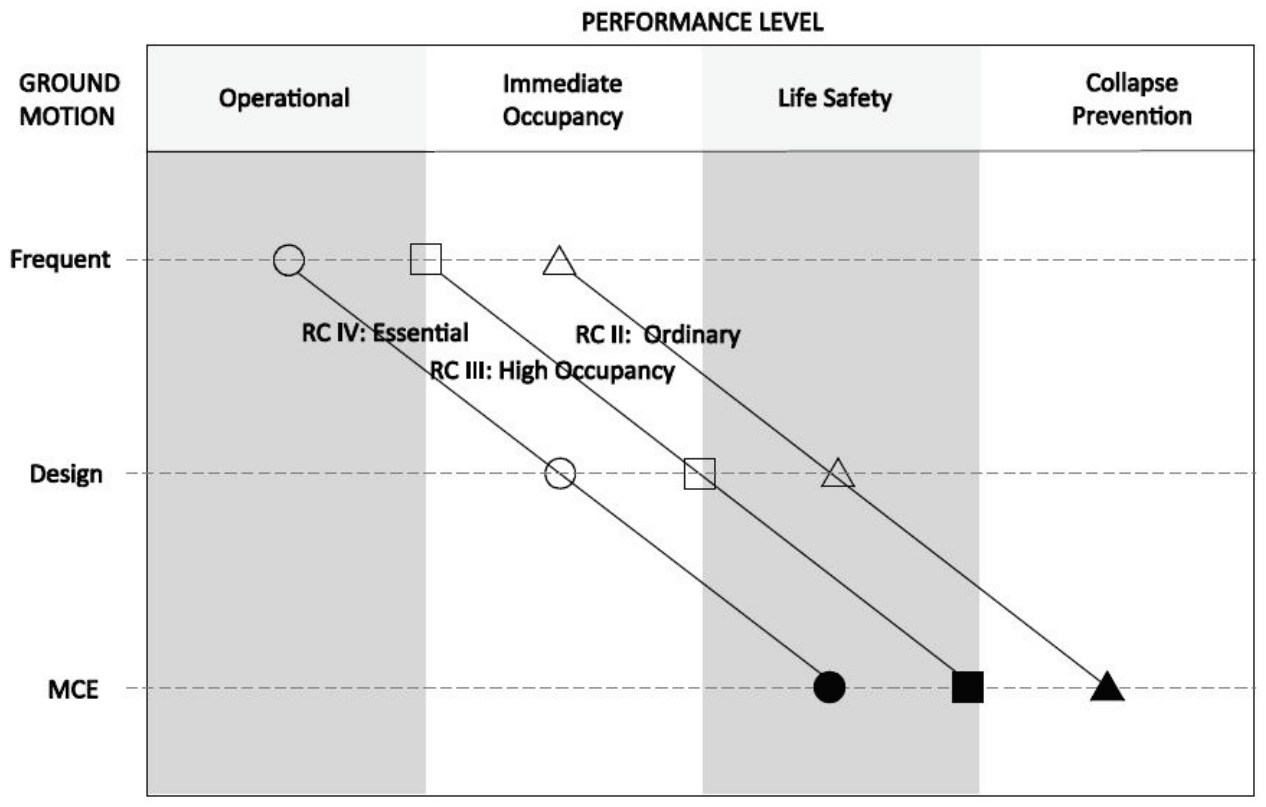

Figure 2-1 Performance matrix from 2015 NEHRP Provisions (FEMA, 2015b).

The next major update to seismic performance definitions came in the 2009 Edition of NEHRP Recommended Seismic Provisions for New Buildings and Other Structures, (FEMA, 2009b) with the introduction of risk-targeted seismic hazard parameters. The uncertainty inherent in performance predictions was recognized. The 2009 NEHRP Provisions adopted the performance objective that the seismic force-resisting system shall not have more than $10 \%$ probability of collapse conditioned on the $\mathrm{MCE}_{\mathrm{R}}$. This characterization of performance was expanded in the commentary of the general provisions chapter of ASCE/SEI 7-10 (ASCE, 2010), which contained estimated anticipated probabilities of collapse given $\mathrm{MCE}_{\mathrm{R}}$ shaking for buildings of all risk categories satisfying the requirements of ASCE/SEI 7-10. These values are shown in Table 2-1, reproduced from the commentary of ASCE/SEI 7-10. However, most structures were still only required to be designed for the Design Earthquake (DE) which was still taken as $2 / 3$ of the $\mathrm{MCE}_{\mathrm{R}}$ because studies indicated that the seismic design load and detailing requirements were sufficient to achieve the $\mathrm{MCE}_{\mathrm{R}}$ performance goal. This is still true in ASCE/SEI 7-16.

Although Table 2-1 addresses structural safety only, the performance expectations associated with buildings satisfying the requirements of ASCE/SEI 7 are broader. 
The Commentary to ASCE/SEI 7-10 (Chapter C1) states "the requirements of ASCE/SEI 7 and its companion reference standards are intended to go beyond protection against structural failure and are also intended to provide property and economic protection for small events, to the extent practical, as well as to improve the probability that critical facilities will be functional after severe storms, earthquakes and similar events." That statement is expounded upon in Section 1.1 of the 2015 edition of NEHRP Recommended Seismic Provisions for New Buildings and Other Structures, (FEMA, 2015b), which also includes objectives to avoid serious injury or loss of life due to failure of nonstructural components and systems and release of hazardous materials and to preserve means of egress. The objectives of the 2015 NEHRP Provisions are "to provide reasonable assurance of seismic performance that will:

1. Avoid serious injury and life loss due to
a. Structural collapse
b. Failure of nonstructural components or systems
c. Release of hazardous materials

2. Preserve means of egress

3. Avoid loss of function in critical facilities, and

4. Reduce structural and nonstructural repair costs where practicable." Table 2-1 ASCE/SEI 7-10 Table C.1.3.1b Anticipated Reliability (Maximum
Probability of Failure) for Earthquake

\begin{tabular}{ll}
\hline & Risk Category I and II \\
\hline Total or partial structural collapse & $\begin{array}{l}10 \% \text { conditioned on the occurrence of Maximum } \\
\text { Considered Earthquake shaking }\end{array}$ \\
$\begin{array}{l}\text { Failure that could result in endangerment of } \\
\text { individual lives }\end{array}$ & $\begin{array}{l}25 \% \text { conditioned on the occurrence of Maximum } \\
\text { Considered effects }\end{array}$ \\
Risk Category III & \\
Total or partial structural collapse & $\begin{array}{l}6 \% \text { conditioned on the occurrence of Maximum } \\
\text { Considered Earthquake shaking }\end{array}$ \\
$\begin{array}{l}\text { Failure that could result in endangerment of } \\
\text { individual lives }\end{array}$ & $\begin{array}{l}15 \% \text { conditioned on the occurrence of Maximum } \\
\text { Considered Earthquake shaking }\end{array}$ \\
\hline Total or partial structural collapse & Risk Category IV \\
\hline $\begin{array}{l}\text { Failure that could result in endangerment of } \\
\text { individual lives }\end{array}$ & $\begin{array}{l}3 \% \text { conditioned on the occurrence of Maximum } \\
\text { Considered Earthquake shaking }\end{array}$ \\
\hline
\end{tabular}

Note: Refer to NEHRP Recommended Provisions Seismic Regulation for Buildings and Other Structures, FEMA P750, for discussion of the basis of seismic reliabilities. 
In recognition of the absence of comprehensive nonstructural performance objectives, Resource Paper 1 of the 2015 NEHRP Provisions (FEMA, 2015c) proposed a performance framework for nonstructural performance targets. It delineated two categories of nonstructural components: those not required to function following the design earthquake and those expected to function following the design earthquake. The framework proposed the use of $\mathrm{MCE}_{\mathrm{R}}$ levels of shaking for consideration of safety-related risks and a Function-Level Earthquake level of shaking where post-earthquake operability is needed. The original version of Resource Paper 1 generated lively discussion and considerable controversy, and it was not possible to achieve sufficient consensus to incorporate it into the provisions. Resource Paper 1 is an abridged version of the original proposal.

Parallel with recent building code developments for new design, the ASCE/SEI Standards Committee on Seismic Rehabilitation has made considerable progress in establishing building performance objectives. ASCE/SEI 41-17, Seismic Evaluation and Retrofit of Existing Buildings, (ASCE, 2017b) is the national standard for seismic evaluation and retrofit of existing buildings that evolved from FEMA 273. It maintains the original concept of marrying seismic shaking intensities with specific structural and nonstructural performance levels. ASCE/SEI 41-17 provides two tables that delineate combinations of performance levels with seismic hazard levels for code-equivalent performance and a reduced performance that has been historically permitted for existing buildings. The nonstructural performance levels defined in ASCE/SEI 41 are Operational, Position Retention, Life Safety, and Hazards Reduced. For code-equivalent performance to that of new buildings, the seismic hazard level for which nonstructural design is required is the Design Earthquake.

The first two nonstructural performance objectives in ASCE/SEI 41-17, Operational and Position Retention, are intended to align with the requirements in ASCE/SEI 7 for component Importance Factor, $I_{p}$, equal to 1.5 and 1.0, respectively. The intent of the Operational Performance Objective is that the nonstructural components and systems will not experience damage in the chosen shaking intensity that would compromise their ability to function. Position Retention is the state where components are secured in their place following the chosen shaking intensity, but they may have sustained damage that prevents them from functioning. Position Retention is not intended to provide property protection. Life Safety and Hazards Reduced are intended for subsets of nonstructural components whose failure could cause loss of life or serious injury to one person or many people, respectively. The requirements for Life Safety and Hazards Reduced are the same as Position Retention, but are only intended to apply to specific components. 


\subsection{Development of Nonstructural Performance Objectives for Building Code}

\subsubsection{General}

In everyday operation, buildings provide safe shelter for occupants, and both the buildings and the components within them function effectively for the desired intent. Building occupants and pedestrians outside are not threatened by falling hazards, egress is unimpeded, and hazardous materials are contained. Water intrusion is prevented, breathable air is provided, temperatures are maintained within an acceptable range, fire and smoke protection systems are in place and operable, and power, communications, and plumbing systems function as intended.

In low intensity earthquake shaking, the typical building may experience minor damage of a cosmetic nature. Wall and ceiling finishes may experience minor cracking, acoustical tiles in suspended ceilings may be dislodged, and contents may fall from shelves. As shaking intensity increases, furniture and contents may topple, glazing systems may crack, and partitions and ceiling systems may suffer more damage. Under some level of seismic shaking, a typical building will experience impairment of the structure and the nonstructural systems, resulting in hazards for both occupants and neighbors during the main shock and aftershocks. For example, ceilings may collapse, heavy furniture may be displaced, cladding may fall, and doors may jam, making it difficult to exit the building safely. Pipes may break and discharge contents, and hazardous materials may be released. Electrical cabinets may topple, creating electrocution hazards and plunging parts of the building into darkness. In addition, the need for repairs can render the property unusable for a period of time or indefinitely; and, even if the building remains safe to occupy, important functions within it may be compromised.

Performance objectives help define more precisely the desired expectations for buildings and nonstructural components at different earthquake hazard or shaking levels. For buildings, performance objectives vary depending on the type of building and the functions it houses. Other than protecting against falling hazards in general, performance objectives for nonstructural components currently vary depending primarily on the function of the component and its importance in achieving the functional objectives for the building. The current code includes provisions intended to provide protection for items that may represent a serious threat to property. As such, current performance objectives of nonstructural components are somewhat dependent on the building performance objectives.

Code-based design requirements for new buildings, for both structural and nonstructural components and systems, focus on checking performance in the Design Earthquake, with the assumption that a design satisfying the design level requirements will implicitly lead to an acceptable level of performance at a lower 
"serviceability" level or in some special cases, better performance at higher earthquake levels (1.5 times the Design Earthquake). In the current ASCE/SEI 7 standard, structures are assigned to risk categories, with different levels of performance expectations and objectives for different types of buildings. Thus, "special" buildings, such as a hospital, fire station, police station, or emergency operations center, that provide important functions following a major event have higher objectives than the much more numerous "ordinary" buildings. It can be directly inferred that that these higher objectives are achieved at the Design Earthquake level by reducing the inelastic behavior in structures (represented by the inelastic reduction factor, $R$, divided by the earthquake Importance Factor, $I_{e}$, in calculations of design demands) and, for nonstructural components, by increasing the demands and associated margin against failure (represented by the component Importance Factor, $I_{p}$, in calculation of nonstructural demands). Additionally, there are fewer exemptions from seismic design, more restrictive story drift limits, and requirements to evaluate equipment for operability following Design Earthquake shaking and to provide enhanced quality assurance.

The building code represents a lower bound or "floor" for design. The level of seismic performance provided by a design satisfying minimum code requirements will depend on the specified Risk Category, seismic force-resisting system selected, and attention given to the design of the structural and nonstructural systems. A welldesigned code minimum building is likely to meet or exceed the performance objectives described in the ASCE/SEI 7 Commentary. Owners are free to select higher performance objectives if they have important functions and contents they wish to protect, or if they determine that the level of performance associated with a code minimum design will not meet their requirements. Increasingly, discussions of community and business resilience have raised questions as to whether it may be prudent for the building code or a community to encourage or require higher seismic performance to improve the speed and effectiveness of recovery from a major earthquake, or whether higher Risk Categories should be required for more facilities that are deemed vital to community recovery following a strong earthquake.

In addition to performance goals in the Design Earthquake, there is a general expectation that a building and its important components will continue to function when subjected to small or frequent earthquakes. In theory, the size of the serviceability level earthquake varies depending on the use or Risk Category of the building.

It should be noted that ASCE/SEI 7-16 presumes that the Design Earthquake is the functional level earthquake for buildings and other structures assigned to Risk Category IV. Thus, those nonstructural systems in Risk Category IV buildings that need to function immediately following the Design Earthquake in order for the facility to achieve its performance goals are assigned a component Importance 
Factor, $I_{p}$, of 1.5 and identified as designated seismic systems. In all buildings, certain safety critical nonstructural systems, such as egress stairs and fire protection systems, are also identified as designated seismic systems with a component Importance Factor, $I_{p}$, of 1.5. In ASCE/SEI 7, identifying a nonstructural component and system as a designated seismic system not only increases force and relative displacement demands on attachments, it also triggers requirements for design and analysis of the components or systems themselves, and for certain components, their seismic qualification by testing or earthquake experience data along with installation inspection.

\subsubsection{Philosophy for Nonstructural Performance Objectives}

In order to develop consensus performance objectives, an underlying philosophy must first be established. To help develop and refine a philosophy for nonstructural performance objectives, a range of issues were examined within the project team. The recommendations of the project participants are described below. Where unanimous agreement was not reached but most participants were in agreement, the majority and minority positions are presented. Where there was no clear agreement among participants, the reasons for the lack of agreement are also summarized.

- Should goals for nonstructural components be the same or less stringent than those for structural systems? Generally, unless there is a functional need, nonstructural goals can be less stringent than those for structural systems because for most nonstructural components and systems, the risk to safety given failure is lower. For example, collapse or partial collapse of a building has greater lifesafety consequences than failure of most nonstructural components, so it is reasonable to permit components to experience damage for $\mathrm{MCE}_{\mathrm{R}}$ shaking levels where the structural performance criterion is a low likelihood of building collapse, regardless of the level of structural damage. However, a limited number of nonstructural components critical to protection of life safety may need to maintain their function in strong but less severe shaking, even though some structural damage may be acceptable. For example, functional egress stairs are required for evacuation of occupants from damaged buildings. The performance expectation for egress stairs in the Design Earthquake is more stringent than for the structural system. If economic or functional consequences are considered as part of the design objectives, harmonization of performance levels between structural and nonstructural components is required.

- Should there be explicit performance objectives for nonstructural components at multiple levels of earthquake shaking? This is a controversial issue. It is desirable to establish clear expectations for the performance of nonstructural components across a range of earthquake shaking levels. For small and more frequent levels of ground shaking, it is typical to ask for and expect no 
or limited damage. For shaking at design level demands, some nonstructural damage can generally be tolerated in ordinary buildings, while limitations on damage are required in buildings that need to remain in service after an earthquake. A key question is whether there should be performance objectives for nonstructural components in the $\mathrm{MCE}_{\mathrm{R}}$. There may be a small subset of nonstructural components whose failure is more serious than the partial collapse of a building and thus should have performance objectives in the $\mathrm{MCE}_{\mathrm{R}}$. Additionally, there may be some components in Risk Category III or IV buildings that, because of the consequences of damage, should have performance objectives in the $\mathrm{MCE}_{\mathrm{R}}$. Some project participants believe that perhaps there should be a factor such as 1.5 applied to Design Earthquake forces and displacements rather than specifically stating performance objectives in the $M C E_{R}$. A natural extension of defining performance objectives at the $M C E_{R}$ would be to require both structural and nonstructural evaluations at the $\mathrm{MCE}_{\mathrm{R}}$, which would be a significant expansion of requirements. The majority of project participants felt such an expansion to be unnecessary for most components due to the cost of additional analysis and the limited information available about the performance of nonstructural components and systems in $\mathrm{MCE}_{\mathrm{R}}$ levels of shaking.

\section{- Should there be prescriptive design requirements for nonstructural} components associated with multiple levels of earthquake shaking? No, the building code is already complicated enough. Design should be required for one level of earthquake shaking as we do now. Calibration studies should be conducted to demonstrate that design for one level will generally provide the desired performance at the other earthquake levels.

- Approximately how many people have to be at risk from damage to a nonstructural component before making a mandatory requirement to try to

limit the risk? If one person's life is at risk from nonstructural failure, a reasonable degree of protection should be mandated to protect it. Damage to nonstructural components can often result in potential harm to a small number of people, such as if a single component falls and hurts one individual or a maintenance worker is in a mechanical room when an unanchored large piece of equipment moves and impacts the worker. The component failure could also be more severe such as a fallen heavy cladding unit that blocks an egress path or falls through a neighbor's roof, or the component failure could be quite severe such as a damage that results in large hazardous material release or gas line break than could endanger many. A desirable target is to provide a reasonable degree of protection against failure mechanisms that could realistically be foreseen to cause casualties, even if the impact is localized and the number of people impacted is small. Thus, light acoustic ceiling tile fallout at most locations may be of small concern as the risk of casualties is minimal even though many people 
are exposed, but an unanchored chiller is of concern as it could fall on top of or crush a worker in a mechanical room at the time of the event, even though few people are exposed. More stringent design requirements may be appropriate for nonstructural components that place large numbers of people at significant risk, such as a large canopy over a building entrance, a heavy ceiling over a theater or heavy cladding on a high rise. However, at this time, no explicit design changes are recommended to the minimum code requirements to address this.

- Should there be guidance on how to achieve improved performance for owner- or community-selected enhanced performance? Yes. This guidance will be increasingly important as awareness grows that design for expected performance of buildings is solely to satisfy minimum code requirements. By providing a framework to achieve enhanced performance, more owners are likely to select enhanced objectives and do so with greater effectiveness and economy. While the code will continue to establish minimum requirements, the framework can be used for implementing performance-based design and achieving enhanced performance when desired.

- How should the frequent earthquake be defined, and should it vary with building risk category? There is presently no consensus on defining the shaking intensity of the frequent earthquake. The term "functional level earthquake" has been used by some as a hazard level to include when establishing performance objectives. However, the intensity of shaking at which the building should remain functional varies, depending on what functions are in the building. Thus, for "ordinary" buildings where function is not expected following a design earthquake, the functional earthquake level by definition is less than the design earthquake. For "special" buildings and other structures like a hospital or fire station where function is expected following a design earthquake, the functional earthquake level is the design earthquake. It might be different for owner-selected enhanced functional performance. Given this issue, it is preferred not to use the term "functional level earthquake."

Shaking intensity with a $50 \%$ to $70 \%$ probability of exceedance in 50 -years was proposed by some project participants as a reasonable range for the hazard level used in establishing performance objectives for shaking below the design level earthquake for ordinary buildings and other structures. However, defining the shaking level for a frequent earthquake in probabilistic terms is challenging since depending on the site, the lateral force, expressed as a percentage of $\mathrm{MCE}_{\mathrm{R}}$ shaking, will vary from under $20 \%$ to over $50 \%$ of $\mathrm{MCE}_{\mathrm{R}}$ (compared with the Design Earthquake shaking level which is defined as $67 \%$ (or 2/3) of $\mathrm{MCE}_{\mathrm{R}}$ ). Conversely, if frequent shaking is designed as a percentage of $\mathrm{MCE}_{\mathrm{R}}$ (which would be most convenient for designers) it will represent an inconsistent probability of exceedance from site to site. 
A definition for frequent earthquake shaking could address these considerations by creating a two-fold definition such as: shaking intensity with a $50 \%$ probability of exceedance in 50-years or $25 \%$ of $\mathrm{MCE}_{R}$, whichever is larger. Further study is needed to determine a definition that has both a sound technical basis and widespread support.

\section{- Should there be performance objectives associated with the following?}

- Injury or death due to falling hazards. Yes, this is the most basic objective. It should be associated with "significant" falling hazards that pose a realistic threat of death or severe injury.

- Egress. Yes, this has been a stated goal in the code for many years, yet it lacks specific design provisions. Clear and enforceable design requirements should be developed. For example, in addition to designing stairs themselves to resist earthquake accelerations and drifts, it may be appropriate to impose higher design requirements for heavy cladding above and within a certain distance in plan from building exits and to protect piping, electrical, and other mechanical systems whose collapse or failure might render the exit pathway unusable. In addition, consideration should be given to designing doors of primary egress stairs and main exits of the building to be operable under anticipated building drifts.

- Hazardous materials. Yes, prevention of the release of hazardous materials is a simple and obvious goal. There should be higher requirements for the design, anchoring, and bracing of components and systems containing and distributing hazardous materials, compared to those containing nonhazardous materials. The quantity and type of hazardous materials at which point higher requirements would be triggered are established in the fire and life-safety codes, but this information must be communicated to the designer of the components. Guidance is provided in Chapter 1 of ASCE/SEI 7-16 for heavy industrial facilities containing hazardous materials.

- Property damage. Yes, in some cases. For buildings that must continue to function after an earthquake, damage should be limited to that which can be accommodated without loss of functional capability. For ordinary buildings where losses for select components can be minimized by simple means, design provisions aimed at limiting damage may be appropriate. General design requirements for property protection should not be mandated. However, it is desirable to have standards or guidelines on how to design to limit property damage in order to bring some consistency and reliability to promises of resilience. Clear recommendations for achieving improved nonstructural performance are also expected to foster better design and construction practices. 
- Postearthquake habitability. Yes. Establishing objectives for being able to shelter residents in place following certain size events is increasingly part of the mainstream discussion in the earthquake engineering community. Resilience in a community affected by an earthquake will be significantly impacted by the ability of residents to continue to occupy their dwellings, albeit possibly without full function and with some increased safety risk. Standards or guidelines describing how to design for postearthquake habitability are needed. However, postearthquake habitability should not be a mandated performance objective. There is a subtle but important distinction between habitability and usability. Habitability means a resident can be sheltered by the building with sufficient structural safety, but services may not be functioning such as sewer and water. This is not covered in ATC-20, Procedures for Postearthquake Safety Evaluation of Buildings, (ATC, 1989), the current de facto international standard. As long as there is reasonable access to sewer and water, the residents can still live in the building. This is exactly what was done in certain areas of Christchurch, New Zealand following the 2010 and 2011 earthquakes, where portable toilets, showers, and water were provided so that residents could continue to live in their damaged but still safe and habitable buildings. Jurisdictions may elect to relax certain code requirements after an earthquake in recognition of a lower threshold of acceptance for some occupancies. Further study is needed to develop design recommendations aimed at postearthquake habitability.

$\circ \quad$ Postearthquake operation of required or owner-selected functions. Yes. These will vary depending on the building use. If it is a hospital or fire station, the building code should continue to set minimum requirements aimed at achieving postearthquake functionality in the design earthquake shaking intensity. There should also be ways for owners interested in enhanced assurance of functionality to achieve it, and standards or guidelines to provide some consistency in design. This might include critical corporate data centers, manufacturing facilities, or laboratories.

- Should there be quantitative requirements associated with nonstructural performance objectives? Not at this time. There are insufficient data to calibrate a reliable quantitative risk as is done for buildings. In addition, a format for quantitative nonstructural requirements has not been established. However, this should be a long-term goal. 


\subsection{Recommended Framework for Nonstructural Performance Objectives}

Development of performance objectives begins with identification of the levels of earthquake shaking of interest. The expected damage of code-designed buildings can be described for each selected seismic hazard level. Understanding potential consequences of damage allows identification of behaviors that are to be avoided. Thus, undesirable consequences can be translated into target performance goals. For nonstructural components, a comprehensive and robust set of performance descriptions is needed to capture all components and systems, given the wide range of sizes, types, and functions of nonstructural components. Similar to structural systems, the performance descriptions need to be paired with hazard levels to create performance objectives. Design requirements can be developed from this foundation. This section describes each step in developing a framework for nonstructural performance objectives.

\subsubsection{Hazard Definition}

The level of earthquake shaking associated with performance objectives has been the subject of some debate. Since the publication of the Recommended Lateral Force Requirements and Commentary (SEAOC, 1974), also referred to as the "SEAOC Blue Book," there is general agreement that, as a minimum, buildings should resist minor earthquakes without damage, moderate earthquakes without structural damage but some damage to nonstructural components, and major earthquakes with substantial structural and nonstructural damage but without significant risk of collapse. The challenge is to quantify the hazard levels to allow for the development of clearly defined performance objectives.

It is recommended that nonstructural performance be described at three hazard levels consistent with the general tenets of the 1974 SEAOC Blue Book. In order to translate the performance objectives into the current code framework, use of the Design Earthquake and Risk-Targeted Maximum Considered Earthquake $\left(\mathrm{MCE}_{\mathrm{R}}\right)$ as two of the hazard levels is recommended. Definition of the lower level event, the "frequent earthquake," or "minor earthquake" as referred to in the 1974 SEAOC Blue Book, was the subject of some debate (see Section 2.3.2), and consideration was given to each of the following hazard descriptions:

- $\mathbf{5 0 \%}$ in 50-year hazard level. Based on the current USGS design maps associated with ASCE/SEI 7, the design accelerations $S_{D S}$ and $S_{D I}$ in the $50 \%$ in 50 -year level of shaking is a different percentage of the Design Earthquake at every site. A study that mapped design accelerations at the 50\% in 50-year hazard level in 34 cities in the United States found that they ranged from $7 \%$ to $77 \%$ of the Design Earthquake. Thus, adoption of the 50\% in 50-year hazard 
definition would result in site-specific design standards based on geography, if performance in the frequent earthquake is verified.

- 50\% in 30-year hazard level. The 1999 edition of the SEAOC Blue Book and some tall building alternate design guidelines propose the $50 \%$ in 30 -year hazard level as the frequent earthquake. Similar to the $50 \%$ in 50 -year shaking, accelerations for the $50 \%$ in 30 -year hazard level would be a different percentage of the Design Earthquake at every site, and thus suffers from the same drawback.

- $\quad \mathbf{2 5 \%}$ of $\mathbf{M C E}_{\mathbf{R}}$. Since the Design Earthquake shaking level is defined as $67 \%$ $(2 / 3)$ of $M C E_{R}$, from a design perspective, it would be efficient for the "frequent earthquake" to also be defined as a percentage of the $M C E_{R}$. However, such a definition would provide inconsistent levels of protection in areas of the country that are susceptible to infrequent large earthquakes such as in the east coast, when compared with regions susceptible to more frequent large earthquakes for which the design spectrum is capped.

- $\quad 25 \%$ of $\mathrm{MCE}_{\mathrm{R}}$ or shaking with a $50 \%$ probability in 30-year hazard level, whichever is greater. A criterion that is based on combined consideration of criteria may be a useful definition. In areas of the country subjected to infrequent earthquakes, this definition could serve as the basis for exempting many components and systems since their performance in minor earthquakes can be judged, based on experience, to be acceptable without added design measures.

Further consideration of these options and others will be needed to develop a quantitative "frequent earthquake" hazard definition that is widely accepted and consistent for comprehensive performance-based design. For the purposes of developing the framework for nonstructural performance objectives, the recommended hazard levels to be considered are summarized in Table 2.2.

Table 2-2 Proposed Hazard Levels for Design of Nonstructural Components

Hazard Levels

Frequent Earthquake

Design Earthquake (DE)

Risk-Targeted Maximum Considered Earthquake $\left(\mathrm{MCE}_{\mathrm{R}}\right)$

\subsubsection{Risks Associated with Nonstructural Damage}

Nonstructural damage can cause life loss or injury, property damage, or interruption of building function. Risks associated with nonstructural damage can therefore be grouped into three broad categories: (1) safety; (2) property; and (3) building function. Each is described below. 


\section{Safety}

Nonstructural damage can create safety breaches in many different ways depending on the size and nature of the component. Floor-mounted nonstructural components can slide or overturn under seismic shaking and wall-mounted or suspended components can become dislodged and fall. The consequences of these behaviors vary depending on the size and weight of the component, its contents, the contents of interconnected systems, and location. For example, damage to a lightweight acoustic tile ceiling grid has a low probability of causing serious injury or death. On the other hand, suspended equipment or a heavy ceiling over an auditorium would place many more people at risk of serious injury or death. In extreme cases, damage to nonstructural components could pose a serious safety threat to large numbers of people. In some cases, the threat is not to occupants inside the building, but to people outside the building who are vulnerable to dislodged cladding.

Central to modern building code requirements is the premise that in large earthquakes, damage to structural and nonstructural components is expected, but building occupants will be able to safely exit the building and first responders will be able to enter the building. Thus, nonstructural components should be designed to protect paths of egress including stairwells and exit ways. There is general agreement that in the Design Earthquake, it is desirable for stairs to be free of falling debris, doors of primary egress stairs to be operable, and the areas immediately outside egress doors to be free of heavy fallen debris. In addition, some believe that providing explicit protection from the stair to a safe zone outside the building should be an additional minimum code requirement. Others believe that occupants will ultimately develop an exit strategy and that more explicit design requirements are not appropriate.

Falling debris, jammed doors, and dislodged cladding can pose a safety threat to building occupants when exiting a building. Release of hazardous materials can pose a safety risk to building occupants and the surrounding community. Safety can also be compromised if a fire ignites. Nonstructural components are often the direct source of ignition such as when a gas-fueled piece of equipment moves and breaks the gas line. People can also be put at risk of injury or death if a fire ignites and the fire protection system is inoperable due to damage.

In addition, in some situations, damage to nonstructural components can cause direct damage to the structure such as when large and heavy warehouse contents or an industrial storage rack falls onto a column or bearing wall. In such cases, structural integrity can be at risk.

\section{Property}

If a nonstructural component or system is damaged, it will either need to be repaired or replaced. Depending on the component or system, the damage may require only 
local repair or replacement, such as when a partition cracks or an isolated cabinet overturns. On the other hand, some nonstructural damage can cause substantial indirect losses. For example, a single breach in a pressurized water pipe can cause water damage over a large area. If the release is not quickly stopped, the consequent damage can be orders of magnitude more than the cost of repair of the damaged pipe itself.

Damage may cause environmental breaches in the building enclosure. Consequent damage associated with exposure to weather can result.

\section{Function}

Nonstructural damage can make it difficult or impossible to carry out functions that are normally accomplished in a building.

Depending on the nature of the operations conducted in a building, loss of use or business interruption costs can pose long term financial risks to an organization. If a manufacturing facility loses the use of customized equipment and does not have an alternate means for production, for example, its financial viability could be in jeopardy. If the data systems that underpin an organization are not available due to nonstructural damage, business activities may need to be temporarily suspended until restoration. If a mid-rise or high-rise building does not have a functional elevator, it may not be occupiable. Nonstructural damage, particularly loss of utilities, may result in buildings being deemed unoccupiable by the Authority Having Jurisdiction, thereby preventing post-earthquake habitation.

\section{Expected Performance of Nonstructural Components in Code-Designed Buildings}

Table 2-3 presents the risk of nonstructural damage based on the performance consequences and hazard levels described above. Table 2-3 separates objectives by performance consequences grouped by safety, property, and function. The table separates risk statements into two broad categories: (1) those associated with components that are not required to function following the Design Earthquake, i.e., with a component Importance Factor, $I_{p}$, of 1.0; and (2) those associated with components that are required to function following the Design Earthquake $\left(I_{p}=1.5\right)$.

The risk statements in Table 2-3 are described as qualitative measures of risk. Recognizing that there are multiple types of components, a range of expected performance for each, and scarce data on the post-earthquake performance of code compliant nonstructural components, there is inherent uncertainty in performance and a quantitative statement of risk is not currently feasible. The qualitative statements of risk are proposed to serve as the foundation on which building code requirements for nonstructural components are built. 


\subsubsection{Nonstructural Performance Descriptions}

The performance column in Table 2-3 describes the consequences of nonstructural damage. In order to translate these into performance objectives for code design, the performance needs to be described in terms of performance to be achieved (rather than consequences to be avoided).

Table 2-4 presents nonstructural performance descriptions recommended for use in defining performance objectives. Similar to Table 2-3, the table is organized by the categories of safety, property, and function.

\subsubsection{Recommended Performance Objectives for Nonstructural Components}

While the qualitative nature of Table 2-3 reflects the nuances of performance and the gradation of risk, enforceable criteria require explicit requirements. Table 2-5 couples the performance descriptions of Table 2-4 with the hazard levels of Table 2-2 and presents the recommended nonstructural performance objectives for the building code in terms of explicit performance goals to be achieved. An entry denoted as "X" represents a performance objective for which design is required. Columns for "Frequent Earthquake" and "MCE $\mathrm{R}_{\mathrm{R}}$ " are left blank to highlight the translation and simplification from overarching performance objectives described in Table 2-3 to enforceable performance objectives of Table 2-5.

For ordinary buildings, very few components are required to be functional after the Design Earthquake. These components are designated in Section 13.1.3 of ASCE/SEI 7-16 and include fire protection systems, egress stairs, and components containing or conveying dangerous quantities of hazardous materials. For buildings with code-required functionality performance objectives, such as Risk Category IV buildings, any component necessary for continued operation of the facility should be designed for the more stringent requirements. For Risk Category III buildings, which cover a wide range of building types with earthquake functionality requirements that vary widely, the acceptable post-earthquake condition should be considered in determining which components should be designed for post-earthquake function. These component categories align with two code-defined component Importance Factors: $I_{p}=1.5$ for components required to function or requiring enhanced safety, and $I_{p}=1.0$ for all other components.

For components needed to be functional post-earthquake, it is assumed that the Design Earthquake is the earthquake level for which function must be retained, which is consistent with the current standard of practice. 


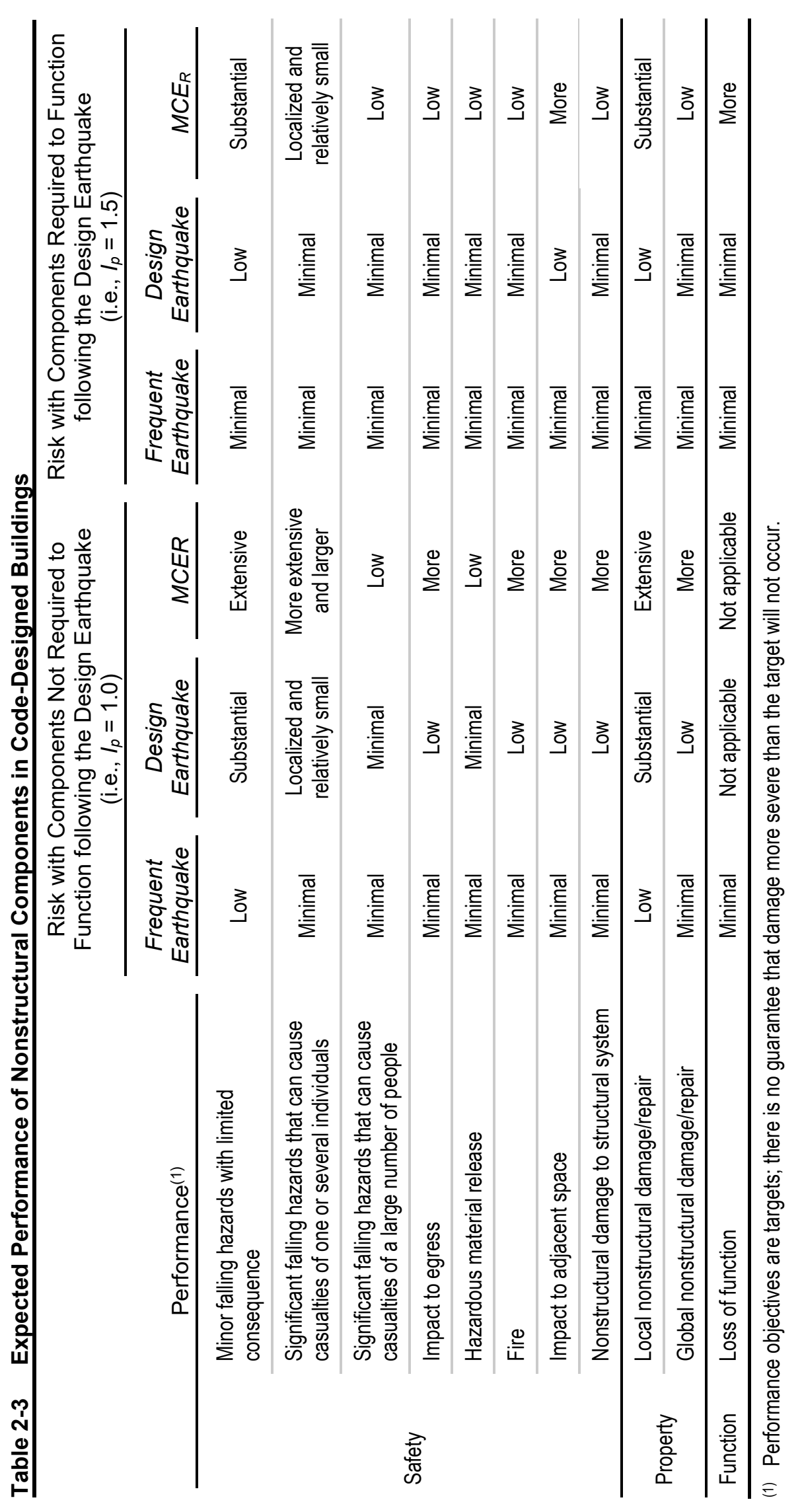




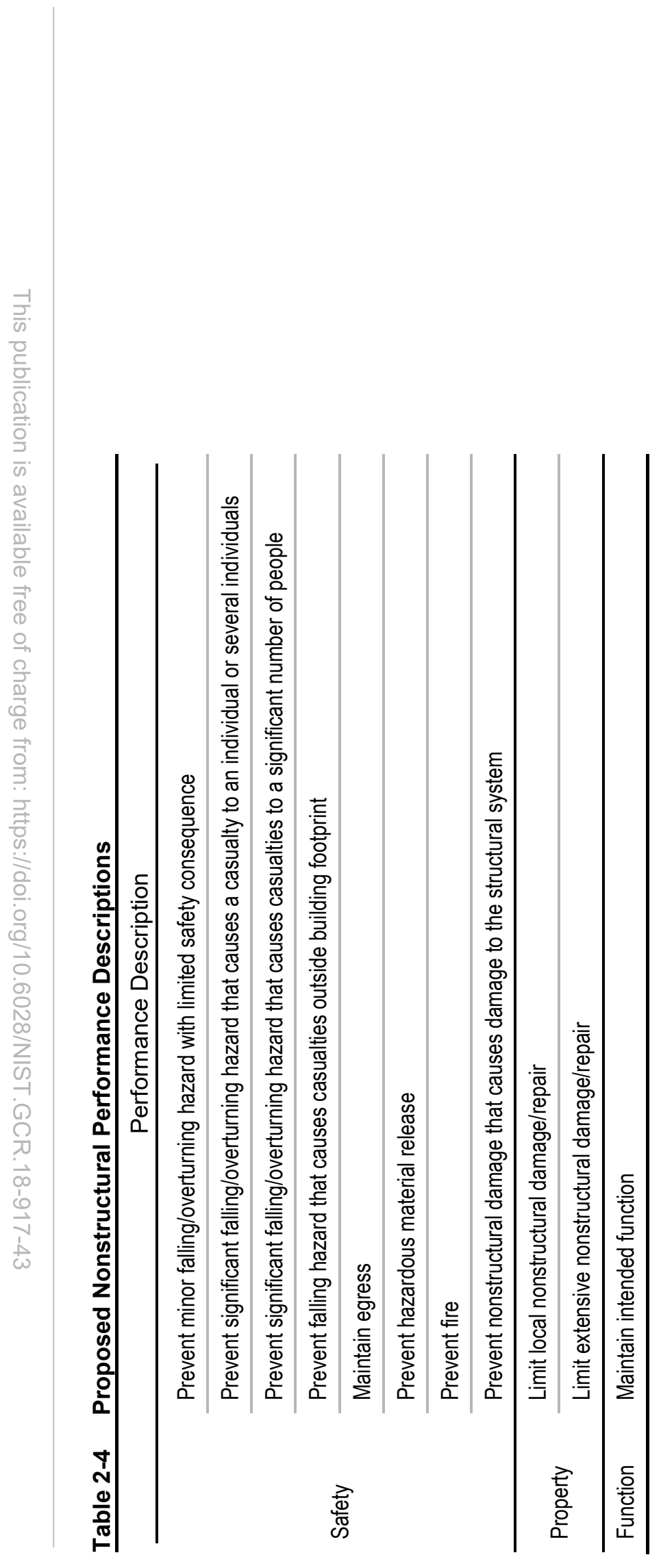




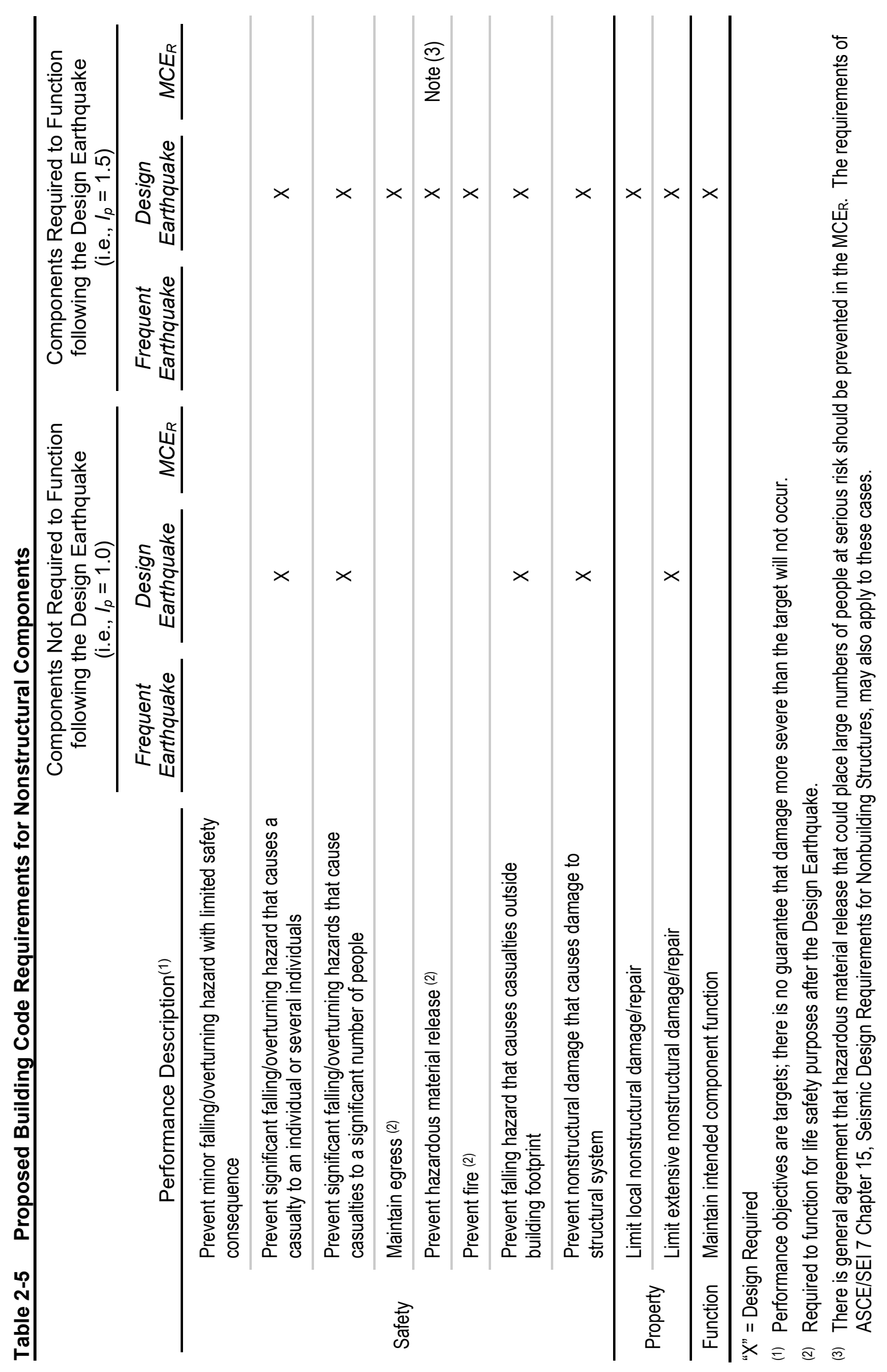

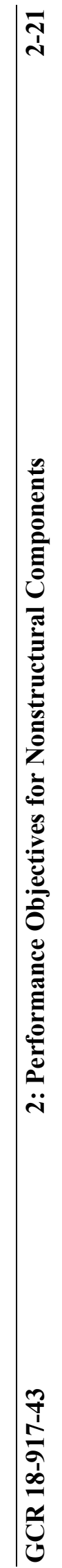


The following observations and clarifications apply to Table 2-5:

1. Consistent with Table 2-4, two separate entries are associated with "preventing significant falling/overturning hazard": one entry where an individual or several individuals are at risk and one where a large number of people are at risk. Although the code design requirements for these conditions are presently the same, the acceptable risk is not. Where large numbers of people are at risk from a falling hazard, such as where there are heavy suspended components over an auditorium, the acceptable risk is lower than when only a few people are at risk. Accordingly, when large numbers of people are at risk, it may be appropriate to design using a component Importance Factor, $I_{p}$, of 1.5 to provide a higher degree of reliability and level of safety.

2. Performance objectives associated with the frequent earthquake indicated in Table 2-3 are expected to be achieved by satisfying the requirements for the Design Earthquake. Additional calibration studies are needed to verify that code design provisions, including code exemptions for selected components, satisfy objectives at the frequent earthquake level.

3. Performance objectives associated with the $M \mathrm{MCE}_{\mathrm{R}}$ indicated in Table 2-3 are expected to be achieved by satisfying the requirements for the Design Earthquake. Additional calibration studies are needed to verify this.

4. Components that are required to function following the Design Earthquake and those for which a higher level of reliability or enhanced safety is desired should be designed using a component Importance Factor of 1.5. In ASCE/SEI 7, assigning a component Importance Factor of 1.5 not only results in higher design seismic force and relative displacement demands on attachments, it also triggers requirements for design, analysis of the components or systems themselves, and for certain components, their seismic qualification by testing or experience along with installation inspection.

Establishing performance objectives does not imply a warranty that the target performance will actually be met. The actual response of nonstructural components depends upon the intensity and characteristics of the actual ground motion, material property variability, structural configuration, the seismic force-resisting system, and as-built construction quality. Rigorous analysis results typically show a very wide range of possible outcomes. As a result, performance objectives are targets; there is no guarantee that damage more severe than the target will not occur. Some components, despite the best of intentions, will fail to meet the intended target.

\subsection{Enhanced Nonstructural Performance Objectives}

Buildings designed to satisfy the minimum building code requirements may suffer substantial nonstructural damage and consequently, may not be habitable or usable 
for extended periods following a large earthquake. In light of this, owners may elect to voluntarily design to a higher level of performance. Similarly, jurisdictions may elect to mandate enhanced levels of performance in an effort to increase community resilience to earthquakes.

In recognition of the economic and social disruption caused by damage residential and commercial buildings, NIST recently published a study identifying steps toward future development of a new immediate occupancy performance objective (NIST, 2018). The report identifies a large portfolio of research and implementation activities that target enhanced performance objectives for residential and commercial buildings.

Practical implementation of enhanced performance objectives in the near term can be tailored to an owner's needs and be limited to specific components or systems. The important first step is identifying those components for which functionality or increased reliability is important and secondly, developing a strategy for achieving enhanced performance.

\subsubsection{Strategies for Enhanced Performance}

Owner-initiated election of performance objectives is the essence of performancebased design. When code minimum design does not include the desired performance objective(s), a performance-based design approach can be employed. The first step is to identify the overarching performance objective for the building. Once that is defined, components or systems that need to be protected beyond the minimum requirements of the code should be identified and acceptable performance for those components should be defined.

When designing new buildings, strategies for protecting nonstructural components start with selection of the structural system. Many nonstructural components and systems, such as cladding, partitions, and piping, are vulnerable to damage associated with interstory drift. Reducing the interstory drift may directly reduce related damage. Most nonstructural components are vulnerable to horizontal accelerations. Thus, selecting systems that reduce floor horizontal accelerations, such as base isolation or highly damped systems, will tend to reduce the likelihood that they will be damaged. With an understanding of the fragilities associated with important nonstructural components and systems, the structural system can be selected and tuned to reduce the potential for damage.

In some cases, the structure may not be capable of achieving adequate limitations on drift or floor acceleration to protect selected nonstructural components in desired levels of shaking. Similarly, in existing buildings, there often is no opportunity to alter the structure for the purpose of reducing the potential for nonstructural damage. 
In these cases, other strategies must be employed. These may include relocating the component to reduce anticipated building deformations and/or floor acceleration. Where floor accelerations govern the design concern, critical nonstructural components are often located at the base of the building where accelerations are generally lowest. Alternatively, substitute components with higher capacities or verified functionality may need to be selected. For example, mechanical or electrical equipment shake-table tested and verified to remain functional under anticipated shaking may need to be specified. Alternatively, cladding may need to be changed or modified to accommodate the required drifts without unacceptable damage.

Another common approach for achieving enhanced performance is to design component anchorage and bracing for higher forces or for higher drifts by simply increasing the assigned Importance Factor. This will increase the shaking intensity at which the components retain their position without damage and increase their reliability in the Design Earthquake. However, it is recognized that simply increasing the design demands on a component is insufficient to increase its performance reliability, because it does not prevent internal component damage.

Providing better nonstructural performance generally involves explicit consideration of the damage that a component is susceptible to and attempting to prevent or reduce unacceptable effects. This goes beyond simply following the requirements in design standards. Nonstructural components are unique and it is not possible to include every factor influencing performance in a design standard. Designing to reduce the likelihood of damage in nonstructural components requires special attention during design and construction including the following:

- Consider the risk caused by all nonstructural components. The building code exempts some components and systems from seismic design requirements based on Seismic Design Category, size, weight, hanger length, and other parameters. However, components exempt from seismic design requirements, while unlikely to pose a significant safety risk, can still cause significant damage. For example, small diameter water pipes are generally exempt from seismic design requirements, but are vulnerable to damage, particularly at connections to equipment. Similarly, furniture and contents are exempt from seismic design requirements, but can still block egress paths, cause injuries, and cause disruption that can delay recovery. For enhanced performance, the consequences of damage to all nonstructural components and contents should be considered and protective measures put in place where anticipated performance is unacceptable.

- Select components that have inherent integrity to withstand earthquakes. For example, very light and tall shelving units or data racks and cabinets may be incapable of resisting significant seismic shaking without damage, even if they are well anchored. Components designed and tested for seismic resistance, or 
components that are inherently rugged, should be specified when component functionality is needed. For active mechanical and electrical components, selecting equipment that has been shake table tested for functionality will enhance reliability.

- Consider the lead time associated with replacing damaged equipment. Some equipment essential to maintaining building function may be damaged during an earthquake and require repair or replacement before service can be restored. Items with long lead times for replacement should be identified during design, and consideration should be given to procuring equipment that has been seismically qualified. The concept of "spares" used in heavy industrial facility design and construction should also be considered.

- Brace and anchor components using materials with demonstrated good performance. The entire load path needs to be explicitly designed using materials that have demonstrated reliable performance, verified by testing whenever possible.

- Provide flexible connections. Flexible connections should be provided between equipment and interconnected piping or distribution systems with loops designed to accommodate relative displacements, whenever there is a potential for significant differential movement between components.

- Consider the displacements of the structural system and adjacent nonstructural components. Although the building code already requires each nonstructural component's seismic interactions to be accounted for in design, this requirement does not address components or systems exempt from seismic design requirements and in practice, may not be rigorously inspected. Often, nonstructural systems are designed by different parties and independently from the design of the structural system. To achieve higher performance, the consequences of structural displacements and the relative motions of the structure and the nonstructural components should be considered to confirm there are no adverse effects. Additionally, the relative movement of adjacent nonstructural systems and how one might impact the other should be explicitly considered. Any potential for impact or other damage should be prevented by installing flexible connections, increasing the separation of systems or limiting the relative movement of all systems. Adverse interactions can be minimized in some cases using detailed 3-dimensional physical modeling of both the structure and nonstructural systems. However, detailed on-site inspections by knowledgeable personnel are still considered invaluable to identify unique conditions that could lead to earthquake damage.

- Provide installation quality control: Testing anchorage to concrete and observation to confirm that all connections were made as required by the design 
documents can significantly increase the likelihood that the intended performance objective will be achieved.

The steps taken to provide higher performance, and what components are selected for higher performance, should be clearly indicated on construction documents. For example, construction documents should indicate which items are simply designed for code minimum, which are designed for higher demands, and which are required to be certified for post-earthquake function and at what intensity. The enhanced performance objectives selected for a project can be tailored to an owner's needs and limited to specific components. The following examples highlight the use of enhanced objectives to satisfy project-specific goals.

\section{Example 1: Hospital}

In general, both the building service systems and the contents of hospitals are complex and expensive. To maintain functionality of the hospital, most of the nonstructural systems are required to perform without interruption after an earthquake. Continued hospital operation is increasingly dependent on nonstructural components and systems, including medical and building equipment. Hospital operations also depend on specialized services, some of which involve storage of hazardous substances, such as pharmaceuticals, toxic chemicals, oxygen, and other gases, that must be protected against spilling. Distribution systems for hazardous gases must be well supported and braced. Unlike most buildings, hospitals require a very extensive plumbing network to supply water throughout the building, and an adequate piping network to supply water for fire sprinklers, which increases the risk of secondary water damage in case of failure of these systems during earthquakes. Finally, hospital functions are becoming increasingly dependent on information technology, including electronic health records, and systems are becoming more integrated and interdependent.

Hospitals are categorized as Risk Category IV in accordance with Table 1.5-1 of ASCE/SEI 7-16. ASCE/SEI 7-16 Chapter 13 states that the component Importance Factor shall be taken as 1.5 if "the component is in or attached to a Risk Category IV structure and is needed for continued operation of the facility or its failure could impair the continued operation of the facility." Thus, ASCE/SEI 7-16 does not require that every nonstructural component in a hospital be classified as having an Importance Factor of 1.5. Rather, it requires consideration of whether a component is needed for continued operation. For example, a refrigerator storing blood or pharmaceuticals is likely needed for continued hospital function, while a refrigerator in the staff lounge is not. Adding to the complexity is that damage to a non-essential component could cause damage to a connected system, such as power, water, or gas, thereby jeopardizing interconnected essential components. 
Rather than requiring classification of nonstructural components on a project-byproject basis, the Office of Statewide Health Planning and Development (OSHPD), which regulates hospital construction in California, requires all nonstructural components in acute care hospitals to be categorized as having an Importance Factor of 1.5. This increases the scope of components requiring seismic design, as well as the design demands.

In addition to requiring explicit seismic design for most components, OSHPD conducts detailed plan reviews to ensure that designs are complete and coordinated and in conformance with the building code. Equipment needed for maintaining essential hospital functions is required to be shake-table tested, as required by the code. On-site inspection during construction is required to confirm that the approved design is implemented. Any deviations or changes to the approved plans are reviewed during construction. Testing and inspection of installations are required and unforeseen conditions that could compromise performance are resolved prior to occupancy.

\section{Example 2: Research Laboratory (Wet Lab)}

Laboratories where chemicals, drugs, or other material or biological matter are tested and analyzed requiring water, direct ventilation, and specialized piped utilities are considered wet laboratories. These facilities typically contain a range of specialized computers, electronic equipment, microscopes, and other mixing, sorting, and measuring equipment, along with storage systems from shelving to freezers, refrigerators, and tanks. Equally important is the value of the research itself. Refrigerators and freezers can contain irreplaceable specimens. Computer hard drives store data for research in progress. Laboratories represent both a concentration of research and a concentration of valuable equipment and ideas.

Laboratories storing irreplaceable specimens, or housing important research activities that could not be easily replicated elsewhere, should be designed for enhanced performance of nonstructural components. This may include designing seismic restraints for most benchtop equipment, which are typically exempt from building code requirements, selecting equipment and designing seismic restraints to increase the likelihood of continued function $\left(I_{p}=1.5\right)$, and providing back-up sources of power, cooling, or other utility services to address potential interruptions.

In addition to requiring explicit seismic design for all vulnerable components, essential equipment needed for maintaining critical functions should be shake-table tested for post-earthquake reliability. Detailed on-site testing and inspection during construction should also be conducted to verify that all vulnerable components are protected and that there are no conditions that could cause adverse interactions between components. 


\section{Example 3: Data Center}

Designing a data center to remain functional following an earthquake requires attention to protecting equipment including data servers, batteries, cable trays/conduit, cooling systems, security systems, and fire suppression systems. In addition, for new building design, cladding should be designed to accommodate anticipated seismic demands without damage that would unacceptably compromise the environmental protection it provides or require repairs that would require removal or replacement of the cladding.

In order to prevent damaging water release in an earthquake, non-water-based fire protection systems are typically used for equipment rooms in data centers.

Data centers are often considered "Essential Facilities" and designed for Risk Category IV. Similar to hospitals and critical labs, essential equipment needed for maintaining critical functions should be shake-table tested for post-earthquake reliability. Detailed on-site testing and inspection during construction should also be conducted to verify that all vulnerable components are protected and that there are no conditions that could cause adverse interactions between components.

Server racks and cable trays in data centers may occasionally undergo relocation. Consequently, a comprehensive plan for enhanced seismic performance should also include periodic inspections after installation. The plan should also include detailed post-earthquake procedures for verifying functionality of all systems and strategies for addressing damage that may occur.

\subsubsection{Beyond Design}

Achieving functionality after an earthquake is related to nonstructural performance, as described. However, there are many additional ways that building owners can increase their resilience in the wake of an earthquake. Effective strategies include:

- Maintaining on-site personnel with planned procedures to quickly identify and repair infrastructure damage, particularly damage to pressurized water piping or other systems that can lead to considerable collateral damage

- Providing redundant services at an alternate site

- Maintaining back-up components to repair or replace damaged equipment

- Having access to materials and workers capable of making repairs in the immediate aftermath of an earthquake

- Having access to engineers specializing in seismic protection of nonstructural components to survey, assess, or assist with designing repairs to nonstructural components. 


\subsubsection{Objectives for Community Resilience}

There has been a growing recognition that the minimum safety requirements in building codes and standards may still result in unacceptable disruption to a community following a major earthquake. The SPUR Resilient City project looked at this paradigm for the City of San Francisco and produced a number of recommendations to enhance the building stock. In addition, NIST undertook a multi-year project to look at community resilience in response to many different types of natural disasters. The resulting NIST Community Resilience Planning Guide (NIST, 2016), and The Resilient City report (SPUR, 2009) recommend that building and infrastructure performance objectives be based on time required to resume function following three different intensity events: moderate, major, and extreme.

The target time to restore functionality depends on the importance of the building function to the community. In order to achieve such goals, consideration of function of specific nonstructural components and the control of damage to other components and systems is important. Often, the requirements of the code for position retention will be insufficient. Communities may elect to augment the requirements of the building code for specific buildings based on their function to the community. For communities with an older building stock, it may be desirable to design selected new buildings for enhanced nonstructural objectives to enhance the likelihood that basic community needs can be met after an earthquake.

\subsubsection{Shelter-In-Place Objectives}

Community resilience requires buildings to remain habitable and repairable so that occupants can live safely in them even before repairs begin. The related performance objective for single- and multi-family housing would be "shelter-in-place." This means that the building may have sustained some damage, but the structure has not been damaged to the point it would receive anything other than a green placard in a postearthquake safety evaluation per ATC-20. Major nonstructural falling hazards that would pose a safety hazard are addressed, for which the current code requirements are sufficient. However, the performance of other nonstructural components and systems is not as clear. Considering the exterior envelope of the building, should it be weather tight or is it acceptable to have limited damage that provides a safe barrier between the inhabitants and the outside? If the former, operational $\left(I_{p}=1.5\right)$ requirements may be sufficient. However, if it is the latter, then some intermediate performance state where the seals between the glazing and the walls may break, but the glazing does not crack and fall out may be acceptable. What about the condition of piping? If pipe breaks cause sufficient water release for an extended period, it may render the space uninhabitable. Thus, careful consideration for protecting pipe breaks would be important during design. 
Key to sheltering in place after an earthquake will be gaining jurisdictional approval for continued occupancy. This will involve considerations of ventilation, water supply, weather protection, heating, sanitation, power, security, and other considerations, which will vary by jurisdiction, climate, and occupancy. In order to allow buildings to be occupied, temporary services for power, water, and sanitation will generally be needed. Advance planning that provides hook-ups for temporary systems may be useful for large buildings potentially sheltering many people following a large earthquake.

\subsubsection{Damage Control Objectives}

In order to rebound quickly after a major earthquake, communities need the ability to contain the effects of earthquakes when they occur, to carry out recovery activities in ways that minimize social disruption and to rebuild in ways that mitigate the effects of future earthquakes. The more quickly a community is able to rebound from a major event, the more resilient it is. Many types of nonstructural damage can extend the length of time required for recovery. For example, dislodged cladding, or cladding that is vulnerable to falling off a building, may require street closures that would severely hamper recovery efforts, particularly if tall buildings are involved. Similarly, extensive damage to fire protection piping can lead to a loss of water pressure thereby reducing firefighting capabilities. It can also trigger the need for building evacuation and cause extensive collateral water damage. These examples highlight the role that nonstructural damage has in community recovery. Jurisdictions interested in becoming more resilient and reducing their vulnerability to damage may elect to enhance enforcement of existing building code requirements, impose higher than code minimum standards, or increase nonstructural inspections. 


\section{Chapter 3}

\section{Review of ASCE/SEI 7-16 Seismic Requirements for Nonstructural Components}

This chapter summarizes the principal findings of a detailed review of the current procedures for seismic design of nonstructural components found in Chapter 13 of ASCE/SEI 7-16, Minimum Design Loads and Associated Criteria for Buildings and Other Structures, (ASCE, 2017a). The nonstructural component seismic requirements in ASCE/SEI 7-16 Chapter 13 apply to components supported within a structure in Seismic Design Categories (SDC) D through F, and, with some exceptions, $\mathrm{B}$ and $\mathrm{C}$. They are also commonly applied to many ground-supported components.

The overall arrangement of Chapter 13 is unchanged from the 2005 and 2010 editions of the standard. The requirements are organized into six major sections:

- Section 13.1: General

- Section 13.2: General Design Requirements

- Section 13.3: Seismic Demands on Nonstructural Components

- Section 13.4: Nonstructural Component Anchorage

- Section 13.5: Architectural Components

- Section 13.6: Mechanical and Electrical Components

Each section of ASCE/SEI 7-16 Chapter 13 was examined for clarity, consistency, and enforceability, and recommendations for improvements are provided. Only the most significant findings and recommendations are discussed in this chapter, and where there were dissenting views on the recommendations, they are presented. Appendix A of this report presents an expanded discussion of technical requirements, recommendations for clarifications, enhancements, and further study pertaining to ASCE/SEI 7-16 Chapter 13. The primary audience for this chapter is members of the 2020 NEHRP Provisions Update Committee's Issue Team 5, Nonstructural Components, and the ASCE/SEI 7-22 Technical Committee TC-08, Nonstructural Components. 
In the following sections, all references are to chapters and sections of ASCE/SEI 7-16, unless designated otherwise. Portions of ASCE/SEI 7-16 have been reprinted in italics, with permission from ASCE.

\subsection{General (ASCE/SEI 7-16 Section 13.1)}

Section 13.1 outlines the general provisions for seismic design of nonstructural components. The section specifies when the provisions of the chapter apply and, if applicable, the specific criteria that will be applied. It provides criteria for identifying critical components, as well as those that are exempt in whole or in part from the requirements. Finally, it provides information on the use of reference standards for seismic design.

Chapter 13 references provisions of other chapters in ASCE/SEI 7-16 related to seismic design when needed. There are references to Chapter 12 for variables used in equations, load combinations for use with the overstrength factor, and output from a building dynamic analysis for use in the alternate lateral force calculation. Users who are familiar with the design requirements for buildings in Chapter 12 will notice that a number of seismic design concepts used for buildings (including torsional effects, bi-directional horizontal loading, and redundancy) are absent in the nonstructural provisions and thus not required.

The general charging language for the chapter is found in Section 13.1.1 as follows:

13.1.1 Scope. This chapter establishes minimum design criteria for nonstructural components that are permanently attached to structures and for their supports and attachments. Where the weight of a nonstructural component is greater than or equal to $25 \%$ of the effective seismic weight, $W$, of the structure as defined in Section 12.7.2, the component shall be classified as a nonbuilding structure and shall be designed in accordance with Section 15.3.2.

The scoping section includes a number of terms that are defined in ASCE/SEI 7-16 Chapter 11:

Component, Nonstructural: A part of an architectural, mechanical, or electrical system within or without a building or nonbuilding structure.

STRUCTURE: That which is built or constructed and limited to buildings and nonbuilding structures as defined herein.

The terms "building" and nonbuilding structure are also defined in ASCE/SEI 7-16 Chapter 11:

BUILDING: Any structure whose intended use includes shelter of human occupants. 
NONBUILDING STRUCTURE: A structure, other than a building, constructed

of a type included in Chapter 15 and within the limits of Section 15.1.1.

Given these definitions, a literal application of Section 13.1.1 suggests that while the definition of nonstructural components includes items "within and without a building or nonbuilding structure," components supported on grade outside of a structure are not subject to the seismic requirements of Chapter 13, since they are not permanently attached to a structure. In practice, most engineers apply Chapter 13 to all nonstructural components, regardless of location, but the ambiguity in scope has been confusing to some. The scope of the nonstructural requirements should be revised to clearly identify those components and systems that require seismic design, regardless of whether they are within or supported by building or nonbuilding structure, or if they are supported on grade.

When the weight of a nonstructural component is greater than or equal to $25 \%$ of the effective seismic weight, $W$, of the supporting structure, the component is designed as a nonbuilding structure supported by a structure, using the procedures in Chapter 15. The requirements for this condition were introduced in the 1988 Edition of the Uniform Building Code (ICBO, 1988) and were included in the 1997 Edition of NEHRP Recommended Provisions for Seismic Regulations for New Buildings and Other Structures (FEMA, 1998). When design recommendations for nonbuilding structures were added to the 2000 Edition of NEHRP Recommended Provisions for Seismic Regulations for New Buildings and Other Structures (FEMA, 2001), these requirements were retained and expanded in the nonbuilding structure chapter. There are continuing concerns regarding the origin and technical basis of this design approach.

A number of items are covered in both the nonstructural and nonbuilding structure chapters. A growing concern in the nonbuilding structures community is the tendency of engineers to refer to ground-supported nonbuilding structures as nonstructural components (especially tanks and vessels). This is done in order to avoid the nonbuilding structure design and anchorage requirements, which are substantially more rigorous than those in the nonstructural provisions. This issue was explored by Bachman and Dowty (2008), who pointed out that the wide variety of real-world items make it very difficult to develop prescriptive criteria to delineate between nonstructural components and nonbuilding structures. They suggested several approaches to differentiate between nonstructural components and nonbuilding structures based on the size of the item, whether it is factory or field assembled, and the basis of design and construction. Other approaches to differentiate between nonstructural components and nonbuilding structures were identified during the review and could be explored - approaches that also consider the period of the item, the potential for dynamic amplification, and whether the item degrades in stiffness during the course of an earthquake. The scoping language 
should be revised to clearly distinguish items subject to Chapter 13 requirements and those that fall under Chapter 15. The design forces produced by the procedures in Chapter 13 and Chapter 15 should be consistent insofar as possible, so that the main difference is the more rigorous analysis procedures required in Chapter 15.

Section 13.1.1 requires design for nonstructural supports, which are defined in Section 11.2:

SUPPORTS: Those members, assemblies of members, or manufactured elements, including braces, frames, legs, lugs, snubbers, hangers, saddles, or struts, and associated fasteners that transmit loads between nonstructural components and their attachments to the structure.

Chapter 13 provides little design guidance for supports, while in contrast Chapter 15 provides design guidance for a variety of supporting structures such as pipe racks, trestles, and equipment platforms, including references to material design standards and detailing criteria based on seismic hazard level. The requirements for the design of nonstructural supports should be expanded, and the possibility of referencing Chapter 15 for some types of supports should be explored as well. When the term "attachments" is used, it is often assumed to describe elements between the component supports and the structure such as anchor bolts, but it also includes other connections between the component and supports. Both types of attachments are of critical importance.

Finally, Chapter 13 "establishes minimum design criteria for nonstructural components that are permanently attached to structures..." This has been viewed as a circular argument for many endeavoring to determine whether seismic restraint is required. If a component is not seismically restrained, does that mean it is not "permanently attached" and therefore restraint is not required? The language tends to be particularly confusing when applied to floor-mounted components weighing less than 400 pounds, which are exempt from Chapter 13 design requirements but must meet some prescriptive requirements.

Section 13.1.2 provides the following criteria for assigning a Seismic Design Category to the nonstructural component:

13.1.2 Seismic Design Category. For the purposes of this chapter, nonstructural components shall be assigned to the same Seismic Design Category as the structure that they occupy or to which they are attached.

The concept of "attached" should include not only structural attachments but also connections through distribution systems such as pipes, ducts, and conduits. For nonstructural components that are outside of a structure, the Seismic Design Category should be based on the facilities with which they are associated. 
Section 13.1.3 defines the component Importance Factor, $I_{p}$, which influences both the force and displacement design demands for nonstructural components. It also may trigger additional design, detailing, testing, and inspection requirements.

Nonstructural components with $I_{p}$ greater than 1 are considered "designated seismic systems." Section 13.1.3 assigns component Importance Factors of 1.5 to components required to function for life-safety purposes after an earthquake, components that convey or contain toxic, hazardous, or explosive materials above a certain amount, and components in or attached to Risk Category IV structures needed for continued operation of the facility. All other components are assigned an $I_{p}$ of 1.0. In some cases, an engineer may wish to use higher lateral forces for the design of select nonstructural components. The provisions should state that designing a nonessential component for a higher lateral force than the code minimum does not trigger the other requirements for designated seismic systems.

The Authority Having Jurisdiction makes the determination of what materials are deemed toxic, highly toxic, or explosive, and establishes the quantities of materials deemed to pose a threat to the public, using criteria in the fire and life safety codes. There should be a requirement that information on the presence of toxic and explosive materials be provided to the design professional. Components required to control and isolate nonstructural systems that contain toxic, highly toxic, or explosive substances so they are in safe condition should also be assigned a component Importance Factor of 1.5.

Section 13.1.4 introduces a list of components and systems that are exempt from all requirements of Chapter 13. Exemptions are provided for furniture, temporary or movable equipment, and certain components in SDC B and C based on the component Importance Factor, and select components in SDC D, E, and F based on the size, weight, and component Importance Factor. In addition to the exemptions listed in Section 13.1.4, there are exceptions in Sections 13.5 and 13.6 for some types of components that exempt them from specific aspects of the seismic design requirements.

There are a number of concerns about the exemptions in Section 13.1.4. The exemption for furniture is felt to be applied too broadly, and the exemption for temporary or movable equipment can be applied to heavy items on casters such as lab benches that, while movable, remain in place for long periods of time. The charging language of Section 13.1.4 states that the nonstructural components listed in the section are exempt from the requirements of Chapter 13. However, distribution systems exempted in Section 13.1.4 Item 7 are still subject to a number of requirements in Section 13.6, and more importantly, the attachment provisions of Section 13.4. The exemptions could be limited to list components which actually are completely exempt from all provisions of the chapter. Components that may be exempt from design and lateral bracing, but must meet criteria, such as positive 
attachment or connection flexibility, could be moved to a new section for components that are exempt from some but not all requirements.

The term "positive attachment" should be defined in the body of Chapter 13. ASCE/SEI 7-16 Commentary Section C13.1.4 states that "Positive attachment is provided when the attachment is carried out using appropriate structural-grade materials whereby explicit design calculations for the anchorage are not required." While calculations are not required for positive attachment, prescriptive requirements based on the size of the component could be developed. The description in the commentary could be modified to describe the nature of the attachments (such as mechanical connection using bolts, welds, screws, or similar means that do not rely on friction) and establish minimum tension and shear capacities for attachments, which could be developed based on the weight of the exempt item. The use of adhesives or other types of fasteners, such as fabric hooks or tethers, for positive attachment could be considered for small items.

\subsection{General Design Requirements (ASCE/SEI 7-16 Section 13.2)}

Section 13.2 provides the procedures for establishing compliance of nonstructural components and systems with the seismic design provisions of ASCE/SEI 7-16. It includes a description of the required scope of the seismic design and the methods permitted for establishing compliance with the standard.

The scope of the seismic design for nonstructural components is determined by referencing Table 13.2-1. Seismic design is required for supports and attachments of all nonstructural components, and for the component itself. In prior editions of ASCE/SEI 7, seismic design of the mechanical and electrical components themselves was only required for designated seismic systems, nonstructural components with a component Importance Factor, $I_{p}$, greater than 1.0. In ASCE/SEI 7-16, the overall scope of seismic design required for architectural, mechanical, and electrical components is identical, regardless of $I_{p}$. However, the detailed design provisions for mechanical and electrical components in Section 13.6 of ASCE/SEI 7-16 limit the instances where design of the component itself is required when $I_{p}$ for the component is equal to 1.0 .

Compliance with the seismic design provisions may be demonstrated by project specific design and documentation by a registered design professional or a manufacturers' certification that the component is seismically qualified. Seismic qualification may be in the form of analysis, testing, or experience data.

Section 13.2.2 provides the requirements for components with $I_{p}=1.5$. It includes active mechanical and electrical components and components with hazardous substances. The building and fire codes define Hazardous Materials as "those chemicals or substances that are physical hazards or health hazards as classified in 
Section 307 and the International Fire Code, whether the materials are in usable or waste condition." The fire and life safety codes guide the Authority Having Jurisdiction in making the determination of what materials are deemed toxic, highly toxic, or explosive, and establishes the quantities of materials deemed to pose a threat to the public. This information must be provided by the designer of the nonstructural components that convey, support or contain these materials so that the appropriate importance factor can be selected. Accordingly, Section 13.1 should include a requirement that information must be provided to the designer on the presence of toxic, highly toxic, or explosive materials contained, conveyed, or supported by nonstructural components under design.

Section 13.2.3 requires that failure of a nonstructural component shall not result in the failure of an essential component. The term "essential component" is not defined in Chapter 11 or Chapter 13, and might be better referred to as a "designated seismic system." The ASCE/SEI 7-16 commentary on Section 13.2.3 suggests a much broader scope for this section than what the standard contains, discussing relative displacements between multiple points of support and displacements between component assemblies, the consideration of impact with other nonstructural components or structural elements, and the flexibility and ductility of the connections between distribution systems and the equipment. An effort should be made to provide provisions for estimating displacement within component assemblies. In lieu of a detailed analysis, a prescriptive requirement to provide a specified clearance between the component and what it might impact could be developed, as is currently provided for the installation of sprinkler piping systems in ASCE/SEI 7-16 Section 13.2.3.1 and Chapter 9 of the 2016 Edition of NFPA 13, Standard for the Installation of Sprinkler Systems, (NFPA, 2016).

Section 13.2.4 is intended to deal with the ability of the component itself to accommodate displacements due to both story drift and deflections of components between points of support, as well as consideration of anchor and support stiffness on component behavior. The section needs to be expanded to more fully align with the intent.

\subsection{Seismic Demands on Nonstructural Components (ASCE/SEI 7-16 Section 13.3)}

Section 13.3 describes the methods for computing the force and displacement demands on nonstructural components. The methods for determining horizontal and vertical seismic forces are described in Sections 13.3.1.1 and 13.3.1.2, respectively. Section 13.3.1.3 covers non-seismic loads greater than the calculated seismic loads. Section 13.3.1.4 provides options for determining the design force using dynamic analysis, including floor response spectra. The technical aspects of the seismic force equations are a focus of studies summarized in Chapters 4 and 5 of this report, and 
are not discussed here. The following discussion is focused on the clarity, consistency, and enforceability of the design requirements.

Horizontal loads, $F_{p}$, must be applied in combination with service or operating loads associated with the component as well as dead loads, although this is not explicitly stated. There are no references to seismic load combination formulas in Chapter 13, aside from the reference to allowable stress design (ASD) load combinations in Section 13.1.8 and a reference to the special load combinations of Section 12.4.3 for anchors in Section 13.3.1. A specific reference to the appropriate load combinations should be made, similar to what is done in Section 15.4.1 Item 8 for nonbuilding structures. In the past, mixing of ASD and load and resistance factor design (LRFD) demands and capacities has occurred, and a discussion of this issue should be added to the commentary.

Section 13.3.2 requires that the effects of seismic displacements be considered. Seismic relative displacements are determined for displacements within structures in Section 13.3.2.1 and between structures in Section 13.3.2.2. There are general requirements that nonstructural components be designed to accommodate relative displacements (Section 13.1.7 Item 2, Sections 13.4.1 and 13.6.2). There is guidance for specific components in Sections 13.5 and 13.6, but there is no general guidance on how the effects of displacements are to be considered for other nonstructural components.

\subsection{Nonstructural Component Anchorage (ASCE/SEI 7-16 Section 13.4)}

This section covers the requirements for attaching components to the structure. Components must be positively attached to the structure, with the exception of rooftop solar panels that meet the requirements of Section 13.6.12. A continuous load path between the component and the structure is required, and must be documented. While this section is titled "Nonstructural Component Anchorage," it should be revised to "Nonstructural Component Attachments," since anchors are a subset of attachments that also includes welds, screws, and other forms of attachment.

There are two load paths to consider: the load path from the component through the supports to the attachments to the supporting structure (or to grade); and, for components supported by a building, nonbuilding structure, or independent foundation, the load path from the point of attachment to the structure to the point in the structure where the loads from the nonstructural component no longer govern the design of structural members or connections. The paragraph should be revised to clarify this intent, and what is meant by "structure" and "supporting structure." 
This section limits the value of the component response modification factor, $R_{p}$, to 6 when calculating demands in attachments. There is a general concern that the use of values of $R_{p}$ of 9 and 12 is inappropriate for nonstructural components in general, as they imply a very high level of inelastic response in the component. In practice, the minimum design force in Section 13.3.1.1 governs in nearly all cases when $R_{p}=9$, and in every case when $R_{p}=12$.

Section 13.4.2 contains the requirements for determining the demands and capacities for cast-in-place and post-installed anchors in concrete and masonry. Factors of safety for post-installed anchors are established through acceptance criteria developed by product evaluation services, not ASCE/SEI 7-16. In recent editions of the International Building Code (IBC), strength design loads for post-installed anchors are determined using statistical evaluation techniques and are based on the $5 \%$ fractile of test results, which provides a very high level of confidence in the anchor capacities. Strength reduction factors varying from 0.60 to 0.75 are applied to account for normally expected variations in anchor resistance, and the capacities of anchors may in some cases be reduced by a further $25 \%$ when resisting seismic forces. Where a ductile steel yielding element cannot be identified in the component load path, these anchor capacities are compared to demands calculated using an overstrength factor, $\Omega_{0}$, that varies from 1 to $2 \frac{1}{2}$. Although these provisions provide conservative estimates of the capacities of anchors in concrete, the degree of conservatism inherent in the design of nonstructural components and their supports is not well understood. The implicit safety factors for both nonstructural components and post-installed anchors are needed to calibrate the values of $\Omega_{0}$ and improve the confidence that nonductile anchors in concrete and masonry have sufficient capacity.

The procedures for the application of component-specific overstrength factors should be reviewed. Determining when the overstrength factor $\Omega_{0}$ should be applied can be difficult for the designer, with criteria included in both ASCE/SEI 7 and the concrete and masonry standards. A discussion of when it is appropriate to apply the overstrength factor to demands on anchors should be included in this section for the convenience of the user, even if it repeats information that is available in the concrete and masonry standards. When determining the design strength of the anchor for comparison with the capacity of the yielding element, it should be clarified that for the purposes of this check, the design strength may be governed by yielding of the anchor itself or a nonductile failure mode, whichever is less. The design requirements should encourage the use of connections with ductile bodies along with capacity design of the other elements of the connection, similar to the procedures in the National Building Code of Canada (NRC, 2015). Criteria for the use of shot pins in concrete and masonry needs clarification, including whether it is intended that $\Omega_{0}$ be applied when using the prescriptive capacities for shot pins. 
Prying occurs in many connections, and the effects of prying on attachments are often ignored in design, especially for eccentric hangers. References can be made in the commentary to other standards that deal directly with prying in connections. In addition, instances where prying can be ignored should be discussed.

The design of multiple attachments at one location is also discussed. Designs of anchorage to concrete in accordance with Chapter 17 of ACI 318, Building Code Requirements for Structural Concrete and Commentary, (ACI, 2014) are considered to satisfy the requirement. The most common application for this requirement is probably in base plates with multiple anchors, although there are other possible applications. For example, an air handler may have a long row of anchor bolts along each side of the component. In such cases, the requirements of ACI 318 Chapter 17 may not adequately address the situation, since ACI 318 deals with groups of anchors in close enough proximity that capacity of an anchor is influenced by an adjacent anchor. In other cases, such as a component where the anchors are spaced several feet apart, it may be necessary to consider the stiffness and ductility of the component supports, the attachments, and the structure, as required in Section 13.4.4.

Power-actuated fasteners are only permitted under seismic loading for limited applications. Section 13.4.1 describes the cases where they may be used. An exemption allowing the use of these fasteners for seismic loading is now applied to other cases, e.g., partition wall sill plate connections in light gage steel framing. A review of the basis for this exemption and applicability to other nonstructural applications should be conducted.

\subsection{Architectural Components (ASCE/SEI 7-16 Section 13.5)}

Section 13.5.1 provides general requirements for seismic design of architectural components. Users are referred to Table 13.5-1 for design coefficients. There are 15 groups of components listed in Table 13.5-1, while design narrative is provided within Section 13.5 for only five groups of components. Additional information is needed on the other 10 groups to aid in the implementation of seismic design for architectural components.

There are no restrictions on the use of nonductile construction for architectural components in regions of high seismic risk. For example, there is no restriction on the use of unreinforced masonry (URM) for chimneys and cantilever nonstructural walls. Limitations on the use of nonductile construction in areas of high seismic risk are needed.

Penthouses are treated as an architectural component. In the 2015 IBC, the aggregate area of all penthouse and other enclosed rooftop structures is limited in Section 1510.2.2 to one-third the area of the supporting roof deck, meaning penthouses can be large structures. Chapter 13 provides no limitations on the structural systems and 
detailing used for penthouses. Ordinary structural systems may be used in regions of high seismic hazard. Even small rooftop enclosures should be designed using an appropriate lateral system and detailing. Chapter 15 includes limitations on the use of nonductile lateral systems in regions of high seismic hazard, and provides references to appropriate standards for different construction materials. The design requirements for penthouses should be moved to Chapter 15, and they should be treated as nonbuilding structures similar to buildings, supported by another structure.

Appendages and ornamentations are not discussed in Chapter 13, aside from their entry in Table 13.5-1, and are only mentioned in passing in the commentary. Appendages are defined in Chapter 11 as "an architectural component such as a canopy, marquee, ornamental balcony, or statuary." Guidance should be provided regarding selection of materials for these components in higher seismic design categories. Nonductile construction, such as unreinforced masonry or ordinary concrete frame elements, should be prohibited.

Section 13.5.2 requires that all architectural components be designed for seismic forces but only some architectural components - those that pose a life-safety hazard - need be designed for relative displacements. This section could be revised to note that for the purposes of determining whether relative displacements need to be considered, life safety includes potential falling hazards and loss of function for essential components such as exit stairs and fire rated partitions. Guidance is needed for determining the component capacity for displacement checks.

Section 13.5.3 provides requirements for exterior nonstructural wall elements that are attached to or enclose the structure. There are requirements for accommodating seismic relative displacements and detailing requirements for connections. Table 13.5-1 has three entries for nonstructural wall elements: wall element, body of wall panel connections, and fasteners of the connecting system. These terms and associated design requirements should be described more fully in the section with an example in the commentary. While ASCE/SEI 7-16 requires design for a single objective, Life Safety at the Design Earthquake shaking level, in practice, many cladding systems are explicitly designed for two design levels. In addition to design for Life Safety, there is a serviceability check for a smaller seismic event. This approach should be discussed in the commentary of ASCE/SEI 7-16.

Section 13.5.6 contains provisions for suspended ceilings, and includes exceptions for suspended ceilings with small areas, gypsum board ceilings surrounded by walls or soffits braced to the structure above, and ceilings with integral construction. The section provides guidance for suspended ceiling systems with lay-in panels and integral ceiling systems that combine the lateral bracing for the fire sprinkler system and ceiling. Other suspended ceilings, such as those above large spaces in theaters and airports or not discussed; nor is guidance provided for suspended gypsum board 
ceilings or cloud ceilings. In recent earthquakes, failures have been noted in some of these systems. Expansion of these provisions to encompass these types of ceiling systems is needed.

Section 13.5.8 provides general requirements for all partitions greater than 6 feet in height and for partitions tied to the ceiling. These partitions must be braced independent of ceiling system bracing. Lateral bracing to the structure is only required for partitions over 6 feet in height. For partition installations that support significant storage, such as book bins, anchorage should be required to maintain stability under seismic loading. This would require that in addition to partition height, the weight of contents in book bins, shelving, or other storage supported by the partitions should be considered when determining if the partition should be designed for seismic forces. An exception for partitions not exceeding 9 feet in height suggests that these partitions do not require any seismic design considerations at all, since it seems to be an exemption from all of Section 13.5.8.1. This could result in inadequate anchorage to the floor below and to the ceiling or deck above. The commentary clarifies that the exemption is only intended to permit the ceiling bracing to provide lateral support for the partition. The provisions should be revised to align with the commentary.

While Section 13.5.10 provides requirements for ensuring adequate drift capacity for egress stairs, it does not provide requirements for other critical elements in the path of egress. The operability of doors at the base of required exit ramps and stairways should be examined, and provisions to improve their operability following a seismic event are needed. The magnitude of the event to be considered must be determined.

\subsection{Mechanical and Electrical Components (ASCE/SEI 7-16 Section 13.6)}

Section 13.6.1 provides general requirements for seismic design of mechanical and electrical components. Users are referred to Table 13.6-1 for design coefficients and to Section 13.4 for attachments to the structure. There is a general requirement that when seismic design is required, the dynamic effects of the components, their contents, supports, and attachments must be considered, as well as interactions between the structure and other components. Sections 13.6.2 and 13.6.3 provide general requirements for mechanical and electrical components, respectively.

Section 13.6.4 provides requirements for mechanical and electrical component supports and the means by which they are attached to the component. While components with an $I_{p}=1.0$ need not be designed for relative displacements, the design for the supports must consider forces and displacements determined in Sections 13.3.1 and 13.3.2. For components with $I_{p}=1.5$, the local region of the support attachment point to the component must be evaluated for load transfer, which 
suggests that the analysis may be limited to only a portion of the component. This is possibly in conflict with Table 13.2-1 that states the component itself needs to be designed for seismic loads, which is broader in scope than the area at the point of attachment of the supports. Section 13.6.4.5 contains four additional requirements for mechanical and electrical supports covering supports, connections in sheet metal housings, cold-form steel supports, and vibration isolators.

\subsubsection{Distribution Systems: Conduit, Cable Tray, Raceways, Ducts, Piping, and Tubing}

Sections 13.6.5, 13.6.6, and 13.6.7 contain general requirements for electrical distribution systems, duct systems, piping, and tubing.

Many electrical distribution systems are exempt from force and relative displacement requirements. Exceptions are provided for electrical distribution systems, ducts, piping and tubing with $I_{p}=1.0$ supported by trapeze assemblies and individual rod hangers, provided they meet weight and configuration requirements. All conduits less than 2.5 inches trade size are exempt, regardless of $I_{p}$. Electrical distribution systems with an $I_{p}=1.5$ that cross seismic joints must be designed for relative seismic displacements, regardless of size.

Depending on the installation configuration, some duct systems are exempt from force and relative displacement requirements, provided they do not carry toxic, highly toxic, or flammable gases, or are not used for smoke control. Ducts with a cross-sectional area less than $6 \mathrm{ft}^{2}$ and weight less than $20 \mathrm{lb} / \mathrm{ft}$ are exempt regardless of $I_{p}$, provided provisions are made to avoid impact with other ducts or mechanical components or to protect the ducts in the event of such impact. There are no requirements to accommodate relative displacements for small ducts crossing a seismic separation when $I_{p}=1.5$; they are exempt from all force and relative displacement requirements.

Piping and tubing systems may be designed and constructed in accordance with the national standards listed in ASCE/SEI 7-16 or be designed in accordance with the requirements in Section 13.6.7. Design requirements for use with the American Society of Mechanical Engineers (ASME) pressure piping system requirements are provided in Section 13.6.7.1; for fire protection sprinkler piping in Section 13.6.7.2; and for elevator system piping in Section 13.6.11. Pressure piping systems and their supports, designed and constructed in accordance with ASME B31, Standards for Pressure Piping, (2014) are deemed to comply with the requirements of ASCE/SEI 7-16, provided the force and displacement requirements of Section 13.3 are used rather than those in ASME B31. Fire protection sprinkler piping designed and constructed in accordance with NFPA 13 is deemed to meet the force and displacement requirements ASCE/SEI 7-16. Guidance on the design of distribution systems with vibration isolated supports is needed. 
Design for the seismic forces of Section 13.3 is not required for piping systems with $I_{p}=1.0$, provided they meet the specified support and pipe size requirements. The exemption from force design is dependent of the pipe diameter and component Importance Factor, and there are separate criteria for pneumatic tube systems. Flexible connections, expansion loops, or other assemblies must be provided to accommodate the relative displacement between components and piping.

Provisions for components installed in-line with distribution systems, such as a valve or pump installed in a run of piping, vary. There are no provisions for components installed in-line with electrical distribution systems. In-line components in duct systems weighing more than 75 pounds must be supported and braced independent of the ducts. Smaller in-line components may be supported by the duct, provided they are attached with mechanical fasteners to rigid duct on both sides. Suspended components that are installed in-line and rigidly connected to and supported by the piping system are considered part of the piping system for the purposes of determining the need for and sizing of lateral bracing. There are no limits on the weight of these in-line components. Where unbraced piping is connected to laterally braced components, flexibility must be provided to accommodate relative movement between the components.

Piping and conduit attached to in-line equipment must be provided with adequate flexibility to accommodate seismic relative displacements. If there is a flexible connection between the distribution system and the in-line component, and the distributed system itself requires bracing, then the in-line item should have a discreet bracing system. Location of restraints (vertical, transverse, and longitudinal) in industrial facilities should be determined from pipe stress analysis considering all loadings (including seismic) and should include the weight of the component. In these situations, the prescriptive requirements for flexible connections should not apply.

\subsubsection{Distribution Systems: Trapezes with a Combination of Systems (ASCE/SEI 7-16 Section 13.6.8)}

Section 13.6.8 addresses the situation where a trapeze meeting the prescriptive requirements in Section 13.6.5 through Section 13.6.7 supports a combination of distribution systems: electrical conduit, raceway, duct, or piping. When this occurs, the trapeze must be designed using the most restrictive requirements for the supported distribution systems from Section 13.6.5 through Section 13.6.7, considering the aggregate weight of the supported system. If any distribution system on the trapeze is not exempted, the trapeze must be braced.

This section should be expanded to provide additional guidance for the design of trapeze supports in general. Guidance is also needed for combinations of systems on common supports other than trapeze systems such as rooftop installations. The 
situation where a trapeze supports distribution systems which due to their size, are exempt when considered individually, is not addressed. For example, given that conduits less than 2.5-inch trade size are exempt from the seismic force and relative displacement requirements, it is unclear if a trapeze assembly that supports only conduits less than 2.5-inch trade size is also exempt, regardless of the total weight supported by the trapeze.

\subsubsection{Boilers and Pressure Vessels (ASCE/SEI 7-16 Section 13.6.10)}

Boilers or pressure vessels designed and constructed in accordance with ASME Boiler and Pressure Vessel Code (ASME, 2015) are deemed to meet the requirements of ASCE/SEI 7-16, provided the force and displacement requirements of Section 13.3 are used in lieu of the force or displacement requirements provided in ASME BPVC. Other boilers and pressure vessels designated as having an $I_{p}=1.5$, but not designed and constructed in accordance with the requirements of ASME BPVC, must comply with the requirements of Section 13.6.10.

Large pressure vessels and large boilers should be designed to the seismic requirements of Section 15.7, which are much more comprehensive than those found in Chapter 13. The definition of "large" should be determined in consultation with the nonbuilding structures design community. For boilers and pressure vessels retained in Chapter 13 as nonstructural components, this section should clarify the requirements for those boilers and pressure vessels with an $I_{p}=1.0$ that are not designed and constructed in accordance with the requirements of ASME BPVC.

\subsubsection{Elevator and Escalator Design Requirements (ASCE/SEI 7-16 Section 13.6.11)}

Elevators and escalators are typically designed to the seismic requirements of ASME A17.1 (2007), as modified by Section 13.6.11, and are deemed to meet the seismic force requirements of ASCE/SEI 7-16. The seismic requirements for elevators and escalators in ASME 17.1 should be reviewed for consistency with the seismic provisions of ASCE/SEI 7-16. This has been done periodically in the past. 



\section{Chapter 4}

\section{Understanding the Response of Nonstructural Components to Earthquakes}

This chapter summarizes the background of the primary nonstructural design force equations in the ASCE/SEI 7-16 standard and presents a proposed new set of the equations, along with discussion of key studies that were used during the development of the revised equations. Case studies are provided to compare the forces using the proposed equations with those using ASCE/SEI 7-16. The chapter is organized into the following sections:

- Section 4.1: The current ASCE/SEI 7-16 nonstructural design equations are presented, together with a list of additional potential parameters that may affect component response.

- Section 4.2: Studies of the influence of individual parameters on nonstructural component response are summarized.

- Section 4.3: A proposed primary nonstructural design equation for horizontal forces is presented, along with a review of the combined effect of different parameters.

- Section 4.4: The proposed minimum or "floor" for the nonstructural design force is presented.

- Section 4.5: The proposed maximum or "cap" for the nonstructural design force is presented.

- Section 4.6: The situation when the building's seismic force-resisting system, height, and/or vertical location of the component in the building are not all known is discussed.

- Section 4.7: Use of dynamic analysis to determine nonstructural seismic design forces is discussed.

- Section 4.8: Tables comparing the current ASCE/SEI 7-16 design values against the values resulting from use of the proposed nonstructural design equations, including minimum and maximum limitations, are presented.

- Section 4.9: Case studies of an interior partition and a floor-mounted cabinet are presented to compare the current ASCE/SEI 7-16 design values and the values 
resulting from the proposed nonstructural design equations. The case studies illustrate the issues that need to be considered in assigning components to various categories for dynamic response and for component ductility.

- Section 4.10: Conclusions and recommendations are presented.

Additional detail on project studies is presented in Appendices B and C. These include evaluations of experiments, instrumental recordings from multiple datasets, and analytical studies of nonlinear building archetypes.

\subsection{Current Equation}

The current primary nonstructural design force equation in ASCE/SEI 7-16, Equation 13.3-1, can be written in the following form:

$$
\frac{F_{p}}{W_{p}}=\frac{\left(0.4 S_{D S} a_{p}\right)}{\left(R_{p} / I_{p}\right)}\left(1+2 \frac{z}{h}\right)
$$

where:

$F_{p} \quad=$ horizontal design force for nonstructural component

$W_{p} \quad$ = component operating weight

$S_{D S}=5 \%$ damped design spectral response acceleration at short periods $(0.2$ seconds) per ASCE/SEI 7-16 and USGS at the project site

$a_{p} \quad=$ component amplification factor

$R_{p} \quad=$ component response modification factor

$I_{p} \quad=$ component Importance Factor

$z \quad=$ height in structure of point of attachment of component with respect to the base

$h \quad=$ average roof height of structure with respect to the base

This equation is a function of several variables: $S_{D S}, a_{p}, R_{p}, I_{p}$, and $z / h$. The following variables in the equation are surrogates for other parameters: $a_{p}$ is an amplification factor of the peak floor acceleration (PFA) that is a function of component period, $T_{\text {comp }}$, and inherent component damping, $\beta_{\text {comp }} ; R_{p}$ is a reduction factor based on the component ductility, $\mu_{\text {comp }}$, and inherent component damping, $\beta_{\text {comp }}$. The floor acceleration is estimated in that equation as the ground acceleration, approximated as $0.4 S_{D S}$, taken as linearly increasing from the ground to three times the ground acceleration at the roof. Additionally, the $I_{p}$ term serves to reduce the effect of $R_{p}$, 
which in turn increases the design force, for critical components, to provide a higher reliability of not failing.

ASCE/SEI 7-16 also includes Equation 13.3-2 to set a maximum design force or "cap" of $F_{p} / W_{p}=1.6 S_{D S} I_{p}$, and Equation 13.3-3 to set a minimum design force or "floor" of $F_{p} / W_{p}=0.3 S_{D S} I_{p}$. They bound the design force from the primary Equation 13.3-1.

In addition, ASCE/SEI 7-16 includes Equation 13.3-4 that allows the use of dynamic analysis to identify project specific PFAs and incorporate them into the design force used for nonstructural components. New in the ASCE/SEI 7-16 edition is an alternative approach presented in ASCE/SEI 7-16 Sections 13.3.1.4.1 and 13.3.1.4.2 that also permits replacing $a_{p}$ with a project specific floor spectra and peak component acceleration (PCA).

ASCE/SEI 7-16 Equations 13.3-1 through 13.3-4 are for horizontal forces. ASCE/SEI 7-16 Section 13.3.1.2 requires that horizontal forces be combined with a concurrent vertical force of $\pm 0.2 S_{D S} W_{p}$. The vertical design force for nonstructural components was not investigated as part of this project. Design for vertical ground motions is an unsettled issue in building design, and even less is known about vertical response of components. There has been relatively limited instrumentation of buildings for vertical response, and in the few buildings with vertical sensors at upper floors, the sensors have often not been placed in a way that would assist in a better understanding of vertical response, such as having sensors at the base of columns, near or columns at upper floors and then at midbay of framing. See Fathali and Lizundia (2011a) for more detailed discussion, examples, and recommendations. In addition, note that a recent study by Ryan, et al. (2016) investigated the effect of vertical floor accelerations on nonstructural components in an instrumented full-scale five-story steel building on the E-Defense shake table in Japan.

ASCE/SEI 7-16 Equation 13.3-1 is a simplification, as there are many different parameters that can affect the force on a nonstructural component. The parameters include the following:

- Ground shaking intensity, expressed in terms of peak ground acceleration (PGA)

- Seismic force-resisting system of the building (SFRS)

- Building's modal periods, $T_{n b l d g}$

- $\quad$ Building ductility, $\mu_{b l d g}$

- Inherent building damping, $\beta_{\text {bldg }}$

- Building configuration (such as plan and vertical irregularities), IRR

- Floor diaphragm rigidity, DIA 
- Vertical location of component within the building, $z / h$

- Component period, $T_{\text {comp }}$

- Component and/or anchorage ductility, $\mu_{c o m p}$

- Inherent component damping, $\beta_{\text {comp }}$

- Component overstrength, $\Omega_{0 c o m p}$

Section 4.2 investigates each parameter in detail.

The primary nonstructural design force formula could be written as a function of the parameters listed above:

$$
\frac{F_{p}}{W_{p}}=f\left(\mathrm{PGA}, \mathrm{SFRS}, T_{n b l d g}, \mu_{b l d g}, \beta_{\text {bldg }}, I R R, D I A, z / h, T_{\text {comp }}, \mu_{\text {comp }}, \beta_{\text {comp }}, \Omega_{0 \text { comp }}\right) \times I_{p}
$$

\subsection{Influence of Parameters}

Studies were conducted to identify the influence of different parameters on nonstructural response. Initial studies typically evaluated each parameter independently to determine the significance of the parameter and are summarized here in Section 4.2. Implications of each study are summarized at the end of each section, as well as in Section 4.2.13 where all of the findings are compiled.

Additional studies evaluated the combined effect of different parameters and are summarized in Section 4.3.

\subsubsection{Peak Ground Acceleration, PGA}

Shaking intensity has a direct effect on the level of excitation of the building and the components within it. Stronger shaking intensity leads to higher component response throughout the building. More subtly, shaking intensity can have an effect on the component response versus building height. Figure 4-1 shows the results of a shaketable experiment where the input earthquake motion (Kobe) to the table was increased from $25 \%$ to $100 \%$ of the recorded value. As input motion increased, PCA increased, but the ratio of PCA/PGA was lower at upper diaphragm levels.

Figure 4-2 shows similar results from a collection of 44 instrumented buildings with PGA $>0.15 \mathrm{~g}$. The effect became more pronounced as the recorded PGA came closer to the design level. Fathali and Lizundia (2011a) showed similar results of how PFA/PGA is larger at higher diaphragm levels (higher $z / h$ ) with lower levels of PGA, as shown in Figure 4-3.

In these studies of instrumental recordings, it is likely that the large majority of records, even those with comparatively higher PGA, had essentially or largely elastic response. The vast majority of records available have relatively low PGA values. 
For example, Figure 4-3 shows that at the time of the Fathali and Lizundia study, of the 2,224 data points used in Figure 4-4, 401 had PGA $\geq 0.1 \mathrm{~g}, 136$ had PGA $\geq 0.2 \mathrm{~g}$, 53 had $P G A \geq 0.3 \mathrm{~g}$, and only 19 had $\mathrm{PGA} \geq 0.4 \mathrm{~g}$.

NEES \#1005; 4-Story, RC Bldg.; 0.43 and $0.31 \mathrm{~s}$ in $\mathrm{X}$ and $\mathrm{Y}$ dir.
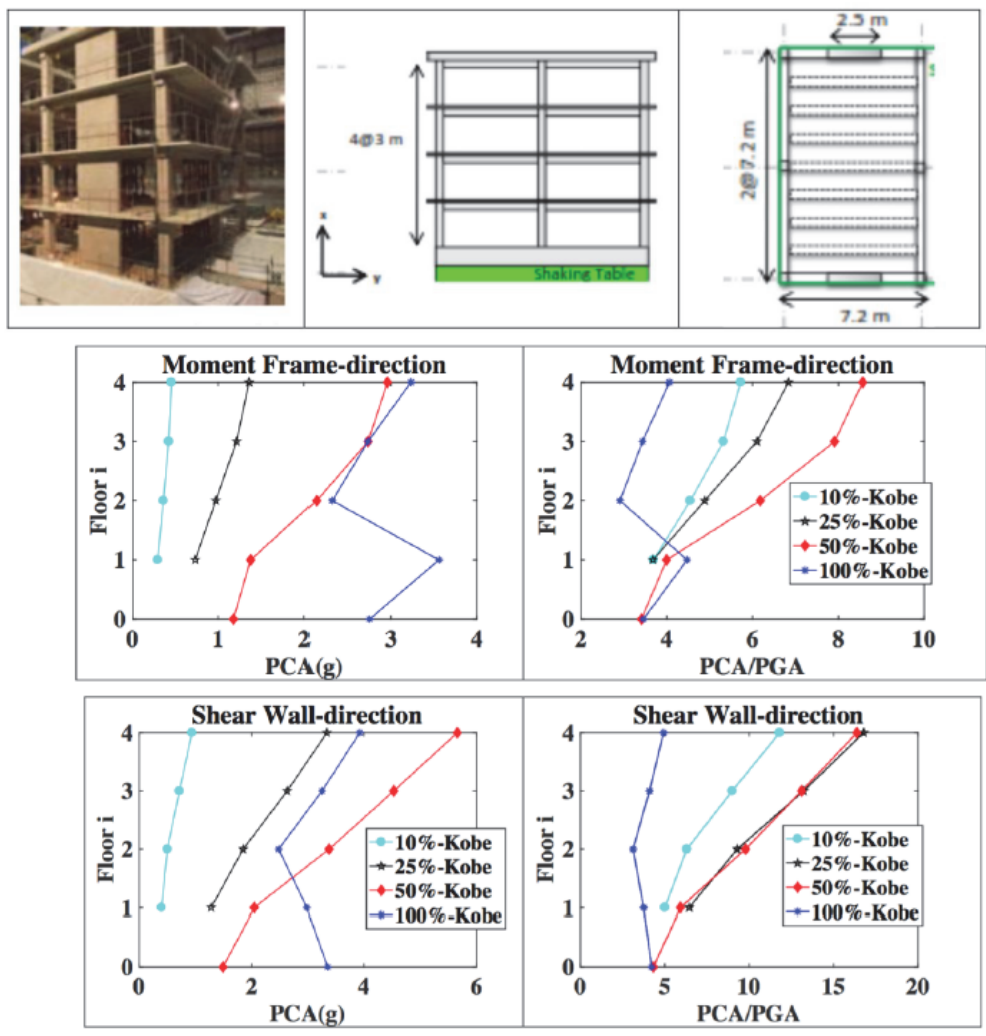

\section{Lateral-load resisting system variation}

\section{GM intensity} variation

Figure 4-1 The effect of ground shaking intensity on PCA and PCA/PGA in a shake table experiment as adapted from Nagae et al. (2011).

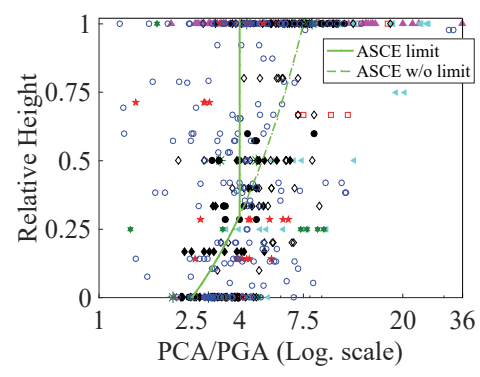

(a) all PGA/PGAdesign

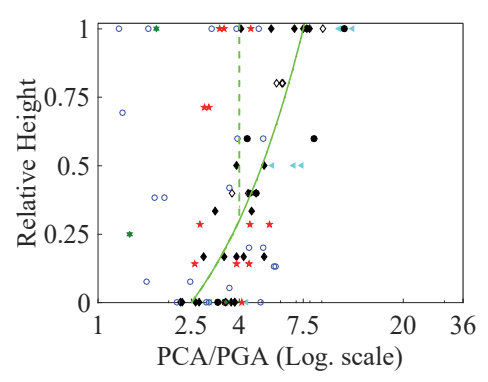

(b) $P G A / P G A_{\text {design }} \geq 0.50$

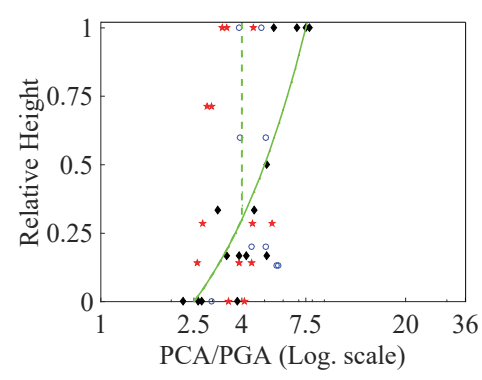

(c) PGA/PGAdesign $\geq 0.75$

Figure 4-2 The effect of PGA on PCA/PGA for instrumental recordings. Figures show PCA normalized by PGA of the instrumented buildings and associated ASCE/SEI 7-16 Equation 13.3-1 for $F_{p}$. The green dashed line is Equation 13.3-1 directly. The green solid line applies the maximum limit from ASCE/SEI 7-16 Equation 13.3-2, where $F_{p} / W_{p}$ $=1.6 S_{D S} I_{p}=1.6(\mathrm{PGA} / 0.4) I_{p}=4$, for the typical case of $I_{p}=1$. An elastic component is assumed with $\beta_{\text {comp }}=5 \%$. PGAdesign is $0.4 S_{D S}$ for the project site. The dataset includes 83 recordings with $P G A>0.15 \mathrm{~g}$. 
With elastic response of the building, from principles of structural dynamics, the ratio of PFA/PGA should not vary with changing PGA. Height, building period, SFRS, and ground motion frequency content, however, can affect the ratio of PFA/PGA.

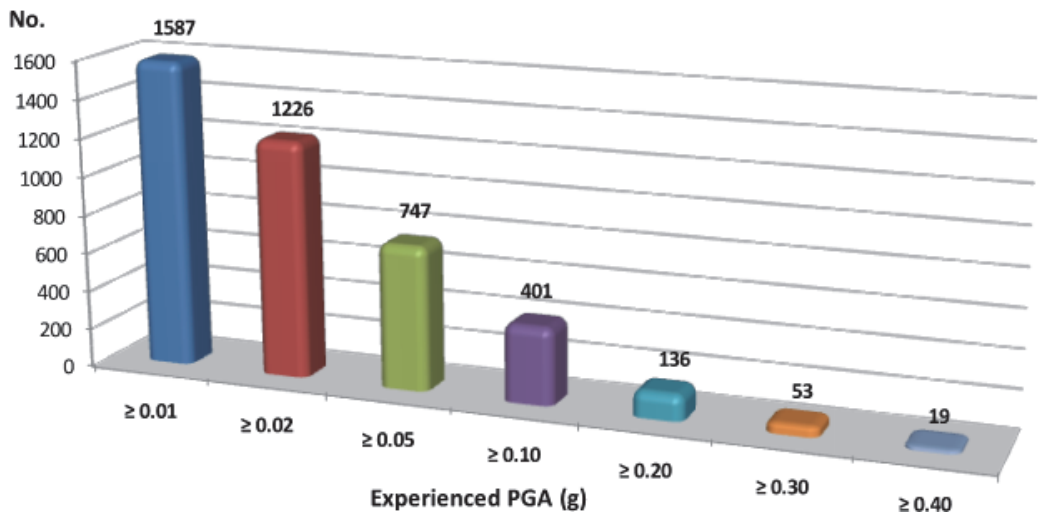

Figure 4-3 Distribution of 2,224 (above ground level) data points from 151 fixed-base building stations used in Fathali and Lizundia (2011a).

For example, the frequency content of the smaller PGA records may be different than that of the larger PGA records, possibly because of the relationship between PGA at the building and the distance from the source. Thus, one explanation of the results in Figures 4-2 and 4-4 is that these other parameters are the source of the reduction in PFA/PGA with increasing PGA. This has not been explored in those datasets. Taghavi and Miranda (2006) showed that record-to-record variability (changes in PFA/PGA produced exclusively by changes in frequency content) has a coefficient of variation of approximately 0.25 .

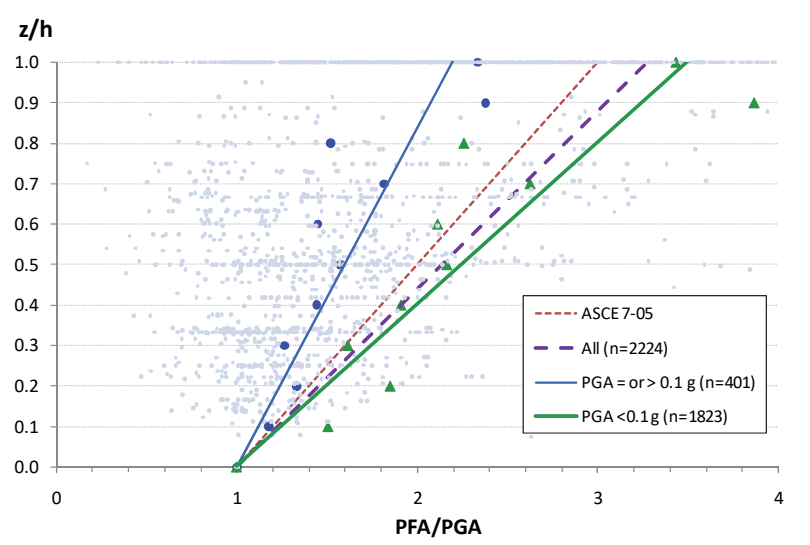

\begin{tabular}{|c|c|c|}
\hline Line Name & \multicolumn{1}{|c|}{ Type } & \multicolumn{1}{|c|}{ Formula } \\
\hline ASCE7-05 & $\begin{array}{c}\text { Building } \\
\text { Code }\end{array}$ & $\frac{P F A}{P G A}=1+2.00(Z / h)$ \\
\hline All & $\begin{array}{c}\text { Linear } \\
\text { regression }\end{array}$ & $\frac{P F A}{P G A}=1+2.27(Z / h)$ \\
\hline PGA $\geq 0.1 \mathrm{~g}$ & $\begin{array}{c}\text { Linear } \\
\text { regression }\end{array}$ & $\frac{P F A}{P G A}=1+1.19(Z / h)$ \\
\hline PGA $<0.1 \mathrm{~g}$ & $\begin{array}{c}\text { Linear } \\
\text { regression }\end{array}$ & $\frac{P F A}{P G A}=1+2.49(Z / h)$ \\
\hline
\end{tabular}

Figure 4-4 The effect of PGA on PFA/PGA from Fathali and Lizundia (2011a). The regression lines are for the mean plus one standard deviation values of 2,224 data points taken from 151 fixed-base building stations.

With nonlinear response of the building, the floor accelerations that the structure can deliver to the nonstructural component are effectively limited. PFA and PCA demands increase at a smaller rate with increasing PGA, and the PFA spectral shapes change with wider peaks at higher levels of PGA. The reduction in PFA/PGA with 
nonlinear building response has been shown in several studies including Sullivan et al. (2013) and Vukobratović and Fajfar (2016).

\section{Implication for this Study}

Given the significant effect of ground shaking on nonstructural component response, it was decided to continue to include the intensity of ground shaking in the proposed primary nonstructural design equation. The relatively limited amount of recorded data with large shaking levels underscores the importance of using analytical studies where shaking at the design earthquake level and beyond can be investigated.

\subsubsection{Seismic Force-Resisting System (SFRS)}

Different seismic force-resisting systems can have different dynamic characteristics including building modal periods and change in stiffness with height. This has been shown to affect the PCA/PFA response by Fathali and Lizundia (2011a) and others. One approach is to categorize buildings into "stiff" (such as shear walls) and "flexible" (such as moment frames) groups and compare their response. Figure 4-5 shows the differences in the PCA/PGA spectral shape between stiff buildings and flexible buildings, with $T_{\text {comp }}$ on the x-axis. Figure 4-6 shows similar results when the $\mathrm{x}$-axis is normalized by $T_{\text {comp }} / T_{\text {lbldg. }}$. Another approach is simply to use the building period as a surrogate for SFRS.

\section{Implications for this Study}

The effect of SFRS was evaluated further in archetype analytical studies described ahead, and it is incorporated in building ductility assumptions. In addition, the use of spectral shapes influenced by SFRS for more sophisticated alternatives to the derivation of nonstructural component forces is discussed later.

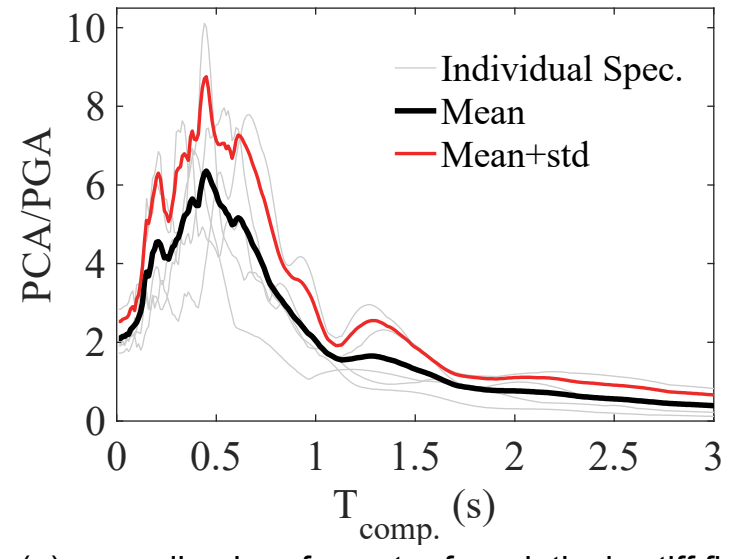

(a) normalized roof spectra for relatively stiff five-to -seven story buildings (a sample size of seven)

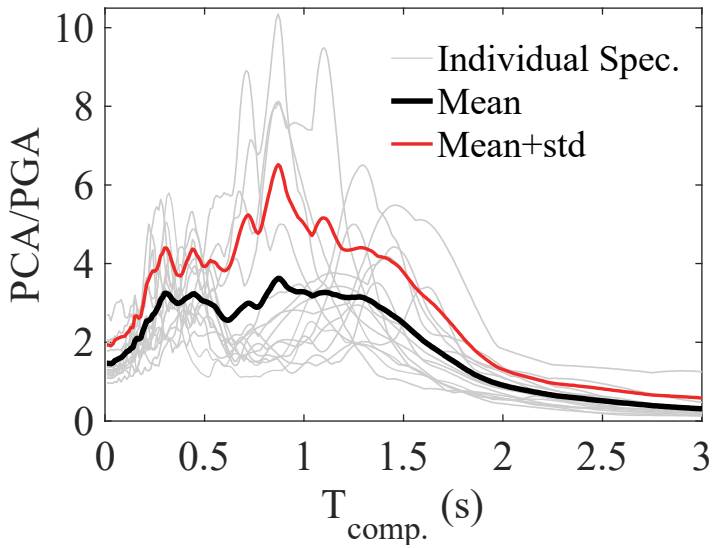

(b) normalized roof spectra for relatively flexible five-to-seven story buildings (a sample size of 24)

Figure 4-5 The effect of building stiffness on PCA/PGA for instrumental recordings. An elastic component is assumed with $\beta_{\text {comp }}=5 \%$. The dataset includes recordings with PGA $>0.15 \mathrm{~g}$. 


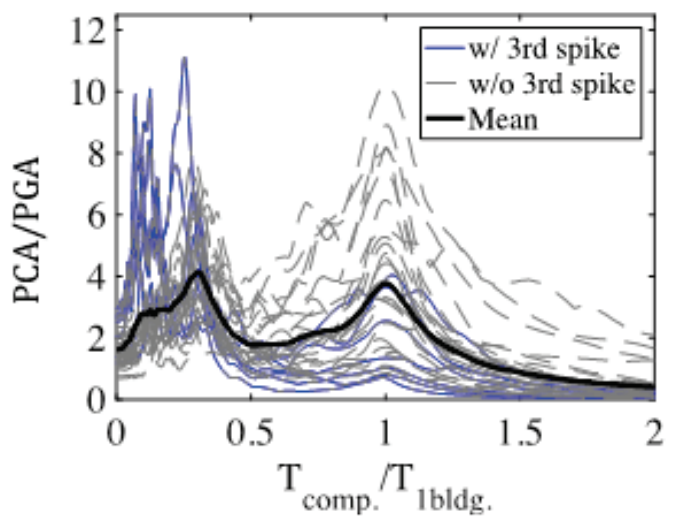

(a) MRF buildings (33 cases)

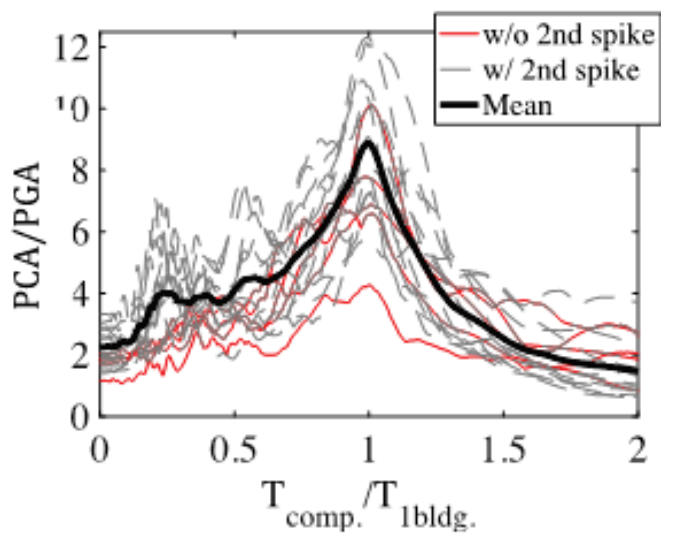

(b) SW buildings (16 cases)

Figure 4-6 The effect of building stiffness on PCA/PGA for instrumental recordings with a normalized $x$-axis. Spikes represent higher building modes of vibration where there is increased response. An elastic component is assumed with $\beta_{\text {comp }}=5 \%$. The dataset includes 49 recordings with PGA > $0.15 \mathrm{~g}$.

\subsubsection{Fundamental Period of the Building, $T_{b l d g}$}

There are a number of different parameters related to building period. For this report, the following are used:

$T_{\text {bldg }} \quad=$ the period for fundamental or first horizontal translational mode of the building in the direction of interest.

$T_{n b l d g}=$ the period for $n$-th horizontal translational mode of the building in the direction of interest, such as $T_{1 b l d g}, T_{2 b l d g}$. Note that $T_{l b l d g}$ is the same as $T_{\text {bldg. }}$

$T_{n I D b l d g}=$ the period for the $n$-th horizontal translational mode of the building in the direction of interest as determined by system identification on recorded motions, such as $T_{\text {IIDbldg }}, T_{2 \text { IDbldg. }}$.

$T_{\text {IDbldg }}=$ the resonant (dominant) period for horizontal translational modes of the building in the direction of interest as determined by system identification on recorded motions. When the fundamental or first horizontal translational mode is the resonant period, $T_{\text {IDbldg }}$ is the same as $T_{I I D b l d g}$.

$T_{\text {abldg }}=$ the approximate fundamental translational period of the building per ASCE/SEI 7-16 Equation 12.8-7.

Building modal periods have been shown to affect both PFA/PGA and PCA/PGA. Buildings with longer fundamental periods tend to have less amplification of PFA up the height of the building (see Miranda and Taghavi (2009) and Fathali and Lizundia (2011a)). 
Figure 4-7 and Figure 4-8 from Miranda and Taghavi (2009) are based on mean values from linear elastic models subjected to 80 recorded ground motions and show how a longer fundamental period of the building resulted in a lower ratio of PFA/PGA for both shear wall buildings and moment-resisting frame buildings and for buildings with lateral system stiffness somewhere in between. Figure 4-7 plots the impact of the fundamental period of the building on PFA/PGA for three different lateral stiffness ratios. Figure 4-8 conversely plots the impact for four different periods.
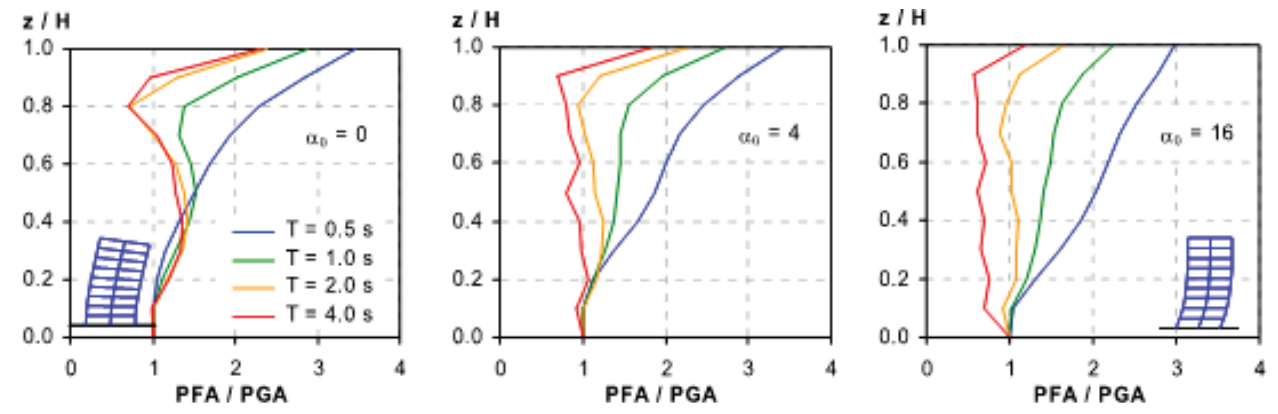

Figure 4-7 The effect of period of vibration and lateral system stiffness on PFA/PGA (from Miranda and Taghavi, 2009). The parameter $\alpha$ is the lateral stiffness ratio defined as $\alpha_{0}=H(G A / E I)^{0.5}$, where $H$ is height, $G A$ is the shear rigidity of a shear beam and $E l$ is the flexural stiffness. A value of $\alpha_{0}=0$ represents a pure flexural model; a value of $\alpha$ approaching infinity represents a pure shear beam.
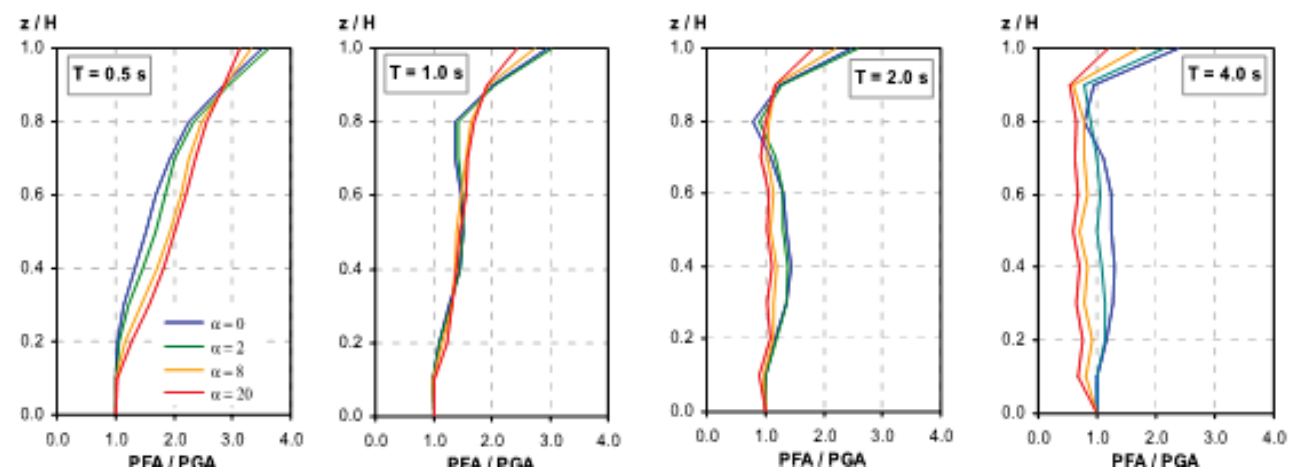

Figure 4-8 The effect of period of vibration and lateral system stiffness on PFA (from Miranda and Taghavi, 2009). The parameter $\alpha_{0}$ is defined in Figure 4-7.

Component response tends to be amplified when $T_{\text {comp }}$ and $T_{b l d g}$ approach resonance. This effect typically occurs at the first, second, and even third building modes in low to mid-rise buildings. For taller structures, large amplifications can occur at modes higher than the third mode as well.

\section{Implications for this Study}

Although higher modes can be important, for simplicity, it was decided to use the fundamental translational period of the building in the direction of interest in the 
nonstructural design equation in the derivation of PFA/PGA as well as in aspects of PCA/PFA.

\subsubsection{Building Ductility, $\mu_{b l d g}$}

Building ductility has been shown to affect component response. Typically, PCA/PGA is larger when the building is elastic and lower when there is nonlinearity of the building. Studies showed significant reduction in PCA/PFA with increasing levels of shaking, though PCA itself still increases with increasing levels of shaking. It can be difficult to separate building ductility from ground shaking intensity. Figure 4-9 shows how PCA increases with ground motion intensity, but PCA/PGA reduces for analytical studies of a steel special moment-resisting frame (SMRF) archetype structure at higher intensity levels where there is more nonlinearity. Similar results were obtained for a special reinforced concrete shear wall (RCSW) archetype and are shown in Appendix B.

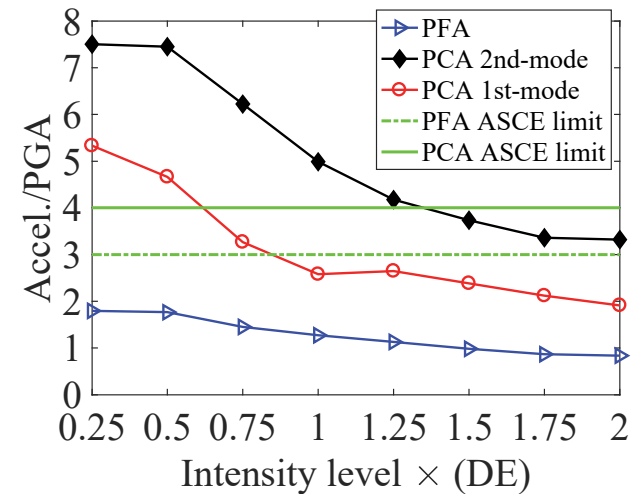

(a)

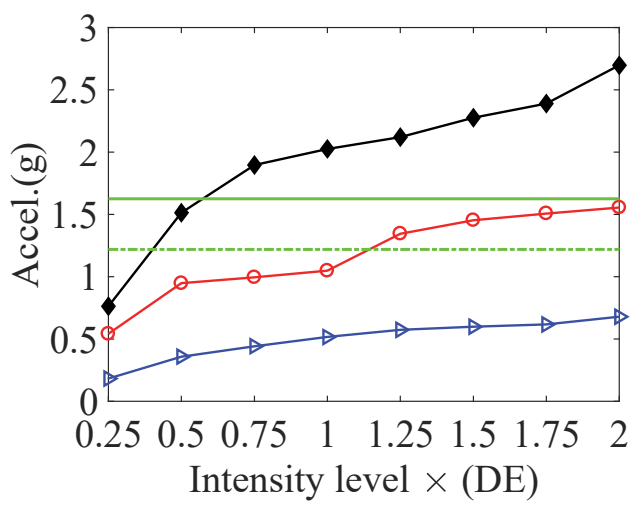

(b)

Figure 4-9 The effect of building ductility and ground shaking intensity on PFA, PCA, PFA/PGA, and PCA/PGA. An elastic component is assumed with $\beta_{\text {comp }}=5 \%$. Peak values are taken from the PCA/PGA spectra from both the first and second building mode response and from PFA response at roof level versus ground motion intensity level for sixstory steel SMRF archetype building (a) normalized to PGA and (b) absolute value. From Anajafi and Medina (2018d).

The effect of building ductility is not only to reduce the PFA/PGA and PCA/PFA ratios. If an earthquake ground motion induces inelastic response in the supporting structure, the floor spectral accelerations will saturate over a wider non-structural period range because of the lengthening of the effective period of the supporting structure. Sullivan et al. (2013) showed the change in floor acceleration response spectral shapes resulting from the inelastic response of supporting structures.

In Figure 4-9, shaking intensity is a surrogate for building ductility. Figure 4-10 shows results for the same 6-story steel SMRF archetype where building ductility is presented more explicitly. The parameter $R_{c b}$ is equal to the ratio of the floor 
response spectrum ordinate of the elastic version of the archetype model to the floor response spectrum ordinate of the baseline archetype model. Thus, a value of $R_{c b}>1$ implies that building inelasticity reduces PCA responses. Component damping ratios are varied from $0.1 \%$ to $5 \%$, and floor spectra are presented at the roof level and at the second-floor level for an elastic nonstructural component. Figure 4-10 shows that for all damping levels and for both the roof and second floor, the mean $R_{c b}$ of 20 spectrum compatible (SC) records is above 1.0, except for a few periods where it is just a bit below 1.0. There are some individual records with values of $R_{c b}<1$, typically at lower component periods, meaning in those cases building nonlinearity increased component response. The effect of building nonlinearity is more significant at the primary building modal periods. For example, at the building fundamental mode, for 5\% damping at the roof, a nonlinear building reduces PCA by a factor of about 2 compared to an elastic version of the same steel SMRF archetype.

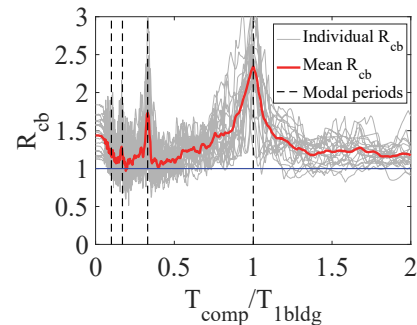

damping $0.1 \%$

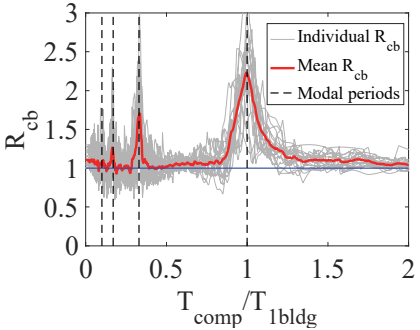

damping $0.1 \%$

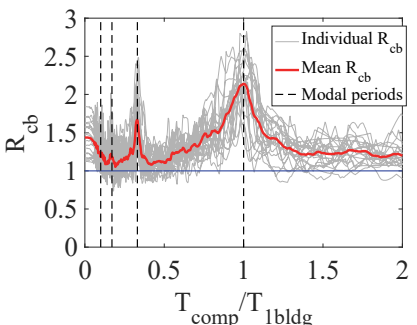

$1 \%$

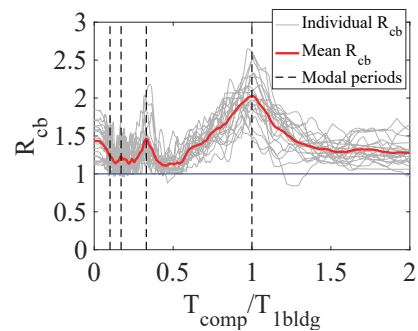

$5 \%$

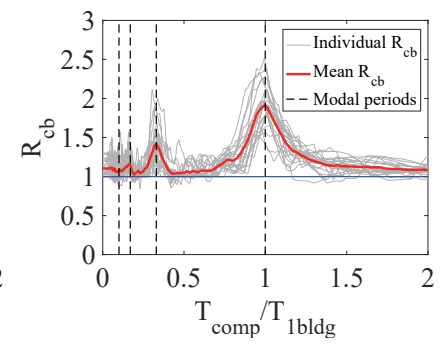

$5 \%$

(b) Second-floor level

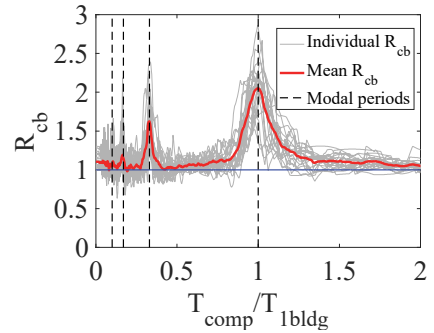

$1 \%$

Figure 4-10 Effect of building nonlinearity on PCA; baseline archetype six-story steel SMRF.

It is important to appreciate that inelastic deformations are almost never uniformly distributed in a building. Very often, only some portions of the structure yield while others remain elastic. Even in cases where yielding occurs at all levels, rarely is the level of inelastic deformation uniformly distributed, and the distributions will vary with different seismic force-resisting systems. Furthermore, location and amplitude depend of the level of ground motion intensity and the strength of the structure. For example, Gupta and Krawinkler (1999) observed that medium-rise and tall momentresisting frame buildings would often initiate yielding toward the top of the building 
and with increasing ground motion intensity these would move downward in the building in what is described as "a downward migration of drift demands."

Figure 4-11 takes the same steel SMRF archetype shown in Figure 4-10, but the members are re-proportioned to concentrate yielding at the top and bottom of the first story columns to produce a weak story mechanism. Comparing Figure 4-10 with Figure 4-11, the benefit of building nonlinearity in reducing nonstructural demands is diminished when building nonlinearity is concentrated. For example, at the fundamental mode, for $5 \%$ damping at the roof, the reduction value of 2 for the model with distributed yielding shown in Figure 4-10 drops to about 1.6 in Figure 4-11 for the model with a weak story mechanism.

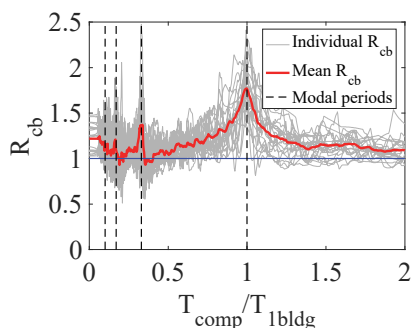

damping $0.1 \%$

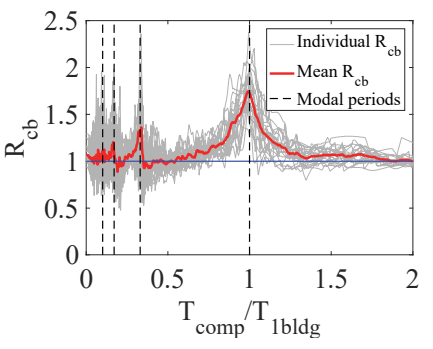

damping $0.1 \%$

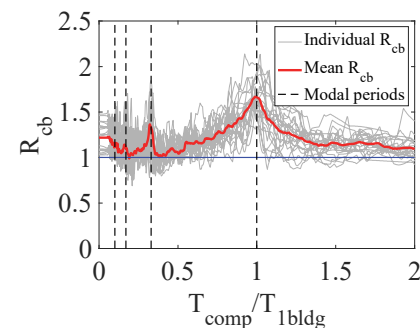

$1 \%$

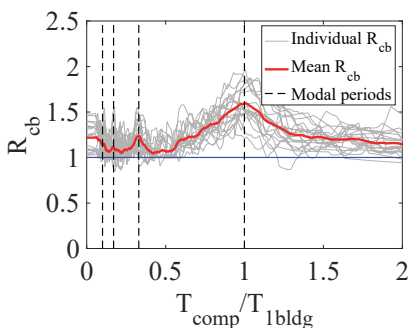

$5 \%$

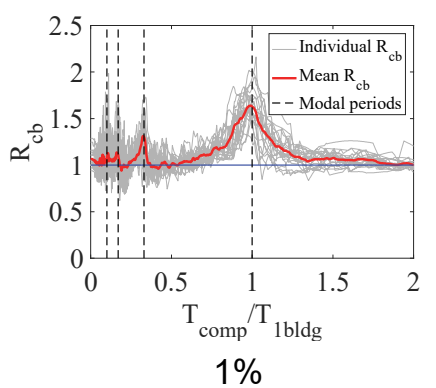

(b) Second-floor level

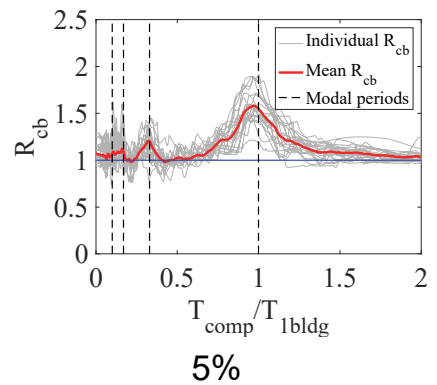

$5 \%$

Figure 4-11 Effect of building nonlinearity on PCA; weak first story archetype sixstory steel SMRF.

Figure 4-12 presents another approach to evaluate the effect of building global ductility on nonstructural component response. Normalized floor spectra are shown for two types of archetypes: the baseline two- and six-story steel SMRF, and baseline eight-story RCSW archetypes, as well as their corresponding "overdesigned" models. In this context, an overdesigned archetype is one in which a baseline model is modified by an overdesign factor that increases both lateral strength and stiffness; this factor accounts for increases in strength and stiffness in addition to the inherent overstrength that results from the design of the baseline archetype models. For instance, an overdesign factor of 1.5 was used for the six-story steel SMRF and eightstory RCSW archetypes. An overdesign factor of 1.5 implies that both the strength and stiffness properties of the baseline archetype models are increased by $50 \%$. 
Overdesign factors of 2.0 and 3.0 were used on the two-story steel SMRF and twostory RCSW archetypes, respectively.
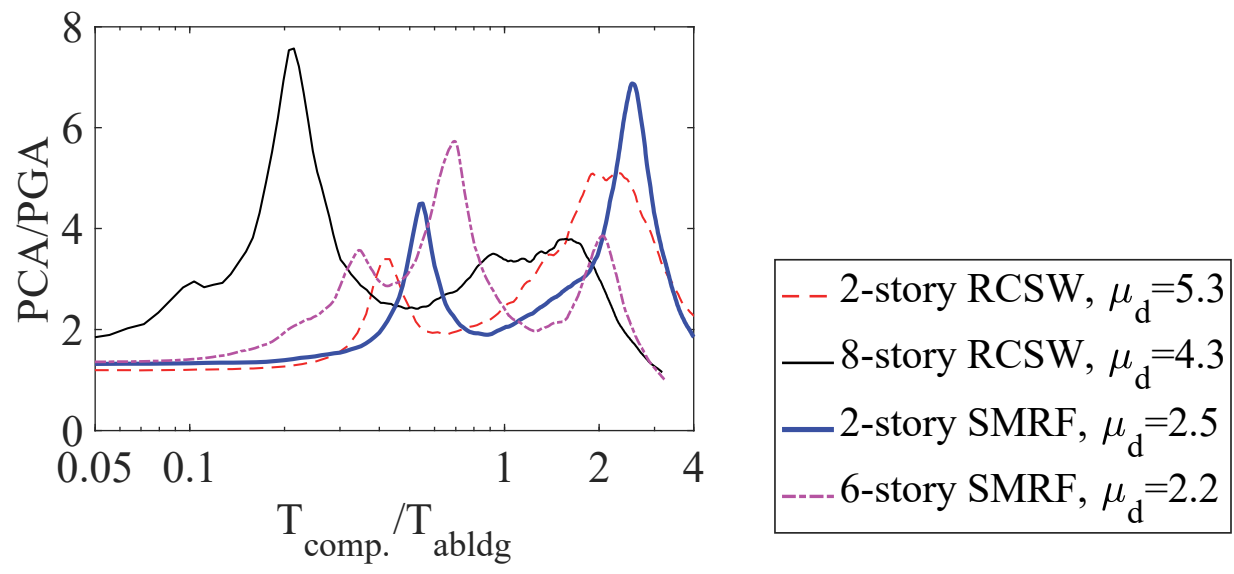

(a) Baseline archetypes

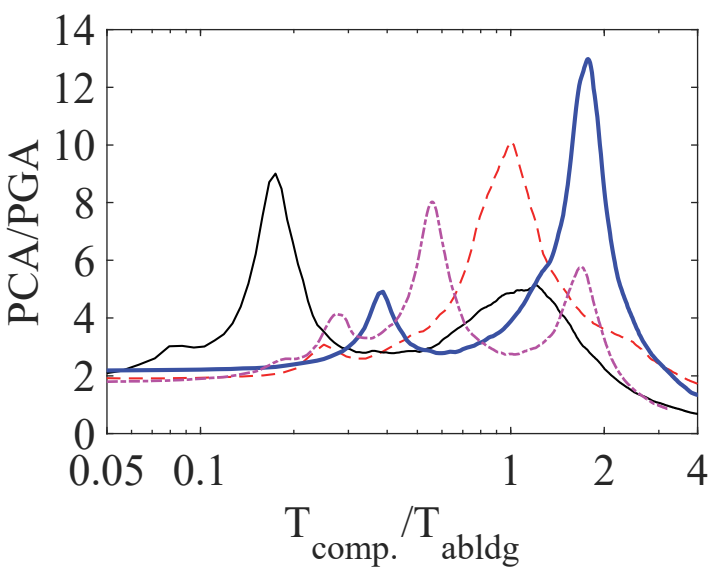

- 2-story RCSW, $\mu_{\mathrm{d}}=1.4$
- 8-story RCSW, $\mu_{\mathrm{d}}=3.6$
- 2-story SMRF, $\mu_{\mathrm{d}}=1.4$
--- 6-story SMRF, $\mu_{\mathrm{d}}=1.5$

(b) Overdesigned archetypes

Figure 4-12 Mean PCA/PGA ratios for the (a) baseline and (b) overdesigned archetype buildings and their associated building global displacement ductility values. An elastic component is assumed with $\beta_{\text {comp }}=5 \%$. The results are at roof level from the analytical study of the eight archetype structures exposed to the set of 20 spectrum compatible ground motions at the design earthquake level.

In Figure 4-12, for each model, the term $\mu_{d}$ represents the ratio of the mean of the maximum roof displacement from response history analyses using the set of 20 spectrum-compatible ground motions normalized by an estimate of the yield roof displacement from a nonlinear static (pushover) analyses of a building (using an inverted triangular load pattern as well as a load pattern based on a force distribution from response spectrum analyses resulted in similar estimates of yield roof displacements). Thus, $\mu_{d}$ is used herein as an approximate measure of building ductility, $\mu_{\text {bldg. }}$. PCA/PGA ratios are shown as a function of $T_{\text {comp }} / T_{\text {abldg. }}$. Each spectrum represents the mean roof spectrum from the individual responses for each building model when exposed to the set of 20 spectrum-compatible ground motions. Because the horizontal axis presents the ratio of the component period normalized by 
$T_{\text {abldg, }}$ which is the same value for both baseline and overdesigned archetypes, the peak values of floor spectra tend to shift to the left for the overdesigned archetypes. The incorporation of the overdesigned factor results in an increase of the stiffness of a baseline frame which in turns results in a decrease in period. Figure 4-12 demonstrates that for these models, in general, an increase in global system ductility results in a decrease in the maximum value of the ratio of PCA/PGA (i.e., decrease in PCA demands) over the normalized period range of interest. The nonlinear static analysis (pushover) curves for the archetypes are shown in Appendix B, together with additional details on the studies.

\section{Implications for this Study}

Given the importance of building ductility, it was decided to include a parameter to capture the effect of building ductility on reducing nonstructural component response in the proposed primary nonstructural design equation. The system response modification factor, $R$, defined in the building code for all SFRS was selected for simplicity. This is described in detail in Section 4.3.4.3.

\subsubsection{Inherent Building Damping, $\beta_{b l d g}$}

Damping in a building can be categorized into inherent (or viscous) and hysteretic. Hysteretic damping occurs when there is yielding of the structural elements and subsequent post-yield ductility. Hysteretic building damping is thus covered by Section 4.2.4 regarding building ductility. Inherent building damping is addressed in this section.

Although a single value for inherent damping is often used as a shorthand, in reality, buildings have many modal damping ratios just like they have many modal periods. Rarely, modal damping ratios are the same for different modes. Research by Cruz and Miranda (2016) has found that modal damping ratios tend to increase with increasing modal frequency (as modal periods decrease). More precisely, a variable for inherent building damping would depend on the mode and could be identified as $\beta_{\text {nbldg. }}$

Inherent building damping has a relatively small effect on component response as shown in Figure 4-13. Figure 4-13 compares PCA for different levels of inherent building damping for the nonlinear six-story steel SMRF building exposed to the Design Earthquake level suite of records. In the vicinity of the second mode (which dominates floor spectra), when the building damping changes from $2.5 \%$ to $1 \%$ and $5 \%$, the variation in the mean PCA values is limited to $+18 \%$ and $-16 \%$, respectively. In the vicinity of the fundamental mode, this variation is insignificant. Appendix B summarizes additional studies for a RCSW building and for building archetypes with elastic response and with nonlinear response. 


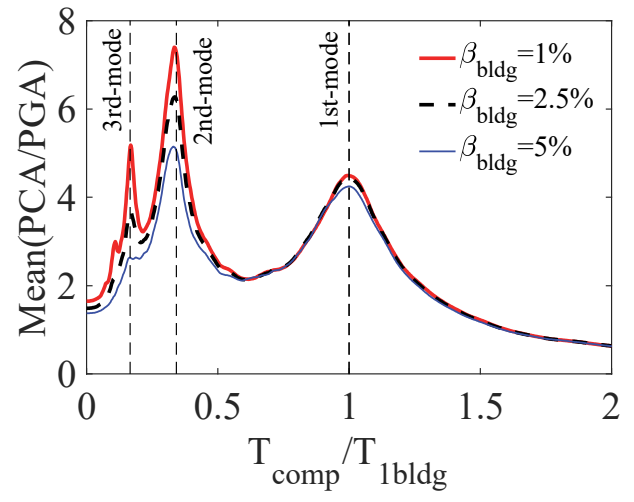

(a)

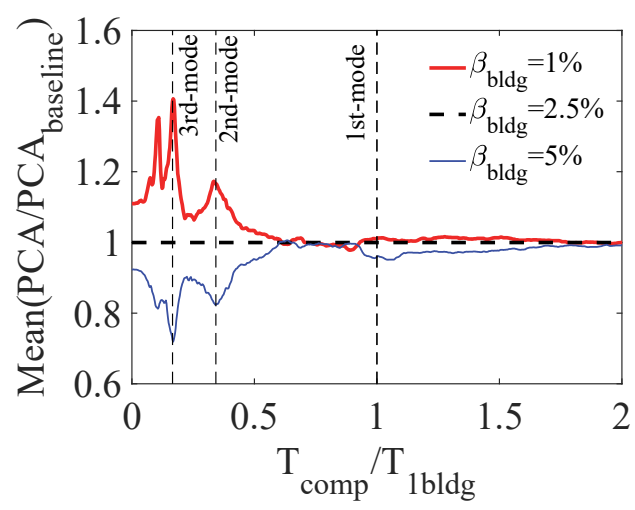

(b)

Figure 4-13 Effect of inherent building damping on PCA from analytical studies of a archetype six-story steel SMRF model exposed to the spectrum compatible record set at the Design Earthquake level: (a) mean roof spectra for building models with different damping ratios; (b) mean value of roof spectra normalized to the roof spectra corresponding to the building model with $2.5 \%$ damping. An elastic component is assumed with $\beta_{\text {comp }}=5 \%$.

Table 4-1 shows the percent reduction in PCA demands due to increasing the inherent building damping ratio from $2.5 \%$ to $5 \%$ for the cases shown in Figure 4-13 for the 6-story steel SMRF and for an 8-story RCSW in Appendix B. The normalized PCA demands shown in this table are quantified as the maximum demands (peaks) in the higher-mode and first-mode region of the floor spectra.

Table 4-1 Reduction in PCA Demands

\begin{tabular}{|c|c|c|c|c|c|c|}
\hline & \multicolumn{3}{|c|}{ 6-story steel SMRF Building } & \multicolumn{3}{|c|}{ 8-story RCSW Building } \\
\hline & $2.5 \%$ & $5 \%$ & Reduction & $2.5 \%$ & $5 \%$ & Reduction \\
\hline 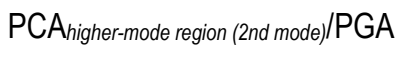 & 6.3 & 5.1 & $19 \%$ & 7.4 & 6.3 & $15 \%$ \\
\hline $\mathrm{PCA}_{1 \text { st-mode region }} / \mathrm{PGA}$ & 4.4 & 4.2 & $5 \%$ & 3.7 & 3.6 & $3 \%$ \\
\hline
\end{tabular}

Implications for this Study

Given the relatively small effect of inherent building damping on component response when compared to the effect of other parameters evaluated, it was decided not to include inherent building damping in the proposed primary nonstructural design equation.

\subsubsection{Building Configuration}

Building plan and vertical irregularities can affect the PFA. For example, a penthouse or a setback on a story can concentrate and amplify PFA. An L-shaped building with a reentrant corner can have increased amplification of PFA at the tips of the building wings. Although there are design requirements to address building structural system irregularities, the influence of building configuration is not included 
in the ASCE/SEI 7-16 nonstructural design equation. Studies were conducted to carefully scrutinize the building configuration of instrumented buildings, identify buildings with irregularities, and observe whether they can lead to increased PFA and PCA. These studies concluded that, in many instrumented buildings, the shape and magnitude of the floor response spectra can significantly depart from those obtained from two-dimensional numerical models. One of the primary reasons for these inconsistencies is the primary building's mass and/or stiffness irregularity. Detailed results from the project studies are presented in Appendix B. See also Anajafi and Medina (2018c).

\section{Implications for this Study}

Given the complexity of the issues, it was decided not to include the effects of building configuration in the proposed primary nonstructural design equation.

\subsubsection{Floor and Roof Diaphragm Rigidity}

When project-specific dynamic analysis is used to determine nonstructural seismic design forces in ASCE/SEI 7-16 Section 13.3.1.4, ASCE/SEI 7-16 Equation 13.3-4 includes a torsional amplification factor, $A_{x}$, that accounts for torsional increases at the diaphragm perimeter. This approach is rarely employed in practice. Typically, ASCE/SEI 7-16 Equation 13.3-1 is used. It assigns the same force to nonstructural component design regardless of where the component is located on the diaphragm and regardless of whether the diaphragm is rigid or flexible. With a rigid diaphragm, there will be both actual and accidental torsional response that will increase PFA at the perimeter of the diaphragm with respect to PFA at the center of rigidity. With a flexible diaphragm, there can be substantial amplification of PFA at the center of the diaphragm as compared to the ends of the diaphragm over walls.

Torsional PFA increases in rigid diaphragms are dependent in part on how recordings are processed. For example, some studies simply take the mean of all the recordings at any floor in a particular direction. Others take the worst recording in the direction. See Fathali and Lizundia (2011a) for a detailed summary of various potential approaches. The extent of PFA increase at the perimeter depends on the building floor geometry, SFRS layout and nonlinearity, and location of the perimeter point of interest with respect to the center of rigidity of the floor. For flexible diaphragms, the increase in midspan PFA needs to be evaluated carefully to account for interaction of component period. It is also dependent on the diaphragm aspect ratio and SFRS layout and nonlinearity.

Studies conducted as part of this project demonstrate that the in-plane diaphragm flexibility and torsional responses of the supporting buildings can significantly alter the shape and magnitude of the floor spectra with respect to those obtained from equivalent numerical building models that incorporate rigid diaphragms and 
symmetry in strength and stiffness of the SFRS elements. Amplifications in PFA and PCA responses in single-story buildings with plywood diaphragms can be as large as 5.0, whereas for the studied multistory buildings they are bounded to 2.0. Torsional responses of the primary building can also increase the floor acceleration responses as well as acceleration demands on nonstructural components located in the floor periphery. This amplification is bounded to approximately 1.5 for the studied instrumented buildings. Detailed results from the project studies are presented in Appendix B. See also Anajafi and Medina (2018c).

\section{Implications for this Study}

Given the complexity of the issue, it was decided not to include the effects of diaphragms in the proposed primary nonstructural design equation. Response is based primarily on mean results from rigid diaphragm buildings. Response at the perimeter of buildings with significant torsion or at the midspan of flexible diaphragms may be worse. Additional discussion of diaphragm effects is provided in Section 4.3.3.1.

\subsubsection{Vertical Location of Component within the Building, $z / h$}

PFA and PCA are known to increase with the height within the building. The ASCE/SEI 7-16 equation uses a linear increase from PGA at the ground to three times PGA at the roof. Fathali and Lizundia (2011a) showed that this is generally conservative. Buildings with larger periods have less amplification. As noted above, they also found that amplification is lower with higher levels of PGA. Studies under this project found similar results. Fathali and Lizundia (2011a) developed equations for different levels of shaking and for PFA/PGA for $T_{\text {abldg }}<0.5$ seconds, $0.5<T_{\text {abldg }}$ $<1.5$ seconds, and $T_{a b l d g}>1.5$ seconds. The drawback is that there is a step between each group (see Figure 4-14). The sample equation in Figure 4-14 was based on the mean plus one standard deviation response of all recordings at each floor in a particular direction for 136 records that had PGA $>0.20 \mathrm{~g}$.

Additional project studies were conducted using instrumental data from buildings PCA $>0.9 \mathrm{~g}$ to develop a nonlinear equation for PFA/PGA that depends only on $z / h$ and $T_{\text {abldg }}$ but does not have steps at different periods. The equation is shown below.

$$
\left(\frac{\mathrm{PFA}}{\mathrm{PGA}}\right)=1+a_{1}\left(\frac{z}{h}\right)+a_{2}\left(\frac{z}{h}\right)^{10}
$$

where:

$a_{1}=\frac{1}{T_{a B l d g}} \leq 2.5$

$a_{2}=\left[1-\left(0.4 / T_{\text {abldg }}\right)^{2}\right]>0$

$T_{\text {abldg }}=$ ASCE/SEI 7-16 Equation 12.8-7 

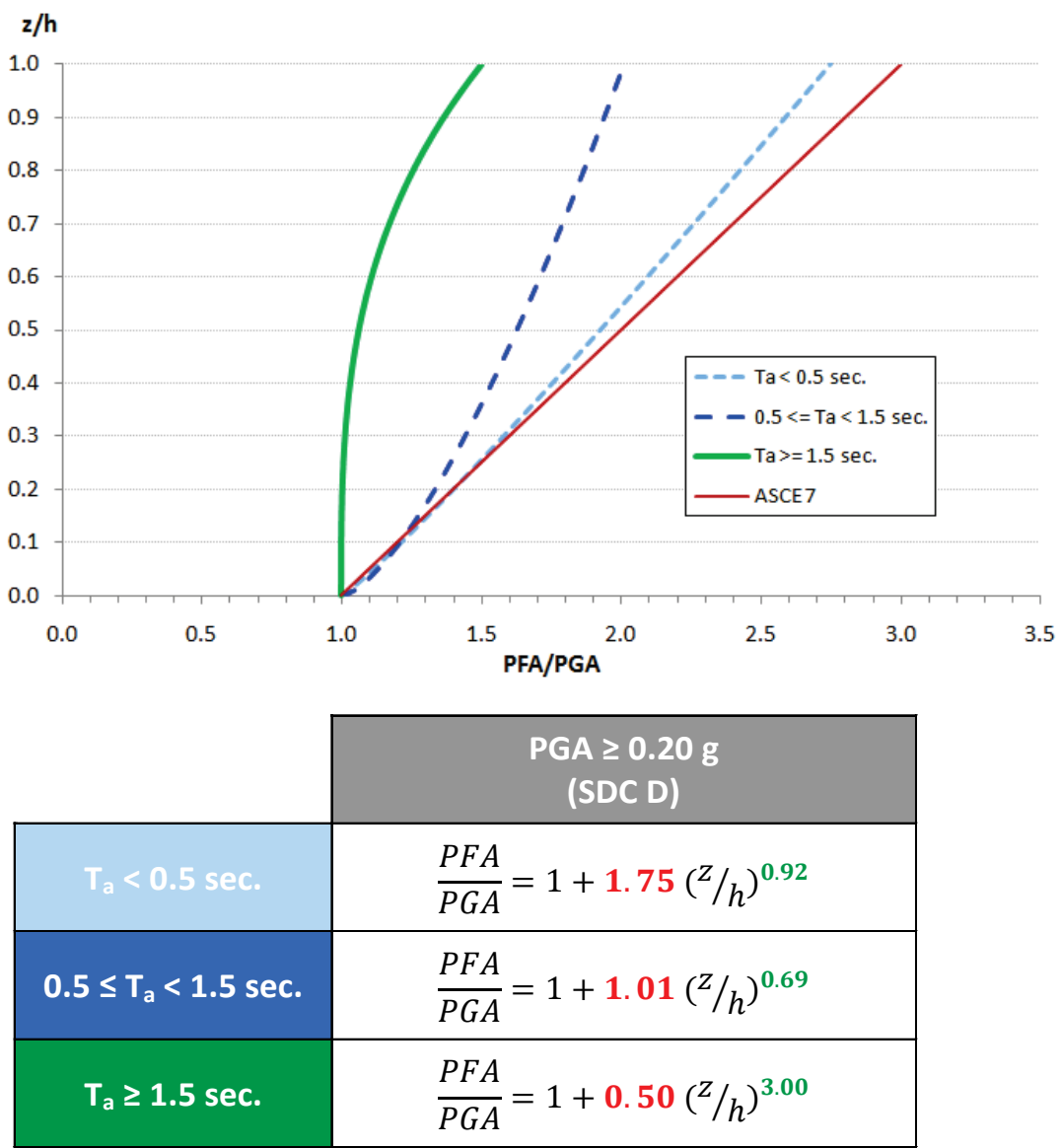

Figure 4-14 Sample equation for PFA/PGA for PGA > 0.20g from Fathali and Lizundia (2011a).

The equation is based on both the recorded variation in PFA normalized by PGA in instrumented buildings and the mean (average) variation computed in simplified continuous models consisting on a flexural beam laterally coupled with a shear beam as adapted from Taghavi and Miranda (2006) and from Alonso-Rodríguez and Miranda (2016). Figure 4-15 shows results for different building periods.

For instrumented buildings, processed data were used. Earlier studies by others have often used uncorrected data. In some buildings, there are large differences between PFAs in uncorrected data and in processed data. Whenever possible, the PFA/PGA normalization is done using an instrument located at ground level directly below the upper sensors. The model was validated by comparing recorded versus computed floor acceleration time histories and floor spectra in more than 100 instrumented buildings in California. The mean results were slightly modified to take into account both small variations in PFA/PGA between uniform and non-uniform buildings, and the difference between actual periods of vibration in the building and approximate equations computed by the code. It is well known that code equations typically underestimate building fundamental periods in order not to underestimate force demands (Goel and Chopra, 1997 and Goel and Chopra, 1998). Since the ASCE/SEI 
7-16 formula for approximate fundamental period was selected for use in the proposed design equations, modifications were made in the PFA/PGA relationship developed using measured or calculated periods to correlate the relationship with the code formula.

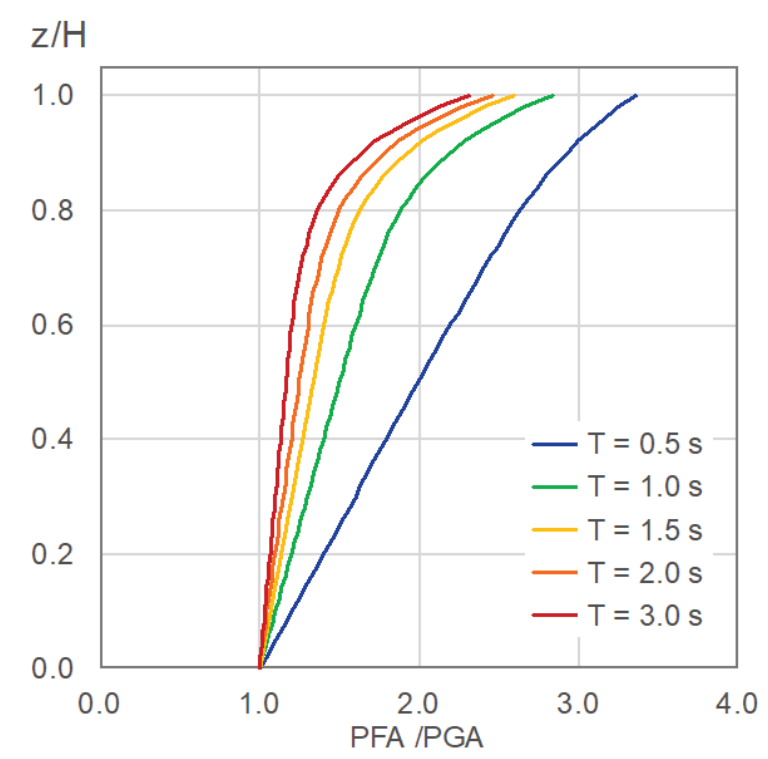

Figure 4-15 Sample equation for PFA/PGA for PCA $>0.9 \mathrm{~g}$.

\section{Implications for this Study}

It was decided to use the PFA/PGA relationship developed as part of the project.

\subsubsection{Component Period, $T_{\text {comp }}$}

Component period has been shown to have a significant effect on PCA/PFA response. Floor spectra are characterized by ordinates equal or approximately equal to the peak floor acceleration for frequencies larger than about $30 \mathrm{~Hz}$ and with large amplifications at frequencies near or equal to modal frequencies of the building. Nonstructural components with component periods longer than about two times the fundamental period of the building (although this rarely occurs) typically undergo accelerations smaller than the peak floor acceleration. Figures 4-5 and 4-6 show some example spectra that illustrate the general shape and some of the variations of instrumentally recorded floor spectra. The current ASCE/SEI 7-16 Equation 13.3-1 simplifies this effect with the $a_{p}$ factor, such that PCA/PFA is equal to 1 for up to $T_{\text {comp }}=0.06$ seconds and then jumps to PCA/PFA $=2.5$ for $T_{\text {comp }}>0.06$ seconds. Figure 4-16 compares the ASCE/SEI 7-16 formula with the maximum, mean plus one standard deviation, and mean for 3,743 floor acceleration histories (for an elastic component with $5 \%$ inherent component damping). 


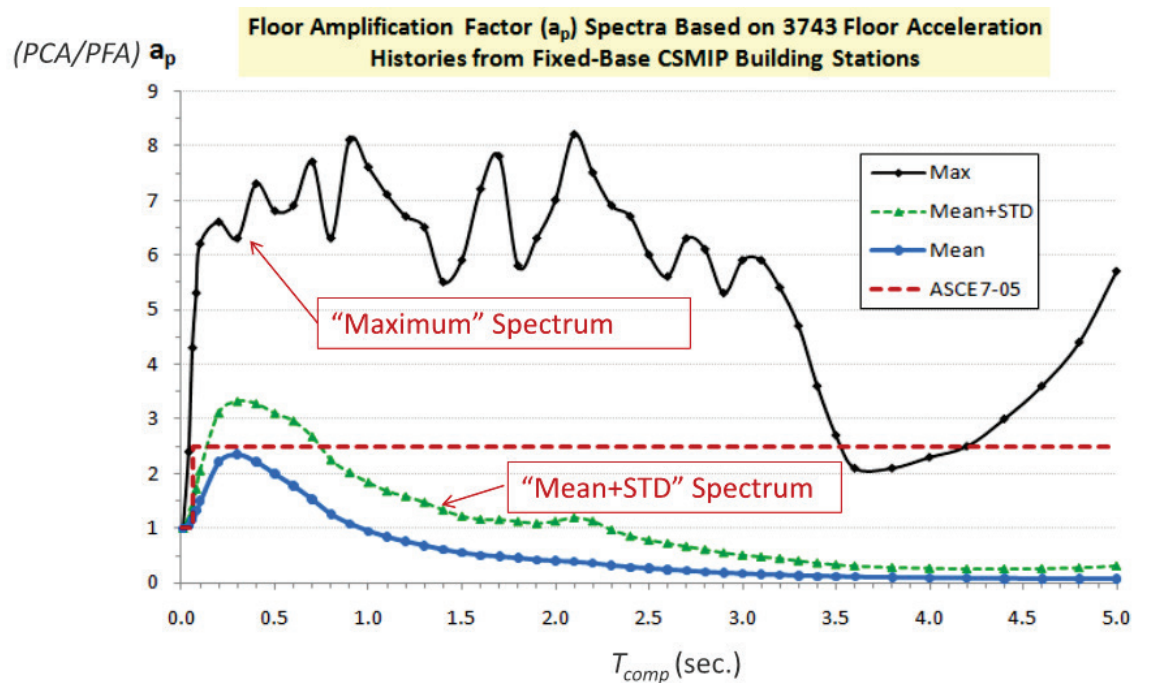

Figure 4-16 PCA/PFA versus $T_{\text {comp }}$ in Fathali and Lizundia (2011a). An elastic component is assumed with $\beta_{\text {comp }}=5 \%$.

It has also been shown that PCA/PFA rises significantly as $T_{\text {comp }}$ and $T_{\text {bldg }}$ approach resonance. Figure 4-17 illustrates the PCA/PFA amplification factor with the spectral ordinates of the average of eight different recorded motions based on $T_{\text {comp }}$ and the same motions with the x-axis normalized to $T_{\text {comp }} / T_{I D b l d g}$. These records come from eight different buildings and five different earthquakes, and were selected from a suite of 86 records with 5\% PCA values over $0.9 \mathrm{~g}$. The significant amplification of demand when the component period matches one of the building periods, typically referred to as resonance, was an important subject of investigation since the peak component accelerations can greatly exceed those typically used for design.

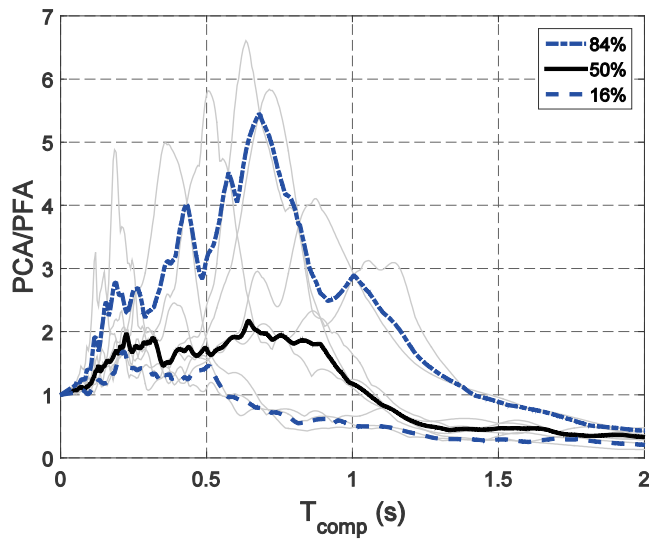

(a) not normalized

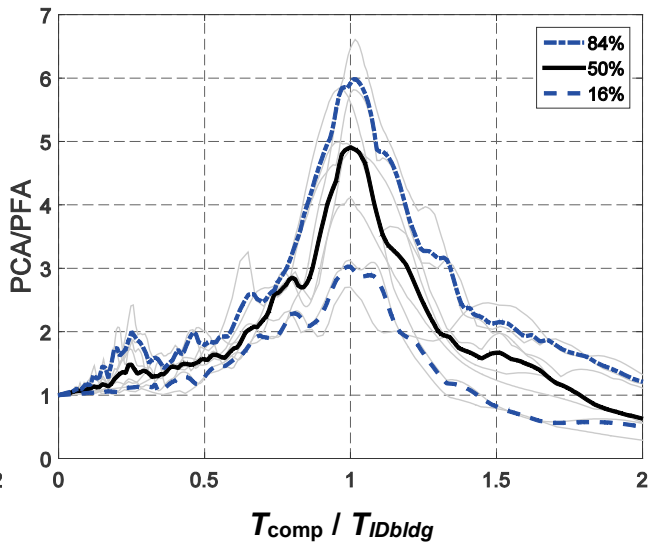

(b) normalized

Figure 4-17 Relationship between PCA/PFA comparing spectra (a) without and (b) with normalization by $T_{\text {IDbldg. An elastic component is assumed }}$ with $\beta_{\text {comp }}=5 \%$. The dataset includes eight recordings with PCA > $0.9 \mathrm{~g}$. From Kazantzi et al. (2018).

Although ASCE/SEI 7-16 Equation 13.3-1 does not explicitly include a factor for $T_{\text {comp }} / T_{\text {bldg, }}$, the commentary in ASCE/SEI 7-16 Section C13.3.1 does show Figure 
C13.3-1 for determining $a_{p}$ when $T_{\text {comp }} / T_{\text {bldg }}$ is known, based on research from the National Center for Earthquake Engineering Research. There are other modern building codes that do explicitly include the $T_{\text {comp }} / T_{\text {bldg }}$ ratio in the code design formulas, such as the Eurocode 8 (CEN, 2004).

\section{Implications for this Study}

It was decided to include the effect of resonance and the presentation approach of normalizing response against $T_{\text {comp }} / T_{\text {bldg }}$ in project studies and in the proposed primary nonstructural design equation. See Section 4.3.4.4.

\subsubsection{Inherent Component Damping, $\beta_{\text {comp }}$}

Similar to damping for buildings, component damping can also be categorized into inherent (viscous) and hysteretic. Also like buildings, hysteretic component damping occurs when there is component yielding and thus component ductility (which is addressed in Section 4.2.11).

Analytical studies of buildings and nonstructural components have typically used 5\% inherent damping for both. Actual inherent damping in buildings is known to be substantially more complicated, depending on the building characteristics and the level of shaking. For nonstructural components, various literature sources were investigated, and it was found that inherent damping in nonstructural components is typically less than $5 \%$, with some as low as $2 \%$.

Figure 4-18 summarizes information from Seismic Evaluation Procedure for Equipment in U.S. Department of Energy Facilities, (U.S. Department of Energy, 1997), which covers a database of information from equipment used in nuclear plants.

Figure 4-19 is from a shake table testing research project that included a rooftop cooling tower at University of California, San Diego (Astroza et al., 2015).

Watkins et al. (2010) summarized a set of surveys performed by University of California, San Diego researchers for eight buildings: six buildings at the university, one hospital, and one office building. Their dataset of 1,093 components included 166 components with more detailed surveys and 19 components with impact hammer testing to obtain natural frequencies, damping values, and mode shapes. Those with hammer testing had a mean inherent component damping value of $2.1 \%$ of critical with a minimum of $0.67 \%$ and a maximum of $4.9 \%$. The mean natural frequency of the floor mounted components was $19 \mathrm{~Hz}$ (period of 0.05 seconds), with a minimum of $6 \mathrm{~Hz}$ (period of 0.17 seconds) and a maximum of $52 \mathrm{~Hz}$ ( 0.019 seconds). 


\begin{tabular}{|c|c|c|c|}
\hline Equipment Class & \multicolumn{2}{|c|}{$\begin{array}{l}\text { Typical Maximum Weight } \\
\text { or Weight Density }\end{array}$} & $\begin{array}{l}\text { Typical Natural } \\
\text { Frequency }{ }^{(b)} \text { and } \\
\text { Damping }\end{array}$ \\
\hline $\begin{array}{l}\text { Motor Control Centers } \\
\text { (Section 8.1.2) }\end{array}$ & \multicolumn{2}{|c|}{$800 \mathrm{lb}$ per cabinet ${ }^{(\mathrm{d})}$} & $\begin{array}{c}\text { Flexible } \\
5 \% \text { Damping }\end{array}$ \\
\hline $\begin{array}{l}\text { Low-Voltage Switchgear } \\
\text { (Section 8.1.3) }\end{array}$ & \multicolumn{2}{|l|}{$35 \mathrm{lb} / \mathrm{ft}^{3}$} & $\begin{array}{c}\text { Flexible } \\
5 \% \text { Damping }\end{array}$ \\
\hline $\begin{array}{l}\text { Medium-Voltage } \\
\text { Switchgear (a) } \\
\text { (Section 8.1.4) }\end{array}$ & \multicolumn{2}{|l|}{$31 \mathrm{lb} / \mathrm{ft}^{3}$} & $\begin{array}{c}\text { Flexible } \\
\text { 5\% Damping }\end{array}$ \\
\hline $\begin{array}{l}\text { Transformers } \\
\quad \text { (Section 8.1.6) }\end{array}$ & $\begin{array}{c}\text { Rating (KVA) } \\
3,000 \\
2,500 \\
2,000 \\
1,000 \\
100\end{array}$ & $\begin{array}{c}\text { Weight (lb) } \\
15,000 \\
11,050 \\
9,400 \\
6,300 \\
975\end{array}$ & $\begin{array}{c}\text { Flexible } \\
\text { 5\% Damping }\end{array}$ \\
\hline $\begin{array}{l}\text { Horizontal Pumps with } \\
\text { Motors } \\
\text { (Section 8.2.3) }\end{array}$ & $\begin{array}{c}\text { Power (HP) } \\
1,000 \\
600 \\
500 \\
400 \\
200 \\
100\end{array}$ & $\begin{array}{c}\text { Weight (lb) } \\
\\
20,000 \\
16,500 \\
12,000 \\
8,600 \\
6,000 \\
3,600\end{array}$ & $\begin{array}{c}\text { Rigid } \\
\text { 5\% Damping }\end{array}$ \\
\hline \multirow[t]{3}{*}{$\begin{array}{l}\text { Vertical Pumps with Motors } \\
\text { (Section 8.2.4) }\end{array}$} & Power (HP) & Weight (lb) & \multirow{5}{*}{$\begin{array}{c}\text { Flexible } \\
\text { 3\% Damping } \\
\text { Rigid } \\
\text { 5\% Damping }{ }^{(e)}\end{array}$} \\
\hline & 150 & 4.000 & \\
\hline & $\begin{array}{r}500 \\
2,000\end{array}$ & $\begin{array}{r}9,000 \\
48,000\end{array}$ & \\
\hline \multirow[t]{2}{*}{ c. Deep-Well } & \multirow[t]{2}{*}{500} & $\begin{array}{r}9,000 \\
\text { (motor) }\end{array}$ & \\
\hline & & $\begin{array}{l}14,000 \\
\text { (pump) }\end{array}$ & \\
\hline $\begin{array}{l}\text { Air Compressors } \\
\text { (Section 8.2.6) }\end{array}$ & $\begin{array}{c}\text { Power (HP) } \\
50 \\
200\end{array}$ & $\begin{array}{l}\text { Weight (lb) } \\
4,000 \\
10,000\end{array}$ & $\begin{array}{c}\text { Rigid } \\
\text { 5\% Damping } \\
\text { (c) }\end{array}$ \\
\hline
\end{tabular}

\begin{tabular}{|c|c|c|}
\hline Equipment Class & $\begin{array}{l}\text { Typical Maximum Weight } \\
\text { or Weight Density }\end{array}$ & $\begin{array}{c}\text { Typical Natural } \\
\text { Frequency }^{(b)} \text { and } \\
\text { Damping }\end{array}$ \\
\hline $\begin{array}{l}\text { Motor-Generators } \\
\text { (Section 8.2.7) }\end{array}$ & (Not Available) & $\begin{array}{c}\text { Rigid } \\
\text { 5\% Damping }\end{array}$ \\
\hline $\begin{array}{r}\text { Batteries on Racks } \\
\text { (Section 8.1.1) }\end{array}$ & $\begin{array}{l}0.11 \mathrm{lb} / \mathrm{in}^{3} \text { for batteries, } \\
\text { plus weight of racks }\end{array}$ & $\begin{array}{c}\text { Flexible } \\
5 \% \text { Damping }\end{array}$ \\
\hline $\begin{array}{l}\text { Battery Chargers and Inverters } \\
\text { (Section 8.1.7) }\end{array}$ & $45 \mathrm{lb} / \mathrm{ft}^{3}$ & $\begin{array}{c}\text { Flexible } \\
\text { 5\% Damping }\end{array}$ \\
\hline $\begin{array}{r}\text { Engine-Generators } \\
\text { (Section 8.2.8) }\end{array}$ & (Not Available) & $\begin{array}{c}\text { Rigid } \\
\text { 5\% Damping }{ }^{(\mathrm{c})}\end{array}$ \\
\hline $\begin{array}{r}\text { Instrument Racks } \\
\text { (Section 8.1.9) }\end{array}$ & $20 \mathrm{lb} / \mathrm{ft}^{2}$ of vertical face & $\begin{array}{c}\text { Flexible } \\
3 \% \text { Damping }\end{array}$ \\
\hline $\begin{array}{l}\text { Generic Equipment Cabinets } \\
\text { (Section 8.1.5) }\end{array}$ & $\begin{array}{l}3 \text { times the weight of cabinet } \\
\text { housing }\end{array}$ & $\begin{array}{c}\text { Flexible } \\
\text { 5\% Damping }\end{array}$ \\
\hline $\begin{array}{l}\text { Walk-Through Control Panels } \\
\text { (Section 8.1.8) }\end{array}$ & $\begin{array}{l}\text { Determine and use weight } \\
\text { per foot of length }\end{array}$ & $\begin{array}{c}\text { Flexible } \\
\text { 5\% Damping }\end{array}$ \\
\hline
\end{tabular}

(a) Medium voltage switchgear are called "Metal-Clad Switchgear" in Reference 41.

(b) The lowest natural frequencies of the overall structural mode are given as either Rigid ( $>$ about $20 \mathrm{~Hz}$ ) or Flexible (< about $20 \mathrm{~Hz}$ ) and apply only to anchorage evaluations.

(c) A damping value of $5 \%$ can be used for rigid equipment since the seismic accelerations can be taken from the ZPA which is not affected significantly by damping level.

(d) Note: When using the screening tables in the EPRI Anchorage Report (Reference 41) an average weight per MCC section of 625 pounds was used rather than the 800 pounds shown in this table.

Figure 4-18 Inherent component damping values from Table 6.4-1 of Seismic Evaluation Procedure for Equipment in U.S. Department of Energy Facilities (U.S. Department of Energy, 1997).

\begin{tabular}{|c|c|c|c|c|c|}
\hline \multirow[b]{2}{*}{ Mode } & \multirow[b]{2}{*}{ Direction } & \multicolumn{2}{|c|}{ Empty Tower } & \multicolumn{2}{|c|}{ Water-filled Tower } \\
\hline & & $\begin{array}{c}\text { Period }(\mathrm{s}) \\
\text { Frequency } \\
(\mathrm{Hz})\end{array}$ & $\begin{array}{l}\text { Damping } \\
\text { ratio (\%) }\end{array}$ & $\begin{array}{c}\text { Period }(\mathrm{s}) \\
\text { Frequency } \\
(\mathrm{Hz})\end{array}$ & $\begin{array}{l}\text { Damping } \\
\text { ratio (\%) }\end{array}$ \\
\hline 1 & Vertical (UD) & $0.21 / 4.87$ & $3.5-4.5$ & $0.22 / 4.65$ & $3.5-4.5$ \\
\hline 2 & Transverse (EW) & $0.18 / 5.64$ & $3.0-4.0$ & $0.19 / 5.26$ & $3.0-4.0$ \\
\hline 3 & Longitudinal (NS) & $0.15 / 6.70$ & $2.5-3.5$ & $0.15 / 6.52$ & $2.5-3.5$ \\
\hline 4 & Torsion & $0.12 / 8.48$ & $4.0-5.0$ & $0.12 / 8.28$ & $4.5-5.5$ \\
\hline 5 & Rocking around transverse axis & $0.10 / 10.31$ & $4.0-5.0$ & $0.10 / 9.84$ & $4.0-5.0$ \\
\hline 6 & Rocking around longitudinal axis & $0.07 / 14.03$ & $2.0-3.0$ & $0.07 / 14.02$ & $2.0-3.0$ \\
\hline
\end{tabular}
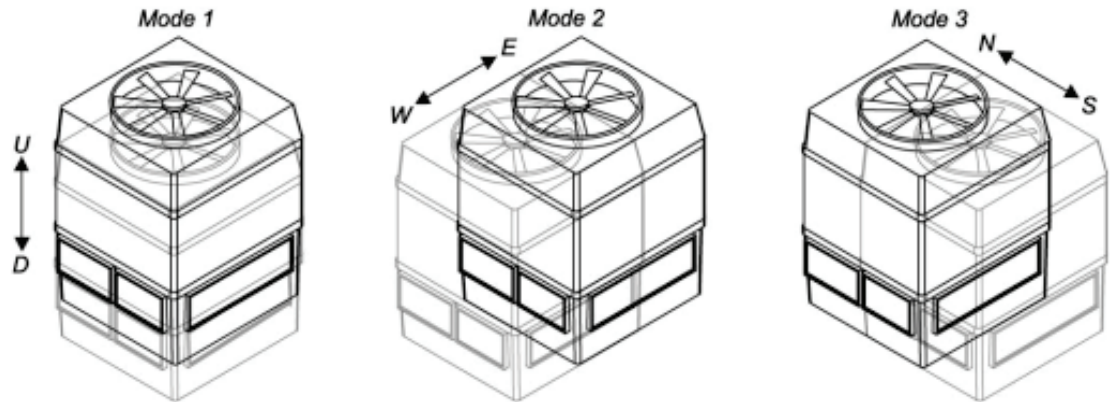

Figure 4-19 Inherent component damping values from translational modes in a cooling tower system (from Aztroza et al., 2015). E-W is the primary shake table loading direction. 
Figure 4-20 shows the effect of inherent component damping on PCA. At $T_{\text {comp }} / T_{\text {IDbldg }}$ resonance, PCA for $2 \%$ inherent component damping is 1.6 times that with 5\% inherent component damping. This ratio drops to about 1.2 for $T_{\text {comp }} / T_{\text {IDbldg }}<0.7$ and $T_{\text {comp }} / T_{\text {IDbldg }}>1.7$.

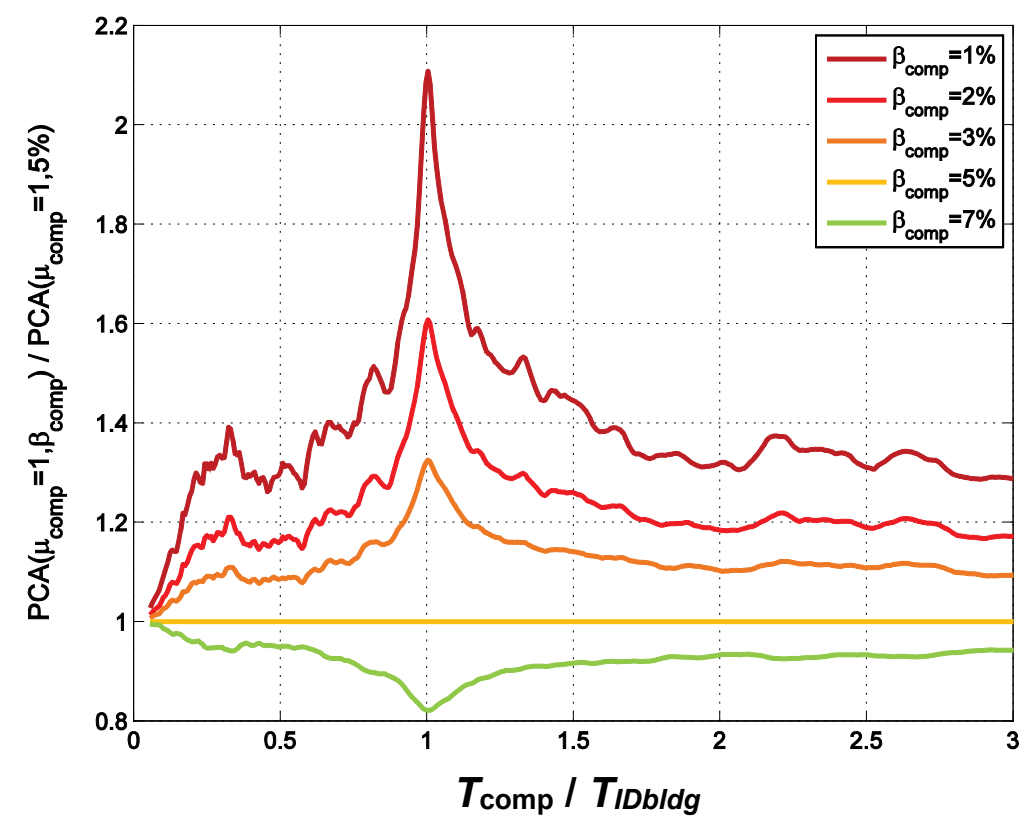

Figure 4-20 Mean elastic PCA ratios between inherent component damping, $T_{\text {comp }}$, of $5 \%$ and other damping levels. The dataset includes 86 recordings with PCA $>0.9 \mathrm{~g}$.

Figure 4-21 provides spectral plots comparing the effect of $2 \%$ component damping with that of 5\% component damping. Figures 4-21a and 4-21b show results for buildings with large first mode responses; Figures 4-21c and 4-21d show results for buildings with large second or third mode responses.

\section{Implications for this Study}

Initially, $2 \%$ inherent component damping was tentatively selected as the underlying basis of the proposed primary nonstructural design equation. However, there is concern that there is insufficient research on damping for many components, particularly at high shaking levels of interest where it is assumed that damping will be larger; that distributed system components will likely have higher levels of damping; and that use of $2 \%$ is inconsistent with the underlying 5\% assumption of the equations in ASCE/SEI 7-16 Chapter 15 for nonbuilding structures and would lead to inconsistencies. As a result, it was decided to continue with the traditional assumption of 5\% inherent component damping and highlight the need for additional research. 


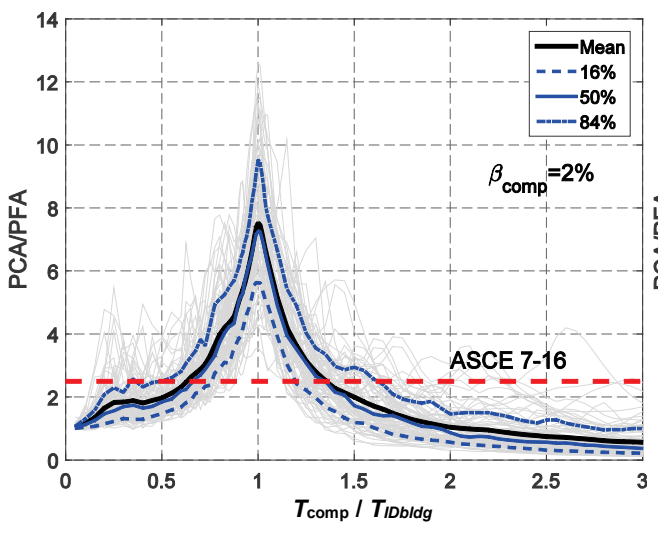

(a)

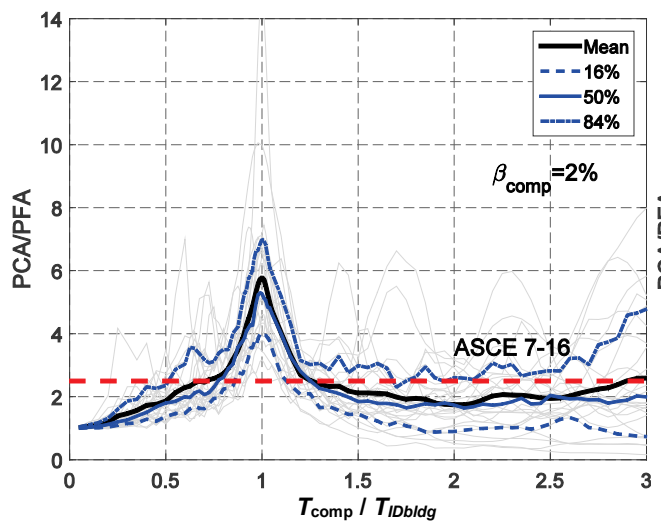

(c)

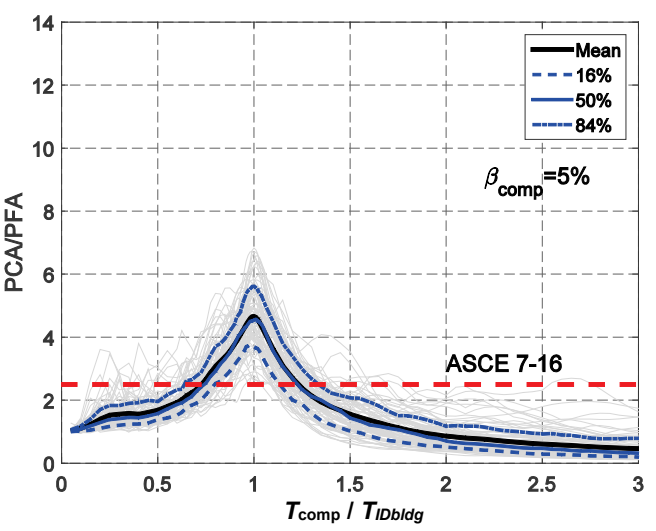

(b)

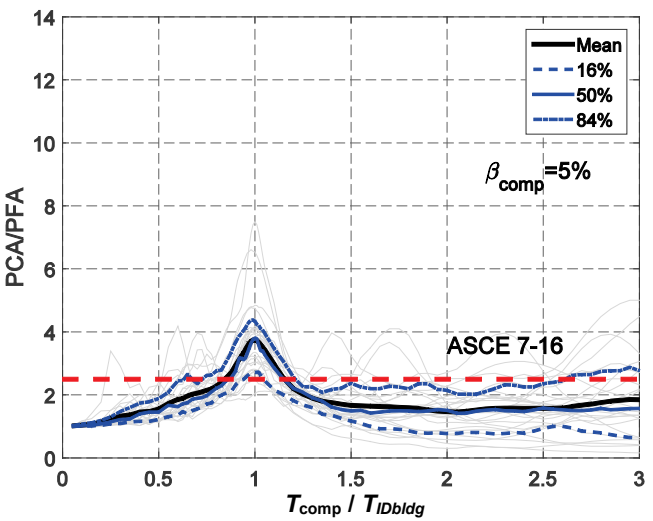

(d)

Figure 4-21 PCA/PFA versus $T_{\text {comp }} / T_{\text {IDbldg }}$ for $T_{\text {comp }}=2 \%$ in (a) and (c) and $T_{\text {comp }}$ $=5 \%$ in (b) and (d). An elastic component is assumed. Figures (a) and (b) are for 86 recordings with first mode PCA response $>0.9 \mathrm{~g}$. Figures (c) and (d) are for 27 recordings with higher mode PCA response $>0.9 \mathrm{~g}$. From Kazantzi et al. (2018).

\subsubsection{Component and/or Anchorage Ductility, $\mu_{\text {comp }}$}

ASCE/SEI 7-16 Equation 13.3-1 includes the $R_{p}$ factor that indirectly accounts for the reductions in response that component ductility can provide, but there is not an explicit link in the code between the $R_{p}$ and $\mu_{\text {comp }}$. The New Zealand nonstructural design code (NZS, 2004a), on the other hand, does explicitly permit incorporation of component ductility and provides design values to use for different levels of component ductility, and the commentary (NZS, 2004b) to code provides component ductility values for a set of common components.

There can be ductility in the component, the attachment of the component to the anchor, the anchor itself, or a combination of any of the items. Anchorage ductility is often difficult or impossible to achieve given practical considerations of available substrate depth for anchor. Project studies lumped these three potential sources of component and anchorage ductility together into one simple model where the singledegree-of-freedom (SDOF) oscillator representing a component yields and then 
continues to deform, providing a measure of component ductility. Component ductility was found to have a significant effect.

For $\beta_{\text {comp }}=2 \%$ inherent component damping, Figure 4-22 shows PCA/PFA plots for an elastic component $\mu_{\text {comp }}=1$, and for $\mu_{\text {comp }}$ of $1.25,1.5$, and 2 , including mean response and one standard deviation bounds. Figure 4-23 shows similar plots for PCA/PFA for $\beta_{\text {comp }}=5 \%$ inherent component damping. Figure 4-24 overlays the mean response for each component ductility level. For $\beta_{\text {comp }}=2 \%$ at $T_{\text {comp }} / T_{\text {bldg }}=1$ resonance, PCA/PFA drops from 7.5 for an elastic component, to about 3.8 for a component with a ductility, $\mu_{\text {comp }}$, of 1.25 , to about 2.4 for $\mu_{\text {comp }}=1.5$, and then to about 1.5 for $\mu_{\text {comp }}=2$. For $\beta_{\text {comp }}=5 \%$ at $T_{\text {comp }} / T_{\text {bldg }}=1$ resonance, PCA/PFA drops from about 4.6 for an elastic component, to about 2.8 for a component with a ductility, $\mu_{\text {comp }}$, of 1.25 , to about 2.0 for $\mu_{\text {comp }}=1.5$, then to about 1.4 for $\mu_{\text {comp }}=2$. Note that for these "constant component ductility" PCA/PFA spectra, the strength of the component is different for each level of $\mu_{\text {comp }}$ at each value of $T_{\text {comp }}$.

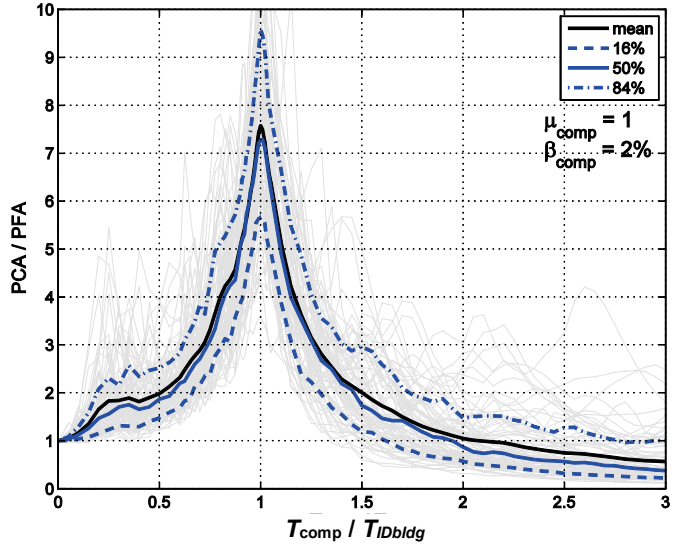

(a)

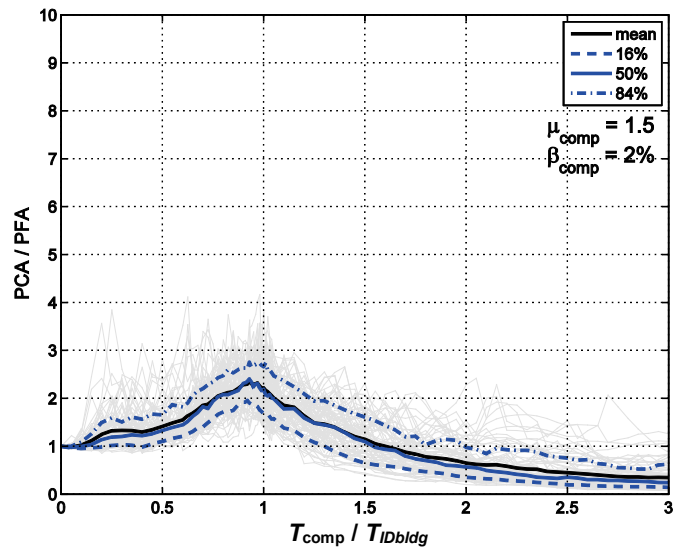

(c)

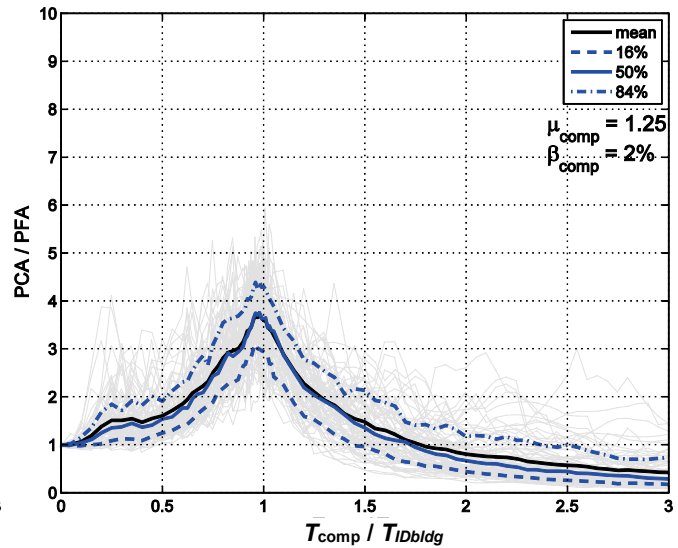

(b)

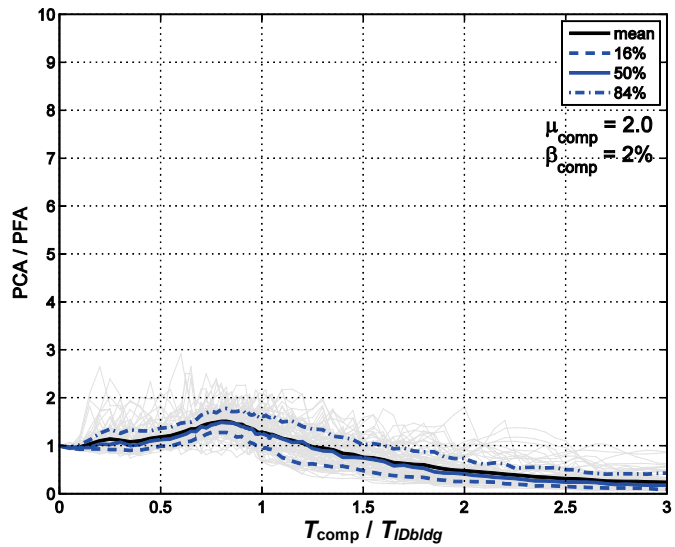

(d)

Figure 4-22 Comparison of PCA/PFA versus $T_{\text {comp }} / T_{\text {IDbldg }}$ for different levels of component ductility. Figure (a) is an elastic component with $\mu_{\text {comp }}=$ 1 ; (b) is for $\mu_{\text {comp }}=1.25$; (c) is for $\mu_{\text {comp }}=1.5$; and (d) is for $\mu_{\text {comp }}=2$. $\beta_{\text {comp }}=2 \%$ inherent component damping is assumed. The dataset includes 86 recordings with $\mathrm{PCA}>0.9 \mathrm{~g}$. 


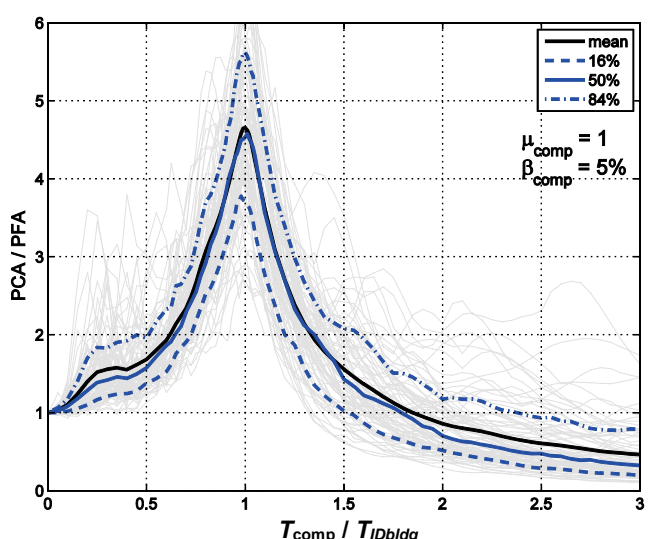

(a)

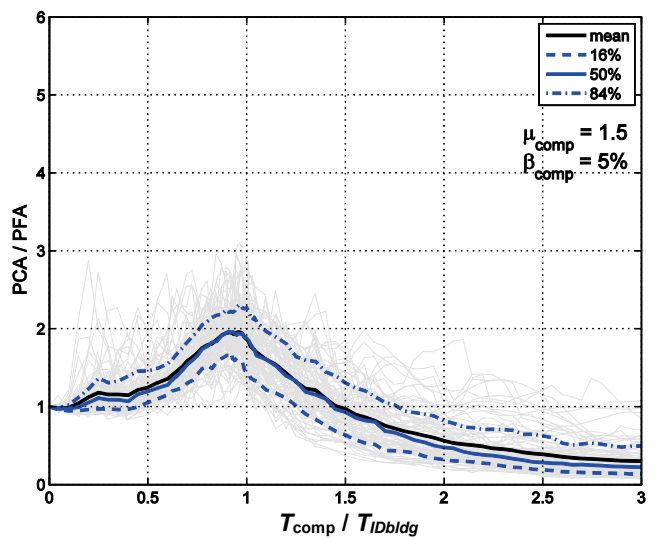

(c)

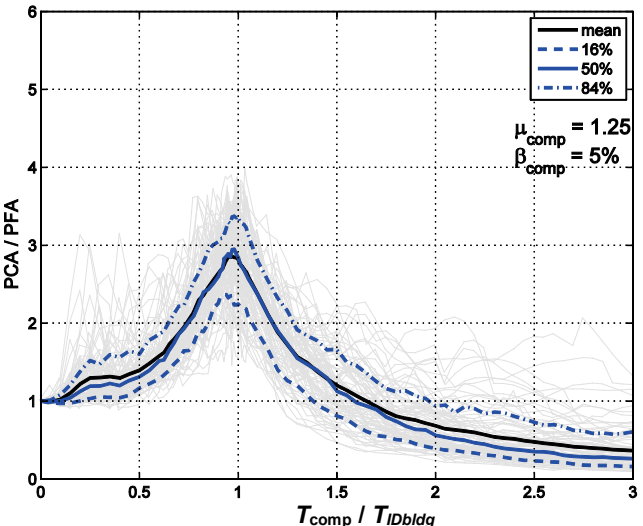

(b)

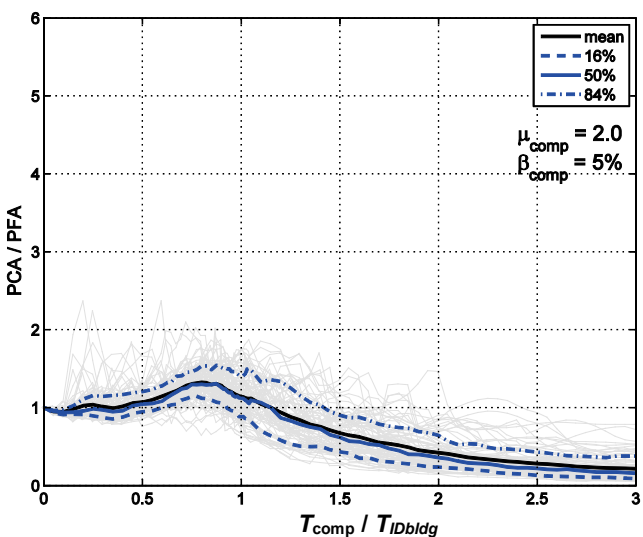

(d)

Figure 4-23 Comparison of PCA/PFA versus $T_{\text {comp }} / T_{\text {IDbldg }}$ for different levels of component ductility. Figure (a) is for an elastic component with $\mu_{\text {comp }}$ $=1$; (b) is for $\mu_{\text {comp }}=1.25$; (c) is for $\mu_{\text {comp }}=1.5$; and (d) is for $\mu_{\text {comp }}=$ 2. $\beta_{\text {comp }}=5 \%$ inherent component damping is assumed. The dataset includes 86 recordings with PCA $>0.9 \mathrm{~g}$.

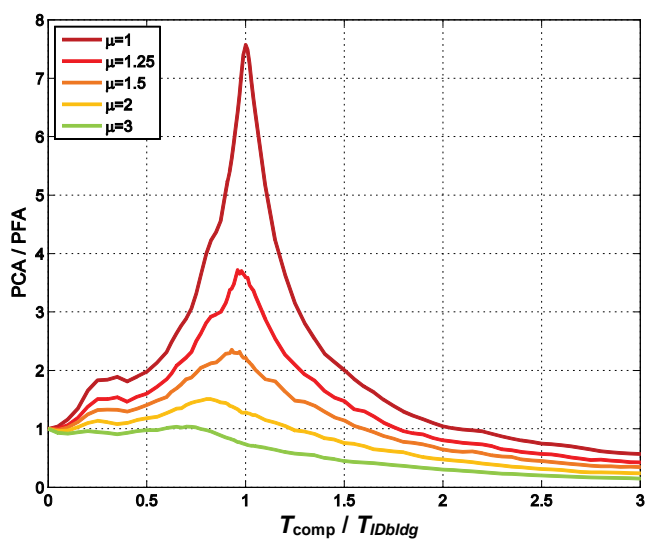

(a)

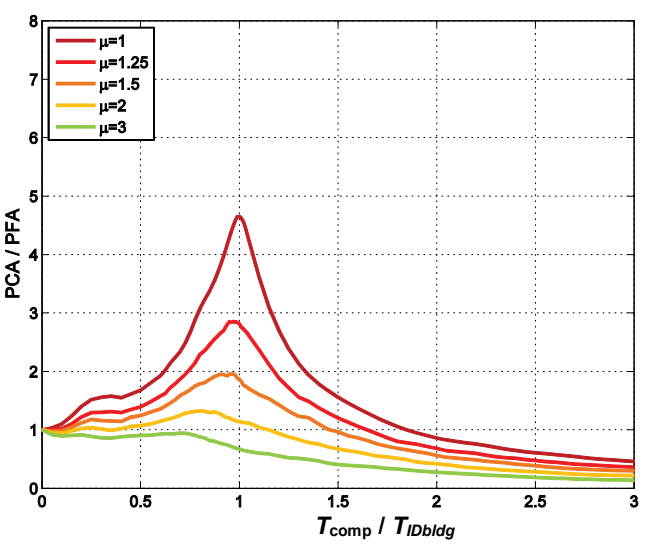

(b)

Figure 4-24 Comparison of mean response of PCA/PFA versus $T_{\text {comp }} / T_{\text {IDbldg }}$ for different levels of component ductility. Figure (a) is for $\beta_{\text {comp }}=2 \%$ inherent component damping; (b) is for $\beta_{\text {comp }}=5 \%$. The dataset includes 86 recordings with $\mathrm{PCA}>0.9 \mathrm{~g}$. 
Figure 4-25 shows the ratio of component response to that of an elastic response at different levels of component ductility at $T_{\text {comp }} / T_{I D b l d g}=1$ resonance. This ratio is proportional to PCA/PFA. Reductions from elastic response are 0.6 at $\mu_{\text {comp }}=1.25$, 0.4 at $\mu_{\text {comp }}=1.5$, and 0.25 at $\mu_{\text {comp }}=2$.

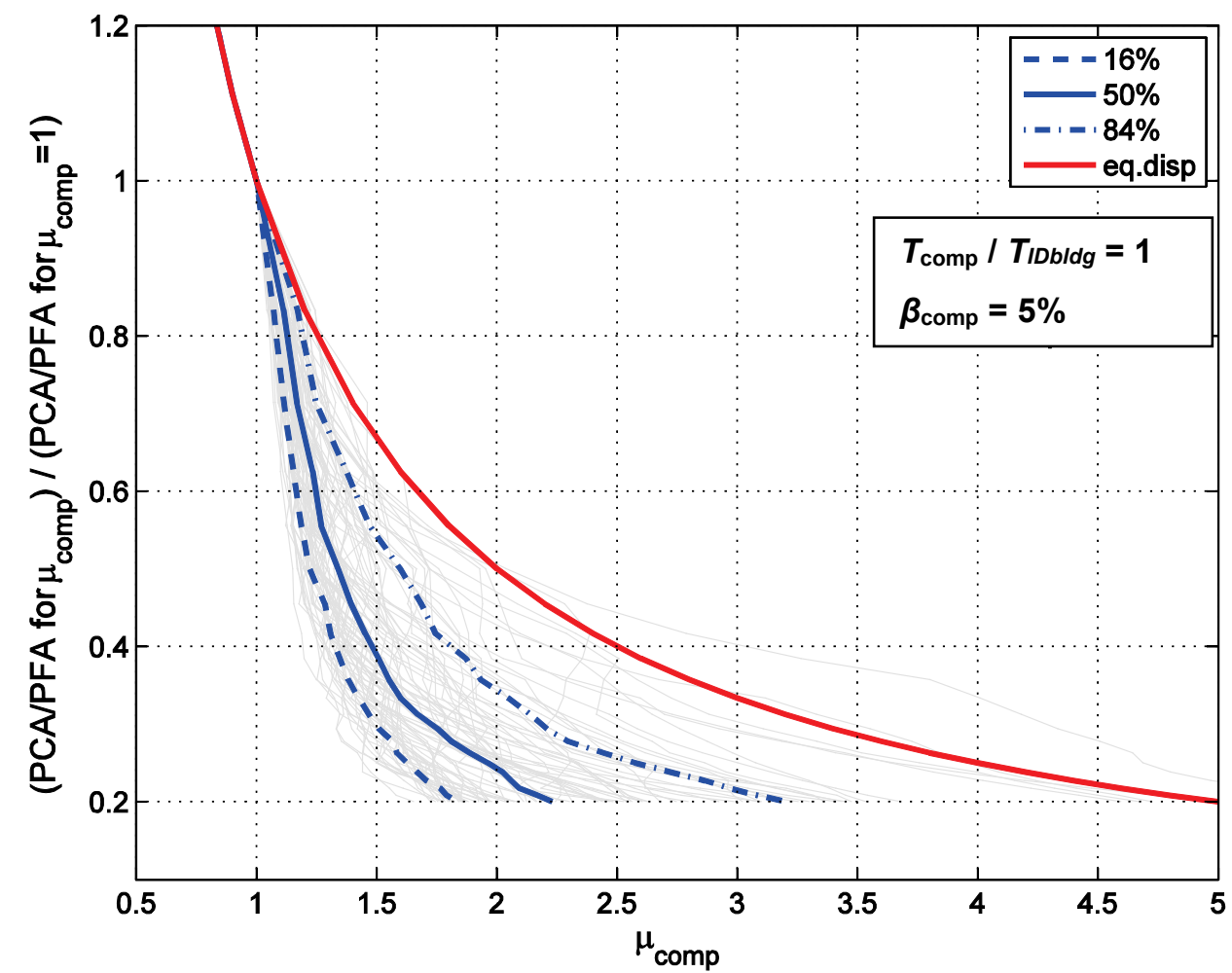

Figure 4-25 Reduction in PCA/PFA response for a component tuned to the building's fundamental period $\left(T_{\text {comp }}=T_{\text {IDbldg }}\right)$ with varying levels of component ductility. $\beta_{\text {comp }}=5 \%$ inherent component damping is assumed. The dataset includes 86 recordings with PCA $>0.9 \mathrm{~g}$.

\section{Implications for this Study}

Given the significant effect of component and/or anchorage ductility on component response, it was decided to explicitly incorporate this effect in the proposed nonstructural component design equation.

\subsubsection{Component Reserve Strength Margin}

For building design, there is an inherent reserve strength margin between the design value and the eventual peak strength. This comes in part from capacity reduction factors, $\phi$, but also as a result of other design factors, design simplifications, redundancy, and design decisions. This inherent reserve strength margin is a substantial part of the response modification coefficient, $R$, that is used to reduce elastic response levels down to design levels. See the discussion on $R_{o}$ in the SEAOC Recommended Lateral Force Requirements and Commentary (SEAOC, 1999). 
It is assumed that components also have some inherent reserve strength margin that occurs as part of the design process. This inherent reserve strength margin has traditionally been considered by code writers in the development of nonstructural design equations. While a component's inherent reserve strength margin factor has not been explicitly identified, effects have been considered as part of the $R_{p}$ factor.

The component reserve strength margin factor is related to the component itself and should not be confused with the component anchorage overstrength design force increase factor, $\Omega_{0}$, provided in Tables 13.5-1 and 13.5-2 of ASCE/SEI 7-16. The background on the development of the component anchorage overstrength design force increase factor is complicated.

The overstrength factor, $\Omega_{0}$, was first introduced in the design of structural systems in the 1997 Uniform Building Code (ICBO, 1997) and was based on an identical term being developed simultaneously for the 1997 Edition of NEHRP Recommended Provisions for Seismic Regulations for New Buildings and Other Structures (FEMA, 1998). Previous editions of the Uniform Building Code had used the term $3 / 8 R_{w}$ for basically the same purpose. The overstrength factor was to be used for design of certain items in the structural system including connections and anchorage. Where overstrength factors were specified to increase the design forces for certain items, AISC 341, Seismic Provisions for Structural Steel Buildings, (AISC, 1997) called these amplified design forces and applied them to the anchorage to concrete of certain structural steel systems.

Problems arose in 2008 in the anchorage design force arena when developers of ACI 318, Building Code Requirements for Structural Concrete and Commentary, Appendix D decided independently for anchorage in higher seismic areas to assign a value of 0.40 to the resistance factor, $\phi$, basically decreasing the design capacity by a factor of approximately 2.0. This was in addition to the 0.75 factor for reduced seismic capacity for high seismic areas. Also independently, code changes to Chapter 19 of the 2009 and 2012 editions of the International Building Code, (ICC, 2009 ; 2012) required that design forces for anchorage be increased by the overstrength factor and, if one was not assigned, then value of 2.5 was to be used. Meanwhile, the nonstructural force equations of Chapter 13 of ASCE/SEI 7-10 specified design force increase factors for anchorage but did not use an overstrength factor to determine these forces.

It was realized in late 2010 that all these well-meaning changes had resulted in very high design forces combined with very low design capacity for anchors in concrete in high seismic areas especially for nonstructural components and revisions were necessary. To make things workable, the following compromise was made: In ACI 318-11 Appendix D, adopted in the 2015 International Building Code, (ICC, 2015a) the resistance factor, $\phi$, was restored to its normal value for all areas including high 
seismic areas, and in ASCE/SEI 7-10 Supplement 1 (ASCE, 2013), adopted in the 2015 IBC, the Chapter 13 seismic increase factors for anchorage in concrete for nonstructural components were replaced by forces determined using anchorage overstrength factors provided in Chapter 13. It was made clear in Chapter 13 that these factors were only to be used for anchorage design. The values of the overstrength factors that were assigned were 2.5 and 2.0 and based on judgment considering the values of overstrength assigned to structural systems. Further testing and analytical studies done at San Diego State University (Johnson and Dowell, 2017; and Johnson et al., 2018) supported the concept of reducing the values of these anchorage overstrength factors and consequently, in ASCE/SEI 7-16 Chapter 13, the values of these factors were reduced to 2.0 and 1.5 .

These anchorage design force increase factors are still substantial, and it is recommended that further studies and testing be conducted to determine where further reductions are warranted especially in light of the new nonstructural design equations developed as part of this project.

\section{Implications for this Study}

It was decided to explicitly incorporate a placeholder value for the effect of component inherent reserve strength margin in the proposed primary nonstructural component design equation. The project team decided to assume a placeholder value of 1.3 for the inherent reserve strength margin factor to reduce seismic design forces to account for these inherent reserve strength properties. This reduction factor is termed $R_{\text {pocomp }}$. Further studies should be conducted by the NEHRP Provisions Update Committee Issue Team 5, Nonstructural Components and the ASCE/SEI 7 Subcommittee on Seismic Loads Technical Committee TC-08 to determine if this factor can be increased. It was also decided to continue to use the component anchorage overstrength factors and provisions of ASCE/SEI 7-16 for anchorage design.

\subsubsection{Summary}

A review of available research and studies conducted on influence of parameters was provided in the previous sections. The following is a summary of lessons learned by the project team that led to the development of the new proposed primary nonstructural component design equation presented in Section 4.3.

- Peak Ground Acceleration: Given the significant effect of ground shaking on nonstructural component response, it was decided to continue to include the intensity of ground shaking in the proposed nonstructural design equation. The relatively limited amount of recorded data with large shaking levels underscores the importance of using analytical studies where shaking levels at the design earthquake level and beyond can be investigated. 
- Seismic Force-Resisting System: The effect of SFRS was evaluated further in archetype analytical studies, and it is incorporated in building ductility assumptions. In addition, the use of spectral shapes influenced by SFRS for more sophisticated alternatives to the derivation of nonstructural component forces is discussed later.

- Building Modal Periods: The building fundamental period will be used in the nonstructural design equation in the derivation of PFA/PGA, as well as in aspects of PCA/PFA.

- Building Ductility: Given the importance of building ductility, a parameter to capture the effect of building ductility on reducing nonstructural response is included in the proposed nonstructural design equation. The system response modification factor, $R$, defined in the building code for all SFRS, was selected for simplicity.

- Inherent Building Damping: Given the small effect of inherent building damping on component response, inherent building damping is not included in the proposed nonstructural design equation.

- Building Configuration: Given the complexity of the issue, the effect of building configuration is not included in the proposed nonstructural design equation.

- Floor and Diaphragm Flexibility: Given the complexity of the issue and the available time and resources, the effects of diaphragms are not included in the proposed nonstructural design equation. Response is based primarily on mean results from rigid diaphragm buildings. Response at the perimeter of buildings with significant torsion or at the midspan of flexible diaphragms may be worse.

- Vertical Location of Component within the Building: The PFA/PGA relationship developed as part of this project was selected for use in the proposed nonstructural design equation.

- Component Period: It was decided to include the effect of resonance and the presentation approach of normalizing response against $T_{\text {comp }} / T_{\text {bldg }}$ in project studies and in the proposed nonstructural design equation.

- Inherent Component Damping: Initially, $2 \%$ inherent component damping was tentatively selected as the underlying basis of the nonstructural design equation. However, there is concern that there is insufficient research on damping for many components, particularly at high shaking levels of interest where it is assumed that damping will be larger; that distributed system components will likely have higher levels of inherent damping; and that use of $2 \%$ is inconsistent with the underlying $5 \%$ assumption of the equations in ASCE/SEI 7-16 Chapter 15 for nonbuilding structures and would lead to 
inconsistencies. As a result, it was decided to continue with the traditional assumption of 5\% inherent component damping, highlight the need for additional research, and account for potentially lower levels of damping in some components like rigid mechanical equipment by potentially assigning them to lower ductility categories.

- Component and/or Anchorage Ductility: Given the significant effect of component and/or anchorage ductility on component response, it was decided to explicitly incorporate this effect in the proposed nonstructural component design equation.

- Component Reserve Strength Margin: It was decided to explicitly incorporate a placeholder value for the effect of component reserve strength in the proposed nonstructural component design equation. The project team decided to assume a placeholder value of 1.3 for the inherent component reserve strength margin. This is termed $R_{\text {pocomp }}$.

\subsection{Proposed Primary Equation and Combined Effect of Multiple Parameters}

Section 4.2 focused on evaluating the significance of individual parameters. Section 4.3 examines the combined effect of the different parameters working together, and summarizes the development of a new proposed primary nonstructural design equation that accounts for parameters considered to be of significance while balancing the need for relative simplicity in implementation for practicing engineers.

\subsubsection{Other Recent Studies}

Several recent studies have focused on developing improved floor spectra for nonstructural component seismic design forces and they have investigated the effect of multiple variables.

Sullivan et al. (2013) developed equations for use in predicting floor response spectra based on elastic and inelastic SDOF models and a suite of scaled 47 instrumental records. It accounts for the ratio of building period, component period, and inherent building damping. They showed improved results compared to ASCE/SEI 7, New Zealand, and Eurocode standards. This work was later extended in Calvi and Sullivan (2014) to elastic multi-degree-of-freedom (MDOF) models using reinforced concrete wall archetypes models. Component damping and component ductility were not explicitly addressed. Welch and Sullivan (2017) extended this approach to inelastic MDOF systems.

Vukobratović and Fajfar (2016) also developed equations for predicting floor spectra considering elastic and inelastic SDOF and MDOF models and elastic components. The focus was on a three-story reinforced concrete moment frame and a three-story 
steel moment-resisting frame. Vukobratović and Fajfar (2017) extended this work to include component ductility. Figure 4-26 shows floor spectra for six permutations: an elastic structure with three levels of component ductility, and an inelastic structure with three levels of component ductility.

These previous studies clearly underscore concerns about the accuracy of current code equations and the importance of including more parameters, but the equations are fairly complicated and can require combination of different structural mode effects. Sections 4.3.2 to 4.3.4 describe the approach taken on this project to develop a new equation for practicing engineers.

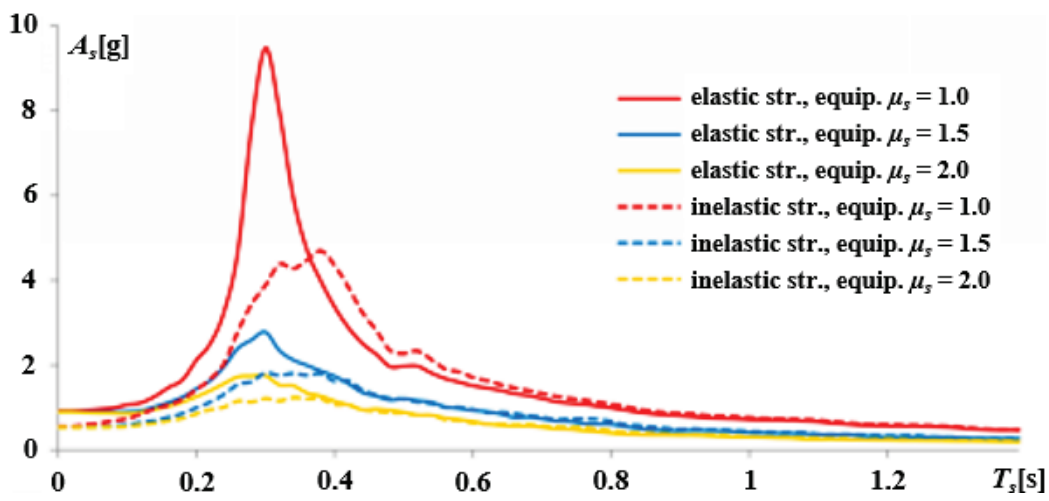

Figure 4-26 Floor acceleration spectra for elastic and inelastic (elasto-plastic) SDOF equipment supported by a SDOF primary structure. For these studies inherent component damping is $\beta_{\text {comp }}=1 \%$ and inherent building damping is $\beta_{\text {bldg }}=5 \%$. The component ductility in the figure shown as $\mu_{s}$ is the same as $\mu_{\text {comp }}$ used in this study. The x-axis, $T_{s}$, and y-axis, $A_{s}$, are the same as $T_{\text {comp }}$ and PCA used in this study. The inelastic structures had building ductility of $\mu_{b l d g}=2$. From Vukobratović and Fajfar (2017).

\subsubsection{General Framework for Proposed Primary Equation}

The proposed primary nonstructural design equation can be rewritten as three individual terms, recognizing that the earthquake force on a nonstructural component is dependent on the level of ground shaking, the modification of shaking resulting from building response, and further modification of shaking associated with the component itself:

$$
\frac{F_{p}}{W_{p}}=\mathrm{PGA} \times\left(\frac{\mathrm{PFA}}{\mathrm{PGA}}\right) \times\left(\frac{\mathrm{PCA}}{\mathrm{PFA}}\right) \times I_{p}
$$

where:

PGA = peak ground acceleration measured at the base of the structure $\left(\frac{\mathrm{PFA}}{\mathrm{PGA}}\right)=\mathrm{a}$ factor that converts the peak ground acceleration into the peak floor acceleration 


$$
\begin{aligned}
\left(\frac{\mathrm{PCA}}{\mathrm{PFA}}\right)= & \text { a factor that converts the peak floor acceleration into the peak component } \\
& \text { acceleration }
\end{aligned}
$$

Ground shaking intensity is directly captured by the PGA term in the above equation. Modification of ground shaking intensity from soil-structure interaction is not included in the formulation for simplicity.

The proposed equation framework makes the assumption that PFA/PGA and PCA/PFA can be effectively separated. This provides a distinction where PFA/PGA primarily relates to what the building does, and PCA/PFA relates to how the components respond to what the building is doing. For example, the SFRS, building modal periods, building ductility, building damping, building configuration, floor diaphragm rigidity, and vertical location of the component will all affect the PFA/PGA term, as they are a function of the building. Similarly, the PCA/PFA term is affected by the component period, component ductility, and component damping. However, the SFRS, building modal periods, and building ductility can also have a significant impact on the general floor spectra that the PCA/PFA term is attempting to capture. Thus, it is recognized that the terms and underlying parameters are not independent. A few project studies were conducted with a focus on PCA/PGA and thus effectively combining the PFA/PGA and PCA/PFA terms; this has also been done by some researchers in the past. However, it was decided to keep the PFA/PGA and PCA/PFA terms separated for simplicity. It should also be recognized that the presumed size of the nonstructural mass is considered sufficiently small enough that the influence of the nonstructural component on the building response is neglected. This is sometimes termed the "cascading analysis" approach.

Details on the influence of various parameters on component response were described in Section 4.2. Additional information is described in Sections 4.3.4 and 4.3.5.

\subsubsection{Initial Proposed Primary Equation}

As an initial step, the following equation was proposed for the design of nonstructural components.

$$
\frac{F_{p}}{W_{p}}=\mathrm{PGA} \times\left[\frac{\left(\frac{\mathrm{PFA}}{\mathrm{PGA}}\right) \times \gamma_{t o r} \times \gamma_{\text {diaph }}}{R_{\mu b l d g}}\right] \times\left[\frac{\left(\frac{\mathrm{PCA}}{\mathrm{PFA}}\right) \times B_{\beta c o m p}}{R_{\mu c o m p}}\right] \times I_{p}
$$

The following discussions explore this equation. 


\subsubsection{Condensation of Diaphragm Effects}

$\gamma_{\text {tor }}$ is a parameter to account for building configuration irregularity, particularly torsional irregularity. It accounts for the increase in floor acceleration at the perimeter as compared to the center of rigidity. The component location is not included in the equation. At issue then is the level of conservatism to use in accounting for location and potential increases from torsion.

Project studies evaluated each direction of loading and compared the peak value at a perimeter recording versus the average of the peak values of all the recordings on a floor. This ratio is one possible measure of the increase in demand due to rotation of the floor and was found to be on the order of about 1.2. However, the peak values for each recording do not necessarily occur at the same moment in time. A more detailed evaluation would involve making the comparison of the perimeter recording versus the average of all at every time step of the record and then determining the potential increase. Use of a torsional term assumes both that PFA/PGA is derived from mean response (or more precisely center of rigidity values) and a desire to distinguish response of components located at the center of rigidity versus the perimeter of the floor. The project team recommends future study of this issue, but chose not to include a torsional factor in the nonstructural design equation.

$\gamma_{\text {diaph }}$ is a parameter to account for amplification in floor acceleration due to the diaphragm being flexible. Midspan PFA is often substantially larger than the PFA above shear walls. The project team decided that establishing rules for design about component location with respect to diaphragm span would be difficult in actual building configurations and would overly complicate the proposed primary design equation. Research still needs to be conducted to determine if the increased flexibility of a long span diaphragm reduces the period such that the increase in forces due to diaphragm flexibility cancels out. Since there is not sufficient research to recommend inclusion of this effect at this time, a diaphragm factor is not included in the proposed primary nonstructural design equation.

\subsubsection{Condensation of PCA/PFA Effects}

The second bracketed portion of the equation relates to how the floor acceleration is amplified to produce the component spectra. The component spectra can be expressed as a function of either the component period or component period normalized against the first, second, or higher building modes, $T_{\text {comp }} / T_{n b l d g}$, as shown in Figure 4-17. Component spectra are very sensitive to component damping. As described above, initially, the project team tentatively selected $2 \%$ inherent component damping as the underlying basis of the nonstructural design equation. However, there is concern that there is insufficient research on damping for many components, particularly at high shaking levels of interest where it is assumed that damping will be larger; that distributed system components will likely have higher 
levels of damping; and that use of $2 \%$ is inconsistent with the underlying $5 \%$ assumption of the equations in ASCE/SEI 7-16 Chapter 15 for nonbuilding structures and would lead to inconsistencies. The project team decided as a result to continue with the traditional assumption of 5\% inherent component damping, highlight the need for additional research, and account for potentially lower levels of damping in some components like rigid mechanical equipment by potentially assigning them to lower ductility categories.

$B_{\beta c o m p}$ is a factor to adjust the component spectra from the 5\%-damped spectra that the PGA parameter is based on. $B_{\beta c o m p}$ is 1.0 for $5 \%$ inherent component damping, and would be taken as as a value larger than 1.0 with $2 \%$ inherent component damping. Per Figure 4-20, at the resonant peak of $T_{\text {comp }} / T_{\text {IDbldg }}=1$, the increase is a value of 1.6 for $2 \%$ vs. $5 \%$ damping. The value is less farther away from the resonant peak; at $T_{\text {comp }} / T_{\text {IDbldg }}=0.75$ and 1.5 , for example, it is about 1.25 . In ASCE/SEI 7-16, in Table 17.5-1 of the base isolation Chapter 17 and Table 18.7-1 of the damping Chapter 18, the increase for a reduction in damping from $5 \%$ to $2 \%$ is set at $(1.0 / 0.8)=1.25$. Note that in equations of ASCE/SEI 7-16 Chapters 17 and 18, the damping adjustment factor is placed in the denominator. $B_{\beta c o m p}$ is placed in the numerator for Equation 4-1 simply for consistency with Figure 4-20. Numerically, the overall result is the same.

$R_{\mu c o m p}$ is a parameter to account for nonlinear behavior in the component's anchorage or in the component itself. The yielding necessary for nonlinear behavior reduces the acceleration that the component experiences by effectively establishing a cap to PCA equal to the strength capacity of the component divided by component mass and by increasing damping through hysteretic response of the component. The studies carried out indicated that even a small amount of component ductility, $\mu_{\text {comp }}$, on the order of 1.5 or 2 , can produce a significant reduction in the maximum acceleration a component experiences. It is proposed that this term be revised from the current $R_{p}$ term.

Given that a fixed component value is assumed for $\beta_{\text {comp }}$ and because PCA/PFA dynamic amplification due to component flexibility, deamplification due to component ductility, and component damping are all interrelated, it was decided to combine these effects into one factor, termed PCA/PFA.

\subsubsection{Addition of Component Reserve Strength Margin Factor}

Per the discussion above, a component reserve strength margin factor, termed $R_{\text {pocomp }}$, has been included to account for inherent overstrength in typical nonstructural component design. A value of 1.3 has been selected as a placeholder for $R_{\text {pocomp }}$. 


\subsubsection{Refined Equation}

Given the above condensations, the proposed nonstructural design equation takes the following form. Details of each term are described in Sections 4.3.4.1 through 4.3.4.4.

$$
\frac{F_{p}}{W_{p}}=\mathrm{PGA} \times\left[\frac{\left(\frac{\mathrm{PFA}}{\mathrm{PGA}}\right)}{R_{\mu b l d g}}\right] \times\left[\frac{\left(\frac{\mathrm{PCA}}{\mathrm{PFA}}\right)}{R_{\text {pocomp }}}\right] \times I_{p}
$$

where:

PGA = peak ground acceleration. Use $0.4 S_{D S}$ until this is directly provided in future ASCE/SEI 7 editions.

$$
\left(\frac{\mathrm{PFA}}{\mathrm{PGA}}\right)=1+a_{1}\left(\frac{z}{h}\right)+a_{2}\left(\frac{z}{h}\right)^{10}
$$

where:

$$
\begin{aligned}
& a_{1} \quad=\frac{1}{T_{a B l d g}} \leq 2.5 \\
& a_{2} \quad=\left[1-\left(0.4 / T_{\text {abldg }}\right)^{2}\right]>0 \\
& T_{\text {abldg }}=\text { ASCE/SEI 7-16 Equation 12.8-7 } \\
& R_{\mu b l d g}=\text { reduction factor to account for building global ductility } \\
& \text { where: } \\
& R_{\mu b l d g}=\left(R_{D}\right)^{1 / 2}=\left(1.1 R / \Omega_{0}\right)^{1 / 2} \\
& \text { where } R \text { and } \Omega_{0} \text { are the response modification coefficient and the } \\
& \text { overstrength factor from ASCE/SEI 7-16 Table 12.2-1. } R_{\mu b l d g} \text { need } \\
& \text { not be taken as less than 1.0. } \\
& \left(\frac{\text { PCA }}{\text { PFA }}\right)=\text { factor to account for component amplification, inherent } \\
& \text { component damping, and component ductility per Table 4-2. } \\
& R_{\text {pocomp }}=\text { inherent component reserve strength margin factor. A value of } \\
& 1.3 \text { is used as a placeholder. }
\end{aligned}
$$


Table 4-2 PCA/PFA Values

\begin{tabular}{|c|c|c|c|c|}
\hline \multirow[b]{2}{*}{$\begin{array}{l}\text { Location of } \\
\text { Component }\end{array}$} & \multirow[b]{2}{*}{$\begin{array}{c}\text { Possibility of Being in } \\
\text { Resonance with Building }\end{array}$} & \multicolumn{2}{|c|}{ Component Ductility } & \multirow[b]{2}{*}{$\left(\frac{P C A}{P F A}\right)_{(2)}$} \\
\hline & & Category(1) & $\begin{array}{l}\text { Assumed } \\
\text { Ductility }\end{array}$ & \\
\hline \multirow{5}{*}{ Ground } & \multirow{4}{*}{ More Likely } & Elastic & $\mu_{\text {comp }}=1$ & 2.5 \\
\hline & & Low & $\mu_{\text {comp }}=1.25$ & 2.0 \\
\hline & & Moderate & $\mu_{\text {comp }}=1.5$ & 1.8 \\
\hline & & High & 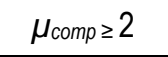 & 1.4 \\
\hline & Less Likely & Any & -- & 1.0 \\
\hline \multirow{5}{*}{$\begin{array}{l}\text { Roof or } \\
\text { Elevated Floor }\end{array}$} & \multirow{4}{*}{ More Likely } & Elastic & $\mu_{\text {comp }}=1$ & 4.0 \\
\hline & & Low & $\mu_{\text {comp }}=1.25$ & 2.8 \\
\hline & & Moderate & $\mu_{\text {comp }}=1.5$ & 2.2 \\
\hline & & High & $\mu_{\text {comp }} \geq 2$ & 1.4 \\
\hline & Less Likely & Any & -- & 1.0 \\
\hline
\end{tabular}

(1) Categories will be assigned to components similar to ASCE/SEI 7-16 Table 13.5-1. Categories need to be determined.

(2) Inherent component damping of $5 \%$ is assumed as a default.

\subsubsection{PGA}

The PGA parameter can be obtained directly from the forthcoming proposed USGS multi-period spectra plots or approximated as $0.4 S_{D S}$.

\subsubsection{PFA/PGA}

The equation for PFA/PGA is based on the mean response of all recordings. Thus, it does not directly capture increases in PFA at the perimeter due to torsion, but since many sensors are located at the building perimeter, values are higher than at the center of rigidity. This is judged to be adequate for the proposed nonstructural design equation.

\subsubsection{3 $R_{\mu b l d g}$}

Based on project studies, building ductility typically reduces component response. Section 105.3.2 of SEAOC (1999) defined the seismic response modification factor, $R$, as:

$$
R=R_{D} \times R_{o}
$$

where:

$R_{D} \quad=$ global ductility coefficient (commonly identified as $\mu$ and termed $\mu_{b l d g}$ in this report) at design earthquake level

$R_{o} \quad=$ global overstrength coefficient 
where:

$\Omega_{0} \quad=1.1 R_{o}$

$R_{D}$ then equals $1.1 R / \Omega_{0}$

Initially, it was assumed that the reduction in PFA is proportional to the square root of $R_{D}$. The factor for reduction is termed $R_{\mu b l d g}$, and it is then defined as follows.

$$
R_{\mu b l d g}=\left(R_{D}\right)^{1 / 2}=\left(1.1 R / \Omega_{0}\right)^{1 / 2}
$$

Sample values for $R, \Omega_{0}, R_{D}$, and $R_{\mu b l d g}$ are given in Table 4-3.

Table 4-3 Building Ductility Reduction Factor, $\boldsymbol{R}_{\mu b l d g}$

\begin{tabular}{|c|c|c|c|c|}
\hline Seismic Force-Resisting System & $\begin{array}{c}\text { Response } \\
\text { Modification } \\
\text { Coefficient, } R \\
\end{array}$ & $\begin{array}{l}\text { Overstrength } \\
\text { Factor, } \Omega_{0} \\
\end{array}$ & $\begin{array}{l}\text { Global Ductility } \\
\text { Coefficient, } R_{D} \\
\end{array}$ & $R_{\mu b l d g}$ \\
\hline Steel special moment-resisting frame & 8 & 3 & 2.93 & 1.71 \\
\hline Special reinforced concrete moment frame & 8 & 3 & 2.93 & 1.71 \\
\hline $\begin{array}{l}\text { Special reinforced concrete shear wall (building } \\
\text { frame system) }\end{array}$ & 6 & 2.5 & 2.64 & 1.62 \\
\hline $\begin{array}{l}\text { Special reinforced concrete shear wall (bearing } \\
\text { wall system) }\end{array}$ & 5 & 2.5 & 2.20 & 1.48 \\
\hline Steel eccentrically braced frame & 8 & 2 & 4.40 & 2.10 \\
\hline Steel buckling-restrained braced frame & 8 & 2.5 & 3.52 & 1.88 \\
\hline Steel special concentrically braced frame & 6 & 2 & 3.30 & 1.82 \\
\hline Steel ordinary concentrically braced frame & 3.25 & 2 & 1.79 & 1.33 \\
\hline Steel ordinary moment-resisting frame & 3.5 & 3 & 1.28 & 1.13 \\
\hline
\end{tabular}

Studies focused on the exponent in the $R_{\mu b l d g}=\left(R_{D}\right)^{x}$ equation were conducted to test the effectiveness of assuming $x=1 / 2$. Figure 4-27 shows the ratio of $F_{p \text {,actual }} / F_{p, \text { proposed }}$ for a 6 -story steel moment-resisting frame archetype at the roof level.

$F_{p, \text { actual }}$ is the mean of 20 spectrum-compatible ground motions, and $F_{p, p r o p o s e d}$ is the proposed equation for the more likely in resonance case, with $\mu_{c o m p}=1.5$, and with $5 \%$ inherent component damping. Note that when calculating $F_{p \text {,actual }} / F_{p, p r o p o s e d}$, the term $R_{\text {pocomp }}$ (component reserve margin factor) is not included. Essentially, the designer uses a design force reduced by $R_{\text {pocomp }}$, but then the component inherently has the same value of overstrength, so the final or actual strength should not be reduced by $R_{\text {pocomp. }}$ Figure 4-28 shows similar results for an 8-story concrete shear wall building. Studies were done with archetypes built directly to code and those with some additional strength to simulate overdesign ratios that often occur in real buildings. The righthand panels of Figures 4-27 and 4-28 show archetypes that use an overdesign ratio of 1.5, which is added over and above the values that come straight from code design such as $\phi$ factors and drift requirements. The peaks in 
Figure 4-27 from right to left are for the first mode, second mode, and third mode of the building. The first mode peak is not at $T_{\text {comp }} / T_{\text {abldg }}$ because the actual first mode period for the building, $T_{1 b l d g}=1.56$ seconds, in the archetype analysis is longer than the code formula $T_{\text {abldg }}=0.93$ seconds. Peaks from the first three modes can also be seen in Figure 4-28, though the amplification for the third mode is modest. To capture shorter, stiffer buildings, a 2-story steel moment-resisting frame with an overdesign ratio of 2.0 and a 2-story concrete shear wall with an overdesign ratio of 3.0 were also evaluated with results shown in Figure 4-29. The code periods and modal periods of the various archetypes are shown in Table 4-4.
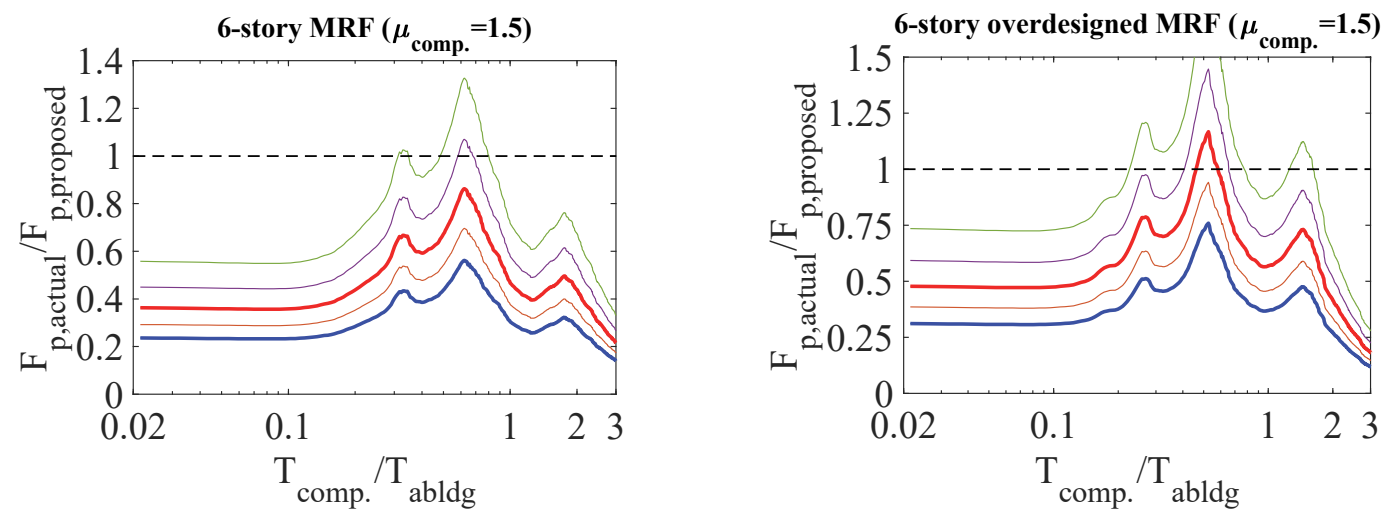

Figure 4-27 Ratio of $F_{p, \text { actual }} / F_{p, \text { proposed }}$ at the roof for a 6-story steel moment frame archetype $T_{\text {abldg }}=0.93 \mathrm{~s}$, assuming $\mu_{\text {comp }}=1.5$ and $\beta_{\text {comp }}=5 \%$ inherent

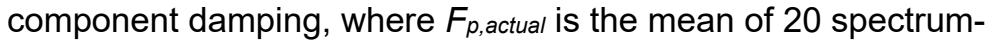
compatible ground motions. The plots are for different values of " $x$ " in the $R_{\mu b l d g}=\left(R_{D}\right)^{X}$, with the dark blue at the bottom being 0.1 , the dark red in middle being 0.5 , and the light green at the top being 0.9 . The "overdesigned" archetype on the right has an additional strength of 1.5 compared to the baseline archetype on the left.
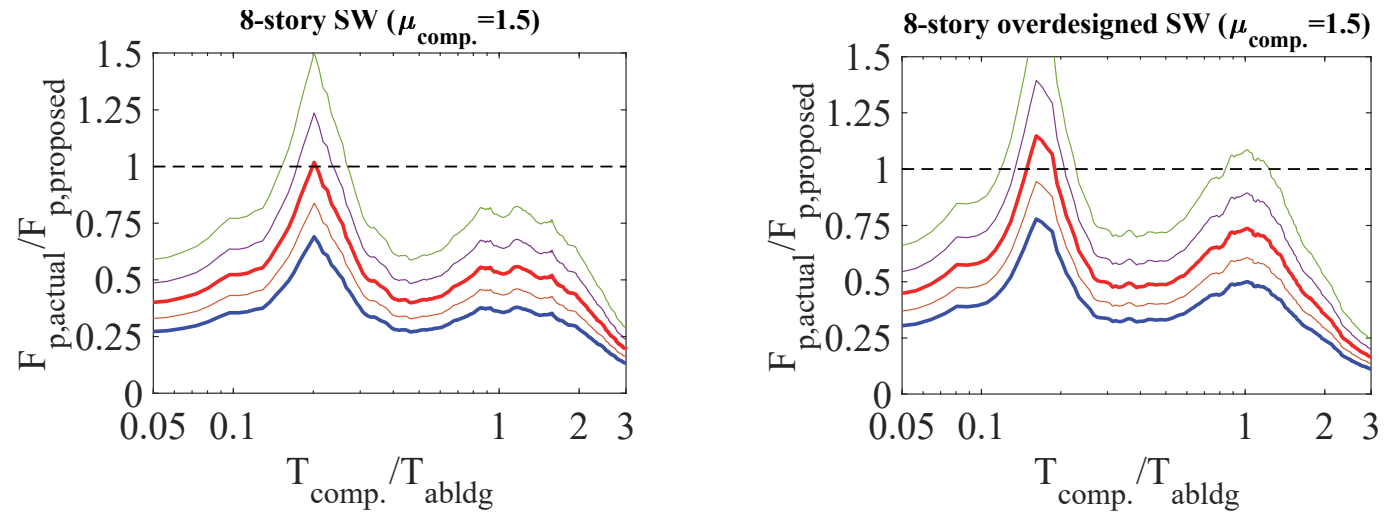

Figure 4-28 Ratio of $F_{p, \text { actual }} / F_{p, \text { proposed }}$ at the roof for an 8-story concrete shear wall archetype with $T_{\text {abldg }}=0.62 \mathrm{~s}$, assuming $\mu_{\text {comp }}=1.5$ and $\beta_{\text {comp }}=5 \%$ inherent component damping, where $F_{p \text {,actual }}$ is the mean of 20 spectrumcompatible ground motions. The plots are for different values of " $x$ " in the $R_{\mu b l d g}=\left(R_{D}\right)^{X}$, with the dark blue at the bottom being 0.1 , the dark red in middle being 0.5 , and the light green at the top being 0.9 . The "overdesigned" archetype on the right has an additional strength of 1.5 compared to the baseline archetype on the left. 

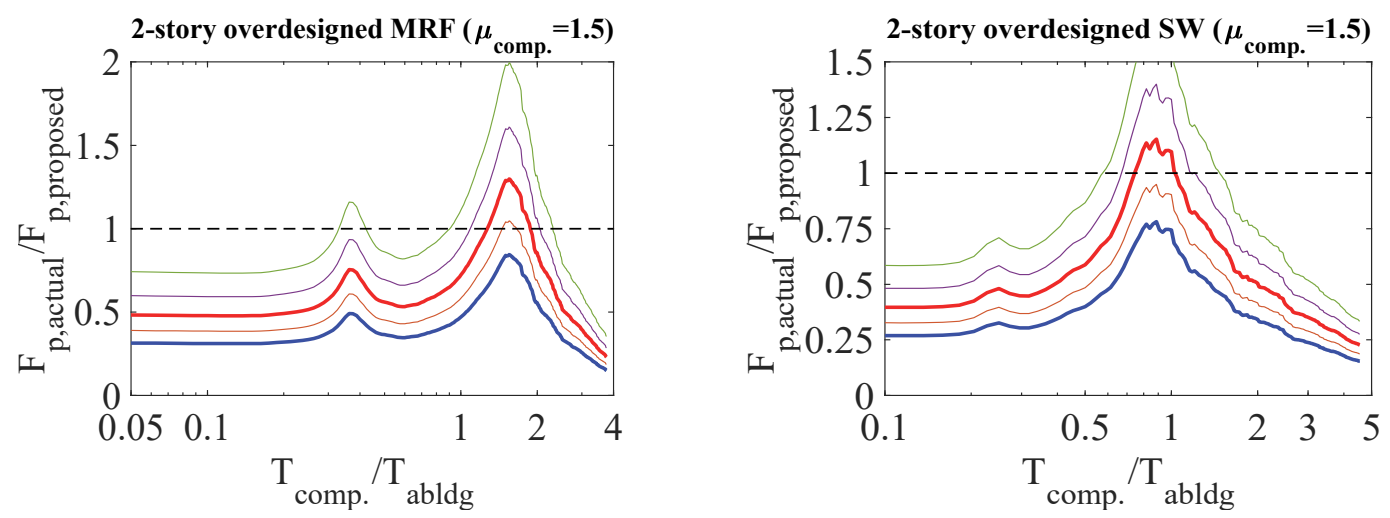

Figure 4-29 Ratio of $F_{p, \text { actual }} / F_{p, \text { proposed }}$ at the roof for a 2-story moment frame archetype (left, with $T_{\text {abldg }}=0.40 \mathrm{~s}$ ) and 2-story concrete shear wall archetype (right, with $T_{\text {abldg }}=0.40 \mathrm{~s}$ ), assuming $\mu_{\text {comp }}=1.5$ and $\beta_{\text {comp }}=5 \%$ inherent

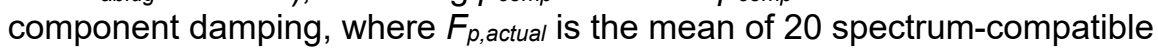
ground motions. The plots are for different values of " $x$ " in the $R_{\mu b l d g}$ $=\left(R_{D}\right)^{X}$, with the dark blue at the bottom being 0.1 , the dark red in middle being 0.5 , and the light green at the top being 0.9. The moment frame has an overdesign ratio of 2.0 , and the shear wall has as an overdesign ratio of 3.0, compared to baseline archetypes.

Table 4-4 Code and Modal Periods of Various Archetypes

\begin{tabular}{|c|c|c|c|c|c|c|c|}
\hline System & $\begin{array}{c}\text { \# of } \\
\text { stories }\end{array}$ & $h(\mathrm{ft})$ & Design Scenario(2) & $T_{\text {abldg }}(\mathrm{s})$ & $T_{1 b l d g}(\mathrm{~s})$ & $T_{2 b l d g}(\mathrm{~s})$ & $T_{3 b l d g}(\mathrm{~s})$ \\
\hline \multirow{2}{*}{$\begin{array}{l}\text { Steel } \\
\text { SMRF(1) }^{(1)}\end{array}$} & \multirow{2}{*}{6} & \multirow{2}{*}{80} & Baseline & 0.93 & 1.93 & 0.63 & 0.32 \\
\hline & & & with an OD of 1.5 & 0.93 & 1.55 & 0.52 & 0.26 \\
\hline \multirow{2}{*}{$\begin{array}{l}\text { Steel } \\
\text { SMRF(1) }^{(1)}\end{array}$} & \multirow{2}{*}{2} & \multirow{2}{*}{28} & Baseline & 0.40 & 1.01 & 0.21 & - \\
\hline & & & with an OD of 2.0 & 0.40 & 0.71 & 0.15 & - \\
\hline \multirow{2}{*}{$\operatorname{RCSW}(1,3)$} & \multirow{2}{*}{8} & \multirow{2}{*}{97} & Baseline & 0.62 & 1.03 & 0.17 & 0.06 \\
\hline & & & with an OD of 1.5 & 0.62 & 0.80 & 0.12 & 0.05 \\
\hline \multirow{2}{*}{$\operatorname{RCSW}(1,3)$} & \multirow{2}{*}{2} & \multirow{2}{*}{25} & Baseline & 0.22 & 0.52 & 0.09 & - \\
\hline & & & with an OD of 3.0 & 0.22 & 0.17 & 0.04 & - \\
\hline
\end{tabular}

(1) SMRF: special moment-resisting frame; RCSW: special reinforced concrete shear wall

(2) OD: overdesign factor

(3) The RCSW buildings have been modeled using nonlinear shell elements, so modal periods were estimated based on the spikes observed in the mean roof floor response spectra.

A value of 0.5 for the exponent envelopes the entire response (i.e., $F_{p \text {,actual }} / F_{p, p r o p o s e d}$ is at or below 1.0) for both the 6-story moment frame and the 8-story shear wall baseline cases. A value of 0.5 for the exponent also captures the majority of the response for the overdesign cases.

The spectrum-compatible records used in Figures 4-27 through 4-29 were scaled to a target spectrum $\left(S_{D S}=1.0\right.$ and $\left.S_{D I}=0.55\right)$ similar to the one used in FEMA P-695, Quantification of Building Seismic Performance Factors, (FEMA, 2009a) for the 
buildings designed based on higher seismic loads $\left(S_{D S}=1.0\right.$ and $\left.S_{D I}=0.6\right)$. In order to better understand the influence of dispersion from record-to-record variability, several studies were run using the FEMA P-695 far-field record set. Spectrumcompatible ground motions were used in these studies to estimate mean responses and not variability, as spectrum-matched records artificially reduce the variability in response parameters. Although Seifried and Baker (2016) have shown that, in some cases, performing response history analyses with spectrum-matched ground motions is known to result in unconservatively biased median demand estimates, the spectrum-compatible results shown herein generally enveloped the results obtained from response history analysis using the FEMA P-695 far-field record set. Thus, the spectrum-compatible results are considered conservative for the purpose of this evaluation. See Appendix B for details.

\subsubsection{PCA/PFA}

The PCA/PFA term has a number of features embedded within it. These include narrow band amplification due to resonance with building periods, component ductility, the concept of flexible versus rigid components, ground versus superstructure response, and component ductility effects. Each topic is discussed below.

\section{Narrow Band Amplification}

As previously discussed, the effect of amplification of the floor acceleration based on the period of the component occurs when the component is in resonance with one of the building periods. This narrow band amplification is significant, but may not be likely. A study was conducted to look at two groups of common building equipment. The first set was for equipment that was rigidly attached to the floor or roof. The second set was equipment that had flexible supports, such as vibration isolators. Figures 4-30a and 4-30b show histograms of component frequencies for rigid and vibration-isolated components. Although this would not be an exhaustive list of all possible components in a building and their frequencies, it represents a large enough sample size to develop a probability distribution of component frequencies for nonstructural components commonly found in a building. Note that vibrationisolated equipment is not necessarily representative of all flexible components. Looking at the data distribution in the two histograms, it appears that each set of equipment may have its period represented as a lognormal distribution. The rigid equipment has an average period of $0.12 \mathrm{~s}$ and a coefficient of variation of 0.7 . The vibration isolated equipment has an average period of $0.33 \mathrm{~s}$ and a coefficient of variation of 0.6 . 


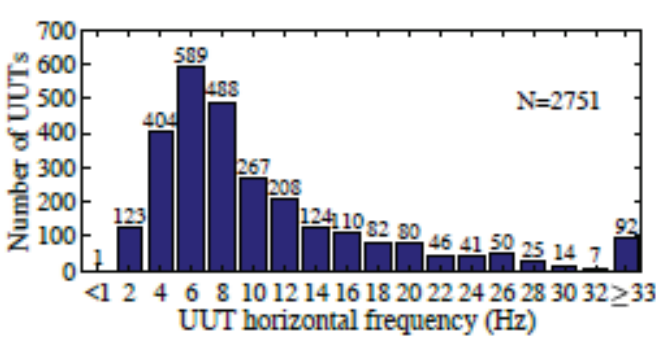

(a)

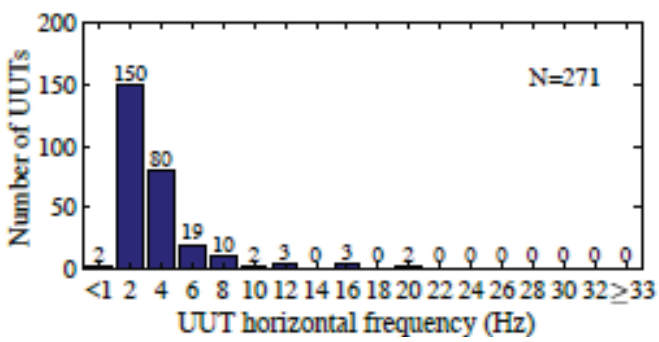

(b)

Figure 4-30 The horizontal natural frequency distribution of a unit under test (UUT) developed based on test data available from the California Office of Statewide Health Planning and Development (OSHPD) OSP special seismic certification program for: (a) equipment rigidly mounted on the floor and (b) components with spring isolators mounted on the floor. From NIST (2017).

To investigate how frequently the components would be in resonance with the building period, a histogram of building periods was created based on instrumental buildings from the California Strong Motion Instrumentation Program (CSMIP) database. It is noted that this database likely is biased toward higher period buildings because more significant and larger buildings are more likely to be instrumented as part of CSMIP. The histogram of the building periods is shown in Figure 4-31.

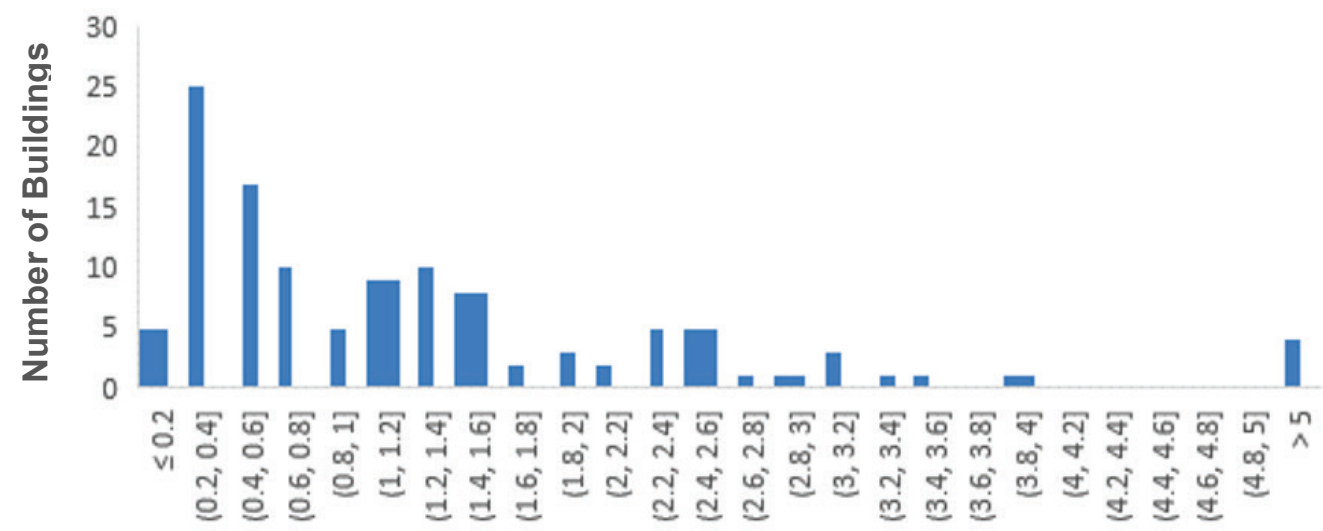

\section{Building Period Range}

Figure 4-31 Histogram of building fundamental periods for buildings studied.

The building data also appear to show that building periods could be expressed using a lognormal probability distribution. Table 4-5 shows the mean and beta values for the components and the buildings. The second and third mode periods were approximated as $1 / 3$ and $1 / 2$ of the average previous mode period, respectively. The coefficient of variation for the building periods is approximately 1.1 .

To study the likelihood of resonance, the probability of being within a region with narrow band acceleration was investigated by comparing the probabilities of the ratio of the component period to the building period being within the narrow band where amplifications occurs. The first study simply looked at the likelihood of a component 
being in resonance with one of the first three modes $\left(T_{\text {comp }} / T_{n b l d g}=1\right)$ assuming neither the component period nor the building period are known. The second study looked at the likelihood of a component being in resonance if the building's period was calculated to be 0.35 seconds.

Table 4-5 Mean Period and Beta for Buildings and Components

\begin{tabular}{lccc} 
& Mean Period & COV \\
\cline { 2 - 3 } Building first mode & $0.85 \mathrm{~s}$ & 1.1 \\
Building second mode & $0.30 \mathrm{~s}$ & 1.1 \\
Building third mode & $0.15 \mathrm{~s}$ & 1.1 \\
Rigid components & $0.12 \mathrm{~s}$ & 0.7 \\
Flexible components & $0.33 \mathrm{~s}$ & 0.6 \\
\hline
\end{tabular}

For the first study, the ratio of the component period to the first, second, or third mode period, $T_{\text {comp }} / T_{n b l d g}$, was expressed as a lognormal probability distribution function based on the mean being the mean of the rigid or flexible component dataset divided by the mean of the building dataset with the coefficient of variation equal to the square root sum of the squares of the two datasets' coefficients of variation. By looking at the cumulative distribution function for $T_{\text {comp }} / T_{n b l d g}$, one can identify the probability of being within the narrow band where significant amplification of the component acceleration with respect to the floor acceleration occurs. This was defined as $0.75<T_{\text {comp }} / T_{\text {lbldg. }}<1.25$ in Figure 4-32. When looking at rigid components versus the first mode of a building, the cumulative distribution function in Figure 4-32 shows that there is significantly less than a $10 \%$ probability of $0.75<$ $T_{\text {comp }} / T_{\text {nbldg }}<1.25$; it is on the order about $4 \%$.

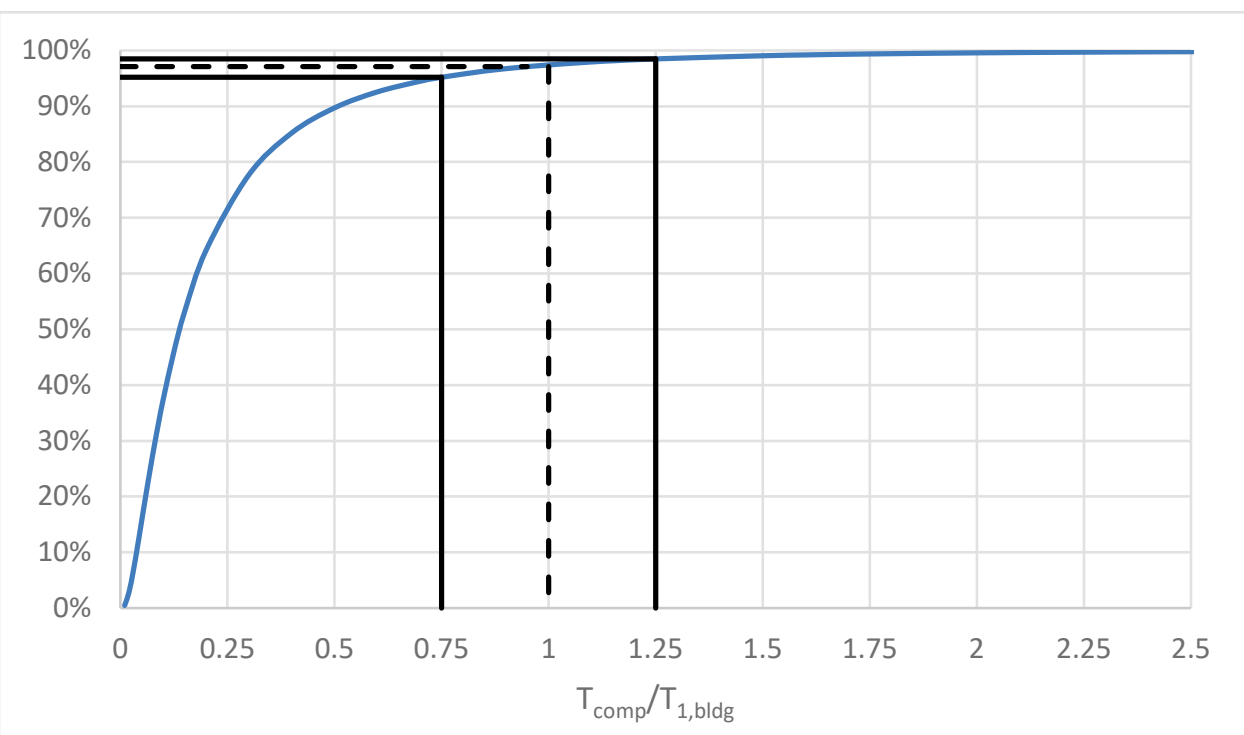

Figure 4-32 Cumulative distribution function for $T_{\text {comp,rigid }} / T_{1 b l d g}$. 
Figure 4-33 shows that for flexible components, there is about a $15 \%$ probability of being between $0.75<T_{\text {comp }} / T_{\text {lbldg }}<1.25$, and there is about a $10 \%$ probability of being between $0.85<T_{\text {comp }} / T_{\text {lbldg }}<1.15$.

Figures 4-34 and 4-35 compare the ratio of periods for rigid and flexible components to the second mode period of the building. For both rigid and flexible components, there is about a $10 \%$ probability of being between $0.85<T_{\text {comp }} / T_{2 b l d g}<1.15$.

Figures 4-36 and 4-37 show similar plots for the third mode of the building. For both rigid and flexible components, there is about a $10 \%$ probability of being between $0.85<T_{\text {comp }} / T_{3 b l d g}<1.15$.

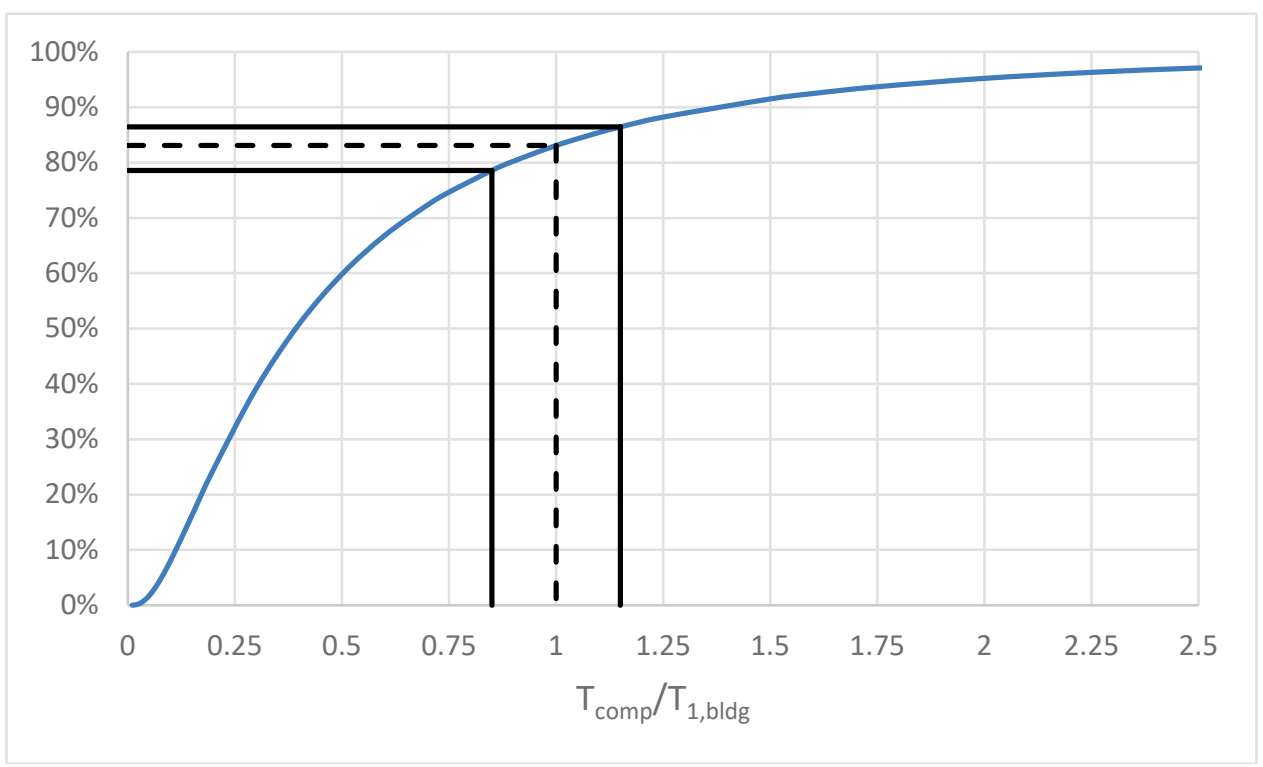

Figure 4-33 Cumulative distribution function for $T_{\text {comp,flex }} / T_{1 \text { bldg. }}$.

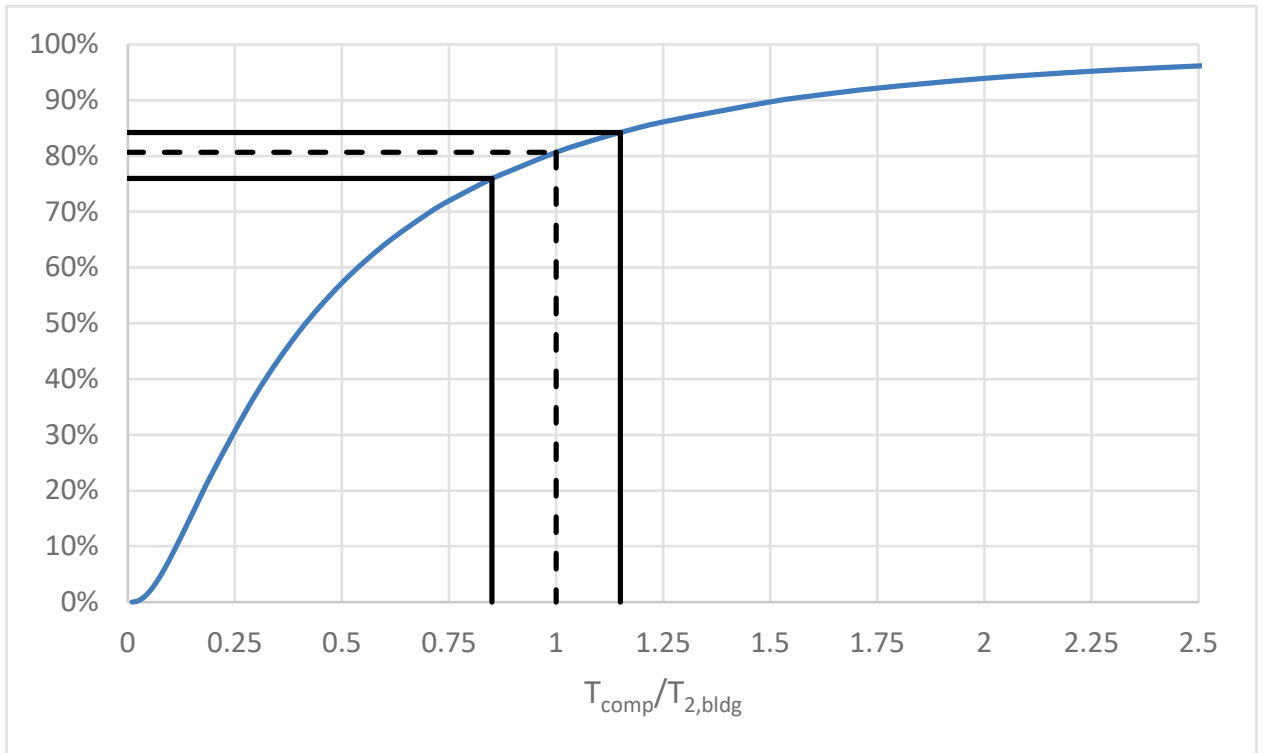

Figure 4-34 Cumulative distribution function for $T_{\text {comp, rigid }} / T_{2 b l d g}$. 


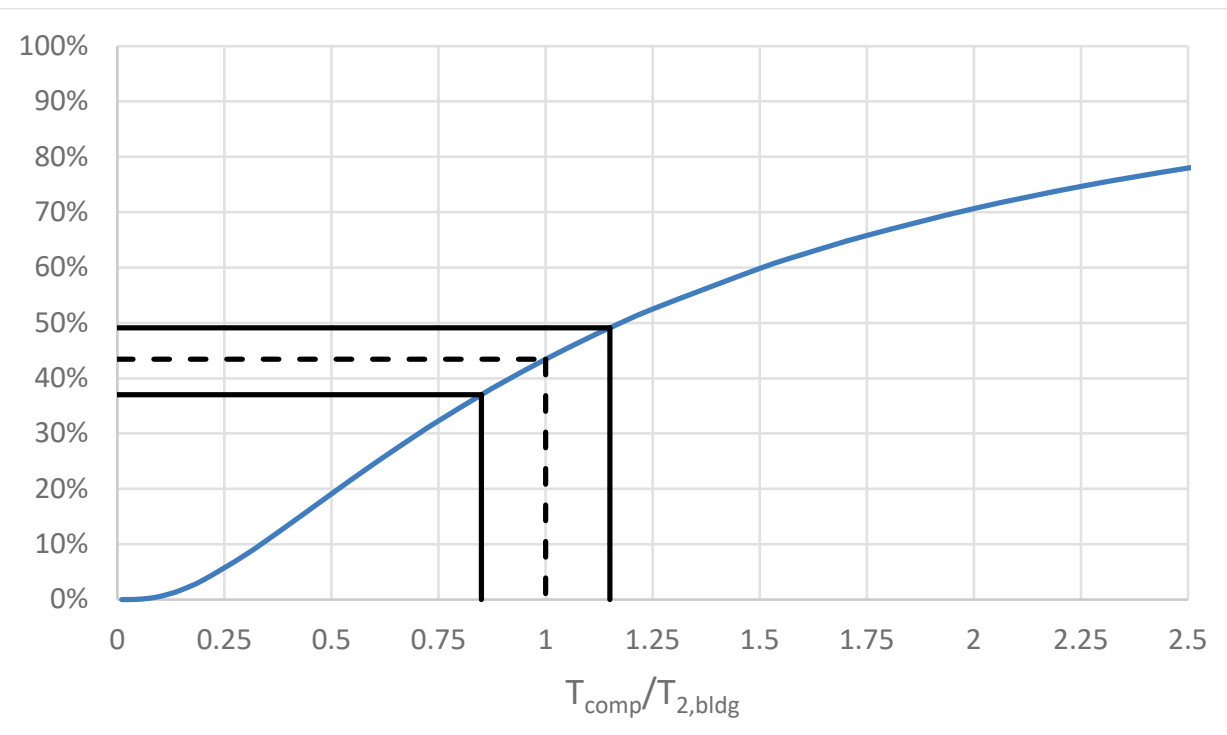

Figure 4-35 Cumulative distribution function for $T_{\text {comp,flex }} / T_{2 b l d g}$.

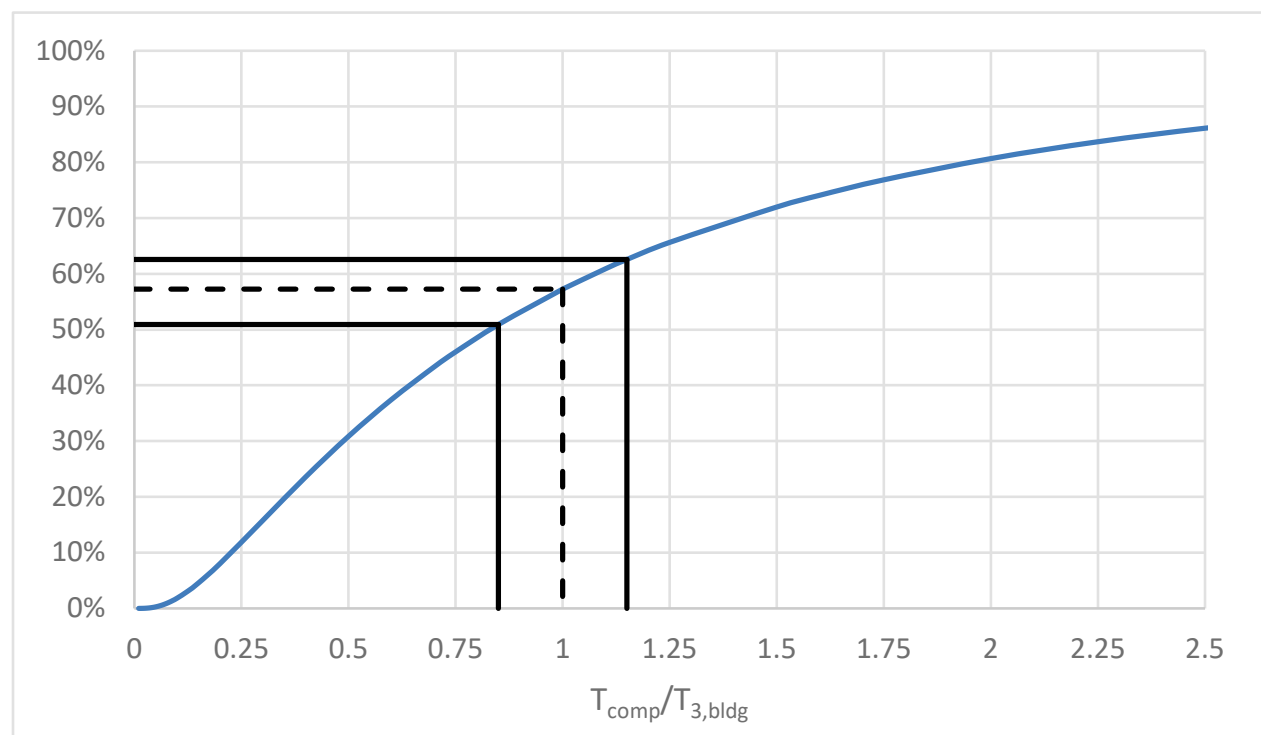

Figure 4-36 Cumulative distribution function for $T_{\text {comp,rigid }} / T_{3 b l d g}$.

When $0.75<T_{\text {comp }} / T_{\text {nbldg }}<1.25$ is associated with a $10 \%$ probability band in the cumulative distribution functions, and if it is acceptable to have a $10 \%$ probability of forces exceeding those predicted by the equation, then PCA/PFA could be capped at some level. Using the $84^{\text {th }}$ percentile curve from Figure 4-38, the capped value for PCA/PFA would be a value of 3 with $0.75<T_{\text {comp }} / T_{\text {nbldg }}<1.25$. When $0.85<T_{\text {comp }} / T_{\text {nbldg }}<1.15$ is associated with the $10 \%$ probability band in the cumulative distribution function, then the capped value would increase to a value of 4 in the $84^{\text {th }}$ percentile curve from Figure 4-38. 


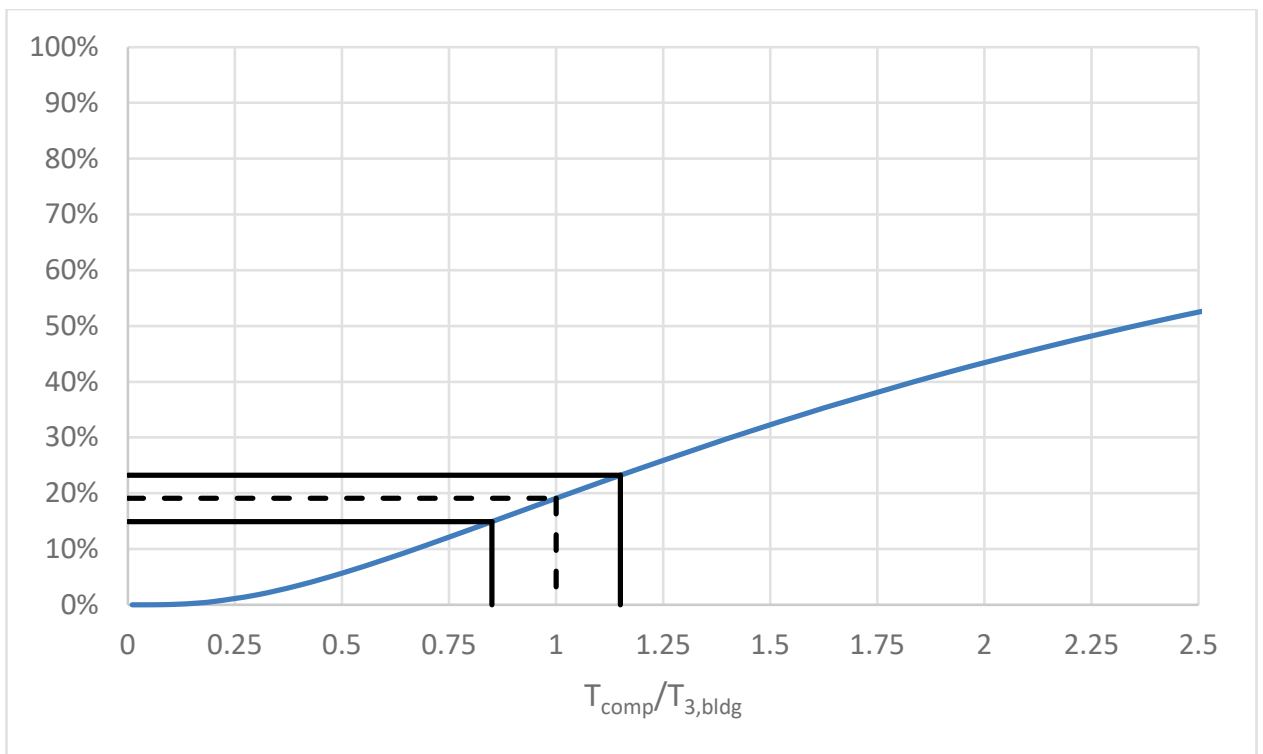

Figure 4-37 Cumulative distribution function for $T_{\text {comp,flex }} / T_{3 \mathrm{bldg}}$.

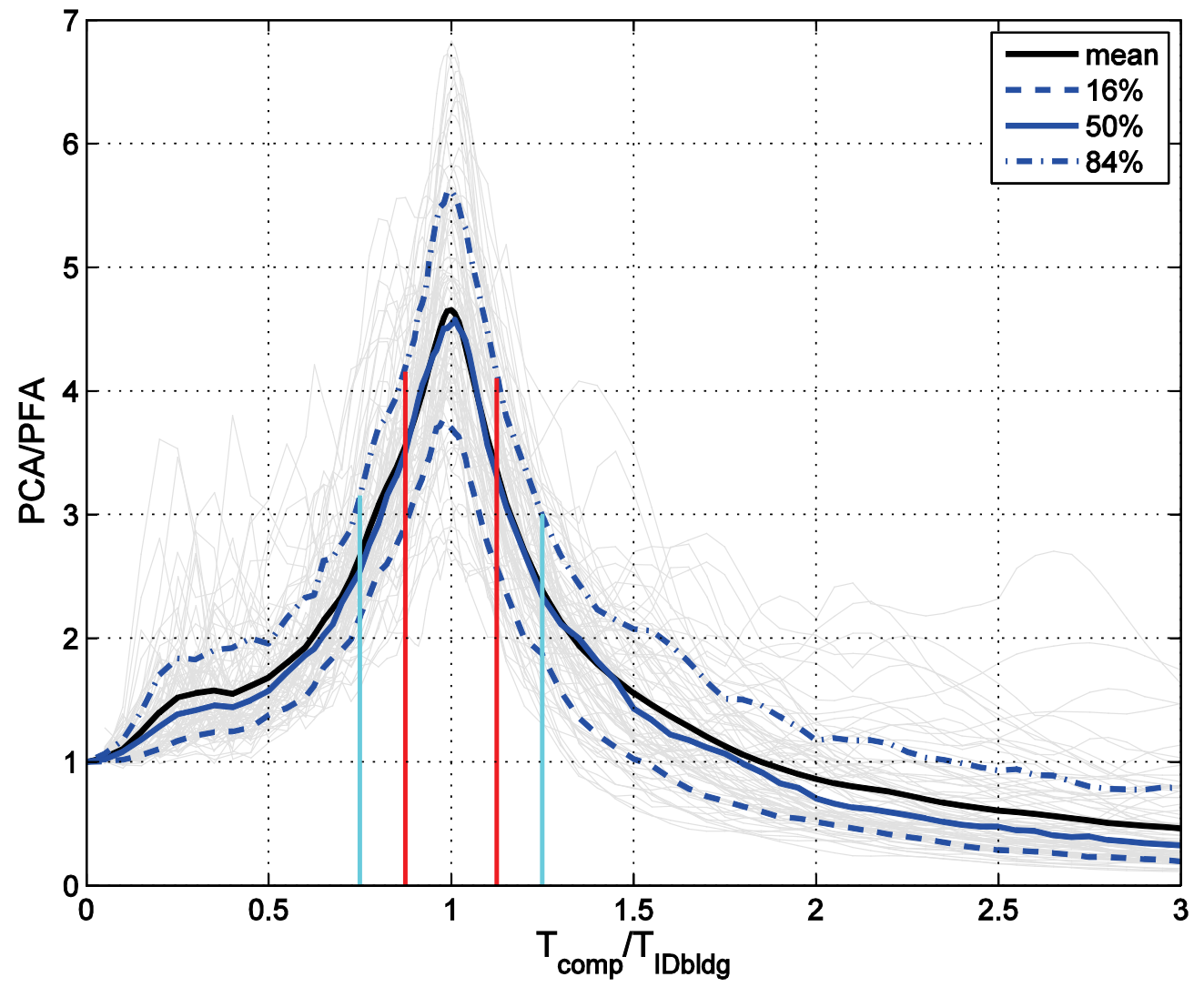

Figure 4-38 Component amplification and capping of PCA/PFA. Values outside the red band capture all cases except those with $0.85<T_{\text {comp }} / T_{\text {nbldg }}<$ 1.15. Similarly, values outside the cyan band capture all cases except those with $0.75<T_{\text {comp }} / T_{\text {nbldg }}<1.25$. $\beta_{\text {comp }}=5 \%$ inherent component damping is assumed. The dataset includes 86 recordings with $\mathrm{PCA}>0.9 \mathrm{~g}$. 
Since the building and the component databases used to develop the probability distribution functions were limited, further study looking at a specific short-period building was conducted. A sample building was selected with a calculated period equal to approximately 0.35 . The coefficient of variation between the calculated period and the actual period is assumed to be 0.15 .

Using a similar methodology of dividing the mean component period by the building period and assuming the coefficient of variation is the square root sum of squares of the component period and building period coefficients of variation yields the cumulative distribution functions in Figures 4-39 and 4-40 for rigid and flexible components respectively. The rigid components only have about a 5\% probability of being within $0.85<T_{\text {comp }} / T_{\text {bldg }(0.3 s)}<1.15$, meaning that capping the PCA/PFA at 4 is acceptable. The flexible components have about a $20 \%$ probability of being within $0.85<T_{\text {comp }} / T_{\text {bldg }(0.3 s)}<1.15$. They have about a $10 \%$ probability of being within 0.92 $<T_{\text {comp }} / T_{\text {bldg( }(0.3 s)}<1.08$. If PCA/PFA of 4 were used in Figure $4-38$ with the $0.92<$ $T_{\text {comp }} / T_{\text {bldg }(0.3 s)}<1.08$ band, then it would intersect closer to the mean curve, rather than the $84^{\text {th }}$ percentile curve. If PCA/PFA of 4.5 were used in Figure 4-38 with the $0.85<T_{\text {comp }} / T_{\text {bldg( } 0.3 s)}<1.15$ band, then it would intersect with the $84^{\text {th }}$ percentile curve.

There are other reasons for capping the amount of amplification that can occur when $T_{\text {comp }} / T_{n b l d g}$, including the limited amount of time that the building and component are likely to be in phase, the likely reduction that more realistic hysteresis loops than those used in the research analysis would show, and the changing of both building and component periods during the event.

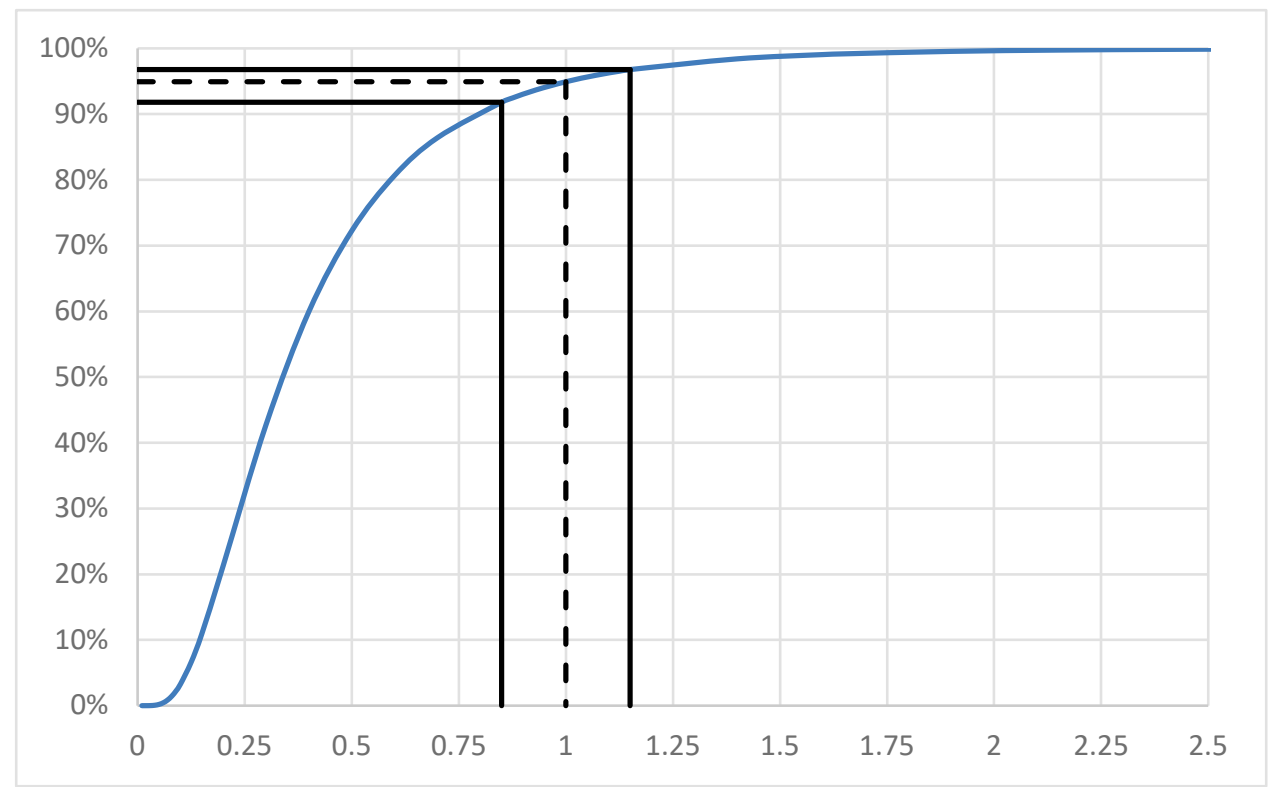

Figure 4-39 Cumulative distribution function for $T_{\text {comp, rigid }} / T_{\text {bldg }}(0.3 \mathrm{~s})$. 


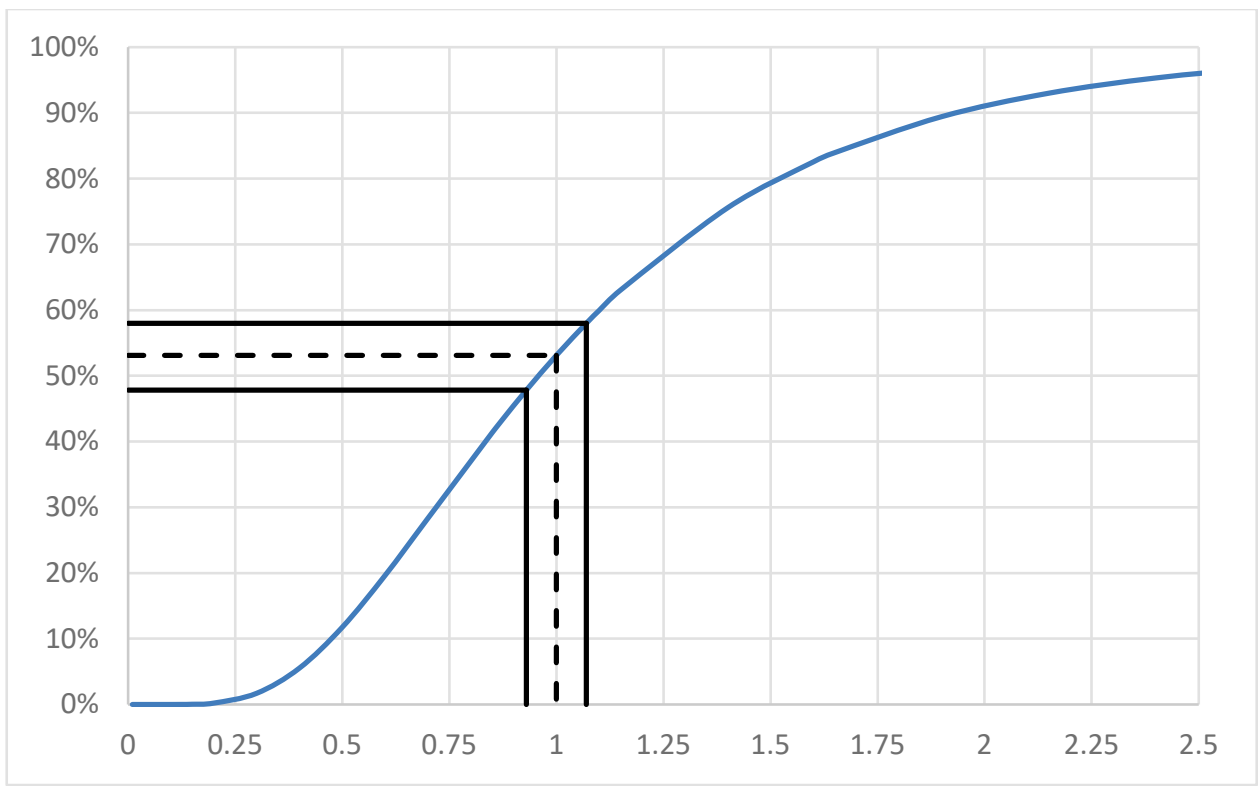

Figure 4-40 Cumulative distribution function for $T_{\text {comp,flexible }} / T_{\text {bldg(o.3 s). }}$

The results from Figures 4-25 and 4-38 are combined with the capping study to help derive the PCA/PFA values in Table 4-2 as shown in Table 4-6, with $\beta_{\text {comp }}=5 \%$ inherent component damping for flexible components. The $84^{\text {th }}$-percentile value of Figure 4-38 is used.

Table 4-6 Basis for PCA/PFA Values for Flexible Components at Roof and Suspended Floors

\begin{tabular}{|c|c|c|c|c|}
\hline Category & $\begin{array}{l}\text { Assumed } \\
\text { Ductility }\end{array}$ & $\begin{array}{l}\text { Peak Value } \\
\text { for PCA/PFA }\end{array}$ & $\begin{array}{c}\text { Reduction } \\
\text { from Capping } \\
\end{array}$ & PCA/PFA \\
\hline Elastic & $\mu_{\text {comp }}=1$ & $5.6 \times 1.0=5.6$ & 1.4 & 4.0 \\
\hline Low & $\mu_{\text {comp }}=1.25$ & $5.6 \times 0.6=3.4$ & 1.2 & 2.8 \\
\hline Moderate & $\mu_{\text {comp }}=1.5$ & $5.6 \times 0.4=2.2$ & Not applied & 2.2 \\
\hline High & $\mu_{\text {comp }} \geq 2$ & $5.6 \times 0.25=1.4$ & Not applied & 1.4 \\
\hline
\end{tabular}

* The narrow band features of PCA/PFA response are more pronounced for an elastic component. The value of 1.4 for an elastic component is taken directly from Figure 4-38. The values for the other categories are from engineering judgment.

The value of PCA/PFA $=1.0$ in Table 4-2 for the rigid cases simply results from using Figure 4-23 at $T_{\text {comp }}=0$ seconds.

Since the building and the component databases used to develop the cumulative distribution functions were limited, further study changing the mean first mode period from 0.85 seconds to 0.5 seconds produced similar results. 


\section{Component Ductility}

Additional archetype studies were performed using the proposed equation and different levels of component ductility. A peak-oriented (stiffness degrading) model with 3\% strain hardening was used to account for the hysteretic behavior of the component. Additional details are shown in Appendix B. Results for four archetypes (2-story steel SMRF, 6-story steel SMRF, 2-story RCSW, and 8-story RCSW) are shown in Figures 4-41 to 4-44. The proposed equation uses the values for components likely to be in resonance. Thus, the comparison is most relevant when $T_{\text {comp }} / T_{\text {abldg }}$ is not small and not large. All of these archetypes include an overdesign factor that has been shown to be conservative. Results for $\mu_{\text {comp }}=1.0,1.5,2.0,3.0$, and 4.0 are shown. The focus here is on the 1.0, 1.5, and 2.0 values. In general, the proposed equation envelopes the majority of response, though $\mu_{c o m p}=1.0$ and 2.0 are less conservative than the other values. For the $\mu_{\text {comp }}=3.0$ and 4.0 runs, the PCA/PFA values for $\mu_{\text {comp }}=2.0$ were assumed.

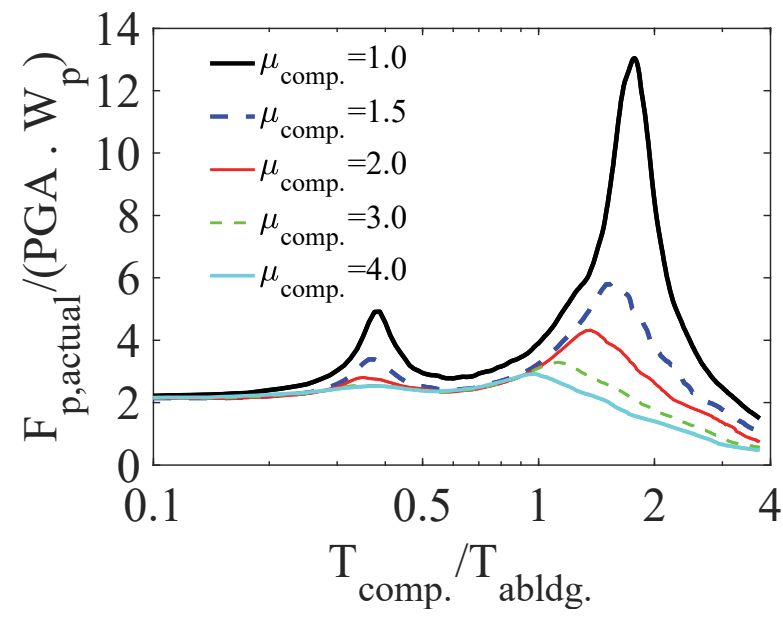

(a)

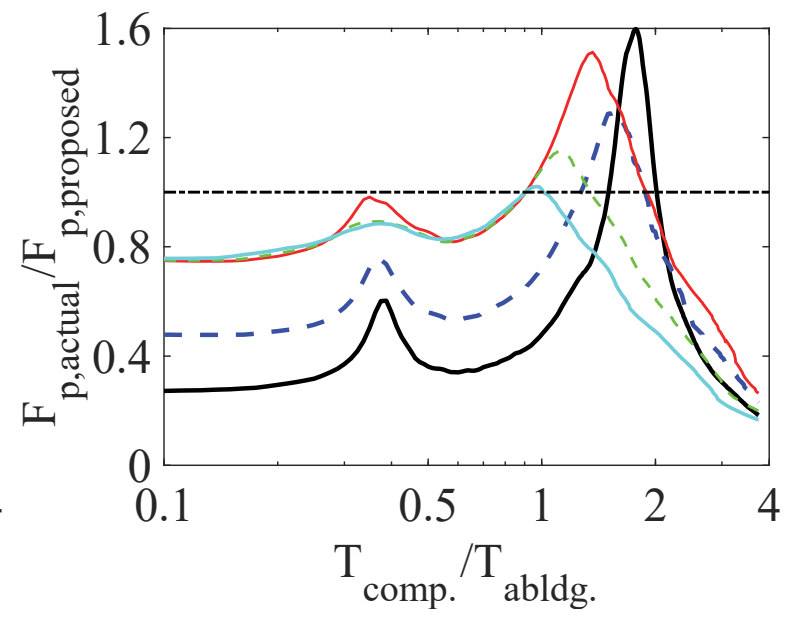

(b)

Figure 4-41 (a) Mean of the simulated $F_{p \text {,actual }}$ normalized by PGA and (b) normalized by $F_{p, \text { proposed }}$ at the roof for a 2-story steel moment-resisting frame archetype assuming an overdesign factor of $2.0, \mu_{\text {comp }}=1.0-4.0$, and $\beta_{\text {comp }}=5 \%$ inherent component damping, where $F_{p \text {,actual }}$ is the mean of 20 spectrum-compatible ground motions. $F_{p, \text { proposed }}$ is for components likely to be in resonance. 


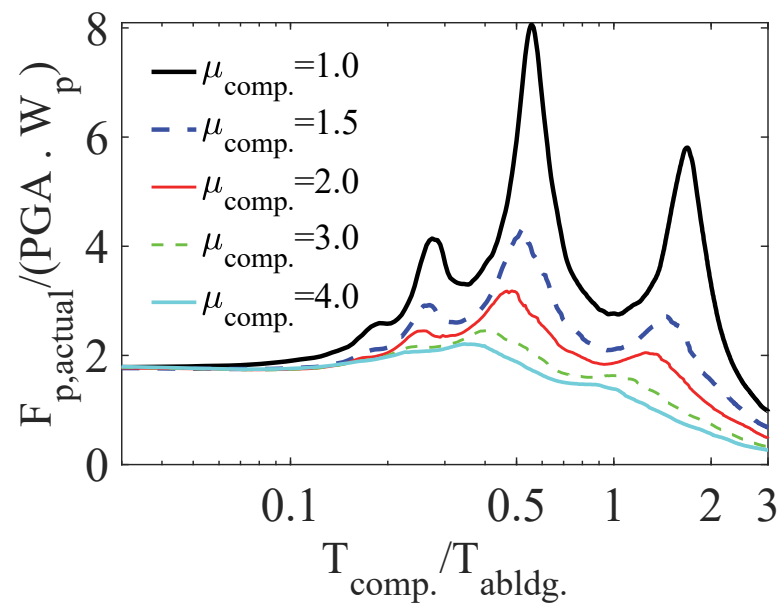

(a)

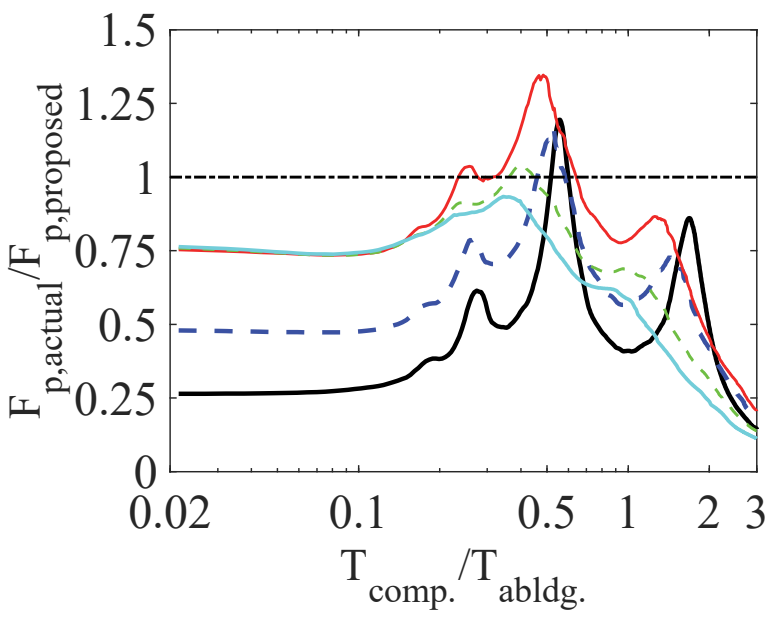

(b)

Figure 4-42 (a) Mean of the simulated $F_{p \text {,actual }}$ normalized by PGA and (b) normalized by $F_{p, \text { proposed }}$ at the roof for a 6-story steel moment-resisting frame archetype assuming an overdesign factor of $1.5, \mu_{\text {comp }}=1.0-4.0$, and $\beta_{\text {comp }}=5 \%$ inherent component damping, where $F_{p, \text { actual }}$ is the mean of 20 spectrum-compatible ground motions. $F_{p, \text { proposed }}$ is for components likely to be in resonance.

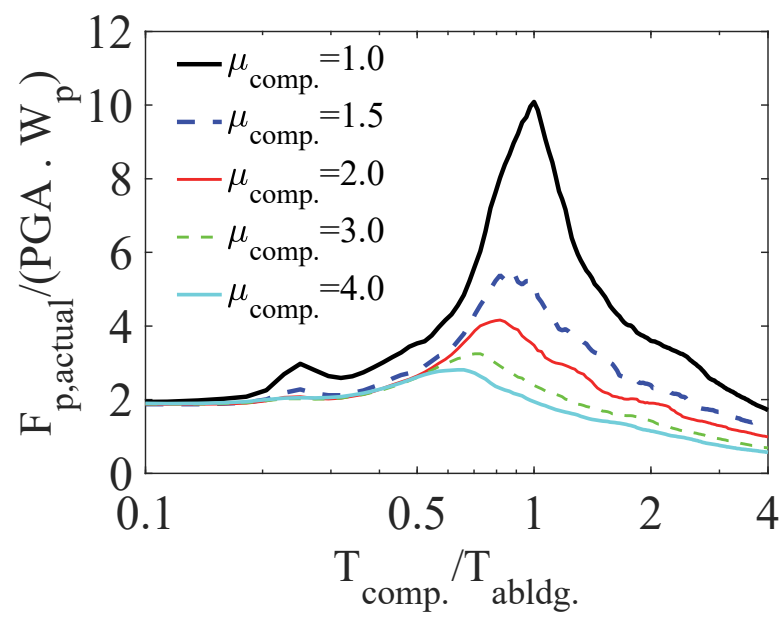

(a)

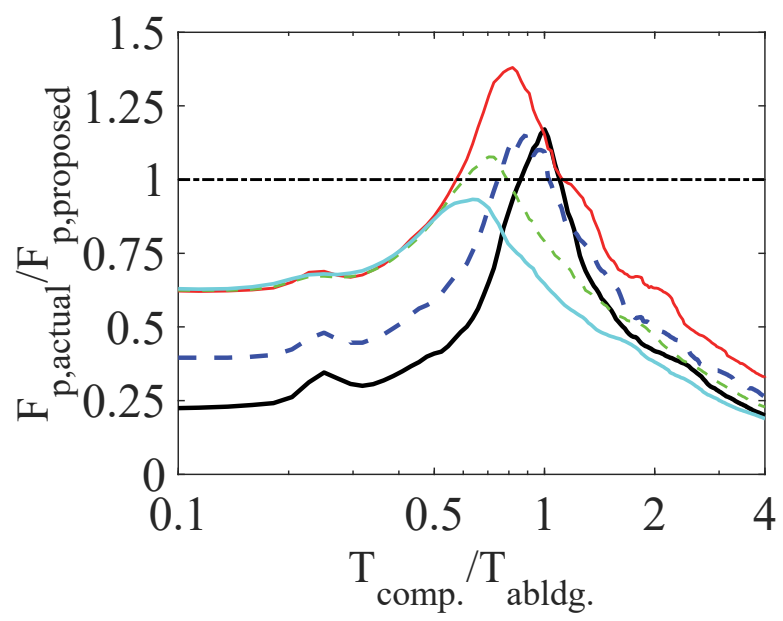

(b)

Figure 4-43 (a) Mean of the simulated $F_{p \text {,actual }}$ normalized by PGA and (b) normalized by $F_{p, \text { proposed }}$ at the roof for a 2-story concrete shear wall archetype assuming an overdesign factor of 3.0, $\mu_{\text {comp }}=1.0-4.0$, and $\beta_{\text {comp }}=5 \%$ inherent component damping, where $F_{p, \text { actual }}$ is

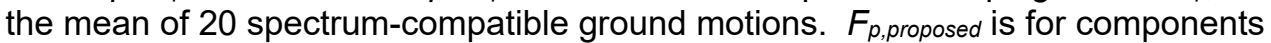
likely to be in resonance. 


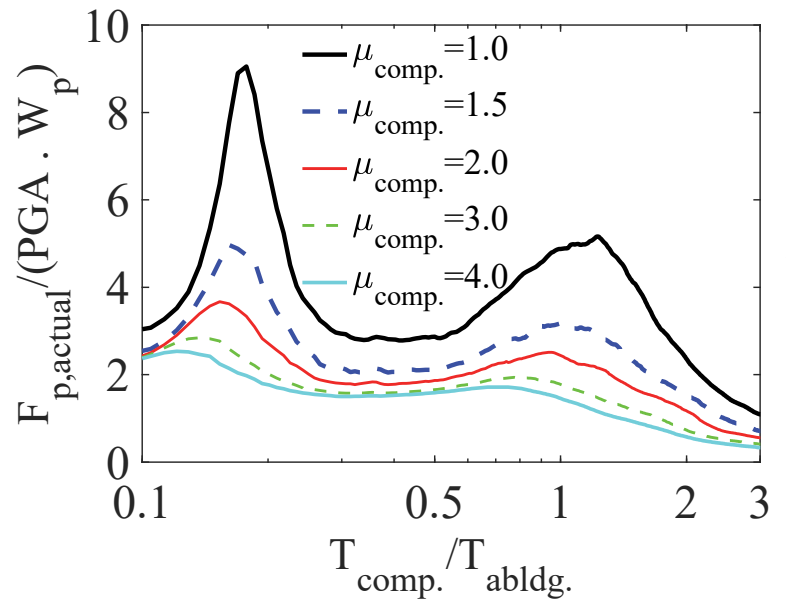

(a)

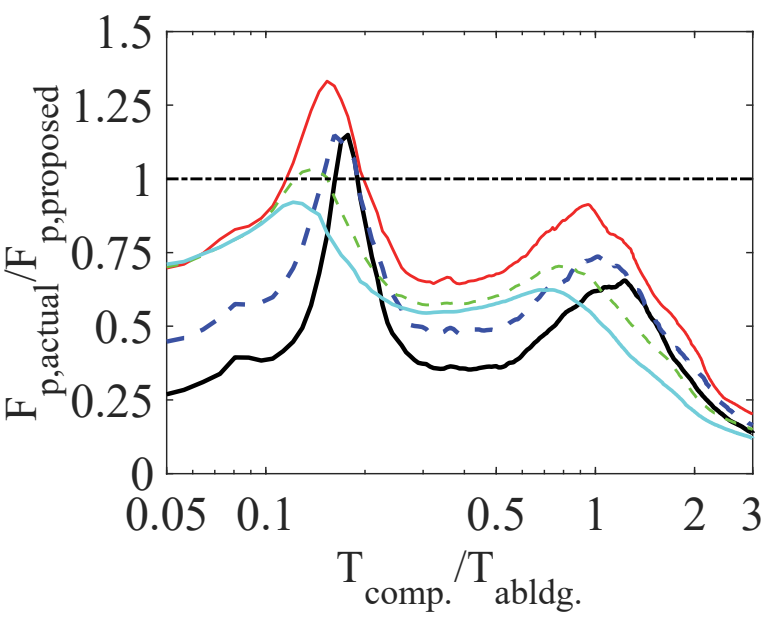

(b)

Figure 4-44 (a) Mean of the simulated $F_{p, \text { actual }}$ normalized by PGA and (b) normalized by $F_{p, \text { proposed }}$ at the roof for an 8-story concrete shear wall archetype assuming an overdesign factor of $1.5, \mu_{\text {comp }}=1.0-4.0$, and $\beta_{\text {comp }}=5 \%$ inherent component damping, where $F_{p, \text { actual }}$ is the mean of 20 spectrum-compatible ground motions. $F_{p, \text { proposed }}$ is for components likely to be in resonance.

\section{Flexible versus Rigid Components}

ASCE/SEI 7-16, like many previous codes, defines "rigid" components as those with $T_{\text {comp }} \leq 0.06$ seconds, and "flexible" components as those with $T_{\text {comp }}>0.06$ seconds.

Rigid components are assigned an $a_{p}$ (effectively PCA/PFA) of 1 . Few components actually have $T_{\text {comp }} \leq 0.06$ seconds, particularly if base and anchorage flexibility are included. Nonetheless, ASCE/SEI 7-16 Tables 13.5-1 and 13.6-2 have many common components with an $a_{p}=1$, including partitions, ceilings, cabinets, and the body of cladding. Part of the original thinking of code writers behind assigning these components a value of $a_{p}=1$ was not that they rigorously could be shown to have $T_{\text {comp }} \leq 0.06$ seconds, but rather they were more likely to be out-of-phase with typical building periods and thus PCA/PFA ratios were comparatively small. As an approximate placeholder, this could be assumed to effectively mean widening the bands in Figure 4-38 to say $T_{\text {comp }} / T_{\text {IDbldg }}<0.5$ or $T_{\text {comp }} / T_{\text {IDbldg }}>1.5$. As such, the project team has chosen to replace the terms "flexible" and "rigid" with "more likely to be in resonance with the building" and "less likely to be in resonance with the building." For simplicity, those that are less likely to be in resonance are assigned a value of PCA/PFA $=1.0$. The resulting effect is similar to the ASCE/SEI 7-16 approach, but it is more descriptively precise.

Figures 4-41 through 4-44 compared the proposed equation against results from four archetype buildings where the proposed equation represented the values for components likely to be in resonance. Figures 4-45 through 4-48 apply the same approach except that $F_{p, p r o p o s e d}$ represents the values for components unlikely to be in resonance and should thus be compared against low and high values of $T_{\text {comp }} / T_{\text {abldg. }}$. 
As Figures 4-45 through 4-48 show, as $T_{\text {comp }}$ approaches zero, the proposed equation matches the archetype results.

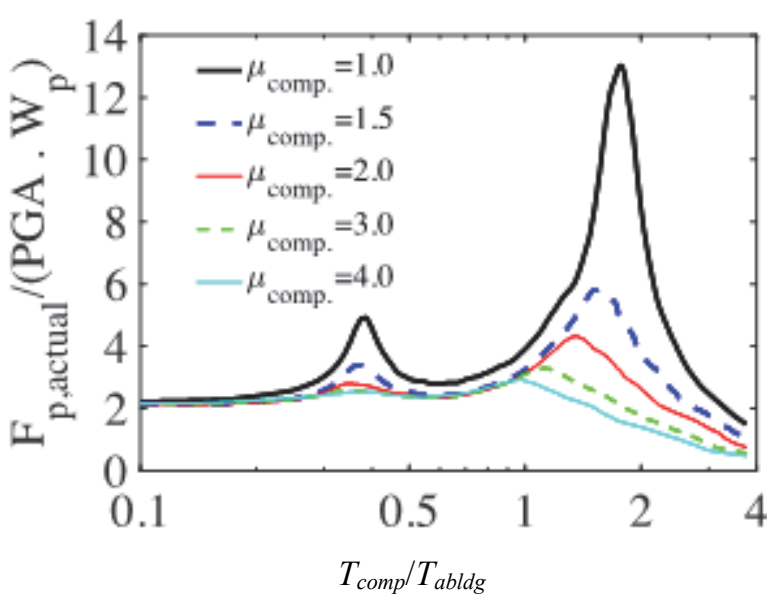

(a)

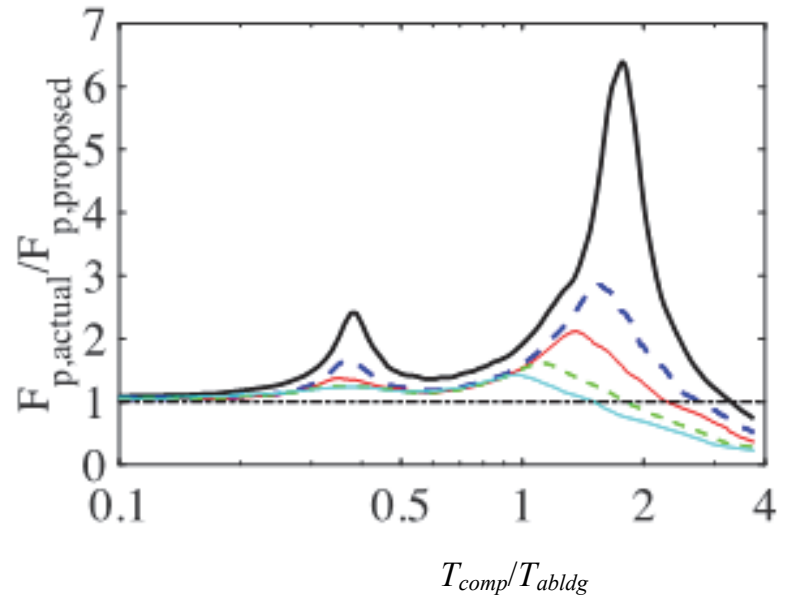

(b)

Figure 4-45 (a) Mean of the simulated $F_{p \text {,actual }}$ normalized by PGA and (b) normalized by $F_{p, \text { proposed }}$ at the roof for a 2-story steel moment-resisting frame archetype assuming an overdesign factor of 2.0, $\mu_{\text {comp }}=1.0-4.0$, and $\beta_{\text {comp }}=5 \%$ inherent component damping, where

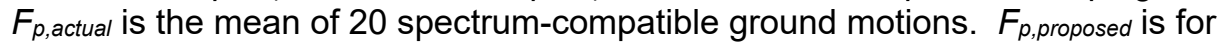
components unlikely to be in resonance.

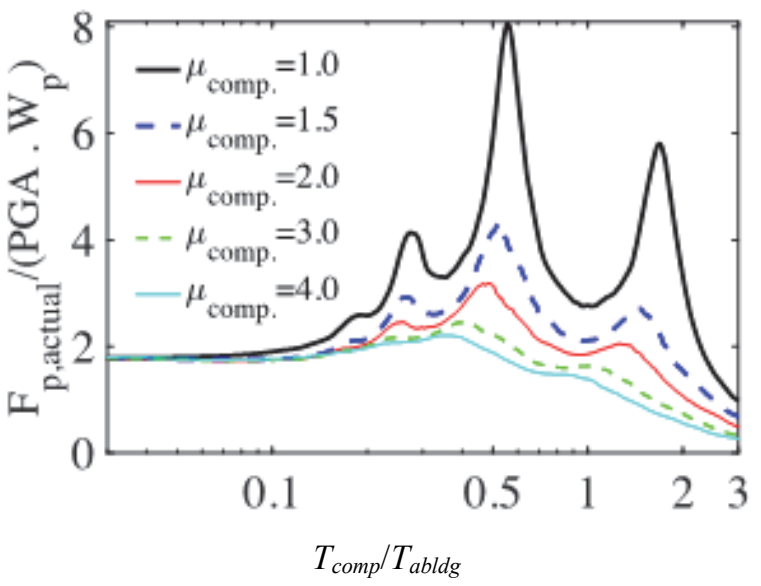

(a)

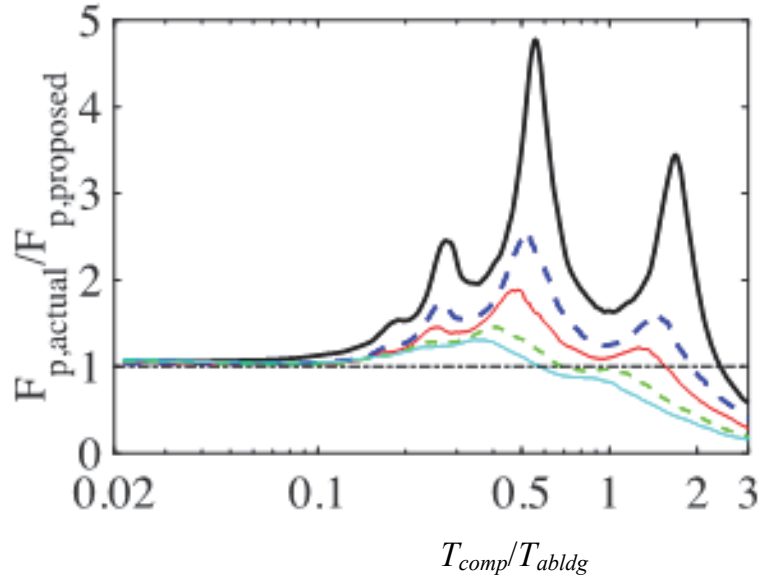

(b)

Figure 4-46 (a) Mean of the simulated $F_{p \text {,actual }}$ normalized by PGA and (b) normalized by $F_{p, \text { proposed }}$ at the roof for a 6-story steel moment-resisting frame archetype assuming an overdesign factor of 1.5, $\mu_{\text {comp }}=1.0-4.0$, and $\beta_{\text {comp }}=5 \%$ inherent component damping, where

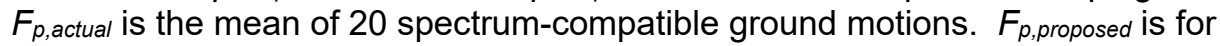
components unlikely to be in resonance. 


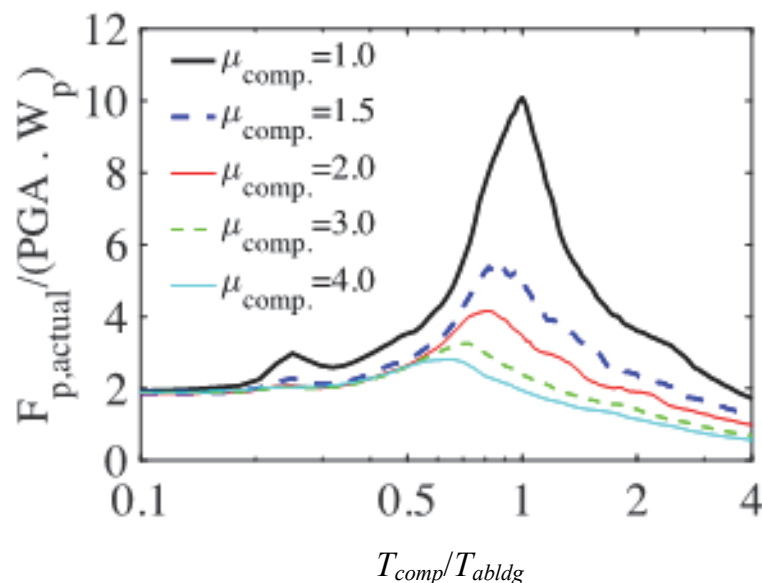

(a)

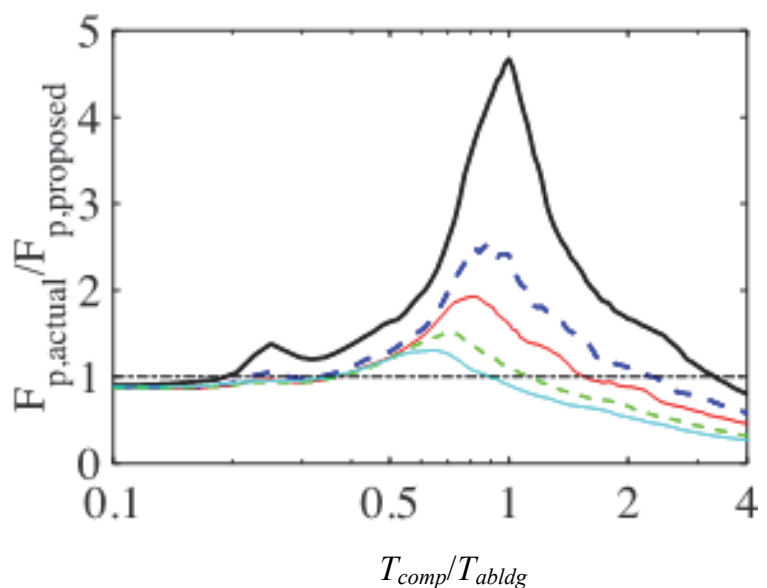

(b)

Figure 4-47 (a) Mean of the simulated $F_{p, \text { actual }}$ normalized by PGA and (b) normalized by $F_{p, \text { proposed }}$ at the roof for a 2-story concrete shear wall archetype assuming an overdesign factor of 3.0, $\mu_{\text {comp }}=1.0-4.0$, and $\beta_{\text {comp }}=5 \%$ inherent component damping, where $F_{p \text {,actual }}$ is the mean of 20 spectrum-compatible ground motions. $F_{p, \text { proposed }}$ is for components unlikely to be in resonance.

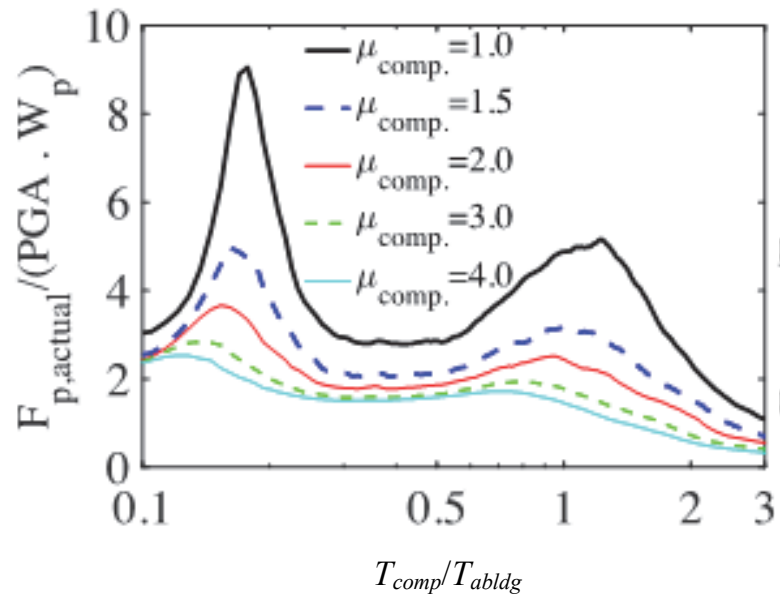

(a)

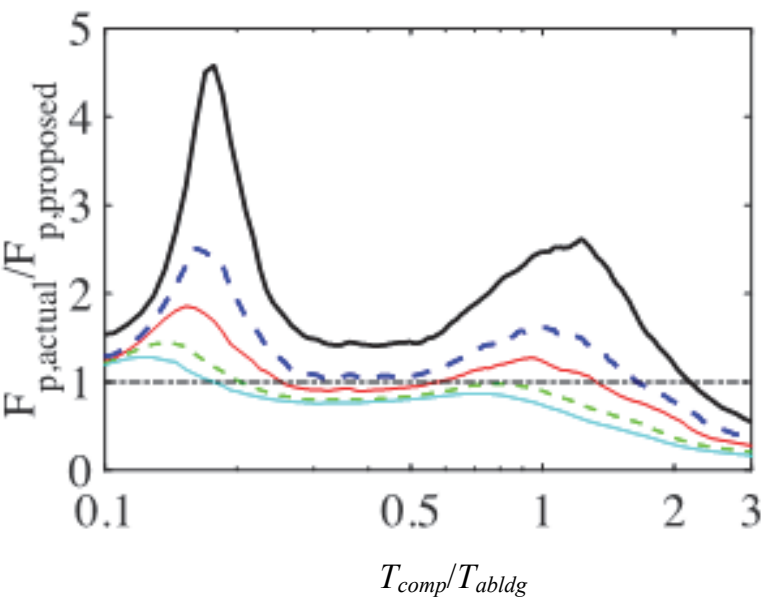

(b)

Figure 4-48 (a) Mean of the simulated $F_{p, \text { actual }}$ normalized by PGA and (b) normalized by $F_{p, \text { proposed }}$ at the roof for an 8-story concrete shear wall archetype assuming an overdesign factor of $1.5, \mu_{\text {comp }}=1.0-4.0$, and $\beta_{\text {comp }}=5 \%$ inherent component damping, where $F_{p \text {,actual }}$ is the mean of 20 spectrum-compatible ground motions. $F_{p, \text { proposed }}$ is for components unlikely to be in resonance.

\section{Height of Component within the Building}

The study results depicted above all focused on nonstructural component response at the roof. Additional studies evaluated the proposed nonstructural design equation against archetype results at lower heights in the building. Figures 4-49 through 4-52 show results against the proposed equation for components likely to be in resonance for four archetypes. For these studies, an elastic component $\left(\mu_{\text {comp }}=1.0\right)$ with $\beta_{\text {comp }}=$ $5 \%$ inherent component damping is assumed. 


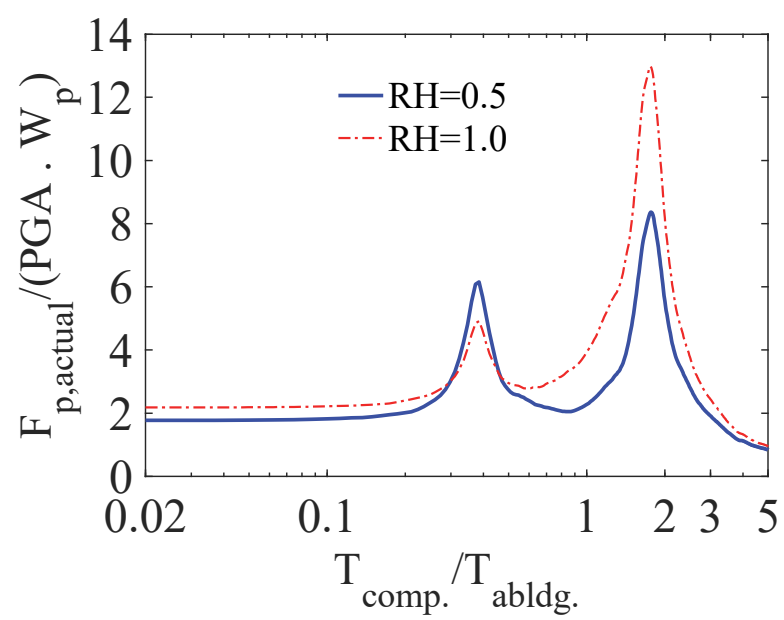

(a)

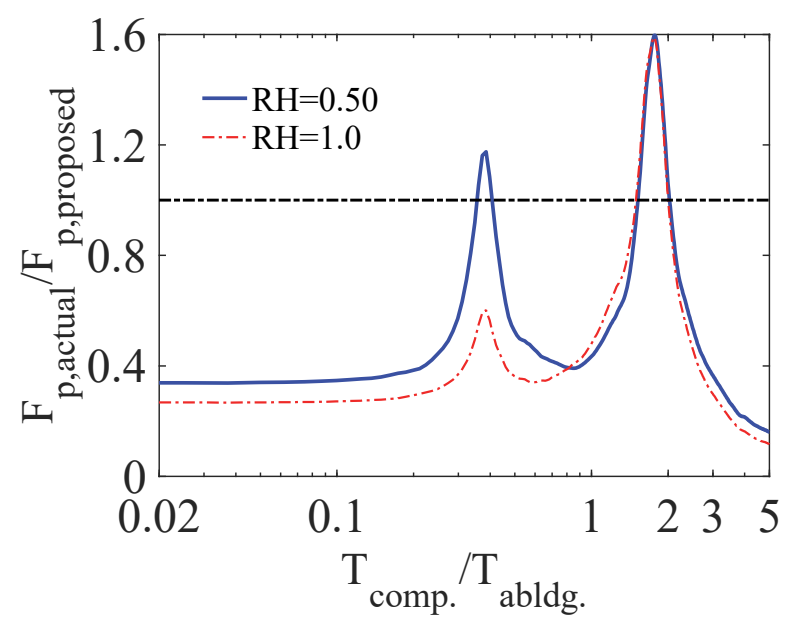

(b)

Figure 4-49 (a) Mean of the simulated $F_{p \text {,actual }}$ normalized by PGA and (b) normalized by $F_{p, \text { proposed }}$ at the roof and second floor for a 2-story steel moment-resisting frame archetype assuming an overdesign factor of 2.0, $\mu_{\text {comp }}=1.0$, and $\beta_{\text {comp }}=5 \%$ inherent component damping, where $F_{p \text {,actual }}$ is the mean of 20 spectrum-compatible ground motions. $F_{p, \text { proposed }}$ is for components likely to be in resonance. $\mathrm{RH}=$ relative height in the building $(z / h)$.

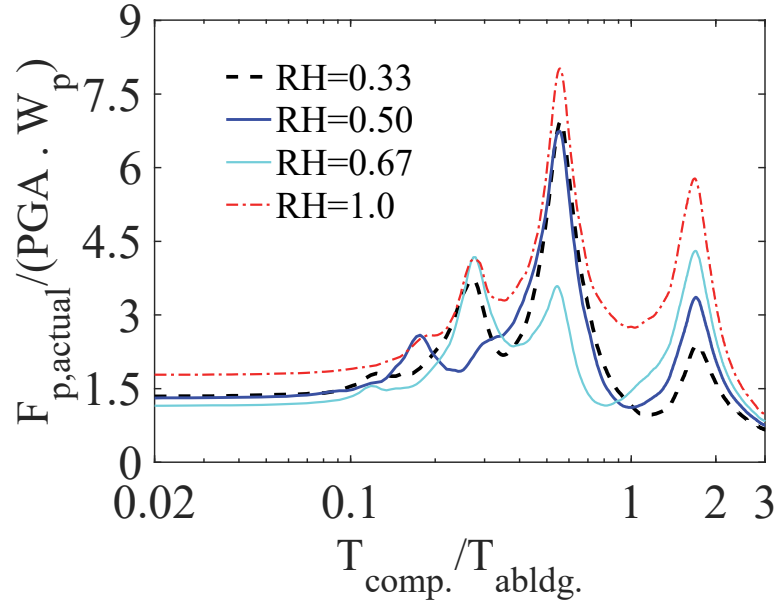

(a)

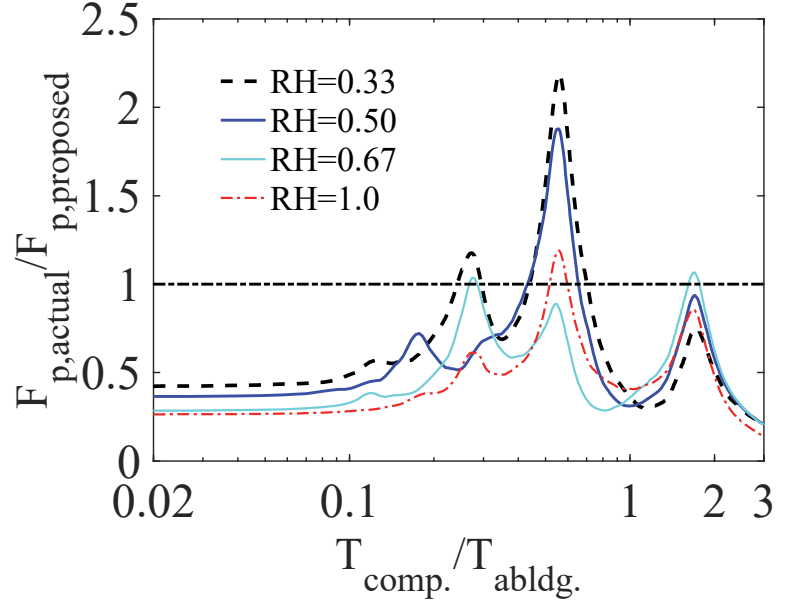

(b)

Figure 4-50 (a) Mean of the simulated $F_{p, \text { actual }}$ normalized by PGA and (b) normalized by $F_{p, \text { proposed }}$ at the roof, fifth, fourth, and third levels for a 6-story steel moment-resisting frame archetype assuming an overdesign factor of $1.5, \mu_{\text {comp }}=1.0$, and $\beta_{\text {comp }}=5 \%$ inherent component damping, where $F_{p \text {,actual }}$ is the mean of 20 spectrum-compatible ground motions. $F_{p, \text { proposed }}$ is for components likely to be in resonance. $\mathrm{RH}=$ relative height in the building $(z / h)$. 


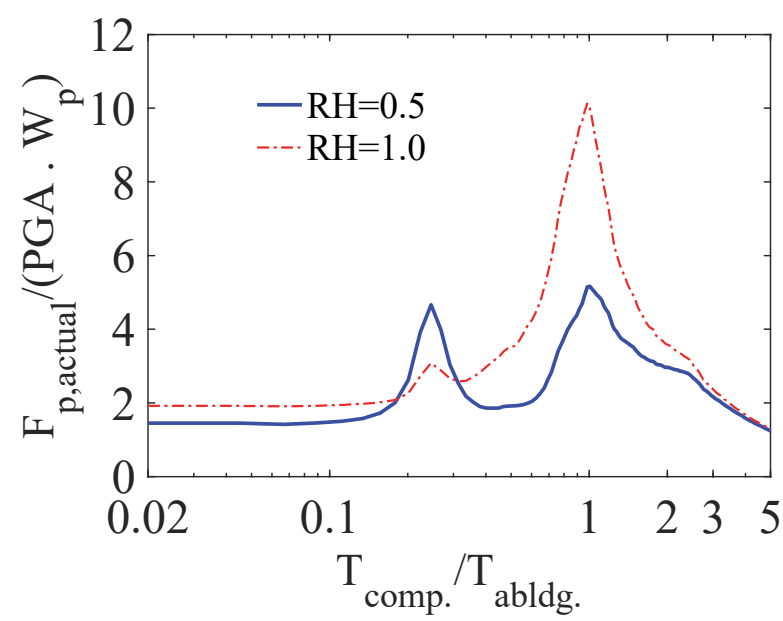

(a)

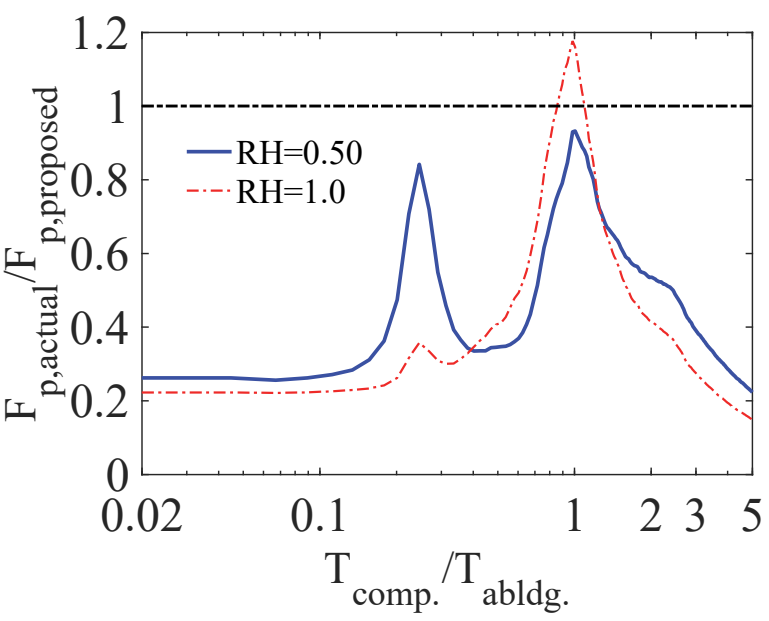

(b)

Figure 4-51 (a) Mean of the simulated $F_{p \text {,actual }}$ normalized by PGA and (b) normalized by $F_{p, \text { proposed }}$ at the roof and second floor for a 2-story concrete shear wall archetype assuming an overdesign factor of $3.0, \mu_{c o m p}=1.0$, and $\beta_{\text {comp }}=5 \%$ inherent component damping, where $F_{p, \text { actual }}$ is the mean of 20 spectrum-compatible ground motions. $F_{p, \text { proposed }}$ is for components likely to be in resonance. $\mathrm{RH}=$ relative height in the building $(z / h)$.

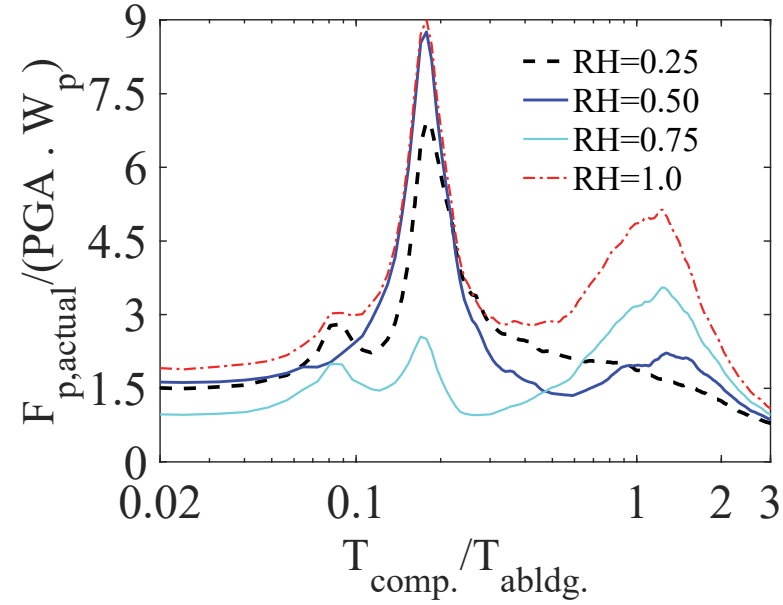

(a)

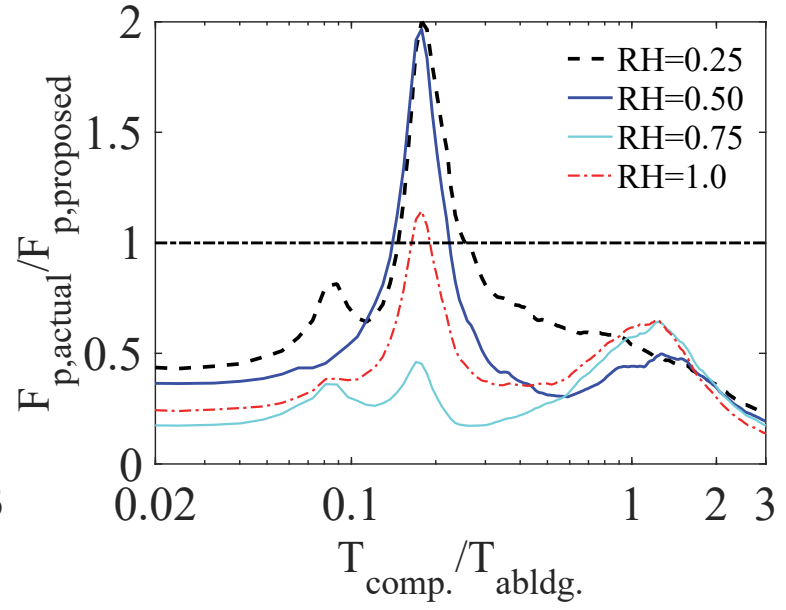

(b)

Figure 4-52 (a) Mean of the simulated $F_{p, \text { actual }}$ normalized by PGA and (b) normalized by $F_{p, \text { proposed }}$ at the roof and selected lower levels for an 8-story concrete shear wall archetype assuming an overdesign factor of $1.5, \mu_{\text {comp }}=1.0-4.0$, and $\beta_{\text {comp }}=5 \%$ inherent component damping, where $F_{p, \text { actual }}$ is the mean of 20 spectrum-compatible ground motions. $F_{p, \text { proposed }}$ is for components likely to be in resonance. $\mathrm{RH}=$ relative height in the building $(z / h)$.

Figure 4-49 through Figure 4-52 show several trends. One trend is that, in most cases, the proposed primary equation results in values that are greater than those obtained for analysis, especially at the roof level (a relative height, $\mathrm{RH}=1$ ) and the proposed equation is thus conservative for those cases. A second trend is that while response reduces at lower levels for the first mode region of the building, there is much less reduction and occasionally even an increase for the second mode. This is 
because higher modes have a greater effect on the response at lower building levels. A third trend is that the proposed primary equation underestimates the analytical results close to first mode peak (i.e., the resonance region or tuning condition) at lower levels $(\mathrm{RH}=0.25$ to 0.50$)$ for the taller 6-story and 8-story archetypes. As discussed in the "Narrow Band Amplification" section where the focus was on the roof level, some capping in the resonance region is assumed to be reasonable given the probability of components and the building being in resonance. A similar approach can be applied to some degree at lower elevations. One possible explanation for the potential lower level of conservatism in the proposed equation at lower elevations in the building is that $R_{\mu b l d g}$ reduction factor for building ductility may not apply uniformly at all elevations of the building for nonlinear buildings. Further study of this issue is recommended. In addition, note that a minimum or floor has not been incorporated in the proposed primary design equation here. The minimum often governs over the primary design equation at lower elevations. The minimum is discussed ahead in Sections 4.4 and 4.8.

\section{Ground versus Superstructure}

Part of the amplification of PCA/PFA as $T_{\text {comp }} / T_{I D b l d g}$ values approach 1 comes from narrow band filtering of response by the dynamic properties of the building. Components that are ground supported see dynamic amplification due to component flexibility, based on structural dynamics, but this amplification is less than what occurs in the building. Given that there are both theoretical and numerical differences between the ground and superstructure cases, the project team chose to distinguish the two. Table 4-7 provides PCA/PFA values and the underlying assumptions for the ground case.

Table 4-7 PCA/PGA for Ground-Supported Components

\begin{tabular}{lcc}
\hline \multicolumn{1}{c}{ Category } & Assumed Ductility & PCA/PFA \\
\cline { 1 - 2 } Elastic & $\mu_{\text {comp }}=1$ & 2.5 \\
Low & $\mu_{\text {comp }=1.25}$ & 2.0 \\
Moderate & $\mu_{\text {comp }=1.5}$ & 1.8 \\
High & $\mu_{\text {comp } \geq 2}$ & 1.4 \\
\hline
\end{tabular}

Notes: $\mathrm{PCA} / \mathrm{PGA}$ is assumed to be $2.5 \times \mathrm{PGA}$ for an elastic component, similar to the traditional building response spectrum.

This amplification is reduced by a reduction factor from Chopra (2012) equal to $R_{\text {comp }}=\left(2 \mu_{\text {comp }}-1\right)^{1 / 2}$ at $\beta_{\text {comp }}=5 \%$.

\section{Application of Component Ductility}

ASCE/SEI 7-16 Tables 13.5-1 and 13.6-1 provide $a_{p}$ and $R_{p}$ values for different components. $R_{p}$ values provide reductions based on component ductility and they apply even for "rigid" components and those assigned an $a_{p}=1$. In fact, the majority 
of the cases in ASCE/SEI 7-16 Table 13.5-1 have $a_{p}=1.0$ and $R_{p}=2.5$. However, studies found that component ductility provides limited reduction as $T_{\text {comp }}$ reduces to zero. At $T_{\text {comp }}=0$, PCA/PFA converges to 1.0 regardless of the value of $\mu_{\text {comp }}$. The project team chose to only apply component ductility reduction to components that are more likely to be in resonance with the building (what was previously termed "flexible"). This is a significant decision, since $R_{p}$ values larger than 1.0 directly lead to substantial reductions in PCA/PFA and the final value of $F_{p} / W_{p}$.

\section{Anchorage Design}

The focus of this work was on the primary nonstructural force equation for components, and there was relatively limited investigation of anchorage design other than to generally agree to continue with the current code concept of increasing forces through the use of the $\Omega_{0}$ factor when the anchorage is not ductile or the component does not have a limit on the forces that can be delivered (such as through a capacity design fuse). Anchorage design is a complicated issue from a code perspective as well, since there are requirements in ASCE/SEI 7-16 as well as ACI 318 for concrete and TMS 402, Building Code Requirements and Specification for Masonry Structures and Related Commentaries, (TMS, 2011) for masonry. The project team decided that design of anchors in concrete and in masonry will follow the same approach as ASCE/SEI 7-16 for components likely to be in resonance with the building. Values similar to those in ASCE/SEI 7-16 Tables 13.5-1 and 13.6-1 will be used and associated with low, moderate, and high ductility components. For components that are unlikely to be in resonance, it is considered overly conservative to add the full $\Omega_{0}$ factors from ASCE/SEI 7-16. Instead, a value of $\Omega_{0}=1.5$ is used to provide some added protection and to acknowledge that some flexibility in the component and its anchorage is possible in most cases so that some additional response above that which occurs at $T_{\text {comp }}=0$ seconds is warranted.

\subsection{Proposed Minimum (or Floor) for Nonstructural Component Design}

ASCE/SEI 7-16 and the building codes that precede it set a minimum (or floor) for the nonstructural component design force, even if ASCE/SEI 7-16 Equation 13.3-1 has a lower value. The minimum will often govern at lower levels of the building where the PFA/PGA increase is small and when $R_{p}$ is large.

The minimum design force $F_{p}=0.3 S_{D S} I_{p} W_{p}$ in ASCE/SEI 7 was originally established based on a calibration with the 1991 Uniform Building Code (ICBO, 1991). The 1991 UBC seismic forces were specified to be used with allowable stress design. The $F_{p}$ force in the 1991 UBC was:

$$
F_{p}=Z I_{p} C_{p} W_{p}
$$


where:

$Z=0.40$ (the effective peak ground acceleration in Seismic Zone 4)

$C_{p}=0.75$ or 2.0 depending on the component type

$I_{p}=$ Seismic Importance Factor

Therefore, the smallest permitted value of $F_{p}$ was $F_{p}=Z I_{p} 0.75 W_{p}$. Furthermore, the value of $C_{p}$ for elements, components, and equipment laterally self-supported at or below the ground level could be taken in the $1991 \mathrm{UBC}$ as two thirds of the $C_{p}$ value. Therefore, the minimum value was:

$$
\begin{gathered}
F_{p}=Z I_{p} 0.75 W_{p} \times 2 / 3 \text { or } \\
F_{p, \min }=0.5 Z I_{p} W_{p}
\end{gathered}
$$

For the 1991 Seismic Zone 4 plateau areas in ASCE/SEI 7-05, the peak ground acceleration was equal to $0.4 S_{D S}$ where $S_{D S}=1.0$. Substituting $0.4 S_{D S}$ for $Z$ yields:

$$
F_{p, \min }=0.5\left(0.4 S_{D S}\right) I_{p} W_{p}=0.2 S_{D S} I_{p} W_{p}
$$

To convert from allowable stress design of the 1991 UBC to strength design, which is the basis of the ASCE/SEI 7 equations, allowable strength design values are multiplied by either 1.4 or 1.5 depending on the load combination. Using 1.5 results in:

$$
F_{p, \min }=1.5 \times 0.2 S_{D S} I_{p} W_{p}=0.3 S_{D S} I_{p} W_{p}
$$

Therefore, the lower bound forces in ASCE/SEI 7-16 are the same as those in the 1991 UBC. One subtle, but noteworthy, point is that the $I_{p}$ value in the 1991 UBC was tied to the building importance factor. This was revised in the 1994 UBC where the $I_{p}$ factor was established based on component importance.

However, there are additional justifications for the lower bound $F_{p}$ force. For rigid items without component ductility, the design force should equal the peak floor acceleration divided by the margin between actual strength and design strength. At the ground level, the peak floor acceleration is the peak ground acceleration, which equals $0.4 S_{D S}$. For this project, the value of 1.3 , denoted as $R_{\text {pocomp }}$, was adopted as the margin between actual strength and design strength. Therefore, for rigid components at grade where the peak floor acceleration is the lowest is:

$$
F_{p, \min }=0.4 S_{D S} W_{p} / 1.3=0.31 S_{D S} W_{p}
$$

Applying an Importance Factor, $I_{p}$, and rounding down, the following is obtained for rigid components.

$$
F_{p, \min }=0.3 S_{D S} I_{p} W_{p}
$$


For non-rigid components that are moderately or very ductile items per ASCE/SEI $7-16$, if $a_{p}=2.5$ and $R_{p}=3$ are assumed at the ground level, then the following is obtained:

$$
\begin{gathered}
F_{p}=0.4 S_{D S} a_{p} W_{p} /\left(R_{p} / I_{p}\right)=0.4 S_{D S} \times 2.5 I_{p} W_{p} / 3 \\
F_{p}=0.33 S_{D S} I_{p} W_{p}
\end{gathered}
$$

Considering the above, it is reasonable to utilize the following lower limit for moderately and very ductile items:

$$
F_{p, \min }=0.3 S_{D S} I_{p} W_{p}
$$

This is for both non-rigid (likely to be in resonance with the building) components and rigid (unlikely to be in resonance) components.

\subsection{Proposed Maximum (or Cap) for Nonstructural Component Design}

\subsubsection{Background}

ASCE/SEI 7-16 and the building codes that precede it set a need-not-exceed maximum (or cap) for the nonstructural component design force, even if ASCE/SEI 7-16 Equation 13.3-1 has a higher value. The maximum will often govern at higher levels of the building where the PFA/PGA increases beyond 1.0 and where $R_{p}$ is small.

For example, assuming values of $a_{p}=2.5, z / h=1$ for roof of a building, and $R_{p}=1.5$, then ASCE/SEI 7-16 Equation 13.3-1 yields:

$$
\begin{aligned}
F_{p} & =\left(0.4 a_{p} S_{D S}[1+2(z / h)] /\left(R_{p} / I_{p}\right)\right) W_{p} \\
& =0.4 \times 2.5 \times S_{D S}[1+2(1)] /\left(1.5 / I_{p}\right) W_{p} \\
& =2.0 S_{D S} I_{p} W_{p}
\end{aligned}
$$

The maximum design force $F_{p}=1.6 S_{D S} I_{p} W_{p}$ of ASCE/SEI 7-16 Equation 13.3-2 is thus less in this case than the value from ASCE/SEI 7-16 Equation 13.3-1 of $F_{p}=$ $2.0 S_{D S} I_{p} W_{p}$.

The maximum nonstructural design force of $F_{p}=1.6 S_{D S} I_{p} W_{p}$ was established in ASCE/SEI 7-05 in part considering the inferred maximum value specified in the 1991 UBC. The 1991 UBC seismic forces were at the allowable stress design level. The $F_{p}$ force in the 1991 UBC was:

$$
F_{p}=Z I_{p} C_{p} W_{p}
$$

where:

$Z=0.40$ (the effective peak ground acceleration in Seismic Zone 4)

$C_{p}=0.75$ or 2.0 depending on the component type

$I_{p}=$ Seismic Importance Factor 
Therefore, the largest value of $F_{p}$ was not to exceed $F_{p, \max }=2.0 Z I_{p} W_{p}$.

For the largest 1991 Seismic Zone 4 plateau areas in ASCE/SEI 7-05, the peak ground acceleration was equal to $0.4 S_{D S}$ where $S_{D S}=1.0$. Substituting $0.4 S_{D S}$ for $Z$, yields:

$$
F_{p, \max }=2.0\left(0.4 S_{D S}\right) I_{p} W_{p}=0.8 S_{D S} I_{p} W_{p}
$$

To convert from allowable stress design of the 1991 UBC to strength design, which is the basis for the ASCE/SEI 7 equations, allowable strength values are multiplied by either 1.4 or 1.5 depending on the load combination. Using 1.5 results in:

$$
F_{p, \max }=1.5 \times 0.8 S_{D S} I_{p} W_{p}=1.2 S_{D S} I_{p} W_{p}
$$

By comparison, the 1994 NEHRP Recommended Provisions (FEMA, 1995) nonstructural seismic design equation can be written as:

$$
F_{p}=\left(a_{p} A_{p} I_{p} / R_{p}\right) W_{p}
$$

Using values of $a_{p}=2.5, A_{p}=4.0 C_{a}$ for the maximum at the roof of a building, $C_{a}$ 0.40 with the Zone 4 value of $A_{v}=0.4$ and thus $A_{p}=4.0 C_{a}=1.6, R_{p}=1.5$, then:

$$
F_{p}=\left(a_{p} A_{p} I_{p} / R_{p}\right) W_{p}=\left(2.5 \times 1.6 \times I_{p} / 1.5\right) W_{p}=2.67 I_{p} W_{p}=2.67 I_{p} S_{D S} W_{p}
$$

It was the judgment of Technical Subcommittee 8 (TS-08) of the 1994 NEHRP and 1997 NEHRP Provisions Update Committees that developed the nonstructural seismic design equations found in ASCE/SEI 7-05 that the value of $F_{p, \max }=$ $1.2 S_{D S} I_{p} W_{p}$ was too low, considering the fact that the value could be as high as $F_{p}=$ $2.67 S_{D S} I_{p} W_{p}$ using the nonstructural seismic design equation from the $1994 \mathrm{NEHRP}$ Provisions and $F_{p}=2.0 S_{D S} I_{p} W_{p}$ using the nonstructural seismic design equation from the 1997 NEHRP Provisions. It was also the judgment of TS-08 that multiplication of the individual factors would produce a design force that would be unreasonably high, considering the expected nonlinear response of the supporting structure and the component itself. Therefore, it was TS-08's judgment and subsequently the judgment of the ASCE/SEI 7 code development committees that a value of $F_{p \text {, } \max }=$ 1. $6 S_{D S} I_{p} W_{p}$ was adequately conservative and was therefore adopted as the need-notexceed upper limit for ASCE/SEI 7 nonstructural seismic design equations. The maximum has remained unchanged in ASCE/SEI 7-10 and ASCE/SEI 7-16.

\subsubsection{Proposed Maximum}

Nonstructural response is larger when the component is located higher in the building, and when there is lower component and building ductility. To establish a maximum, it is assumed that the component is located at the roof $(z / h=1)$. It is assumed that nearly all components will have at least some amount of ductility, so a low ductility $\left(\mu_{\text {comp }}=1.25\right)$ value is used to help define an assumption for a reasonable design force maximum. The archetype studies in Section 4.3.4.4 using 
the proposed equation for four different archetypes had relatively large $R$ values for the building ( $R=6$ for the special reinforced concrete shear wall buildings [with a building frame system] and $R=8$ for the steel moment-resisting frame buildings), but they also include overdesign factors that will reduce the level of actual building ductility. The analytical studies generally show that, for a roof level location and low component ductility case, the proposed equation envelopes response except in a narrow region where component and building resonance occur.

Section 4.8 provides comparisons using the proposed equations for four different SFRSs. Two are for the same archetypes used in the analytical studies (6-story special steel moment-resisting frame and 8-story special reinforced concrete shear wall), but the other two have lower $R$ values ( $R=3.25$ for a 4-story ordinary steel concentric braced frame and $\mathrm{R}=3.5$ for a 2 -story ordinary steel moment-resisting frame). Comparisons show that the current ASCE/SEI 7-16 maximum of $F_{p, \max }=$ 1.6 $S_{D S} I_{p} W_{p}$ is insufficient to bound the primary proposed equation for components likely in resonance with the building for lower ductility SFRSs. As such, it is found prudent to increase the maximum to $F_{p} / W_{p}=2.0 S_{D S} I_{p}$. This value envelopes the primary proposed equation values for the 6-story steel moment-resisting frame and 8 -story reinforced concrete low ductility cases and comes much closer to the low ductility cases for the 4-story steel ordinary braced frame and 2-story ordinary moment-resisting frame.

\subsection{When Building SFRS, Height, and/or Location of Component within the Building are Not Known}

\subsubsection{When Location within the Building is Not Known}

A common situation that can occur is when the nonstructural design engineer is given the building SFRS and height, but not the location of the component within the building or the component is located at multiple floor and/or roof levels. In this situation, the proposed nonstructural design equation can be used, except $z / h=1$ is assumed.

\subsubsection{When SFRS and Height are Also Not Known}

In some cases, the nonstructural design engineer is not given any information about the building or is asked to design anchorage and bracing that could work for any building type, height, and location in the building. In this situation, the proposed equation for the maximum can be used. 


\subsection{Use of Dynamic Analysis to Determine Nonstructural Design Forces}

\subsubsection{ASCE/SEI 7-16 Provisions}

ASCE/SEI 7-16 Section 13.3.1.4 allows the use of building specific dynamic analyses to calculate nonstructural component seismic force demands. Several different techniques are included. The first is covered by ASCE/SEI 7-16 Equation 13.3-4, which is similar to previous editions of ASCE/SEI 7 where floor accelerations can be calculated from response history analysis and then combined with the code $a_{p}$ values. There are two other new alternatives in ASCE/SEI 7-16 Sections 13.3.1.4.1 and 13.3.1.4.2 that can be used to create floor spectra and are based on using ASCE/SEI 7-16 Figure 13.3-1 for what is called DAF, but is the same as PCA/PFA in this study. This figure has a normalized $x$-axis using $T_{\text {comp }} / T_{\text {bldg }}$ and a peak value of 5 for PCA/PFA from $0.75<T_{\text {comp }} / T_{\text {bld }}<1.25$. It thus produces a value of twice the $a_{p}=2.5$ used in ASCE/SEI 7-16 Equation 13.3-1.

\subsubsection{Proposed Revisions}

Nonlinear response history analyses can be used with the proposed equations in this study to provide a better estimate of PFA in a similar way to that of ASCE/SEI 7-16. Assuming the floor acceleration determined from nonlinear response history analyses is PFA, then the proposed equation from Section 4.3.4 would reduce to:

$$
F_{p} / W_{p}=(\mathrm{PFA} \text { from analysis }) \times\left[(\mathrm{PCA} / \mathrm{PFA}) / R_{p o c o m p}\right] \times I_{p}
$$

\subsection{General Comparisons between ASCE/SEI 7-16 and Proposed Nonstructural Design Equation}

To better understand the implications of the currently proposed equation, some general studies have been developed to compare ASCE/SEI 7-16 with the proposed design equations. Table 4-8 shows the results for ASCE/SEI 7-16 using $S_{D S}=1.0$ (which is $2.5 \times \mathrm{PGA}=0.4$ ) and $I_{p}=1.0$. Common values for $R_{p}$ of 1.5, 2.5, and 3.5 from ASCE/SEI 7-16 Table 13.5-1 are used. In Table 4-8, green values are those that go below the minimum value from ASCE/SEI 7-16 Equation 13.3-3, and red values are those that exceed the maximum value from ASCE/SEI 7-16 Equation 13.3-2. Table 4-9 incorporates the minimum and maximum limits. ASCE/SEI 7-16 Section 13.4.2 covers anchors in concrete and masonry. Anchors that do not have ductile yielding or a limiting force from a mechanism in the component need to be designed for the design forces times the $\Omega_{0}$ factor. Table 4-10 takes the forces in Table 4-9 and multiplies them by common values of $\Omega_{0}$ in ASCE/SEI 7-16 Table 13.5-1. 
Table 4-8 $\quad F_{p} / W_{p}$ for ASCE/SEI 7-16

\begin{tabular}{|c|c|c|c|c|c|c|c|c|c|}
\hline \multirow[b]{2}{*}{$z / h$} & \multirow[b]{2}{*}{$R_{p}:$} & \multicolumn{3}{|c|}{ Flexible: $a_{p}=2.5$} & \multicolumn{3}{|c|}{ Rigid: $a_{p}=1.0$} & \multirow{2}{*}{$\begin{array}{c}\operatorname{Min} \\
0.3 S_{D S} \\
\end{array}$} & \multirow{2}{*}{$\begin{array}{c}\operatorname{Max} \\
1.6 S_{D S} \\
\end{array}$} \\
\hline & & 1.5 & 2.5 & 3.5 & 1.5 & 2.5 & 3.5 & & \\
\hline 1 & & 2.00 & 1.20 & 0.86 & 0.80 & 0.48 & 0.34 & 0.30 & 1.60 \\
\hline 0.75 & & 1.67 & 1.00 & 0.71 & 0.67 & 0.40 & 0.29 & 0.30 & 1.60 \\
\hline 0.5 & & 1.33 & 0.80 & 0.57 & 0.53 & 0.32 & 0.23 & 0.30 & 1.60 \\
\hline 0.25 & & 1.00 & 0.60 & 0.43 & 0.40 & 0.24 & 0.17 & 0.30 & 1.60 \\
\hline 0 & & 0.67 & 0.40 & 0.29 & 0.27 & 0.16 & 0.11 & 0.30 & 1.60 \\
\hline
\end{tabular}

Table 4-9 $\quad F_{p} / W_{p}$ for ASCE/SEI 7-16 Incorporating Minimum and Maximum

\begin{tabular}{|c|c|c|c|c|c|c|c|c|c|}
\hline \multirow[b]{2}{*}{$z / h$} & \multirow[b]{2}{*}{$R_{p}:$} & \multicolumn{3}{|c|}{ Flexible: $a_{p}=2.5$} & \multicolumn{3}{|c|}{ Rigid: $a_{p}=1.0$} & \multirow{2}{*}{$\begin{array}{c}\operatorname{Min} \\
0.3 S_{D S}\end{array}$} & \multirow{2}{*}{$\begin{array}{c}\operatorname{Max} \\
1.6 S_{D S}\end{array}$} \\
\hline & & 1.5 & 2.5 & 3.5 & 1.5 & 2.5 & 3.5 & & \\
\hline 1 & & 1.60 & 1.20 & 0.86 & 0.80 & 0.48 & 0.34 & 0.30 & 1.60 \\
\hline 0.75 & & 1.60 & 1.00 & 0.71 & 0.67 & 0.40 & 0.30 & 0.30 & 1.60 \\
\hline 0.5 & & 1.33 & 0.80 & 0.57 & 0.53 & 0.32 & 0.30 & 0.30 & 1.60 \\
\hline 0.25 & & 1.00 & 0.60 & 0.43 & 0.40 & 0.30 & 0.30 & 0.30 & 1.60 \\
\hline 0 & & 0.67 & 0.40 & 0.30 & 0.30 & 0.30 & 0.30 & 0.30 & 1.60 \\
\hline
\end{tabular}

Table 4-10 $F_{p} / W_{p}$ for ASCE/SEI 7-16 for Anchors

\begin{tabular}{|c|c|c|c|c|c|c|c|}
\hline \multirow[b]{3}{*}{$z / h$} & \multirow[b]{2}{*}{$R_{p}:$} & \multicolumn{3}{|c|}{ Flexible: $a_{p}=2.5$} & \multicolumn{3}{|c|}{ Rigid: $a_{p}=1.0$} \\
\hline & & 1.5 & 2.5 & 3.5 & 1.5 & 2.5 & 3.5 \\
\hline & $\Omega_{0}:$ & 1.5 & 2 & 2.5 & 1.5 & 2 & 2.5 \\
\hline 1 & & 2.40 & 2.40 & 2.14 & 1.20 & 0.96 & 0.86 \\
\hline 0.75 & & 2.40 & 2.00 & 1.79 & 1.00 & 0.80 & 0.75 \\
\hline 0.5 & & 2.00 & 1.60 & 1.43 & 0.80 & 0.64 & 0.75 \\
\hline 0.25 & & 1.50 & 1.20 & 1.07 & 0.60 & 0.60 & 0.75 \\
\hline 0 & & 1.00 & 0.80 & 0.75 & 0.45 & 0.60 & 0.75 \\
\hline
\end{tabular}

Table 4-11 provides a parallel set of values using the new proposed equation. The ASCE/SEI 7-16 equation does not depend on the building seismic force-resisting system, but the proposed nonstructural design equation does. Table 4-11 provides results for four building systems: (1) a 6-story steel special moment-resisting frame (SMRF); (2) an 8-story special reinforced concrete shear wall with a building frame system (RCSW); (3) a 4-story steel ordinary concentric braced frame (OCBF); and (4) a 2-story steel ordinary moment frame (OMF). Table 4-12 revises the values to the proposed minimum and maximum limits given in Sections 4.4 and 4.5. 
Table 4-11 $F_{p} / W_{p}$ for Proposed Equation

\begin{tabular}{|c|c|c|c|c|c|c|c|c|}
\hline \multirow[b]{3}{*}{ SFRS } & \multirow[b]{3}{*}{$z / h$} & \multicolumn{4}{|c|}{ Likely Resonance } & \multirow{3}{*}{$\begin{array}{c}\text { Unlikely } \\
\text { Resonance }\end{array}$} & \multirow{3}{*}{$\begin{array}{c}\operatorname{Min} \\
0.3 S_{D S}\end{array}$} & \multirow{3}{*}{$\begin{array}{r}\operatorname{Max} \\
2.0 S_{D S} \\
\end{array}$} \\
\hline & & \multicolumn{4}{|c|}{ Component Ductility } & & & \\
\hline & & Elastic & Low & Moderate & High & & & \\
\hline 6-story & 1.00 & 2.08 & 1.45 & 1.14 & 0.73 & 0.52 & 0.30 & 2.00 \\
\hline Steel & 0.75 & 1.33 & 0.93 & 0.73 & 0.47 & 0.33 & 0.30 & 2.00 \\
\hline \multirow[t]{3}{*}{ SMRF } & 0.50 & 1.10 & 0.77 & 0.61 & 0.39 & 0.28 & 0.30 & 2.00 \\
\hline & 0.25 & 0.91 & 0.64 & 0.50 & 0.32 & 0.23 & 0.30 & 2.00 \\
\hline & 0 & 0.45 & 0.36 & 0.32 & 0.25 & 0.18 & 0.30 & 2.00 \\
\hline 8-story & 1.00 & 2.42 & 1.70 & 1.33 & 0.85 & 0.61 & 0.30 & 2.00 \\
\hline Special & 0.75 & 1.70 & 1.19 & 0.94 & 0.60 & 0.43 & 0.30 & 2.00 \\
\hline RCSW & 0.50 & 1.37 & 0.96 & 0.75 & 0.48 & 0.34 & 0.30 & 2.00 \\
\hline (Building & 0.25 & 1.06 & 0.74 & 0.59 & 0.37 & 0.27 & 0.30 & 2.00 \\
\hline Frame) & 0 & 0.47 & 0.38 & 0.34 & 0.27 & 0.19 & 0.30 & 2.00 \\
\hline 4-story & 1.00 & 3.21 & 2.25 & 1.77 & 1.12 & 0.80 & 0.30 & 2.00 \\
\hline Steel & 0.75 & 2.61 & 1.83 & 1.44 & 0.91 & 0.65 & 0.30 & 2.00 \\
\hline \multirow[t]{3}{*}{ OCBF } & 0.50 & 2.04 & 1.43 & 1.12 & 0.72 & 0.51 & 0.30 & 2.00 \\
\hline & 0.25 & 1.48 & 1.04 & 0.82 & 0.52 & 0.37 & 0.30 & 2.00 \\
\hline & 0 & 0.58 & 0.46 & 0.41 & 0.32 & 0.23 & 0.30 & 2.00 \\
\hline 2-story & 1.00 & 3.80 & 2.66 & 2.09 & 1.33 & 0.95 & 0.30 & 2.00 \\
\hline Steel & 0.50 & 2.44 & 1.70 & 1.34 & 0.85 & 0.61 & 0.30 & 2.00 \\
\hline OMF & 0 & 0.68 & 0.54 & 0.49 & 0.38 & 0.27 & 0.30 & 2.00 \\
\hline
\end{tabular}

Table 4-12 $F_{p} / W_{p}$ for Proposed Equation Incorporating Minimum and Maximum

\begin{tabular}{|c|c|c|c|c|c|c|c|c|}
\hline \multirow[b]{3}{*}{ SFRS } & \multirow[b]{3}{*}{$z / h$} & \multicolumn{4}{|c|}{ Likely Resonance } & \multirow{3}{*}{$\begin{array}{c}\text { Unlikely } \\
\text { Resonance } \\
\end{array}$} & \multirow{3}{*}{$\begin{array}{c}\operatorname{Min} \\
0.3 S_{D S} \\
\end{array}$} & \multirow{3}{*}{$\begin{array}{r}\operatorname{Max} \\
2.0 S_{D S} \\
\end{array}$} \\
\hline & & \multicolumn{4}{|c|}{ Component Ductility } & & & \\
\hline & & Elastic & Low & Moderate & High & & & \\
\hline 6-story & 1.00 & 2.00 & 1.45 & 1.14 & 0.73 & 0.52 & 0.30 & 2.00 \\
\hline Steel & 0.75 & 1.33 & 0.93 & 0.73 & 0.47 & 0.33 & 0.30 & 2.00 \\
\hline \multirow[t]{3}{*}{ SMRF } & 0.50 & 1.10 & 0.77 & 0.61 & 0.39 & 0.30 & 0.30 & 2.00 \\
\hline & 0.25 & 0.91 & 0.64 & 0.50 & 0.32 & 0.30 & 0.30 & 2.00 \\
\hline & 0 & 0.45 & 0.36 & 0.32 & 0.30 & 0.30 & 0.30 & 2.00 \\
\hline 8-story & 1.00 & 2.00 & 1.70 & 1.33 & 0.85 & 0.61 & 0.30 & 2.00 \\
\hline Special & 0.75 & 1.70 & 1.19 & 0.94 & 0.60 & 0.43 & 0.30 & 2.00 \\
\hline RCSW & 0.50 & 1.37 & 0.96 & 0.75 & 0.48 & 0.34 & 0.30 & 2.00 \\
\hline (Building & 0.25 & 1.06 & 0.74 & 0.59 & 0.37 & 0.30 & 0.30 & 2.00 \\
\hline Frame) & 0 & 0.47 & 0.38 & 0.34 & 0.30 & 0.30 & 0.30 & 2.00 \\
\hline
\end{tabular}


Table 4-12 $F_{p} / W_{p}$ for Proposed Equation Incorporating Minimum and Maximum (continued)

\begin{tabular}{|c|c|c|c|c|c|c|c|c|}
\hline \multirow[b]{3}{*}{ SFRS } & \multirow[b]{3}{*}{$z / h$} & \multicolumn{4}{|c|}{ Likely Resonance } & \multirow{3}{*}{$\begin{array}{c}\text { Unlikely } \\
\text { Resonance } \\
\end{array}$} & \multirow{3}{*}{$\begin{array}{c}\operatorname{Min} \\
0.3 S_{D S}\end{array}$} & \multirow{3}{*}{$\begin{array}{r}\operatorname{Max} \\
2.0 S_{D S} \\
\end{array}$} \\
\hline & & \multicolumn{4}{|c|}{ Component Ductility } & & & \\
\hline & & Elastic & Low & Moderate & High & & & \\
\hline (Building & 0.25 & 1.06 & 0.74 & 0.59 & 0.37 & 0.30 & 0.30 & 2.00 \\
\hline Frame) & 0 & 0.47 & 0.38 & 0.34 & 0.30 & 0.30 & 0.30 & 2.00 \\
\hline 4-story & 1.00 & 2.00 & 2.00 & 1.77 & 1.12 & 0.80 & 0.30 & 2.00 \\
\hline Steel & 0.75 & 2.00 & 1.83 & 1.44 & 0.91 & 0.65 & 0.30 & 2.00 \\
\hline \multirow[t]{3}{*}{ OCBF } & 0.50 & 2.00 & 1.43 & 1.12 & 0.72 & 0.51 & 0.30 & 2.00 \\
\hline & 0.25 & 1.48 & 1.04 & 0.82 & 0.52 & 0.37 & 0.30 & 2.00 \\
\hline & 0 & 0.58 & 0.46 & 0.41 & 0.32 & 0.30 & 0.30 & 2.00 \\
\hline 2-story & 1.00 & 2.00 & 2.00 & 2.00 & 1.33 & 0.95 & 0.30 & 2.00 \\
\hline Steel & 0.50 & 2.00 & 1.70 & 1.34 & 0.85 & 0.61 & 0.30 & 2.00 \\
\hline OMF & 0 & 0.68 & 0.54 & 0.49 & 0.38 & 0.30 & 0.30 & 2.00 \\
\hline
\end{tabular}

The steel SMRF building is 80 feet tall. This enables calculation of the building approximate fundamental period from ASCE/SEI 7-16 Equation 12.8-7, $T_{a b l d g}=C_{t} h_{n}{ }^{x}$ $=0.028 \times 80^{0.8}=0.93$ seconds. The RCSW building is 97 feet tall, and the approximate fundamental period is $T_{\text {abldg }}=C_{t} h_{n}{ }^{x}=0.020 \times 97^{0.75}=0.62$ seconds. The steel OCBF is 56 feet tall, and the approximate fundamental period is $T_{a b l d g}=C_{t} h_{n}{ }^{x}=$ $0.020 \times 56^{0.75}=0.41$ seconds. The steel OMF building is 28 feet tall, and the approximate fundamental period is $T_{a b l d g}=C_{t} h_{n}{ }^{x}=0.028 \times 28^{0.80}=0.40$ seconds.

As the comparison between the steel SMRF and RCSW shows, the stiffer RCSW has higher values. This comes from the PFA/PGA equation in part and also from the lower $R_{\mu b l d g}$ value. The OCBF and OMF cases are even stiffer and have lower ductilities and thus lower $R_{\mu b l d g}$ values, leading to higher nonstructural design equation forces. Note that results are plotted at $z / h$ values of $0.25,0.5,0.75$, and 1 to permit direct comparison with Table 4-8. For the 6-story building, although, there are no actual diaphragms at $z / h=0.25$ and 0.75 . The closest would be Level $3(z / h=$ $0.33)$ and Level $5(z / h=0.67)$.

The comparisons above are for the architectural component $a_{p} / R_{p}$ values in ASCE/SEI 7-16 Table 13.5-1. The $R_{p}$ values for mechanical and electrical components in ASCE/SEI 7-16 Table 13.6-1 are in some cases much larger and would show substantial differences to the proposed equation, though the ASCE/SEI 7-16 minimums will typically govern.

Table 4-13 provides values for anchors using a set of the same $\Omega_{0}$ values as those in Table 4-10 using the results from Table 4-11 without the minimum and maximum. 
Table 4-14 uses the results from Table 4-12 that have the minimum and maximum limits and the value of $\Omega_{0}=1.5$ for the unlikely resonance category.

Table 4-13 $F_{p} / W_{p}$ for Proposed Equation for Anchors

\begin{tabular}{|c|c|c|c|c|c|c|c|}
\hline \multirow[b]{4}{*}{ SFRS } & \multirow[b]{4}{*}{$z / h$} & & \multicolumn{4}{|c|}{ Likely Resonance } & \multirow{3}{*}{$\begin{array}{c}\text { Unlikely } \\
\text { Resonance } \\
\end{array}$} \\
\hline & & & \multicolumn{4}{|c|}{ Component Ductility } & \\
\hline & & & Elastic & Low & Moderate & High & \\
\hline & & $\Omega_{0}:$ & 1.00 & 1.50 & 2.00 & 2.50 & 1.00 \\
\hline 6-story & 1 & & 2.08 & 2.18 & 2.28 & 1.82 & 0.52 \\
\hline Steel & 0.75 & & 1.33 & 1.40 & 1.46 & 1.16 & 0.33 \\
\hline \multirow[t]{3}{*}{ SMRF } & 0.50 & & 1.10 & 1.16 & 1.21 & 0.97 & 0.28 \\
\hline & 0.25 & & 0.91 & 0.96 & 1.00 & 0.80 & 0.23 \\
\hline & 0 & & 0.45 & 0.54 & 0.65 & 0.63 & 0.18 \\
\hline 8-story & 1 & & 2.42 & 2.54 & 2.67 & 2.12 & 0.61 \\
\hline Special & 0.75 & & 1.70 & 1.79 & 1.87 & 1.49 & 0.43 \\
\hline RCSW & 0.50 & & 1.37 & 1.44 & 1.51 & 1.20 & 0.34 \\
\hline (Building & 0.25 & & 1.06 & 1.12 & 1.17 & 0.93 & 0.27 \\
\hline Frame) & 0 & & 0.47 & 0.57 & 0.68 & 0.66 & 0.19 \\
\hline 4-story & 1 & & 3.21 & 3.37 & 3.53 & 2.81 & 0.80 \\
\hline Steel & 0.75 & & 2.61 & 2.74 & 2.87 & 2.28 & 0.65 \\
\hline \multirow[t]{3}{*}{ OCBF } & 0.50 & & 2.04 & 2.15 & 2.25 & 1.79 & 0.51 \\
\hline & 0.25 & & 1.48 & 1.56 & 1.63 & 1.30 & 0.37 \\
\hline & 0 & & 0.58 & 0.69 & 0.83 & 0.81 & 0.23 \\
\hline 2-story & 1 & & 3.80 & 3.99 & 4.18 & 3.32 & 0.95 \\
\hline Steel & 0.50 & & 2.44 & 2.56 & 2.68 & 2.13 & 0.61 \\
\hline OMF & 0 & & 0.68 & 0.81 & 0.98 & 0.95 & 0.27 \\
\hline
\end{tabular}

Table 4-14 $F_{p} / W_{p}$ for Proposed Equation for Anchors

\begin{tabular}{|c|c|c|c|c|c|c|c|}
\hline \multirow[b]{4}{*}{ SFRS } & \multirow[b]{4}{*}{$z / h$} & & \multicolumn{4}{|c|}{ Likely Resonance } & \multirow{3}{*}{$\begin{array}{c}\text { Unlikely } \\
\text { Resonance } \\
\end{array}$} \\
\hline & & & \multicolumn{4}{|c|}{ Component Ductility } & \\
\hline & & & Elastic & Low & Moderate & High & \\
\hline & & $\Omega_{0}:$ & 1.00 & 1.50 & 2.00 & 2.50 & 1.50 \\
\hline 6-story & 1.00 & & 2.00 & 2.18 & 2.28 & 1.82 & 0.78 \\
\hline Steel & 0.75 & & 1.33 & 1.40 & 1.46 & 1.16 & 0.50 \\
\hline \multirow[t]{3}{*}{ SMRF } & 0.50 & & 1.10 & 1.16 & 1.21 & 0.97 & 0.45 \\
\hline & 0.25 & & 0.91 & 0.96 & 1.00 & 0.80 & 0.45 \\
\hline & 0.00 & & 0.45 & 0.54 & 0.65 & 0.75 & 0.45 \\
\hline
\end{tabular}


Table 4-14 $F_{p} / W_{p}$ for Proposed Equation for Anchors (continued)

\begin{tabular}{|c|c|c|c|c|c|c|c|}
\hline \multirow[b]{4}{*}{ SFRS } & \multirow[b]{4}{*}{$z / h$} & & \multicolumn{4}{|c|}{ Likely Resonance } & \multirow{3}{*}{$\begin{array}{c}\text { Unlikely } \\
\text { Resonance }\end{array}$} \\
\hline & & & \multicolumn{4}{|c|}{ Component Ductility } & \\
\hline & & & Elastic & Low & Moderate & High & \\
\hline & & $\Omega_{0}:$ & 1.00 & 1.50 & 2.00 & 2.50 & 1.50 \\
\hline 8-story & 1.00 & & 2.00 & 2.54 & 2.67 & 2.12 & 0.91 \\
\hline Special & 0.75 & & 1.70 & 1.79 & 1.87 & 1.49 & 0.64 \\
\hline RCSW & 0.50 & & 1.37 & 1.44 & 1.51 & 1.20 & 0.51 \\
\hline (Building & 0.25 & & 1.06 & 1.12 & 1.17 & 0.93 & 0.45 \\
\hline Frame) & 0.00 & & 0.47 & 0.57 & 0.68 & 0.75 & 0.45 \\
\hline 4-story & 1 & & 2.00 & 3.00 & 3.53 & 2.81 & 1.20 \\
\hline Steel & 0.75 & & 2.00 & 2.74 & 2.87 & 2.28 & 0.98 \\
\hline OCBF & 0.50 & & 2.00 & 2.15 & 2.25 & 1.79 & 0.77 \\
\hline & 0.25 & & 1.48 & 1.56 & 1.63 & 1.30 & 0.56 \\
\hline & 0 & & 0.58 & 0.69 & 0.83 & 0.81 & 0.45 \\
\hline 2-story & 1 & & 2.00 & 3.00 & 4.00 & 3.32 & 1.42 \\
\hline Steel & 0.50 & & 2.00 & 2.56 & 2.68 & 2.13 & 0.91 \\
\hline OMF & 0 & & 0.68 & 0.81 & 0.98 & 0.95 & 0.45 \\
\hline
\end{tabular}

\subsubsection{Comparisons of Proposed Equations with ASCE/SEI 7-16}

To compare the proposed equations with ASCE/SEI 7-16 results, the closest approximation would be that "likely in resonance" corresponds to $a_{p}=2.5$, "unlikely to be in resonance" corresponds to $a_{p}=1.0$, "low ductility" corresponds to $R_{p}=1.5$, "moderate ductility" corresponds to $R_{p}=2.5$, and "high ductility" corresponds to $R_{p}=3.5$. Table $4-15$ provides the ratio of the proposed equation to that of ASCE/SEI 7-16 for the nonstructural design equations, and Table 4-16 addresses the same ratio for anchors without ductile design. The minimum and maximum limitations for both the proposed equations and the ASCE/SEI 7-16 results are included. Values in blue are lower for the proposed equation, those in black are equal, and those in orange are higher. For the "not likely to be in resonance" category, there is no variation for ductility (since from basic dynamic theory, component ductility does not reduce forces at $T_{\text {comp }}=0$ seconds), but there are $R_{p}$ values in ASCE/SEI 7-16. The comparison is still provided. 
Table 4-15 Ratio of $F_{p} / W_{p}$ for Proposed Equation versus ASCE/SEI 7-16

\begin{tabular}{|c|c|c|c|c|c|c|c|c|}
\hline \multirow[b]{4}{*}{ SFRS } & \multirow[b]{4}{*}{$z / h$} & \multirow[b]{3}{*}{ Proposed } & \multicolumn{3}{|c|}{ Likely Resonance } & \multicolumn{3}{|c|}{ Unlikely Resonance } \\
\hline & & & \multicolumn{3}{|c|}{ Component Ductility } & \multicolumn{3}{|c|}{ Component Ductility } \\
\hline & & & Low & Moderate & High & $N A$ & $N A$ & $N A$ \\
\hline & & $A S C E R_{p}$ & 1.50 & 2.50 & 3.50 & 1.50 & 2.50 & 3.50 \\
\hline 6-story & 1.00 & & 0.91 & 0.95 & 0.85 & 0.65 & 1.08 & 1.51 \\
\hline Steel & 0.75 & & 0.58 & 0.73 & 0.65 & 0.50 & 0.83 & 1.11 \\
\hline \multirow[t]{3}{*}{ SMRF } & 0.50 & & 0.58 & 0.76 & 0.68 & 0.56 & 0.94 & 1.00 \\
\hline & 0.25 & & 0.64 & 0.84 & 0.74 & 0.75 & 1.00 & 1.00 \\
\hline & 0.00 & & 0.54 & 0.81 & 1.00 & 1.00 & 1.00 & 1.00 \\
\hline 8-story & 1.00 & & 1.06 & 1.11 & 0.99 & 0.76 & 1.26 & 1.77 \\
\hline Special & 0.75 & & 0.74 & 0.94 & 0.83 & 0.64 & 1.06 & 1.42 \\
\hline RCSW & 0.50 & & 0.72 & 0.94 & 0.84 & 0.64 & 1.07 & 1.14 \\
\hline (Building & 0.25 & & 0.74 & 0.98 & 0.87 & 0.75 & 1.00 & 1.00 \\
\hline Frame) & 0.00 & & 0.57 & 0.85 & 1.00 & 1.00 & 1.00 & 1.00 \\
\hline 4-story & 1.00 & & 1.25 & 1.47 & 1.31 & 1.00 & 1.67 & 2.34 \\
\hline Steel & 0.75 & & 1.14 & 1.44 & 1.28 & 0.98 & 1.63 & 2.17 \\
\hline \multirow[t]{3}{*}{ OCBF } & 0.50 & & 1.07 & 1.41 & 1.25 & 0.96 & 1.60 & 1.70 \\
\hline & 0.25 & & 1.04 & 1.36 & 1.21 & 0.93 & 1.24 & 1.24 \\
\hline & 0.00 & & 0.69 & 1.04 & 1.07 & 1.00 & 1.00 & 1.00 \\
\hline 2-story & 1.00 & & 1.25 & 1.67 & 1.55 & 1.19 & 1.98 & 2.77 \\
\hline Steel & 0.50 & & 1.28 & 1.67 & 1.49 & 1.14 & 1.90 & 2.03 \\
\hline OMF & 0.00 & & 0.81 & 1.22 & 1.27 & 1.00 & 1.00 & 1.00 \\
\hline
\end{tabular}

Table 4-16 Ratio of $F_{p} / W_{p}$ for Proposed Equation versus ASCE/SEI 7-16 for Anchors

\begin{tabular}{|c|c|c|c|c|c|c|c|c|}
\hline \multirow[b]{4}{*}{ SFRS } & \multirow[b]{4}{*}{$z / h$} & & \multicolumn{3}{|c|}{ Likely Resonance } & \multicolumn{3}{|c|}{ Unlikely Resonance } \\
\hline & & & \multicolumn{3}{|c|}{ Component Ductility } & \multicolumn{3}{|c|}{ Component Ductility } \\
\hline & & Proposed & Low & Moderate & High & $N A$ & $N A$ & $N A$ \\
\hline & & ASCE $R_{p}$ & 1.50 & 2.50 & 3.50 & 1.50 & 2.50 & 3.50 \\
\hline 6-story & 1.00 & & 0.91 & 0.95 & 0.85 & 0.65 & 0.81 & 0.91 \\
\hline Steel & 0.75 & & 0.58 & 0.73 & 0.65 & 0.50 & 0.62 & 0.66 \\
\hline \multirow[t]{3}{*}{ SMRF } & 0.50 & & 0.58 & 0.76 & 0.68 & 0.56 & 0.70 & 0.60 \\
\hline & 0.25 & & 0.64 & 0.84 & 0.74 & 0.75 & 0.75 & 0.60 \\
\hline & 0.00 & & 0.54 & 0.81 & 1.00 & 1.00 & 0.75 & 0.60 \\
\hline
\end{tabular}


Table 4-16 Ratio of $F_{p} / W_{p}$ for Proposed Equation versus ASCE/SEI 7-16 for Anchors (continued)

\begin{tabular}{|c|c|c|c|c|c|c|c|c|}
\hline \multirow[b]{4}{*}{ SFRS } & \multirow[b]{4}{*}{$z / h$} & & \multicolumn{3}{|c|}{ Likely Resonance } & \multicolumn{3}{|c|}{ Unlikely Resonance } \\
\hline & & & \multicolumn{3}{|c|}{ Component Ductility } & \multicolumn{3}{|c|}{ Component Ductility } \\
\hline & & Proposed & Low & Moderate & High & $N A$ & $N A$ & $N A$ \\
\hline & & $A S C E R_{p}$ & 1.50 & 2.50 & 3.50 & 1.50 & 2.50 & 3.50 \\
\hline 8-story & 1.00 & & 1.06 & 1.11 & 0.99 & 0.76 & 0.95 & 1.06 \\
\hline Special & 0.75 & & 0.74 & 0.94 & 0.83 & 0.64 & 0.80 & 0.85 \\
\hline RCSW & 0.50 & & 0.72 & 0.94 & 0.84 & 0.64 & 0.80 & 0.69 \\
\hline (Building & 0.25 & & 0.74 & 0.98 & 0.87 & 0.75 & 0.75 & 0.60 \\
\hline Frame) & 0.00 & & 0.57 & 0.85 & 1.00 & 1.00 & 0.75 & 0.60 \\
\hline 4-story & 1.00 & & 1.25 & 1.47 & 1.31 & 1.00 & 1.25 & 1.40 \\
\hline Steel & 0.75 & & 1.14 & 1.44 & 1.28 & 0.98 & 1.22 & 1.30 \\
\hline \multirow[t]{3}{*}{ OCBF } & 0.50 & & 1.07 & 1.41 & 1.25 & 0.96 & 1.20 & 1.02 \\
\hline & 0.25 & & 1.04 & 1.36 & 1.21 & 0.93 & 0.93 & 0.74 \\
\hline & 0.00 & & 0.69 & 1.04 & 1.07 & 1.00 & 0.75 & 0.60 \\
\hline 2-story & 1.00 & & 1.25 & 1.67 & 1.55 & 1.19 & 1.48 & 1.66 \\
\hline Steel & 0.50 & & 1.28 & 1.67 & 1.49 & 1.14 & 1.43 & 1.22 \\
\hline OMF & 0.00 & & 0.81 & 1.22 & 1.27 & 1.00 & 0.75 & 0.60 \\
\hline
\end{tabular}

Observations include the following:

1. The SFRS and the associated variation in the PFA/PGA parameter and the building ductility make a significant difference. The ratios of the proposed equations to ASCE/SEI 7-16 equations are lowest with the 6-story SMRF, then the 8-story special RCSW, then the 4-story steel OCBF, and finally the 2-story steel OMF has the highest ratios. Results for the member design and for anchors show similar trends.

2. Many of the ratios of the proposed equations to ASCE/SEI 7-16 equations for the 6-story SMRF and the 8-story steel RCSW are less than one; most of the ratios for the 4-story steel OCBF and 2-story OMF are higher than one.

3. Ratios of the proposed equations to ASCE/SEI 7-16 equations are reduced at lower elevations, due to the PFA/PGA formulation.

4. Comparisons for the "unlikely in resonance" results depend on which ASCE/SEI 7-16 $R_{p}$ category is used. For many cases, the force from the proposed equation is lower than the results from ASCE/SEI 7-16 for $R_{p}=1.5$, but the force from the proposed equation is more than the results from ASCE/SEI 7-16 for $R_{p}=2.5$ and $R_{p}=3.5$. 
5. For anchors applied to components with likely resonance, application of the $\Omega_{0}$ factors to the low, moderate, and high ductility categories generally produce results that envelope the elastic results or comes close. For example, as shown in Table 4-13, at the roof for the SMRF, the elastic value is $2.08 \mathrm{~g}$, and the low ductility category is a bit higher at $2.18 \mathrm{~g}$ and somewhat lower at $1.82 \mathrm{~g}$ for the high ductility category.

\subsection{Case Study Example Comparisons between ASCE/SEI 7-16 and Proposed Nonstructural Design Equation}

The proposed primary nonstructural design equation PCA/PFA values in Table 4-2 depend on whether a component is likely or unlikely to be in resonance with the building and the amount of assumed component ductility, $\mu_{\text {comp }}$. This is similar to ASCE/SEI 7-16 Tables 13.5-1 and 13.6-1 that have values that vary the $a_{p}$ and the $R_{p}$ factors. It is assumed that if code development committees were to adopt the proposed nonstructural design equations and approach in this study, then similar tables would be developed to associate specific components or groups of components with the likely and unlikely to be in resonance categories and with the assumed component ductility categories. In this section, two example components are discussed to illustrate some of the considerations and to compare them to ASCE/SEI 7-16.

\subsubsection{Interior Wall and Partition Case Study Example}

ASCE/SEI 7-16 Table 13.5-1 has two interior wall and partition categories: Plain (unreinforced) masonry and all other partition types. As discussed elsewhere, this study recommends prohibiting unreinforced masonry walls and partitions in areas with seismic shaking of significance. As such, the focus here is on the remaining wall and partition types, which in ASCE/SEI 7-16 Table 13.5-1 have $a_{p}=1$ and $R_{p}=2.5$. Thus, there is an implied presumption that dynamic amplification of floor acceleration is minimal, and the partitions have moderate ductility. As noted above, however, per structural dynamic theory, component ductility does not reduce response for components as $T_{\text {comp }}$ approaches zero.

There following issues are considered for partitions:

- Partitions typically span out-of-plane between diaphragms. Thus, their displacements and accelerations are affected by two diaphragms that will have different dynamic response. Out-of-phase behavior between the two diaphragms is likely to reduce partition response.

- The behavior of reinforced concrete masonry unit (CMU) partitions is likely to be different from wood and metal stud partitions with gypboard finishes. CMU partitions are likely to have to have less flexibility and ductility than wood and metal stud partitions, and CMU partitions will weigh more. Out-of-plane 
cracking of gypboard may mean that wood and metal stud walls and partitions have higher damping which could reduce response.

- For wood and metal stud walls and partitions, height may impact dynamic amplification. As the walls and partitions get taller, the out-of-plane period lengthens, and there is more likelihood that the component could become more in resonance with the building.

Given these issues, it would be reasonable to establish the following three wall and partition categories:

- Reinforced masonry: Reinforced masonry partitions are assumed to have short periods and a low $T_{\text {comp }} / T_{\text {abldg }}$ ratio, and thus they are unlikely to be in resonance with the building. Reinforced masonry partitions are assumed to have a moderate degree of ductility.

- Short, all other walls and partitions: These are assumed to be wood and metal stud partitions of 9 feet high or less. A cutoff height would best determined by investigating periods of partitions of different heights and with different finishes, including composite behavior effects. These walls and partitions are assumed to have relatively short periods and a comparatively low $T_{\text {comp }} / T_{\text {abldg }}$ ratio, and thus are unlikely to be in resonance with the building.

- Tall, all other walls and partitions: These are assumed to be wood and metal stud partitions of over 9 feet in height. They are assumed to have longer periods and a $T_{\text {comp }} / T_{\text {abldg }}$ ratio moving toward a central value, and thus they have the potential to be in resonance with the building. They also are assumed to have desirable damping and a high level of ductility.

A numeric comparison on the second and third types is done here with the 6-story steel SMRF and a partition at midheight of the building $(z / h=0.5)$ to illustrate the results of the above assumptions. Per Table 4-9 above, with $a_{p}=1$ and $R_{p}=2.5$, $F_{p} / W_{p}$ is $0.32 \mathrm{~g}$, which is just above the $0.30 \mathrm{~g}$ minimum. For a short, metal stud partition, per Table 4-12 above, with the assumption of "unlikely to be in resonance," $F_{p} / W_{p}$ is $0.30 \mathrm{~g}$, which is governed by the $0.30 \mathrm{~g}$ minimum. For a tall, metal stud partition, with the assumption of "likely to be in resonance" and "high ductility," $F_{p} / W_{p}$ is $0.39 \mathrm{~g}$, which is above the $0.30 \mathrm{~g}$ minimum.

\subsubsection{Floor-Mounted Cabinet Case Study Example}

ASCE/SEI 7-16 Table 13.5-1 has two cabinet categories: (1) permanent floorsupported cabinets more than $6 \mathrm{ft}$ tall; and (2) permanent floor supported library shelving, book stacks, and bookshelves more than $6 \mathrm{ft}$ tall. For both cases, $a_{p}=1$, $R_{p}=2.5$, and $\Omega_{0}=2$. Thus, there is an implied presumption that dynamic amplification of floor acceleration is minimal, and the cabinets have moderate 
ductility. As noted above, however, per structural dynamic theory, component ductility does not reduce response for components as $T_{\text {comp }}$ approaches zero.

The following issues are considered for cabinets:

- Rigidity, response, and earthquake performance can be quite different in the narrower, out-of-plane direction than in the wider, in-plane direction.

- For the in-plane direction, the cabinet is stiffer and generally stronger and less likely to have dynamic amplification of floor motion.

- For the out-of-plane direction, the cabinet is typically more flexible and will place a larger demand on the anchors.

Given these issues, it would be reasonable to establish the following two cabinet categories:

- In-plane direction: These are assumed to have short periods and a low $T_{\text {comp }} / T_{\text {abldg }}$ ratio, and thus they are unlikely to be in resonance with the building. They are assumed to have a moderate degree of ductility.

- Out-of-plane direction: They are assumed to have longer periods and a $T_{\text {comp }} / T_{\text {abldg }}$ ratio moving toward a central value, and thus they have the potential to be in resonance with the building. They also are assumed to have desirable damping and a moderate level of ductility.

A numerical comparison of anchor requirements for both categories is done here with the 4-story steel OCBF and a cabinet at the fourth floor of the building $(z / h=0.75)$ to illustrate the results the above assumptions. It is assumed that the anchors do not have a ductile mechanism and need to be designed at the $\Omega_{0}$ level. Per Table 4-10, with $a_{p}=1, R_{p}=2.5$, and $\Omega_{0}=2, F_{p} / W_{p}$ is $0.80 \mathrm{~g}$. For the in-plane direction, per Table 4-14, with the assumption of "unlikely to be in resonance," $F_{p} / W_{p}$ is $0.98 \mathrm{~g}$. For the out-of-plane direction, with the assumption of "likely to be in resonance," moderate ductility, and $\Omega_{0}=2, F_{p} / W_{p}$ is $2.87 \mathrm{~g}$ from Table 4-14, which is substantially higher than the value from ASCE/SEI 7-16. This very large difference is driven primarily by the ASCE/SEI 7-16 assumption of an essentially rigid component that can still somehow benefit from component ductility. The difference is much less in the 8-story steel SMRF case with $F_{p} / W_{p}=1.46 \mathrm{~g}$ because it benefits from building ductility.

\subsection{Conclusions and Recommendations}

The proposed nonstructural seismic design equations should be implemented in the next edition of the NEHRP Recommended Seismic Provisions for Buildings and Other Structures and ASCE/SEI 7, Minimum Design Loads and Associated Criteria for Buildings and Other Structures, with the following considerations: 
- The guidance in this report should be leveraged to categorize nonstructural design components into those likely to be in resonance with the building dynamic properties and those not likely to be in resonance and then to assign components to low, moderate, and high component ductility categories.

- A code proposal and associated commentary should be developed for balloting by the Provisions Update Committee to implement the proposed nonstructural seismic design equations into the next edition of the NEHRP Provisions.

- Following adoption into the NEHRP Provisions, the proposed nonstructural seismic design equations should be incorporated into the next edition of ASCE/SEI 7.

In addition, areas for further development are identified in the following recommendations.

1. Additional research is recommended to better understand the response of nonstructural components in earthquakes and to refine nonstructural seismic design equations in the future.

a. A database of information on component damping should be developed to collect and organize new and existing testing results, and to determine if refinements in the assumed levels of component damping underlying the proposed nonstructural design equation are warranted. The database should consider the full range of displacement and force amplitudes that nonstructural components can experience during earthquake shaking. Damping data collected from small amplitude vibration tests (e.g., impact hammer tests) are typically only adequate to characterize inherent component damping, but would not provide information on component hysteretic damping.

b. The database should be supplemented with information on actual component ductility from new testing and synthesis of existing testing, preferably distinguishing sources in ductility, such as the component, the connection of the component to anchors, and the anchors themselves.

c. The database should be supplemented with information on component periods of vibration.

d. Testing results should be studied to better quantify the component reserve strength margin.

e. The archetype analysis studies of this project were done for a selected set of common seismic force-resisting systems. Additional studies should be conducted, particularly for seismic force-resisting systems with low response modification coefficients, to confirm the adequacy of the proposed nonstructural design equation for those systems. 
f. The archetype analysis studies should be augmented with additional analyses using amplitude-scaled response histories.

2. Building strong motion instrumentation protocols of the California Strong Motion Instrumentation Program (CSMIP) and the USGS should be revised to better provide information needed to understand nonstructural component response as follows.

a. Protocols should be expanded to record horizontal response to include selected nonstructural components in addition to structural elements so that in-situ measurements of peak component amplification, peak floor acceleration, and peak ground acceleration can be compared, and component damping levels can be better understood.

b. As discussed in Fathali and Lizundia (2011), there are a fair number of vertical sensors that have been installed to date in buildings. "However, they have often been placed in atypical locations such as at the tip of a cantilever or mid span of a long truss, without any associated reference sensor adjacent to a column. Thus, there is no way to effectively separate overall vertical response at a floor from a local effect. More broadly, there are a very small number of buildings with vertical sensors in a consistent stack adjacent to columns or walls up the building. In addition, usually only one elevated floor is chosen for vertical sensors. In order to effectively study vertical amplification of motion up the building, CSMIP [and USGS] should instrument a select number of buildings with a stack of sensors adjacent to a stiff column to try to diminish floor amplification effects. The stack should include at a minimum the lowest floor, the roof, and a mid-height sensor. The next step would be to locate a sensor at a point of local interest in the floor such as mid span along a girder building columns or in the middle of a flat slab bay. The difference in response between the local sensor and the sensor adjacent to the column at that floor can allow the local effect to be studied directly." A vertical sensor on a nonstructural component at the midspan or mid-bay location should be included to better understand the relationship between vertical floor response and vertical component response and then assist in developing improved nonstructural design equations for vertical response. 


\section{Chapter 5}

\section{Ductile Design of Nonstructural Supports and Attachments}

\subsection{Introduction}

The analytical studies described in Chapter 4 show that there can be significant amplification of forces when the nonstructural component is in resonance with one of the modes of the structure to which it is attached. Considering the equally significant reduction in force when some level of ductility is provided in the load path between the component and the supporting structure, it is desirable to incorporate such ductility in the design of the nonstructural component and its supports and attachments.

This chapter reviews some key findings of Chapter 4 regarding the response of nonstructural components in Section 5.2, describes the concept of ductile design for nonstructural components in Section 5.3, and presents illustrative examples in Section 5.4 through Section 5.7 exploring considerations for implementing ductile design. Section 5.8 presents conclusions and recommendations.

\subsection{Effect of Resonance on Design}

Figures 5-1 and 5-2 illustrate an elastic component where the peak component acceleration (PCA) is amplified in excess of seven times when compared to peak floor acceleration (PFA). Whether the structural system remains elastic or exhibits nonlinearity, there is significant amplification of the component acceleration with respect to the floor acceleration when the period of the component is in resonance with the period of one of the fundamental modes of vibration of the structure. Because the extent of nonlinearity in the structure reduces the overall amount of the increased acceleration on the component, a parameter to account for this is included in the proposed primary equation in Chapter 4. However, large increases in accelerations due to resonance are still observed when nonlinearity in the structure occurs, which is why the proposed primary equation in Chapter 4 includes separate parameters to account for component ductility and resonance effects. 


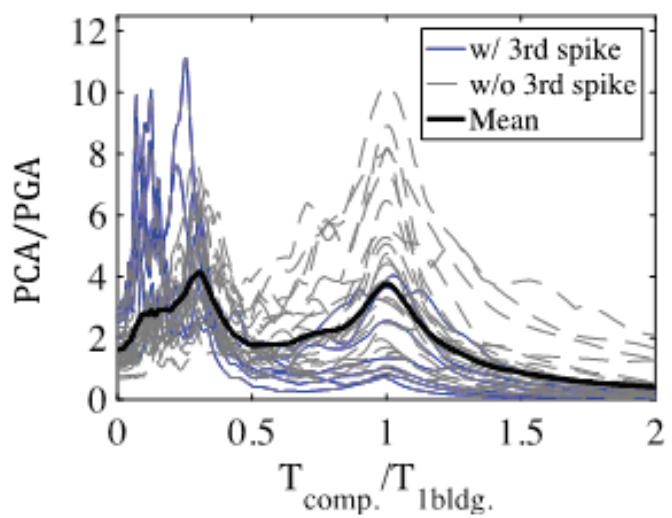

(a)

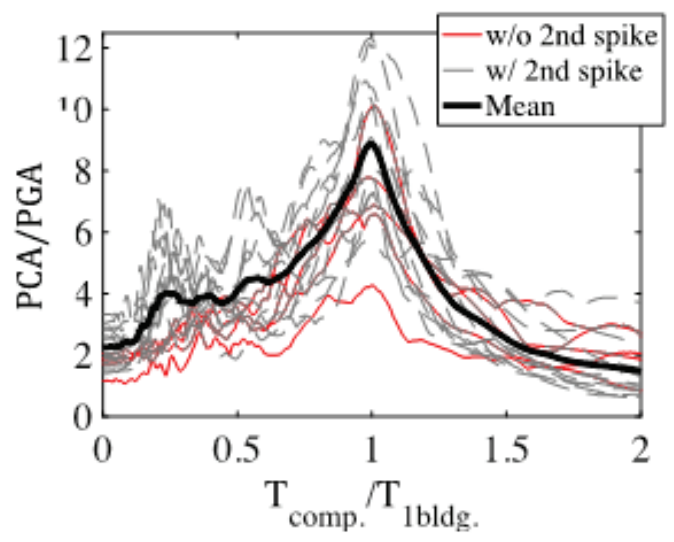

(b)

Figure 5-1 The effect of building stiffness on PCA/PGA for instrumental recordings with a normalized $x$-axis (from Chapter 4). Spikes represent higher building modes of vibration where there is increased response. An elastic component is assumed with $\beta_{\text {comp }}=5 \%$. The data set includes 49 recordings with PGA > $0.15 \mathrm{~g}$.

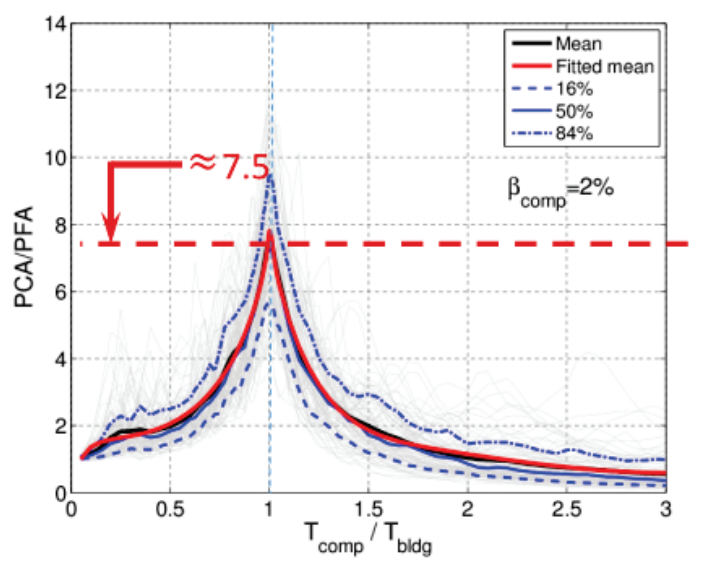

(a)

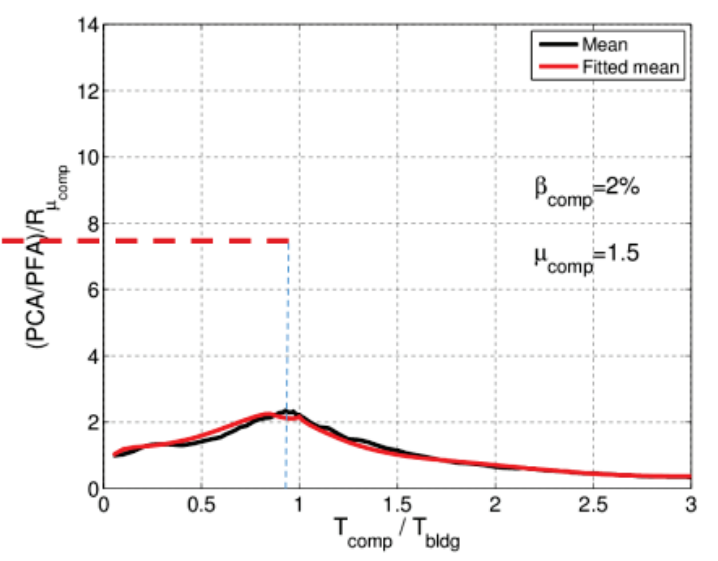

(b)

Figure 5-2 Comparison of PCA/PFA with (a) an elastic component $\mu_{\text {comp }}=1$; and (b) a nonlinear component with $\mu_{\text {comp }}=1.5 .2 \%$ component damping is assumed.

Figures 5-2 presents the response of components that were allowed to exhibit some limited nonlinearity. The results show that when a modest amount of component ductility was permitted, such as $\mu_{\text {comp }}=1.5$, the increase in acceleration to the component reduced significantly. In addition to a reduction in absolute acceleration, there was also a significant reduction in the coefficient of variation of the results.

The significant reductions in accelerations observed affirm the current design provisions that reduce the elastic design forces based on an assumed level of ductility. ASCE/SEI 7-16 presents tables that provide a component response modification factor, $R_{p}$, based on an assumed amount of ductility in the component or the component's attachments and supports. These factors are similar to the $R$ factors used for building design in that they reduce the design force on the component to a level that, presumably, would proportion the attachments and supports with sufficient 
strength to limit damage to the component and prevent it from falling or toppling. Unlike structural design, however, there are few explicit rules for designing the component, its bracing, and anchorage such one element in the load path behaves in a ductile manner.

\subsection{Ductile Design Philosophy}

The concept of ductile design for building structures has been commonplace for the past thirty years and has undergone several evolutions. Currently, new structures in regions of high seismicity are required to use "special" systems. Special systems have strict design provisions that identify certain elements in the system as ductile elements or fuses. There are rules for the design and detailing of the ductile fuses. Additionally, there are rules for proportioning the remaining components of the structural systems to allow the fuse element to yield while all other elements in the system remain elastic. For example, in a steel special concentric braced frame (SCBF) seismic force-resisting system, the brace is the ductile fuse and is intended to yield in tension and buckle in compression. The connections of the braces to the beams and columns are to remain elastic, as are the beams and columns to which the braces attach. Further, the attachment of the frame to the foundation should also remain elastic. This is accomplished by following rules set forth in AISC 341, Seismic Provisions for Structural Steel Buildings, (AISC, 2016). AISC 341 requires that the beams, columns, brace connections, and anchorage to the foundation all be designed for the expected tension capacity of the brace, including some allowance for strain hardening. AISC 341 also requires the braces to meet certain requirements related to section compactness and unbraced length.

Conversely, nonstructural components are designed with a uniform force derived from a single equation. The equation has a factor that accounts for some nonlinear response of the component, $R_{p}$, but there are no provisions that require the designer to explicitly identify what the ductile fuse is and, more importantly, what elements should not yield. The only requirements currently in Chapter 13 of ASCE/SEI 7-16 that attempt to prevent brittle failure are related to the design of anchors to concrete or masonry. The anchors must be designed such that they yield in a ductile manner, and the component yields prior to the anchorage failing. If that cannot be accomplished, the anchors must be designed for forces amplified by an overstrength factor, $\Omega_{0}$. There are also requirements that power-actuated fasteners not be used to resist sustained tension forces and that friction clips not be used to resist permanent loads and seismic forces (with the exception of C-type pipe hangers meeting requirements in NFPA 13 (NFPA, 2016)). Similar requirements attempting to limit brittle anchor failure are in the National Building Code of Canada (NRC, 2015). The requirements to limit brittle anchor failure, while very important, are significantly 
less numerous than the requirements for designing special structural systems for ductile behavior.

The studies discussed in Chapter 4 show that component acceleration can significantly exceed floor acceleration when the component is in resonance with one of the modes of vibration of the structure. Ductility in the component, bracing, or anchorage reduces the acceleration on the rest of the component. Furthermore, providing a ductile fuse can better protect the component against seismic forces in excess of those considered in the design of the component and its anchorage and bracing.

To illustrate the concept of ductile design for a nonstructural component and its attachments and supports, consider the nonstructural component anchored to the floor of a building by four angles in Figure 5-3. The angles are screwed into the side of the component and attached to the floor slab with anchors. In an earthquake, the component will be subjected to an acceleration, which if in or close to resonance with key structural modes of vibration would be amplified to be greater than the floor acceleration. The component, the screws between the component to the angles, the angles, the anchorage of the angle to the floor slab, the floor slab, and its supporting structural framing all need to be designed for the inertial forces from the component.

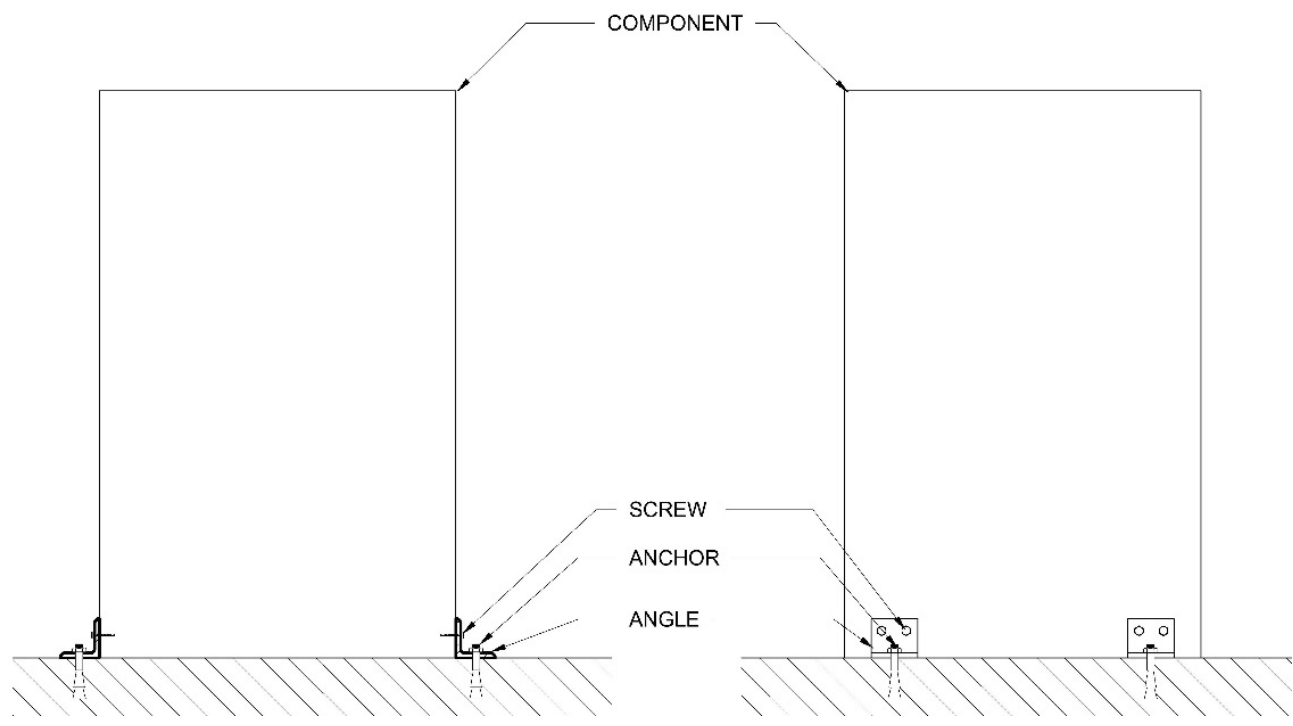

Figure 5-3 Component with angle anchorage to floor.

Assuming that the component, floor slab, and structural framing are stronger than the screws, angle, and anchors, one of the latter three components will yield or fail first. If the anchor to concrete were governed by breakout, which is often the case when components are attached to structural slabs, that failure would be brittle, and the component would shift, rock, or topple - an unacceptable response. Therefore, the anchor would need to be proportioned for the maximum force that could be experienced by the component. Furthermore, the anchorage would only be strong 
enough to resist the forces from the design seismic event. If a larger event occurred, then the potential for failure would increase. If, on the other hand, the angles were proportioned to be weaker than the anchor or the screws connecting to the component, forces in excess of the angle leg's bending capacity would simply deform the angle, as shown in Figure 5-4. Although this deformation may lead to minor movement in the component, a sufficiently robust angle (something that would require minimum design rules to define sufficiently robust) would allow the component to essentially remain in its position. If forces larger than those anticipated with the Design Earthquake shaking were to occur, the angle might deform more than anticipated, but likely still retain some level of integrity and prevent the anchors from failing.
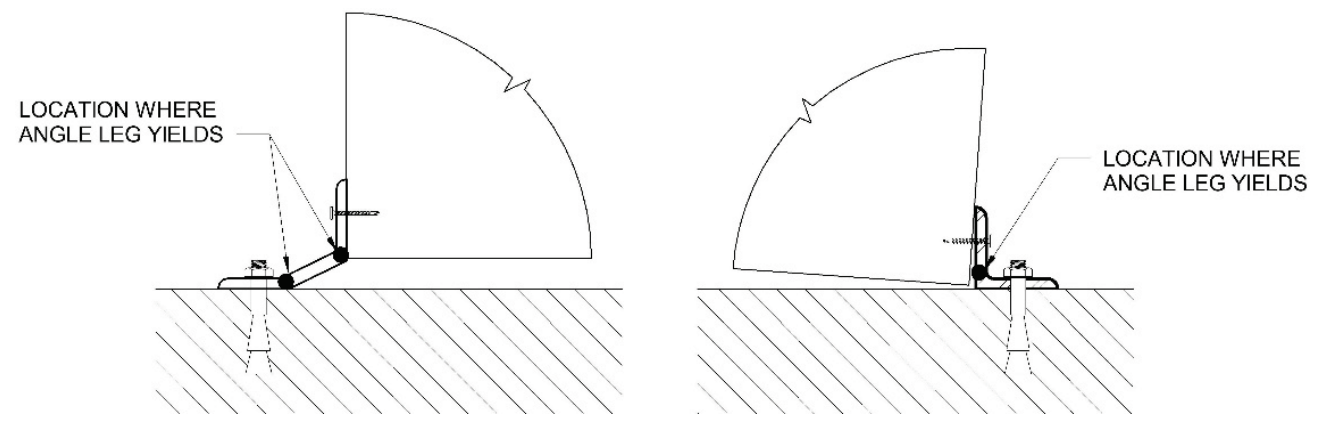

Figure 5-4 Anchorage deformations due to angle yielding.

Given the uncertainties in predicting seismic shaking intensity and how accelerations are amplified through the structure and imparted on the components, it is desirable to have the angle yield rather than trying to predict the correct force to design the anchor and the screw attachment of the component. Providing some form of ductility in the load path between the component and the structure supporting it would be the ideal design requirement.

The remainder of this chapter is devoted to examining considerations for implementing ductile design, whether ductile design for nonstructural components could be standardized, and what changes would need to be made to nonstructural design provisions to allow for explicit ductile design. Several examples investigate how the design would change if explicit ductile design were required.

\subsection{Elevated Vessel Design Example}

This example illustrates the design of the support and anchorage of an elevated vessel. The vessel weighs 5,500 lbs and is supported by the second level of a threelevel structure $(z / h=0.6)$, located in Seismic Design Category D, where $S_{D S}=1.0$. Per ASCE/SEI 7-16, the vessel is treated as a rigid component with $a_{p}=1.0$ and has

$R_{p}=2.5$. The building is an ordinary reinforced concrete shear wall (with a building frame system) with $R=5$ with a fundamental period of 0.4 seconds calculated using ASCE/SEI 7-16 Equation 12.8-7. The $a_{p}$ of 1.0 implies the component is rigid and 
not in resonance with any of the structure's modes. The $R_{p}$ of 2.5 implies some limited ductility in the component or, more likely, the supporting structure. It should be noted that the studies discussed in Chapter 4 show that when there is no resonance, there is no reduction in acceleration between the floor acceleration and the component acceleration due to ductility in the load path between the component and the floor.

Figure 5-5 shows a code-compliant design of the supporting structure. In this design, all elements are designed for the resultant $F_{p}$ force with the anchorage of the platform to the supporting structural slab designed for forces amplified by $\Omega_{0}=2$ ( $2.5 \mathrm{in}$ ASCE/SEI 7-10). In this design, no consideration is given to what should be the ductile fuse or to explicitly design connections of the bracing and the supporting frame columns for any higher forces than the braces. It is possible that the weld between the braces and the columns may fail before the brace buckles or yields in tension, leading to collapse of the supporting frame. While ASCE/SEI 7 makes an assumption of ductile response, the design requirements are not sufficient to provide reliable assurance that such response will occur.

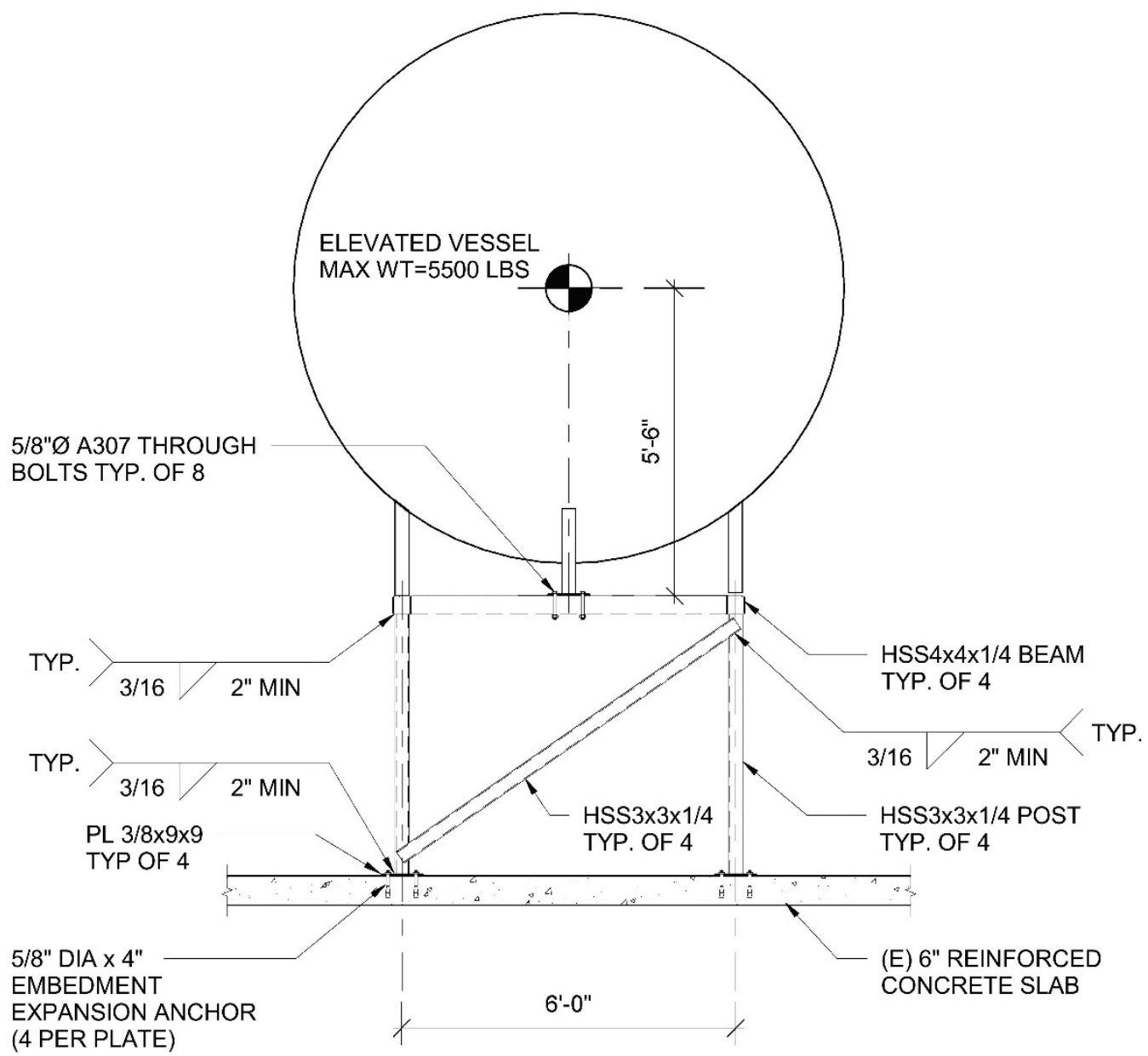

Figure 5-5 Code-compliant design of elevated vessel support structure and anchorage. 
Another potential issue with the current design is the assumption that the vessel is not in resonance with the structure. ASCE/SEI 7-16 explicitly states that an elevated vessel should have an $a_{p}=1.0$ because it is not supported by a skirt or within the scope of ASCE/SEI 7-16 Chapter 15. If the vessel were attached directly to the structural slab, an assumption of a rigid component not in resonance would be reasonable. However, with the vessel on a supporting structure, the system may be more flexible. In this case, the fundamental period of the vessel and supporting structure can be approximated as 0.9 seconds based on the supporting braced frame's lateral stiffness and the vessel's mass. A period that large could likely be in resonance with that of a three-story structure, especially if the three-story structure is a steel or concrete moment frame. Therefore, the forces the vessel and supporting structure might experience would be underestimated by the nonstructural force, $F_{p}$, equation currently provided in ASCE/SEI 7-16. It is possible that the designer may recognize the flexibility of the supporting structure, and to address this, choose to design for an $a_{p}=2.5$ instead, but this would be going above and beyond the minimum required by the design standard.

If the supporting structure were designed using the proposed nonstructural force equation from Chapter 4, the most logical ductile fuse would be the braces. Using the proposed nonstructural force equation, the design force would vary depending on the amount of nonlinearity permitted in the brace. The proposed forces, $F_{p}$, are compared against the current design forces, $F_{p(A S C E / S E I ~ 7-16)}$, in Tables 5-1 and 5-2 for $S_{D S}$ equal to 1.0. Table 5-1 shows the design force for the current ASCE/SEI 7-16 equation and the proposed equation using component ductility values, of 1.25 (low ductility), 1.5 (moderate ductility), and 2.0 (high ductility). For context, the elastic case with a component ductility of 1.0 is included. The rigid condition is also included for reference, but it is assumed that a designer using the proposed equation would recognize the potential for flexibility in the supporting frame and assume that resonance might be possible. Table 5-2 presents the same information, with the exception that the ASCE/SEI 7-16 forces were derived with an $a_{p}=2.5$.

\section{Table 5-1 Comparison of Design Force Values for Elevated} Vessel, $a_{p}=1.0$

\begin{tabular}{|c|c|c|}
\hline Condition & $F_{p}$ & $\left.F_{p} / F_{p(A S C E / S E I} 7-16\right)$ \\
\hline ASCE/SEI 7-16 $\left(a_{p}=1.0 / R_{p}=2.5\right)$ & $0.35 W_{p}$ & -- \\
\hline$\mu_{c o m p}=1.0\left(R_{p, \text { eff }}=1.0\right)$ & $2.1 W_{p}$ & 6.0 \\
\hline$\mu_{\text {comp }}=1.25\left(R_{p, \text { eff }}=1.4\right)$ & $1.5 W_{p}$ & 4.3 \\
\hline$\mu_{\text {comp }}=1.5\left(R_{p, \text { eff }}=1.8\right)$ & $1.2 W_{p}$ & 3.4 \\
\hline$\mu_{\text {comp }}=2.0\left(R_{p, \text { eff }}=2.8\right)$ & $0.75 W_{p}$ & 2.1 \\
\hline Resonance less likely & $0.52 W_{p}$ & 1.5 \\
\hline
\end{tabular}


Table 5-2 Comparison of Design Force Values for Elevated Vessel, $a_{p}=2.5$

\begin{tabular}{|c|c|c|}
\hline Condition & $F_{p}$ & $F_{p} / F_{p(A S C E / S E I 7-16)}$ \\
\hline ASCE/SEI 7-16 $a_{p}=2.5\left(R_{p}=2.5\right)$ & $0.9 W_{p}$ & -- \\
\hline$\mu_{\text {comp }}=1.0\left(R_{p, \text { eff }}=1.0\right)$ & $2.1 W_{p}$ & 2.4 \\
\hline$\mu_{\text {comp }}=1.25\left(R_{p, e f f}=1.4\right)$ & $1.5 W_{p}$ & 1.6 \\
\hline$\mu_{\text {comp }}=1.5\left(R_{p, \text { eff }}=1.8\right)$ & $1.2 W_{p}$ & 1.3 \\
\hline$\mu_{\text {comp }}=2.0\left(R_{p, \text { eff }}=2.8\right)$ & $0.75 W_{p}$ & 0.8 \\
\hline
\end{tabular}

As noted above, the building is an ordinary reinforced concrete shear wall building with a period of 0.4 seconds, calculated using the approximate period equation in ASCE/SEI 7-16, which can underestimate the building period. Therefore, the resonance likely condition would be the conservative assumption. In computing the forces from the proposed equation, it was assumed that the equipment might be in resonance. Although the proposed frame has a period of 0.9 seconds, which is more than twice the approximated period, the building could be more flexible than the approximated period and the final frame design could be stiffer. Changing the structural system from an ordinary shear wall to a steel special moment-resisting frame or a special reinforced concrete moment-resisting frame with more ductile $R=8$ values would result in a $20 \%$ reduction in design force and increase the likelihood of resonance. Regardless of the structural system and component ductility, the forces from the proposed equation would still be greater than currently required per ASCE/SEI 7-16.

The only instance where the design forces from the proposed equation could be less than the design forces calculated using the current equation in ASCE/SEI 7-16 would be if an $a_{p}=2.5$ and high ductility anchorage design are assumed. Even then, the reduction in design forces is only around $20 \%$. Part of this is due to the high $R_{p}$ value assumed in ASCE/SEI 7-16. Computing an effective $R_{p}$ value as the ratio of the force from the elastic case $\left(\mu_{c o m p}=1.0\right)$ divided by the force from the different ductility assumptions shows that $R_{p, \text { eff }}$ is only greater than 2.5 when high ductility is provided. This result implies that the ASCE/SEI 7-16 equation assumes high ductility, while providing only few requirements to actually achieve such ductility.

Choosing the braces as the ductile fuse would result in similar sized brace elements, provided moderate or high ductility were assumed. If that were the case, the entire design of the frame would need to ensure moderate to high ductility and thus become more complicated. The brace connections and the columns would need to develop the capacity of the braces. That means the current design of welding the angle directly to the columns would not be sufficient. Gusset plates would need to be incorporated into the design, as shown in Figure 5-6, and the connection of the brace to the gusset plates would require significantly more welding. 


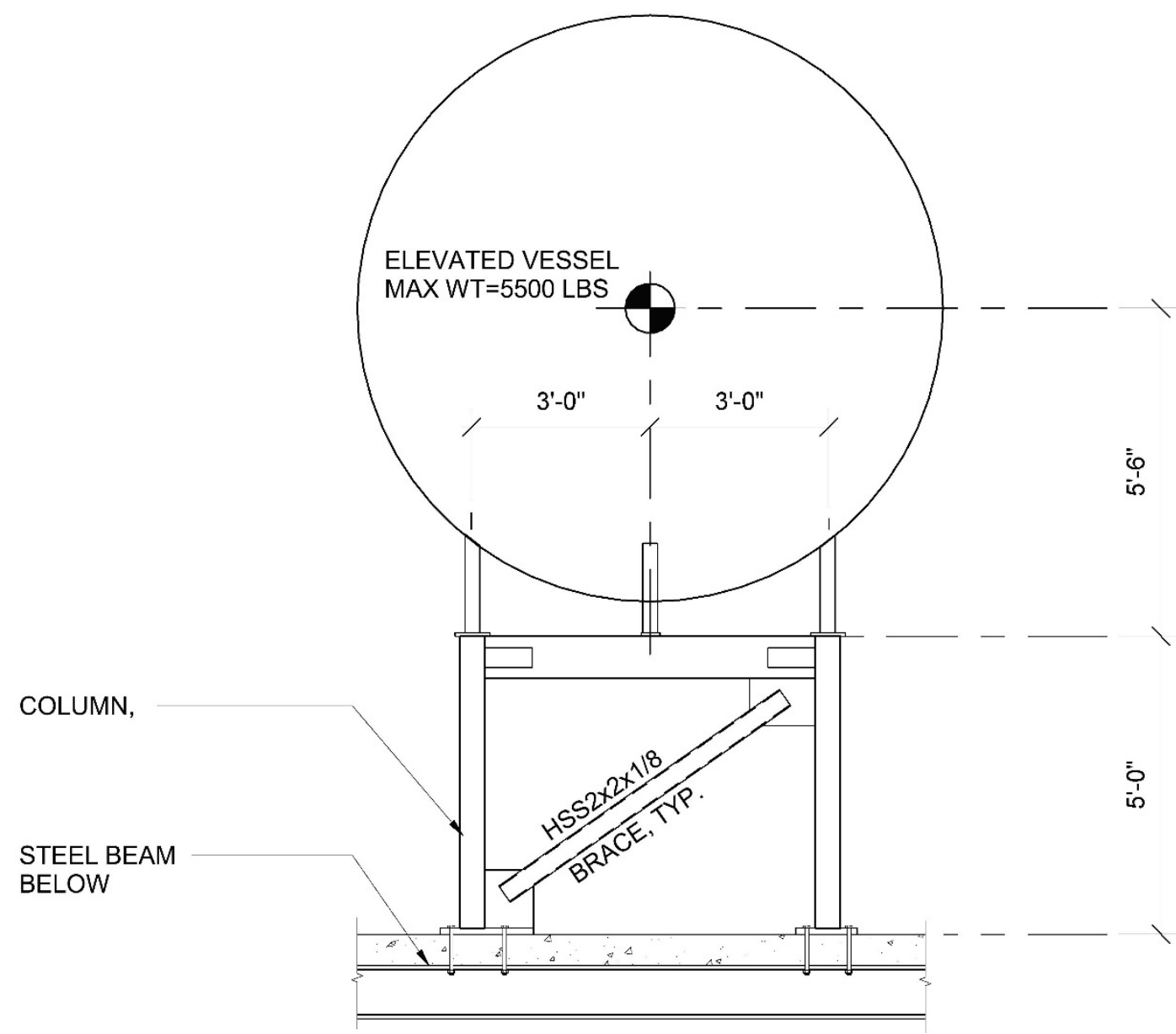

Figure 5-6 Ductile design of elevated vessel support structure and anchorage.

In addition to an increase in complexity of the frame due to the need for gusset plates, the anchorage to the supporting floor and the forces the floor must be designed to withstand must increase significantly. In the current code design, the anchors would need to be designed for $\Omega_{0}=2.0$ times the computed force and the floor framing for the overturning from the $F_{p}$ equation. Those forces, including the $0.2 S_{D S} W_{p}$ vertical earthquake force, are calculated as follows:

$$
\begin{gathered}
F_{p}=\frac{0.4 \times 1.0 \times 1.0 \times 5,500 \mathrm{lbs}}{2.5 / 1.0}(1+2 \times 0.6)=1,940 \mathrm{lbs} \\
T=\frac{1}{2 \text { posts }+6^{\prime}}\left[\left(1,940 \mathrm{lbs}\left(\Omega_{0}=2\right) \times 10.5\right)-(0.9+0.2 \times 1.0) \times 5,500 \mathrm{lbs}\left(\frac{6^{\prime}}{2}\right)\right] \\
T=2,430 \mathrm{lbs}
\end{gathered}
$$

In the ductile design case, the anchorage forces would need to develop the tension capacity of the HSS $2 \times 2 \times 1 / 8$ brace, which would be 47 kips when strain hardening and material overstrength $\left(1.1 R_{y}\right)$ per AISC 341 were included. The anchorage force to develop that brace tension capacity would be $30 \mathrm{kips}$, which is an increase of 13 
times the current design force. Even if an $a_{p}=2.5$ had been used, the anchorage forces to develop the brace forces would still increase by 5 times the current design force. This would likely require through bolting of the vessel to the floor and more significant supplemental floor framing.

Had the design been carried out assuming no ductility and simply proportioning all frame components for the elastic force from the proposed equation including vertical earthquake forces, the anchorage force would be:

$$
\begin{gathered}
F_{p}=2.1 \times 5,500 \mathrm{lbs}=11,550 \mathrm{lbs} \\
T=\frac{1}{2 \text { posts } \times 6^{\prime}}\left[\left(11,550 \mathrm{lbs} \times 10.5^{\prime}\right)-(0.9-0.2 \times 1.0) \times 5,500 \mathrm{lbs}\left(\frac{6^{\prime}}{2}\right)\right]=9,140 \mathrm{lbs}
\end{gathered}
$$

The anchorage force required for an assumed elastic component and supporting structure are less than half of those required for ductile design of the supporting structure, but three times higher than the current design forces with overstrength included. The design forces for the other frame members would be increased by approximately three times, leading to larger framing members, making it more likely for the anchorage to fail before the braces buckle or yield. It may be possible to design the base plate to yield instead of the braces; however, the size of the base plate would need to increase to provide sufficient distance between the bolts and the column post to allow the baseplate to yield. Prying of the base plate would likely still lead to increased demands on the anchors, but likely considerably less than those forces required for the brace to remain elastic.

There are other options for providing ductility, but each has its own potential issues. The first would be to allow the beam supporting the vessel leg to yield in flexure as the vessel attempts to rock. Another would be to allow the floor framing supporting the vessel and platform to yield while the platform, vessel, and all other components remain elastic. With either of these two options, the designer would need to think through the load path and proportion everything else based on the maximum yield force of the beams. Further, rules would need to be developed for how much inelastic deformation should be permitted in the frame beam or floor beam and whether additional ductile design requirements, like compactness of steel beams or additional shear reinforcement in concrete beams, are necessary.

Another alternate design attempt to provide a more balanced ductile design is to design the frame as a moment-resisting frame instead of a braced frame. While this could reduce the anchor demands, it would likely lead to larger frame member sizes and even more complicated beam-to-column connections to provide for yielding in the beams prior to connection failure.

This example illustrates that designing for moderate or high ductility would complicate the frame design and potentially lead to a more robust supporting 
structure. It is not clear whether there are advantages for using ductile design from the standpoint of design economy and simplicity as opposed to an elastic design. Further, the "no ductility" design would be cap the force at $2.0 W_{p}$, about $20 \%$ less than the forces from the proposed equation. Therefore, for this specific example, the incentive to conduct a ductile design lies in the ability to achieve better, more predictable performance and greater reliability to resist forces from earthquakes larger than the Design Earthquake, not because a more efficient design could be achieved.

\subsection{Partition Wall Design Example}

This example illustrates the design of wall studs with casework attached. The casework weighs $100 \mathrm{lbs}$ and is attached to a 4 inch partition wall spanning between floor and the underside of the metal deck above. The casework in located on the third floor of a three-story building in Seismic Design Category D, with $S_{D S}=1.3$. The building is an ordinary steel concentrically braced frame with and $R=3.25$ and a fundamental period calculated per ASCE/SEI Equation 12.8-7 of 0.3 seconds. Per ASCE/SEI 7-16, partition walls are treated as rigid components not in resonance with the building, $a_{p}=1.0$, and have an $R_{p}=2.5$. The $R_{p}$ of 2.5 implies some limited ductility in the partition studs. Since the studs span between the roof and third floor, a conservative assumption would be to take $z / h=0.8$, which is the average $z / h$ for the roof and the third floor, instead of using $z / h$ of the third floor.

Figure 5-7 shows a code-compliant design of the wall studs and attachment of the casework to them. In this example, all elements were designed for the resultant $F_{p}$ force with the anchorage of the top and bottom track amplified by $\Omega_{0}=2$. In this design, no consideration is given to what should be the ductile fuse or to explicitly design connections of the top and bottom tracks or their attachment being able to develop yielding in the studs. It is possible that the attachment of the casework to the studs or the top or bottom track to the slabs might fail before the studs bend or the legs of the top or bottom track bend, which comprise the ductile mechanism.

Similar to the elevated vessel, the potential issue with the current design assumption is that the studs and casework are not in resonance with the building. ASCE/SEI 7-16 explicitly states that partitions should use an $a_{p}=1.0$. Metal studs in flexure can be flexible depending on the amount of composite action engaged with the gypsum wallboard. In this case, the fundamental period of the casework and partition system can be approximated as 0.2 seconds, primarily due to the heavy mass affixed to near the middle of the studs. That period is based on bending of the studs with uniform mass for the wall and lumped mass for the casework, assuming no composite action between the studs and the gypsum wallboard. (If composite action between the gypsum wallboard and the metal studs were taken in to account, it would create a much stiffer system, and the period would be smaller.) A period that flexible could 
likely be in resonance with the actual first or second mode period of a three-story structure. Therefore, the forces the partitions might be subjected to would be underestimated by the current $F_{p}$ equation. A designer using ASCE/SEI 7-16 may recognize the flexibility of the supporting structure and choose to design for an $a_{p}=$ 2.5 , but this would be going above and beyond the minimum required by the design standard.

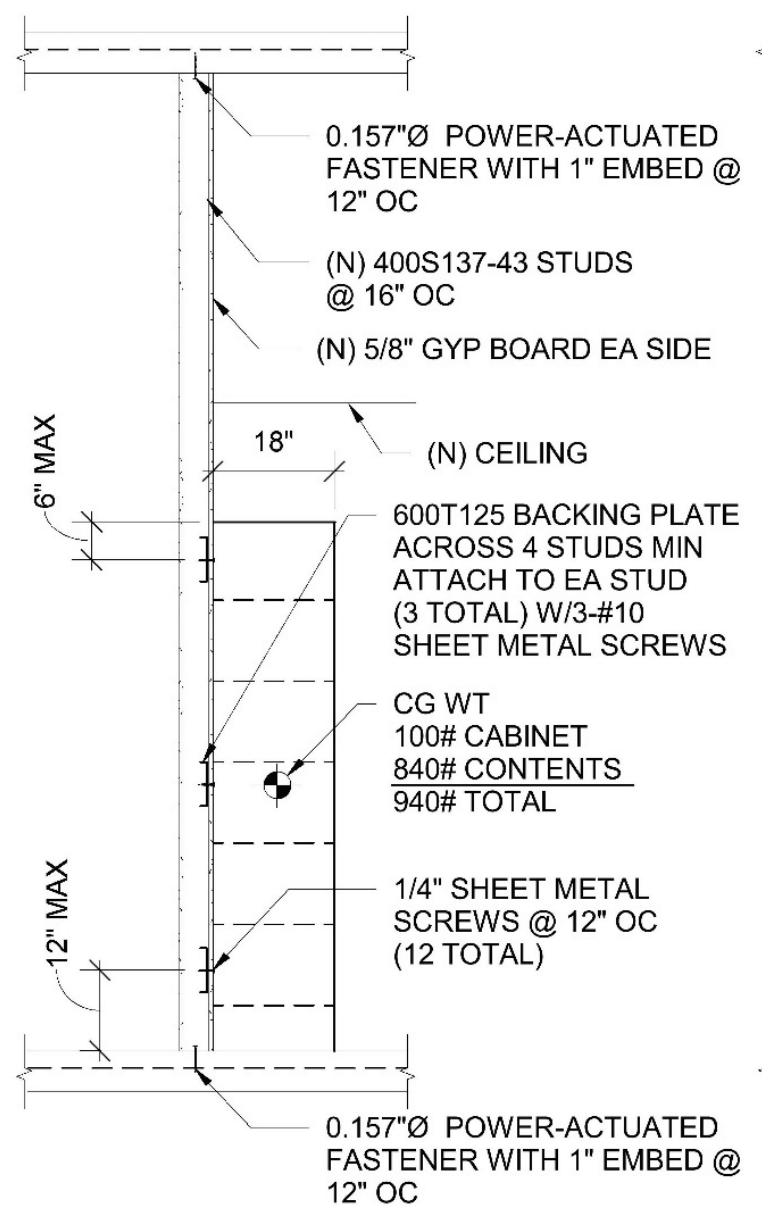

SIDE VIEW

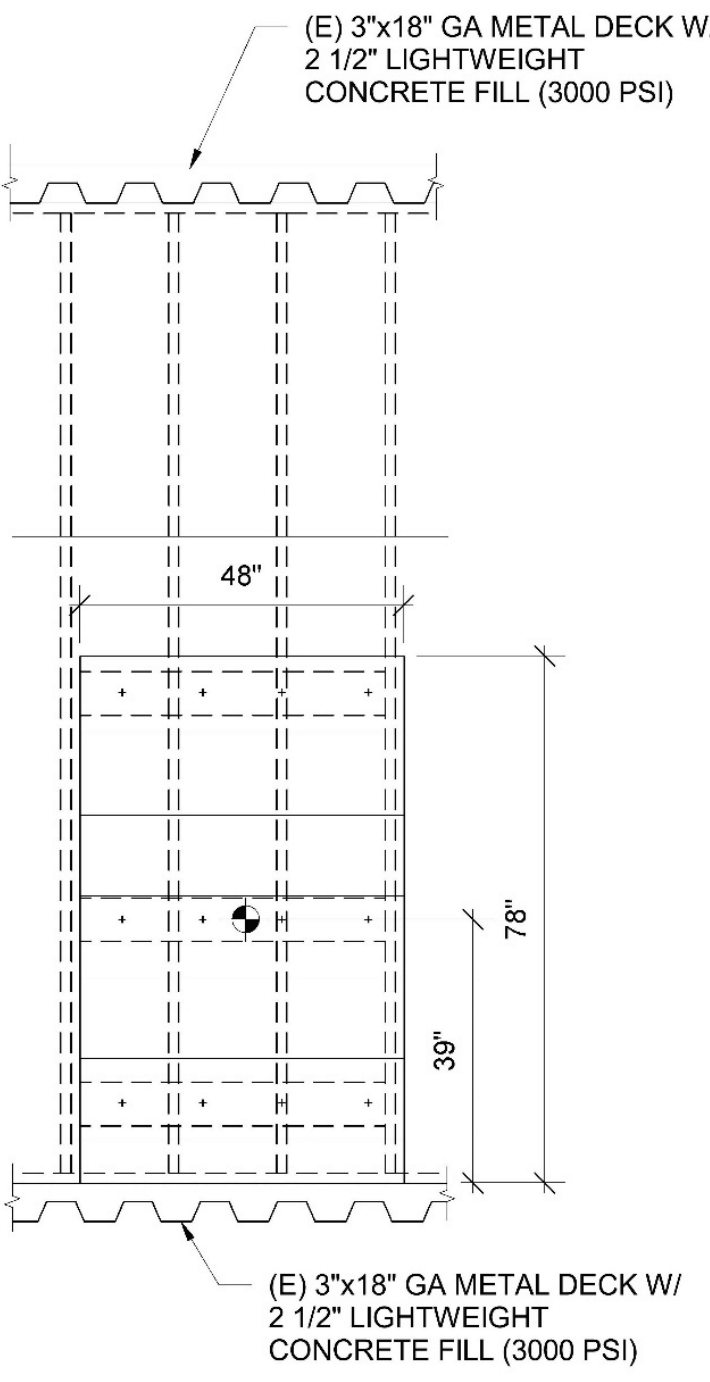

FRONT VIEW

Figure 5-7 Code-compliant partition wall with casework attached.

As noted above, in computing forces with the proposed equation from Chapter 4, the building was assumed to be an ordinary steel braced frame building with a period of 0.3 seconds, calculated using the approximate period equation in ASCE/SEI 7-16, which can underestimate the building period. Therefore, the resonance likely condition would be the conservative assumption. In computing the forces from the proposed equation, it is assumed that the equipment might be in resonance. Although 
the proposed frame has a period of 0.2 seconds, which is less than the approximated period, the building could be stiffer than the approximated period or the second mode could be closer to the period of the wallboard-stud system. Changing the structural system assumption from an ordinary braced frame to a special braced or bucklingrestrained braced frame system could result in 30\% reduction in design force and increase the likelihood of resonance with the first mode. However, there would still be a potential for resonance with the second mode. Regardless of the structural system and component ductility, the forces from the proposed equation would still be greater than currently required per ASCE/SEI 7-16.

If the supporting structure were designed using the proposed nonstructural force equation from Chapter 4, the most logical ductile fuse would be bending of the vertical studs. Bending of the vertical legs of the top and bottom tracks could also be a potential ductile fuse. Using the proposed nonstructural force equation, the design force would vary depending on the amount of nonlinearity permitted in the brace. Tables 5-3 and 5-4 compare the proposed forces, $F_{p}$, against the current design forces, $F_{p(A S C E / S E I ~ 7-16)}$. Table 5-3 shows the design force for the current ASCE/SEI 7-16 equation and the proposed equation using ductility values of $1.25,1.5$, and 2.0. For comparison, the elastic case of a component with a ductility of 1.0 is provided. The rigid condition is also included for reference, but it is assumed that a designer using the proposed equation would recognize the potential for flexibility in the supporting frame and assume resonance might be possible. Table 5-4 presents the same information, with the exception that the ASCE/SEI 7-16 forces were derived with an $a_{p}=2.5$.

Table 5-3 Comparison of Design Force Values for Partition Walls, $a_{p}=1.0$

\begin{tabular}{|c|c|c|}
\hline Condition & $F_{p}$ & $F_{p} / F_{p(A S C E / S E I 7-16)}$ \\
\hline ASCE/SEI 7-16 $\left(a_{p}=1.0 / R_{p}=2.5\right)$ & $0.55 W_{p}$ & -- \\
\hline$\mu_{\text {comp }}=1.0\left(R_{p, \text { eff }}=1.0\right)$ & $3.7 W_{p}$ & 6.7 \\
\hline$\mu_{\text {comp }}=1.25\left(R_{p, \text { eff }}=1.4\right)$ & $2.6 W_{p}$ & 4.7 \\
\hline$\mu_{\text {comp }}=1.5\left(R_{p, \text { eff }}=1.9\right)$ & $2.0 W_{p}$ & 3.7 \\
\hline$\mu_{\text {comp }}=2.0\left(R_{p, \text { eff }}=2.8\right)$ & $1.3 W_{p}$ & 2.4 \\
\hline Resonance less likely & $0.92 W_{p}$ & 1.7 \\
\hline
\end{tabular}

Table 5-4 Comparison of Design Force Values for Partition Walls, $a_{p}=\mathbf{2 . 5}$

\begin{tabular}{llll}
\hline \multicolumn{1}{c}{ Condition } & & $F_{p}$ & $F_{p} / F_{p(A S C E / S E I 7-16)}$ \\
\cline { 1 - 1 }$/ \mathrm{SEI} 7-16 a_{p}=2.5\left(R_{p}=2.5\right)$ & & $1.4 W_{p}$ & -- \\
$\mu_{\text {comp }}=1.0\left(R_{p, \text { eff }}=1.0\right)$ & & $3.7 W_{p}$ & 2.6 \\
$\mu_{\text {comp }}=1.25\left(R_{p, \text { eff }}=1.4\right)$ & & $2.6 W_{p}$ & 1.9 \\
$\mu_{\text {comp }}=1.5\left(R_{p, \text { eff }}=1.9\right)$ & & $2.0 W_{p}$ & 1.4 \\
$\mu_{\text {comp }}=2.0\left(R_{p, \text { eff }}=2.8\right)$ & $1.3 W_{p}$ & 0.9 \\
\hline
\end{tabular}


In computing the forces from the proposed equation, it is assumed that the partition and casework system are likely to be in resonance, which is a conservative assumption. Changing structural system assumption from an ordinary steel braced frame to a steel buckling-restrained braced frame system results in a $30 \%$ reduction in design force. Regardless of the structural system and component ductility, the forces from the proposed equation would still be greater than currently required per ASCE/SEI 7-16. The only instance where the design forces could be less than ASCE/SEI 7-16 would be if an $a_{p}=2.5$ was assumed in the ASCE/SEI 7-16 design, and the new forces assumed a high ductility category. Even then, the reduction in design forces is only around $10 \%$.

Choosing the studs as the ductile fuse and assuming high ductility would result in similar sized studs with a reduction in the maximum contents weight that could be stored on the casework from $840 \mathrm{lbs}$ to $210 \mathrm{lbs}$. If low or no ductility were assumed, the 4-inch nominal wall might not be possible, and 6" studs would be required. To provide high ductility, the attachment of the top and bottom tracks would need to be made with expansion anchors instead of power-actuated fasteners.

The most significant change to the design of the partition and casework system is due to the consideration of resonance more than the need to change the detail to provide ductile detailing. Considering the casework and partition system as being in resonance results in an increase anywhere from 2 to nearly 5 times the design forces from ASCE/SEI 7-16. If one were to use the design forces from ASCE/SEI 7-16 assuming an $a_{p}=2.5$, the design forces would still be higher in all but the high ductility case. It is likely that in all cases the wall would need to increase from a 4inch nominal to a 6-inch nominal wall. In Chapter 4, for out-of-plane loading as shown in this example, a tentative threshold of 9 feet for metal stud partitions is suggested, where partitions taller than 9 feet would be assumed to be likely in resonance and those at 9 feet or less would be assumed to be unlikely in resonance. For the stiffer in-plane loading direction, the component is assumed to be unlikely in resonance.

One significant issue with the high ductility assumption relates to cold-formed steel studs being able to actually achieve a ductility of 2.0. Cold-formed steel studs are susceptible to local buckling when stressed in flexure. This mechanism can limit the ductility of the member considerably. ASCE/SEI 41-17, Seismic Evaluation and Retrofit of Existing Buildings, (ASCE, 2017b) includes tables to provide a backbone curve for cold-formed steel light-frame components. Using the 4" stud specified in this example, the curve reaches the point of strength degradation at a ductility of approximately 1.5 and the point where it cannot support any load at a ductility of approximately 2.0. Therefore, assuming anything greater than a ductility of 1.5 may not be appropriate. These values may be conservative, as they are for beams in coldformed steel moment frames, which are intended to support gravity load in addition 
to seismic forces, so it is possible that studs could sustain greater ductility when only loaded laterally. This points out the need for research to determine the maximum acceptable levels of ductility for various nonstructural components, their supports, and attachments.

Accordingly, performing a ductile design of the casework partition system would require an increase in the studs from 4" to 6" nominal to accommodate a similar casework capacity. The attachment of the partition top and bottom tracks would need to be changed from power actuated fasteners to expansion anchors and with spacing reduced from 12" to 4". If the designer were to elect to use elastic design instead of moderate ductility design, design forces would be increased by a factor of 1.8 , if no cap on forces were applied. If a cap on forces is applied as proposed in the previous chapter, or $2.0 S_{D S} I W_{p}=2.3 W_{p}$, the design forces would only increase by a factor of 1.4. Larger studs would still be required, but the anchorage of the top track might be reduced.

In this example, the changes to design are driven more by the consideration of resonance and the likelihood that there is no force reduction that an $R_{p}$ factor would imply when not in resonance, than because of the need to progressively oversize all the other components in the load path. This example also illustrates that there is a need to incorporate substantial amount of discussion in seismic standards devoted to requirements describing what can and cannot be the ductile portion of the load path. Additionally, research is needed to identify the maximum permissible ductility for a wall stud or the bending of the top and bottom track flanges and whether there would need to be specific limits on the thickness to length of the flanges.

\subsection{Mechanical Unit Design Example}

This example illustrates the design of anchorage for a fixed mechanical unit both internally isolated and with external vibration isolators. The unit weighs $2,700 \mathrm{lbs}$, and is attached to a housekeeping pad atop a concrete filled metal deck. The unit is located on the roof of a building. Per ASCE/SEI 7-16, vibration-isolated mechanical equipment is treated as a flexible component, potentially in resonance with the building, with $a_{p}=2.5$ and $R_{p}=2.0$. The $R_{p}$ of 2.0 implies some limited ductility in the anchorage, the isolators, or the component housing.

Figure 5-8 presents a plan of the unit. Figure 5-9 presents a code-compliant anchorage design if the component is internally isolated. Figure 5-10 presents a code-compliant anchorage design if the unit is on external vibration isolators. In this example, all elements were designed for the resultant $F_{p}$ force with the anchorage amplified by $\Omega_{0}=2$. No consideration was given to the selection of the ductile fuse. 


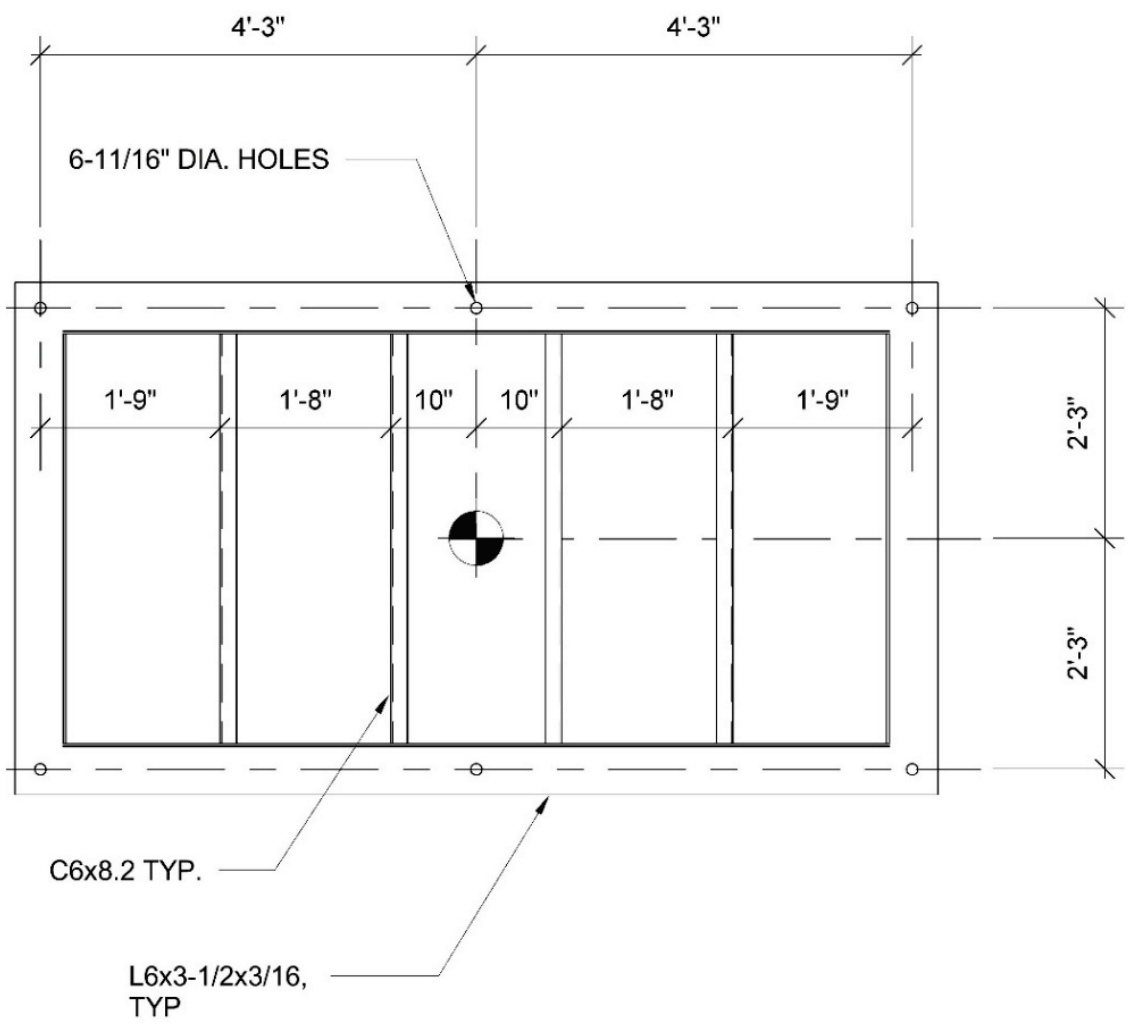

Figure 5-8 Plan view of mechanical unit.

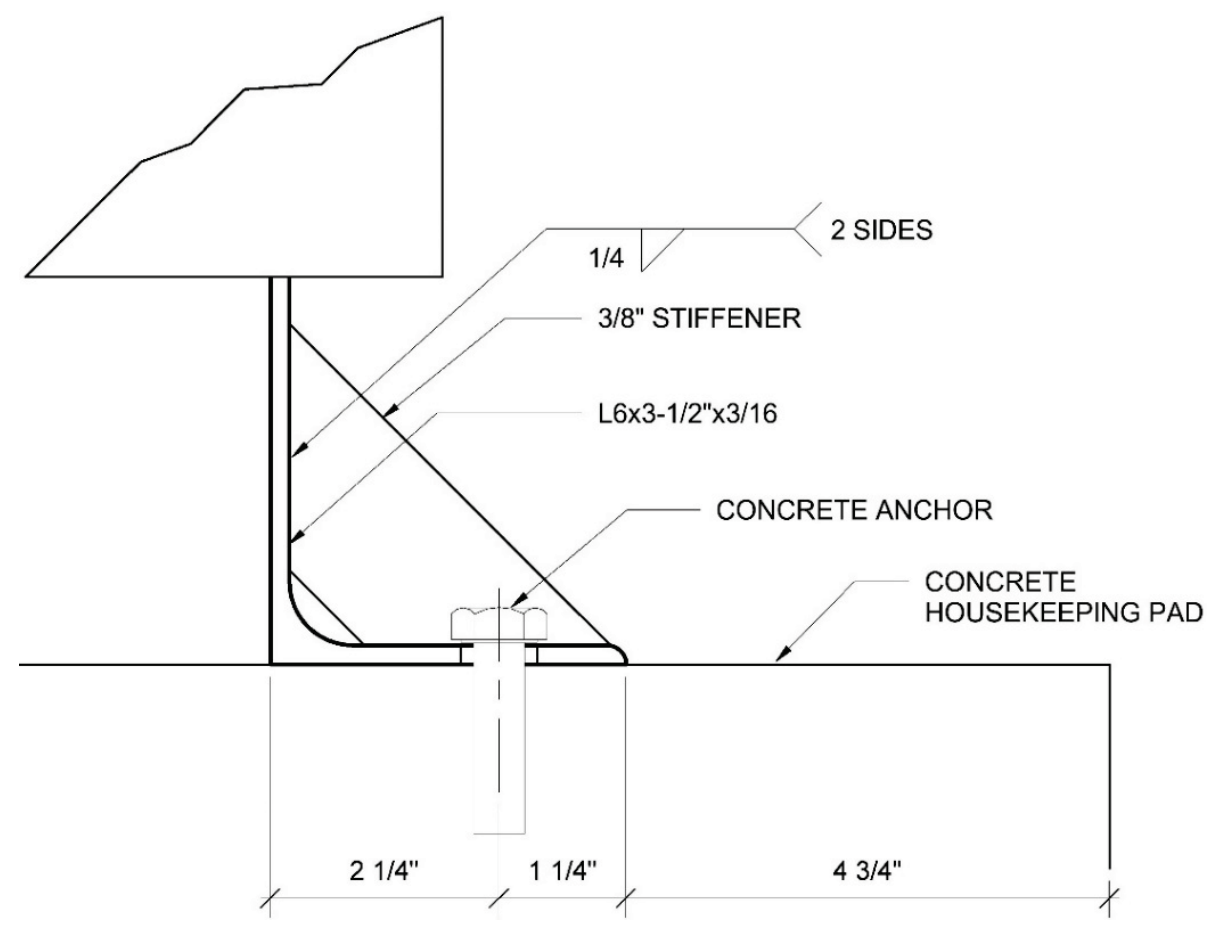

Figure 5-9 Code-compliant design of internally-isolated mechanical unit anchorage. 


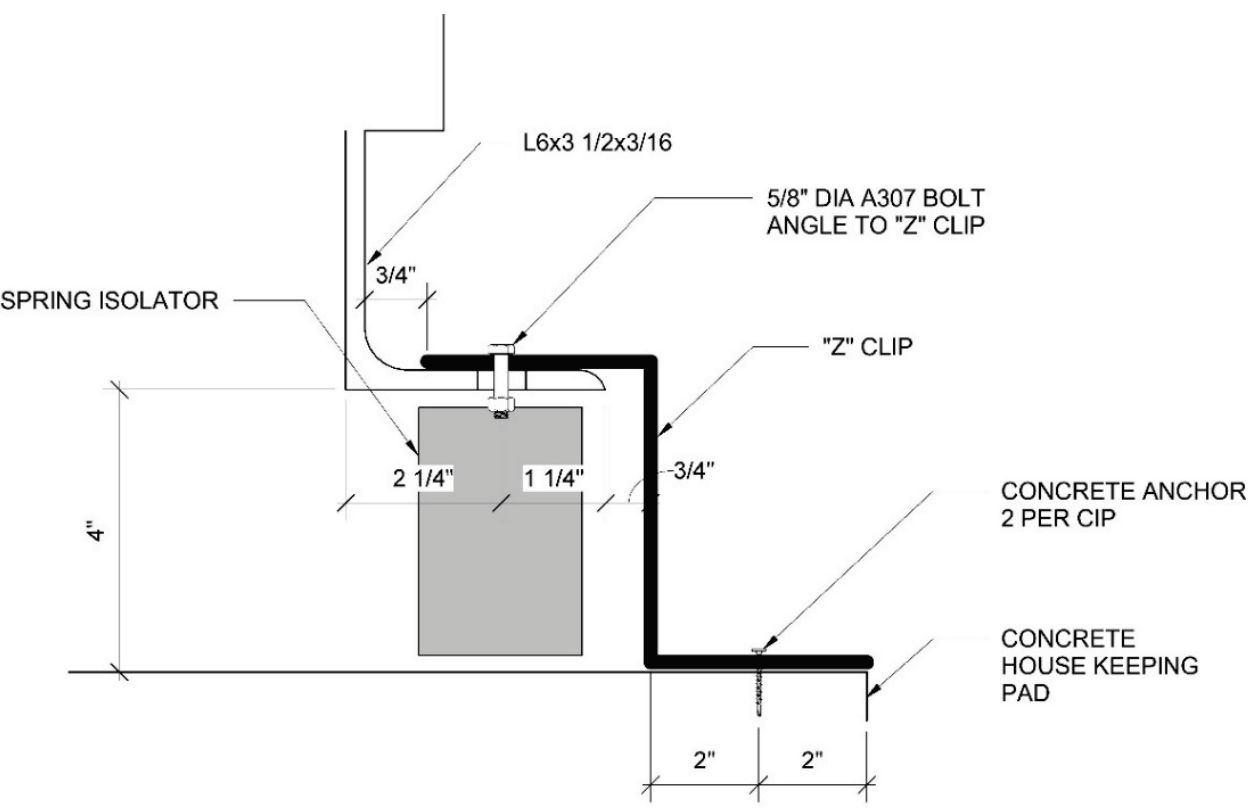

Figure 5-10 Code-compliant design of externally-isolated mechanical unit anchorage.

Using the proposed nonstructural force equation from Chapter 4 amplifies the design force similar to the values in Table 5-2 for the elevated vessel example for a building with an ordinary structural system, such as ordinary reinforced concrete shear wall or steel ordinary concentrically braced frame. In this case, the most logical ductile fuse in the internally isolated unit would be the bending of the angle to which the anchor attaches. However, there are some issues with this approach. The fact that the angle is continuous means that a significant number of additional anchors would be required to ensure the angle is bent before the anchors fail.

Alternatively, the continuous angle could be changed to discrete angles to limit the length of angle that would bend to reduce the number of anchors required. However, this approach to providing ductility only works in the direction where seismic forces are acting parallel to the short direction, where the component may rock. In the longer direction, it is very unlikely that rocking would occur, so the ductile response would either have to be yielding of the housing around the components or yielding of the bolt holes around the anchor. With the anchor design being governed by concrete actions instead of yielding of the steel, the thickness of the angle would need to be reduced to allow for yielding around the bolt hole, which may not be possible given it supports the weight of the unit.

For the vibration-isolated unit, the ductile mechanism could be bending of the " $\mathrm{z}$ " clips, similar to the bending of the angles discussed in Section 5.2. If the " $z$ " clips are selected to be the ductile fuse, the only specific consideration a design would need to abide by would be to increase the number of clips to 8 , where 4 clips are 
oriented so they were snubbing the unit in in one direction and the other 4 are snubbing in the other direction.

\subsection{Piping Support Design Example}

This example of a piping system is only discussed conceptually. Providing ductile design in piping systems would require a designer to select bending of the piping or yielding of the bracing system as the ductile fuse.

If bending of the piping is selected as the ductile fuse, care would need to be exercised to make sure the pipe bends away from a joint and is made of a material that could accommodate large amounts of ductility while maintaining the integrity of the pipe against leaks.

If the ductile fuse is placed in the bracing system, there are several potential options. Figure 5-11 presents a common seismic bracing system for a hung pipe.

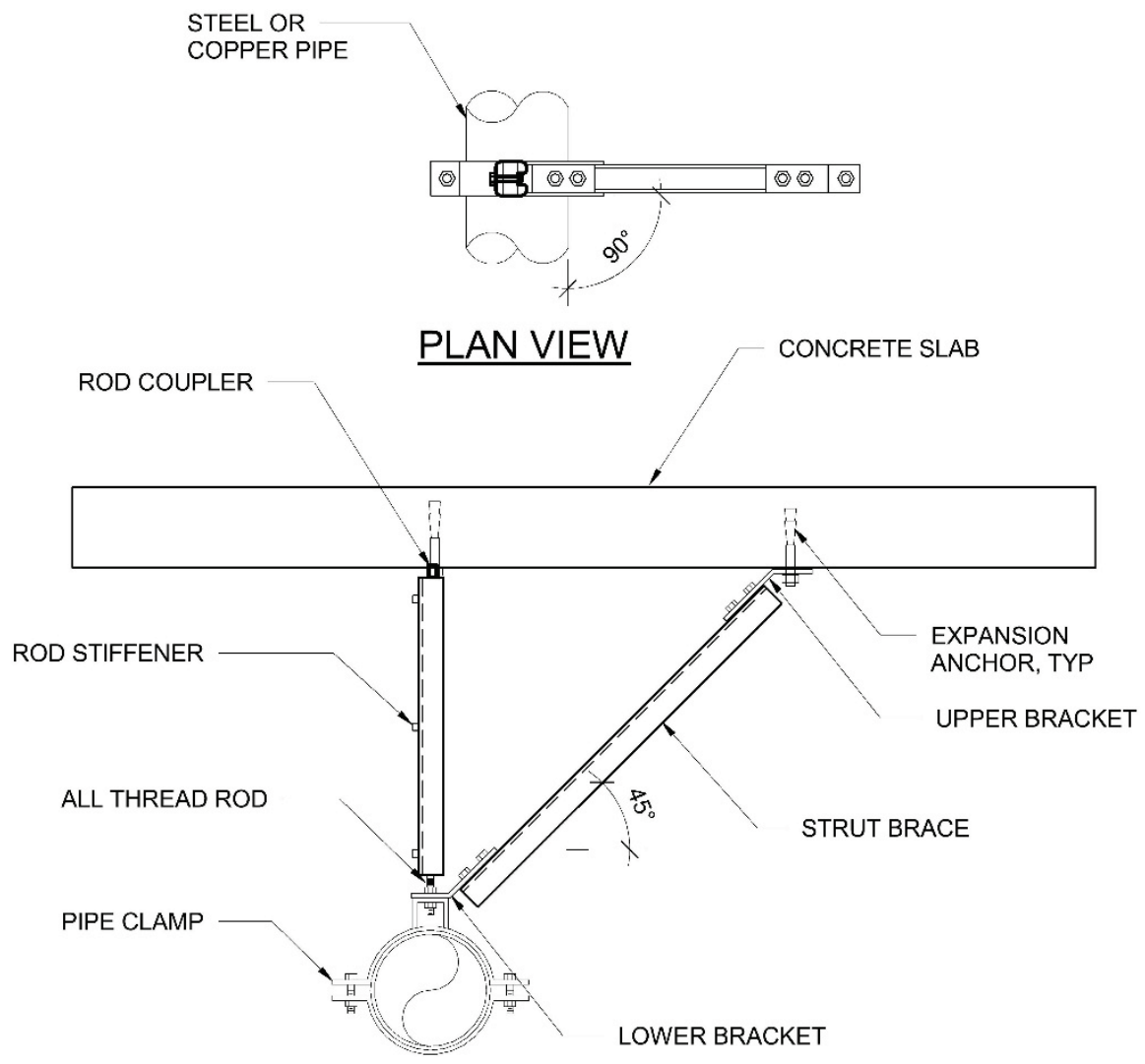

Figure 5-11 Typical pipe support and seismic bracing.

The diagonal strut bracing element could be designed to buckle or yield. However, that would require a significantly more robust connection that is typically used. Yielding of the bolt connecting the brace to the slab or structural member is another option. Another option would be to allow bending of the vertical portion of the bracket the pipe hangs from. Most of these yielding states would require the testing 
of such limit states and probably modifications to current strut and bracket systems. In this example, there are many locations where the manufacturer of the bracing components could create specific pieces within the bracing system that serve as yielding elements. Such elements would need to be tested, but for something as common and repetitive as pipe bracing, there would be advantages to doing so.

\subsection{Conclusions and Recommendations}

Analytical studies on component response to floor acceleration have shown that ductility in the component or its anchorage can have a significant reduction in forces required to design the bracing and anchorage. Given the uncertainties and variability in input ground motion, amplification of ground motion throughout the structure, and amplification of accelerations from floor to component, it is desirable to have some mechanism deform with a reasonable amount of ductility, as opposed to attempting to define the maximum force that must be resisted with limited inelasticity. Ductile fuses would also provide greater resilience for ground motions larger than those explicitly considered in the design. For very simple examples, such as bending of clip angles, this could easily be specified. However, for most nonstructural components, creating design provisions to require ductile fuses would become challenging.

When ductile structure systems are required, the material design standards have significant requirements that must be adhered to in order to provide the desired ductile response. These provisions are quite extensive, and only apply to three discrete structural systems: walls, moment frames, and braced frames. Nonstructural components, their supporting structures and bracing systems are much more unique and varied than building structural systems. Thus, developing design provisions and detailing rules for even the most common types of nonstructural components and systems would be a significant undertaking. Further, it is unclear whether such rules would be followed without being explicitly mandated.

Currently, nonstructural design is carried out with very little consideration for what the ductile fuse should be. With the exception of anchors into concrete and masonry, there are no rules to make any component stronger than other components. As several examples have shown, such rules would result in designs that are more robust, complicated, and costly than one could achieve using the provisions for an elastic system. That is not to say that designers should not consider providing ductility in their design, especially for critical components.

The discussions in Chapter 4 and the examples in this chapter illustrate that if a designer thinks through the load path, a ductile fuse can often be found. Thus, designers should be encouraged to review the load path and identify possible sources for ductility. Also, designers should look to identify the most brittle elements in the 
component, its anchorage, and bracing system, and seek to design them for amplified forces or for the maximum forces that can be delivered by a ductile component.

The following are recommendations that can be implemented to provide some confidence of ductile response:

1. The current overstrength requirements for anchorage to concrete or masonry when forces to the anchor are not limited by yielding of a ductile element should be retained.

2. The upper bound lateral design force, $F_{p, \max }$, for nonstructural components should be increased when resonance between the structure and nonstructural component is likely to occur. The proposed design equations in Chapter 4 have increased the maximum cap on design forces accordingly.

3. Amplifying lateral forces by an overstrength factor for connections such as welds should be considered.

4. Clarification on which components may likely be in resonance should be provided. This will likely increase the number of components being designed for higher forces due to dynamic interaction between the component and structure. Chapter 4 discusses some considerations to help code writing bodies in making the necessary determinations.

5. Companies making products commonly used for nonstructural component anchorage and bracing should be encouraged to develop and test special pieces that can serve as the ductile fuse in an anchorage or bracing system.

If ductile design were to be required, the components and systems that would benefit the most are those that currently are designed with $I_{p}=1.5$. These are the components and systems that are essential for function of critical buildings, function of the buildings' life safety systems, and containment of hazardous materials. Because the failure of these components has such high consequences, the enhanced reliability that one would gain from ductile design would likely justify the increased design effort and cost.

Chapter 4 presented discussion on a number of issues related to variability of the design force on a nonstructural component or system relative to the ground acceleration. However, the chapter did not discuss the variation in ground shaking or the evolution of the "design" ground motion as knowledge of regional seismicity changes. Even if design rules cannot be written for ductile design of every type of nonstructural component and system, it is hoped that discussions in this chapter can provide encouragement for designers to spend more time thinking about the load path of a critical nonstructural component's bracing and anchorage that may lead them to providing a ductile mechanism. 


\section{Chapter 6}

\section{Holistic Approach to Protecting Nonstructural Components}

\subsection{Introduction}

The preceding chapters presented many aspects of nonstructural design, performance, and response. This chapter synthesizes the interdependence of these parts and their importance to the goal of achieving acceptable seismic performance of nonstructural components, and presents an overarching "holistic" approach to protecting nonstructural components from earthquakes.

\subsection{Scope}

The nonstructural universe contains a myriad of components and systems that enable buildings to function for their intended purpose. It includes architectural components that enclose buildings and create usable interior space; mechanical, electrical, and plumbing systems that provide the basic services needed for occupancy; and contents needed for occupants to function in the space. The variations in scale and importance of components are extreme.

Installation conditions for nonstructural components are also wide ranging. Components may be supported on the ground or in a building. When installed in conjunction with construction of a new building, the structural characteristics of the building may be fully known. In other instances, new components are installed in existing buildings for which little or no structural information is available.

Components may be restrained with anchorage at the base, suspended and braced from above, wall-mounted, or any combination of these. The load path from the component to the supporting structure or ground can be simple and direct, or via a complex assemblage of interconnected links and fasteners, each with their own behavior and response to seismic excitation.

Adding to the complexity of developing a design strategy that covers all nonstructural components is the challenge of accurately predicting earthquake motions at the site, which are dependent not only on the magnitude, location, and faulting mechanism of the earthquake, but are also affected by wave propagation and diffraction from the source to the site, possible basin effects in the vicinity of the site, site effects on shallow soil deposits, or soil-structure interaction effects. 


\subsection{Uncertainty and Reliability}

The many interdependent and complicated factors associated with determining seismic demands and component response give rise to large uncertainties in the estimation of force and deformation demands-larger than those involved in estimating the response of the building itself. Recognition of these uncertainties should guide and inform how these elements are designed and installed in seismic regions.

The building code establishes minimum design requirements that are intended to achieve acceptable performance in most instances. While significant effort has been made to estimate the reliability of the primary gravity and seismic force-resisting systems in buildings, a rigorous estimation of reliability of nonstructural components is still not technically feasible at this time. The diverse nature of nonstructural components and their support conditions, limited data on the response of a broad range of nonstructural components to strong earthquake shaking, and constant innovation and evolution of nonstructural components present an ever-changing target. In addition, as code provisions for nonstructural elements have been developed over the years, the expected performance of architectural, mechanical, and electrical elements differed; for some it is just position retention, others are designed for damage control, and others for functionality. Also, as with other design requirements found in the building code, the design force equation and cap on design demands proposed in Chapter 4 were selected not to envelope all possible demands, but rather to provide a design approach likely to yield acceptable performance in most cases.

Chapter 5 proposed an alternative approach and philosophy to reducing uncertainties in the estimation of forces in nonstructural components, their supports and attachments and thereby increasing the reliability of designs. By designing a yielding mechanism or ductile "fuse" in the seismic load path, the force demand on a nonstructural component no longer depends on the earthquake ground motion intensity and the dynamic characteristics of the structure, but rather on the strength of the yielding element. In cases where it is possible and practical to take this design approach, more reliable seismic designs can be achieved. Observations of nonstructural performance in past earthquakes have demonstrated that unacceptable performance is often a result of factors other than design demands. Missing restraints, improper component installations, and adverse interactions between components are frequent contributors to poor performance. Thus, increasing the reliability of nonstructural protection requires attention to not only the quantitative aspect of design, but also identification of components requiring protection and oversight during construction to ensure their proper installation. 


\subsection{Holistic Approach}

A holistic approach is needed to integrate the many variables associated with nonstructural design and construction into a technically sound and practical implementation strategy. The recommended approach for protecting nonstructural components and systems provides a comprehensive strategy that can be used for new components in the context of new building design projects. As described below, portions of the approach can also be incorporated into the design of new components in existing buildings.

The holistic design approach can be managed in a series of coordinated tasks. In the following description of the process, tasks are grouped largely on a chronological basis according to typical design and construction projects. It is recognized that the design and construction process is not always linear, is often iterative, and that the holistic approach may require adjustments to suit particular project needs and adapt to unique project conditions.

It is important to recognize that successful implementation of the proposed holistic approach requires buy-in and advocacy from the owner and managers of the project. It also requires diligent, and sometimes exhausting efforts to coordinate the work of all trades and verify that project requirements are met.

\subsubsection{Assign Responsibility}

Design begins with identifying the general nature and scope of vulnerable nonstructural components and systems. This requires knowledge of the architectural, mechanical, electrical, plumbing, and infrastructure components and systems, as well as the installed furnishings, fixtures, and building contents.

One of the first project management tasks is delegating responsibility for design of the seismic protection of nonstructural components and systems. The responsibility may be delegated to an entity who will oversee all related designs on the project, such as the Structural Engineer of Record, as is most common for hospital projects in California. On other projects, oversight may be delegated to a designated "Nonstructural Coordinator" hired by the owner. Alternatively, responsibility may be more diffuse and be assigned to several entities. For example, the design professional responsible for specifying a component or system may also take responsibility for seismic protection.

It is becoming more and more common for specialized systems to be treated as "delegated designs," particularly in a design-build or other form of integrated project delivery method. For example, in a typical office project, design of cladding, stairs, HVAC, plumbing, electrical systems, and/or other systems are often delegated to "design partners," subcontractors or vendors, who are responsible for not only 
producing, procuring and installing these systems, but also for their design. When detailed design of systems, including seismic design, is delegated, design specifications must go beyond the traditional set of material, product, and performance requirements to address the following questions:

- What is the scope of designed elements and systems?

- Who is responsible for seismic design?

- What are the seismic design requirements? How are these requirements transmitted to the various subcontractors and vendors who need them? Typically, both floor accelerations and interstory drifts required for design would be provided by the Structural Engineer of Record.

- What documentation must the contractor provide? Details, plans, and calculations stamped by a licensed Professional Engineer would typically be required.

- What is the review process for delegated designs?

- What level of coordination with other trades is required? Is a Building Information Modeling (BIM) model required? If so, what are the BIM requirements? What interactions with adjacent systems must be considered and who is responsible for addressing interactions?

- If components or systems are fabricated off-site, what level of inspection is required? What documentation must be provided to the owner before accepting fabricated parts on-site? Will the owner require Special Inspection independent of the contractor's Quality Assurance and Quality Control (QA/QC) program?

- What on-site testing and inspection is required and at what frequency? Who is responsible for performing the tests and inspections, and who has financial responsibility for testing and inspection? What protocols are required for nonconformance?

It is important that responsibility be established at the outset of the project for several reasons. For new building design projects, this will help ensure that critical design issues are addressed while there is still an opportunity to influence the structural design. In addition, for all projects, it will enable the responsible party to include in their fee the costs associated with seismic design or review, as well as any costs associated with procurement of designated seismic systems that may have a cost impact and/or require project-specific testing to satisfy project requirements.

\subsubsection{Select Performance Objectives}

The next step is to identify the desired performance objectives for the building. This requires an understanding of the intended use of the building and the owner's or 
occupant's post-earthquake needs. Open and candid communication between the design team and owner is recommended to communicate options and help guide performance-related decisions.

Once the owner's overarching performance objectives for the building are established, they need to be translated into component-specific performance objectives. For ordinary components, the performance objectives proposed for the building code may be adequate. For buildings in which post-earthquake functionality is required in the Design Earthquake, an understanding of the components and systems that are required to maintain continuity of operations is needed, and there should be agreement on what constitutes acceptable damage or acceptable performance. For buildings susceptible to hazardous materials release, requirements in the Design Earthquake may be based on limiting/controlling release and the ability to safely shut-down systems. For buildings housing important irreplaceable contents, the objective may be no damage to the contents in the Design Earthquake, while damage to other building systems is acceptable. Each building is unique and selecting performance objectives for nonstructural components and systems requires consideration of each owner or occupant's project goals.

Selection of performance objectives is rarely done without consideration of cost. The need to satisfy minimum code requirements establishes the baseline cost for a given project. Enhanced objectives generally increase project costs for the following reasons:

- More components are often restrained. For example, ASCE/SEI 7 may exempt pipes below a specified diameter from the requirements for seismic bracing if certain conditions are satisfied. For enhanced performance, smaller pipes may also be braced, thereby increasing the project scope. Similarly, the building code does not regulate most contents or furniture, yet related earthquake damage may extend recovery time. For enhanced performance, contents or furnishings that could create unacceptable disruption may also be restrained or otherwise protected from damage.

- Equipment that has been shake-table tested to demonstrate functionality is often sold at a premium.

- Designing to limit damage can be time consuming, thereby increasing design costs. It can also lead to more expensive installations. For example, a cladding system that must retain full environmental protection in the Design Earthquake may require special detailing over one designed solely for safety. Mock-up tests on enhanced performance cladding systems are often undertaken to demonstrate that performance objectives can be satisfied. The tests themselves, as well as the special detailing and implementation of the design, tend to increase costs. 
- Components and systems designed for enhanced performance are often designed for a higher seismic demand. This may impact costs, although, this premium is often negligible.

- Components or systems designed for enhanced performance generally have more quality control. This may translate to more site inspection, material testing, or proof-loading of anchors. For suspended systems, this may also include on-site inspections to observe whether there is a potential for adverse interactions of systems installed in close proximity to one another.

- When required to install systems with enhanced performance, some contractors may charge a premium that is not reflective of the actual added cost. This may be a consequence of a preconceived notion of costs, lack of understanding of the actual increased scope of labor or materials, or "value pricing" since there are limited data with which to refute added costs.

While there are little published quantitative data to help estimate the costs of designing for enhanced objectives, a few projects have reported as little as $1 \%$ increase in construction cost for a new building to achieve higher likelihood of occupancy following the Design Earthquake. Such a low premium is possible when the holistic approach described herein is embraced by all members of the owner/designer/contractor team, and when structural and nonstructural systems are selected and designed with performance in mind from the beginning. Costs of designing for enhanced performance can vary widely based on the specific objectives, site seismicity, complexity of the components and systems, nature of the structure, experience of designers and contractors, and many other factors. In a 270,000 square foot academic laboratory and research building under construction in San Francisco, the owner reported "an approximate 1-2\% premium on the construction costs of the project to meet our enhanced seismic requirements which is essentially a building in Risk Category 4. This cost is specifically shown in the following scope categories: Foundation, structure, superstructure, exterior vertical enclosure, suspended ceiling system, MEP distribution, equipment anchoring, seismic peer review, geotech studies and structural engineering design (non-linear analysis, ground motions, etc.)" (Mazzeo, 2018).

\subsubsection{Establish Structural Design Parameters}

As described in Chapter 4, structural characteristics will have a substantial impact on the demands to which nonstructural components and systems are subjected. For new building design, there is an opportunity to refine the structural design to help satisfy nonstructural performance objectives. For nonstructural components and systems installed in existing buildings, the building must be accepted as-is and design demands must be determined without detailed understanding of the dynamic characteristics of the structure. 


\section{New Buildings}

For new building design, an important step is to determine whether the attributes of the selected structural system are compatible with the performance objectives identified for the nonstructural components. There are practical limitations to the performance that some nonstructural components can achieve. One way to address this is by explicitly designing the structure within the limitations of the nonstructural components. For example, a building may be provided with added stiffness to enable a desired cladding system to be used, while another building may be base-isolated to protect contents sensitive to horizontal accelerations. A stiff base-isolated building may be selected to protect both acceleration- and drift-sensitive components.

Another consideration is design of the substrate that nonstructural components will be connected to. For example, floor-mounted equipment is commonly anchored to concrete floors using post-installed anchors. The anchors require a specified minimum embedment. Floor slab thickness may prohibit the use of large diameter anchors with deep embedment, which might be required for tall or heavy nonstructural components. For new buildings, these considerations can be addressed early in the design process and floor slab details can be chosen accordingly. For metal deck on concrete fill, this may lead to using fill of greater thickness than is required for fire-rating or strength considerations. For post-tensioned slabs, this may include increasing the cover to tendons to prevent damage caused by drilling for postinstalled anchors.

Another opportunity available when designing a new building is the ability to determine design floor accelerations and interstory drifts directly from the building analysis. Related procedures are described in ASCE/SEI 7-16.

\section{Existing Buildings}

When nonstructural components and systems are installed in existing buildings, details of the supporting substrate must be determined. This often includes determination of material, thickness, and strength. Without this basic information, it is not possible to reliably design support, bracing, or anchorage of nonstructural components. If drawings illustrating the existing construction are not available, field investigation and sometimes testing of in situ materials using destructive or nondestructive means is required.

When installing new nonstructural components in existing buildings, it is often not practical, from a time or cost perspective, to perform analysis of the building to estimate floor accelerations or drifts. Design in accordance with the building code using default parameters, with a floor and a ceiling on demands, is common practice. Unless otherwise justified, the maximum interstory drift permitted by code is often used as the interstory drift required for design. 


\subsubsection{Select Nonstructural Components}

Nonstructural components should be selected to provide the optimum balance of functionality and life-cycle cost. This should include consideration of specified seismic performance objectives. In practice, however, most nonstructural components are selected simply on the basis of required function and initial cost.

Special consideration must be given to components for which post-earthquake functionality or limited damage are desired. For example:

- Active mechanical and electrical equipment that must remain operable after the Design Earthquake (i.e., designated seismic systems), can be shake-table tested to increase the likelihood of operability.

- Mock-ups of cladding systems can be built and tested under prescribed interstory drifts to help confirm acceptable performance.

- Components and systems can be analytically modeled and analyzed to assess acceptability under prescribed levels of acceleration and drift.

In order to ensure that components are selected with consideration of seismic performance objectives, design requirements for all nonstructural components must be clearly specified, typically by the Structural Engineer of Record. One approach is to create a single location in the project construction documents for the seismic design requirements. Ideally, design demands are contained on drawings, rather than specifications, which can be more difficult to locate for future reference. Project specifications should clearly reference the required seismic design demands and associated performance objectives. Specifications should also describe submittal requirements, qualifications of the designer and performance and quality assurance requirements. The responsible design professional or nonstructural coordinator should be designated to review related designs to confirm that project requirements have been satisfied.

Given the number of components and systems installed in any building, it can be a daunting task to ensure that each complies with the seismic performance objectives established for the building. For Risk Category II buildings that are not explicitly designed for post-earthquake operability, the number of components that are part of the designated seismic systems and required to function after the Design Earthquake is limited and can generally be addressed by the design team through carefully prepared specifications and drawings, and a QA/QC process overseeing compliance. For complex buildings designed for enhanced performance, management of the selection of nonstructural components requires considerably more time and effort by knowledgeable entities. It also requires the philosophical and financial commitment of the project owner. 


\subsubsection{Design Nonstructural Component Restraint}

For most nonstructural components and systems, code-based design is expected to be adequate to achieve desired performance objectives. The following list is intended to reinforce code requirements that are sometimes overlooked and provide guidance to improve the overall level of seismic protection provided by design:

- Where components form part of a larger system, all components in the system should be designed to achieve the intended performance objective. This is becoming increasingly important as more equipment and systems are interconnected via monitoring and control systems. Building operations often rely on data, voice, and other communication technologies to operate effectively. The convergence and interdependence of these systems increases the need for comprehensively-designed seismic protection systems.

- Adverse interactions between nonstructural components should be considered. Components can be restrained to prevent adverse interactions, or adequate clearances provided to avoid damaging impacts. The use of Building Information Modeling (BIM) may be used to help identify potential conflicts that could lead to unacceptable damage. A recent study discusses the effectiveness of using BIM for the seismic design of nonstructural building components (Perrone and Filiatrault, 2017). There are also practical limitations to the use of BIM when all installed elements are not modeled.

- When designing seismic restraints, consideration should be given to whether the component will need to be moved on a regular basis for service or maintenance. If the component will be moved regularly, restraints should be designed to accommodate easy removal and reinstallation.

- Connections between distribution systems and equipment are often vulnerable to damage resulting from differential movement. Where post-earthquake functionality or limitation on damage is desired, flexible connections or loops should be provided at these connections to minimize the potential for pipe leaks or breaks.

- For critical components for which a high degree of reliability is needed due to the consequences of damage, the design should consider connections containing a ductile fuse in the load path. Design of brittle connections or elements in the load path should be based on the capacity of the ductile fuse.

\subsubsection{Testing, Inspection, and Observation of Installed Components}

Testing, inspection, and observation of the installation of nonstructural components and systems are needed to assure that intended design objectives are met. 
Chapter 17 of the 2018 International Building Code (ICC, 2018) requires the registered design professional in responsible charge to prepare a Statement of Special Inspection and sets forth minimum requirements for Periodic Special Inspection of nonstructural components designed for seismic resistance. Requirements include testing and inspection of selected architectural, plumbing, mechanical, and electrical components in designated seismic design categories. Development of a projectspecific Statement of Special Inspection should also be based on an understanding of the performance objectives established for the building. In general, nonstructural components required to function after the Design Earthquake and those designed for enhanced performance require higher levels of testing, inspection, and observation than other components. Thus, minimum code requirements for Periodic Special Inspection may be insufficient when higher performance or higher reliability in performance is desired.

Inspection is required to verify that installations are in accordance with the approved design documents and to provide confidence that intended designs are implemented. Inspection should also be used to verify that installed equipment that is part of a Designated Seismic System contains proper certification of post-earthquake functionality. Thus, a Statement of Special Inspection should identify the party responsible for inspecting installed components and systems. Given the complex nature of some installations, several different specialized inspectors may be needed to complete inspection of all aspects of the built project. It should be recognized that the Authority Having Jurisdiction (AHJ) should not be depended upon to do this inspection. In addition, unless specifically assigned to the Structural Engineer of Record as part of construction administration services, "Structural Observation" will not be often or thorough enough to adequately cover this task. Most projects are better served by assigning the responsibility to an independent, third-party special inspector qualified in this work. For design-build projects where the contractor is responsible for both the complete design and installation of nonstructural component anchorage, it is recommended that the special inspector work directly for the owner rather than under the contractor to avoid conflicts of interest. In order to ensure complete inspection of all the nonstructural systems for complex projects, an electronic management system that can be accessed in the field in real time may be beneficial.

Testing of nonstructural components is often used to validate the installation of postinstalled anchors. Post-installed anchor inspection is required to be "periodic" in the building code but this leaves the frequency up to the special inspector and may not be appropriate in all cases. It is recommended that the Structural Engineer of Record and owner base the frequency and nature of testing on consideration of the consequences of failure of the anchor. Where a system is installed with considerable redundancy or has small anchor demands, less frequent testing may be needed (such 
as suspended acoustic ceilings). On the other hand, anchors supporting heavy suspended components with little redundancy or anchors restraining components of critical importance, should be tested at a higher frequency.

Observation by the Design Professional(s) of Record or other professional who understand the seismic aspects of the nonstructural design will often enhance the overall quality of the project. In projects for which post-earthquake functionality is a goal, such observation is highly recommended as there are many conditions that can inadvertently short-circuit performance, but may not be evident unless observed by someone with detailed knowledge and understanding of the performance of nonstructural components in earthquakes. For components and systems requiring post-earthquake functionality, final inspection should be conducted after all systems are installed to identify conditions where adverse interactions of adjacent components can lead to unacceptable damage.

\subsubsection{Additional Strategies to Increase Resilience (Optional)}

Resilient buildings either maintain functionality after an earthquake or regain functionality within an acceptable period of time. This requires building components to be selected and systems to be designed to achieve stated resiliency criteria, both independently and interdependently with other systems. Resilient design requires an understanding of how failures can cascade to increase recovery time, and what can be done to mitigate the effects of failure. Resilience can be enhanced by:

- Maintaining back-up components to repair or replace damaged equipment

- Providing shut-off valves at easily accessible locations to isolate locations where there may be breaches in distribution systems

- Having access to materials and workers capable of making repairs in the immediate aftermath of an earthquake

- Providing redundant services at an alternate site

- Ensuring that maintenance and repair personnel are aware of the importance of seismic anchorage and bracing, and that after any work is performed on nonstructural components the lateral restraints are fully restored.

- Locating critical equipment at or below grade where accelerations are expected to be lower than at other locations in the building.

One example of employing strategies to increase resilience involves water damage. Water released from suspended pressured piping, such as fire sprinkler piping, can have devastating effects on post-earthquake functionality. Water damage from a compromised pipe can ruin materials, grow mold, and flow into several floors below the pipe break, greatly compounding the damage. The duration of the leak will dramatically impact the magnitude of the damage and the time it takes for a portion, 
or the entirety, of the building to regain its full functionality. There is at least one example where a single pipe breech allowed to continue flowing for hours led to building closure for months (FEMA, 2015a). Strategies that could be employed to enhance resiliency against water leaks could include:

- Providing flexible sprinkler head connections

- Providing a restraint system designed to limit pipe system movement and protect joints, as well as to prevent adverse interaction with adjacent systems

- Increasing the quantity of and strategically locating shut-off valves so problems are localized to the smallest area practical

- Creating exemplary shut-off valve wayfinding and accessibility

- Providing leak detection and alert system

- Training maintenance personnel in shut-off locations and procedures to reduce the duration of the leak

- Installing curbs at slab penetrations to prevent water from flowing from floor to floor

- Installing finish materials that can get wet and dry out without needing replacement 


\section{Chapter 7}

\section{Recommendations}

This chapter summarizes the results of an effort to approach seismic design of nonstructural components from many different perspectives.

During the course of the project, study was focused on four main areas:

- The societal expectations for seismic performance of nonstructural components as a whole were juxtaposed with what can practically be achieved considering economic constraints associated with current and emerging design and construction technologies. The products of this effort are performance objectives for nonstructural components that can ultimately serve as the foundation for building code requirements. These can also be adapted for use when enhanced performance is desired.

- A comprehensive review was conducted of all factors contributing to seismic performance of nonstructural components and systems, using the latest information from instrumented buildings, laboratory tests, and analytical studies. The primary factors influencing seismic force demands on nonstructural components and the individual roles and combined effects of these factors on component response were studied, including the influence of various characteristics of nonstructural components and the supporting structures on nonstructural response. This effort provided a deeper understanding of the factors that contribute to the response of nonstructural components to shaking. A framework for improved design force equations for nonstructural components was developed.

- An alternative "philosophy" for nonstructural design based on capacity-design principles was proposed with the intent of providing increased reliability, lower design forces, and greater control over nonstructural response.

- A detailed review of the ASCE/SEI 7-16 nonstructural design provisions was performed. The clarity, consistency, and technical appropriateness of the provisions were examined, and recommendations for improvements and an implementation roadmap for future code-writing bodies were provided.

Each of these efforts resulted in recommendations for implementation for improved seismic provisions, and topics for further study, which are summarized below. Consideration was also given to the broad range of nontechnical factors that directly 
or indirectly contribute to the performance of nonstructural components. Related recommendations are also provided.

\subsection{Seismic Performance Objectives for Nonstructural Components}

Seismic performance objectives for nonstructural components are not only technical in nature, but have broad public policy implications. The performance objectives for nonstructural systems and components proposed in this report are intended to foster community-wide discussions to arrive at a consensus set of objectives. These objectives should be developed and affirmed through the code-development process, with a final goal of adoption in future building codes and standards. These objectives would also be translated into explicit goals used for a performance-based design of nonstructural components and systems. The principal recommendations to achieve this vision are:

1. Adopt the proposed nonstructural performance objectives into the next edition of NEHRP Recommended Seismic Provisions for Buildings and Other Structures, which forms the basis for future building code requirements.

2. Conduct calibration studies to determine whether acceptable risks for nonstructural components subject to different earthquake shaking intensities are achieved with current code design procedures.

3. In future earthquakes, collect detailed and comprehensive information about the performance of nonstructural components and impacts on component and building functionality to inform future developments of the nonstructural seismic performance objectives and code requirements.

4. Evaluate the adequacy of code design requirements for critical stairs and egress pathways, considering the vulnerability of egress pathways to nonstructural damage, the operability of stairway doors, and cladding or other nonstructural components over exit pathways. Develop clear, detailed, and enforceable code requirements to address gaps that may exist in current provisions.

5. Study the seismic vulnerability posed by information technology and the interconnected nature of systems essential to functionality.

6. Study requirements for post-earthquake habitability and function to determine whether any changes to nonstructural practice or codes are needed achieve the desired performance objectives.

7. Gather nonstructural best practices by industry or building type to help owners identify vulnerabilities and address them. 
8. Develop a consensus definition for the "frequent earthquake," and methods of confirming that performance objectives are being achieved when such an earthquake occurs.

9. Develop quantitative risk targets for nonstructural components.

\subsection{Response of Nonstructural Components in Earthquakes}

Studies were performed to identify the influence of different factors that influence the response of nonstructural components subjected to earthquake shaking. Based on this work, a new approach has been developed for determination of seismic force demands on nonstructural components that can be incorporated in the building code.

The proposed nonstructural seismic design equations should be implemented in the next edition of the NEHRP Provisions and ASCE/SEI 7 standard, Minimum Design Loads and Associated Criteria for Buildings and Other Structures, with the following considerations:

- The guidance in this report should be leveraged to categorize nonstructural design components into those likely to be in resonance with the building dynamic properties and those not likely to be in resonance and then to assign components to low, moderate, and high component ductility categories.

- A code proposal and associated commentary should be developed for balloting by the Provisions Update Committee to implement the proposed nonstructural seismic design equations into the next edition of the NEHRP Provisions.

- Following adoption into the NEHRP Provisions, the proposed nonstructural seismic design equations should be incorporated into the next edition of ASCE/SEI 7.

In addition, areas for further development are identified in the following recommendations.

1. Conduct additional research to better understand the response of nonstructural components in earthquakes and to refine nonstructural seismic design equations in the future:

a. A database of information on component damping should be developed to collect and organize new and existing testing results, and to determine if refinements in the assumed levels of component damping underlying the proposed nonstructural design equation are warranted. The database should consider the full range of displacement and force amplitudes that nonstructural components can experience during earthquake shaking. Damping data collected from small amplitude vibration tests (e.g., impact hammer tests) are typically only adequate to characterize inherent component 
damping, but would not provide information on component hysteretic damping.

b. The database should be supplemented with information on actual component ductility from new testing and synthesis of existing testing, preferably distinguishing sources in ductility, such as the component, the connection of the component to anchors, and the anchors themselves.

c. The database should be supplemented with information on component periods of vibration.

d. Testing results should be studied to better quantify the component reserve strength margin.

e. The archetype analysis studies of this project were done for a selected set of common seismic force-resisting systems. Additional studies should be conducted, particularly for seismic force-resisting systems with low response modification coefficients, to confirm the adequacy of the proposed nonstructural design equation for those systems.

f. The archetype analysis studies should be augmented with additional analyses using amplitude-scaled response histories.

2. Revise the building strong motion instrumentation protocols of the California Strong Motion Instrumentation Program (CSMIP) and the USGS to better provide information needed to understand nonstructural component response as follows:

a. Protocols should be expanded to record horizontal response to include selected nonstructural components in addition to structural elements so that in-situ measurements of peak component amplification, peak floor acceleration, and peak ground acceleration can be compared, and component damping levels can be better understood.

b. As discussed in Fathali and Lizundia (2011), there are a fair number of vertical sensors that have been installed to date in buildings. "However, they have often been placed in atypical locations such as at the tip of a cantilever or mid span of a long truss, without any associated reference sensor adjacent to a column. Thus, there is no way to effectively separate overall vertical response at a floor from a local effect. More broadly, there are a very small number of buildings with vertical sensors in a consistent stack adjacent to columns or walls up the building. In addition, usually only one elevated floor is chosen for vertical sensors. In order to effectively study vertical amplification of motion up the building, CSMIP [and USGS] should instrument a select number of buildings with a stack of sensors adjacent to a stiff column to try to diminish floor amplification effects. The stack should 
include at a minimum the lowest floor, the roof, and a mid-height sensor. The next step would be to locate a sensor at a point of local interest in the floor such as mid span along a girder building columns or in the middle of a flat slab bay. The difference in response between the local sensor and the sensor adjacent to the column at that floor can allow the local effect to be studied directly." A vertical sensor on a nonstructural component at the midspan or mid-bay location should be included to better understand the relationship between vertical floor response and vertical component response and then assist in developing improved nonstructural design equations for vertical response.

\subsection{Ductile Design of Nonstructural Supports and Attachments}

The concept of ductile design for building structures has been commonplace for the past thirty years, while all elements in the load path for nonstructural components are designed with a uniform force derived from a single equation. There are no provisions that require the designer to explicitly identify the ductile behavior of the elements in the load path and, more importantly, what elements should not yield. Studies performed in this project identified the potential benefits of ductile behavior on the response of nonstructural components.

The principles of ductile design for nonstructural components are deceptively simple. However, in practice, application of these principles can be complex. The following recommendations have been collected based on ductile design case studies:

1. Retain current overstrength requirements for anchorage to concrete or masonry when forces to the anchor are not limited by yielding of a ductile element.

2. Increase the upper bound lateral design force, $F_{p, \max }$, for nonstructural components when resonance between the structure and nonstructural component is likely to occur. The proposed design equations in Chapter 4 have increased the maximum cap on design forces accordingly.

3. Consider amplification of lateral design forces by an overstrength factor for brittle connections in the load path, such as welds.

4. As noted in Section 7.2, provide clarification on what components may likely be in resonance. This will likely increase the number of components being designed for higher forces due dynamic interaction between the component and structure.

\subsection{Review of ASCE/SEI 7-16 Seismic Requirements for Nonstructural Components}

The nonstructural seismic design provisions in ASCE/SEI 7-16 represent decades of work dedicated to improving performance in strong earthquakes. A number of opportunities for improving the clarity and technical merit of the ASCE/SEI 7-16 
nonstructural provisions have been identified. The most significant recommendations are listed below. Some of the recommendations can be implemented immediately, while others represent longer-term efforts that will require significant resources. In some cases, issues have been identified for which there is not a clear path forward to a solution at this time. Finally, some recommendations address issues that are outside the scope of the nonstructural component design chapter and should be referred to the appropriate responsible groups.

1. Improve the clarity and technical accuracy of the seismic design provisions for nonstructural components as follows:

a. Revise the scoping of nonstructural design provisions to clearly identify components subject to the seismic design requirements. This includes clarifying the qualifying conditions for exemptions.

b. Coordinate ASCE/SEI 7-16 Chapter 13 (Nonstructural Components) with Chapter 15 (Nonbuilding Structures) to clearly identify those items that are to be designed as nonstructural components and those to be designed as nonbuilding structures, including penthouses, billboards, large tanks, and vessels.

c. Review the application of the overstrength factor applied to anchors in concrete and masonry, and application of the factor to power-driven fasteners.

d. Limit the use of nonductile materials and systems in nonstructural components, supports, and attachments.

2. Resolve the following issues to improve the clarity and technical accuracy of the design provisions:

a. Review the organization of the nonstructural design provisions, and expand coverage for design requirements where design information is limited or lacking.

b. Develop methods for estimating nonstructural component displacements and criteria for accommodating these displacements.

c. Develop design requirements to maintain egress following a specified earthquake shaking level.

\subsection{Additional Recommendations to Improve Nonstructural Performance}

A clear, technically sound, and comprehensive set of code requirements for seismic design of nonstructural components is necessary but not sufficient to achieve acceptable performance of nonstructural components in future earthquakes. The provisions must be enforced to be effective. Requirements must also be understood 
by the broad range of design professionals responsible for specification and design of nonstructural components. Additionally, a clear understanding of performance objectives underlying the code, and their related limitations, is needed to enable appropriate decision making on a project-by-project basis. The following recommendations are intended to foster improved design and construction practices:

1. Develop educational tools to expand awareness and understanding of nonstructural seismic performance. Work to engage all disciplines in understanding their role in designing to limit earthquake damage.

2. Develop guidance documents and training to improve enforcement of nonstructural code requirements.

3. Create tools to help designers communicate project objectives on a system-bysystem and component-by-component basis.

4. Obtain cost data for projects designed for enhanced nonstructural performance. Identify conditions that lead to higher or lower cost premiums for enhanced performance. Publish data in a format to support early project planning. 



\section{Appendix A}

\section{Detailed Review of ASCE/SEI 7-16 Seismic Requirements for Nonstructural Components}

This Appendix is an expanded version of Chapter 3 of this report, with additional details on the current procedures for the seismic design of nonstructural components found in Chapter 13 of ASCE/SEI 7-16, Minimum Design Loads and Associated Criteria for Buildings and Other Structures, (ASCE, 2017a). Much of the material in Chapter 3 is repeated for context and clarity. Recommendations for clarifications, enhancements, or further study are more extensive and contain additional detail. Flowcharts are provided to describe complex interrelationships between the different design requirements.

All references are to chapters and sections of ASCE/SEI 7-16, unless designated otherwise. Portions of ASCE/SEI 7-16 have been reprinted in italics, with permission from ASCE.

\section{A.1 General (ASCE/SEI 7-16 Section 13.1)}

Section 13.1 outlines the general provisions for seismic design of nonstructural components. The current seismic design process for nonstructural components is shown in Figure A-1.

The applicable requirements for seismic design for nonstructural components are established in ASCE/SEI 7-16 Section 11.1.3 as follows:

11.1.3 Applicability. Structures and their nonstructural components shall be designed and constructed in accordance with the requirement of the following chapters based on the type of structure or component:

a. Buildings: Chapter 12;

b. Nonbuilding Structures: Chapter 15;

c. Nonstructural Components: Chapter 13;

d. Seismically Isolated Structures: Chapter 17; and

e. $\quad$ Structures with Damping Systems: Chapter 18. 


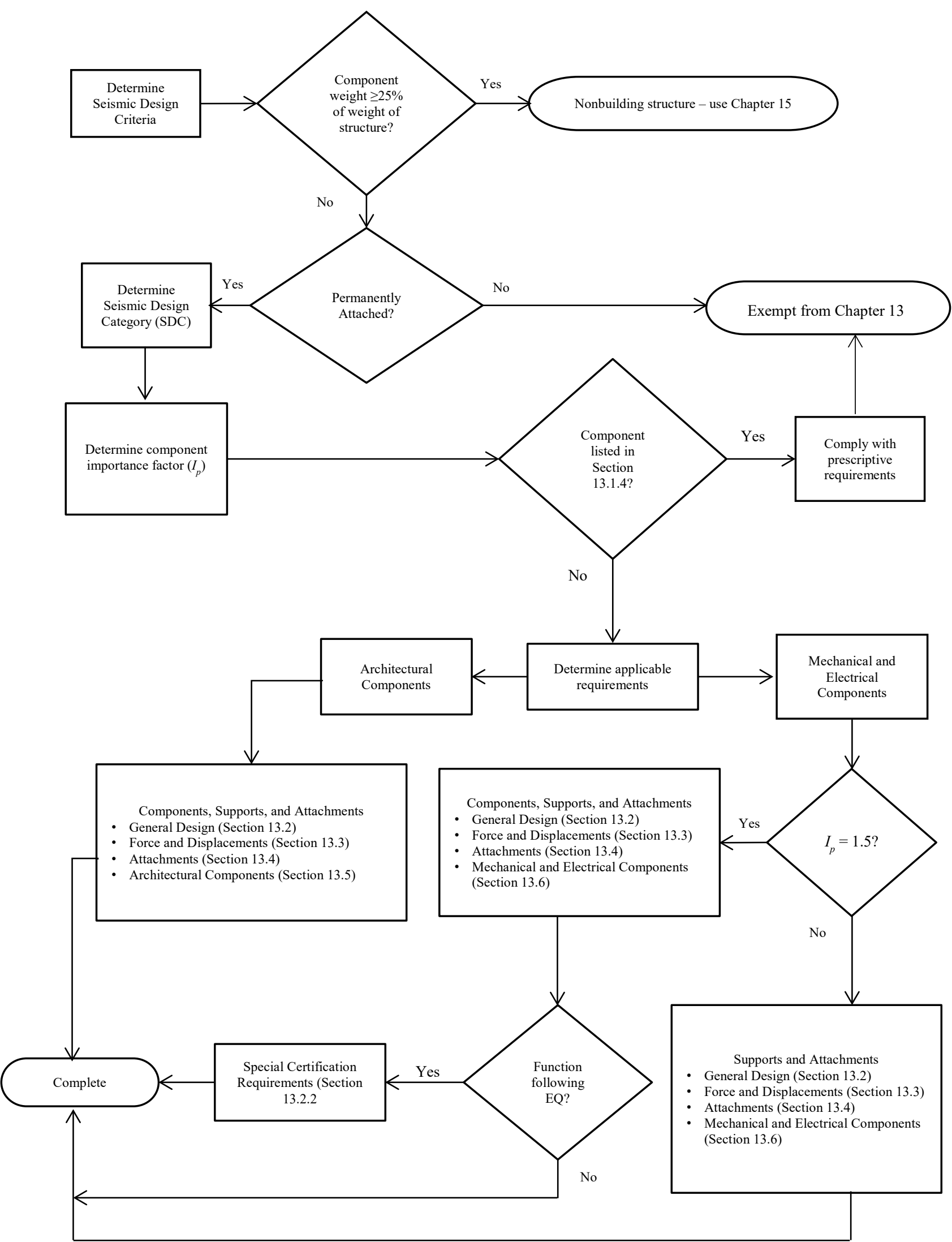

Figure A-1 Seismic design process of ASCE/SEI 7-16 for nonstructural components. 
Buildings whose purpose is to enclose equipment or machinery and whose occupants are engaged in maintenance or monitoring of that equipment, machinery, or their associated processes shall be permitted to be classified as nonbuilding structures designed and detailed in accordance with Section 15.5 of this standard.

Although Section 11.1.3 allows some buildings to be designed as nonbuilding structures, this applies only to seismic design. Chapter 13 references provisions of other chapters in ASCE/SEI 7-16 related to seismic design when needed. There are references to Chapter 12 for variables used in equations, load combinations for use with the overstrength factor, and output from a building dynamic analysis for use in the alternate lateral force calculation that uses. In general, if a requirement outside of Chapter 13 is applicable to nonstructural components; it should be referenced within Chapter 13. There are some provisions, such as load combinations, that should be referenced in Chapter 13 but are not.

\section{A.1.1 Scope (ASCE/SEI 7-16 Section 13.1.1)}

The general charging language for the chapter is found in Section 13.1.1:

13.1.1 Scope. This chapter establishes minimum design criteria for nonstructural components that are permanently attached to structures and for their supports and attachments. Where the weight of a nonstructural component is greater than or equal to $25 \%$ of the effective seismic weight, $W$, of the structure as defined in Section 12.7.2, the component shall be classified as a nonbuilding structure and shall be designed in accordance with Section 15.3.2.

The scoping section includes a number of terms that are defined in ASCE/SEI 7-16 Chapter 11:

Component, Nonstructural: A part of an architectural, mechanical, or electrical system within or without a building or nonbuilding structure.

STRUCTURE: That which is built or constructed and limited to buildings and nonbuilding structures as defined herein.

The terms "building" and "nonbuilding structure" are also defined in ASCE/SEI 7-16 Chapter 11:

BUILDING: Any structure whose intended use includes shelter of human occupants.

NONBUILDING STRUCTURE: A structure, other than a building, constructed of a type included in Chapter 15 and within the limits of Section 15.1.1.

A literal application of Section 13.1.1 suggests that while the definition of nonstructural components includes items "within and without a building or 
nonbuilding structure," components supported on grade outside of a structure are not subject to the seismic requirements of Chapter 13, since they are not permanently attached to a structure. However, they may be subject to the requirements of Chapter 15, Nonbuilding Structures, depending on the nature of the item. In practice, most engineers apply Chapter 13 to all nonstructural components, regardless of location, but the ambiguity in scope has been used to argue that if a component is not attached to a structure, it is exempt. It was never the intent to allow a designer to evade the seismic requirements by not "attaching" an item to a structure.

There is a long-standing concern with whether a given item should be designed as nonstructural component or a nonbuilding structure. A number of items are covered in both the nonstructural and nonbuilding structure chapters. This issue was explored by Bachman and Dowty (2008), who pointed out that the wide variety of real-world items make it very difficult to develop prescriptive criteria to delineate between nonstructural components and nonbuilding structures. They suggested several approaches to differentiate between nonstructural components and nonbuilding structures:

- Size. Nonstructural components are generally small and nonbuilding structures are large. Small items would be able to fit within a building, and have a height of 10 feet or less. The weight of such items is small compared to the weight of the building.

- Factory versus Field Assembly. Nonbuilding structures are typically assembled in the field while nonstructural equipment components are factory-built. Many architectural components such as ceilings and partitions, and mechanical and electrical distribution systems are assembled in the field, but it was felt that there is usually no question that these items should be considered nonstructural components.

- Basis of Design and Construction. Nonstructural components are designed and constructed to function for architectural, mechanical, and electrical purposes.

Nonbuilding structures are designed to maintain stability and support gravity and lateral loads.

Bachman and Dowty recommended that in areas where an item could be reasonably designed either way, the most conservative of the nonstructural and nonbuilding structure criteria be used. In practice, only a small number of items can potentially be classified as both nonstructural components and nonbuilding structures, including billboards and signs, chimneys, conveyers, cooling towers, stacks, tanks, towers, and vessels.

Chapter 13 only applies to "permanently attached" components. The term "permanently attached" is discussed in commentary Section C13.1.2, and is intended 
to delineate between movable or temporary components, and permanent ones. One difference between temporary and permanent components is the nature of the connections between the component and the building utilities, such as gas, water, and electricity. Large components with casters are often categorized as temporary, even though they are supported on levelling mounts and remain in one place for extended periods.

A growing concern in the nonbuilding structures design community is the tendency of engineers to refer to ground supported nonbuilding structures as nonstructural components (especially tanks and vessels). This is done in order to avoid the nonbuilding structure design and anchorage requirements, which are substantially more rigorous than those in the nonstructural provisions. Often, these tanks and vessels are much too large to qualify as nonstructural components using any of the three criteria discussed by Bachman and Dowty.

Chapter 13 requires design for nonstructural supports, defined as members, assemblies of members, or manufactured elements, including braces, frames, legs, lugs, snubbers, hangers, saddles, or struts, and associated fasteners, that transmit loads between nonstructural components and their attachments to the structure. However, Chapter 13 provides little design guidance for supports, while Chapter 15 provides design guidance for a variety of supporting structures such as pipe racks, trestles, and equipment platforms, including references to material design standards and detailing criteria based on seismic hazard level.

There is also some concern regarding the oriding and technical basis of the requirements for considering dynamic interaction between a nonstructural component and the supporting structure. When the weight of a nonstructural component is greater than or equal to $25 \%$ of the effective seismic weight, $W$, of the supporting structure, the component is required to be designed as a nonbuilding structure supported by a structure, using the procedures in Chapter 15. The requirements for this condition were introduced in the 1988 Edition of the Uniform Building Code (ICBO, 1988) and were included in the 1997 Edition of NEHRP Recommended Provisions for Seismic Regulations for New Buildings and Other Structures (FEMA, 1998), but the origins of the procedures are unclear. When design recommendations for nonbuilding structures were added to the 2000 Edition of NEHRP Recommended Provisions for Seismic Regulations for New Buildings and Other Structures (FEMA, 2001), these requirements were retained and expanded in the nonbuilding structure chapter.

The first statement of Chapter 13, "establishes minimum design criteria for nonstructural components that are permanently attached to structures....," has been viewed as a circular argument for many endeavoring to determine whether seismic restraint is required. If a component is not seismically restrained, does that mean it is 
not "permanently attached" and therefore restraint is not required? The language tends to be particularly confusing when applied to floor-mounted components weighing less than 400 pounds, which are exempt from Chapter 13 design requirements but must meet some prescriptive requirements.

\section{Recommendations}

1. The clarity of Section 13.1 suffers from imprecise terminology regarding the scope of the chapter, the identification of nonstructural components that are subject to seismic design, and selection of the proper design procedures (Chapter 13 or Chapter 15). The scope of the nonstructural requirements should be revised to clearly identify those components and systems that require seismic design, regardless of whether they are within or supported by building or nonbuilding structure, or if they are supported on grade.

2. The scoping language should clearly distinguish items subject to Chapter 13 requirements and those that fall under Chapter 15. Currently, designers often seek out the "least conservative" set of provisions for components that fall in gray areas. As part of this effort, components where both Chapter 13 and Chapter 15 can be used should be reduced to the practical minimum, and clear criteria provided to identify when Chapter 15 is to be used. It is possible to require that all billboards and signs, conveyors, large tanks and vessels, chimneys, and stacks be designed as nonbuilding structures in accordance with Chapter 15. The definition of large would be developed jointly by the nonstructural component and the nonbuilding structure design communities. A desirable side benefit of this approach will be to limit the use of nonductile systems for these items in regions of high seismic risk. Mechanical and electrical components supported by a structure or on grade would be designed as nonstructural components if they meet size and weight restrictions and as nonbuilding structures if they exceed them. Other approaches to differentiate between nonstructural components and nonbuilding structures were identified during the review and could also be explored. For example, classification of an item as a nonstructural component could consider the period of the item, the potential for dynamic amplification, and whether the item degrades in stiffness during the course of an earthquake. The design forces produced by the procedures in Chapter 13 and Chapter 15 should be consistent insofar as possible, so that the main difference is the more rigorous analysis procedures required in Chapter 15.

3. The requirements for the design of nonstructural supports should be expanded, and the possibility of referencing Chapter 15 for some types of supports should be explored as well. A two-stage analysis procedure could be used for components with significant support framing, using separate lateral designs for the component and the supports. Chapter 13 would be used to generate lateral 
forces, considering the nature of the support system when determining the lateral design force for the supports. Chapter 15 would provide design criteria for the supports. Criteria for supports constructed of cold-formed steel, wood, and concrete walls would be added to Chapter 15 .

4. It should be clarified that sections of Chapter 11, Chapter 12, and Chapter 15 may apply to nonstructural components, but only when explicitly referenced.

5. The definition of "permanently attached" and "temporary" in the commentary should be reviewed and possibly included in the body of the standard. Criteria could also be based on the length of time the components are left in the same place, although it is unclear how such a requirement could be enforced. Installation requirements for components exempt from the bulk of Chapter 13 requirements should be made more explicit.

6. The technical basis of the design provisions for dynamic interaction between nonstructural components should be reviewed. The review should verify that a mass trigger alone is sufficient when screening for dynamic interaction effects.

\section{A.1.2 Seismic Design Category (ASCE/SEI 7-16 Section 13.1.2)}

Section 13.1.2 provides the criteria for assigning a Seismic Design Category to the nonstructural component:

13.1.2 Seismic Design Category. For the purposes of this chapter, nonstructural components shall be assigned to the same Seismic Design Category as the structure that they occupy or to which they are attached.

\section{Recommendations}

The concept of "attached" should include not only structural attachments but also connections through distribution systems such as pipes, ducts, and conduits. For nonstructural components that are outside of a structure, the Seismic Design Category should be based on the facilities with which they are associated.

\section{A.1.3 Component Importance Factor (ASCE/SEI 7-16 Section 13.1.3)}

The component Importance Factor influences both the force and displacement design demands for nonstructural components. It also may trigger additional design, detailing, testing, and inspection requirements. Section 13.1.3 states:

13.1.3 Component Importance Factor. All components shall be assigned a component Importance Factor as indicated in this section. The component Importance Factor, $I_{p}$, shall be taken as 1.5 if any of the following conditions apply: 
1. The component is required to function for life-safety purposes after an earthquake, including fire protection sprinkler systems and egress stairways.

2. The component conveys, supports, or otherwise contains toxic, highly toxic, or explosive substances where the quantity of the material exceeds a threshold quantity established by the Authority Having Jurisdiction and is sufficient to pose a threat to the public if released.

3. The component is in or attached to a Risk Category IV structure or facility, and it is needed for continued operation of the facility or its failure could impair the continued operation of the facility.

4. The component conveys, supports, or otherwise contains hazardous substances and is attached to a structure or portion thereof classified by the Authority Having Jurisdiction as a hazardous occupancy.

All other components shall be assigned a component Importance Factor, $I_{p}$, equal to 1.0.

The Authority Having Jurisdiction makes the determination of what materials are deemed toxic, highly toxic, or explosive, and establishes the quantities of materials deemed to pose a threat to the public, using criteria in the fire and life safety codes. This information must be provided to the designer of the nonstructural components so that the appropriate Importance Factor can be selected. There is a discussion of toxic, highly toxic, or explosive substances in Commentary Section C1.5.3, which identifies some of the common methods of categorizing structures storing these materials. There was an interest in reviewing the criteria for determining what materials are deemed toxic, highly toxic, or explosive, and the quantities of materials deemed to pose a threat to the public be included in the nonstructural components chapter. Determination of the types and quantities of substances which trigger Section 13.1.3 Items 2 and 4 are outside of the scope of ASCE/SEI 7. Even if criteria could be consolidated from the various sources and be placed in ASCE/SEI 7, it is uncertain whether the all users would have the background and training to properly interpret and apply it.

Nonstructural components with $I_{p}$ greater than 1.0 are "designated seismic systems." The term is used later in Section 13.1 and defined in Section 11.2. All the components listed in Section 13.1.3 Item 1 through Item 4 are designated seismic systems, but are not identified as such in the section.

The term "Attachments" is defined in ASCE/SEI 7-16 Chapter 11 as:

ATTACHMENTS: Means by which nonstructural components or supports of nonstructural components are secured or connected to the seismic force-resisting system of the structure. Such attachments include anchor bolts, welded connections, and mechanical fasteners. 
In Section 13.1.3 Item 3, the component under consideration is described as "in or attached" to a structure, while in Item 4, the component is described as "attached to a structure or a portion thereof." It is unclear if these variations in the descriptions of "attachment" are intended to be substantive or stylistic.

\section{Recommendations}

1. The term "attachment" should be consistent with both the structural definition of "attachment" as physical connection to the structure, and functional connections through distribution systems such as pipes, ducts, and conduit. The definition should include functional connections to components with independent foundations, such as equipment mounted outside the structure on a slab-on-grade.

2. When the term "attachments" is used, it is often assumed to describe elements between the component supports and the structure, but it also includes elements that connect the component to the supports. Both types of attachments are of critical importance and should be discussed in the definition of the term.

3. Section 13.1.3 Item 4 should be expanded to include components that are functionally associated with, but not structurally attached to, a Risk Category IV structure, as well as components that may serve multiple structures, one or more of which are Risk Category IV.

4. Components required to control and isolate nonstructural systems that contain toxic, highly toxic, or explosive substances so they are in safe condition should also be assigned a component Importance Factor of 1.5.

5. A provision should be added stating that information must be provided to the design professional if the presence of toxic, highly toxic, or explosive materials exceeds a threshold quantity established by the Authority Having Jurisdiction and is sufficient to pose a threat to the public if released. The fire threat posed by gas piping may warrant including gas pipes among those components requiring $I_{p}=1.5$.

6. In some cases, an engineer may wish to use higher lateral forces than the code minimums for the design of select nonstructural components. The provisions should state that designing a nonessential component for a higher lateral force does not trigger the other requirements for designated seismic systems.

\section{A.1.4 Exemptions (ASCE/SEI 7-16 Section 13.1.4)}

This section introduces a list of components and systems that are exempt from all requirements of Chapter 13. It states:

13.1.4 Exemptions. The following nonstructural components are exempt from the requirements of this Chapter: 
1. Furniture (except storage cabinets as noted in Table 13.5-1).

2. Temporary or movable equipment.

3. Architectural components in Seismic Design Category B, other than parapets, provided that the component Importance Factor, $I_{p}$, is equal to 1.0.

4. Mechanical and electrical components in Seismic Design Category B.

5. Mechanical and electrical components in Seismic Design Category C provided that either:

a. The component importance factor, $I_{p}$, is equal to 1.0 and the component is positively attached to the structure; or

b. The component weighs $20 \mathrm{lbs}(89 \mathrm{~N})$ or less.

6. Discrete mechanical and electrical components in Seismic Design Categories D, E, or F that are positively attached to the structure, provided that either:

a. The component weighs $400 \mathrm{lbs}(1780 \mathrm{~N})$ or less, the center of mass is located 4 feet $(1.22 \mathrm{~m})$ or less above the adjacent floor level, flexible connections are provided between the component and associated ductwork, piping and conduit, and the component Importance Factor, $I_{p}$, is equal to 1.0; or

b. The component weighs 20 pounds $(89 \mathrm{~N})$ or less.

7. Distribution systems in Seismic Design Categories D, E, or F included in the exceptions for conduit, cable tray and raceways in Section 13.6.5, duct systems in Section 13.6.6 and piping and tubing systems in Section 13.6.7.3. Where in-line components such as valves, in-line suspended pumps, and mixing boxes require independent support, they shall be addressed as discrete components and shall be braced considering the tributary contribution of the attached distribution system.

Although Item 1 through Item 4 are straightforward, there are concerns about the exemptions. The exemption for furniture is felt to be applied too broadly, and items such as lab benches and heavy items on casters are classified as furniture and are exempt, when it was felt they should be seismically braced. For context, the Merriam-Webster Dictionary definition of furniture is "movable articles used in readying an area (such as a room or patio) for occupancy or use." This definition would exclude counters and casework, as they are attached to floors or walls. The exemption for temporary or movable equipment can be applied to items such as lab benches that, while movable, remain in place for long periods of time and are connected to the structure's utility systems. 
Section 13.1.4 Item 7 references exemption criteria for distribution systems provided in Section 13.6. The charging language of Section 13.1.4 states that the nonstructural components listed in the section are exempt from the requirements of Chapter 13. However, the components listed in Item 7 are subject to a number of requirements in Section 13.6, and therefore are not truly "...exempt from the requirements of this Chapter." Item 7 also includes requirements for when inline components require independent support. However, there are no criteria elsewhere in Chapter 13 for determining when independent support of in-line items are required, except for a 75pound limit for items in-line with ducts (Section 13.6.6). For piping systems there is no limit on the size of in-line items, provided they are "...installed in-line and rigidly connected to and supported by the piping system..." (Section 13.6.7). There are no requirements for components in-line with electrical distribution systems.

\section{Recommendations}

1. Exemptions in this section should be limited to components that actually are completely exempt from all provisions of the chapter. Some components listed in Section 13.1.4 Items 5 and 6 may be exempt from design and lateral bracing, but must meet criteria regarding positive attachment or connection flexibility and are therefore subject to some requirements of Chapter 13. The descriptions of components in Section 13.1.4 Items 5 and 6 could be expanded to clarify the extent of the exception and the qualifying conditions under which the exemption is granted, or they could be moved to a new section for components that require only positive attachment and flexible connections to distribution systems. Components in Section 13.1.4 Item 7 are subject to a number of requirements in Section 13.6 and therefore should not be included in a section listing items that are completely exempt from Chapter 13.

2. Although there is a desire in some cases to regulate furniture and temporary or movable items, the implications of providing requirements for these items must be carefully considered. The 2015 International Building Code (ICC, 2015a) Section 105.2 states that "nonfixed and movable fixtures, cases, racks, counters, and partitions not over 5 feet-9 inches in height" do not require a building permit. If furniture and movable items become subject to the seismic design provisions of Chapter 13, it is reasonable to assume that a building permit will be needed to install, modify, or move them, and appropriate fees and documentation will be required. If provisions for these items are placed in the standard but permitting is not required in the building code, the seismic provisions will likely be ignored.

3. The criteria for determining if a component is temporary are discussed in the commentary of ASCE/SEI 7-16. A definition should be included in the provisions. Countertop equipment, which varies widely in weight, is often considered "contents" by default, although many items are not really movable and have hard-connections to the building utility systems. It should be clarified 
that components that are over a threshold weight limit and that are permanently connected to the building utility systems must be designed for seismic forces, whether they are independently supported or rest on casework. Countertop equipment that is permanently connected to the building utilities and resting on casework should be subject to the seismic requirements if the combined weight of the component and casework exceeds the threshold specified in Section 13.1.4 Item 5 and Item 6 . Casework would be considered a support for equipment.

4. The term "positive attachment" should be defined in the body of Chapter 13. ASCE/SEI 7-16 Commentary Section C13.1.4 states that "positive attachment is provided when the attachment is carried out using appropriate structural-grade materials whereby explicit design calculations for the anchorage are not required." Although calculations are not required, prescriptive requirements based on the size of the component could be developed. The definition could be modified to describe the nature of the attachments, such as mechanical connection using bolts, welds, screws, or similar means that do not rely on friction solely due to the effects of gravity, and establish minimum tension and shear capacities for attachments, which could be developed based on the weight of the exempt item. The use of adhesives for positive attachment could be considered for small items.

\section{A.1.5 Pre-Manufactured Modular Mechanical and Electrical Systems (ASCE/SEI 7-16 Section 13.1.5)}

This section addresses pre-manufactured modular mechanical rooms, which may be placed at grade or supported by a structure. The modular plant itself is designed as a nonbuilding structure in accordance with ASCE/SEI 7-16 Chapter 15. The nonstructural components are designed in accordance with Chapter 13.

\section{Recommendations}

None.

\section{A.1.6 Application of Nonstructural Component Requirements to Nonbuilding Structures (ASCE/SEI 7-16 Section 13.1.6)}

This section addresses nonbuilding structures such as storage racks and tanks when they are supported by other structures. Storage racks are a narrowly defined in ASCE/SEI 7-16 as:

STORAGE RACKS: Include industrial pallet racks, moveable shelf racks, and stacker racks made of cold-formed or hot-rolled structural members. Does not include other types of racks such as drive-in and drive-through racks, cantilever racks, portable racks, or racks made of materials other than steel. 


\section{Recommendations}

As previously noted, it may be desirable to require that all billboards and signs, conveyors, large tanks and vessels, chimneys, and stacks be designed as nonbuilding structures in accordance with Chapter 15.

\section{A.1.7 Reference Documents (ASCE/SEI 7-16 Section 13.1.7)}

This section discusses the use of reference documents as a basis for seismic design of nonstructural components and places specific restrictions on the use of provisions in those documents. In general, the design earthquake forces in the reference document cannot be less than those determined in accordance with Section 13.3.1.

\section{Recommendations}

Provisions should be added that design displacements obtained from reference standards should not be less than those obtained from Section 13.3.2.

\section{A.1.8 Reference Documents Using Allowable Stress Design (ASCE/SEI 7-16 Section 13.1.8)}

This section discusses the use of reference documents that use allowable stress design as a basis for seismic design of nonstructural components.

\section{Recommendations}

None.

\section{A.2 General Design Requirements (ASCE/SEI 7-16 Section 13.2)}

Section 13.2 provides the procedures for establishing compliance of nonstructural components and systems with the seismic design provisions of ASCE/SEI 7-16. It includes a description of the required scope of the seismic design, and the methods permitted for establishing compliance with the standard.

\section{A.2.1 Applicable Requirements for Architectural, Mechanical, and Electrical Components, Supports, and Attachments (ASCE/SEI 7-16 Section 13.2.1)}

The scope of the seismic design required for nonstructural components is provided in Table 13.2-1. Seismic design is required for supports and attachments of all nonstructural components, as well as for the components themselves. In prior editions of ASCE/SEI 7, seismic design of the component itself was required for designated seismic systems, components with an Importance Factor, $I_{p}$ greater than 1.0, and for all architectural components. In ASCE/SEI 7-16, the scope of seismic design for architectural, mechanical, and electrical components is identical, regardless of $I_{p}$. However, there are exceptions in Sections 13.5 and 13.6 for some 
types of components that exempt them from specific aspects of the seismic design requirements.

Compliance with the seismic design provisions may be demonstrated by project specific design and documentation by a registered design professional or a manufacturers' certification that the component is seismically qualified. Seismic qualification may be in the form of analysis, testing, or experience data.

\section{Recommendations}

Based on the changes made to the scope of seismic design in ASCE/SEI 7-16, Table 13.2-1 could be eliminated, and the section could state that nonstructural components and their supports and attachments must meet the requirements for general design (Section 13.2), force and displacement (Section 13.3), attachment (Section 13.4), and architectural component (13.5) or mechanical and electrical components (13.6).

Nonstructural components themselves must be designed for seismic forces and displacements, regardless of the assigned an Importance Factor, $I_{p}$. For some types of architectural, mechanical, and electrical components which are inherently rugged, design of the component itself may not be warranted when $I_{p}=1.0$.

\section{A.2.2 Special Certification Requirements for Designated Seismic Systems (ASCE/SEI 7-16 Section 13.2.2)}

This section provides the requirements for active mechanical and electrical components and components with hazardous substances assigned a component Importance Factor $I_{p}=1.5$. The building and fire codes define Hazardous Materials as those chemicals or substances that are physical or health hazards as classified in International Building Code Section 307 (ICC, 2015a) and the International Fire Code (ICC, 2015b), whether the materials are in usable or waste condition. The fire and life safety codes guide the Authority Having Jurisdiction in making the determination of what materials are deemed toxic, highly toxic, or explosive, and establishes the quantities of materials deemed to pose a threat to the public. This information is needed in order to select the appropriate occupancy for the building as well as the component Importance Factor for nonstructural components that convey, support or contain these materials. Commentary in Section C1.5.3 provides a discussion of requirements related to hazardous substances in heavy industrial facilities.

It was discussed whether architectural components should be subject to the requirements of Section 13.2.2. This can occur if they are used to provide containment of hazardous substances. The influence of the failure of an architectural component on a critical component is addressed in Section 13.2.3. 


\section{Recommendations}

The provisions should include a requirement in Section 13.1 stating that information on the presence toxic, highly toxic, or explosive materials exceeding a threshold quantity established by the Authority Having Jurisdiction be provided to the design professional.

\section{A.2.3 Consequential Damage (ASCE/SEI 7-16 Section 13.2.3)}

This section requires that failure of a nonstructural component shall not result in the failure of an essential component. The term "essential component" is not defined in Chapter 11 or Chapter 13, and the defined term "designated seismic system" should be used instead. The ASCE/SEI 7-16 commentary for this section suggests a much broader scope for this section than what the standard contains. It states in part:

... It is the intent of the standard that the seismic displacements considered include both relative displacements between multiple points of support (addressed in Section 13.3.2) and, for mechanical and electrical components, displacement within the component assemblies. Impact of components must be avoided, unless the components are fabricated of ductile materials that have been shown to be capable of accommodating the expected impact loads. With protective coverings, ductile mechanical and electrical components and many more fragile components are expected to survive all but the most severe impact loads. Flexibility and ductility of the connections between distribution systems and the equipment to which they attach is essential to the seismic performance of the system.

The determination of the displacements that generate these interactions is not addressed explicitly in Section 13.3.2.1. That section concerns relative displacement of support points. Consequential damage may occur because of displacement of components and systems between support points.

The potential for impact between components that are in contact with or close to other structural or nonstructural components must be considered. However, where considering these potential interactions, the designer must determine if the potential interaction is both credible and significant. ... Special design consideration is appropriate where the failure of a nonstructural element could adversely influence the performance of an adjacent critical nonstructural component, such as an emergency generator.

\section{Recommendations}

Given the intent of the standard is that the seismic displacements considered include both relative displacement between multiple points of support and, for mechanical and electrical components, displacement within the component assemblies, an effort 
should be made to include provisions for estimating displacement within component assemblies. In lieu of a detailed analysis, a prescriptive requirement to provide a specified clearance between the component and what it might impact could be developed, as is currently provided for the installation of sprinkler piping systems in ASCE/SEI 7-16 Section 13.2.3.1 and Chapter 9 of the 2016 Edition of NFPA 13, Standard for the Installation of Sprinkler Systems, (NFPA, 2016).

\section{A.2.4 Flexibility (ASCE/SEI 7-16 Section 13.2.4)}

This section states:

The design and evaluation of components, their supports, and their attachments shall consider their flexibility and their strength.

The commentary indicates that this section is intended to deal with the ability of the component itself to accommodate displacements due to both story drift and deflections of components between points of support. The section is also intended to require consideration of anchor and support stiffness on component behavior where necessary.

\section{Recommendations}

This section needs to be expanded to more fully align with the intent. The term "flexibility" may not correctly describe what is being sought in this provision. Relative displacement capacity and stiffness might better describe the desired concepts. The introduction of displacement floor response spectra could be a major step forward in evaluating the relative displacement of nonstructural components. Relative displacement spectra for some components can be derived from floor acceleration spectra.

\section{A.2.5 Testing Alternative for Seismic Capacity Determination (ASCE/SEI 7-16 Section 13.2.5)}

This section describes the requirements for using tests to establish compliance with the seismic requirements, and references ICC-ES AC156, Seismic Certification by Shake-Table Testing of Nonstructural Components (ICC-ES, 2015) as an acceptable approach. When this compliance option is used, evidence of compliance must be submitted to the Authority Having Jurisdiction.

\section{Recommendations}

None. 


\section{A.2.6 Experience Data Alternative for Seismic Capacity Determination (ASCE/SEI 7-16 Section 13.2.6)}

This section permits the use of experience data in lieu of analysis to establish compliance with the seismic requirements.

\section{Recommendations}

None.

\section{A.2.7 Construction Documents (ASCE/SEI 7-16 Section 13.2.7)}

This section requires that design of supports and attachments for nonstructural components be shown on construction documents prepared by a registered design professional.

\section{Recommendations}

None.

\section{A.3 Seismic Demands on Nonstructural Components (ASCE/SEI 7-16 Section 13.3)}

Section 13.3 describes the methods for computing the force and displacement demands on nonstructural components.

\section{A.3.1 Seismic Design Force (ASCE/SEI 7-16 Section 13.3.1)}

The methods for determining horizontal and vertical seismic forces are described in Sections 13.3.1.1 and 13.3.1.2, respectively. Section 13.3.1.3 covers non-seismic loads greater than the calculated seismic loads. Section 13.3.1.4 provides options for determining the design force using dynamic analysis including floor response spectra.

\section{Recommendations}

The technical aspects of the seismic force equations are a focus of studies summarized in Chapters 4 and 5 of this report, and are not discussed here. The following recommendations are focused on the clarity, consistency, and enforceability of the requirements.

1. In Section 13.3.1.1, the overstrength factor $\Omega_{0}$, given in Tables 13-5.1 and 13-6.1 is discussed. This variable does not appear in any of the equations in Section 13.3.1.1. The discussion could potentially be located in Section 13.4.2, Anchors in Concrete and Masonry, since this is the only section where the overstrength factor is used.

2. In Section 13.3.1.1, there is a requirement that horizontal forces, $F_{p}$, be applied independently in two orthogonal horizontal directions. It should be clarified that 
the loads should be applied in a manner to generate the largest demands on the component, supports, and attachments.

3. The horizontal loads must be applied in combination with service or operating loads associated with the component as well as dead loads, although this is not explicitly stated. There are no references to seismic load combination formulas in Chapter 13, aside from the reference to allowable stress design (ASD) load combinations in Section 13.1.8 and a reference to the special load combinations of Section 12.4.3 for anchors in Section 13.3.1. A specific reference to the appropriate load combinations should be made, similar to what is done in Section 15.4.1 Item 8 for nonbuilding structures. In the past, mixing of ASD and load and resistance factor design (LRFD) demands and capacities has occurred, and a discussion of this issue should be added to the commentary.

4. Section 13.3.1.2 should include a requirement that vertical seismic loads be combined with other loads.

\section{A.3.2 Seismic Relative Displacements (ASCE/SEI 7-16 Section 13.3.2)}

This section requires that the effects of seismic displacements be considered. Seismic relative displacements are determined for displacements within structures in Section 13.3.2.1 and between structures in Section 13.3.2.2. There are general requirements that nonstructural components be designed to accommodate relative displacements (Section 13.1.7 Item 2, Sections 13.4.1 and 13.6.2). There is no guidance in Section 13.3.2 on how the effects of displacements are to be considered, but there is guidance for some specific components in Sections 13.5 and 13.6.

\section{Recommendations}

In order to fully implement the requirements of Section 13.2.4, methods to estimate relative displacement demands between components on the same floor are needed, as well as criteria for determining relative displacement capacity. The inclusion of generic relative displacement floor response spectra would be of great help in this task.

\section{A.3.3 Component Period (ASCE/SEI 7-16 Section 13.3.3)}

This section provides a method for estimating the component period, $T_{p}$.

\section{Recommendations}

The estimation of component period is often calculated based on the dynamic characteristics of the component as if it were rigidly attached. This is almost never the case, and a component that is anchored to a concrete slab will almost certainly exhibit a dynamic response that is influenced by the anchorage. The feasibility of 
considering anchorage flexibility in the component period calculation should be explored.

\section{A.4 Nonstructural Component Anchorage (ASCE/SEI 7-16 Section 13.4)}

This section covers the requirements for attaching components to the structure. Components must be positively attached to the structure, with the exception of rooftop solar panels that meet the requirements of Section 13.6.12. A continuous load path between the component and the structure is required, and must be documented.

\section{Recommendations}

1. While this section is titled "Nonstructural Component Anchorage," it should be revised to "Nonstructural Component Attachments," since anchors are a subset of attachments that also includes welds, screws, and other forms of attachments.

2. The reference to photovoltaic panels should be an exception, rather than the opening statement of the second paragraph.

3. There are two load paths to consider: the load path from the component through the supports to the attachments to the supporting structure (or to grade), and, for components supported by a building, nonbuilding structure, or independent foundation, the load path from the point of attachment to the structure to the point in the supporting structure where the loads from the nonstructural component no longer govern the design of structural members or connections. The paragraph should be revised to clarify this intent, and what is meant by "structure" and "supporting structure."

\section{A.4.1 Design Force in the Attachment (ASCE/SEI 7-16 Section 13.4.1)}

This section limits the value of the component response modification factor, $R_{p}$, to 6 when calculating demands in attachments.

\section{Recommendations}

There is concern that use of values of $R_{p}$ of 9 and 12 is inappropriate for nonstructural components in general, as they imply a very high level of inelastic response in the component. In practice, the minimum design force in Section 13.3.1.1 governs in nearly all cases when $R_{p}=9$, and in every case when $R_{p}=12$. The values of $R_{p}$ should be revised based on the concepts developed in Chapter 4 of this report, which establish reasonable upper bounds on inelastic behavior. 


\section{A.4.2 Anchors in Concrete or Masonry (ASCE/SEI 7-16 Section 13.4.2)}

This section contains the requirements for determining the demands and capacities for cast-in-place and post-installed anchors in concrete and masonry. For anchors in concrete, reference is made to ACI 318, Building Code Requirements for Structural Concrete and Commentary, (ACI, 2014) Chapter 17. For anchors in masonry, reference is made to TMS 402, Building Code Requirements and Specification for Masonry Structures and Related Commentaries (TMS, 2011), and a description of when use of the overstrength factor $\Omega_{0}$ is indicated. For post-installed anchors in concrete and masonry, ACI 355.2, Qualification of Post-Installed Mechanical Anchors in Concrete and Commentary, (ACI, 2007) is referenced.

\section{Recommendations}

1. The application of component-specific overstrength factors should be reviewed. Determining when the overstrength factor $\Omega_{0}$ should be applied can be difficult for the designer, with criteria included in both ASCE/SEI 7 and the concrete and masonry standards. A discussion of when it is appropriate to apply the overstrength factor to demands on anchors should be included in this section for the convenience of the user, even if repeats information that is available in the concrete and masonry standards. This discussion should further develop the concept of ductile yielding introduced in Section 13.4.2.2 Exception Item 1. Capacity design concepts for anchors used in other design standards such as the National Building Code of Canada (NRC, 2015) should be reviewed as part of this effort.

2. Factors of safety for post-installed anchors are established through acceptance criteria developed by product evaluation services, not ASCE/SEI 7-16. In recent editions of the International Building Code, strength design loads for postinstalled anchors are determined using statistical evaluation techniques and are based on the 5\% fractile of test results, which provides a very high level of confidence in the anchor capacities. Strength reduction factors varying from 0.60 to 0.75 are applied to account for normally expected variations in anchor resistance, and the capacities of anchors may in some cases be reduced by a further $25 \%$ when resisting seismic forces. Where a ductile steel yielding element cannot be identified in the component load path, these anchor capacities are compared to demands calculated using an overstrength factor $\Omega_{0}$ that varies from 1 to $2 \frac{1}{2}$. While these provisions provide conservative estimates of the capacities of anchors in concrete, the degree of conservatism inherent in the design of nonstructural components and their supports is not well understood. The implicit safety factors for both nonstructural components and post-installed anchors are needed to calibrate the values of $\Omega_{0}$ and improve the confidence that nonductile anchors in concrete and masonry have sufficient capacity. 
3. Criteria for the use of shot pins in concrete and masonry needs clarification, including whether it is intended that $\Omega_{0}$ be applied when using the prescriptive capacities for shot pins.

4. It may be desirable to apply a factor to the calculated strength of yielding components in Section 13.4.2.2 Exception Item 1 to account for the effects of strain hardening.

5. When determining the design strength of the anchor for comparison with the capacity of a yielding element in the load path, it should be clarified that for the purposes of this check, the design strength may be governed by yielding of the anchor itself or a nonductile failure mode in the anchor, whichever is less.

6. The design requirements should encourage the use of connections with ductile bodies along with capacity design of the other elements of the connection, similar to the procedures in the National Building Code of Canada.

\section{A.4.3 Installation Conditions (ASCE/SEI 7-16 Section 13.4.3)}

This section requires that the effects of prying action on fasteners must be considered.

\section{Recommendations}

Prying occurs in many connections, and additional guidance in the standard would be helpful. The effects of prying on attachments are often ignored in design, especially for eccentric hangers. References can be made in the commentary to other standards that deal directly with prying in connections. In addition, instances where prying can be ignored should be discussed.

\section{A.4.4 Multiple Attachments (ASCE/SEI 7-16 Section 13.4.4)}

This section addresses design of multiple attachments at one location. Designs of anchorage to concrete in accordance with Chapter 17 of ACI 318 are considered to satisfy the requirement.

\section{Recommendations}

The most common application for this requirement is probably base plates with multiple anchors, although there are other possible applications. For example, an air handler may have a long row of anchor bolts along each side of the component. In such cases, the requirements of Chapter 17 of ACI 318, which are deemed to comply, may not adequately address the situation. Design per Chapter 17 of ACI 318 deals with groups of anchors in close enough proximity that the capacity of an anchor is influenced by an adjacent anchor. Design per Chapter 17 of ACI 318 should be deemed to comply only for groups of anchors in close proximity. In other cases, such 
as a component where there are anchors spaced several feet apart, it may be necessary to consider the stiffness and ductility of the component supports, the attachments, and the structure, as required in Section 13.4.4.

\section{A.4.5 Power-Actuated Fasteners (ASCE/SEI 7-16 Section 13.4.5)}

Power-actuated fasteners are only permitted under seismic loading for limited applications. This section describes the cases where they may be used.

\section{Recommendations}

The exemption permitting the use of these fasteners for seismic loading is now applied to other cases, e.g., partition wall sill plate connections in light gage steel framing. A review of the basis for this exemption and applicability to other nonstructural applications should be conducted.

\section{A.4.6 Friction Clips (ASCE/SEI 7-16 Section 13.4.6)}

This section limits the use of friction clips in Seismic Design Categories D, E, or F.

\section{Recommendations}

The definition of a "friction clip" should be expanded. It is unclear how this section would be applied to items other than beam clamps that rely essentially on friction.

\section{A.5 Architectural Components (ASCE/SEI 7-16 Section 13.5)}

\section{A.5.1 General (ASCE/SEI 7-16 Section 13.5.1)}

Section 13.5.1 provides general requirements for seismic design of architectural components. Users are referred to Table 13.5-1 for design coefficients. An exception is provided for components suspended on chains or cables.

\section{Recommendations}

Additional information is needed to aid in the implementation of seismic design for architectural components. There are 15 groups of components listed in Table 13.5-1, while design narrative is provided within Section 13.5 for only five groups of components. Industry standards should be referenced if they are available.

The following are recommendations for architectural components that lack design narrative:

1. Cantilever elements braced below or above their center of mass. These include elements that are either unbraced or braced to the structural frame below its center of mass, and those that are braced to the structure above their center of mass. They include chimneys, stacks, and parapets. Currently there are no restrictions on the use of nonductile construction for these items or other 
nonstructural components in regions of high seismic risk. For example, there is no restriction on the use of unreinforced masonry for chimneys, parapets, and cantilever nonstructural walls. Limitations on the use of nonductile construction in areas of high seismic risk are needed.

2. Veneer with either limited or low deformability elements or attachments. The user could be directed to the prescriptive requirements in the International Building Code Chapter 14, which include requirements for veneer attachment and supports. Since veneer performance is highly dependent on the behavior of the supporting structure, veneer should be associated with Section 13.5.5, which covers deflection due to out-of-plane bending.

3. Penthouses, except those that are framed by an extension of the building frame. Penthouses are treated as an architectural component. Section 1510.2.2 of the 2015 International Building Code, states that the aggregate area of all penthouse and other enclosed rooftop structures is limited to one-third the area of the supporting roof deck, meaning penthouses can be large structures. Chapter 13 provides no limitations on the structural systems and detailing used for penthouses. Ordinary structural systems may be used in regions of high seismic hazard. The design requirements for penthouses should be moved to Chapter 15, and be treated as nonbuilding structures similar to buildings, supported by another structure. Chapter 15 includes limitations on the use of nonductile lateral systems in regions of high seismic hazard, and provides references to appropriate standards for different construction materials.

4. Cabinets. This includes permanent floor supported storage cabinets, library shelving, book stacks, and bookshelves over 6 feet tall. Given the requirements in Section 13.2.1 for architectural components, a strict reading of the standard would require design of the attachments, supports, and the component itself. In practice, this is rarely done. The seismic design of the component itself could be limited to cantilevered components intended to support heavy items such as book stacks. It is unclear if these provisions apply to casework that is not a storage cabinet and over 6 feet tall. The exception to Section 13.1.4 is for storage cabinets, but Table 13.5-1 also covers library shelving, bookstacks, and bookshelves over 6 feet tall. It should be clarified whether the exemption also applies to these items.

5. Laboratory equipment. Like cabinets, the requirements in Section 13.2.1 for architectural components require design of the attachments, supports, and the equipment itself. Design of the equipment should only be needed for components with an $I_{p}$ of 1.5 .

6. Appendages and ornamentations. These items are not discussed in Chapter 13, aside from their entry in Table 13.5-1, and are only mentioned in passing in the 
commentary. Appendages are defined in Chapter 11 as an architectural component such as a canopy, marquee, ornamental balcony, or statuary. Guidance should be provided regarding selection of materials for these components in higher seismic design categories. Nonductile construction, such as unreinforced masonry or ordinary concrete frame elements should be prohibited.

7. Signs and billboards. These items are also not discussed in Chapter 13 provisions or commentary. These items are currently included in Chapter 15. Removing them from Chapter 13 would mean both ground- and structuresupported components would be subject to design and detailing requirements.

8. Other rigid components and other flexible components. These are catch-all categories for architectural components that do not fit any other description. These components are further delineated by whether they are constructed with high-, limited-, or low-deformability elements and attachments. Deformability of a component is defined in Chapter 11 as a function of the ratio of the ultimate deformation to the limit deformation. Classifying a nonstructural component made up of elements with different configurations and materials in this manner is problematic. The design requirements should be included for nonstructural components made up of multiple elements. Pendant light fixtures continue to perform poorly in earthquakes, with recent examples in the 2014 Napa Earthquake (FEMA, 2015a). These fixtures should not be exempt from seismic design.

\section{A.5.2 Forces and Displacements (ASCE/SEI 7-16 Section 13.5.2)}

This section requires that all architectural components be designed for seismic forces but only some architectural components, those that pose a life-safety hazard, need be designed for relative displacements.

\section{Recommendations}

This section could be revised to note that, for the purposes of determining whether relative displacements need to be considered, Life Safety objective includes potential falling hazards and loss of function for essential components such as exit stairs and fire rated partitions. Guidance is needed for determining the component capacity for displacement checks.

\section{A.5.3 Exterior Nonstructural Wall Elements and Connections (ASCE/SEI 7-16 Section 13.5.3)}

This section provides requirements for exterior nonstructural wall panels or elements that are attached to or enclose the structure. There are requirements for 
accommodating seismic relative displacements and detailing requirements for connections.

\section{Recommendations}

1. There are no design guidelines referenced for cladding connections and minimal discussion of the commentary. References to available resources such as the $P C I$ Design Handbook (PCI, 2017) are needed.

2. Table 13.5-1 has three entries for nonstructural wall elements: wall element, body of wall panel connections, and fasteners of the connecting system. These terms and associated design requirements should be described more fully in the section with an example in the commentary.

3. Section 13.5.3 states "Such elements shall be supported by means of positive and direct structural supports or by mechanical connections and fasteners." The term "positive support" does not appear to be defined in ASCE/SEI 7-16. It should be clarified if this term is intended to cover haunches, corbels, and the connection types.

4. While ASCE/SEI 7-16 has a single design objective, Life Safety at the Design Earthquake shaking level, many cladding systems are explicitly designed for two design levels. In addition to the Life Safety design, there is a serviceability check for a smaller seismic event. This approach should be discussed in the commentary.

\section{A.5.4 Glass (ASCE/SEI 7-16 Section 13.5.4)}

This section only contains a pointer to Section 13.5.9.

\section{Recommendations}

It is recommended that this section be eliminated.

\section{A.5.5 Out-of-Plane Bending (ASCE/SEI 7-16 Section 13.5.5)}

This section requires that transverse and out-of-plane bending or deformation of components or systems subject to seismic forces determined in Section 13.5.2 shall not exceed their capacity. The commentary states that the intent of this section is to preclude out-of-plane failure of heavy materials, such as brick or block, or applied finishes, such as stone or tile.

\section{Recommendations}

This section should be aligned with the commentary, with references to the prescriptive requirements in Chapter 14 of the International Building Code, which includes requirements for veneer attachment and supports. 


\section{A.5.6 Suspended Ceilings (ASCE/SEI 7-16 Section 13.5.6)}

This section contains provisions for suspended ceilings, and includes exceptions for suspended ceilings with small areas, gypsum board ceilings surrounded by walls or soffits braced to the structure above, and ceilings with integral construction. The majority of the section deals with industry standard construction for acoustical tile or lay-in panel ceilings and integral ceiling systems.

\section{Recommendations}

Section 13.5.6 does not provide guidance for suspended ceiling systems other than lay-in types, such as ceilings above large spaces in theaters and airports, nor does it provide guidance for suspended gypsum board ceilings or cloud ceilings. In recent earthquakes, failures have been noted in some of these systems. Expansion of these provisions to encompass these types of ceiling systems is needed.

\section{A.5.7 Access Floors (ASCE/SEI 7-16 Section 13.5.7)}

Section 13.5.7 provides seismic design requirements for seismic access floors and components supported by them.

\section{Recommendations}

None.

\section{A.5.8 Partitions (ASCE/SEI 7-16 Section 13.5.8)}

This section provides general requirements for all partitions greater than 6 feet in height and for partitions tied to the ceiling. These systems must be braced independent of ceiling system bracing. An exception is provided for partitions that do not exceed 9 feet in height and meet weight and lateral force criteria.

\section{Recommendations}

1. ASCE/SEI 7-16 does not put any restrictions on the type of construction used for nonstructural partitions, regardless of the seismic hazard. There is an entry in Table 13.5-1 for "plain (unreinforced) masonry" partitions, which permits them to be used in Seismic Design Category (SDC) C, D, E, and F, regardless of Risk Category. Unreinforced masonry partitions should not be permitted in SDC D, $\mathrm{E}$, and $\mathrm{F}$ and should be subject to additional design requirements for out-of-plane support and isolation from the building structural system in SDC C.

2. A reference is made to providing bracing for partitions such that horizontal deflection at the partition head is compatible with ceiling deflection requirements as determined in Section 13.5.6 for suspended ceilings and "elsewhere in this section for other systems." They are no ceiling deflection requirements in Section 13.5.6. The intent and implementation of this requirement needs clarification. 
3. Lateral bracing to the structure is only required for partitions over 6 feet in height. For partition installations that support significant storage, such as book bins, anchorage should be required to maintain stability under seismic loading. This would require that in addition to partition height, the weight of contents in book bins, shelving, or other storage supported by the partitions be considered when determining if the partition should be designed for seismic forces.

4. An exception for partitions not exceeding 9 feet in height suggests that these partitions do not require any seismic design considerations at all, since it seems to be an exemption from all of Section 13.5.8.1. This could result in inadequate anchorage to the floor below and to the ceiling or deck above. The commentary clarifies that the exemption is only intended to permit the ceiling bracing to provide lateral support for the partition. The provisions should be revised to align with the commentary.

\section{A.5.9 Glass in Glazed Curtain Walls, Glazed Storefronts, and Glazed Partitions (ASCE/SEI 7-16 Section 13.5.9)}

The requirements for glazing systems in this section focus on providing adequate design drift capacity.

\section{Recommendations}

None.

\section{A.5.10 Egress Stairs and Ramps (ASCE/SEI 7-16 Section 13.5.10)}

This section provides requirements for ensuring adequate drift capacity for egress stairs. Connections between stairs and the structure must be designed to accommodate story drifts without loss of vertical support.

\section{Recommendations}

The operability of doors at the base of required exit ramps and stairways should be examined, and provisions to improve their operability following a seismic event are needed. The magnitude of the event to be considered must be determined.

\section{A.6 Mechanical and Electrical Components (ASCE/SEI 7-16 Section 13.6)}

\section{A.6.1 General (ASCE/SEI 7-16 Section 13.6.1)}

Section 13.6.1 provides general requirements for seismic design of mechanical and electrical components. Users are referred to Table 13.6-1 for design coefficients. The user is referred to Section 13.4 for attachments to the structure. An exception is provided for suspended components on chains or cables. There is a general requirement that when seismic design is required, the dynamic effects of the 
components, their contents, supports, and attachments must be considered, as well as interactions between the structure and other components.

\section{Recommendations}

None.

\section{A.6.2 Mechanical Components (ASCE/SEI 7-16 Section 13.6.2)}

This section provides general requirements for mechanical components, including distribution systems and equipment. Mechanical components with an Importance Factor greater than 1.0 are subject to additional design requirements. Section 13.6.2.1 provides acceptance criteria for components that have been qualified in accordance with the requirements of ANSI/AHRI Standards 1270 (I-P) and 1271 (SI), Requirements for Seismic Qualification of HVACR Equipment, (ANSI/AHRI, 2015).

\section{Recommendations}

None.

\section{A.6.3 Electrical Components (ASCE/SEI 7-16 Section 13.6.3)}

This section provides general requirements for electrical components, including distribution systems and equipment. Electrical components with $I_{p}$ greater than 1.0 are subject to additional requirements, which include provisions to avoid seismic impact, detailing requirements for battery racks, transformers, and electrical cabinets, as well as consideration of relative displacements.

\section{Recommendations:}

None.

\section{A.6.4 Component Supports (ASCE/SEI 7-16 Section 13.6.4)}

Section 13.6.4 provides requirements for mechanical and electrical component supports, and the means by which they are attached to the component. While components with an $I_{p}=1.0$ need not be designed for relative displacements, the design for the supports must consider forces and displacements determined in Sections 13.3.1 and 13.3.2.

Section 13.6.4.1 provides guidance if standard supports or proprietary supports are used, such as ASME B31, Standards for Pressure Piping (ASME, 2014), NFPA 13, or MSS SP-58, Pipe Hangers and Supports - Materials, Design, and Manufacture, (MSS, 2002). Section 13.6.4.2 requires the component supports to be designed to accommodate the seismic relative displacements between points of support. Section 13.6.4.3 requires that the connections between the supports and the component be 
designed to accommodate both the design forces and displacements. For components with $I_{p}=1.5$, the local region of the support attachment point to the component must be evaluated for load transfer. Section 13.6.4.4 requires that materials used for supports and attachments be constructed of materials suitable for the application, considering the effects of service conditions.

Section 13.6.4.5 contains four additional requirements for mechanical and electrical supports.

\section{Recommendations}

Section 13.6.4 could benefit from editing to improve clarity. For example, Section 13.6.4.3 states that for components with $I_{p}=1.5$, the region of the component at the point of attachment to the support should be evaluated, which might suggest that the analysis may be limited to only a portion of the component. This is possibly in conflict with Table 13.2-1 that states the component itself needs to be designed for seismic loads, which would include the area at the point of attachment of the supports. The method for determining the relative displacement for which the components are to be designed for should be more clearly defined, and the acceptance criteria for accommodating the relative displacement is needed.

The following recommendations are specific to Section 13.6.4.5:

1. Item 1 needs additional clarification. The commentary does not describe what is meant by "support engagement." Item 4 should include the footnote to Table 13.6-1. It would be helpful to have a sketch of the snubber requirements in the commentary for Section 13.6.4.5.

2. General provisions for the attachment of the piping, conduit, or ducts to in-line components, such as a valve or pump installed in a run of piping, are needed. If there is a flexible connection between the distribution system and the in-line component, and the distributed system itself requires bracing, then the in-line item should have a discreet bracing system. Care must be taken when developing these provisions, since they apply to heavy industrial facilities as well as other types of structures. There are three types of flexible piping connections: flexible hoses, grooved joints, and loops. The first two types of connections are common in non-industrial structures. However, for heavy industrial facilities, the first two types are uncommon and loops are generally used. In heavy industrial facilities, the most common in-line component is a valve, where the valve housing and nozzles are typically stronger than the pipe. Location of restraints (vertical, transverse, and longitudinal) in industrial facilities should be determined from pipe stress analysis considering all loadings (including seismic), and should include the weight of the component. In these situations, the prescriptive requirements for flexible connections should not apply. 


\section{A.6.5 Distribution Systems: Conduit, Cable Tray, and Raceways (ASCE/SEI 7-16 Section 13.6.5)}

This section contains a general requirement that electrical distribution systems be designed to meet the force and relative displacement requirements of Section 13.3. Depending on the installation configuration, many electrical distribution systems are exempt from force and relative displacement requirements. Figure A-2 shows the process for determining whether seismic design of electrical distribution systems for forces and relative displacement are required. Exceptions are provided for raceways and cable trays with $I_{p}=1.0$ supported by trapeze assemblies, and conduit, cable trays, and raceways supported by individual rod hangers, provided they meet certain prescriptive requirements. All conduits less than 2.5 inches trade size are exempt, regardless of $I_{p}$. Conduits greater than 2.5-inch trade size that are subject to relative displacements must be provided with flexible connections or otherwise designed to accommodate the displacement. Electrical distribution systems with an $I_{p}=1.5$ that cross seismic joints must be designed for relative seismic displacements, regardless of size.

\section{Recommendations}

Section 13.6.5 Exception 1.d includes conduit, which is not mentioned in the charging paragraph. This should be clarified. Provisions are needed for components installed in-line with the electrical distribution system.

\section{A.6.6 Distribution Systems: Duct Systems (ASCE/SEI 7-16 Section 13.6.6)}

Figure A-3 shows the process for determining whether seismic design for forces and relative displacement are required for ducts. There is a general requirement that duct systems be designed for seismic forces and seismic relative displacements as required in Section 13.3.

In-line components weighing more than 75 pounds must be supported and braced independent of the ducts. Smaller in-line components may be supported by the duct, provided they are attached with mechanical fasteners to rigid duct on both sides. Piping and conduit attached to in-line equipment must be provided with adequate flexibility to accommodate seismic relative displacements. Depending on the installation configuration, some duct systems are exempt from force and relative displacement requirements, provided they do not carry toxic, highly toxic, or flammable gases, or are not used for smoke control. Exceptions are provided for ducts with $I_{p}=1.0$ supported by trapeze assemblies and individual rod hangers. 


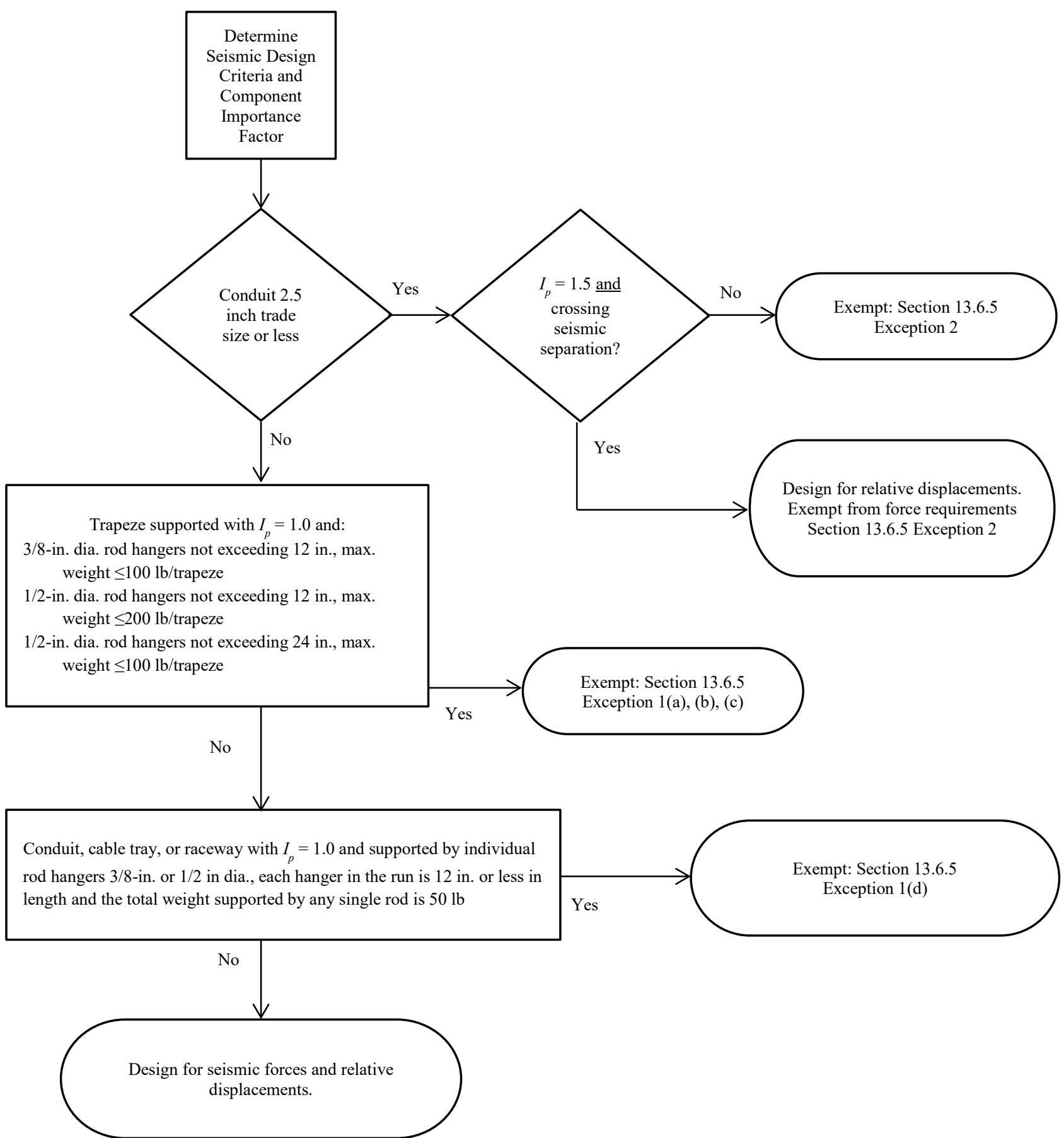

Figure A-2 Seismic design requirements for electrical distribution systems, applicable for SDC C, D, E, and $\mathrm{F}$. 


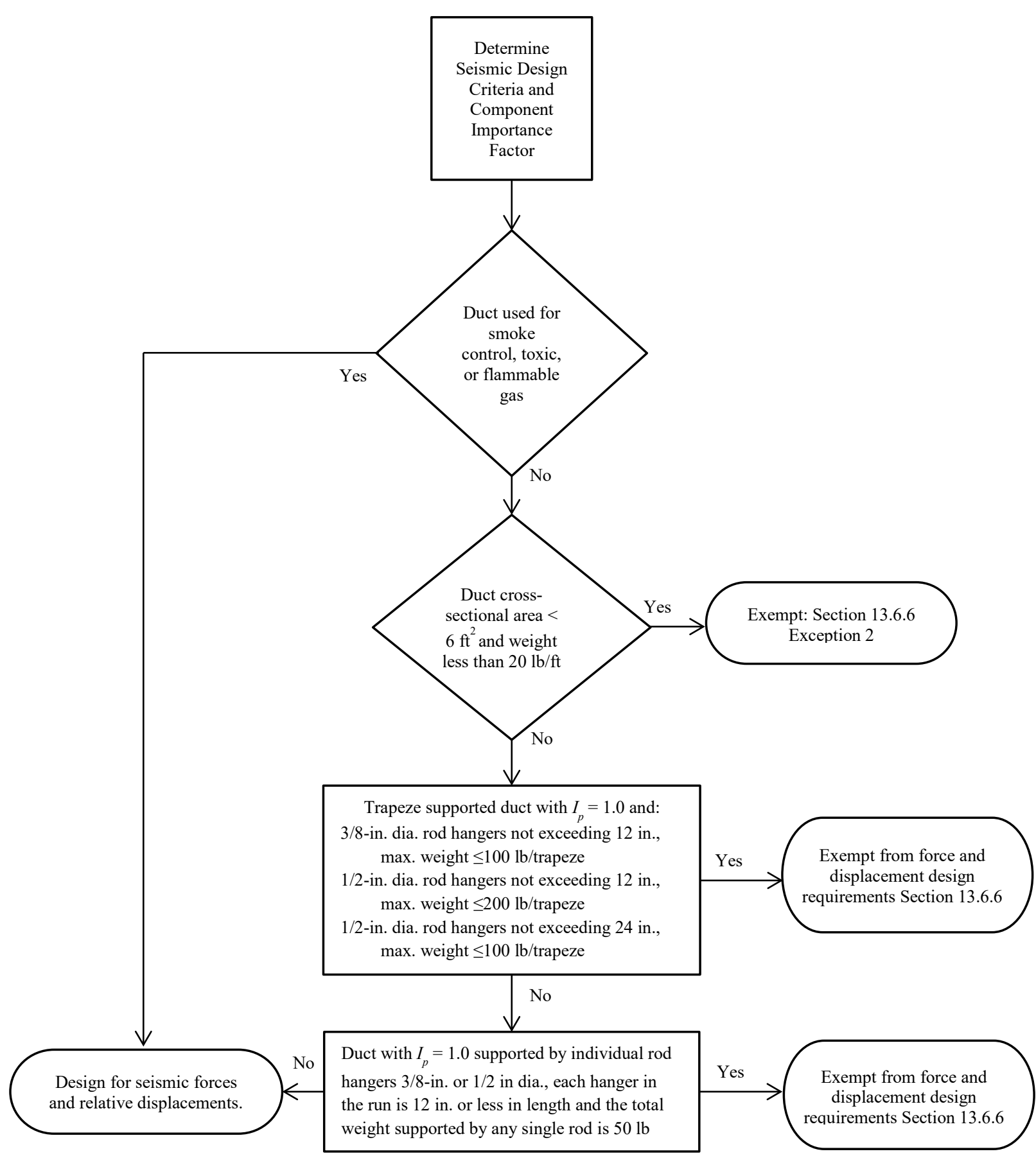

Figure A-3 Seismic design requirements for duct systems, applicable for SDC C, D, E, and F.

All ducts with a cross-sectional area less than $6 \mathrm{ft}^{2}$ and weight less than $20 \mathrm{lbs} / \mathrm{ft}$ are exempt, regardless of $I_{p}$, provided provisions are made to avoid impact with other ducts or mechanical components or to protect the ducts in the event of such impact.

\section{Recommendations}

Given that ducts with a cross-sectional area less than $6 \mathrm{ft}^{2}$ and weighing less than $20 \mathrm{lbs} / \mathrm{ft}$ are exempt from the seismic force and relative displacement requirements, it 
is unclear if a trapeze assembly supporting multiple ducts eligible for this exemption is also exempt, regardless of the total weight supported by the trapeze.

\section{A.6.7 Distribution Systems: Piping and Tubing Systems (ASCE/SEI 7-16 Section 13.6.7)}

Piping and tubing systems may be designed and constructed in accordance with the national standards listed in ASCE/SEI 7-16 or be designed in accordance with the requirements in Section 13.6.7. Design requirements for use with the American Society of Mechanical Engineers (ASME) pressure piping system requirements are provided in Section 13.6.7.1; for fire protection sprinkler piping in Section 13.6.7.2; and for elevator system piping in Section 13.6.11. When these or other approved standards are not used, allowable stresses for combined seismic and service loads are provided for piping and connections. Figure A-4 shows the process for determining whether seismic design for forces and relative displacement are required for piping.

Piping not detailed to accommodate the seismic relative displacements at connections to other components must be provided with connections that have sufficient flexibility to avoid a connection failure between the piping and component. Suspended components that are installed in-line, and that are rigidly connected to and supported by the piping system, are considered part of the piping system for the purposes of determining the need for and sizing of lateral bracing. Where unbraced piping is connected to a braced component, flexibility must be provided to accommodate relative movement between the piping and the component.

Pressure piping systems and their supports, designed and constructed in accordance with ASME B31 are deemed to meet the force, displacement, and other requirements of this section, provided the force and displacement requirements of Section 13.3 are used in lieu of any specific force and displacement requirements provided in ASME B31. Materials meeting the toughness requirements of ASME B31 are considered high-deformability materials. Fire protection sprinkler piping, pipe hangers, and bracing designed and constructed in accordance with NFPA 13 are deemed to meet the force and displacement requirements ASCE/SEI 7-16. The exceptions of Section 13.6.7.3 may not be applied to fire protection sprinkler piping.

Section 13.6.7.3 provides exceptions for piping and tubing systems. Design for the seismic forces of Section 13.3 is not required for piping systems with $I_{p}=1.0$ that meet the specified support and pipe size requirements. The exceptions are dependent on the pipe diameter and component Importance Factor, and there are separate criteria for pneumatic tube systems. Flexible connections, expansion loops or other assemblies must be provided to accommodate the relative displacement between components and piping, and trapeze assemblies or individual rod hangers supporting piping must meet specified criteria. 


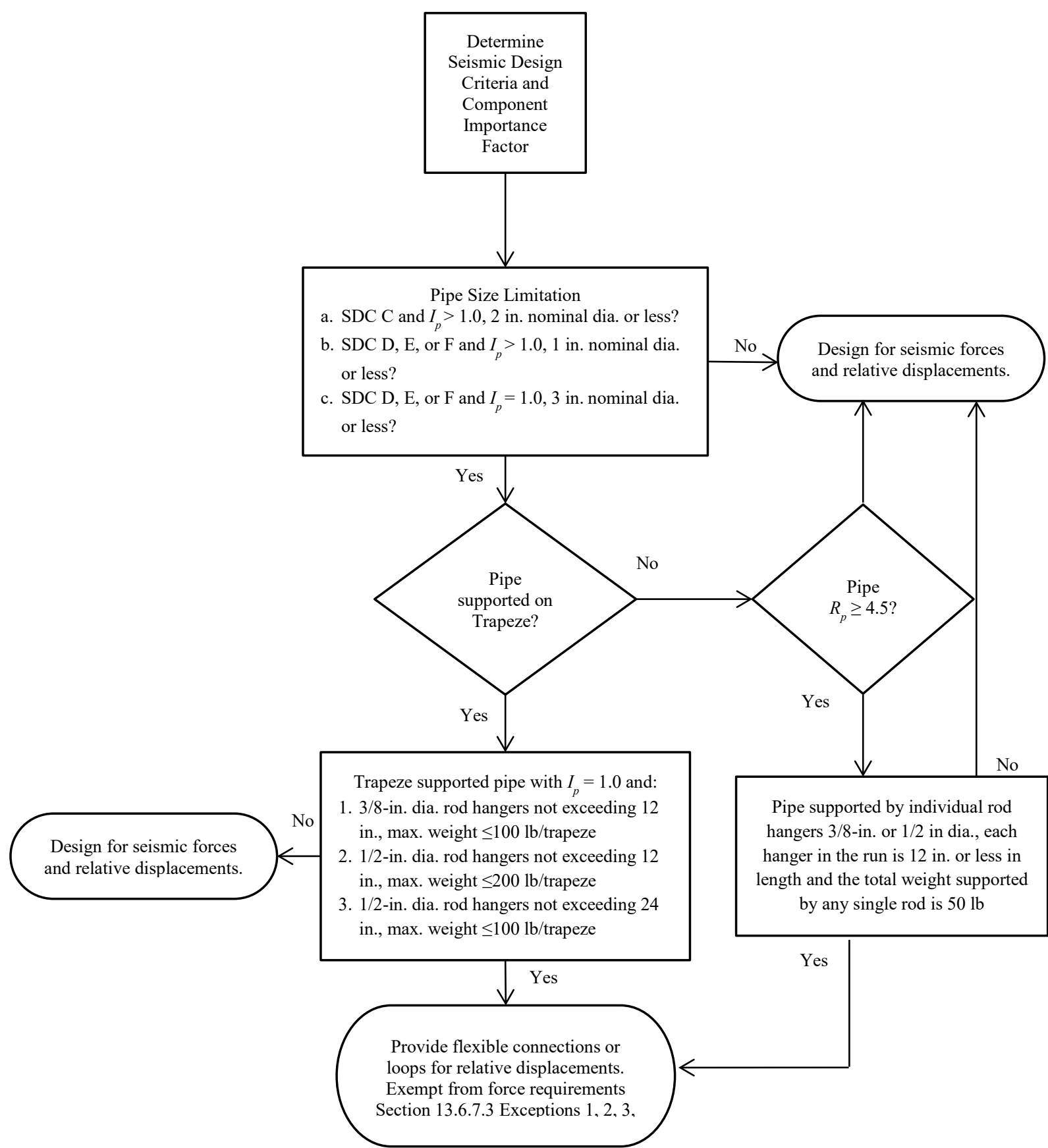

Figure A-4 Seismic design requirements for piping systems, applicable for SDC C, D, E, and F.

Pneumatic tube systems supported with trapeze assemblies using 3/8-inch diameter rod hangers not exceeding 12 inches in length are exempt from design for seismic forces, provided that the total weight supported by any single trapeze is 100 pounds or less. Pneumatic tube systems supported by individual 3/8-inch and 1/2-inch rod hangers are also exempt from design for seismic forces, provided each hanger in the run is 12 inches or less in length and the total weight supported by any single rod is 50 pounds or less. 


\section{Recommendations}

1. In Table 13.6-1 or in an updated version of the commentary, it would be helpful to have a summary of the attributes of ASME B31 piping, which would help the individual doing the seismic bracing design to determine whether a system is compliant or not.

2. Commentary is needed covering what additional forces must be considered when designing for interstory drifts, the requirements for determining relative displacement demands, and the acceptance criteria for relative displacement analysis. The large-scale sprinkler piping systems dynamic tests conducted at the University at Buffalo (Tian et al., 2013; Soroushian et al., 2014) provide detailed measurements of relative displacements of piping and could be used as a starting point for developing displacement criteria for piping systems.

\section{A.6.8 Distribution Systems: Trapezes with a Combination of Systems (ASCE/SEI 7-16 Section 13.6.8)}

This section addresses the situation where a trapeze meeting the prescriptive requirements in Section 13.6.5 through Section 13.6.7 supports a combination of distribution systems, such as electrical conduit, raceway, duct, and piping. When this occurs, the trapeze must be designed using the most restrictive requirements for the supported distribution systems from Section 13.6.5 through Section 13.6.7 considering the aggregate weight of the supported system. If any distribution system on the trapeze is not exempted, the trapeze must be braced.

\section{Recommendations}

1. Since the exceptions for all trapeze-supported distribution systems are nearly identical, consolidation into this Section may improve clarity.

2. This section should be expanded to cover the design of trapeze supports in general. Guidance is also needed for combinations of systems on common supports other than trapeze systems, such as rooftop installations.

3. This section should provide guidance on the design of distribution systems with vibration isolated supports.

4. The situation where a trapeze supports distribution systems which, due to their size, are exempt when considered individually is not addressed. For example, given that conduits less than 2.5 inches trade size are exempt from the seismic force and relative displacement requirements, it is unclear if a trapeze assembly that supports only conduits less than 2.5 inches trade size is also exempt, regardless of the total weight supported by the trapeze. 


\section{A.6.9 Utility and Service Lines (ASCE/SEI 7-16 Section 13.6.9)}

This section requires that utility lines be provided with adequate flexibility to accommodate the anticipated differential movement between adjacent structures or portions of the same structure that may move independently. It also requires consideration of the impact an interruption of utility service may have on designated seismic systems in Risk Category IV, with an emphasis on the vulnerability of underground utilities at the interface between the structure and the soil, especially in areas with liquefiable soils.

\section{Recommendations}

ASCE/SEI 7-16 does not include commentary on this topic. Further description of the vulnerability and methods of mitigating the hazard would be helpful. In some cases the connections may need to accommodate ground movements in three directions.

\section{A.6.10 Boilers and Pressure Vessels (ASCE/SEI 7-16 Section 13.6.10)}

Boilers or pressure vessels designed and constructed in accordance with ASME Boiler and Pressure Vessel Code (ASME, 2015) are deemed to meet the requirements of ASCE/SEI 7-16, provided the force and displacement requirements of Sections 13.3 are used in lieu of the force or displacement requirements provided in ASME BPVC. Other boilers and pressure vessels designated as having an $I_{p}=1.5$, but not designed and constructed in accordance with the requirements of ASME BPVC, must comply with the requirements of Section 13.6.10.

\section{Recommendations}

Large pressure vessels and large boilers should be designed to the seismic requirements of Section 15.7, which are much more comprehensive than those found in Chapter 13. The definition of "large" will be determined in consultation with the nonbuilding structures design community. For boilers and pressure vessels retained in Chapter 13 as nonstructural components, this section should clarify the requirements for those boilers and pressure vessels with an $I_{p}=1.0$ that are not designed and constructed in accordance with the requirements of ASME BPVC.

\section{A.6.11 Elevator and Escalator Design Requirements (ASCE/SEI 7-16 Section 13.6.11)}

Elevators and escalators are typically designed to the seismic requirements of ASME A17.1, Safety Code for Elevators and Escalators, (ASME, 2007), as modified by Section 13.6.11 and are deemed to meet the seismic force requirements of ASCE/SEI 7-16. The exceptions of Section 13.6.7.3 do not apply to elevator piping. Escalators, elevators, and hoistway structural systems, along with elevator equipment, and controller supports and attachments must be designed to meet the force and displacement requirements of Sections 13.3.1 and 13.3.2. Elevators operating with a 
speed of $150 \mathrm{ft} / \mathrm{min}(46 \mathrm{~m} / \mathrm{min})$ or greater must be provided with seismic switches.

Retainer plates are required at the top and bottom of the elevator cars and

counterweights.

\section{Recommendations}

The seismic requirements for elevators and escalators in ASME 17.1 should be reviewed for consistency with the seismic provisions of ASCE/SEI 7-16. This has been done periodically in the past.

\section{A.6.12 Rooftop Solar Panels (ASCE/SEI 7-16 Section 13.6.12)}

Rooftop solar panels and their attachments must be designed for the forces and displacements determined in Section 13.3, unless they meet the exception criteria for ballasted arrays. Ballasted arrays must meet prescriptive criteria for building height, roof slope, and support configuration. They must be able to accommodate seismic displacement through sliding without impact, instability, or loss of support. The required displacement can be calculated or determined by shake-table testing or nonlinear response-history analysis. The array framing must meet strength criteria and the required space around the component needed to accommodate the expected displacement must be clearly marked on the structure.

\section{Recommendations}

None.

\section{A.6.13 Other Mechanical and Electrical Components (ASCE/SEI 7-16 Section 13.6.13)}

This section provides design requirements for mechanical and electrical components not otherwise covered in Section 13.6. The components and their supports and attachments must comply with the requirements of Sections 13.4, 13.6.3, and 13.6.4. Permissible strengths for materials are provided for mechanical components with hazardous substances and assigned an $I_{p}=1.5$, and for boilers and pressure vessels that are not designed in accordance with ASME BPVC.

\section{Recommendations}

None.

\section{A.7 Consensus Standards and Other Referenced Standards (ASCE/SEI 7-16 Section 13.7)}

This section refers the user to the standards in ASCE/SEI 7-16 Chapter 23 that are referenced in Chapter 13.

\section{Recommendations}

None. 



\section{Appendix B}

\section{Studies to Support the Development of Revised Nonstructural Design Force Equations}

This appendix summarizes the studies conducted to support the development of new proposed nonstructural design force equations in the ASCE/SEI 7-16 standard, which are introduced in Chapter 4. These studies encompass the evaluation of the response of instrumented buildings and archetype numerical models exposed to sets of spectrum compatible and recorded ground motions. This evaluation focuses on identifying the influence of different parameters on nonstructural response. An assessment is included to compare the forces using the proposed equations with those obtained using archetype models. Studies presented in this appendix underlie a number of sections in Chapter 4, including those on the influence of individual parameters (Section 4.2.1 on peak ground acceleration, Section 4.2.2 on seismic force-resisting systems, Section 4.2.4 on building ductility, Section 4.2.5 on inherent building damping, Section 4.2.6 on building configuration, and Section 4.2.7 on roof and floor diaphragm rigidity), and Section 4.3.4, which covers the combined effect of multiple parameters and proposed design equations.

Unless otherwise noted in the body of this appendix, floor spectra are evaluated at the roof level for elastic nonstructural components with a damping ratio of $5 \%$. This appendix is organized into the following sections.

- Section B.1: A description of the instrumented buildings and their recorded ground motions followed by a description of the archetype numerical models and ground motion sets used for response history analysis.

- Section B.2: Studies on the effect of ground motion intensity.

- Section B.3: The influence of building modal periods and the seismic forceresisting system (SFRS).

- Section B.4: Studies on the effect of building nonlinearity.

- Section B.5: The influence of inherent building viscous damping.

- Section B.6: Studies on the effect of building configuration.

- Section B.7: Evaluation of the effect of building floor and roof diaphragm rigidity. 
- Section B.8: Incorporation of the effect of building nonlinearity (i.e., building ductility) in the proposed equation.

- Section B.9: Studies on the effect of using different ground motion record sets.

- Section B.10: Evaluation of proposed $F_{p}$ equation using archetype models.

\section{B.1 Buildings, Seismic Force-Resisting Systems, and Ground Motions}

The buildings evaluated included instrumented buildings and archetype numerical models. Different types of seismic force-resisting systems (SFRS) were investigated with a focus on steel moment-resisting frame (MRF) and reinforced concrete shear wall (RCSW) systems. Archetype studies were based on special systems whereas the instrumented studies combine both special and non-special systems. In terms of ground motions, spectrum-compatible and recorded ground motions were used.

\section{B.1.1 Instrumented Buildings and their Ground Motion Recordings}

Instrumented buildings were selected from the CESMD database (Center for Engineering Strong Motion Data www.strongmotioncenter.org). Buildings equipped with control systems (e.g., base-isolation, damper) were excluded. All steel and reinforced concrete multistory instrumented buildings that have recorded earthquake ground motions with a peak ground acceleration (PGA) greater than $0.15 \mathrm{~g}$, at least in one principal horizontal direction, were selected. For single-story buildings, adopting this threshold provided only three individual buildings; therefore, in this case, the threshold was changed to $0.10 \mathrm{~g}$ to provide a bigger sample size. In the entire CESMD database, 44 individual buildings satisfy these criteria. For some of these buildings, results are available for more than one earthquake event. Hence, the database has an overall size of 59 building-earthquake samples. Given that the dynamic characteristics of the building and the recorded ground motions in two orthogonal horizontal directions are different, a database with a total size of 118 building directions was created. All the floor motions (approximately 600 motions) available for these buildings in the CESMD database were used. The last download was conducted in November 2016.

The database generated as part of this study includes a wide range of structural and ground motion characteristics (e.g., different building configurations in terms of height, modal periods and SFRS, and ground motions with different intensity levels and frequency contents). An evaluation of the characteristics of the selected instrumented building-earthquake samples demonstrates that 16 samples (i.e., 32 individual principal directions) are single-story structures, and 43 samples (i.e., 86 individual principal directions) are taller than a single-story. Detailed information on the SFRS of the selected buildings is presented in Table B-2. The type of SFRS has an influence on the shape an amplitude of floor spectra (e.g., in a typical MRF 
building, two discernible spikes are expected in the vicinity of the first two modal periods of the building, i.e., $T_{1 b l d g}$ and $T_{\text {lbldg }} / 3$ ). Table B-1 presents a classification of the selected building-earthquake samples based on their SFRS. An evaluation of this table, reveals that the SFRS in most of the multistory building samples (i.e., 46 principal directions out of 86) is a MRF system. This implies that the results of this study are applicable to multi-story buildings with MRF and shear wall (SW) systems. Further evaluation of the selected buildings indicates that $75 \%$ of these buildings were designed before 1975 (denoted herein as pre-modern code design), and the rest were designed after 1975 (denoted herein as modern design). At least 12 individual buildings exhibit at least a moderate degree of irregularity (e.g., asymmetric geometry, asymmetric SFRS elements in plan, irregularity in floor mass or story stiffness). Ground motion records from 21 different earthquake events are present in the compiled database for this study. The 1994 Northridge and the 1989 Loma Prieta earthquakes with 21 and 9 record pairs, respectively, are the largest represented events in the prepared database. The PGA of the individual recorded ground motions varies from $0.04 \mathrm{~g}$ to $0.80 \mathrm{~g}$ with an average of $0.20 \mathrm{~g}$.

Table B-1 Seismic Force-resisting Systems for Instrumented Building-Earthquake Samples Used in this Study ${ }^{(1)}$

\begin{tabular}{|c|c|c|c|}
\hline \multicolumn{2}{|c|}{ Single-Story Building-Earthquake Samples } & \multicolumn{2}{|c|}{$\begin{array}{l}\text { Multi-Story Building-Earthquake } \\
\text { Samples }\end{array}$} \\
\hline SFRS & $\begin{array}{l}\text { Sample } \\
\text { size }\end{array}$ & SFRS & $\begin{array}{l}\text { Sample } \\
\text { size }\end{array}$ \\
\hline Shear wall (SW) with plywood diaphragm & 12 & SW & 28 \\
\hline SW with plywood sheathing over steel joists & 8 & $\begin{array}{l}\text { Moment-resisting frame } \\
\text { (MRF) }\end{array}$ & 46 \\
\hline SW with metal/concrete diaphragm & 6 & Hybrid in height (2) & 4 \\
\hline Steel bracing with concrete diaphragm & 4 & Steel bracing (BR) & 5 \\
\hline Wood frame with composite wood diaphragm & 2 & $\begin{array}{l}\text { Steel MRF and BR } \\
\text { (denoted as dual) }\end{array}$ & 3 \\
\hline
\end{tabular}

(1) For single-story buildings, SWs are either masonry or concrete; for multistory buildings, SWs are mostly RCSW and in a few cases steel SW. MRF systems are either steel or concrete. More detailed information on the structural system can be found in Table B-2.

(2) Hybrid systems with SW at upper stories and MRF at the ground level (analyses show that three of these cases behave as an MRF).

Figure B-1a illustrates the distribution of the selected instrumented buildings in terms of the number of above-grade stories. Most of the samples (i.e., 88 out of 118) are 10 stories tall or shorter. The tallest building in the compiled database is a 52-story steel structure. Figure B- $1 \mathrm{~b}$ shows the distribution of the recorded motions in terms of PGA. As seen, most of the recoded PGAs $(83 \%)$ are in the $0.10 \mathrm{~g}-0.35 \mathrm{~g}$ range. 


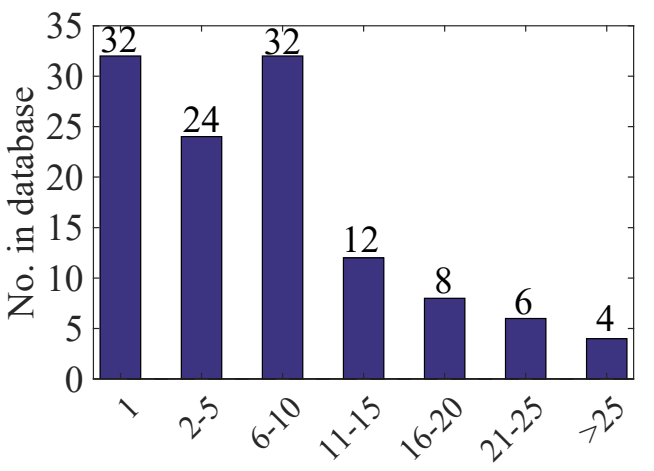

No. of stories

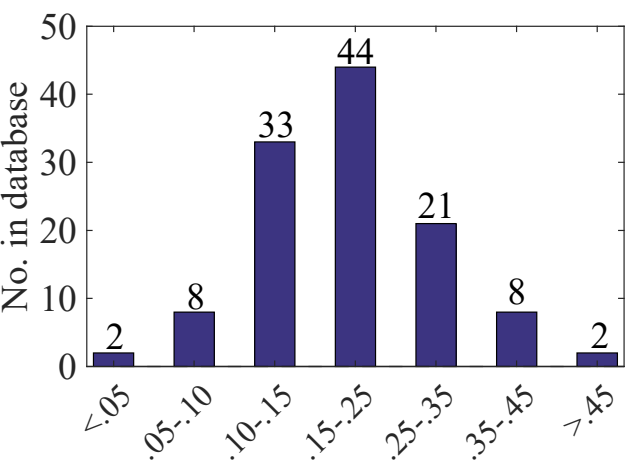

Recorded PGA(g)

Figure B-1 Distribution of selected instrumented building directions in terms of (a) number of above-grade stories; and (b) recorded PGA. From Anajafi and Medina (2018a).

Figure B-2 shows the estimated fundamental periods, $T_{1 b l d g}$, for all building directions considered in this study. Table B-2 provides the list of $T_{\text {lbldg }}$ for all instrumented buildings. The ASCE/SEI 7-16 equations for determining the approximate fundamental period for steel MRF and SW systems, assuming a structural height equal to the number of stories times 13 feet, are also illustrated in this figure.

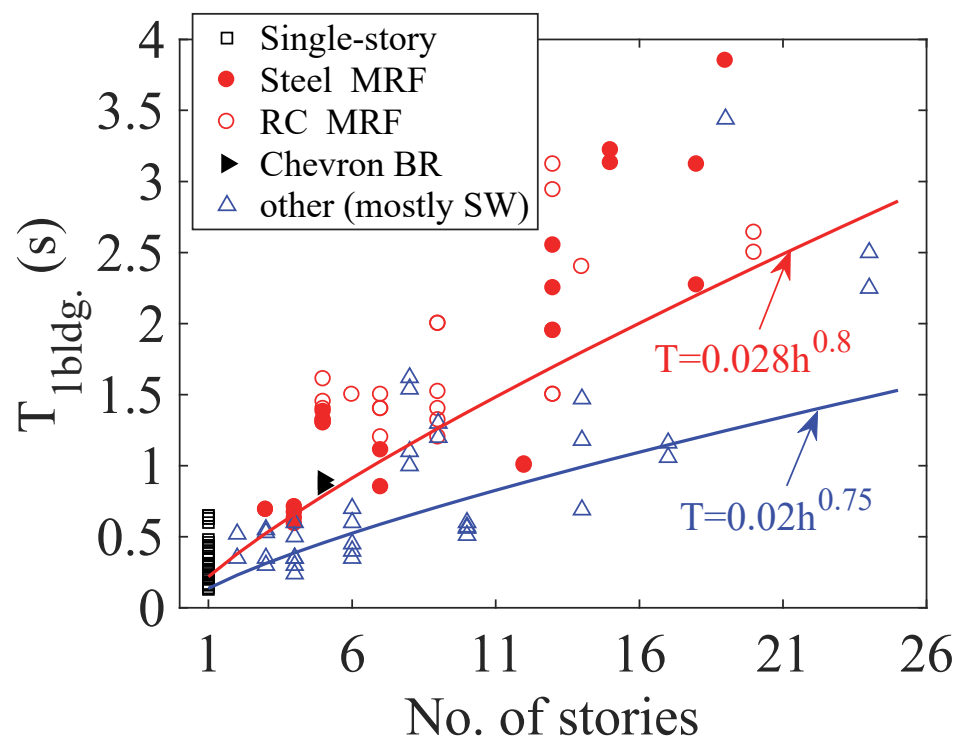

Figure B-2 Estimated fundamental periods of instrumented building directions versus number of stories (periods of 47- and 52-story buildings are not shown). From Anajafi and Medina (2018a). 

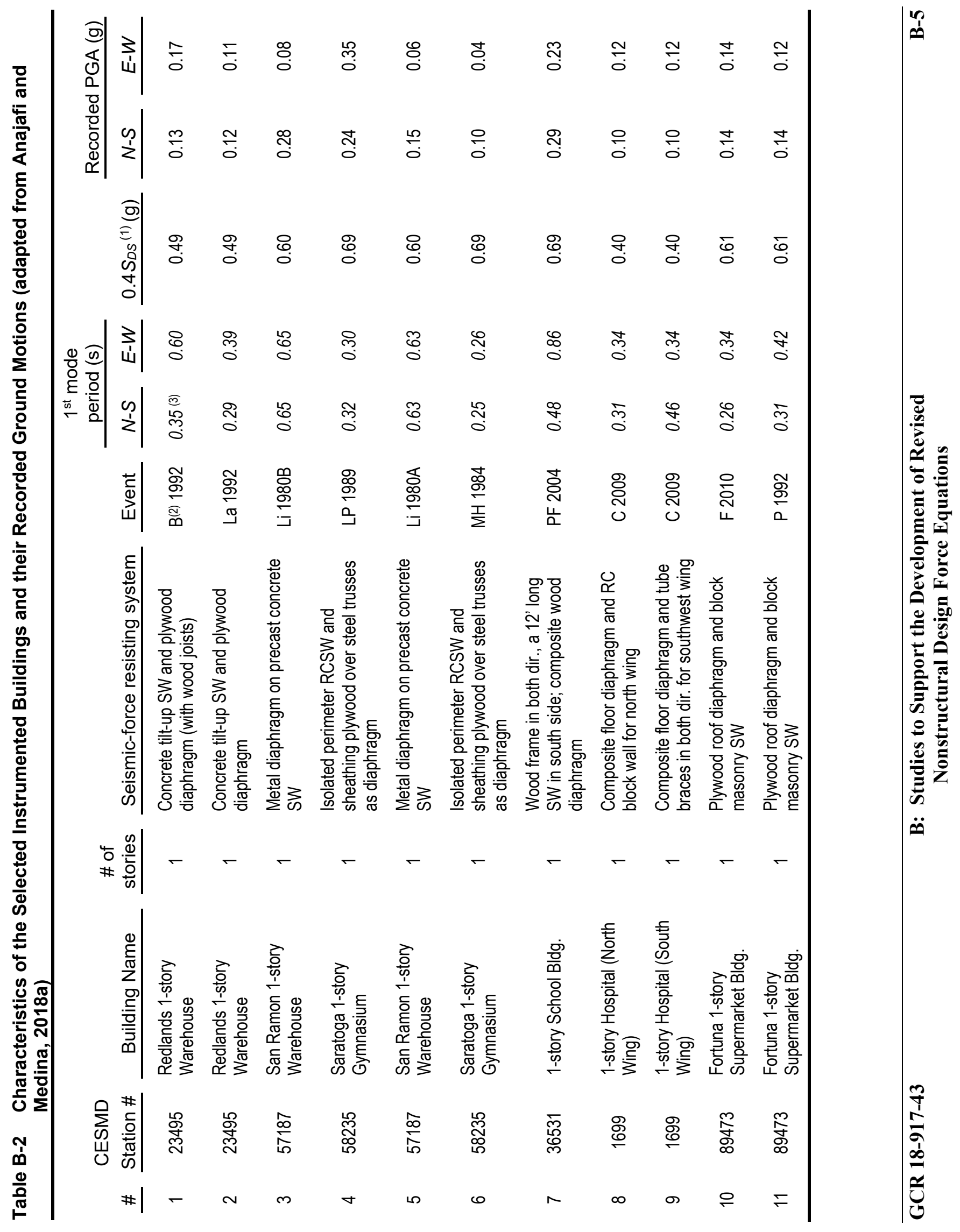

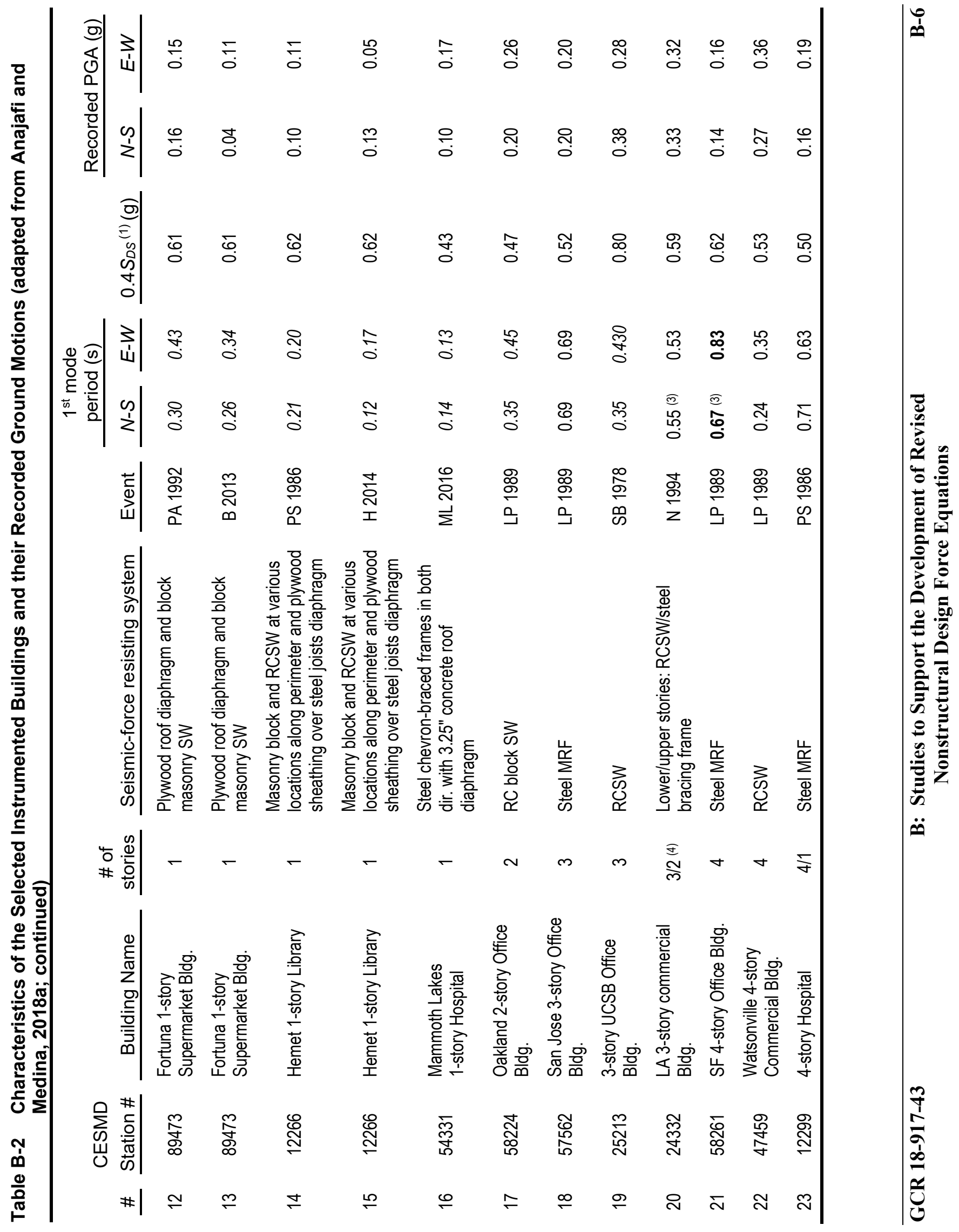

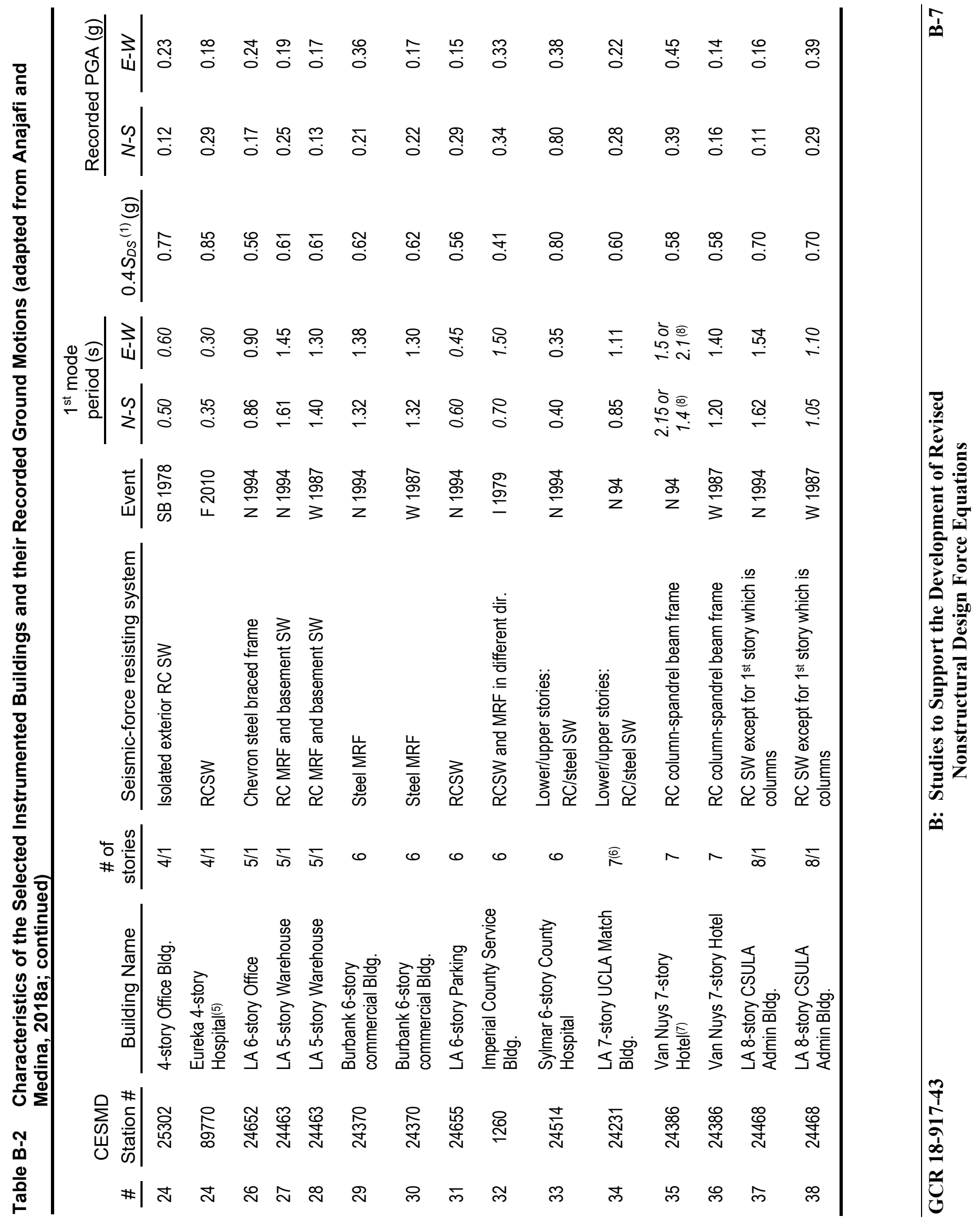


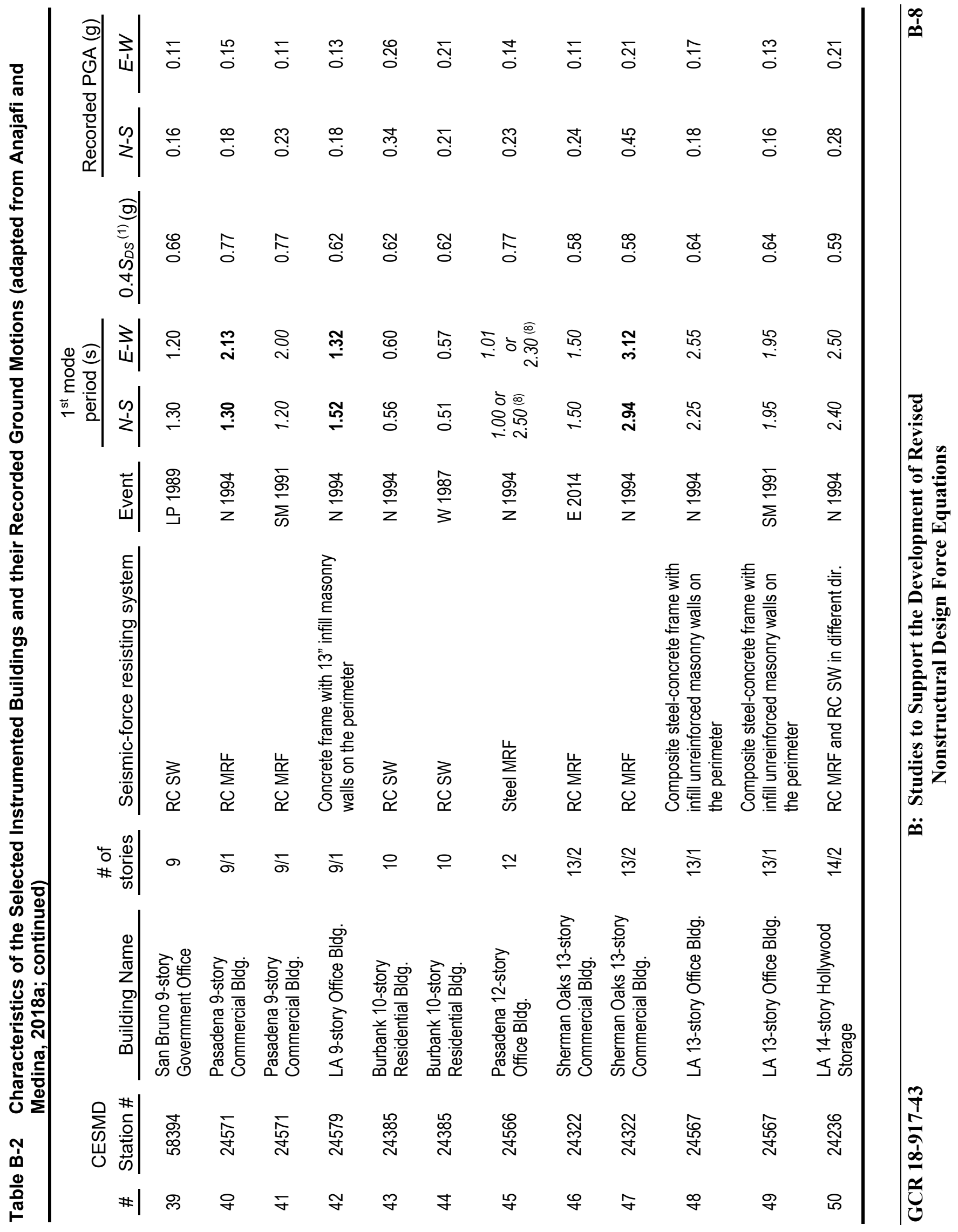



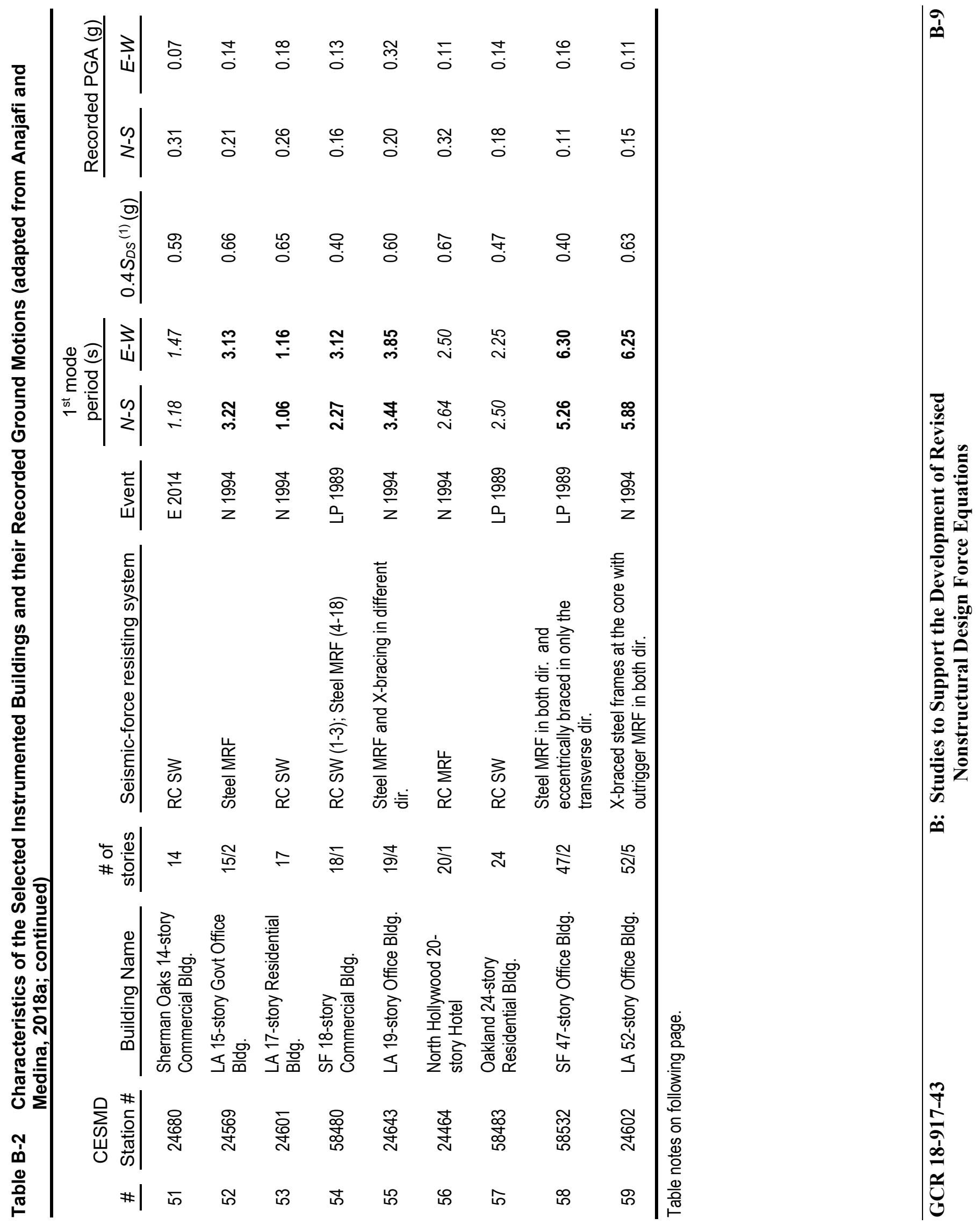
Notes on Table B-2:

(1) $0.40 S_{D S}$ (calculated using https://earthquake.usgs.gov/designmaps/us/application.php) corresponds to the design PGA for the building site and is presented for comparing a recorded ground motion intensity with its corresponding design value.

(2) The following nomenclature is used for different earthquake events:

B: Big Bear; La: Lander; Li: Livermore; LP: Loma Prieta; MH: Morgan Hill; PF: Parkfield; C: Calexico; F: Ferndale; P: Petrolia; PA: Petrolia Aftershock; B: Bayview; PS: Palm Springs; H: Hemet; ML: Mammoth Lakes; SB: Santa Barbara; N: Northridge; W: Whittier; I: Imperial; SM: Sierra Madre; E: Encino; SM: Sierra Madre.

(3) Numbers in "italic" are fundamental periods roughly estimated based on the spikes observed in roof floor response spectra; "bolded" numbers are fundamental periods calculated using system identification method performed by Bernal et al. (2015); other numbers are fundamental periods based on Goel and Chopra (1997);

(4) $m / n$ implies " $m$ " stories above and " $n$ " stories below the ground level. For this particular building, the existence of a significant difference between floor motions at the lowermost basement and the ground level implies that the seismic base could be established at the lowermost basement; in other words, this building essentially behaves like a five-story structure. Estimating the real base level for a building with a basement is challenging; in this document when it is not possible to investigate this issue (because of the lack of enough sensors at different levels). The seismic base is, conservatively, assumed to be at the foundation level.

(5) This building is highly irregular in height (i.e., multiple setbacks along the height is observed).

(6) Because of the presence of thick shear walls between the first and third floor levels, floor motions at the ground and at the third floors are nearly close, and hence, a better estimate of the seismic base location could be the third floor (in other words, this building seems to be an equivalent five-story structure).

(7) This building was significantly damaged during the 1994 Northridge earthquake.

(8) Estimating the first mode periods based on floor spectra alone is challenging.

\section{B.1.2 Archetype Numerical Models and Selected Ground Motions}

\section{B.1.2.1 Archetype Numerical Models}

Structural models with heights of two, six, and eight stories were the basic archetype structures (baseline models) utilized in this study. Additional studies with archetypes with different heights ranging from one- to 12-stories were also conducted, and the overall trends and behavioral patterns discussed herein were consistent (Anajafi, 2018). Steel special moment-resisting frame (SMRF) and special reinforced concrete shear wall (RCSW) archetype buildings were considered for multi-story structures to represent flexible and stiff SFRS, respectively. These archetype buildings were consistent with the buildings designed as part of the ATC-63 project that developed FEMA P-695, Quantification of Building Seismic Performance Factors, (FEMA, 2009a). For instance, FEMA P-695 does not consider a six-story SMRF. However, a six-story SMRF archetype was designed for this study following the same design approach of FEMA P-695 (i.e., loading, variation of beam and column sections over the height). For RCSW, the steel reinforcing of the FEMA P-695 archetypes, especially the confinement provided to the boundary elements, was modified to improve the system global ductility capacity. Nonlinear two-dimensional (2D) numerical models of the archetype buildings were developed. The direct 
contributions to the lateral strength and stiffness from the gravity system were neglected in these models. The global P-Delta effects of gravity loads that are not tributary to the lateral load-resisting elements were incorporated via a leaning column with zero flexural stiffness attached to the $2 \mathrm{D}$ finite element model with axially rigid pin-ended members. To approximate the inherent viscous damping of the building, the Rayleigh damping approach is used, assigning a 2.5\% viscous damping ratio to $2 T_{\text {lbldg }}$ and $T_{2 b l d g}$, where $T_{i b l d g}$ is the period of the $i$-th mode of vibration. The value of $2 T_{\text {lbldg }}$ is selected to limit the viscous damping ratio of the effective fundamental period when the system transitions to the nonlinear behavior, and the effective fundamental period changes.

The two- and six-story SMRF buildings were consistent with the FEMA P-695 building group RSA- $D_{\max }$ characteristics. These buildings were designed for a high seismic loading based on the modal response spectrum analysis approach subjected to the ASCE/SEI 7-16 requirements using a response modification coefficient, $R$, of 8.0. The SMRF buildings have a rectangular plan configuration with dimensions of $140 \mathrm{ft}$ $(42.7 \mathrm{~m})$ and $100 \mathrm{ft}(32.5 \mathrm{~m})$, consisting of a three-bay perimeter frame of equal spans $(20 \mathrm{ft}, 6.1 \mathrm{~m})$ on each side. Story heights are selected to be $15 \mathrm{ft}(4.57 \mathrm{~m})$ in the first story and $13 \mathrm{ft}(3.96 \mathrm{~m})$ in the remaining stories. Reduced-beam sections were used. The representative building plan, which is the same for all SMRF archetypes, is shown in Figure B-3a. Nonlinear analysis models were generated in SAP2000 v19 (CSI, 2017) based on a concentrated plastic hinge approach. A monotonic moment-rotation backbone curve was used to define the hysteretic behavior. The plastic rotations corresponding to different damage states, and strength degradation, were defined based on ASCE/SEI 41-13 (ASCE, 2014). 3\% strain hardening was assumed in defining the post-yield stiffness of the backbone curve. The effects of the composite floor slab were not considered. The panel zone was not modeled. The bases of the two-story SMRF columns were assumed to be pinned while the bases of six-story SMRF columns were assumed to be fixed. Localized P$\mathrm{M}$ hinges with five different $\mathrm{P}-\mathrm{M}$ interaction surfaces for five selected axial force levels (ranging from 0.1 to 0.5 of the column axial strength capacity) were defined and assigned to the columns at both ends. Beams and columns sections are ASTM A992 W sections. Material properties for structural steel sections are specified according to the FEMA P-695 with an expected yield strength and an expected ultimate strength of 55 and $71.5 \mathrm{ksi}$, respectively.

For this study, the two- and eight-story RCSW buildings were based on the FEMA P-695 building group with lower axial force and higher seismic design load.

Proportioning and detailing of RCSWs was based on ACI 318-08 requirements, subject to ASCE/SEI 7-05 Chapter 14 amendments (using an R-factor of 6 for an assumed building frame system). To produce lower-bound designs without excessive overstrength, the plan dimensions and length of walls in each direction were varied in 
each archetype to optimize strength relative to the level of seismic design loading (see Figure B-3 and Table B-3). Story heights were selected to be $13 \mathrm{ft}(3.96 \mathrm{~m}$ ) in the first story and $12 \mathrm{ft}(3.66 \mathrm{~m})$ in the remaining stories. The eight-story building is rectangular in plan with dimensions of $110 \mathrm{ft}(33.5 \mathrm{~m})$ and $105 \mathrm{ft}(32.0 \mathrm{~m})$ in the two principal directions. For this building, the SFRS consists of special RCSWs for building frame systems with the length of $32 \mathrm{ft}(9.76 \mathrm{~m})$ at the building perimeter. The two-story building is rectangular in plan with dimensions of $280 \mathrm{ft}(85.3 \mathrm{~m})$ and $240 \mathrm{ft}(73.2 \mathrm{~m})$ in the two principal directions. For this building, the SFRS consists of special RCSWs for building frame systems with the length of $24 \mathrm{ft}(7.3 \mathrm{~m})$ at the building perimeter. The RCSWs were modeled in SAP2000 v19 using nonlinear shell elements based on steel reinforcing and concrete material characteristics provided in FEMA P-695. The reinforcing steel, especially the confining rebar, was modified in some cases with respect to the FEMA P-695 models to improve the system global ductility. For unconfined concrete, the peak expected strength parameter and the corresponding strain were selected as $6.25 \mathrm{ksi}$ and 0.0027 , respectively, which yielded an initial modulus of approximately 4,500 ksi. For confined concrete, the modeling parameters were determined based on the Mander's model (Mander et al., 1988), which uses the unconfined concrete parameters and the boundary reinforcement details to determine the confined concrete peak stress and strain, and the post-peak behavior parameters. The rebar material is defined using the Bilinear Kinematic Hardening model. The expected yield strength and the ultimate strength of the reinforcing rebars are $66 \mathrm{ksi}$ and $98 \mathrm{ksi}$, respectively. A tensile strain value of $5 \%$ is defined as the limit state associated with rebar buckling and subsequent rebar fracture.

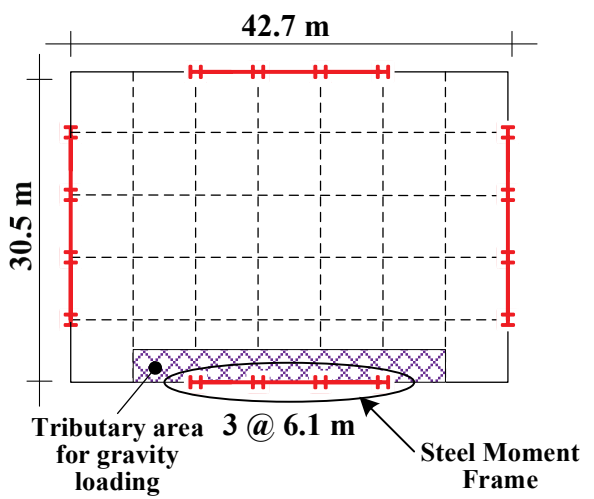

(a)

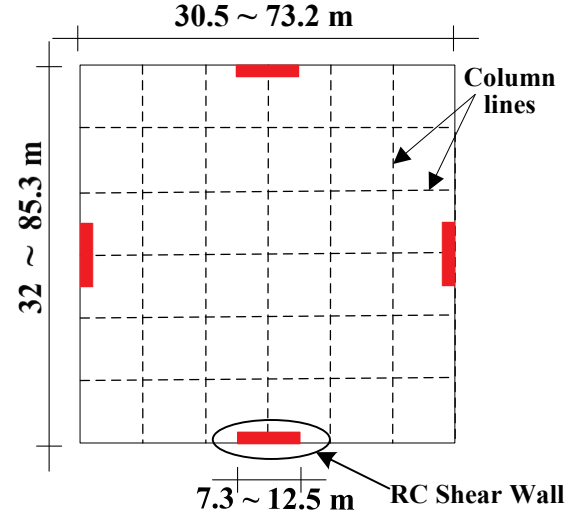

(b)

Figure B-3 Plan configuration of typical archetypes (a) SMRF; and (b) RCSW buildings (Note: the wall length of $12.5 \mathrm{~m}$ corresponds to archetypes taller than eight stories, which do not form part of the baseline models). 
Table B-3 Characteristics of Baseline Archetype Buildings

\begin{tabular}{|c|c|c|c|c|c|c|}
\hline \multirow[b]{2}{*}{ SFRS } & \multirow{2}{*}{$\begin{array}{c}\text { \# of } \\
\text { stories }\end{array}$} & \multirow{2}{*}{$\begin{array}{l}\text { Height } \\
(\mathrm{m})\end{array}$} & \multirow{2}{*}{$\begin{array}{l}\text { Plan dimensions } \\
(\mathrm{m} \times \mathrm{m})\end{array}$} & \multicolumn{3}{|c|}{ Modal periods ${ }^{(1)} T_{i b l d g}(\mathrm{~s})$} \\
\hline & & & & $T_{1 \text { bldg }}$ & $T_{2 b l d g}$ & $T_{3 b / d g}$ \\
\hline \multirow{2}{*}{ SMRF } & 2 & 8.5 & \multirow{2}{*}{$42.7 \times 30.5$} & 1.01 & 0.21 & $N A^{(2)}$ \\
\hline & 6 & 24.4 & & 1.93 & 0.63 & 0.32 \\
\hline \multirow{2}{*}{ RCSW } & 2 & 7.6 & $85.3 \times 73.2$ & 0.49 (c) & 0.09 & NA \\
\hline & 8 & 29.6 & $33.5 \times 30.5$ & 1.03 & 0.13 & 0.07 \\
\hline
\end{tabular}

(1) Including P-delta effects

(2) NA = Not applicable

(3) Modal periods of the RCSWs, which were modeled using nonlinear shell elements, are estimated based on the spikes observed in the mean roof floor response spectra using the set of spectrumcompatible ground motions at the Design Earthquake (DE) level.

Basic member sizes for the baseline model of the six- and two-story SMRF archetype buildings are shown in Table B-4 and Table B-5, respectively.

Table B-4 Member Sizes for Six-story SMRF Archetype Building

\begin{tabular}{|c|c|c|c|}
\hline Story \# & Beam Size & $\begin{array}{l}\text { Exterior } \\
\text { Colum Size }\end{array}$ & $\begin{array}{c}\text { Interior } \\
\text { Colum Size }\end{array}$ \\
\hline 1 & $W 27 \times 94$ & W24×131 & W24×162 \\
\hline 2,3 & W30×108 & $W 24 \times 131$ & W24×162 \\
\hline 4 & W24×84 & $W 24 \times 131$ & $W 24 \times 162$ \\
\hline 5,6 & W24×84 & $W 24 \times 131$ & $W 24 \times 131$ \\
\hline
\end{tabular}

Table B-5 Member Sizes for Two-story SMRF Archetype Building

\begin{tabular}{|c|c|c|c|}
\hline Story \# & Beam Size & $\begin{array}{c}\text { Exterior } \\
\text { Colum Size }\end{array}$ & $\begin{array}{c}\text { Interior } \\
\text { Colum Size }\end{array}$ \\
\hline 1 & W30×132 & W24×131 & W24×162 \\
\hline 2 & $W 16 \times 31$ & $W 24 \times 131$ & $W 24 \times 162$ \\
\hline
\end{tabular}

Table B-6 and Table B-7 present the eight-story and two-story RCSW archetype building design characteristics.

Table B-6 Design Characteristics of Eight-story Special RCSW Building

\begin{tabular}{|c|c|c|c|c|}
\hline \multirow[b]{2}{*}{ Story \# } & \multirow{2}{*}{$\begin{array}{c}\text { Thickness } \\
(\mathrm{m})\end{array}$} & \multicolumn{2}{|c|}{ Longitudinal Reinf. } & \multirow{2}{*}{$\begin{array}{l}\text { Boundaries } \\
\text { Confinement }\end{array}$} \\
\hline & & $W e b$ & Boundaries & \\
\hline 1,2 & 0.35 & $\# 5 @ 0.25 \mathrm{~m}$ & $14 \# 11$ & \#4@ 0.15 m \\
\hline 3,4 & 0.35 & $\# 5 @ 0.25 \mathrm{~m}$ & $14 \# 9$ & \#4@ 0.15 m \\
\hline 5,6 & 0.35 & \#5@ 0.25 m & $14 \# 5$ & \#4@ $0.20 \mathrm{~m}$ \\
\hline 7,8 & 0.35 & $\# 5 @ 0.25$ m & - & \\
\hline
\end{tabular}


Table B-7 Design Characteristics of Special Two-story RCSW Building

\begin{tabular}{|c|c|c|c|c|}
\hline \multirow[b]{2}{*}{ Story \# } & \multirow{2}{*}{$\begin{array}{l}\text { Thickness } \\
(\mathrm{m})\end{array}$} & \multicolumn{2}{|c|}{ Longitudinal Reinf. } & \multirow{2}{*}{$\begin{array}{l}\text { Boundaries } \\
\text { Confinement }\end{array}$} \\
\hline & & Web & Boundaries & \\
\hline 1,2 & 0.35 & \#4@0.25 m & $14 \# 11$ & \#4@ 0.15 m \\
\hline
\end{tabular}

In some cases, deviations from the baseline archetypes are used in the evaluation presented in this chapter. When needed, the characteristics of the modified models are explained in the relevant section of this appendix.

\section{B.1.2.2 Selected Ground Motions}

Two suites of ground motion records were used to analyze the archetype models: a set of spectrum-compatible and a set of recorded far-field (FF) records. As illustrated by Anajafi and Medina (2018b), a relatively large variation can be observed about the mean value of structural responses, especially in the high-frequency region of floor spectra, under a set of spectrum-compatible records even when individual records are tightly matched to the same target spectrum. Hence, a total of 20 spectrumcompatible ground motions, which are generated through matching the individual $5 \%$-damped response spectra of 20 actual far-field records to the target spectrum, were used. The basic (initial) evaluation of results was performed on mean values from response history analyses conducted using this record set. The spectral matching was conducted using the wavelet adjustment technique (Al Atik and Abrahamson, 2010). The target spectrum used for generating simulated records in this document is based on $S_{D S}=1.0 \mathrm{~g}$ and $S_{D I}=0.55 \mathrm{~g}$, which is similar to the elastic 5\%-damped design spectrum implemented in FEMA P-695 for designing the archetype buildings based on higher seismic loads (in that case, $S_{D S}=1.0 \mathrm{~g}$ and $S_{D I}=$ $0.6 \mathrm{~g}$ were used). The spectral misfit (i.e., deviation of response spectrum ordinates from the target spectrum) over the period range $0.05 \mathrm{~s}-5.0 \mathrm{~s}$ for all simulated records was limited to $2 \%$.

The second suite of ground motion records used in this study was the FEMA P-695 FF record set amplitude-scaled based on ASCE/SEI 7-16 provisions. This set includes 44 ground motions, which were recorded in stiff soils (i.e., NEHRP site class D), have a moment magnitude that varies from 6.5 to 7.6 with an average of 7.0, and closest distances to the fault rupture that vary from 11.1 to $26.4 \mathrm{~km}$ with an average of $16.4 \mathrm{~km}$. For the original record set (i.e., before amplitude scaling), PGA values vary from $0.21 \mathrm{~g}$ to $0.82 \mathrm{~g}$ with an average of $0.43 \mathrm{~g}$. Peak ground velocity (PGV) values vary from 19 to $115 \mathrm{~cm} / \mathrm{s}$ with an average of $46 \mathrm{~cm} / \mathrm{s}$. Approximately $60 \%$ of the records are from California earthquakes. Detailed information on the FF ground motions can be found in FEMA P-695. These ground motions were referred to as far-field in FEMA P-695 primarily because their recording distance to the fault rupture area was greater than $10 \mathrm{~km}$. Most of the response history analyses were 
performed using spectrum-compatible records, and in specific cases, the FF record set was used for the validation purposes.

Figure B-4a presents the individual response spectra and mean spectrum for the spectrum-compatible records. Figure B-4b shows the individual response spectra for the unscaled FF records, the unscaled mean spectrum and the amplitude-scaled mean spectrum for the six-story SMRF building. Figure B-4c presents similar graphs or the eight-story RCSW building.

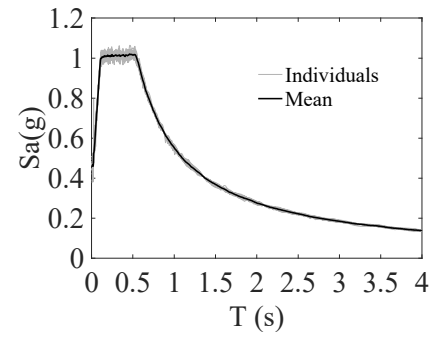

(a)

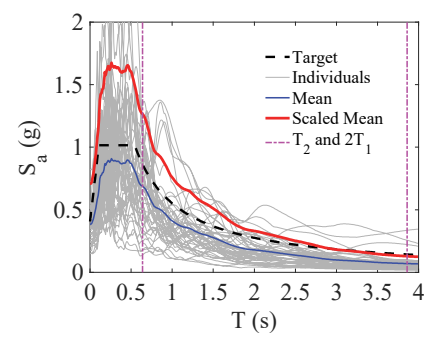

(b)

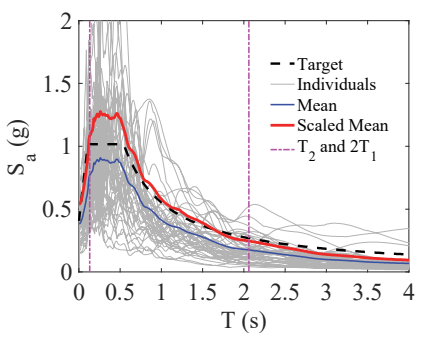

(c)

Figure B-4 5\%-damped ground response spectra for the (a) 20 spectrum compatible records; (b) 44 scaled far-field records from FEMA P-695 for the baseline six-story SMRF; (c) 44 scaled far-field records from FEMA P-695 for the baseline eight-story RSCW.

\section{B.2 Effect of Ground Motion Intensity}

\section{B.2.1 Evaluation Based on the Response of Instrumented Buildings}

Many previous numerical studies have illustrated that the ground motion intensity can significantly influence the magnitude of the floor spectral acceleration responses, likely because the level inelastic behavior in the supporting building increases with increasing ground motion intensity. Therefore, any evaluation of instrumented building responses should consider these potential effects. A simplified approach is adopted herein to approximately estimate, albeit in a very crude manner, whether an instrumented building behaved in the elastic or inelastic behavior range. Let $\left[S a_{\text {TIbldg. }}\right]_{G M}$ be the elastic 5\%-damped pseudo-spectral acceleration response of the recorded ground motion at the base of a given instrumented building direction at a period equal to $T_{\text {Ibldg. }}$. Let $\left[\mathrm{Sa}_{\text {Tibldg }}\right]_{\text {Design }}$ be the elastic pseudo-spectral ordinate of the $5 \%$-damped design spectrum for the building site at $T_{\text {lbldg. }}$. A dimensionless normalized ground motion intensity measure (IM) parameter, defined as the ratio $\left[S a_{\text {TIbld }}\right]_{G M} /\left[S a_{\text {TIbldg }}\right]_{\text {Design }}$ is introduced to approximately estimate the level of inelastic behavior experienced in the supporting building direction of interest. Note that $\left[\mathrm{Sa}_{\text {TIbldg }}\right]_{\text {Design }}$ is calculated for all individual building directions based on their estimated fundamental periods, the information provided in CESMD database regarding the building site, and using the USGS tool. For a building with a codebased design exposed to a ground motion, if this parameter is greater than $1 / R_{d}$, where $R_{d}$ is the ductility-dependent response modification factor $\left(R_{d}=R / \Omega_{0}\right.$, where $R$ 
is the response modification coefficient and $\Omega_{0}$, the overstrength factor), an inelastic behavior could be expected. For typical MRF and SW systems, $R_{d}$ might range from 2.0 to 3.0. Assuming an average value of 2.5 , one can expect that if the normalized IM for an instrumented building direction is greater than 0.4 , the building is more likely to experience an inelastic behavior. Figure B-5a presents the value of the normalized ground motion intensity measure for different instrumented buildingdirections. In the figure, most data points are well below the approximate linearbehavior threshold of 0.4. Based on information presented in Figure B-5a, the percentage of building directions for which the normalized IM exceeds a given value is computed and shown in Figure B-5b. The figure shows that less than $25 \%$ of the studied instrumented building directions exceeded the IM threshold of 0.4, implying that, under these assumptions, many of these structures most likely responded elastically. This IM can be used for interpreting the results of the conducted evaluations on the floor response spectra as it relates the effect of ground motion intensity, and indirectly, on building nonlinearity.

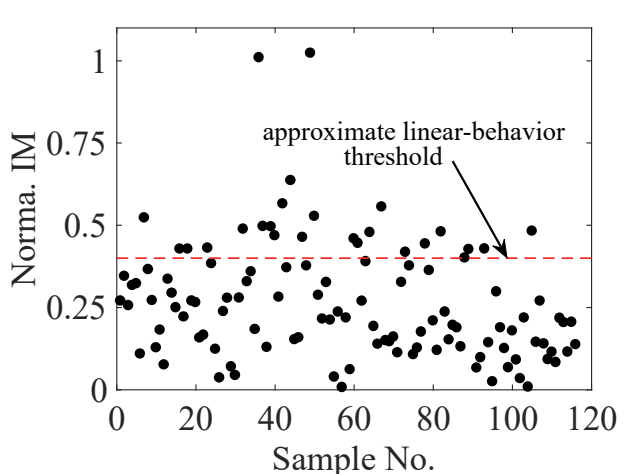

(a)

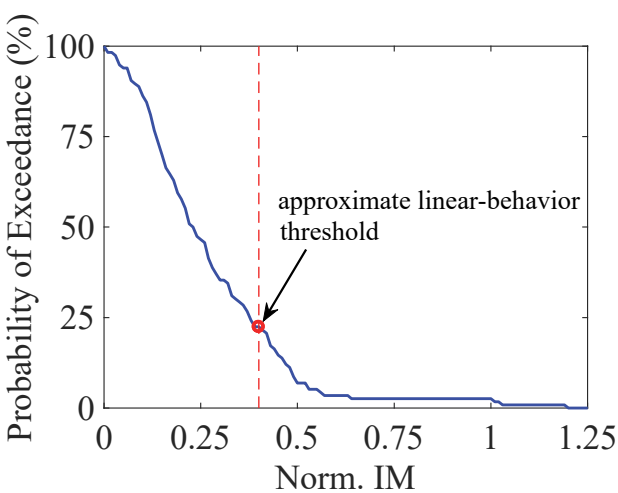

(b)

Figure B-5 (a) The normalized ground motion intensity measure for different instrumented building-directions; and (b) probability of exceeding normalized ground motion intensity measure (Anajafi and Medina, 2018a).

In this study, the design PGA, which is equal to $0.4 S_{D S}$, is denoted herein as $\mathrm{PGA}_{\text {design. }}$. An evaluation of the percentage of the data points smaller than a specific

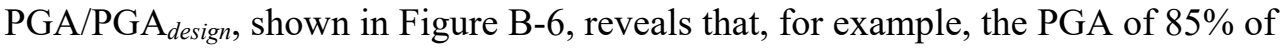
these records is less than $0.5 \mathrm{PGA}_{\text {design }}$. Hence, given this information and the information in Figure B-5, it is reasonable to infer that most of these structures behaved in the linear-elastic range. This elastic behavior could significantly bias any evaluation of the ASCE/SEI 7-16 $F_{p}$ equation based on the response of instrumented buildings alone. To clarify his statement, normalized PCA responses for three different bins are shown in Figure B-7 for instrumented building directions with PGA/PGA design larger than $0.05,0.50$, and 0.75 in panels a, b, and c, respectively. With increasing ground motion intensity, the relatively large normalized PCA responses are not observed. ASCE/SEI 7-16 Equation 13.3-2 sets a maximum for 
nonstructural design forces at $F_{p} / W_{p}=1.6 S_{D S} I_{p}=1.6(\mathrm{PGA} / 0.4) I_{p}=4$, for the typical case of $I_{p}=1$. In Figure B-7a, where the responses of building directions with all PGA/PGA ${ }_{\text {design }}$ ratios are considered, the PCA/PGA responses in many cases significantly (in some cases by a factor as large as 9.0) exceed the ASCE/SEI 7-16 upper limit of 4.0 (see vertical green dashed line in Figure B-7). However, in Figure $\mathrm{B}-7 \mathrm{c}$, where only the building directions with $\mathrm{PGA} / \mathrm{PGA}_{\text {design }} \geq 0.75$ are present, the value of the PCA/PGA is limited to 7.8. If the upper limit of 4.0 is not applied to the ASCE/SEI 7-16 $F_{p}$ equation (solid green line in Figure B-7), this equation results in a normalized value of 7.5 for the roof level, which is close to the observed value of 7.8. Figure B-7 is reproduced as Figure 4-2 in Chapter 4.

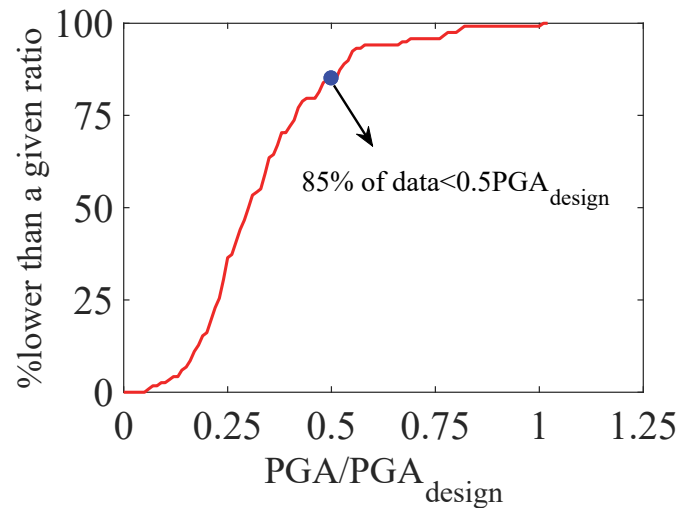

Figure B-6 Percentage of data points below PGA/PGAdesign.

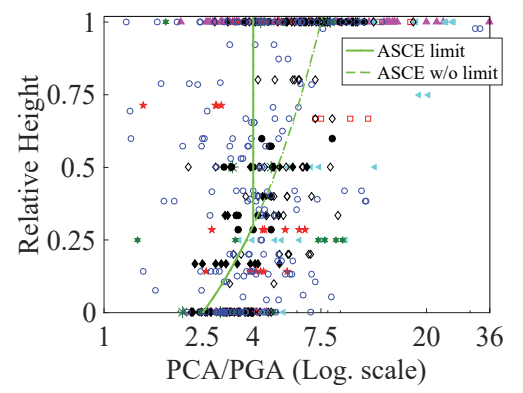

(a)

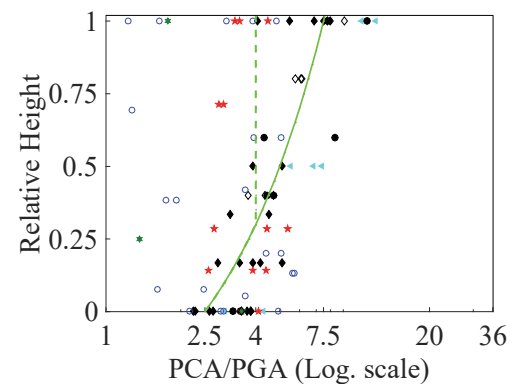

(b)

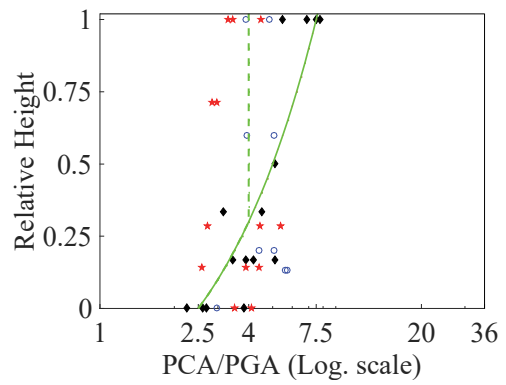

(c)

Figure B-7 PCA/PGA versus the relative height for instrumented building directions with PCA/PGAdesign greater than (a) 0.05; (b) 0.50; and (c) 0.75 (Note: "ASCE w/o limit" means without applying the ASCE/SEI 7-16 $F_{p}$ upper limit of 4.0).

Since ASCE/SEI 7-16 is meant to provide seismic demands for the DE, an adequate evaluation of the ASCE/SEI 7-16 equation cannot be performed solely based on the response from instrumented buildings that might have been exposed primarily to ground motions at levels significantly smaller than the DE. To further investigate the effect of the supporting building nonlinearity on the evaluation of the ASCE/SEI 7-16 $F_{p}$ equation, the response of archetype buildings exposed to various intensity levels was studied. 


\section{B.2.2 Evaluation Based on the Response of Archetype Structures}

A single spectrum-compatible ground motion record is used in most response history analyses in this section. The target spectrum for generating this ground motion is shown in Figure B-4a. It is recognized that applying the spectral matching approach cannot completely remove the record-to-record variability in seismic responses. For example, a large dispersion can be observed about the mean PCA response of a set of spectrum-compatible records closely matched to the same target spectrum (e.g., Reyes et al. 2014, Jiang et al. 2015). Anajafi and Medina (2018b) illustrated that if spectral matching is conducted at a lower damping ratio (e.g., when the reference time series is matched to the $2 \%$-damped target spectrum) such variability will decrease significantly. They used 100 spectrum-compatible ground motions, generated through matching 20 reference records to a target spectrum at five different damping ratios varying from 0.01 to 0.05 , and estimated the spectral misfit (i.e., average deviation of a response spectrum with respect to the target spectrum) of all simulated records in a wide period and damping range. They also calculated floor spectra for several elastic and inelastic building models (including the six-story baseline SMRF building studied herein) exposed to the simulated records. Anajafi and Medina showed that the spectrum-compatible record generated using the HectorHEC090 record as the seed motion matched to the 2\%-damped target spectrum is associated with the minimum spectral misfit. In addition, this simulated record produced floor spectra with a low deviation from the mean floor spectra from the set of spectrum-compatible records (this simulated record underestimates the mean roof PCA responses of the six-story SMRF building by $30 \%$ in the vicinity of the first mode, but in the vicinity of the second mode, which dominates the floor spectra, it underestimates the mean by $8 \%$ ). Unless otherwise noted, this record, for which ground response spectra for different damping ratios are shown in Figure B-8, is used for the basic response history analyses in this section (e.g., in some sections, the mean response of the 20 spectrum-compatible records are used).

The response of the archetype buildings is simulated for different intensity levels varying from $0.25 \mathrm{DE}$ to $2.0 \mathrm{DE}$ with a $0.25 \mathrm{DE}$ increment. Floor spectra are developed based on an uncoupled analysis of the supporting building and nonstructural components, meaning that the component-structure-interaction is neglected. This assumption is considered to be sufficiently accurate if the nonstructural component mass is smaller than that of the supporting building by a factor of at least one thousand. If this factor is smaller, the floor spectra are usually conservative (see Adam and Furtmüller, 2008; and Adam, Furtmüller et al., 2013). 


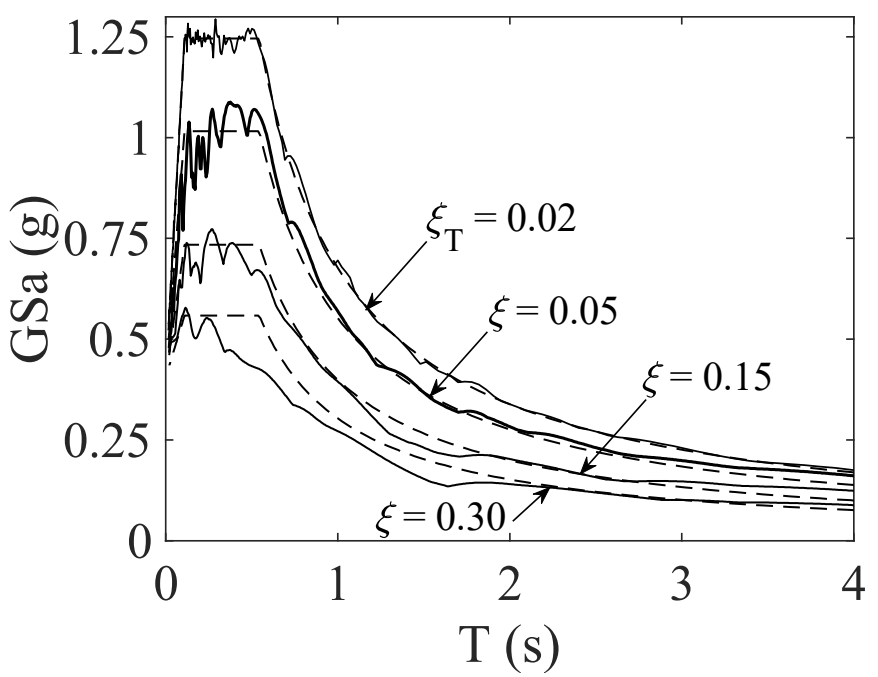

Figure B-8 Ground response spectra for the basic spectrum-compatible record used in this study; $G S_{a}$ is the pseudo-spectral acceleration. From Anajafi and Medina (2018d).

\section{B.2.2.1 Simulation Results for the Baseline Six-Story SMRF Archetype Building}

Nonlinear response history analyses were performed for all intensity levels $(0.25 \mathrm{DE}$ to $2.0 \mathrm{DE}$ with a $0.25 \mathrm{DE}$ increment), and floor response spectra (FRS) are calculated for all floor levels for the baseline six-story SMRF archetype. As an example, Figures B-9a and B-9b illustrate normalized and absolute roof PCA responses, respectively, for some selected intensity levels. According to Figure B-9a, for this structure, increasing the intensity level results in a reduction of normalized PCA responses (PCA/PGA). In other words, with successive yielding of the supporting building and the subsequent detuning, the amplification in nonstructural component pseudo-spectral acceleration response with respect to the PGA reduces. This reduction rate in the vicinity of the building modal periods, especially the first mode, is larger than near other nonstructural component periods. As illustrated in Figure B-9a, if a ground motion induces nonlinearity in the supporting building, the normalized peak acceleration demands do not increase and instead, high acceleration demands start to affect a wider range of nonstructural component periods because the effective period of the supporting building changes.

As seen in Figure B-9a, for intensity levels lower than the DE, the ASCE/SEI 7-16 upper limit of 4.0 is significantly exceeded, especially in the vicinity of the second mode; for example, maximum (PCA/PGA) at $0.25 \mathrm{DE}$ is 7.50 . For the DE level, PCA/PGA at the second mode is 5.0 meaning that it exceeds the ASCE/SEI 7-16 limit by $25 \%$ while at other nonstructural component periods, including the first mode, the ratio obtained from ASCE/SEI 7-16 overestimates the demands. Figure B- 
$9 \mathrm{~b}$ shows absolute roof spectra for the selected intensity levels. As illustrated, unlike the trend observed in Figure B-9a for the normalized PCA responses, high intensity levels govern absolute PCA responses. For intensity levels lower than the DE, absolute PCA responses in all cases (except for the $0.75 \mathrm{DE}$ level in the vicinity of the second mode) are below the ASCE/SEI 7-16 limit for the absolute PCA. These observations suggest that the adequacy of the ASCE/SEI 7 equations should not be assessed exclusively using building responses obtained from exposing structures to ground motion intensity levels that do not induce inelastic building responses.

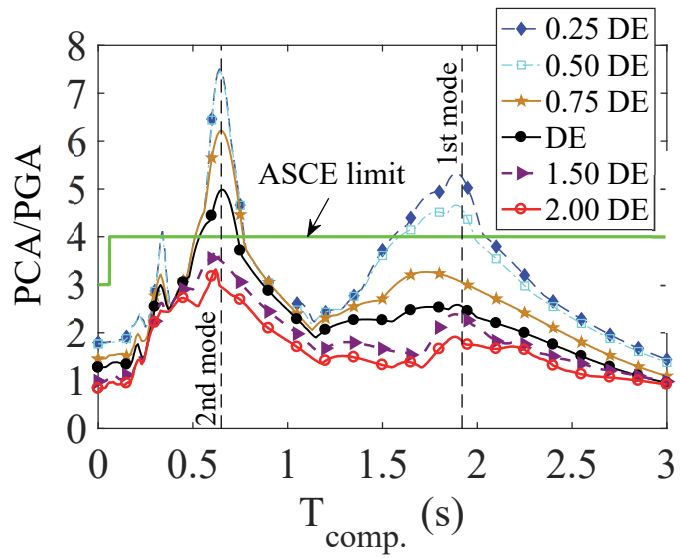

(a)

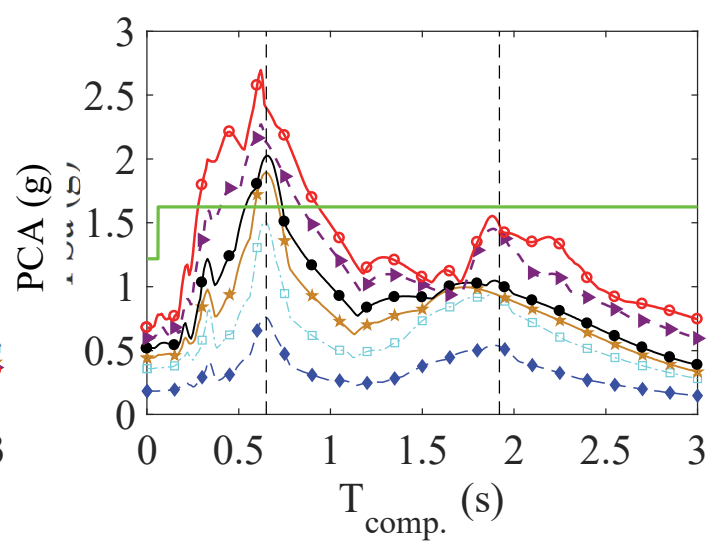

(b)

Figure B-9 5\%-damped roof floor response spectra for six-story SMRF archetype building, elastic components. From Anajafi and Medina (2018d).

Figure B-10a illustrates normalized PFA and normalized PCA in the vicinity of the first two modes versus the ground motion intensity level for the roof of the six-story SMRF archetype building. With increasing ground motion intensity, all normalized responses consistently decrease. The reduction rate at the start point of the nonlinearity (almost at $0.50 \mathrm{DE}$ ) has the highest value (see the curves slopes in Figure B-10a). According to Figure B-10a, with increasing the intensity from $0.25 \mathrm{DE}$ to 1.0DE, normalized PFA responses decrease from 1.8 to 1.3. This reduction for the PCA response in the vicinity of the second mode is from 7.5 to 5.0, and for the PCA response in the vicinity of the first mode is from 5.3 to 2.6 . Considering the $0.25 \mathrm{DE}$ level as the linear-elastic case, for the $\mathrm{DE}$ level the acceleration response modification factors of 1.4, 1.5, and 2.0 are achieved for the PFA, PCA of the second mode, and PCA of the first mode, respectively. As seen, in this case, the supporting building nonlinearity mitigates PFA responses at a lower rate than PCA responses. This observation, consistent with the instrumented buildings results, suggests that PFA is mostly governed by the rigid-body translation of the ground rather than the supporting building inelasticity when compared to the PCA responses. An evaluation of the PCA of the first-mode and second-mode reveals that the first-mode dominated responses exhibit levels of inelasticity that are larger than those experienced by the higher-mode dominated responses. 
Figure B-10b illustrates absolute PFA and PCA responses at the roof level of the sixstory SMRF building versus the ground motion intensity level. As seen, for all ground motion intensity levels, even for those greater than the DE, the absolute PFA responses are consistently below the ASCE/SEI 7-16 design value. Unlike the trend observed in the PCA responses of the second mode, the PCA responses of the first mode and also PFA responses increase at a relatively slow rate. Figure B-10 is reproduced as Figure 4-9 in Chapter 4.

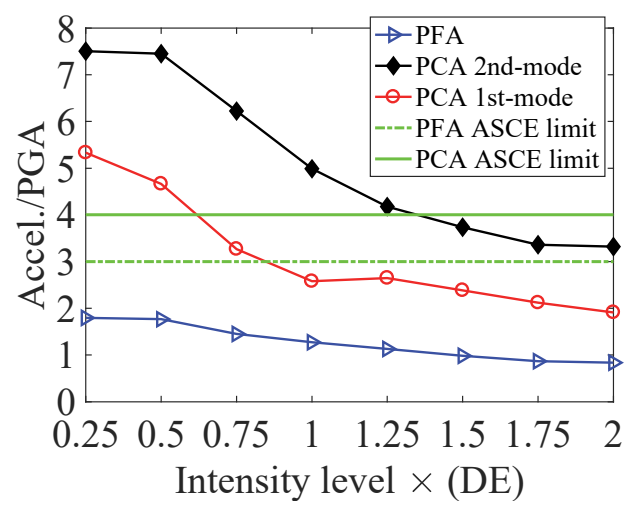

(a)

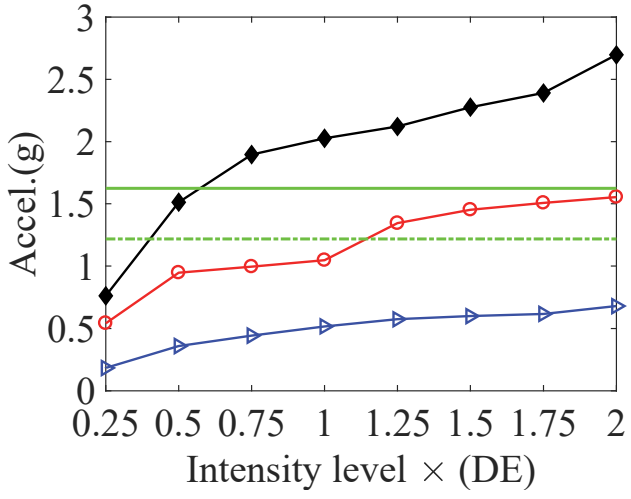

(b)

Figure B-10 PCA and PFA response at roof level versus ground motion intensity level for six-story steel MRF archetype building (a) normalized to PGA; and (b) absolute value. From Anajafi and Medina (2018d).

\section{B.2.2.2 Simulation Results for eight-story Reinforced Concrete Shear Wall (RCSW) Archetype Building}

Simulation results for the baseline eight-story RCSW building, summarized in Figures B-11 and B-12, present similar general trends as those obtained in the previous section from studying the force-resisting system of the SMRF building (see Figures B-9 and B-10). They show that at the DE level the ASCE/SEI 7-16 equation overestimates the PFA responses at all floor levels while the PCA responses, especially when the nonstructural components are tuned to the second mode, tend to be underestimated. The results also confirm that the relatively large normalized acceleration responses are due to the elastic behavior of the supporting building, and with increasing the ground motion intensity (or the supporting building inelasticity), peak normalized acceleration responses significantly decrease. In the following paragraphs, some of observations that are slightly different than those obtained in the previous section are discussed.

An evaluation of the 5\%-damped roof spectra of the RCSW building, illustrated in Figures B-11a and B-11b, suggests that acceleration demands in this structure are consistently larger than those of the six-story SMRF building. Considering the modal periods of the two buildings, this is consistent with expectations. 


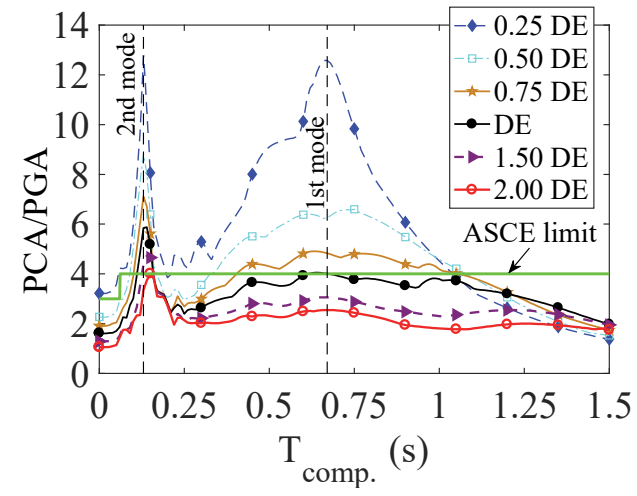

(a)

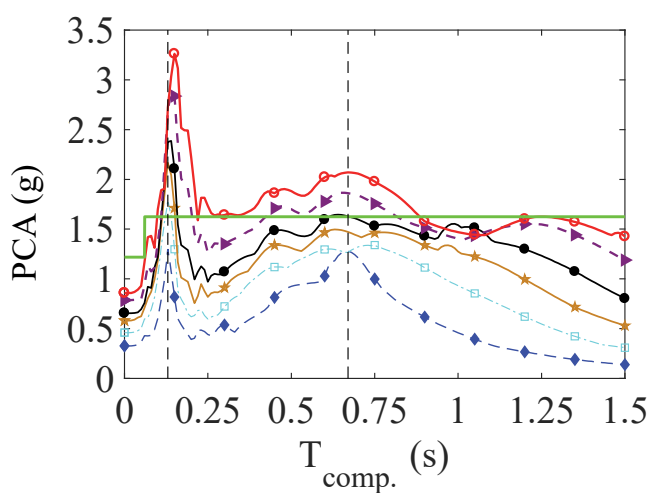

(b)

Figure B-11 5\%-damped roof floor response spectra for eight-story RCSW archetype building, elastic components. From Anajafi and Medina (2018d).

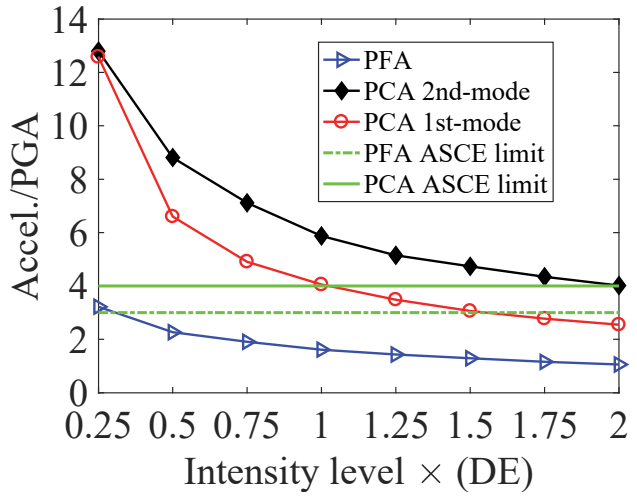

(a)

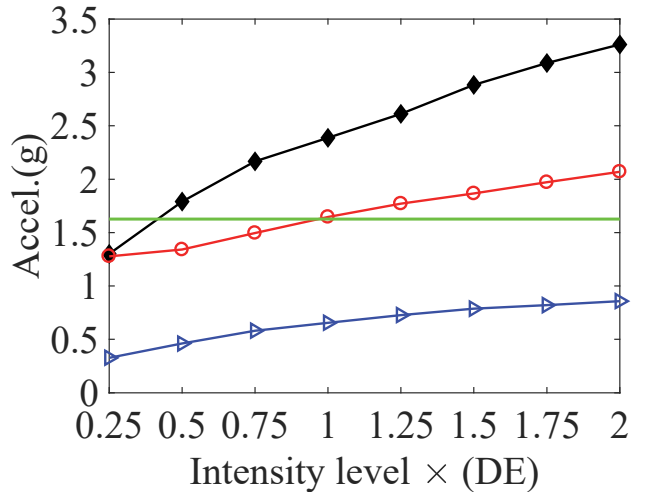

(b)

Figure B-12 PCA and PFA response at roof level versus ground motion intensity level for eight-story RCSW archetype building (a) normalized to PGA; and (b) absolute values. From Anajafi and Medina (2018d).

Absolute and normalized peak acceleration responses at the roof floor of the eightstory RCSW building versus the ground motion intensity level are illustrated in Figures B-12a and B-12b, respectively. As seen in Figure B-12a, with increasing the ground motion intensity from $0.25 \mathrm{DE}$ to $1.0 \mathrm{DE}$, the normalized PFA response decreases from 3.2 to 1.6. This reduction for the PCA of the second-mode region is from 12.8 to 5.9, and for the PCA of the fundamental-mode region, the reduction is from 12.6 to 4.1. Considering the 0.25DE level as the elastic case, for the DE level response, the acceleration modification factors of 2.0, 2.2, and 3.1 are obtained for the PFA, PCA of the second mode, and PCA of the first mode, respectively. These values are larger than those observed in the six-story SMRF example; however, the overall message regarding the difference between the response modification factors of the PFA and PCA is the same. Figure B-12b illustrates that in the case of the RCSW, a near-saturation limit is observed in the PFA responses only. 


\section{B.3 Influence of the Building Modal Periods and Seismic Force- Resisting System (SFRS)}

\section{B.3.1 Evaluation Based on the Response of Multistory Instrumented Buildings}

For the evaluation conducted in this section, roof floor motions obtained from all multistory instrumented building directions are used. Overall, 84 roof floor motions are available for these buildings. Floor motions that were significantly influenced by building characteristics such as in-plane diaphragm flexibility or primary building irregularity (for more information see Sections B.6 and B.7) were removed from the evaluation of this section. These cases are not used herein as the basis for understanding the effect of modal periods and supporting building SFRS on the roof spectra because they are heavily influenced by a secondary parameter (e.g., a significant irregularity in mass or stiffness).

After removing the aforementioned cases, 54 remained roof spectra were categorized based on their SFRS. The SFRS for 27, 16, and five principal building directions are steel and concrete MRFs (combined into one group), steel and concrete SW (combined into one group), and steel bracing system, respectively. Three cases with dual SFRS and three cases with hybrid systems are also present and exhibit characteristics similar to the steel MRF systems. Hence, they are considered part of the MRF family. Because five cases cannot provide a sufficient population size to identify a reliable trend for the steel bracing family, they are not considered in this evaluation. With the aforementioned modifications, all remaining building directions are either MRF (33 cases) or SW (16 cases) systems. The 5\%-damped elastic roof spectra for the MRF and SW cases are presented in Figure B-13 below.

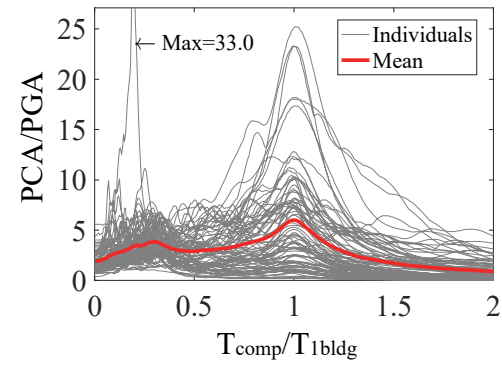

(a)

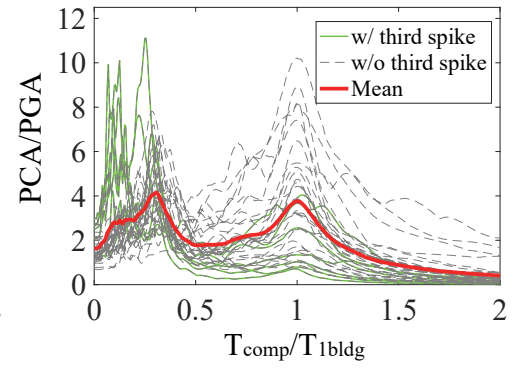

(b)

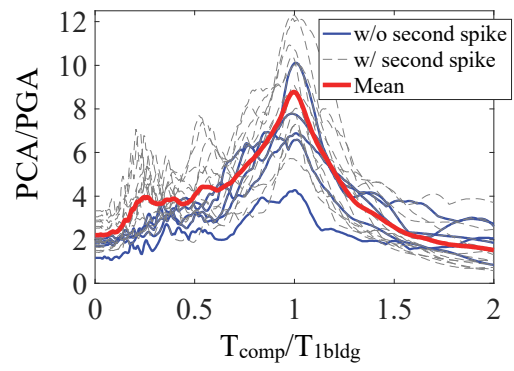

(c)

Figure B-13 5\%-Damped normalized roof spectra for the multistory buildings (a) all data points (84 cases); (b) and (c) buildings consistent with the behavior observed in regular 2D numerical MRF (33 cases) and SW (16 cases) models, respectively.

As seen in Figure B-13:

- The modal periods of most MRF building directions follow the general approximation of $T_{2 b l d g} / T_{\text {Ibldg }}=1 / 3$. For the $\mathrm{SW}$ cases, this ratio is between 0.25 
and 0.75 , which is different from the $T_{2 b l d g} / T_{1 b l d g}=1 / 5$ approximation for flexural SWs.

- The contribution of higher modes is evident in most MRF building directions. However, some SW cases do not exhibit a clear contribution of higher modes. This latter behavior generally occurs in short SW building directions whose second modal period situates in the range 0.1-0.2 s for which typical ground motions do not have significant energy content.

- The PCA responses of the SW cases are, on average, larger than those of the MRF cases. This is consistent with the observations obtained from previous numerical studies.

- The variation in the roof spectra of the MRF cases is larger than those of the SWs because the range of modal periods in the MRF building directions is larger.

- For taller and flexible MRF building directions, a discernible third-mode spike is observed in the roof spectra because the third-mode of these cases is located in the period range that can be excited by typical ground motions. For the shorter MRF building directions, spectral ordinates in the vicinity of the fundamental mode dominate the roof spectra whereas for the taller MRF cases, the spike in the vicinity of the third mode governs the roof spectra.

The above observations are based on instrumented buildings that mostly experienced ground motions with relatively low intensities with respect to the DE for the building sites (see Section B.1). Many previous studies (e.g., Sankaranarayanan and Medina, 2007) have illustrated that the supporting building nonlinearity significantly influences the floor spectral ordinates (see also results in Section B.2.2). Hence, it can be postulated that a more realistic evaluation of the ASCE/SEI 7-16 $F_{p}$ equation should be conducted using code-based designed buildings exposed to DE level ground motions. However, the evaluation presented in this section using instrumented building responses, consistent with previous numerical studies, still reveals significant deficiencies associated with the ASCE/SEI 7-16 $F_{p}$ equation. This evaluation shows a significant difference between the shape and magnitude of the floor spectra for MRF and SW systems, as well as for short-period and long-period buildings. These observations illustrate that the floor spectral ordinates strongly depend on the type of SFRS and modal periods of the supporting building, which is not explicitly taken into account in the current ASCE/SEI 7-16 $F_{p}$ equation.

\section{B.3.2 Evaluation Based on the Response of Archetype Building Models}

An evaluation of Figures B-9 and B-11 in Section B.2.2 further confirms the results from many past research studies as well as those discussed in Section B.3.1. It is evident that the magnitude and shape of floor response spectra are strongly dependent on the modal periods of the supporting structure and the SFRS. 


\section{B.4 Effect of Building Nonlinearity}

\section{B.4.1 Potential Amplification of Peak Component Acceleration Demands (with Respect to the Elastic Case) Due to Building Nonlinearity}

The combined results from past studies (e.g., Sewell et al., 1986, Chaudhuri and Villaverde, 2008; Sankaranarayanan and Medina, 2008) suggest that the rate of increase observed in the absolute values of PCA (Figures B-10b and B-12b) could be larger when the supporting building exhibits a concentration of inelasticity along its height (or, in general, non-uniform yielding with height such as the formation of a story plastic mechanism), the nonstructural component is located in the bottom half of the structure, the nonstructural component has a damping ratio smaller than 0.05, and the nonstructural component has a period in the vicinity of the higher modal periods of the supporting building. Under these conditions, inelasticity in the supporting building can amplify demands with respect to those observed for a linear elastic building when both buildings are exposed to the same ground motion intensity level.

This section uses the set of 20 spectrum-compatible ground motions to evaluate this behavior in a representative archetype building.

Figure B-14 shows results for the six-story SMRF baseline archetype i.e., a wellbehaved structure in which plastification occurs at the beam ends and at the bottom of the first story columns and is generally uniformly distributed over the height under a DE ground motion. Figure B-15 presents results for a modified version of the sixstory SMRF baseline structure in which member sizes and boundary conditions remain the same; however, plastification can only occur at the top and bottom of the first story columns (i.e., weak first-story mechanism), i.e., the rest of the structure remains in the linear elastic range. In these figures, component damping ratios are varied from $0.1 \%$ to $5 \%$, and floor spectra are presented at the roof level and at the second-floor level for elastic nonstructural components. The parameter $R_{c b}$ is equal to the ratio of the floor response spectrum ordinate of the elastic archetype model to the floor response spectrum ordinate of the baseline archetype model (Figure B-14) or the weak first-story archetype model (Figure B-15). Thus, a value of $R_{c b}<1$ implies that building inelasticity amplifies PCA responses. Figures B-14 and B-15 are reproduced as Figures 4-10 and 4-11 in Chapter 4.

It can be observed from these figures that the trends identified in the preceding paragraph are consistent with the results from this evaluation. The general trend is that, on average, building nonlinearity reduces PCA demands (i.e, mean values of $R_{c b}$ $>1$ ) for both baseline and weak-first story archetypes. It is important to note, however, that in some individual cases, building nonlinearity amplifies PCA responses. 


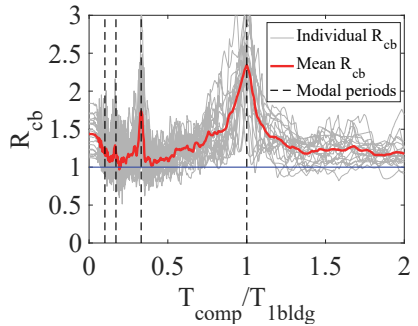

Component damping $0.1 \%$

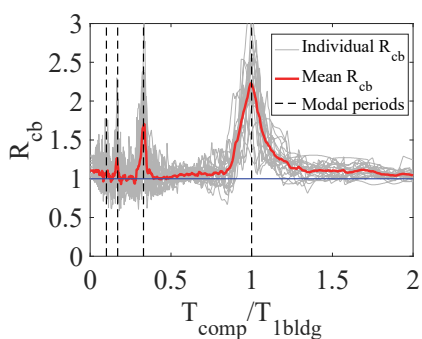

Component damping $0.1 \%$

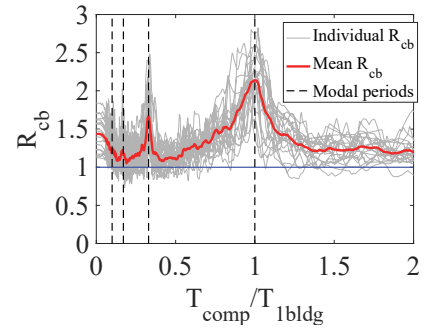

$1 \%$

(a) Roof level

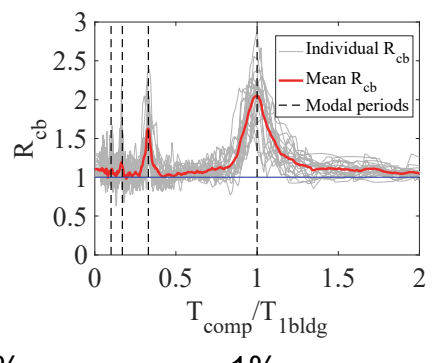

$1 \%$

(b) Second-floor level

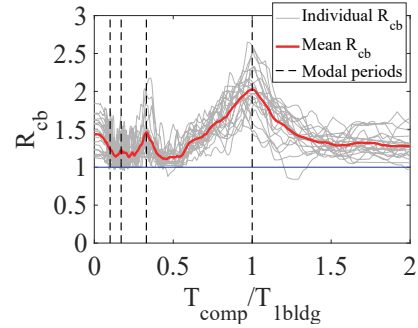

$5 \%$

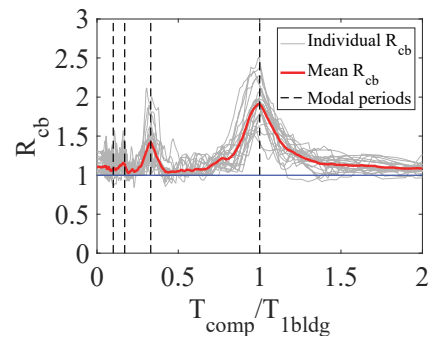

$5 \%$

Figure B-14 Effect of building nonlinearity on PCA; baseline archetype 6-story SMRF.

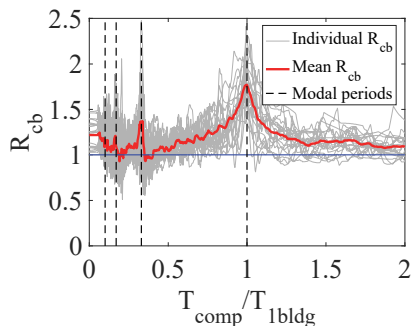

Component damping $0.1 \%$

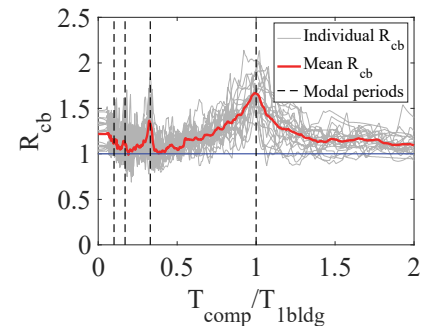

$1 \%$

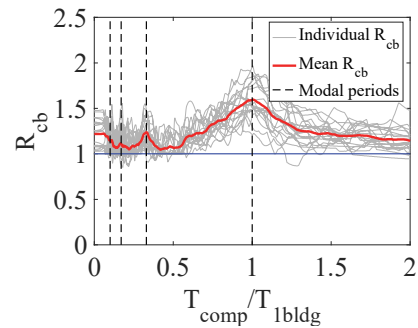

$5 \%$

(a) Roof level

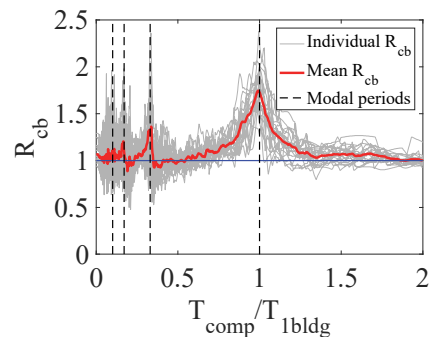

Component damping $0.1 \%$

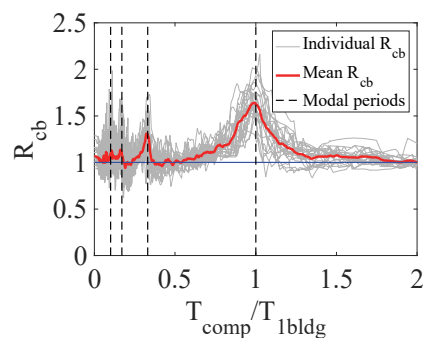

$1 \%$

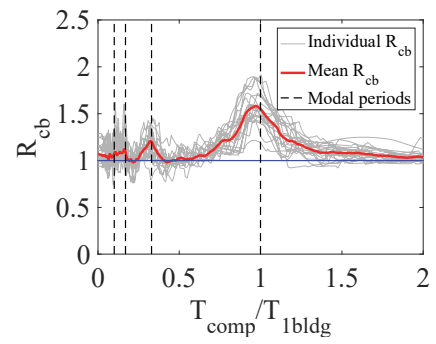

$5 \%$

(b) Second-floor level

Figure B-15 Effect of building nonlinearity on PCA; weak first story archetype 6story SMRF.

Moreover, an evaluation of the results of this section illustrates that localized plasticity can lead to smaller $R_{c b}$ values with respect to cases with widespread plasticity. For example, the maximum value of $R_{c b}$ in Figure B-14 for the baseline building is 2.4 whereas the corresponding value for the building with a weak-story 
mechanism, shown in Figure B-15, is 1.7. It is also observed that the detrimental effect of the building inelasticity on nonstructural component seismic demands (i.e., increasing the seismic demand on nonstructural components) is more significant in the building with a weak-story mechanism. This latter conclusion corroborates the observations made by previous studies. For example, Chaudhuri and Villaverde (2008) state that "the peak acceleration response of a linear nonstructural component may increase when the supporting building goes from linear to localized nonlinear behavior but not when the building goes from linear to widespread nonlinear behavior."

\section{B.4.2 Alternative Evaluation of Building Nonlinearity Based on Global Ductility}

To explicitly evaluate the effect of building nonlinearity on PCA demands, this subsection presents normalized floor spectra for two types of archetypes: the baseline two- and six-story SMRF, and baseline eight-story RCSW archetypes, as well as their corresponding overdesigned models. Thus, a total of eight archetypes are used. In this context, an overdesigned archetype is one in which a baseline model is modified by an overdesign factor that increases both lateral strength and stiffness; this factor accounts for increases in strength and stiffness in addition to the inherent overstrength that results from the design of the baseline archetype models. For instance, an overdesign factor of 1.5 was used for the six-story SMRF and eight-story RCSW archetypes. An overdesign factor of 1.5 implies that both the strength and stiffness properties of the baseline archetype models are increased by $50 \%$.

Overdesign factors of 2.0 and 3.0 were used or the two-story SMRF and two-story RCSW archetypes, respectively. The approximate period computed based on ASCE/SEI 7-16, $T_{\text {abldg, }}$, and the computed modal periods of the various archetype models (with and without the overdesign factor) are shown in Table B-8.

\section{Table B-8 Code and Modal Periods of Various Archetypes}

\begin{tabular}{|c|c|c|c|c|c|c|c|}
\hline System & $\begin{array}{c}\text { \# of } \\
\text { stories } \\
\end{array}$ & $\begin{array}{c}h \\
(\mathrm{ft}) \\
\end{array}$ & Design scenario & $T_{\text {abldg }}(\mathrm{s})$ & $T_{1 \text { bldg }}(\mathrm{s})$ & $T_{2 b l d g}(\mathrm{~s})$ & $T_{3 b l d g}(\mathrm{~s})$ \\
\hline \multirow{2}{*}{ SMRF } & \multirow{2}{*}{6} & \multirow{2}{*}{80} & Baseline & 0.93 & 1.93 & 0.63 & 0.32 \\
\hline & & & With an OD of 1.5 & 0.93 & 1.55 & 0.52 & 0.26 \\
\hline \multirow{2}{*}{ SMRF } & \multirow{2}{*}{2} & \multirow{2}{*}{28} & Baseline & 0.40 & 1.01 & 0.21 & - \\
\hline & & & With an OD of 2.0 & 0.40 & 0.71 & 0.15 & - \\
\hline \multirow{2}{*}{ RCSW } & \multirow{2}{*}{8} & \multirow{2}{*}{97} & Baseline & 0.62 & 1.03 & 0.17 & 0.06 \\
\hline & & & With an OD of 1.5 & 0.62 & 0.80 & 0.12 & 0.05 \\
\hline \multirow{2}{*}{ RCSW } & \multirow{2}{*}{2} & \multirow{2}{*}{25} & Baseline & 0.22 & 0.52 & 0.09 & - \\
\hline & & & With an OD of 3.0 & 0.22 & 0.17 & 0.04 & - \\
\hline
\end{tabular}

$\mathrm{OD}=$ Overdesign factor 
Normalized floor spectra at the roof level are shown for both baseline and overdesigned archetypes (see Figure B-16) to evaluate the effect of building nonlinearity.
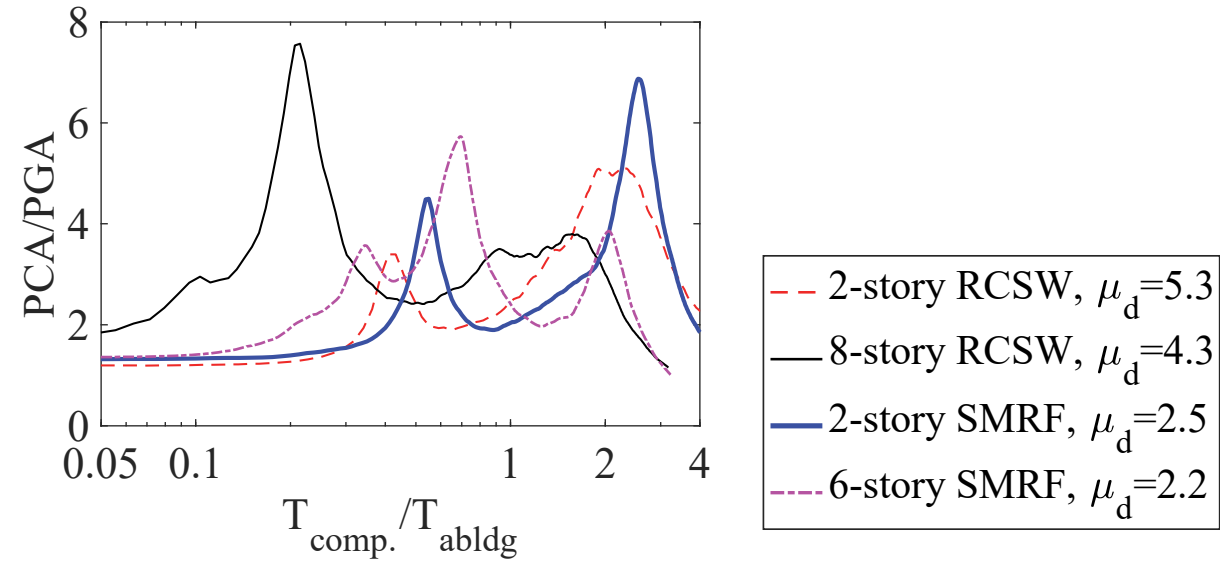

(a) Baseline archetypes
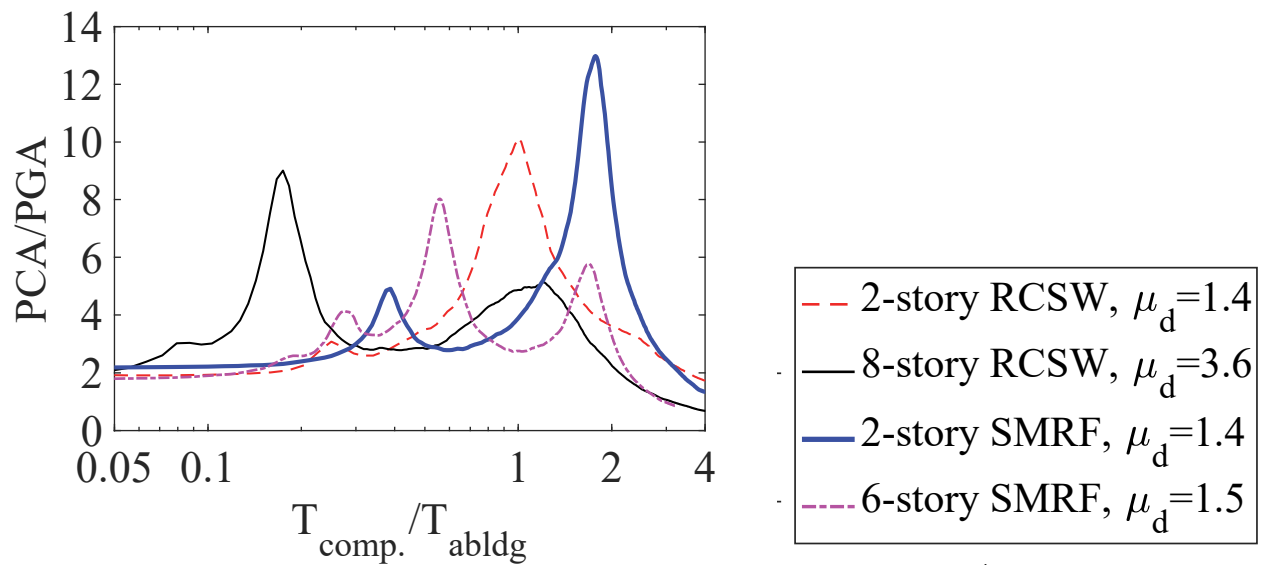

(b) Overdesigned archetypes

Figure B-16 Mean PCA/PGA ratios for the (a) baseline; and (b) overdesigned archetype buildings and their associated building global displacement ductility values. An elastic component is assumed with $\beta_{\text {comp }}=5 \%$. The results are at roof level from the analytical study of the eight archetype structures exposed to the set of 20 spectrum compatible ground motions at the DE.

In this figure, for each model, the term $\mu_{d}$ represents the ratio of the mean of the maximum roof displacement from response history analyses using the set of 20 spectrum-compatible ground motions normalized by an estimate of the yield roof displacement from a nonlinear static (pushover) analyses of a building (using an inverted triangular load pattern as well as a load pattern based on a force distribution from response spectrum analyses resulted in similar estimates of yield roof displacements). Thus, $\mu \mathrm{d}$ is used herein as an approximate measure of building ductility, $\mu_{\text {bldg. }}$. PCA/PGA ratios are shown as a function of $T_{\text {comp }} / T_{\text {abldg. }}$. Each spectrum represents the mean roof spectrum from the individual responses for each building model when exposed to the set of 20 spectrum-compatible ground motions. 
Because the horizontal axis presents the ratio of the component period normalized by $T_{\text {abldg, }}$ which is the same value for both baseline and overdesigned archetypes, the peak values of floor spectra tend to shift to the left for the overdesigned archetypes. The incorporation of the overdesigned factor results in an increase of the stiffness of a baseline frame which in turns results in a decrease in period. Figure B-16 demonstrates that for these models, in general, an increase in global system ductility results in a decrease in the maximum value of the ratio of PCA/PGA (i.e., decrease in PCA demands) over the normalized period range of interest. Figure B-16 is reproduced as Figure 4-12 in Chapter 4. The nonlinear static analysis (pushover) curves are shown for the archetypes are shown in Figure B-17.

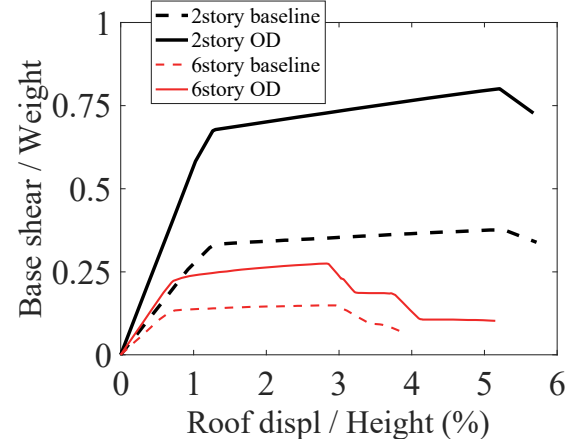

(a)

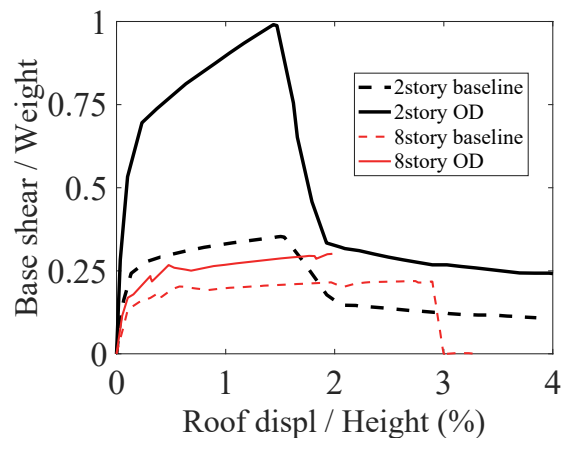

(b)

Figure B-17 Pushover curves for archetype buildings used in this section when exposed to an inverted triangular load pattern (a) SMRF; and (b) RCSW.

\section{B.5 Effect of Inherent Building Viscous Damping}

In general, for a building responding inelastically (i.e., baseline archetype buildings at the DE level), inherent building viscous damping has shown to have a smaller effect on component responses when compared to other influential parameters investigated as part of this study.

This section investigates the effect of inherent building damping on the estimation of PCA demands using the responses of the baseline archetype six-story SMRF building model as well as the baseline archetype eight-story RCSW building model. 20 spectrum-compatible records generated for a target spectrum with 5\% damping was used to compute roof floor response spectra, and mean spectra were used. The buildings are exposed to 20 spectrum-compatible records, and mean responses are used. Analyses were performed at $0.25 \mathrm{DE}$ level and 1.0 DE to simulate the supporting building elastic and inelastic behaviors, respectively. In these models, the six-story SMRF archetype had all the nodes slaved in the horizontal direction at a given floor level. Rayleigh damping based on initial stiffness was used and the same modal damping ratios were assigned to the second mode and at a mode with a period equal to twice the first mode period of each model. Cases with 1, 2.5, and 5\% 
damping ratios were studied with the understanding that $2.5 \%$ damping was more important when evaluating nonlinear responses.

Figure B-18 presents an evaluation of the sensitivity of PCA demands to the value of the supporting building viscous damping ratio for the six-story SMRF building exposed to the DE level spectrum-compatible records. Figure B-18 is reproduced as Figure 4-13 in Chapter 4. Figure B-19 depicts a similar evaluation for the six-story SMRF exposed to the $0.25 \mathrm{DE}$ level spectrum-compatible records. For the inelastic building cases, in the vicinity of the second mode (which dominates floor spectra), when the building damping changes from $2.5 \%$ to $1 \%$ and $5 \%$, the variation in the mean PCA values is limited to $+18 \%$ and $-19 \%$, respectively. In the vicinity of the fundamental mode, this variation is insignificant (less than 5\%). For the elastic building case, shown in Figure B-19, when the building damping changes from 2.5\% to $1 \%$ and $5 \%$, the variation in the mean PCA values in the vicinity of the second mode is up to $+43 \%$ and $-30 \%$, respectively. These observations illustrate that the effect of building viscous damping on PCA responses is more significant in an elastic building. Results of similar analyses for the eight-story RCSW are illustrated in Figure B-20.

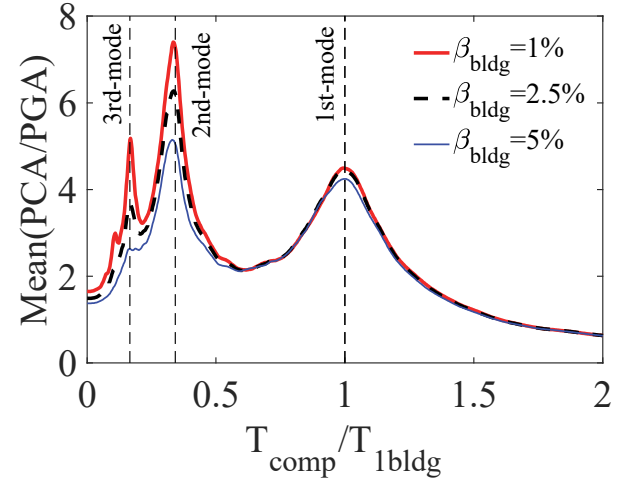

(a)

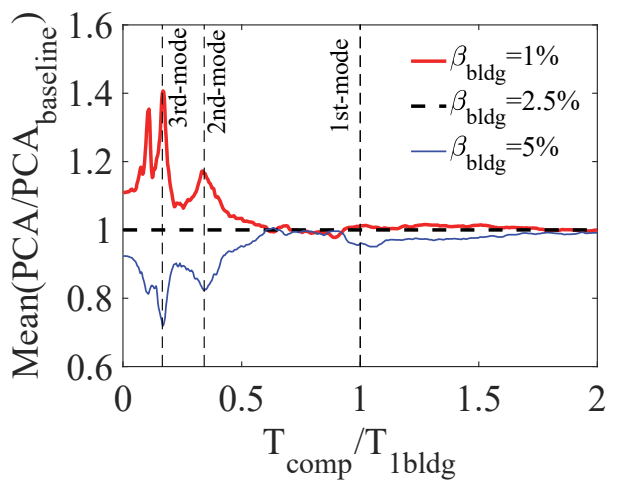

(b)

Figure B-18 Effect of inherent building damping on PCA from analytical studies of the archetype six-story SMRF model exposed to the spectrumcompatible record set at the DE level. (a) mean roof spectra for building models with different damping ratios; and (b) mean value of roof spectra normalized to the roof spectra corresponding to the building model with $2.5 \%$ damping. An elastic component is assumed with $\beta_{\text {comp }}=5 \%$. 


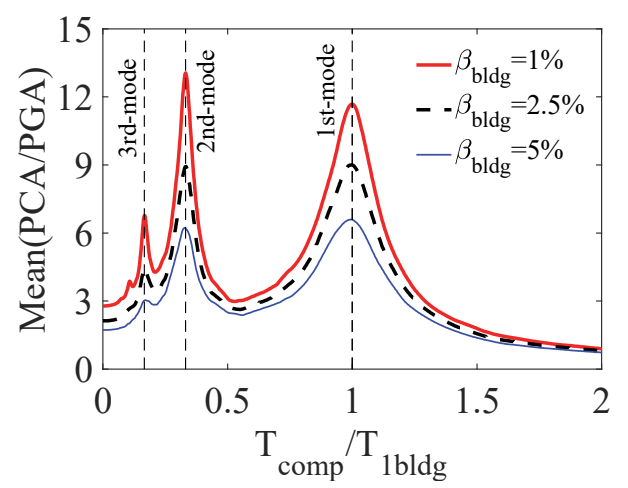

(a)

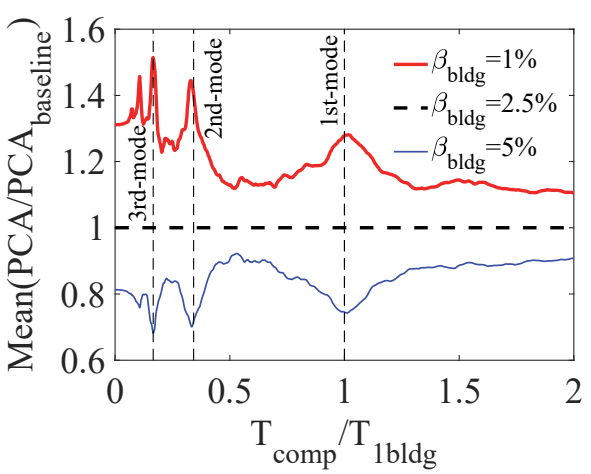

(b)

Figure B-19 Effect of inherent building damping on PCA from analytical studies of the archetype six-story SMRF model exposed to the spectrumcompatible record set at the $0.25 \mathrm{DE}$ level. (a) mean roof spectra for building models with different damping ratios; and (b) mean value of roof spectra normalized to the roof spectra corresponding to the building model with $2.5 \%$ damping. An elastic component is assumed with $\beta_{\text {comp }}=5 \%$.

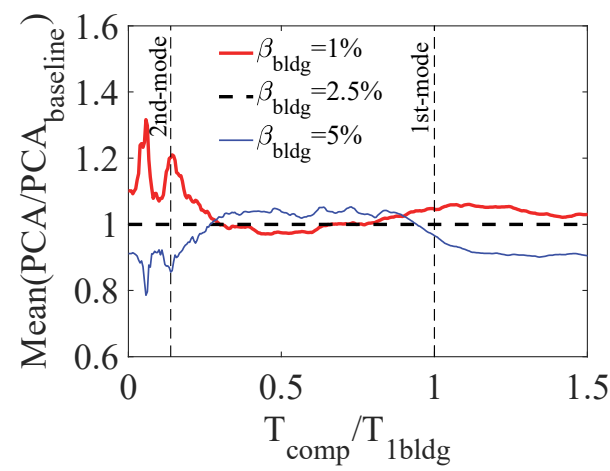

(a)

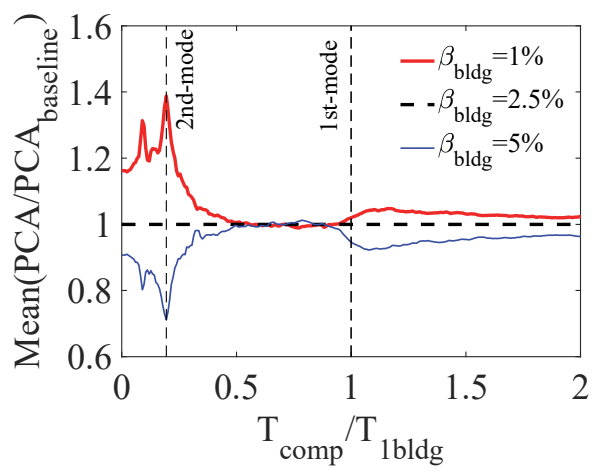

(b)

Figure B-20 Effect of inherent building viscous damping on PCA from analytical studies of the archetype eight-story RCSW model exposed to the spectrum-compatible record set at (a) the DE level; and (b) at the $0.25 \mathrm{DE}$ level. An elastic component is assumed with $\beta_{\text {comp }}=5 \%$.

\section{B.6 Effect of Building Configuration}

As seen in Figure B-13, some floor motions that were significantly influenced by building characteristics such as in-plane diaphragm flexibility or primary building irregularity (i.e., building configuration) were removed from the evaluation in this section. These cases are not used in this study as the basis for evaluating peak component demands as these are heavily influenced by a secondary parameter (e.g., a significant irregularity in mass or stiffness) that is difficult to quantify using twodimensional archetypes, and is not consistent with designs based on modern seismic design criteria and standards. 


\section{B.7 Effect of Building Floor and Roof Diaphragm Rigidity}

Three-dimensional effects such as the in-plane flexibility of the floor diaphragm and torsional responses of the supporting building on the floor motion characteristics are generally not accounted for when using simplified regular 2D numerical models. Recorded accelerations by two parallel sensors installed at different locations of an instrumented building floor can be used to approximately identify the presence of these 3D effects. This identification is approximate given the finite number of sensors and locations in a given building. The acceleration responses of such sensors would be theoretically the same in regular buildings with rigid floor diaphragms that do not exhibit torsional effects. The difference between the responses of these sensors can illustrate the presence of torsional responses and/or in-plane diaphragm flexibility. In the database compiled for this study, 135 floor cases were instrumented with more than one sensor in a principal direction of a building. Different sensor arrangements for these floors are shown in Figure B-21. Assuming a single-span floor with perimeter lateral-load resisting elements, Equations B-1 and B-2 can be used to approximately estimate the PFA amplification due to the torsional responses and due to the in-plane diaphragm flexibility, respectively:

$$
\begin{gathered}
\gamma_{\text {torsion }}^{\mathrm{PFA}}=\max \left(\mathrm{PFA}_{l}, \mathrm{PFA}_{2}\right) / \operatorname{avg}\left(\mathrm{PFA}_{l}, \mathrm{PFA}_{2}\right) \\
\gamma_{\text {flexibility }}^{\mathrm{PFA}}=\mathrm{PFA}_{\text {center }} / \operatorname{avg}\left(\mathrm{PFA}_{l}, \mathrm{PFA}_{2}\right)-2
\end{gathered}
$$

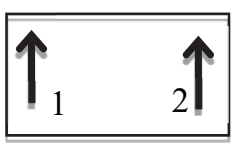

(a)

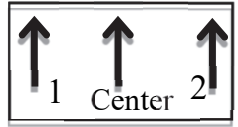

(b)

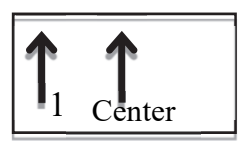

(c)

Figure B-21 Sensor arrangements in building floors that can capture: (a) torsional responses only (a sample size of 80 ); (b) both torsional and in-plane diaphragm flexibility effects (a sample size of 27); and (c) either torsional or in-plane diaphragm flexibility effect (a sample size of 28). From Anajafi and Medina (2018c).

The same equations are used to estimate the PCA amplification due to torsional responses and due to in-plane diaphragm flexibility. Note that for these studies the maximum values for each sensor was used. A more refined version of analyzing the combination of associated sensors at every time step and taking the time step with the maximum ratio was not done.

For situations other than a single-span floor and/or perimeter seismic-force resisting elements, these equations should be modified accordingly (see Anajafi and Medina 2018a for more details). Figure B-22a shows $\gamma_{\text {flexibility }}^{\mathrm{PFA}}$ and $\gamma_{\text {flexibility }}^{\mathrm{PCA}}$ for the singlestory instrumented buildings. In this case, all available single-story instrumented buildings with a suitable sensor arrangement were included in the data set. As seen, $\gamma_{\text {flexibility }}^{\mathrm{PFA}}$ and $\gamma_{\text {flexibility }}^{\mathrm{PCA}}$ are in the ranges 0.7-4.1 and 0.6-5.1, respectively. Figure B- 
$22 \mathrm{~b}$ presents acceleration amplification factors for the single-story buildings illustrating that $\gamma_{\text {torsion }}^{\mathrm{PFA}}$ and $\gamma_{\text {torsion }}^{\mathrm{PCA}}$ are limited to 1.2 and 1.3 , respectively. The amplitudes of parameters $\gamma_{\text {torsion }}$ and $\gamma_{\text {flexibility }}$ depend on the in-plane modal periods of diaphragm (i.e., mass, stiffness/free-span length and aspect ratio), frequency content of the ground excitation, distribution of seismic force resisting system elements, irregularity of the building, and the diaphragm's damping ratio. In general, plywood diaphragms and irregular buildings exhibit larger $\gamma_{\text {flexibility }}$ and $\gamma_{\text {torsion }}$, respectively, which is consistent with expectations (see Anajafi and Medina, 2018a, for more details).

Figures B23-a and B-23b illustrate $\gamma_{\text {flexibility }}^{\mathrm{PFA}}$ and $\gamma_{\text {flexibility }}^{\mathrm{PCA}}$ versus relative height for the multistory buildings. In this case, all available multistory instrumented buildings with a suitable sensor arrangement were included in the data set. There are floor cases for which $\gamma_{\text {flexibility }}^{\mathrm{PFA}}$ is near unity but $\gamma_{\text {flexibility }}^{\mathrm{PCA}}$ is significant, which reiterates that the spectral ordinates at different periods are influenced by the in-plane diaphragm flexibility differently due to the frequency content characteristics of floor motions. As seen, $\gamma_{\text {flexibility }}^{\mathrm{PFA}}$ varies from 0.9 to 1.7 , whereas this range for $\gamma_{\text {flexibility }}^{\mathrm{PCA}}$ is 0.8 to 2.0. Figures B-24a and B-24b depict $\gamma_{\text {torsion }}^{\mathrm{PFA}}$ and $\gamma_{\text {torsion }}^{\mathrm{PCA}}$ versus relative height for the multistory buildings. These parameters vary in the 1.0-1.3 and 1.0-1.5 ranges, respectively.

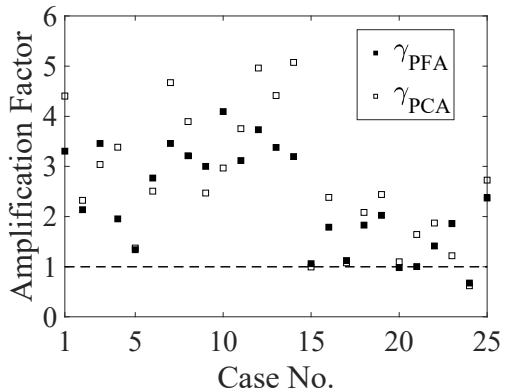

(a)

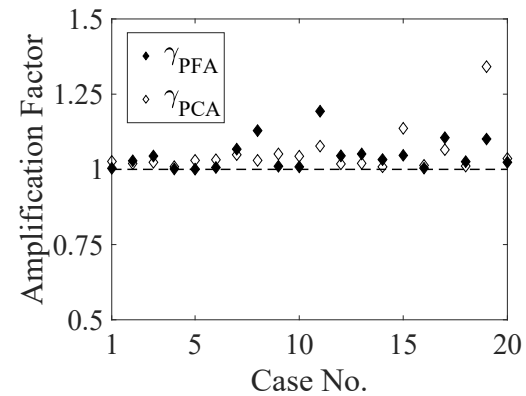

(b)

Figure B-22 Amplified PFA and PCA responses in the single-story instrumented buildings due to: (a) in-plane diaphragm flexibility (sample size of 25 ); and (b) torsional responses of supporting buildings (sample size of 20). Modified from Anajafi and Medina (2018c).
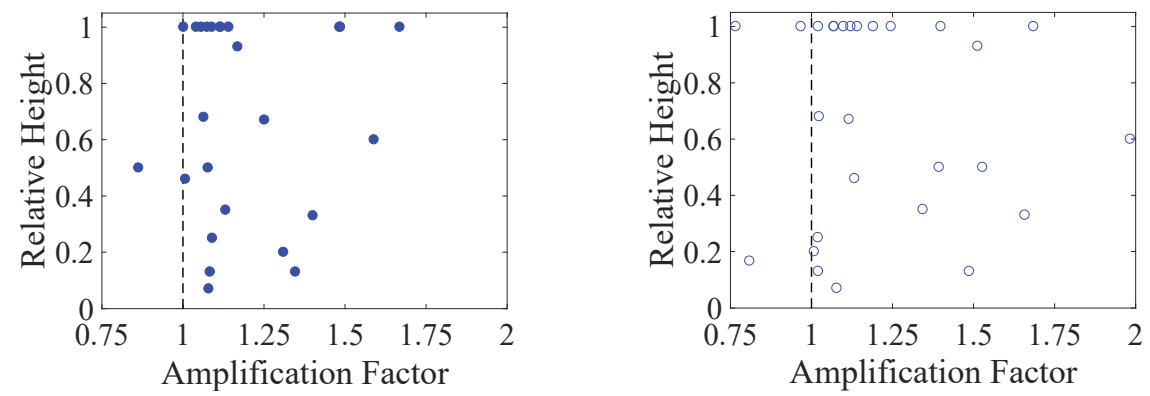

Figure B-23 Amplified (a) PFA and (b) PCA responses with height due to the inplane diaphragm flexibility of the multistory buildings (sample size 27). From Anajafi and Medina (2018c). 

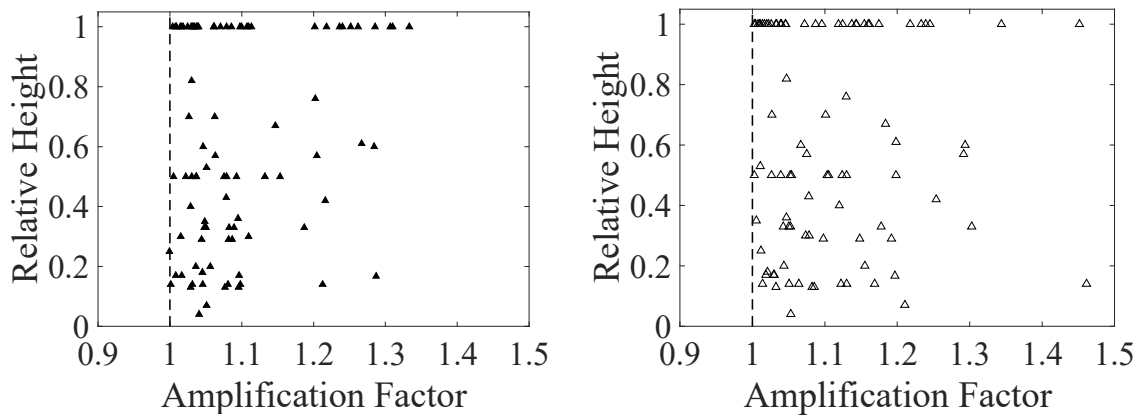

Figure B-24 Amplified (a) PFA and (b) PCA responses with height due to the torsional responses of the multistory buildings (sample size 90). From Anajafi and Medina (2018c).

The sensor arrangement in 18 and 9 floor directions for the single- and multi-story buildings, respectively, allows for a simultaneous evaluation of in-plane diaphragm flexibility and torsional responses (see the sensor arrangement shown in Figure B-21b). An evaluation of $\gamma_{\text {flexibility }}^{\mathrm{PFA}}$ and $\gamma_{\text {flexibility }}^{\mathrm{PCA}}$ for these floor directions is shown in Figures B-25a and B-25b for the single-story and multistory buildings, respectively. For single-story buildings, $\gamma_{\text {flexibility }}^{\mathrm{PFA}}$ varies from 1.1 to 4.1 , while $\gamma_{\text {torsion }}^{\mathrm{PFA}}$ is bounded by 1.2. These observations suggest that nonstructural components mounted on the single-story instrumented buildings studied herein are more influenced by the inplane diaphragm flexibility than torsional responses. As can be observed from Figure B-25b, for the multistory buildings, when one amplification factor is large, the other one is not generally significant (the only exception is case No. 4). It is apparent that, in general, torsional and in-plane diaphragm flexibility effects do not occur simultaneously. These observations suggest that the in-plane diaphragm flexibility can mitigate torsional responses, evidently at the expense of amplified acceleration responses at the middle of an unsupported floor span. This latter statement can be readily observed in Figure B-25a for single-story buildings, where $\gamma_{\text {torsion }}^{\text {PFA values are }}$ mostly near unity but $\gamma_{\text {flexibility }}^{\text {PFA }}$ values are significant. Anajafi and Medina (2018a) present similar trends observed for the PCA responses and a more detailed interpretation of the results. Results of this section indicate that the ASCE/SEI 7-16 $F_{p}$ equation for designing nonstructural components, which does not explicitly consider 3D effects, may underestimate seismic design forces for accelerationsensitive components attached to flexible floors (e.g., those with periods in tune with the horizontal fundamental frequency of the vibrating diaphragm) or components mounted on buildings that are prone to exhibiting torsional responses. Additional studies are needed to further address this issue, and they would include more detailed deaggregation of records by wall (concrete, masonry, wood) and diaphragm (concrete, metal deck, and wood). 

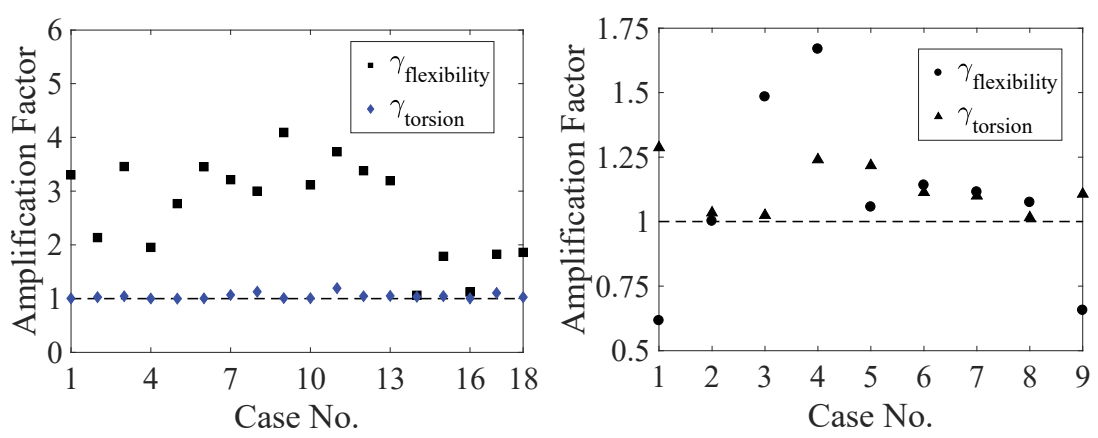

Figure B-25 Comparison of the amplitude of $\gamma_{\text {flexibility }}^{\text {PFA }}$ and $\gamma_{\text {torsion }}^{\text {PFA }}$ for floor directions in which the sensor arrangement allows for better estimation of inplane diaphragm flexibility effects and torsional responses simultaneously for: (a) single-story buildings (sample size of 18); and (b) multistory buildings (sample size of 9). From Anajafi and Medina (2018c).

\section{B.8 Incorporation of the Effect of Building Nonlinearity in the Proposed Equation}

Chapter 4 Section 4.3.4 presents the proposed design equation developed as part of this project. Studies were conducted to evaluate the effectiveness of assuming $x=$ $1 / 2$ in the $R_{\mu b l d g}=\left(R_{D}\right)^{x}$ equation using the mean response from the set of 20 spectrum-compatible ground motions for the four baseline and the four overdesigned archetype structures. The evaluation is based on the $F_{p, \text { actual }} / F_{p, p r o p o s e d}$ ratio, where the quantity $F_{p, p r o p o s e d}$ represents the results from evaluating the proposed $F_{p}$ equation assuming different exponents, $x$, for the "more likely in resonance" case for component ductility values of 1.0 and 1.5 , as well as inherent component damping ratio of 5\%. Note that in this study, for all inelastic component cases, a Clough bilinear stiffness degrading hysteresis model (Clough and Johnston, 1966) with 3\% strain hardening was used to account for the hysteretic behavior of the component. Moreover, when calculating $F_{p \text {,actual }} / F_{p, \text { proposed, }}$, the term $R_{\text {pocomp }}$ (component reserve margin factor) is not applied. Essentially, the designer uses a design force reduced by $R_{\text {pocomp }}$, but then the component inherently has the same value of overstrength, so the final or actual strength should not be reduced by $R_{\text {pocomp}}$. Figures B-26 to B-31 show that the exponent $x=1 / 2$ reasonably envelopes the entire response (i.e., $F_{p, \text { actual }}$ $/ F_{p, p r o p o s e d}$ is at or below 1.0) for both the 6-story moment frame and the 8-story shear wall baseline cases. A value of $x=1 / 2$ captures the majority of the response for the overdesign cases. The overdesigned cases for Figures B-26 to B-31 have been reproduced as Figures 4-27 to 4-29 in Chapter 4. 

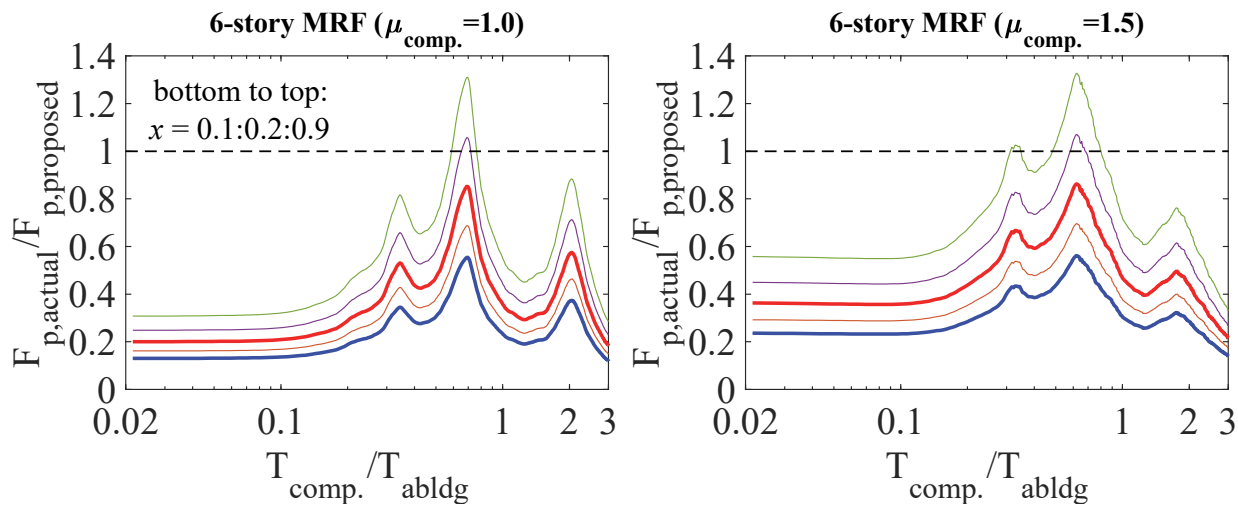

Figure B-26 Mean of the simulated $F_{p}$ normalized by the $F_{p}$ from the proposed equation; baseline 6-story SMRF building ( $\left.T_{\text {abldg }}=0.93 \mathrm{~s}\right)$.
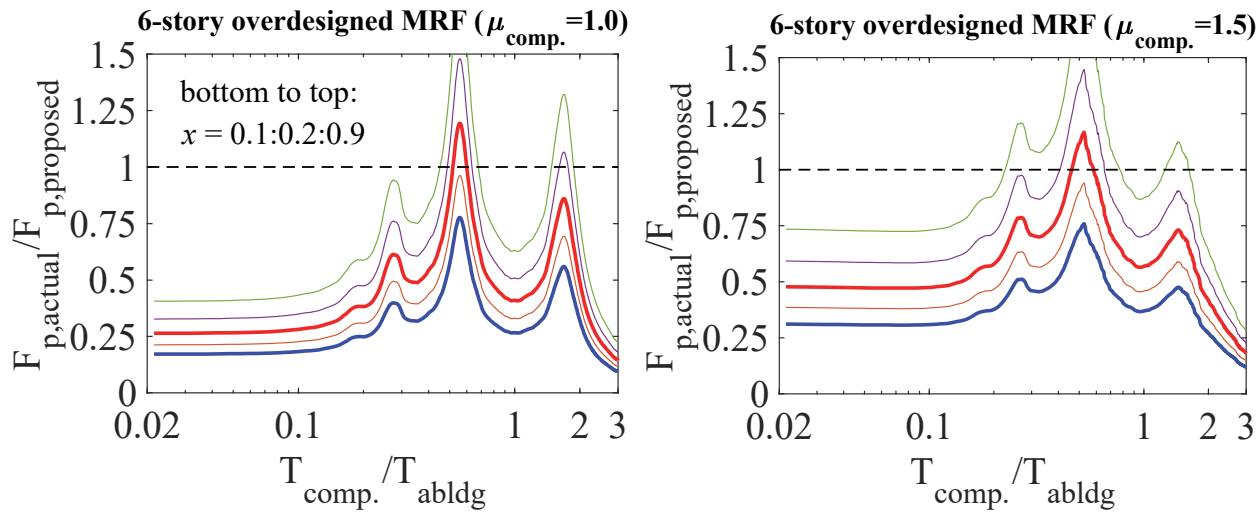

Figure B-27 Mean of the simulated $F_{p}$ normalized by the $F_{p}$ from the proposed equation; 6-story SMRF building with an overdesign factor of 1.5 $\left(T_{\text {abldg }}=0.93 \mathrm{~s}\right)$.
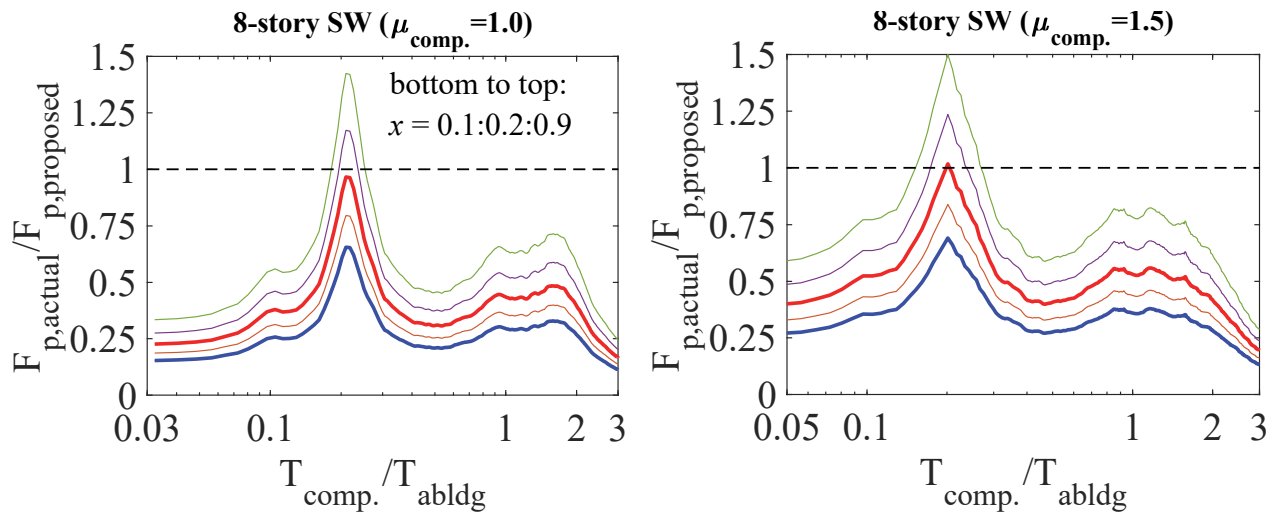

Figure B-28 Mean of the simulated $F_{p}$ normalized by the $F_{p}$ from the proposed equation; baseline 8-story RCSW building $\left(T_{\text {abldg }}=0.62 \mathrm{~s}\right)$. 

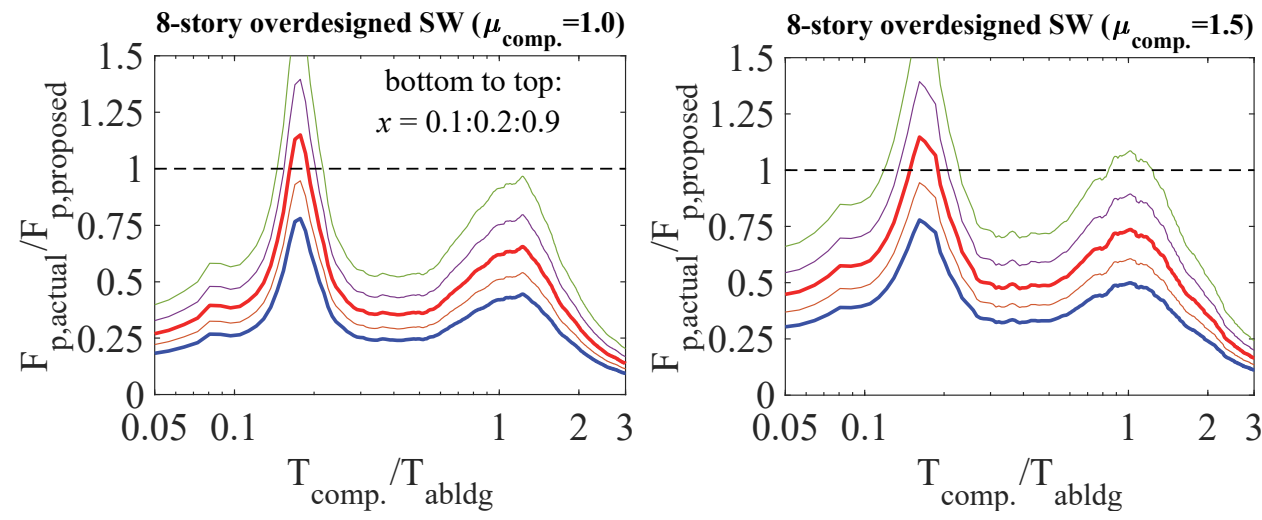

Figure B-29 Mean of the simulated $F_{p}$ normalized by the $F_{p}$ from the proposed equation; 8-story RCSW building with an overdesign factor of 1.5 $\left(T_{\text {abldg }}=0.62 \mathrm{~s}\right)$.
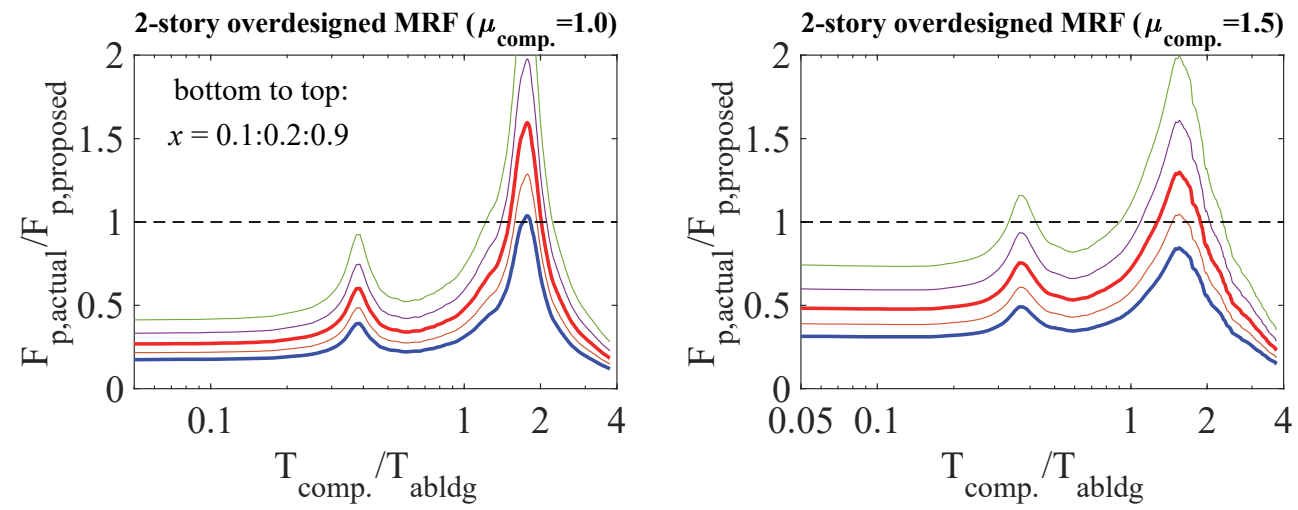

Figure B-30 Mean of the simulated $F_{p}$ normalized by the $F_{p}$ from the proposed equation; 2-story SMRF building with an overdesign factor of 2.0 $\left(T_{\text {abldg }}=0.40 \mathrm{~s}\right)$.
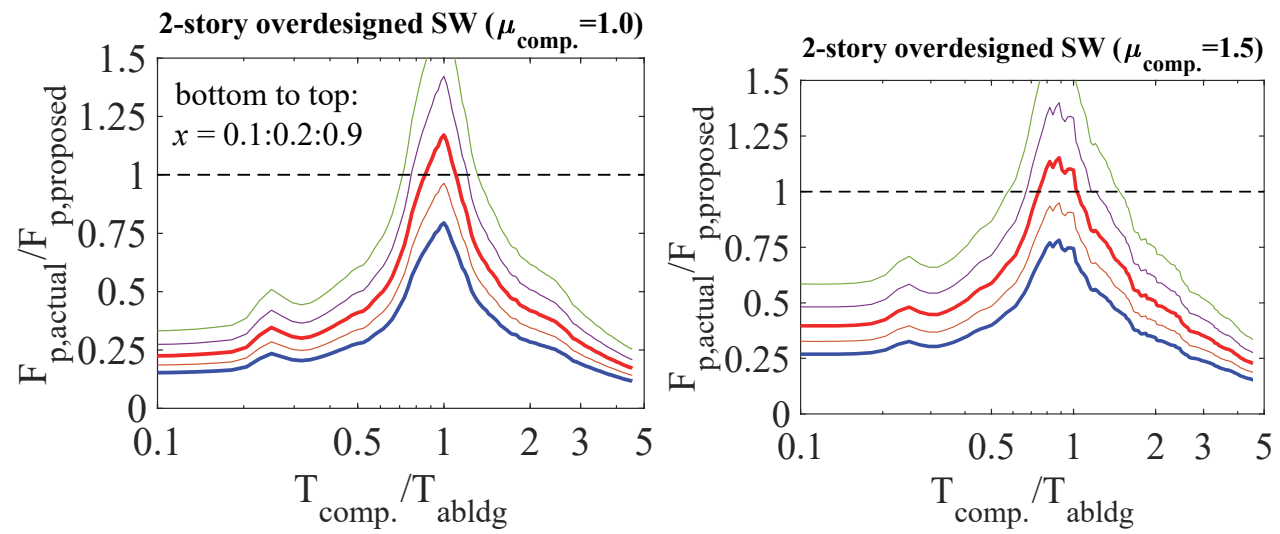

Figure B-31 Mean of the simulated $F_{p}$ normalized by the $F_{p}$ from the proposed equation; 2-story RCSW building with an overdesign factor of 3.0 $\left(T_{\text {abldg }}=0.22 \mathrm{~s}\right)$. 


\section{B.9 Studies on the Effect of Using Different Ground Motion Record Sets}

In this section, studies are conducted to evaluate the effects of using different ground motion sets on the evaluation of floor spectra. The two different set of ground motion records were introduced in Section B.1.2: the spectrum-compatible set of 20 records and the FEMA P-695 FF set of 44 records. Example scaled versions of the record sets used in this comparison are presented in Figure B-4. As stated in Section 4.3, spectrum-matched ground motions were used in these studies to estimate mean responses and not variability, as spectrum-matched records artificially reduce the variability in response parameters. Although Seifried and Baker (2016) have shown that in some cases, performing response history analyses with spectrum-matched ground motions is known to result in unconservatively biased median demand estimates, the spectrum-compatible results shown herein generally envelope the results obtained from response history analysis using the FEMA P-695 far field record set. Thus, the spectrum compatible results are considered conservative for the purpose of this evaluation. This latter point is illustrated in this section.

The evaluation conducted in this section is based on the response of the SMRF and RCSW four baseline (2- and 6-story SMRF; 2- and 8-story RCSW) and two overdesigned archetype structures (6-story SMRF and 8-story RCSW). Components with 5\% inherent damping and an assumed component ductility of 1.0 and 1.5 are used. The component importance factor is assumed to be unity and the evaluation is performed at the roof level.

The refined/proposed equation of Section 4.3.4, including the values from Tables 4-2 and 4.3 , is used. The most important values for the parameters that form part of the proposed equation are shown in Table B-9 below, where $T_{a b l d g}^{\mathrm{MRF}}=0.028 h^{0.8}$ and $T_{\text {abldg }}^{\mathrm{SW}}$ $=0.02 h^{0.75}$.

Table B-9 Parameter Values of the Proposed $F_{p}$ Equation

\begin{tabular}{|c|c|c|c|c|c|c|c|c|c|c|c|c|c|c|}
\hline \multirow[b]{3}{*}{ Sys. } & \multirow{3}{*}{$\begin{array}{l}\text { \# of } \\
\text { Stor } \\
\text {-ies }\end{array}$} & \multirow[b]{3}{*}{$\begin{array}{c}h \\
(\mathrm{ft}) \\
\end{array}$} & \multirow[b]{3}{*}{$R / \Omega_{0}$} & \multirow[b]{3}{*}{$\begin{array}{c}R_{\mu b l d g}= \\
\left(1.1 R / \Omega_{0}\right)^{x}\end{array}$} & \multirow[b]{3}{*}{$\begin{array}{c}T_{\text {abldg }} \\
\text { (s) }\end{array}$} & \multirow[b]{3}{*}{$\alpha_{1}$} & \multirow[b]{3}{*}{$\alpha_{2}$} & \multirow[b]{3}{*}{$\begin{array}{l}\text { PFA/ } \\
\text { PGA } \\
\end{array}$} & \multicolumn{2}{|c|}{ PCA/PFA } & \multicolumn{4}{|c|}{$F_{p} /\left(\mathrm{PGA} W_{p}\right)$} \\
\hline & & & & & & & & & \multirow[b]{2}{*}{$\begin{array}{l}\mu_{\text {comp }} \\
=1 \\
\end{array}$} & \multirow{2}{*}{$\begin{array}{c}\mu_{\text {comp }} \\
= \\
1.5 \\
\end{array}$} & \multicolumn{2}{|c|}{$\mu_{\text {comp }}=1$} & \multicolumn{2}{|c|}{$\mu_{\text {comp }}=1.5$} \\
\hline & & & & & & & & & & & $\begin{array}{l}x= \\
\text { any }\end{array}$ & $\begin{array}{l}x= \\
0.5\end{array}$ & $\begin{array}{c}x= \\
\text { any }\end{array}$ & $\begin{array}{l}x= \\
0.5\end{array}$ \\
\hline SMRF & 6 & 80 & $8 / 3$ & $2.93^{x}$ & 0.93 & 1.07 & 0.82 & 2.89 & 4.0 & 2.2 & $\begin{array}{l}8.89 / \\
2.93^{x}\end{array}$ & 5.19 & $\begin{array}{l}4.89 / \\
2.93^{x}\end{array}$ & 2.85 \\
\hline SMRF & 2 & 28 & $8 / 3$ & $2.93^{x}$ & 0.40 & 2.48 & 0.01 & 3.50 & 4.0 & 2.2 & $\begin{array}{l}10.73 / \\
2.93^{x}\end{array}$ & 6.28 & $\begin{array}{l}5.92 / \\
2.93^{x}\end{array}$ & 3.46 \\
\hline RCSW & 8 & 97 & $6 / 2.5$ & $2.64^{x}$ & 0.62 & 1.62 & 0.58 & 3.20 & 4.0 & 2.2 & $\begin{array}{l}9.84 / \\
2.64^{x}\end{array}$ & 6.03 & $\begin{array}{l}5.41 / \\
2.64^{x}\end{array}$ & 3.33 \\
\hline RCSW & 2 & 25 & $6 / 2.5$ & $2.64^{x}$ & 0.22 & 2.50 & 0 & 3.50 & 4.0 & 2.2 & $\begin{array}{l}10.77 / \\
2.64 x\end{array}$ & 6.63 & $\begin{array}{l}5.92 / \\
2.64^{x}\end{array}$ & 3.65 \\
\hline
\end{tabular}


Figures B-32 to B-37 depict normalized roof floor response spectra as a function of the ground motion record set.

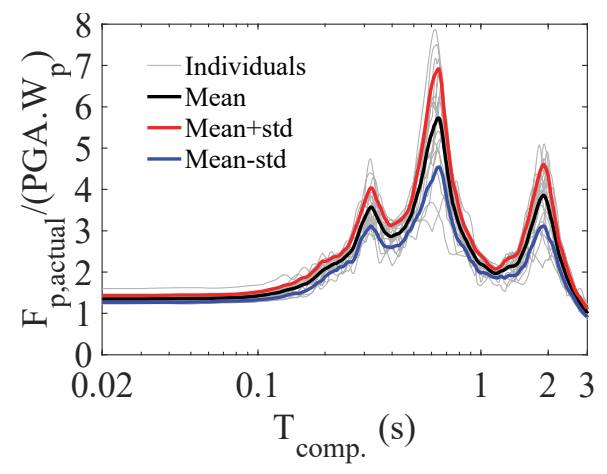

(a)

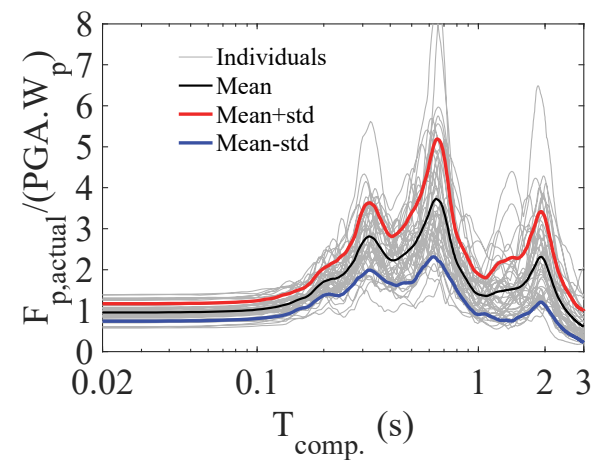

(b)

Figure B-32 Normalized $F_{p \text {,actual }}$ for the baseline 6-story SMRF building ( $T_{1 \text { bldg }}=$ $1.93 \mathrm{~s}$ ) exposed to the (a) 20 spectrum-compatible records; and (b) 44 scaled FF records from FEMA P-695.

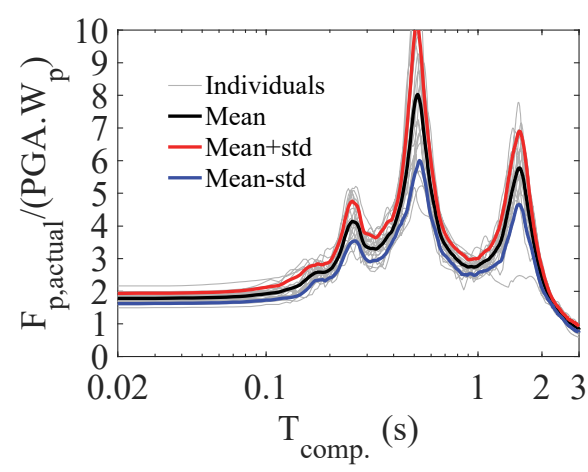

(a)

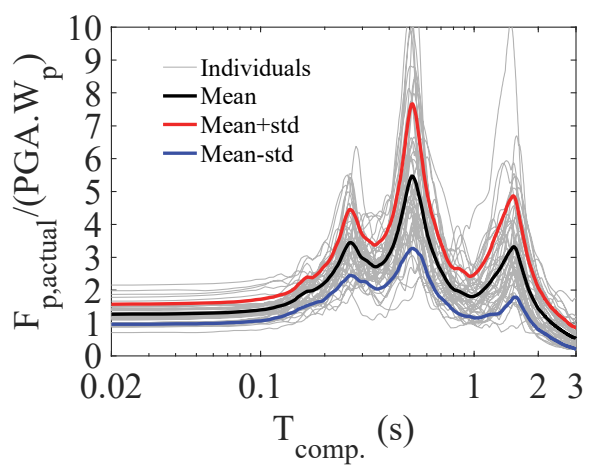

(b)

Figure B-33 Normalized $F_{p, \text { actual }}$ for the 6-story SMRF building with an overdesign factor of $1.5\left(T_{1 b l d g}=1.55 \mathrm{~s}\right)$ exposed to the (a) 20 spectrumcompatible records; and (b) 44 scaled FF records from FEMA P-695.

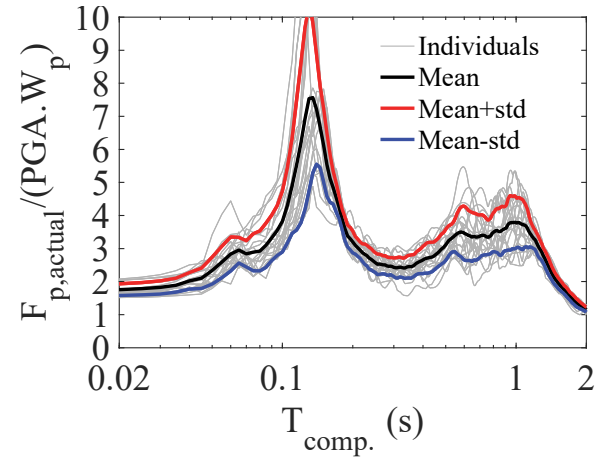

(a)

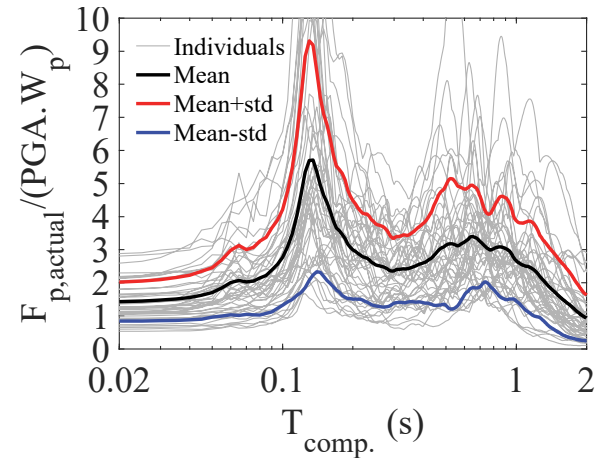

(b)

Figure B-34 Normalized $F_{p \text {,actual }}$ for the baseline 8-story RCSW building ( $T_{1 \text { bldg }}=$ $1.03 \mathrm{~s}$ ) exposed to the (a) 20 spectrum-compatible records; and (b) 44 scaled FF records from FEMA P-695. 


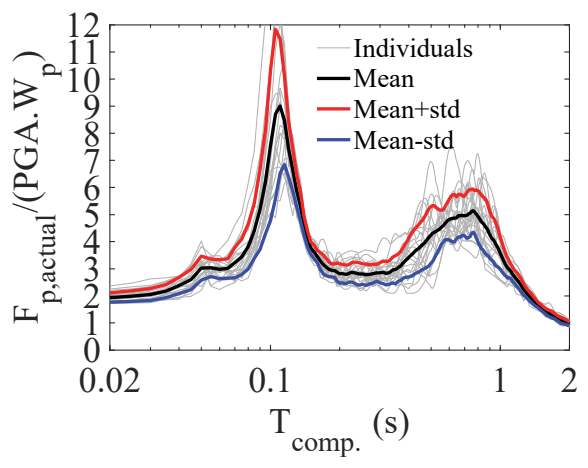

(a)

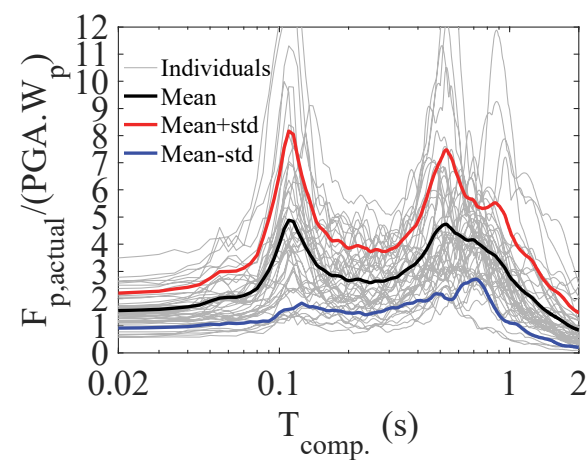

(b)

Figure B-35 Normalized $F_{p \text {,actual }}$ for the 8-story RCSW building with an overdesign factor of 1.5 ( $T_{1 \mathrm{bldg}}=0.8 \mathrm{~s}$ ) exposed to the (a) 20 spectrumcompatible records; and (b) 44 scaled FF records from FEMA P-695.

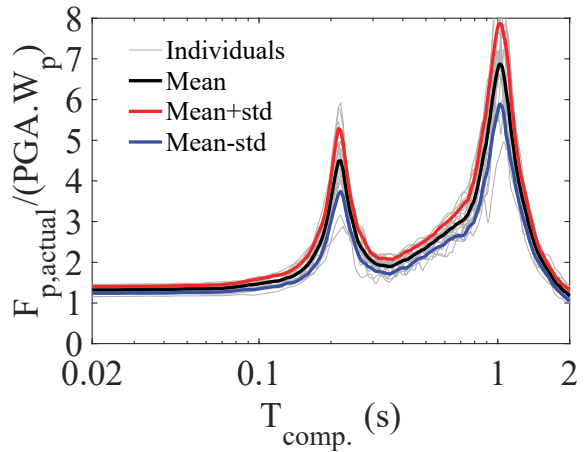

(a)

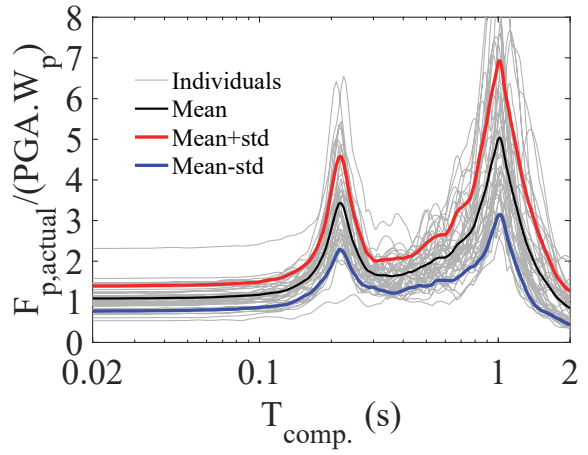

(b)

Figure B-36 Normalized $F_{p \text {,actual }}$ for the baseline 2-story SMRF building ( $T_{1 b l d g}=$ $1.01 \mathrm{~s}$ ) exposed to the (a) 20 spectrum-compatible records; and (b) 44 scaled FF records from FEMA P-695.

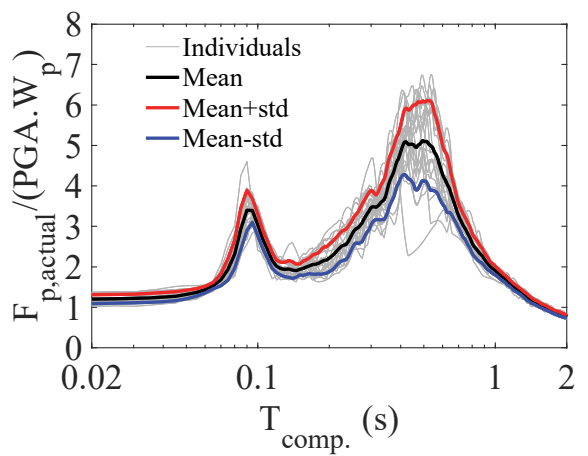

(a)

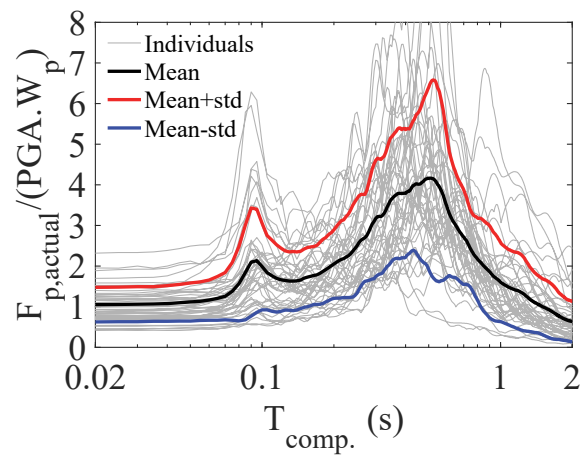

(b)

Figure B-37 Normalized $F_{p \text {,actual }}$ for the baseline 2-story RCSW building ( $T_{1 \text { bldg }}=$ $0.52 \mathrm{~s}$ ) exposed to the (a) 20 spectrum-compatible records; and (b) 44 scaled FF records from FEMA P-695. 
Moreover, Figures B-38 and B-39 present the evaluation of $F_{p, p r o p o s e d}$ at the roof level with respect to $F_{p \text {,actual }}$ obtained from response history analyses using the spectrumcompatible record set and from the FEMA P-695 FF record set assuming an elastic component.

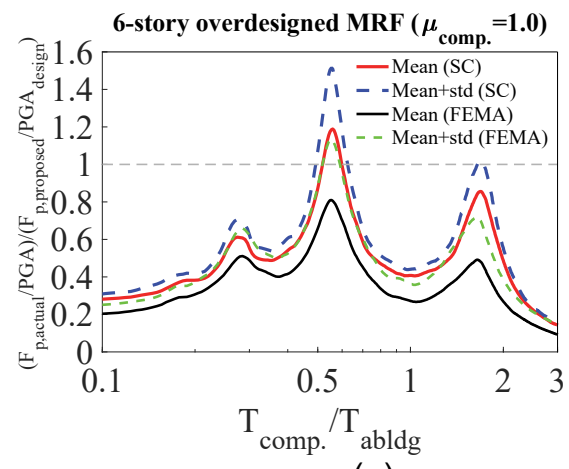

(a)

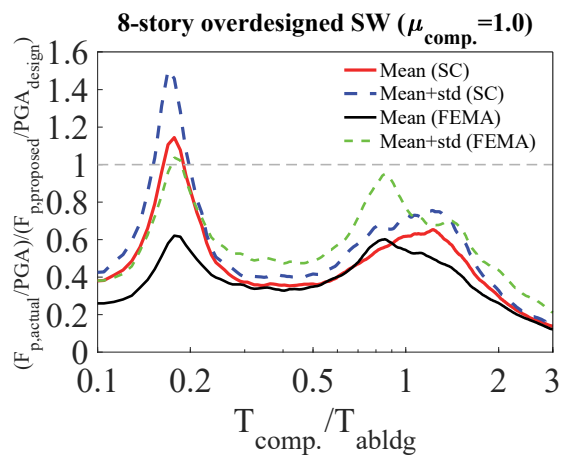

(b)

Figure B-38 Mean and mean plus one standard deviation of the simulated $\left(F_{p} / \mathrm{PGA}\right)$ normalized by the $\left(F_{p} / \mathrm{PGA}\right.$ design $)$ from the proposed equation for the (a) 6 -story SMRF building with an overdesign factor of $1.5\left(T_{a b l d g}=0.93 \mathrm{~s}\right)$; and (b) 8-story RCSW building with an overdesign factor of $1.5\left(T_{\text {abldg }}=0.62 \mathrm{~s}\right)$.

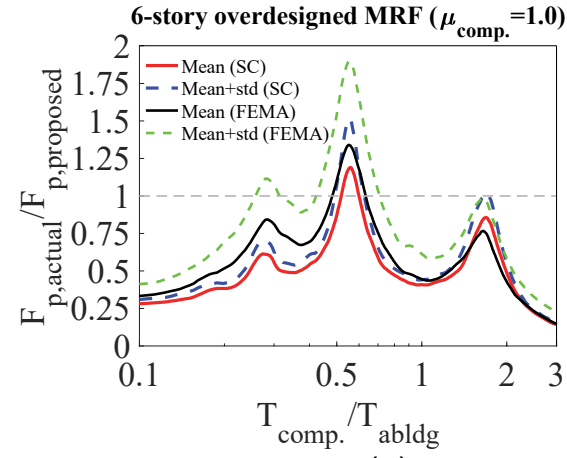

(a)

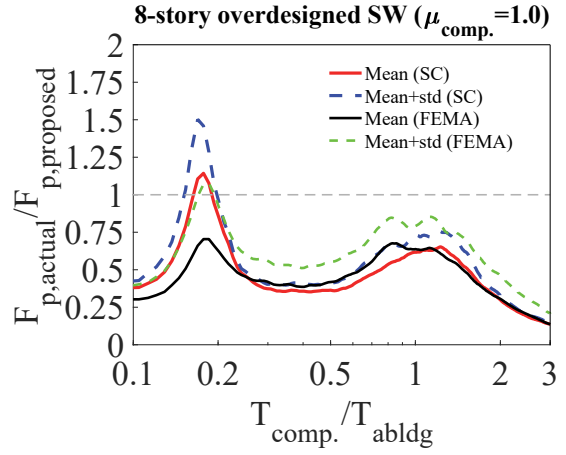

(b)

Figure B-39 Mean and mean plus one standard deviation of the simulated $F_{p}$ (absolute value) normalized by the $F_{p}$ from the proposed equation for the (a) 6-story SMRF building with an overdesign factor of 1.5 ( $T_{\text {abldg }}$ $=0.93 \mathrm{~s}$ ); and (b) 8-story RCSW building with an overdesign factor of $1.5\left(T_{\text {abldg }}=0.62 \mathrm{~s}\right)$.

The general observation from Figure B-38 is that for normalized elastic floor response spectra, the mean FRS of the 20-spectrum compatible ground motions are relatively close to the mean + one standard deviation FRS of the $44 \mathrm{FF}$ records from FEMA P-695 - even when the scaling approach (see Figure B-4) significantly amplifies spectra in the high-frequency (short-period) region for the FEMA P-695 set. The one exception is Figure B-35. This general observation implies that for the purpose of this study, demand evaluation could be conducted based on the mean responses from the set of 20 spectrum-compatible ground motions. Figure B-39 presents results based on absolute (non-normalized) values. 


\section{B.9.1 Role of Component Ductility for Short, Stiff, Elastic Buildings}

This section intends to illustrate a "worst-case scenario" condition, i.e., when the component is elastic, and the supporting building is very stiff and remains in the elastic range. For this evaluation, the FEMA P-695 FF record set is used. As seen in Figure B-40, for the aforementioned combination of parameters, the maximum value of the normalized $F_{p \text {,actual }}$ is about 14 (mean value of all records). This value can be compared with the normalized $F_{p, \text { proposed }}$ times $1.3\left(R_{\text {pocomp}}\right)$ that is 8.62 (see the last row of Table B-9; $6.63 \times 1.3=8.62$ ). This observation suggests that for short buildings, which have a higher likelihood of being significantly overdesigned, components should be designed with a higher target ductility, i.e., the effect of component ductility will be more beneficial in these cases.

In these models, to approximate the inherent viscous damping of the building during elastic response history analyses, the Rayleigh damping approach assigning a 5\% viscous damping ratio to $2 T_{1 b l d g}$ and $T_{2 b l d g}$ was used instead of the $2.5 \%$ value used for the archetypes when exposed to DE level ground motions.

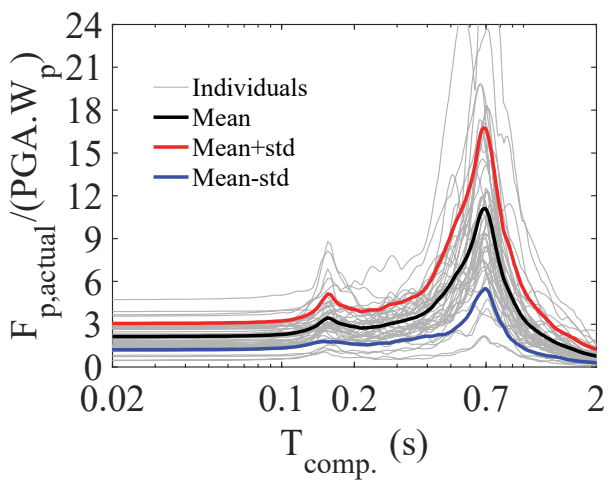

(a)

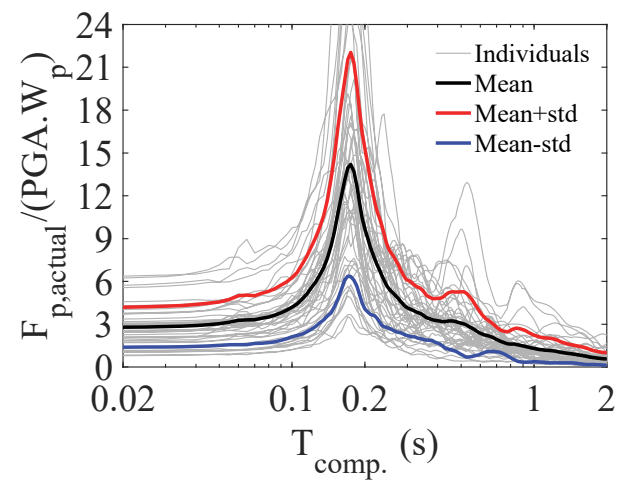

(b)

Figure B-40 Normalized $F_{p \text {,actual }}$ obtained from the 44 scaled FF records from FEMA P-695 for the (a) 2-story overdesigned elastic SMRF $\left(T_{1 b l d g}=\right.$ $0.71 \mathrm{~s}$ ); and (b) 2-story overdesigned elastic RCSW ( $\left.T_{1 b l d g}=0.17 \mathrm{~s}\right)$. The overdesign factors were 2.0 and 3.0, for the SMRF and RCSW archetypes, respectively.

\section{B.10 Evaluation of Proposed $F_{p}$ Equation Using Archetype Models}

\section{B.10.1 Evaluation of Proposed Equation for Different Component Ductilities}

The four overdesigned archetypes (see code and modal periods in Table B-8) were exposed to the set of 20 spectrum-compatible ground motions and mean $F_{p \text {,actual }}$ $/\left(\mathrm{PGA} \times W_{p}\right)$ and $F_{p, \text { actual }} F_{p, p r o p o s e d}$ ratios at the roof level were computed as a function of $T_{\text {comp }} / T_{\text {abldg }}$ for component displacement ductility, $\mu_{\text {comp }}=1.0,1.5,2.0,3.0$, and 4.0. As stated in Section B.8, for all inelastic component cases in this study, a Clough bilinear stiffness degrading hysteresis model (Clough and Johnston, 1966) with 3\% 
strain hardening was used to account for the hysteretic behavior of the component.

The component was assumed to have a 5\% inherent damping ratio.

\section{B.10.1.1 Components Most Likely to be in Resonance with the Building}

As it can be observed from Figures B-41 to B-44, in general, the proposed equation envelopes the majority of response, though $\mu_{c o m p}=1.0$ and 2.0 are less conservative than the other values. For $\mu_{\text {comp }}=3.0$ and 4.0, in order to calculate $F_{p, p r o p o s e d}$, the PCA/PFA values for $\mu_{\text {comp }}=2.0$ were assumed. Figures B-41 to B-44 have been reproduced as Figures 4-41 to 4-44 in Chapter 4.

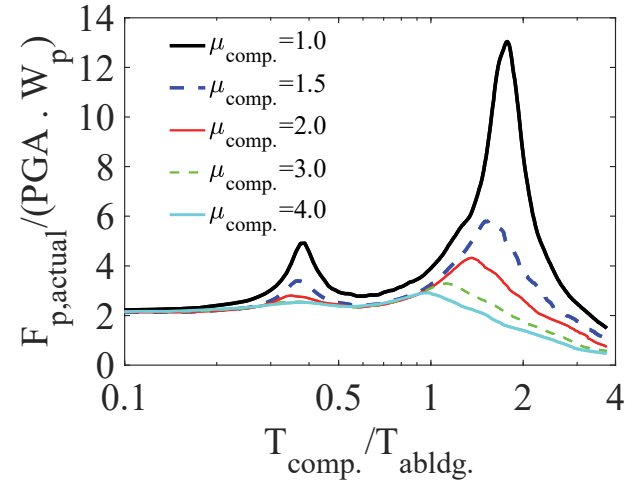

(a)

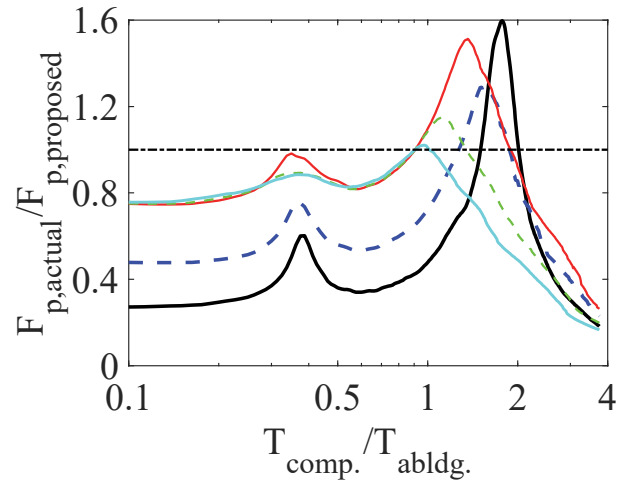

(b)

Figure B-41 Mean of the simulated $F_{p}(\mathrm{a})$ normalized by $\left(\mathrm{PGA} \times W_{p}\right)$; and (b) normalized by the $F_{p}$ from the proposed equation; roof level of the 2story SMRF building with an overdesign factor of 2.0 assuming different $\mu_{\text {comp }}$ values.

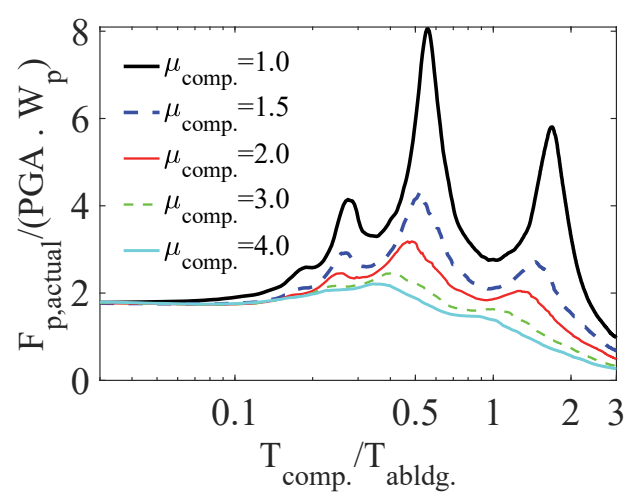

(a)

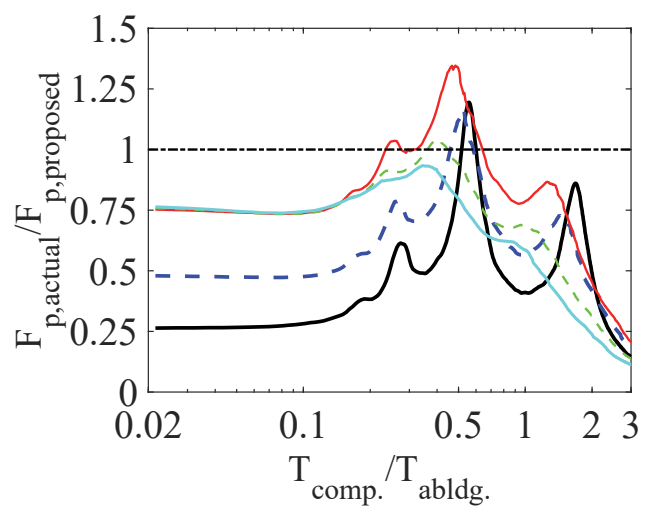

(b)

Figure B-42 Mean of the simulated $F_{p}(\mathrm{a})$ normalized by $\left(\mathrm{PGA} \times W_{p}\right)$; and (b) normalized by the $F_{p}$ from the proposed equation; roof level of the 6story SMRF building with an overdesign factor of 1.5 assuming different $\mu_{\text {comp }}$ values. 


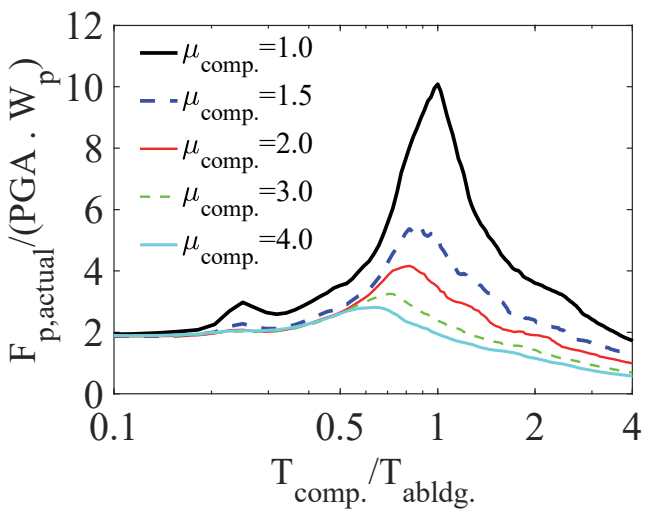

(a)

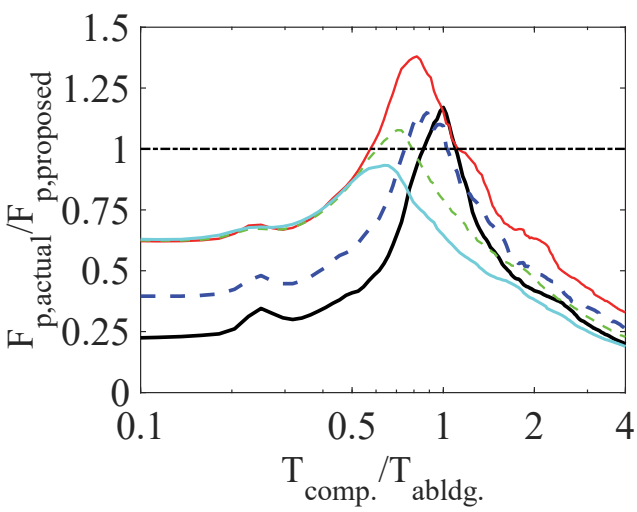

(b)

Figure B-43 Mean of the simulated $F_{p}(\mathrm{a})$ normalized by $\left(\mathrm{PGA} \times W_{p}\right)$; and $(\mathrm{b})$ normalized by the $F_{p}$ from the proposed equation; roof level of the 2story RCSW building with an overdesign factor of 3.0 assuming different $\mu_{\text {comp }}$ values.

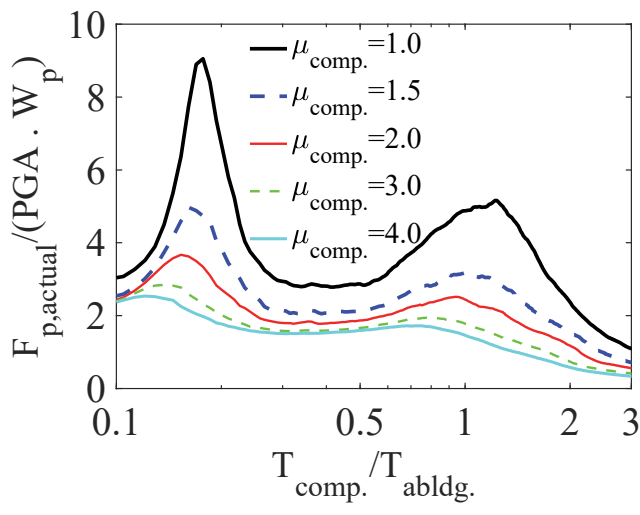

(a)

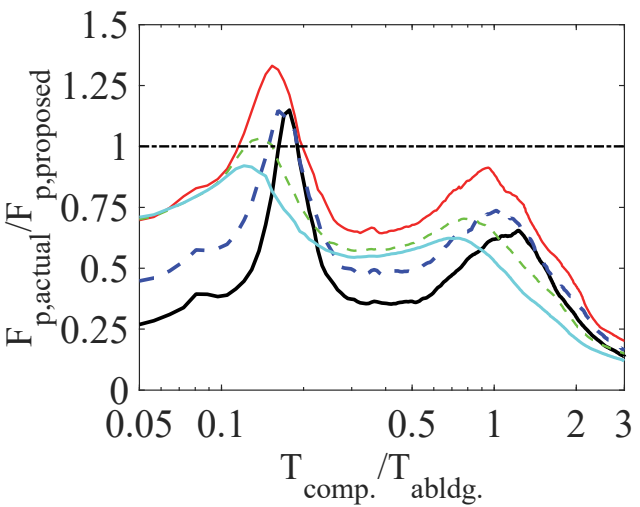

(b)

Figure B-44 Mean of the simulated $F_{p}(\mathrm{a})$ normalized by $\left(\mathrm{PGA} \times W_{p}\right)$; and (b) normalized by the $F_{p}$ from the proposed equation; roof level of the 8story RCSW building with an overdesign factor of 1.5 assuming different $\mu_{\text {comp }}$ values.

\section{B.10.1.2 Components Not Likely to be in Resonance with the Building}

Mean $F_{p, \text { actual }} / F_{p, p r o p o s e d}$ ratios are presented in Figures B-45 to B-46. In these figures, the proposed $F_{p}$ equations should be evaluated at low and high values of $T_{\text {comp }} / T_{a b l d g}$. It can be observed from these figures that as $T_{\text {comp }}$ approaches zero, the proposed equation matches the archetype results. Figures B- 45 and B- 44 have been reproduced as part of Figures 4-45 to 4-48 in Chapter 4. 


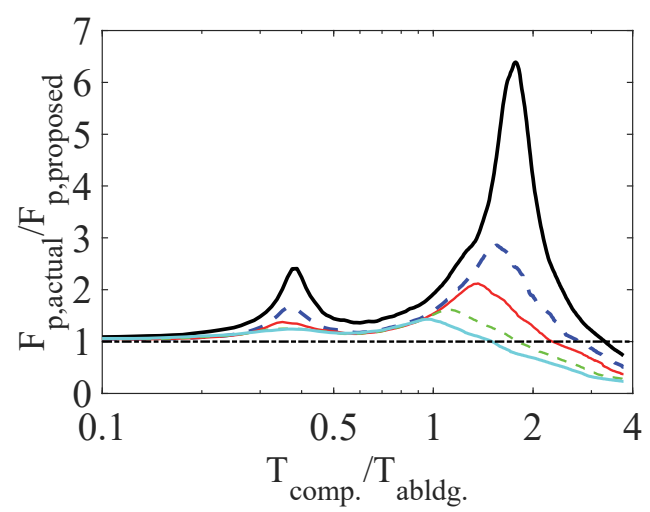

(a)

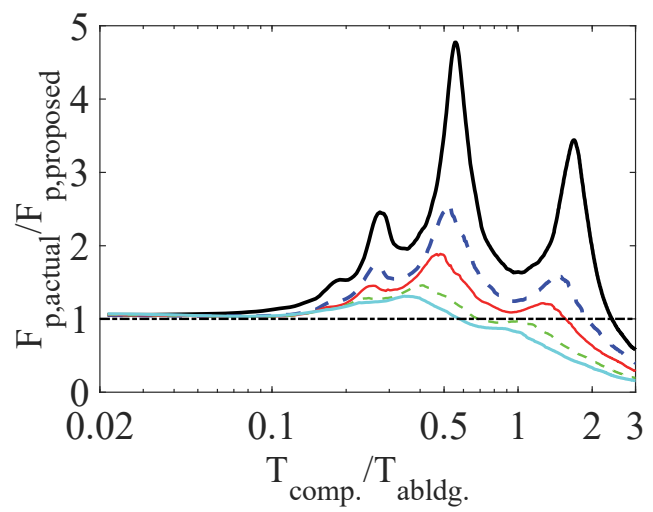

(b)

Figure B-45 Mean of the simulated $F_{p}$ normalized by the $F_{p}$ from the proposed equation; roof level of the (a) 2-story SMRF building with an overdesign factor of 2.0; and (b) 6-story SMRF building with an

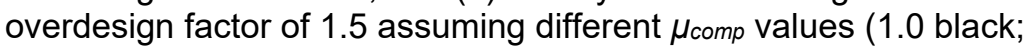
1.5 dashed blue; 2.0 red; 3.0 dashed green; and 4.0 light blue).

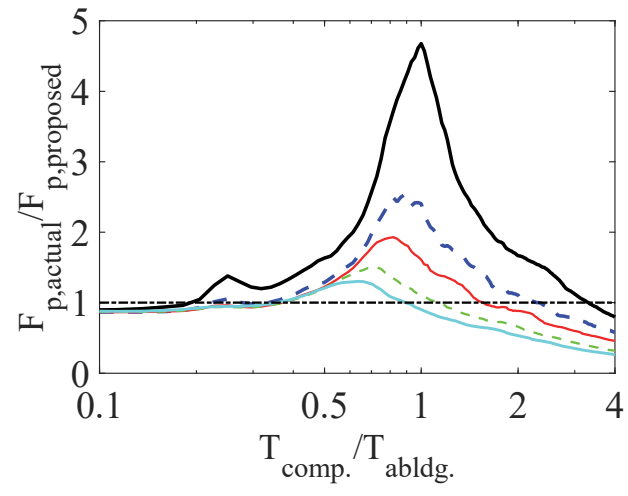

(a)

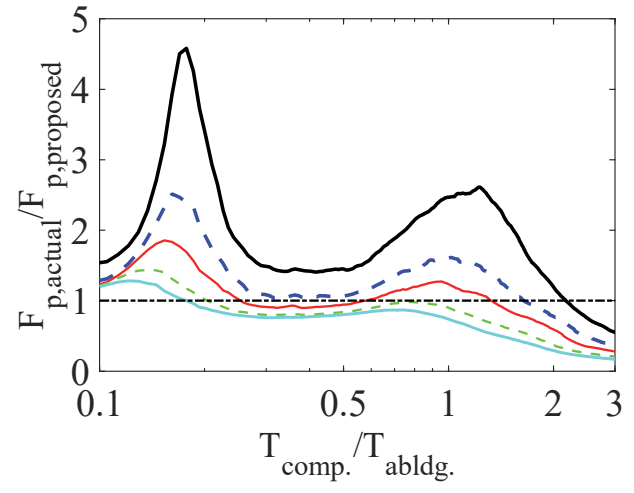

(b)

Figure B-46 Mean of the simulated $F_{p}$ normalized by the $F_{p}$ from the proposed equation; roof level of the (a) 2-story RCSW building with an overdesign factor of 3.0; and (b) 8-story RCSW building with an overdesign factor of 1.5 assuming different $\mu_{\text {comp }}$ values (1.0 black; 1.5 dashed blue; 2.0 red; 3.0 dashed green; and 4.0 light blue).

\section{B.10.2 Evaluation of Proposed $F_{p}$ Equation at Different Relative Heights}

This section deals with the evaluation of the proposed nonstructural design equation against archetype results at different heights. In this evaluation, the lower limit (floor) of the proposed equation is not applied. The four overdesigned archetypes are used, assuming an elastic component $\left(\mu_{\text {comp }}=1.0\right)$ with $\beta_{\text {comp }}=5 \%$. Mean responses corresponding to the analyses using the 20 spectrum-compatible ground motions are presented. The parameter, $\mathrm{RH}$, is the relative height equivalent to the ratio $z / h$.

\section{B.10.2.1 Components Most Likely to be in Resonance with the Building}

It can be observed from Figures B-47 to B-50 that in most cases, the proposed equation results in values that are greater than those obtained from analysis, 
especially at the roof level $(\mathrm{RH}=1.0)$. In some cases, the proposed equation underestimates the analytical results primarily close to peaks (i.e., tuning condition), which is consistent with the approach taken to develop the proposed equation in which a cap was placed on the response of components in tune with one of the building modal periods. However, it is recognized that this level of underestimation is greater for the two tallest archetypes when a component is in tune with a higher modal period of the supporting structure and located below the roof. Figures B-47 to B-50 have been reproduced as Figures 4-49 to 4-52 in Chapter 4.
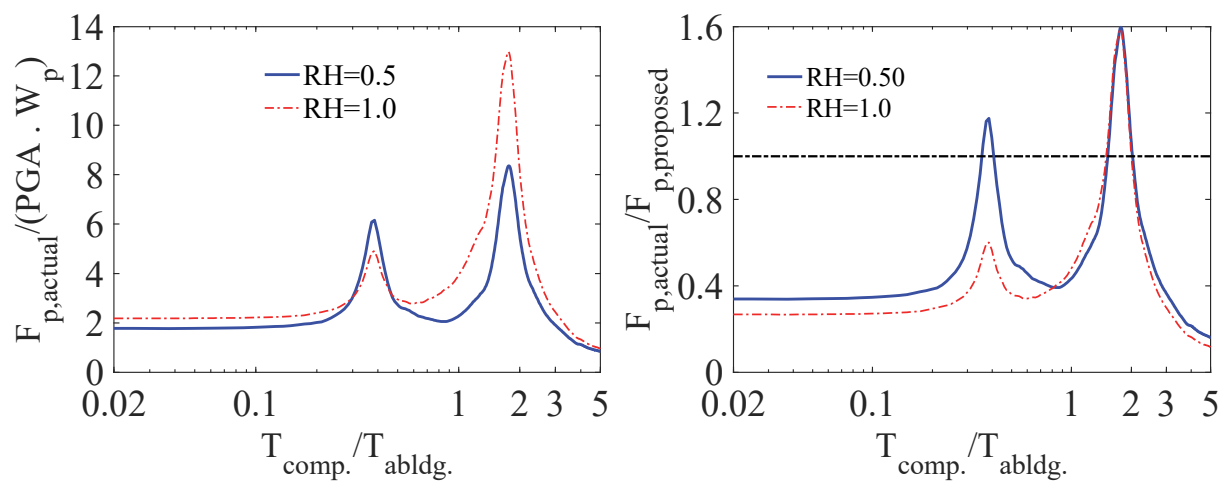

Figure B-47 Evaluation of $F_{p, \text { proposed }}$ based on the responses of the 2-story SMRF building with an overdesign factor of 2.0 .
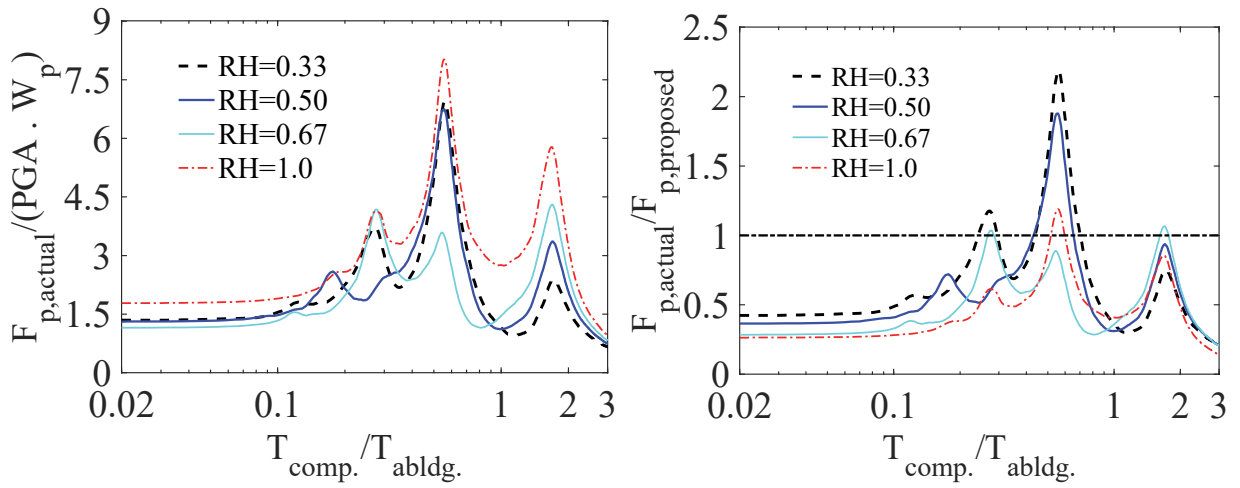

Figure B-48 Evaluation of $F_{p, \text { proposed }}$ based on the responses of the 6-story SMRF building with an overdesign factor of 1.5 .
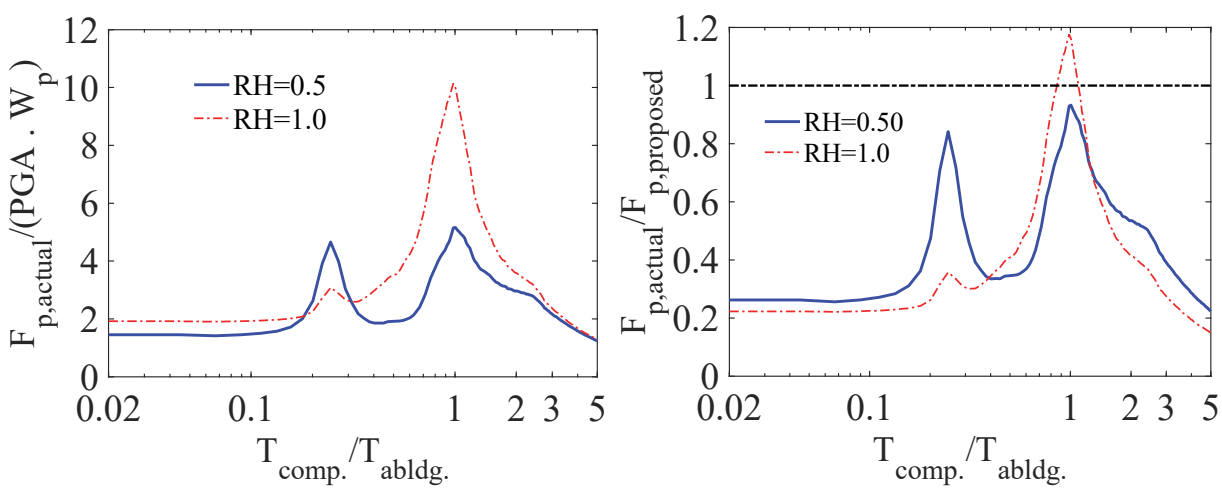

Figure B-49 Evaluation of $F_{p \text {,proposed }}$ based on the responses of the 2-story RCSW building with an overdesign factor of 3.0 . 

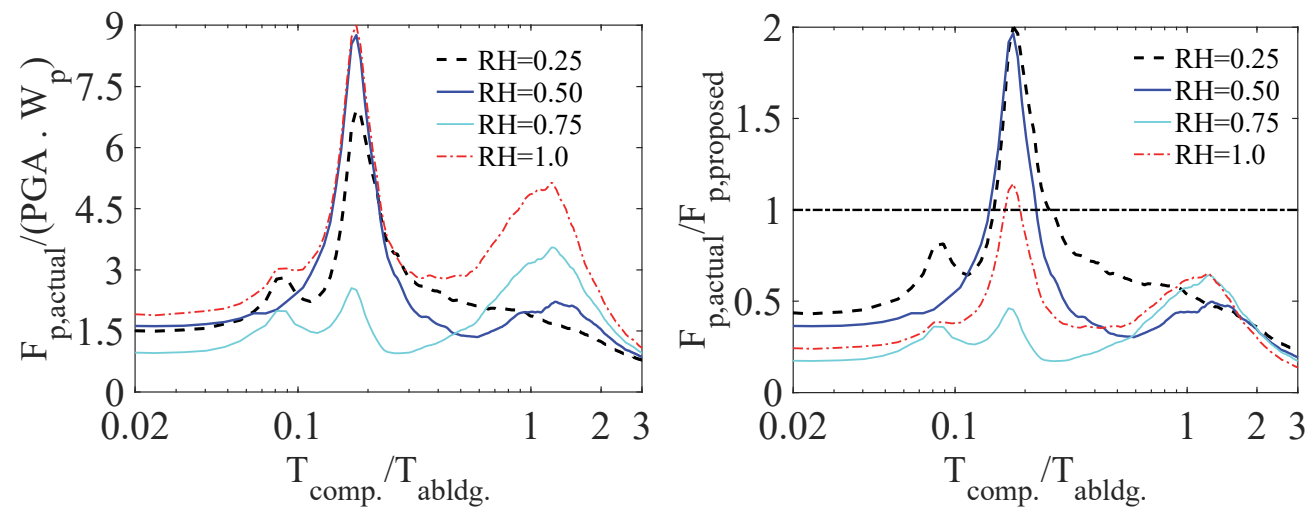

Figure B-50 Evaluation of $F_{p, \text { proposed }}$ based on the responses of the 8-story RCSW building with an overdesign factor of 1.5 .

\section{B.10.2.2 Components Not Likely to be in Resonance with the Building}

It can be observed from Figures B-51 and B-52 that except for the roof level, the proposed equation tends to underestimate the response from the archetype models, and in general, this underestimation increases with a decrease in height. In this evaluation, the lower limit (floor) of the proposed equation was not incorporated.
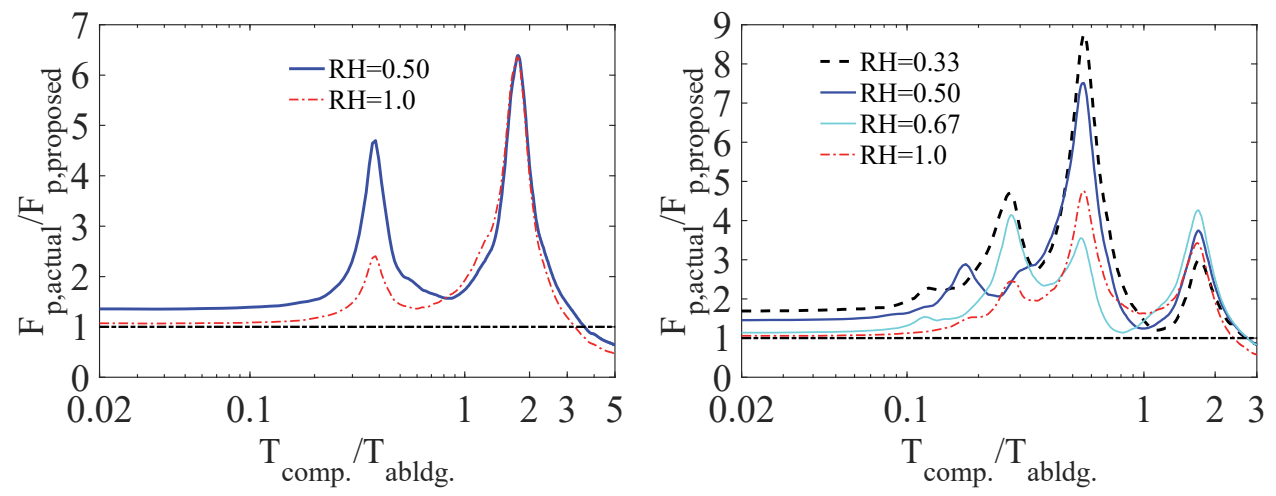

Figure B-51 Evaluation of $F_{p \text {,proposed }}$ based on the responses of the 2-story and 6 -story overdesigned SMRF buildings.
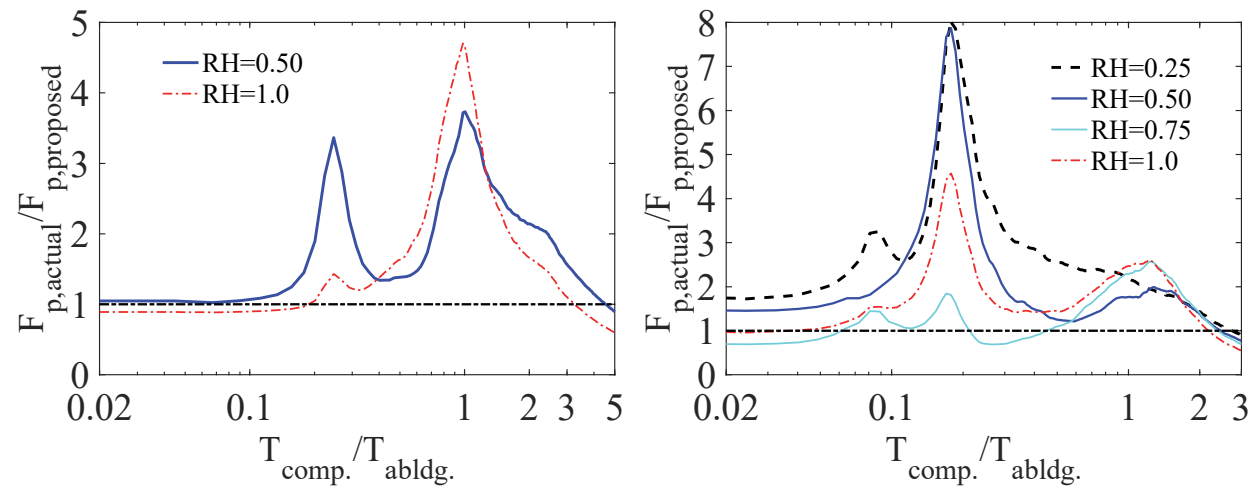

Figure B-52 Evaluation of $F_{p, \text { proposed }}$ based on the responses of the 2-story and 6 -story overdesigned RCSW buildings. 



\section{Appendix C}

\section{Component Period, Damping, and Ductility Studies}

\section{C.1 Introduction}

This appendix summarizes project and related studies of the effects of component period, damping, and ductility on nonstructural component response. Much of the discussion is taken directly or paraphrased from Kazantzi et al. (2018). It provides the basis of information summarized in Chapter 4 for Section 4.2.9 on component period, Section 4.2.10 on inherent component damping, and Section 4.2.11 on component ductility. Studies are based on analyses using strong motion records of instrumented buildings in California. The key metric for component response in the studies is the ratio of peak component amplification to peak floor acceleration (PCA/PFA).

Appendix $\mathrm{C}$ is organized into the following sections:

- Section C.2: Summary of relevant studies from literature; identification of the focus of the project studies; reviews of the strong motion records selected;

reviews of the process of determining building modal periods; and comparison of different approaches to presenting the relationship between PCA/PFA, component period, and building modal periods.

- Section C.3: Analyses of the selected records, including statistical results, and comparison of the effects of different levels of inherent component damping on PCA/PFA.

- Section C.4: Evaluation of the effects of different levels of component ductility on PCA/PFA.

\section{C.2 Background, Study Focus, and Methodology}

\section{C.2.1 Literature Review and Project Focus}

Several studies have examined the characteristics and ways of estimating floor spectra ordinates for structures responding elastically as well as structures experiencing different levels of nonlinearity (Taghavi and Miranda, 2006; Miranda and Taghavi, 2009; Ray-Chaudhuri and Hutchinson, 2011; Sullivan et al., 2013; Vukobratović and Fajfar, 2016). However, there are very few studies that have 
examined nonlinear secondary systems (e.g., Obando and Lopez-Garcia, 2016; Vukobratović and Fajfar, 2017).

The studies summarized in this appendix explore the effect of the component period, $T_{\text {comp }}$, relative to building modal periods, $T_{I D b l d g}$, on the amplification of the peak component acceleration demands along the height of the building and to what extent yielding in the nonstructural component or its bracing could potentially assist in reducing these demands. All analyses are based on recorded floor motions from instrumented buildings in California in the United States.

\section{C.2.2 Record Selection}

Analyses are based on 113 recorded floor motions from instrumented building stations obtained from the Center for Engineering Strong Motion Data (CESMD) website (www.strongmotioncenter.org) with comparatively large values of PCA. The recordings considered include eight major earthquake events (1987 Whittier, 1986 Palm Springs, 1989 Loma Prieta, 1990 Upland, 1992 Landers, 1991 Sierra Madre, 1994 Northridge, and 2010 Ferndale) and 47 stations located in buildings with their number of stories above ground ranging from 2 to 52 . The seismic forceresisting systems of the instrumented buildings include steel moment-resisting frames, steel braced frames, concrete shear walls, concrete moment frames, concrete shear walls with concrete moment frames, precast concrete shear walls, and reinforced masonry shear walls.

The 113 floor motions are subdivided into two subgroups. The first group (denoted as Group 1) contains 86 floor motions that have 5\% damped floor spectral ordinates larger than $0.9 \mathrm{~g}$ at periods tuned to the fundamental period of the building. Group 1 is summarized in Table $\mathrm{C}-1$. The PCA value shown in Table $\mathrm{C}-1$ is the component response associated with the fundamental mode, and the period is the building fundamental period. The second group (denoted as Group 2) consists of 27 floor recordings that have 5\% damped floor spectral ordinates larger than $0.9 \mathrm{~g}$ at periods tuned to either the second or third mode of vibration of the building. Group 2 is summarized in Table C-2. The PCA value shown in Table C-2 is the component response associated with the higher value of the second or third building mode, and the period is the one associated with that mode. 
Table C-1 Group 1 Building Dataset

\begin{tabular}{|c|c|c|c|c|c|c|c|c|}
\hline No. & Station & Earthquake & Dir. & $T(\mathrm{~s})^{(1)}$ & $\begin{array}{c}\text { No. of } \\
\text { stories }^{(2)}\end{array}$ & Resisting system & $\begin{array}{l}\text { Floor } \\
\text { level }\end{array}$ & $\begin{array}{l}\text { PCA } \\
(g)^{(3)}\end{array}$ \\
\hline 1 & 13589 & Landers & EW & 0.800 & 11 & RC shear walls & Roof & 1.05 \\
\hline 2 & 13589 & Landers & NS & 0.715 & 11 & $\mathrm{RC}$ shear walls & Roof & 1.20 \\
\hline 3 & 13589 & Northridge & EW & 0.880 & 11 & $\mathrm{RC}$ shear walls & Roof & 1.08 \\
\hline 4 & 23285 & Landers & EW & 0.625 & 5 & RC shear walls & Roof & 1.54 \\
\hline 5 & 23287 & Landers & NS & 0.505 & 6 & $\mathrm{RC}$ shear walls & Roof & 1.66 \\
\hline 6 & 23287 & Northridge & NS & 0.535 & 6 & $\mathrm{RC}$ shear walls & Roof & 1.48 \\
\hline 7 & 23516 & Landers & EW & 0.620 & 3 & Steel MRFs & Roof & 1.28 \\
\hline 8 & 23516 & Landers & EW & 0.620 & 3 & Steel MRFs & $3^{\text {rd }}$ Floor & 1.06 \\
\hline 9 & 23516 & Landers & NS & 0.610 & 3 & Steel MRFs & Roof & 1.18 \\
\hline 10 & 23516 & Landers & NS & 0.610 & 3 & Steel MRFs & $3^{\text {rd }}$ Floor & 1.01 \\
\hline 11 & 23634 & Landers & EW & 0.495 & 5 & Steel MRFs & Roof & 1.78 \\
\hline 12 & 23634 & Landers & NS & 0.500 & 5 & Steel MRFs & Roof & 1.66 \\
\hline 13 & 23634 & Northridge & EW & 0.500 & 5 & Steel MRFs & Roof & 1.28 \\
\hline 14 & 47459 & Loma Prieta & EW & 0.325 & 4 & $\mathrm{RC}$ shear walls & Roof & 4.43 \\
\hline 15 & 47459 & Loma Prieta & EW & 0.325 & 4 & $\mathrm{RC}$ shear walls & $3^{\text {rd }}$ Floor & 2.65 \\
\hline 16 & 47459 & Loma Prieta & NS & 0.310 & 4 & $\mathrm{RC}$ shear walls & Roof & 2.01 \\
\hline 17 & 47459 & Loma Prieta & NS & 0.310 & 4 & $\mathrm{RC}$ shear walls & $3^{\text {rd }}$ Floor & 1.41 \\
\hline 18 & 57355 & Loma Prieta & EW & 0.800 & 10 & RC shear walls / RC MRFs & Roof & 1.62 \\
\hline 19 & 57355 & Loma Prieta & NS & 1.020 & 10 & RC shear walls / RC MRFs & Roof & 1.38 \\
\hline 20 & 57356 & Loma Prieta & NS & 0.710 & 10 & $\mathrm{RC}$ shear walls & Roof & 1.90 \\
\hline 21 & 57502 & Loma Prieta & EW & 0.185 & 2 & Perforated concrete shear walls & Roof & 2.82 \\
\hline 22 & 57502 & Loma Prieta & NS & 0.265 & 2 & Perforated concrete shear walls & Roof & 1.37 \\
\hline 23 & 57562 & Loma Prieta & EW & 0.660 & 3 & Steel MRFs & Roof & 2.51 \\
\hline 24 & 57562 & Loma Prieta & EW & 0.660 & 3 & Steel MRFs & $3^{\text {rd }}$ Floor & 1.93 \\
\hline 25 & 57562 & Loma Prieta & NS & 0.660 & 3 & Steel MRFs & Roof & 2.11 \\
\hline 26 & 57562 & Loma Prieta & NS & 0.660 & 3 & Steel MRFs & $3^{\text {rd }}$ Floor & 1.58 \\
\hline 27 & 58224 & Loma Prieta & EW & 0.320 & 2 & RC shear walls & Roof & 1.38 \\
\hline 28 & 58261 & Loma Prieta & EW & 0.670 & 4 & Steel MRFs & Roof & 3.75 \\
\hline 29 & 58261 & Loma Prieta & NS & 0.590 & 4 & Steel MRFs & Roof & 3.28 \\
\hline 30 & 58264 & Loma Prieta & EW & 0.375 & 2 & Grouted masonry walls & Roof & 1.88 \\
\hline 31 & 58264 & Loma Prieta & NS & 0.265 & 2 & Grouted masonry walls & Roof & 0.98 \\
\hline 32 & 58348 & Loma Prieta & EW & 0.460 & 3 & $\begin{array}{l}\text { RC shear walls (1-2), RC } \\
\text { cantilever columns (3) }\end{array}$ & Roof & 0.98 \\
\hline 33 & 58364 & Loma Prieta & EW & 0.785 & 10 & Shear walls and concrete frames & Roof & 1.05 \\
\hline
\end{tabular}


Table C-1 Group 1 Building Dataset (continued)

\begin{tabular}{|c|c|c|c|c|c|c|c|c|}
\hline No. & Station & Earthquake & Dir. & $T(\mathrm{~s})^{(1)}$ & $\begin{array}{c}\text { No. of } \\
\text { stories }^{(2)} \\
\end{array}$ & Resisting system & $\begin{array}{l}\text { Floor } \\
\text { level }\end{array}$ & $\begin{array}{l}\text { PCA } \\
(g)^{(3)}\end{array}$ \\
\hline 34 & 58364 & Loma Prieta & NS & 0.555 & 10 & $\begin{array}{l}\text { Shear walls and concrete } \\
\text { frames }\end{array}$ & Roof & 1.32 \\
\hline 35 & 58394 & Loma Prieta & EW & 1.080 & 9 & $\mathrm{RC}$ shear walls & Roof & 1.36 \\
\hline 36 & 58394 & Loma Prieta & NS & 1.275 & 9 & $\mathrm{RC}$ shear walls & Roof & 1.21 \\
\hline 37 & 58462 & Loma Prieta & EW & 0.680 & 6 & $\mathrm{RC}$ shear walls & Roof & 2.21 \\
\hline 38 & 58479 & Loma Prieta & NS & 0.755 & 6 & RC shear walls / RC MRFs & Roof & 1.41 \\
\hline 39 & 58479 & Loma Prieta & NS & 0.755 & 6 & RC shear walls / RC MRFs & $7^{\text {th }}$ floor & 1.34 \\
\hline 40 & 58479 & Loma Prieta & NS & 0.755 & 6 & RC shear walls / RC MRFs & $6^{\text {th }}$ Floor & 1.12 \\
\hline 41 & 58490 & Loma Prieta & EW & 0.975 & 6 & RC MRFs & Roof & 1.48 \\
\hline 42 & 58490 & Loma Prieta & EW & 0.975 & 6 & RC MRFs & $5^{\text {th }}$ floor & 1.20 \\
\hline 43 & 58490 & Loma Prieta & NS & 0.86 & 6 & RC MRFs & Roof & 1.33 \\
\hline 44 & 58490 & Loma Prieta & NS & 0.86 & 6 & RC MRFs & $5^{\text {th }}$ floor & 1.03 \\
\hline 45 & 58492 & Loma Prieta & EW & 0.745 & 8 & $\begin{array}{l}\text { Concrete masonry shear } \\
\text { walls }\end{array}$ & Roof & 1.55 \\
\hline 46 & 58496 & Loma Prieta & EW & 0.34 & 2 & Braced steel frames & Roof & 1.41 \\
\hline 47 & 58496 & Loma Prieta & NS & 0.32 & 2 & Braced steel frames & Roof & 1.90 \\
\hline 48 & 58503 & Loma Prieta & NS & 0.315 & 3 & RC shear walls / RC MRFs & Roof & 1.01 \\
\hline 49 & 14606 & Northridge & EW & 0.715 & 8 & $\begin{array}{l}\text { RC block masonry shear } \\
\text { walls }\end{array}$ & Roof & 1.06 \\
\hline 50 & 14606 & Northridge & NS & 0.555 & 8 & $\begin{array}{l}\text { RC block masonry shear } \\
\text { walls }\end{array}$ & Roof & 1.59 \\
\hline 51 & 24231 & Northridge & EW & 1.105 & 7 & $\begin{array}{l}\text { RC shear walls (1-3) / Steel } \\
\text { MRFs (4-7) }\end{array}$ & Roof & 2.08 \\
\hline 52 & 24231 & Northridge & NS & 0.690 & 7 & $\begin{array}{l}\text { RC shear walls (1-3) / Steel } \\
\text { MRFs (4-7) }\end{array}$ & Roof & 1.95 \\
\hline 53 & 24332 & Northridge & EW & 0.410 & 3 & Steel braced frames & Roof & 3.58 \\
\hline 54 & 24332 & Northridge & NS & 0.530 & 3 & Steel braced frames & Roof & 2.55 \\
\hline 55 & 24385 & Northridge & EW & 0.610 & 10 & Precast concrete shear walls & Roof & 1.57 \\
\hline 56 & 24385 & Northridge & EW & 0.610 & 10 & Precast concrete shear walls & $8^{\text {th }}$ floor & 1.11 \\
\hline 57 & 24385 & Northridge & NS & 0.510 & 10 & Precast concrete shear walls & Roof & 3.09 \\
\hline 58 & 24385 & Northridge & NS & 0.510 & 10 & Precast concrete shear walls & $8^{\text {th }}$ floor & 1.99 \\
\hline 59 & 24385 & Sierra Madre & NS & 0.485 & 10 & Precast concrete shear walls & Roof & 1.92 \\
\hline 60 & 24385 & Sierra Madre & NS & 0.485 & 10 & Precast concrete shear walls & $8^{\text {th }}$ floor & 1.17 \\
\hline 61 & 24385 & Whittier & EW & 0.540 & 10 & Precast concrete shear walls & Roof & 2.10 \\
\hline 62 & 24385 & Whittier & EW & 0.540 & 10 & Precast concrete shear walls & $8^{\text {th }}$ floor & 1.50 \\
\hline 63 & 24385 & Whittier & NS & 0.540 & 10 & Precast concrete shear walls & Roof & 1.71 \\
\hline
\end{tabular}


Table C-1 Group 1 Building Dataset (continued)

\begin{tabular}{|c|c|c|c|c|c|c|c|c|}
\hline No. & Station & Earthquake & Dir. & $T(\mathrm{~s})^{(1)}$ & $\begin{array}{c}\text { No. of } \\
\text { stories }^{(2)}\end{array}$ & Resisting system & $\begin{array}{l}\text { Floor } \\
\text { level }\end{array}$ & $\begin{array}{l}\text { PCA } \\
(g)^{(3)}\end{array}$ \\
\hline 64 & 24385 & Whittier & NS & 0.540 & 10 & Precast concrete shear walls & $8^{\text {th }}$ floor & 1.04 \\
\hline 65 & 24601 & Northridge & EW & 1.060 & 17 & Precast concrete shear walls & Roof & 1.68 \\
\hline 66 & 24601 & Northridge & NS & 1.105 & 17 & Precast concrete shear walls & Roof & 1.87 \\
\hline 67 & 24655 & Northridge & EW & 0.445 & 6 & $\mathrm{RC}$ shear walls & Roof & 1.55 \\
\hline 76 & 24236 & Northridge & EW & 0.715 & 14 & RC MRFs & $12^{\text {th }}$ floor & 1.43 \\
\hline 77 & 12299 & Landers & NS & 0.720 & 4 & Steel MRFs & Roof & 1.42 \\
\hline 78 & 23511 & Upland & EW & 0.325 & 2 & RC MRFs & Roof & 1.07 \\
\hline 79 & 23511 & Upland & NS & 0.285 & 2 & RC MRFs & Roof & 1.64 \\
\hline 80 & 24514 & Northridge & EW & 0.365 & 6 & $\mathrm{RC}$ and Steel shear walls & Roof & 2.95 \\
\hline 81 & 24514 & Northridge & EW & 0.365 & 6 & $\mathrm{RC}$ and Steel shear walls & $4^{\text {th }}$ floor & 1.84 \\
\hline 82 & 24514 & Northridge & NS & 0.405 & 6 & $\mathrm{RC}$ and Steel shear walls & Roof & 6.03 \\
\hline 83 & 24514 & Northridge & NS & 0.405 & 6 & $\mathrm{RC}$ and Steel shear walls & $4^{\text {th }}$ floor & 4.11 \\
\hline 84 & 24579 & Northridge & NS & 0.895 & 9 & RC MRFs & Roof & 1.31 \\
\hline 85 & 24652 & Northridge & EW & 0.875 & 5 & Steel braced frames and MRFs & Roof & 1.98 \\
\hline 86 & 24652 & Northridge & NS & 0.875 & 5 & Steel braced frames and MRFs & Roof & 1.56 \\
\hline
\end{tabular}

(1) $T=T_{11 D b l d g}$

(2) Number of stories above ground level.

(3) PCA is at the fundamental building mode, $T_{1 / D b l d g}$.

Table C-2 Group 2 Building Dataset

\begin{tabular}{|c|c|c|c|c|c|c|c|c|}
\hline No. & Station & Earthquake & Dir. & $T(\mathrm{~s})^{(1)}$ & $\begin{array}{c}\text { No. of } \\
\text { stories }^{(2)}\end{array}$ & Resisting system & $\begin{array}{l}\text { Floor } \\
\text { level }\end{array}$ & $\begin{array}{l}\text { PCA } \\
(g)^{(3)}\end{array}$ \\
\hline 87 & 58354 & Loma Prieta & EW & 0.435 & 13 & Steel MRFs / RC MRFs & Roof & 1.03 \\
\hline 88 & 58354 & Loma Prieta & EW & 0.255 & 13 & Steel MRFs / RC MRFs & Roof & 1.03 \\
\hline 89 & 58483 & Loma Prieta & NS & 0.545 & 24 & $\mathrm{RC}$ shear walls & Roof & 1.46 \\
\hline 90 & 14606 & Northridge & EW & 0.175 & 8 & $\begin{array}{l}\text { RC block masonry shear } \\
\text { walls }\end{array}$ & Roof & 1.06 \\
\hline 91 & 24236 & Northridge & NS & 0.180 & 14 & RC MRFs & Roof & 1.46 \\
\hline 92 & 24322 & Northridge & NS & 0.485 & 13 & RC MRFs & Roof & 1.75 \\
\hline 93 & 24370 & Northridge & EW & 0.450 & 6 & Steel MRFs & Roof & 1.45 \\
\hline 94 & 24370 & Northridge & NS & 0.435 & 6 & Steel MRFs & Roof & 1.39 \\
\hline 95 & 24370 & Whittier & NS & 0.440 & 6 & Steel MRFs & Roof & 1.14 \\
\hline 96 & 24370 & Whittier & NS & 0.440 & 6 & Steel MRFs & $3^{\text {rd }}$ floor & 1.15 \\
\hline 97 & 24385 & Northridge & EW & 0.130 & 10 & $\begin{array}{l}\text { Precast concrete shear } \\
\text { walls }\end{array}$ & Roof & 1.57 \\
\hline
\end{tabular}


Table C-2 Group 2 Building Dataset (continued)

\begin{tabular}{|c|c|c|c|c|c|c|c|c|}
\hline No. & Station & Earthquake & Dir. & $T(\mathrm{~s})^{(1)}$ & $\begin{array}{c}\text { No. of } \\
\text { stories }^{(2)}\end{array}$ & Resisting system & $\begin{array}{l}\text { Floor } \\
\text { level }\end{array}$ & $\begin{array}{l}\text { PCA } \\
(\mathrm{g})^{(3)}\end{array}$ \\
\hline 98 & 24385 & Whittier & EW & 0.125 & 10 & $\begin{array}{l}\text { Precast concrete shear } \\
\text { walls }\end{array}$ & Roof & 2.10 \\
\hline 99 & 24385 & Whittier & NS & 0.145 & 10 & $\begin{array}{l}\text { Precast concrete shear } \\
\text { walls }\end{array}$ & Roof & 1.71 \\
\hline 100 & 24386 & Northridge & EW & 0.340 & 7 & RC MRFs & Roof & 1.57 \\
\hline 101 & 24386 & Northridge & NS & 0.360 & 7 & RC MRFs & Roof & 1.74 \\
\hline 102 & 24464 & Northridge & NS & 0.745 & 20 & RC MRFs & Roof & 2.19 \\
\hline 103 & 24566 & Northridge & NS & 0.440 & 12 & Steel MRFs & Roof & 0.98 \\
\hline 104 & 24601 & Northridge & NS & 0.275 & 17 & $\begin{array}{l}\text { Precast concrete shear } \\
\text { walls }\end{array}$ & Roof & 1.87 \\
\hline 105 & 24602 & Northridge & NS & 0.690 & 52 & $\begin{array}{l}\text { Braced steel frames and } \\
\text { MRFs }\end{array}$ & Roof & 1.29 \\
\hline 106 & 24643 & Northridge & NS & 0.835 & 19 & $\begin{array}{l}\text { Steel MRFs / Braced steel } \\
\text { frames }\end{array}$ & Roof & 2.70 \\
\hline 107 & 24643 & Northridge & NS & 0.225 & 19 & $\begin{array}{l}\text { Steel MRFs / Braced steel } \\
\text { frames }\end{array}$ & Roof & 2.70 \\
\hline 108 & 24655 & Northridge & NS & 0.190 & 6 & $\mathrm{RC}$ shear walls & Roof & 2.34 \\
\hline 109 & 58532 & Loma Prieta & EW & 0.585 & 47 & Steel MRFs & $44^{\text {th }}$ floor & 1.21 \\
\hline 110 & 58532 & Loma Prieta & NS & 1.015 & 47 & Steel MRFs & $44^{\text {th }}$ floor & 3.55 \\
\hline 111 & 24468 & Northridge & NS & 0.460 & 8 & RC shear walls & Roof & 0.94 \\
\hline 112 & 24468 & Whittier & NS & 0.470 & 8 & $\mathrm{RC}$ shear walls & Roof & 2.20 \\
\hline 113 & 24468 & Whittier & NS & 0.470 & 8 & RC shear walls & $2^{\text {nd }}$ & 2.67 \\
\hline
\end{tabular}

(1) $T=T_{\text {IDbldg. }}$ The period is for the mode associated with the peak PCA.

(2) Number of stories above ground level.

(3) PCA is at the larger of the values for the building second or third mode.

\section{C.2.3 Identification of the Building Modal Periods, $T_{I D b l d g}$}

As noted above, Group 1 records are tuned to the fundamental mode of the building; Group 2 records are tuned to higher modes. Figure C-1a illustrates the 5\%-damped pseudo acceleration floor spectra (for roof recording) for a building tuned to its first mode of vibration, i.e., for a building with a larger PCA response near the building fundamental period. Figure $\mathrm{C}-1 \mathrm{~b}$ illustrates one tuned to a higher mode. In many cases, identification of the periods of vibration of the building is straightforward since floor spectral ordinates are greatly amplified at such periods. In most cases, $1 \%$ damped floor spectral ordinates were used to identify these periods. However, in cases where one of the translational modes is coupled with torsional modes, the use of system identification techniques was necessary. A parametric system identification in time domain was used for this purpose by minimizing the difference 
between recorded acceleration time histories in the various sensors in the buildings with those computed with a linear three-dimensional modal response history analysis (Cruz and Miranda, 2016).

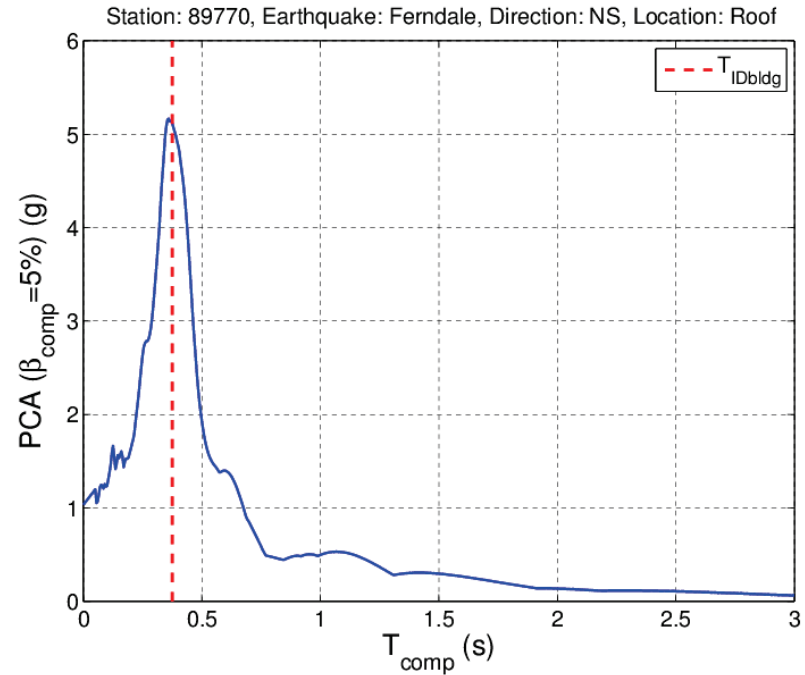

(a)

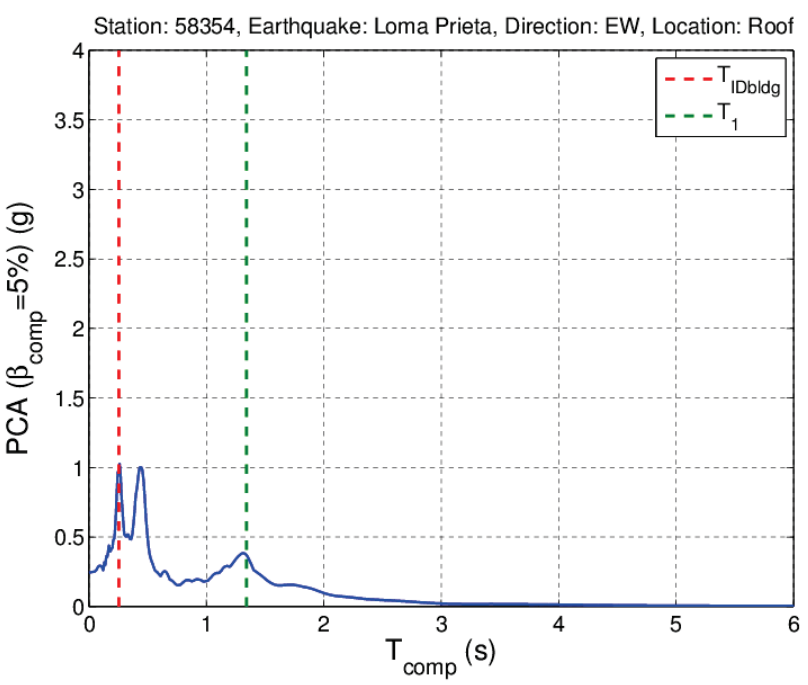

(b)

Figure C-1 $5 \%$ floor spectra computed for a roof recording (a) from Group 1; and (b) from Group 2. For Group 1 in (a), $T_{\text {IDbldg }}$ is the fundamental building period. For Group 2 in (b), $T_{1}$ is the fundamental building period, and $T_{I D b l d g}$ is the third mode period.

\section{C.2.4 Normalization}

A key issue of study is whether to use $T_{\text {comp }}$ on the x-axis of floor spectra such as those shown in Figure C-1 or to "normalize" the x-axis by using the ratio of $T_{\text {comp }} / T_{\text {IDbldg. }}$. To help answer this issue, it is useful to consider first the acceleration spectra averaging process from a qualitative point of view. Averaging several spectra ordinates from components having the same period without first normalizing their period by the building's predominant period essentially means evaluating the mean component response disregarding the fact that these components are located in different buildings. Furthermore, when a building is shaken under the effect of a ground motion record, it is now well established that the level of amplification of the floor motion is dependent on the location within the building where the quantity of interest is measured, as well as on the vibration characteristics (period, damping and lateral stiffness ratio) of the building (Miranda and Taghavi, 2009).

To showcase the importance of normalizing the x-axis of the floor spectra normalizing by the resonant period of the building, $T_{I D b l d g}$, eight recordings were selected from Group 1 and the median component amplification ratio of PCA/PFA as well as the $16 \%$ and $84 \%$ percentiles (i.e., median \pm one standard deviation) were evaluated. The eight recordings (seven roof recordings and one at an intermediate level) correspond to eight different buildings and five different earthquake events. The building fundamental periods $T_{\text {IIDbldg }}$ cover a wide range between $\sim 0.2 \mathrm{~s}$ to $\sim 1 \mathrm{~s}$. 
Figure C-2 illustrates PCA/PFA spectra for the eight different recordings. The trends in Figure $\mathrm{C}-2$ show large peaks for component periods in the region around the predominant period of the building. That essentially implies that a component, which is tuned to the predominant period of the building (i.e., fundamental or any higher resonant mode), will sustain much higher demands during a strong ground motion compared to a non-tuned component.

Figure C-3a illustrates the median (thick black line) as well as the $16^{\text {th }}$ and $84^{\text {th }}$ percentiles (thick blue lines) for the eight PCA/PFA spectra, disregarding the effect of the building in which the component is mounted on (i.e., horizontal axis not normalized to $\left.T_{I D b l d g}\right)$. As illustrated in this figure, if periods are not normalized, the mean component amplification spectrum does not show any clear predominant peak in any component period region like the individual spectra presented in Figure C-2 (also illustrated in Figure C-3a with the light grey lines), and the maximum predicted mean PCA/PFA is approximately equal to 2 in the component period range of interest (i.e., approximately between $0.2 \mathrm{~s}$ to $1 \mathrm{~s}$ ).

Contrary to this observation, though, individual records presented in Figure C-2 demonstrated much higher PCA/PFA ratios, some of which are close to or in excess of 6 . Hence, the averaging process without prior normalization by the building predominant period leads to an underestimation in the evaluated demands for any component that happens to be tuned or nearly tuned to a building's fundamental period. By contrast, if the horizontal axis is normalized by the ratio of component period to the resonant building period, $T_{\text {comp }} / T_{I D b l d g}$, as illustrated in Figure C-3b, then the peak at the critical region, essentially a $T_{\text {comp }} / T_{I D b l d g}$ ratio equal to one (i.e., the component period tuned to the predominant period of the building) is preserved, suggesting a median component amplification factor which is close to 5. That process allows for an explicit consideration of the building in which the component is located and the building's predominant period. 

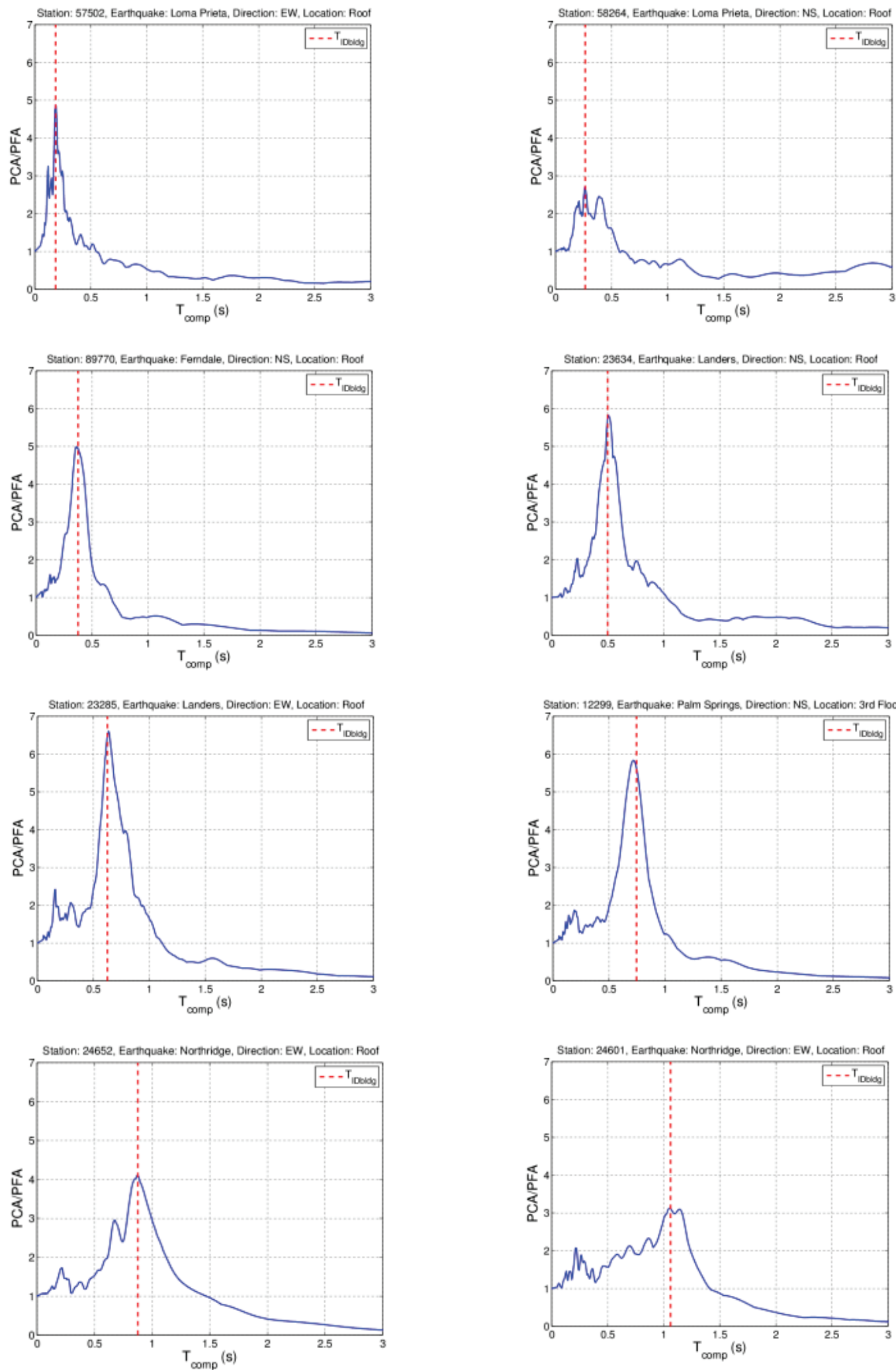

Figure C-2 PCA/PFA spectra for $5 \%$ inherent component damping for eight recorded floor motions, each associated with a particular building, direction, earthquake, and floor level. 


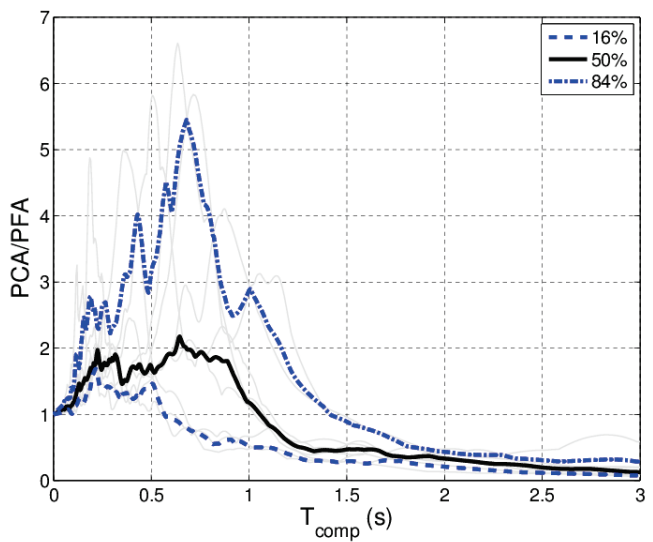

(a)

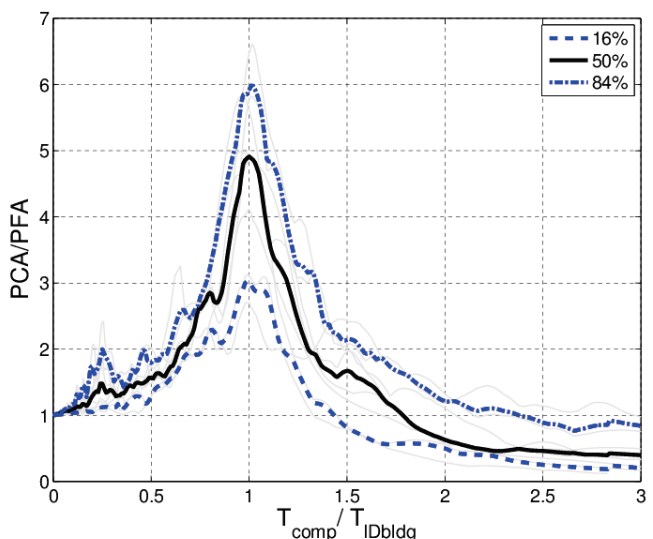

(b)

Figure C-3 The $16^{\text {th }}, 50^{\text {th }}$, and $84^{\text {th }}$ percentiles for PCA/PFA evaluated from eight recorded floor motions selected from Group 1 (a) as a function of $T_{\text {comp; }}$; and (b) as a function of $T_{\text {comp }} / T_{\text {IDbldg. }}$. The light grey curves illustrate the PCA/PFA factors for the eight individual floor recordings.

\section{C.3 Statistics and Fitting of PCA/PFA Data and the Effect of Component Damping}

\section{C.3.1 Statistics of PCA/PFA}

Following the aforementioned methodology, the statistics of PCA/PFA for Group 1 buildings have been evaluated for different levels of inherent component damping. Figure C-4 plots the ratio of the PCA at levels of inherent component damping from $1 \%$ to $7 \%$ divided by the PCA for the $5 \%$ inherent component damping level traditionally assumed. An elastic component is assumed. At $T_{\text {comp }} / T_{\text {lbldg }}$ resonance, PCA for $2 \%$ inherent component damping is 1.6 times that with $5 \%$ inherent component damping. This ratio drops to about 1.2 for $T_{\text {comp }} / T_{\text {lbldg }}<0.7$ and $T_{\text {comp }} / T_{\text {lbldg }}>1.7$. Figure C-4 is reproduced in Chapter 4 as Figure 4-20.

There is relatively limited experimental data on inherent component damping. Section 4.2.10 discusses some of the available information in the literature and notes there are results where experimental data are more in the $2 \%$ range. Although $5 \%$ inherent component damping was selected for developing equations in the project for the reasons described in Section 4.2.10, both Group 1 and Group 2 ground motions have been evaluated for component damping levels of $2 \%$ and $5 \%$ for context and future use.

Figure C-5 presents the statistics of PCA/PFA for both record groups and the two considered damping levels. As a general trend, PCA/PFA increases more rapidly in the $0.75<T_{\text {comp }} / T_{\text {IDbldg }}<1$ range. In fact, the PCA/PFA spectrum shows peaks around $T_{\text {comp }} / T_{\text {IDbldg }}=1$ within a narrow period band, manifesting the so-called narrowband effect, whereas it flattens downward as the period ratio moves away from unity. Moreover, quite notably, for a range of $T_{\text {comp }} / T_{I D b l d g}$ ratios near the 
resonance peak, the PCA/PFA value of 2.5 suggested by ASCE/SEI 7-16 lies well below the median component amplification factor, particularly for the lower $2 \%$ inherent component damping. Figure C-5 is reproduced in Chapter 4 as Figure 4-21.

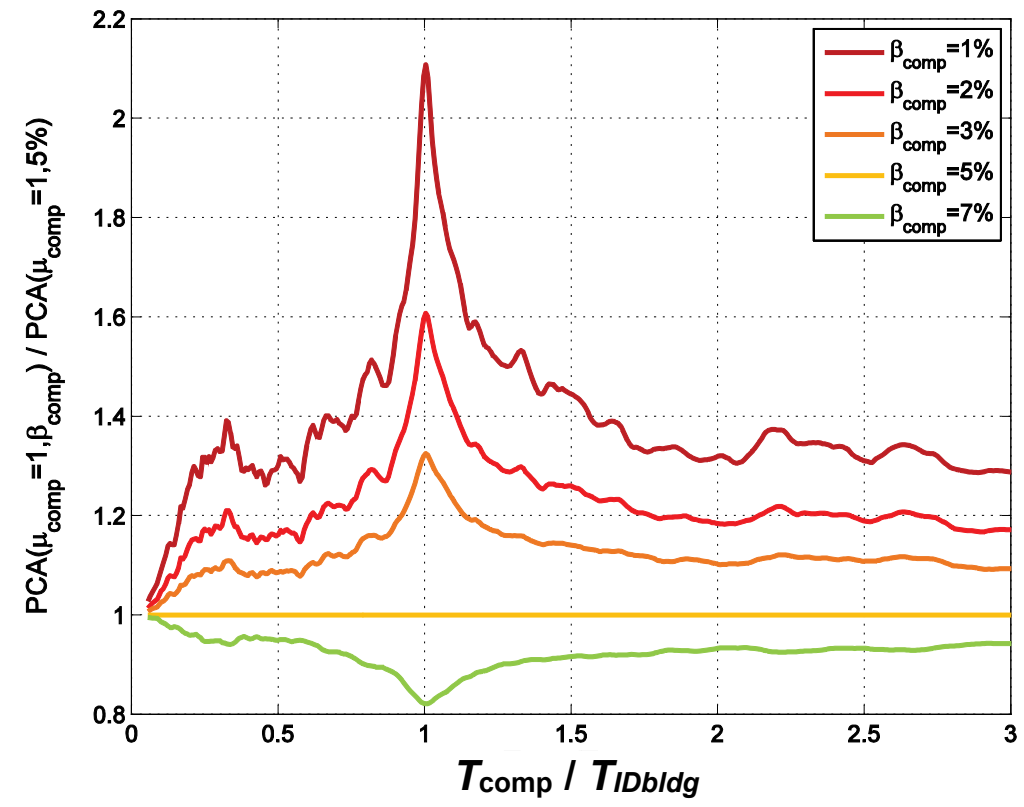

Figure C-4 Mean elastic PCA ratios between inherent component damping of $5 \%$ and other damping levels for Group 1 records.

An additional important observation is related to the damping effect. The effect of damping on systems subjected to floor motions, i.e., narrowband excitations showing peaks within a narrow $T_{\text {comp }} / T_{\text {IDbldg }}$ bin, is very different than that of similar systems subjected to broadband ground motions. The difference in the excitation nature renders the effect of damping in the case of floor motions strongly period dependent, in the sense that it depends on the proximity of the period of the nonstructural component to one of the dominant modal periods of the structure. In general, the effect of damping is much greater when the nonstructural component period is tuned to one of the dominant periods of the building. For instance, with reference to Figures C-5a and C-5b, for $T_{\text {comp }} / T_{I D b l d g}=1$, the mean PCA/PFA is expected to be about $60 \%$ higher for a $2 \%$ damped component (PCA/PFA $\approx 7.5$ ) as opposed to a $5 \%$ damped nonstructural component (PCA/PFA $\approx 4.7$ ).

To quantify the variability of PCA/PFA, the dispersion $\beta$, which is the logarithmic standard deviation $\sigma_{\ln \mathrm{PCA} / \mathrm{PFA}}$, is used. In a manner similar to the evaluation of the mean PCA/PFA, this parameter was estimated for each damping ratio and each group of ground motions. The results are presented in Figure C- 6 . Therein, it can be inferred that an almost constant dispersion plateau characterizes $T_{\text {comp }} / T_{\text {IDbldg }}$ ratios of 0.25 to 1.0 , while an almost linear increase appears for higher period ratios. In the most extreme cases analyzed for $2 \%$ inherent component damping, the dispersion 
reaches a value at $T_{\text {comp }} / T_{\text {IDbldg }}=3$ of approximately $70 \%$ for the records of Group 1 and a value of $90 \%$ for the records of Group 2. Slightly lower dispersion values have been computed for the $5 \%$ nonstructural inherent component damping.

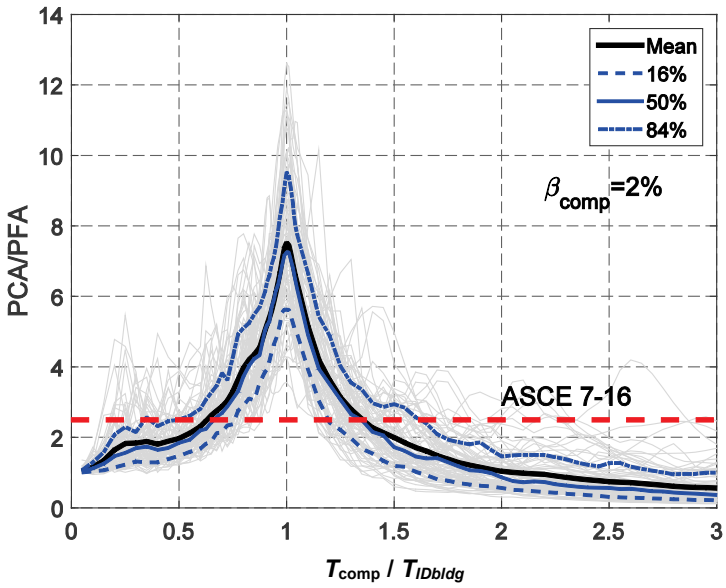

(a)

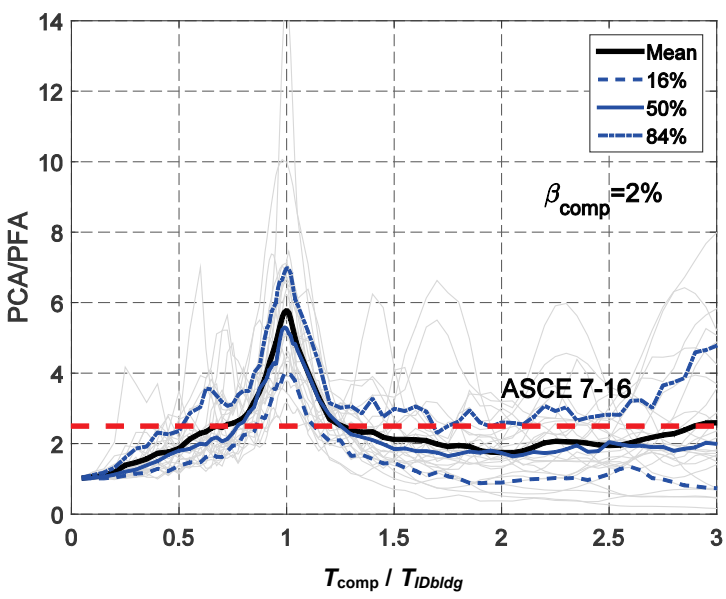

(c)

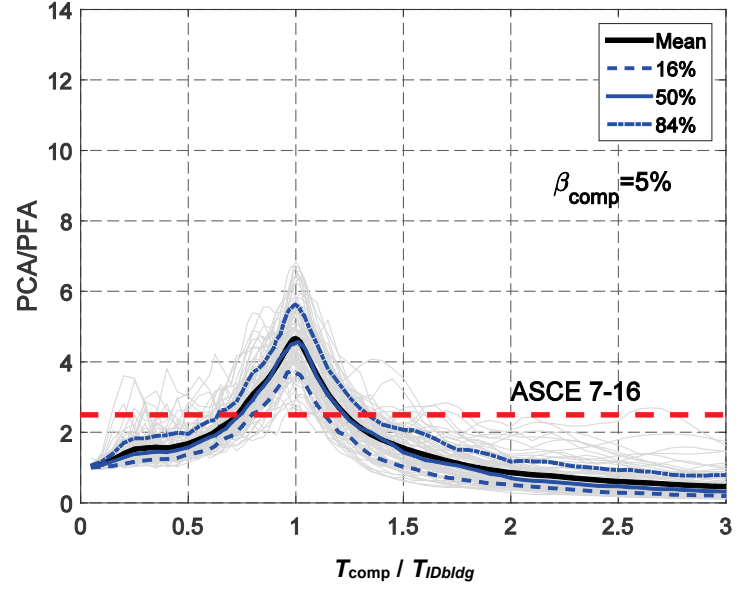

(b)

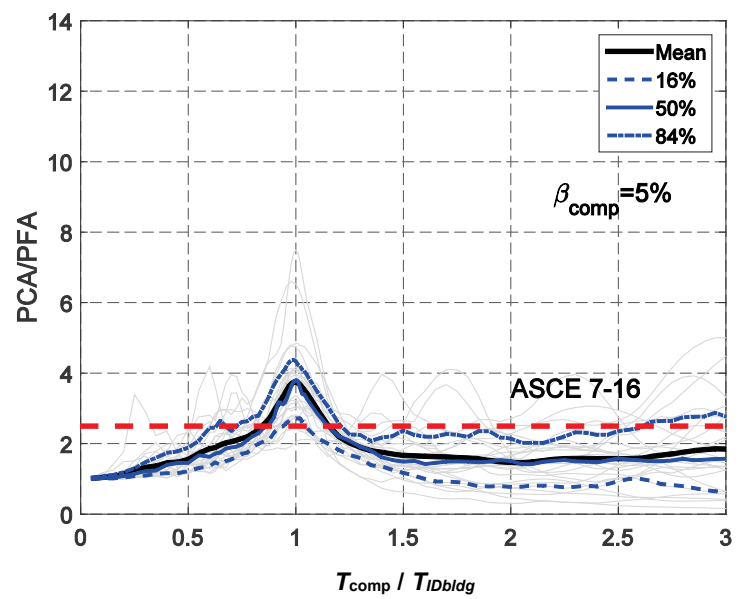

(d)

Figure C-5 The mean and $16^{\text {th }}, 50^{\text {th }}, 84^{\text {th }}$ percentiles for PCA/PFA evaluated for (a) Group 1 records and $2 \%$ inherent component damping; (b) Group 1 records and $5 \%$ inherent component damping; (c) Group 2 records and 2\% inherent component damping; and (d) Group 2 records and 5\% inherent component damping. The light grey lines correspond to the PCA/PFA individual record curves. An elastic component is assumed. 


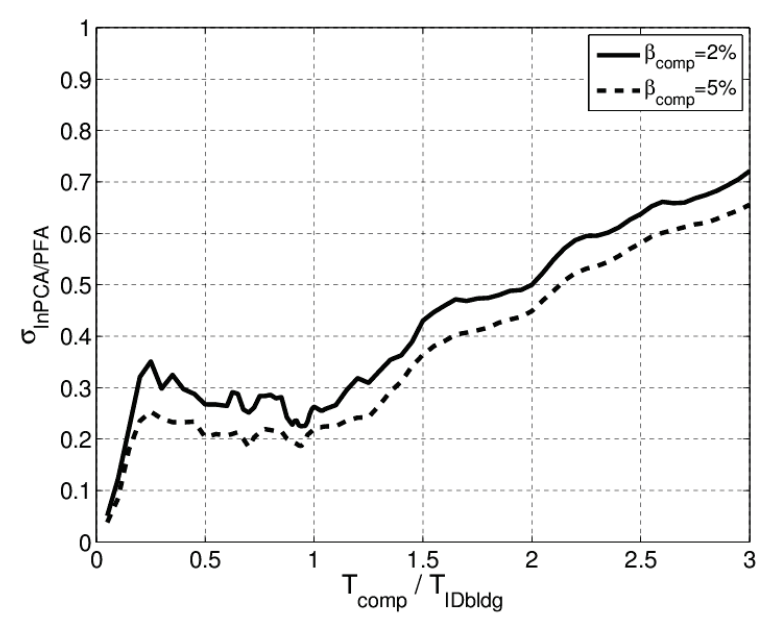

(a)

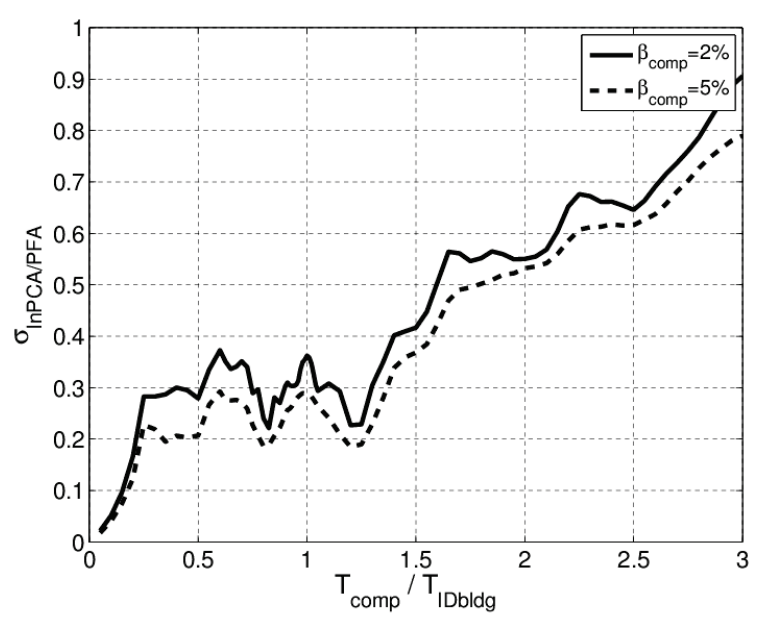

(b)

Figure C-6 Dispersion of PCA/PFA evaluated for (a) Group 1; and (b) Group 2 records.

\section{C.3.2 Fitting of PCA/PFA}

For use in practical applications, a nonlinear expression was employed to relate the mean PCA/PFA to the normalized component period of $T_{\text {comp }} / T_{\text {IDbldg: }}$ :

$$
\begin{aligned}
& \frac{\mathrm{PCA}}{\mathrm{PFA}}= \\
& \quad a \times\left|\left(\frac{T_{\text {comp }}}{T_{\text {IDbldg }}}\right)+b\right|^{c}+d \times \ln \left(\frac{T_{\text {comp }}}{T_{\text {IDbldg }}}\right)+\frac{\left(\frac{T_{\text {comp }}}{T_{\text {IDbldg }}}\right)}{\left(\left(\frac{T_{\text {comp }}}{T_{\text {IDbldg }}}\right)^{e}+f\right)}+g \times \exp \left(\left(\frac{T_{\text {comp }}}{T_{\text {IDbldg }}}\right) h\right)
\end{aligned}
$$

Nonlinear least-squares regression was performed for fitting the constants of Equation C-1, with the results shown in Table C-3 for all four considered cases, i.e., two damping ratios and two ground motion groups. Figure $\mathrm{C}-7$ illustrates the fitted mean PCA/PFA as a function of $T_{\text {comp }} / T_{\text {IDbldg }}$ for the two damping levels considered. As can be inferred, by simply inspecting the fitting, the proposed equation captures satisfactorily the general trend across the entire range of $T_{\text {comp }} / T_{\text {IDbldg }}$ ratios of 0 up to 3 , and it is quite close to the plot of the arithmetic mean. It should be noted here that the mean PCA/PFA for the Group 1 records shows a small second hump in the 0-0.5 period ratio range. To capture this local maximum, a fourth term that is not affecting the fitting outside the aforementioned period ratio bin may be added in Equation C-1, but for brevity this process is not presented here. 
Table C-3 Constants Evaluated for the Regression Equation C-1 of PCA/PFA

\begin{tabular}{|c|c|c|c|c|}
\hline Constant & $\begin{array}{l}\text { Group 1 - } \\
\beta_{\text {comp }}=2 \%\end{array}$ & $\begin{array}{l}\text { Group 1- } \\
\beta_{\text {comp }}=5 \%\end{array}$ & $\begin{array}{l}\text { Group 2- } \\
\beta_{\text {comp }}=2 \%\end{array}$ & $\begin{array}{l}\text { Group 2- } \\
\beta_{\text {comp }}=5 \%\end{array}$ \\
\hline$a$ & -12.584 & -12.584 & -8.193 & -5.138 \\
\hline$b$ & -1.004 & -1.004 & -0.996 & -0.993 \\
\hline c & 0.581 & 0.581 & 0.456 & 0.662 \\
\hline$d$ & 0.866 & 0.866 & 0.516 & 0.439 \\
\hline e & -4.934 & -4.934 & -4.138 & -3.395 \\
\hline$f$ & 0.173 & 0.173 & 0.254 & 0.312 \\
\hline$g$ & 16.482 & 16.482 & 10.853 & 7.570 \\
\hline $\mathrm{h}$ & -0.792 & -0.792 & -0.597 & -0.838 \\
\hline
\end{tabular}

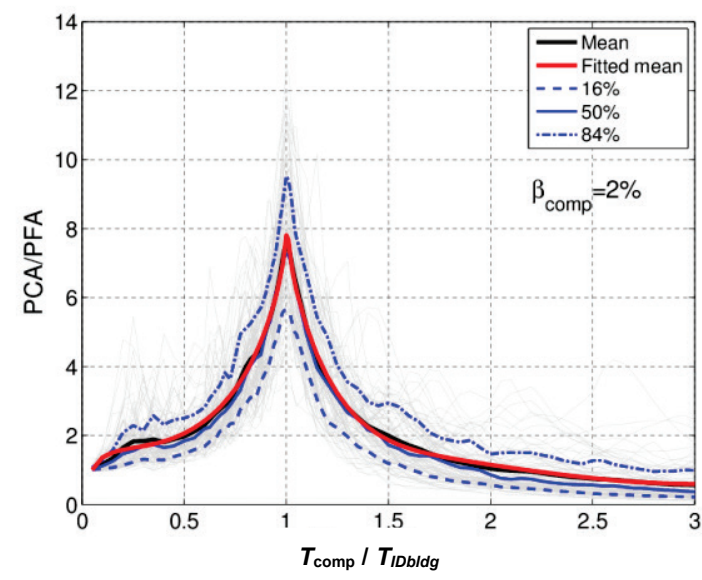

(a)

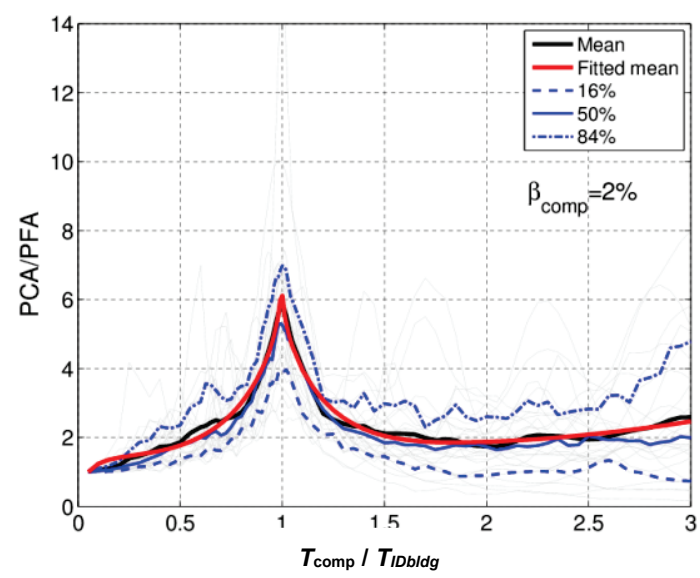

(c)

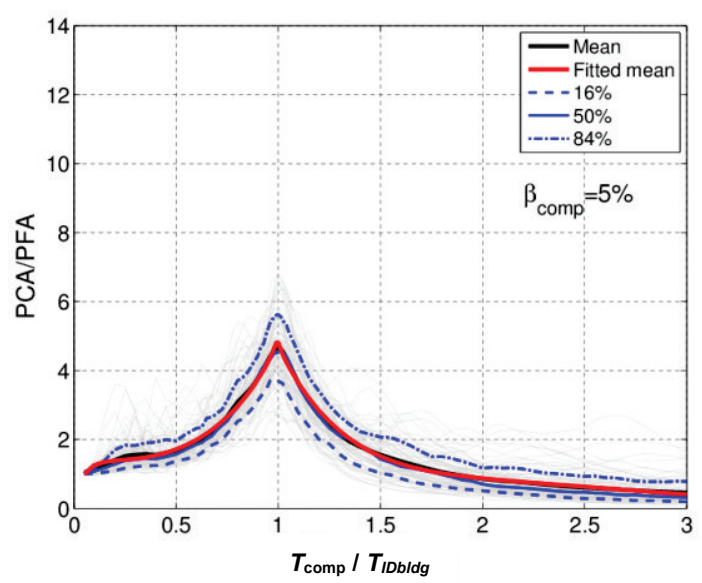

(b)

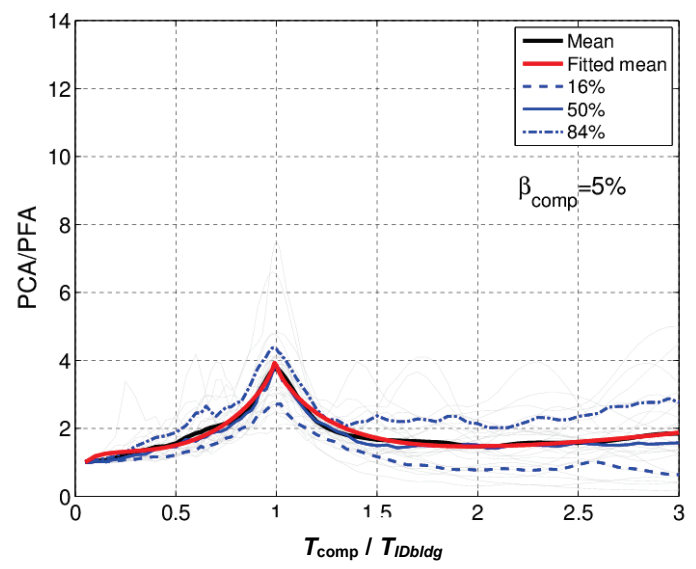

(d)

Figure C-7 The mean PCA/PFA, its $16^{\text {th }}, 50^{\text {th }}$, and $84^{\text {th }}$ percentiles and the fitted curves for (a) Group 1 records and 2\% damping; (b) Group 1 records and 5\% damping; (c) Group 2 records and 2\% damping; and (d) Group 2 records and 5\% damping. The light grey lines correspond to the PCA/PFA individual record curves. An elastic component is assumed. 


\section{C.4 The Effect of Component Ductility}

On the basis of the above findings, a conclusion could be drawn that nonstructural components that are intended to remain elastic during a ground motion should be designed for mean component amplification factors higher than those in ASCE/SEI 7-16. However, most components have some level of ductility in the component, the attachment of the component to the anchor, the anchor itself, or a combination of any of these items. Anchorage ductility is often difficult or impossible to achieve given practical considerations of available substrate depth for anchor. Project studies lumped these three potential sources of component and anchorage ductility together into one simple model where the single degree of freedom oscillator representing a component yields and then continues to deform, providing a measure of component ductility. Component ductility was found to have a significant effect in reducing the demand on the component. Larger levels of ductility produce larger reductions and those lower design demands for components. Chapter 5 discusses techniques for developing specific yielding elements within the nonstructural system, typically in the attachment connecting the component to the anchor, to provide higher and more reliable levels of component ductility.

Figure C-8 illustrates the statistics of the strength reduction factor $R_{\mu c o m p}$ (defined as the ratio of PCA/PFA for an elastic component divided by the PCA/PFA for a component with a ductility larger than 1) across a range of period ratios for Group 1 records and a nonstructural component damping ratio of $2 \%$. Figure $\mathrm{C}-8 \mathrm{a}$ shows results for a component ductility $\mu_{\text {comp }}=1.5$; Figure $\mathrm{C}-8 \mathrm{~b}$ shows results for $\mu_{\text {comp }}=$ 2.0. The strength reduction factor essentially addresses the reduction in strength demands due to the nonlinear behavior of the component, its attachments to anchors, and/or its anchorage (Miranda, 1993).

Figure C-8 suggests that by allowing a ductility of 1.5 or 2.0 in the nonstructural component, the seismic demands are considerably reduced. This is especially the case in the critical $T_{\text {comp }} / T_{\text {IDbldg }}$ range around 1, where the reduction achieved for the considered group of records (Group 1) ranges from $\sim 1.5$ to $\sim 6.5$ with a mean reduction value of $\sim 3.5$ for a ductility of 1.5 (see Figure C-8a) whereas for a ductility of 2.0 the reduction achieved is even greater ranging from $\sim 2.5$ to $\sim 11$ with a mean reduction value of $\sim 6$ (see Figure $\mathrm{C}-8 \mathrm{~b}$ ). 


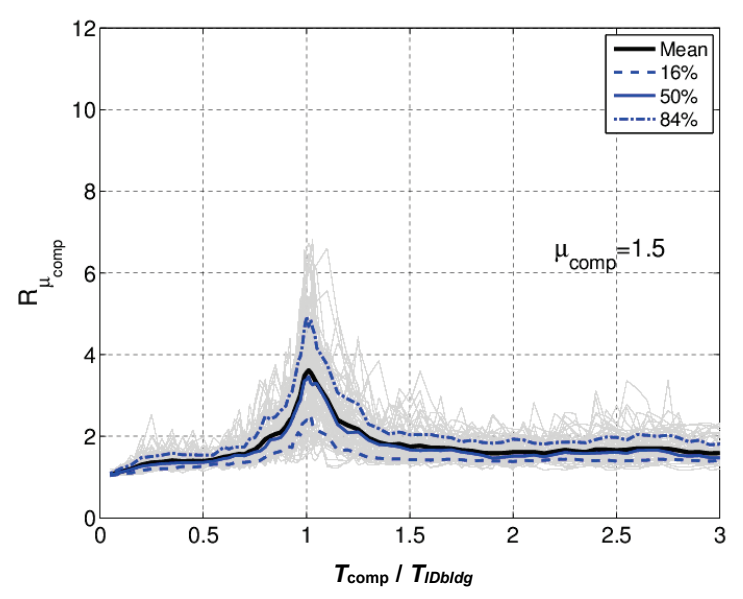

(a)

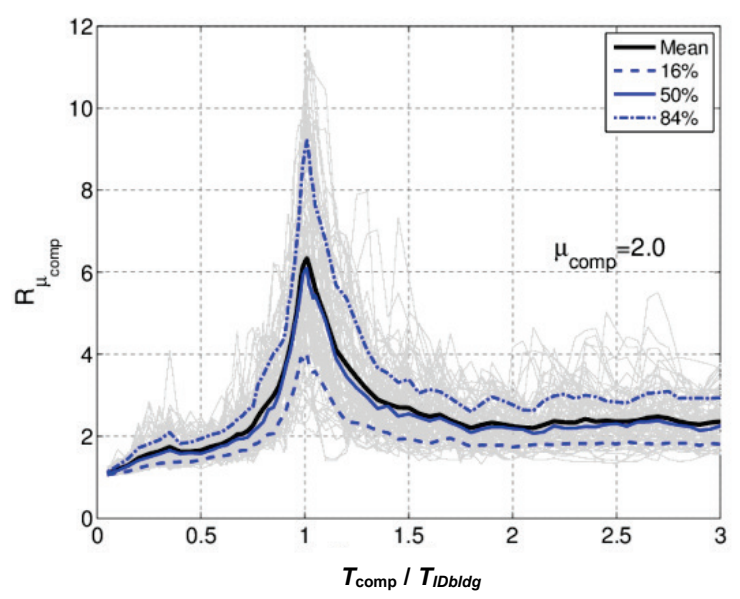

(b)

Figure C-8 The mean strength reduction factor $R_{\mu c o m p}$ and its $16^{\text {th }}, 50^{\text {th }}$, and $84^{\text {th }}$ percentiles for $2 \%$ inherent component damping and Group 1 records for a nonlinear nonstructural component with a component ductility of (a) $\mu_{\text {comp }}=1.5$; and (b) $\mu_{\text {comp }}=2.0$.

Figure C-9 illustrates similar statistics for the strength reduction factor $R_{\mu c o m p}$ across a range of period ratios for Group 2 records and the same ductility levels, i.e., 1.5 and 2.0. Previous observations hold in that case too, with the mean reduction factors for tuned nonstructural components being slightly lower, more likely due to the component in that case being tuned to a higher modal frequency of the building, other than its fundamental, which is essentially linked to a lower mass participation factor.

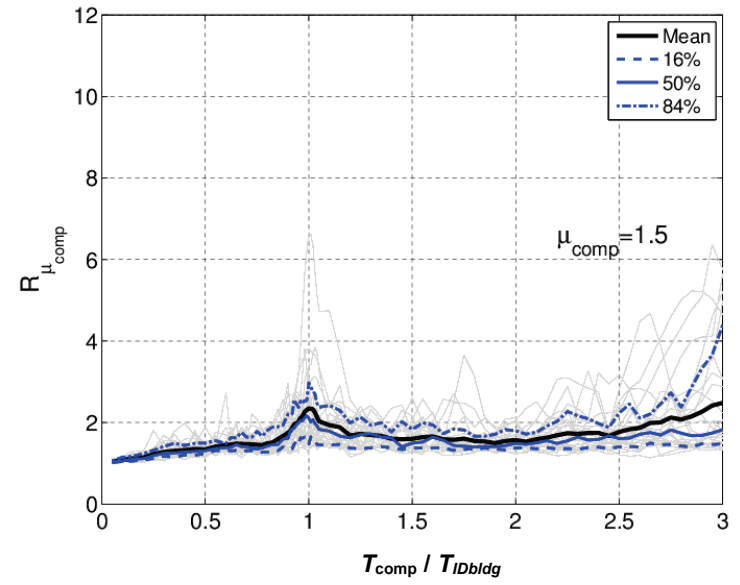

(a)

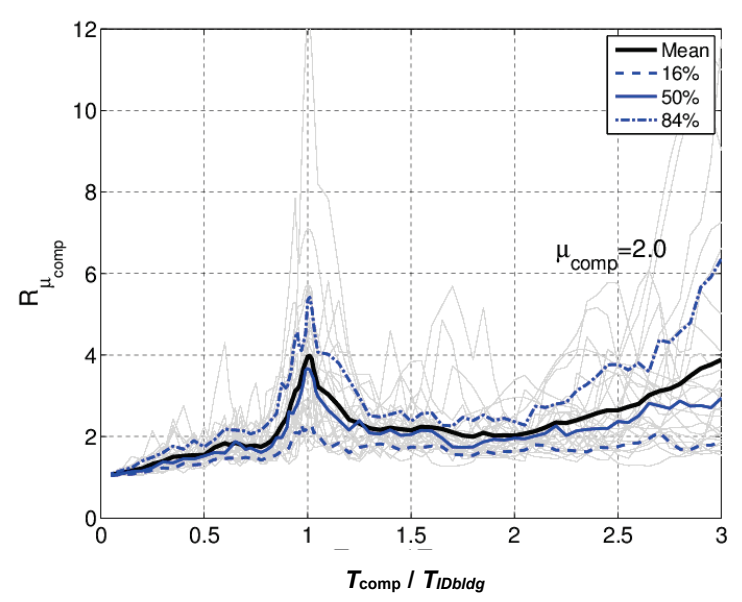

(b)

Figure C-9 The mean strength reduction factor $R_{\mu c o m p}$ and its $16^{\text {th }}, 50^{\text {th }}$, and $84^{\text {th }}$ percentiles for $2 \%$ inherent component damping and Group 2 records for a nonlinear nonstructural component with a component ductility of (a) $\mu_{\text {comp }}=1.5$; and (b) $\mu_{\text {comp }}$ $=2.0$.

For $\beta_{\text {comp }}=2 \%$ inherent component damping, Figure C-10 shows PCA/PFA plots for an elastic component $\mu_{\text {comp }}=1$, and for $\mu_{\text {comp }}$ of $1.25,1.5$, and 2 , including mean response and one standard deviation bounds. Figure $\mathrm{C}-11$ shows similar plots for 
PCA/PFA plots for $\beta_{\text {comp }}=5 \%$ inherent component damping. Figures $\mathrm{C}-10$ and $\mathrm{C}-11$ are reproduced in Chapter 4 as Figures 4-22 and 4-23.

Figure C-12 overlays the mean response for each component ductility level. For $\beta_{\text {comp }}=2 \%$, at $T_{\text {comp }} / T_{\text {bldg }}=1$ resonance, PCA/PFA drops from 7.5 for an elastic component, to about 3.8 for a component with a ductility, $\mu_{\text {comp }}$, of 1.25 , to about 2.4 for $\mu_{\text {comp }}=1.5$, and then to about 1.5 for $\mu_{\text {comp }}=2$. For $\beta_{\text {comp }}=5 \%$, at $T_{\text {comp }} / T_{\text {bldg }}=1$ resonance, PCA/PFA drops from about 4.6 for an elastic component, to about 2.8 for a component with a ductility, $\mu_{\text {comp }}$, of 1.25 , to about 2.0 for $\mu_{\text {comp }}=1.5$, then to about 1.4 for $\mu_{\text {comp }}=2$. Figure C-12 is reproduced in Chapter 4 as Figure 4-24.

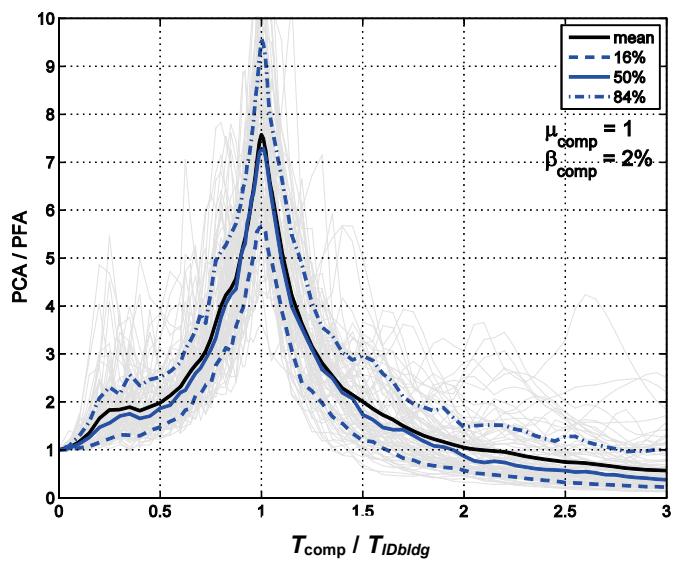

(a)

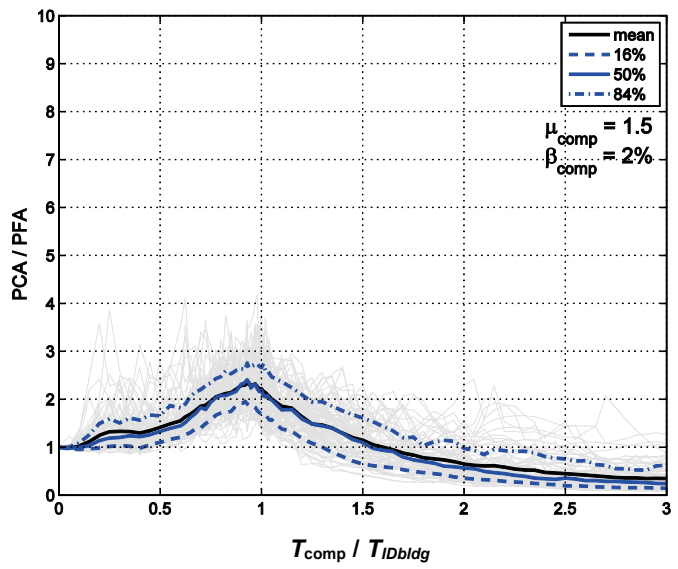

(c)

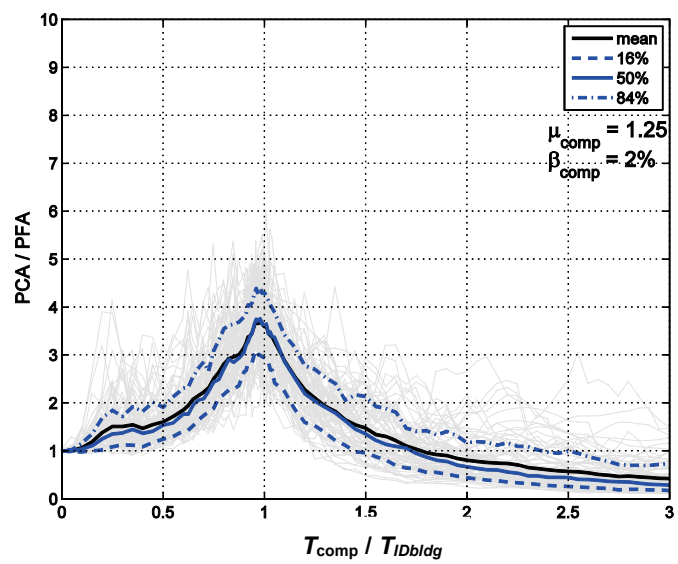

(b)

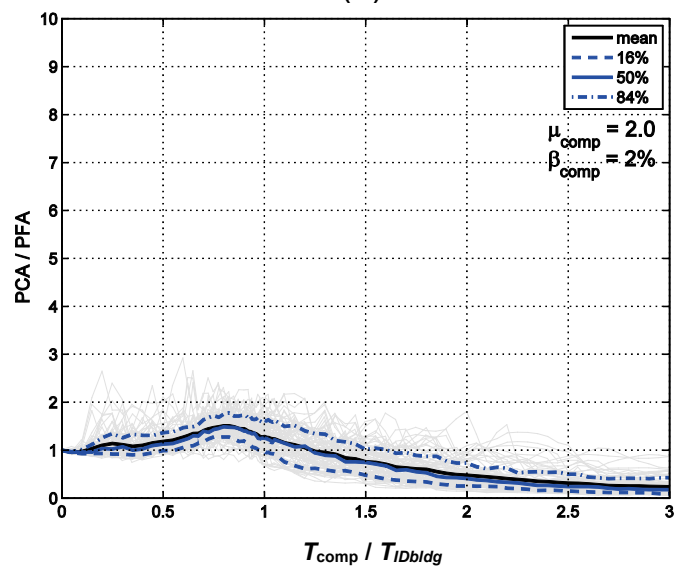

(d)

Figure C-10 Comparison of PCA/PFA versus $T_{\text {comp }} / T_{\text {IDbldg }}$ for different levels of component ductility for Group 1 records. Figure (a) is an elastic component $\mu_{\text {comp }}=1$; (b) is for $\mu_{\text {comp }}=1.25$; (c) is for $\mu_{\text {comp }}=1.5$; and (d) is for $\mu_{\text {comp }}=2$. $\beta_{\text {comp }}=2 \%$ inherent component damping is assumed. 


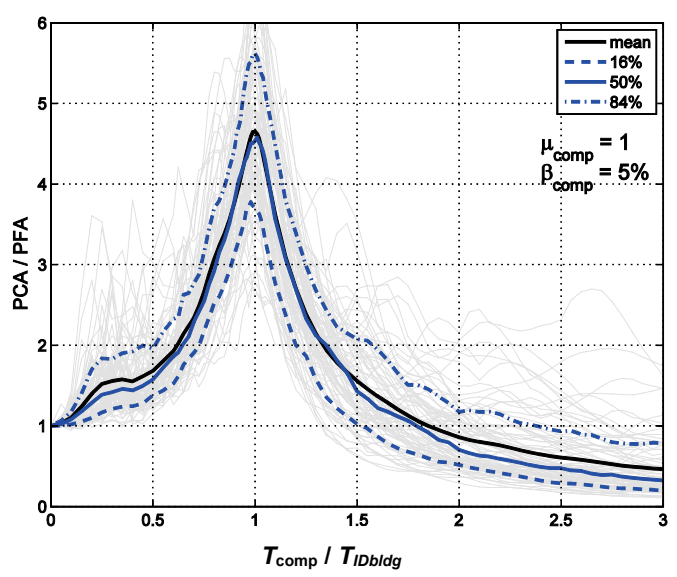

(a)

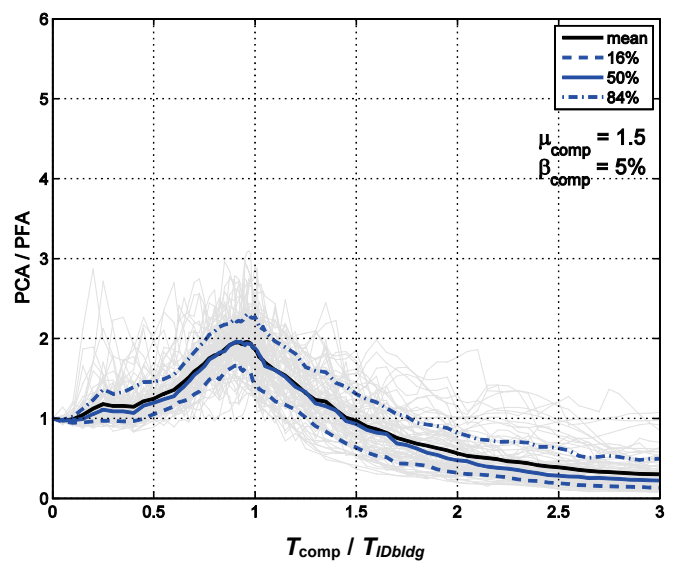

(c)

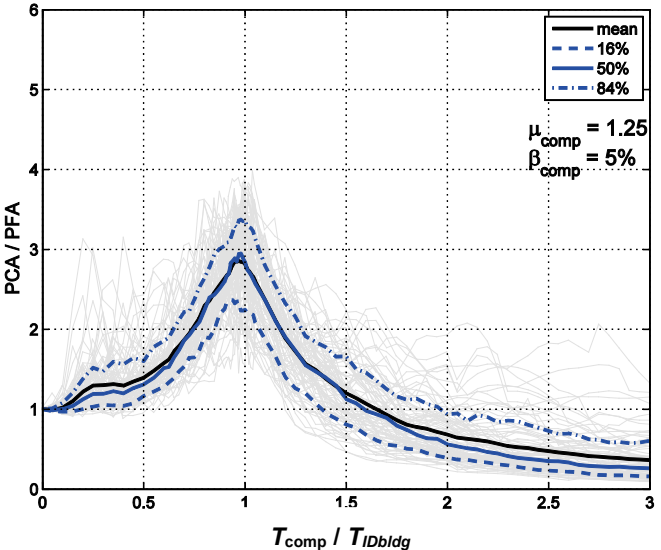

(b)

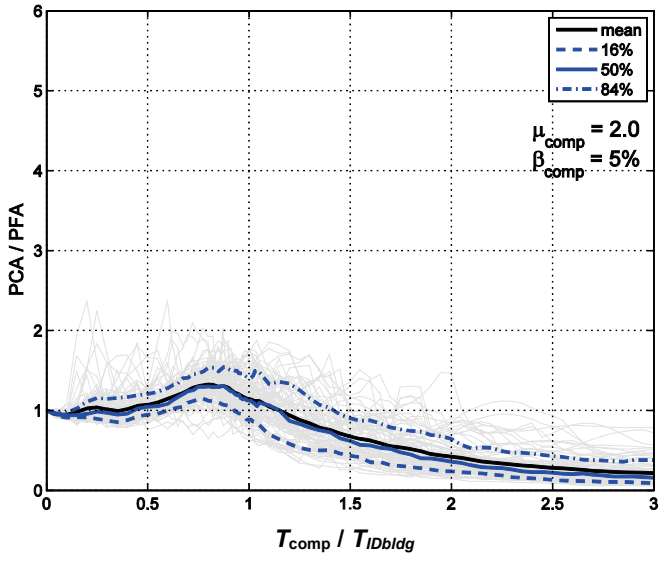

(d)

Figure C-11 Comparison of PCA/PFA versus $T_{\text {comp }} / T_{\text {IDbldg }}$ for different levels of component ductility for Group 1 records. Figure (a) is an elastic component $\mu_{\text {comp }}=1$; (b) is for $\mu_{\text {comp }}=1.25$; (c) is for $\mu_{\text {comp }}=1.5$; and (d) is for $\mu_{\text {comp }}=2$. $\beta_{\text {comp }}=5 \%$ inherent component damping is assumed.

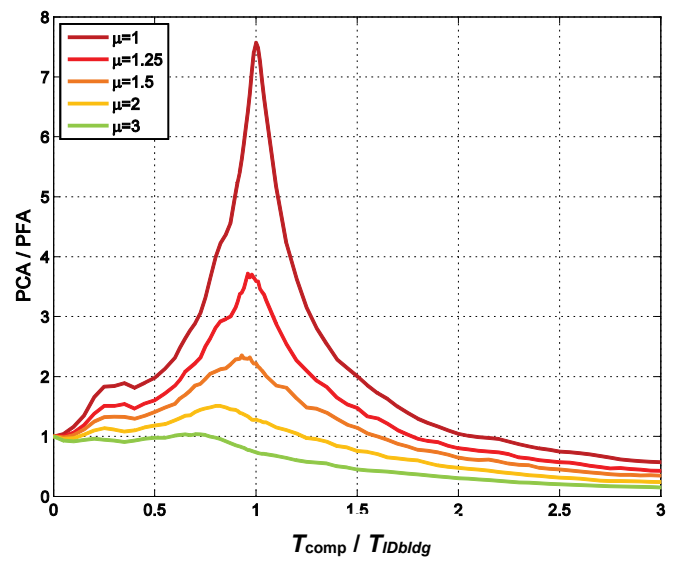

(a)

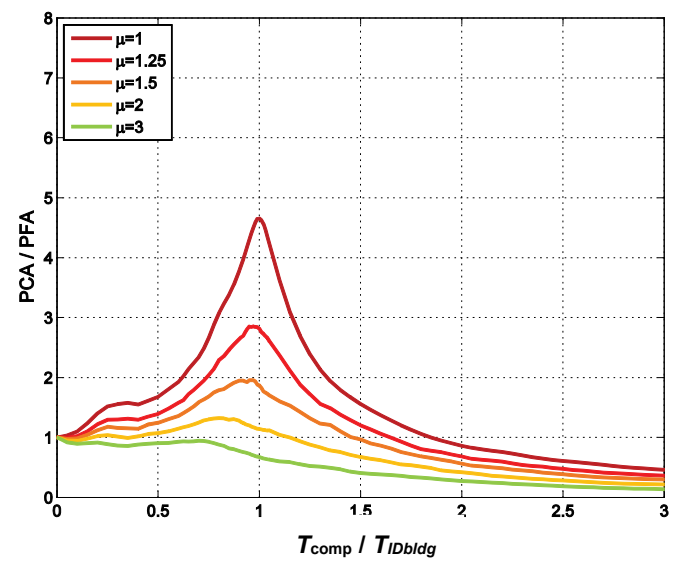

(b)

Figure C-12 Comparison of mean response of PCA/PFA versus $T_{\text {comp }} / T_{\text {IDbldg }}$ for different levels of component ductility for Group 1 records. Figure (a) $\beta_{\text {comp }}=2 \%$ inherent component damping; (b) is for $\beta_{\text {comp }}=5 \%$. 
Figure $\mathrm{C}-13$ shows the ratio of component response to that of an elastic response at different levels of component ductility at $T_{\text {comp }} / T_{\text {bldg }}=1$ resonance.f This ratio is proportional to PCA/PFA. Reductions from elastic response are 0.6 at $\mu_{\text {comp }}=1.25$, 0.4 at $\mu_{\text {comp }}=1.5$, and 0.25 at $\mu_{\text {comp }}=2$. Figure C-13 is reproduced in Chapter 4 as Figure 4-25.

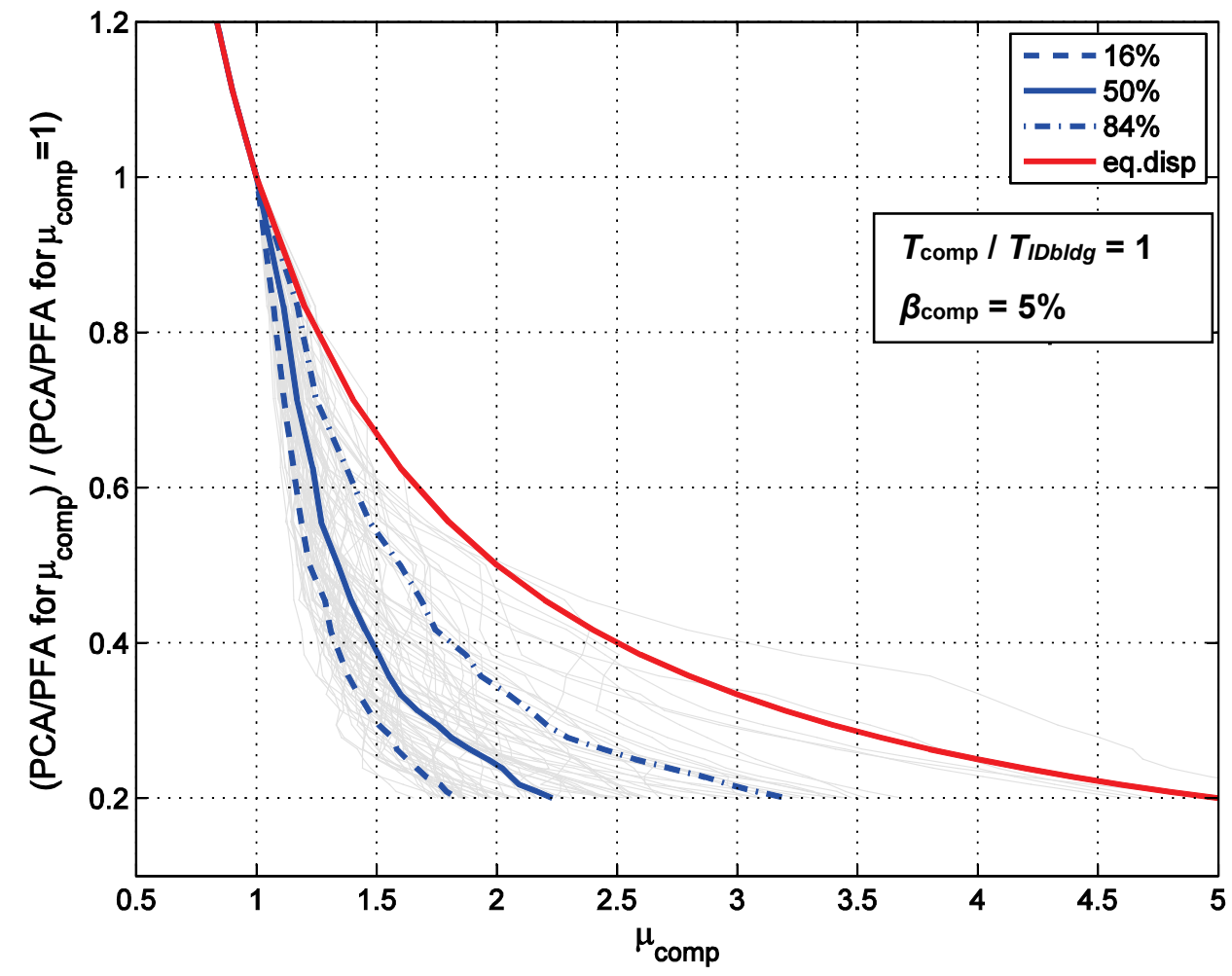

Figure $\mathrm{C}-13$ Reduction in PCA/PFA response for a component tuned to the building's fundamental period $\left(T_{\text {comp }}=T_{\text {IDbldg }}\right)$ with varying levels of component ductility for Group 1 records. $\beta_{\text {comp }}=5 \%$ inherent component damping is assumed.

\section{C.5 Conclusions}

The studies summarized in this appendix show the importance of normalizing the $\mathrm{x}$-axis by the ratio component period by building period in the PCA/PFA spectra, the effects of component damping on response, and the significant reductions in component response near $T_{\text {comp }} / T_{\text {bldg }}$ resonance provided by component ductility. They were used to help develop the proposed nonstructural design equations in Chapter 4. 



\section{Glossary}

This glossary compiles a select list of key terms that are used in this report, with a primary focus on those found in Chapter 4 and Appendices B and C. See Chapter 4 and Appendices $\mathrm{B}$ and $\mathrm{C}$ for more information on the terms.

$F_{p} \quad=$ horizontal design force for nonstructural component

$I_{p} \quad=$ component Importance Factor, per ASCE/SEI 7-16

PCA = peak component acceleration

PFA = peak floor acceleration

PGA = peak ground acceleration

$R \quad=$ reduction modification coefficient in ASCE/SEI 7-16 Table 12.2-1

$R_{\mu b l d g}=$ reduction factor to account for building global ductility $=$ $\left(R_{D}\right)^{1 / 2}=\left(1.1 R / \Omega_{0}\right)^{1 / 2}$

$R_{p} \quad=$ component response modification factor

$R_{\text {pocomp }}=$ inherent component reserve strength margin factor. A value of 1.3 is used as a placeholder.

$S_{D S} \quad=5 \%$ damped design spectral response acceleration at short periods $(0.2$ seconds) per ASCE/SEI 7-16 and USGS at the project site

SFRS = seismic force-resisting system of the building

$T_{\text {abldg }}=$ the approximate fundamental translational period of the building per ASCE/SEI 7-16 Equation 12.8-7

$T_{\text {bldg }} \quad=$ the period for fundamental or first horizontal translational mode of the building in the direction of interest

$T_{\text {comp }}=$ component period

$T_{\text {IDbldg }}=$ the resonant (dominant) period for horizontal translational modes of the building in the direction of interest as determined by system identification on recorded motions. When the fundamental or first horizontal translational mode is the resonant period, $T_{I D b l d g}$ is the same as $T_{I I D b l d g}$.

$T_{n b l d g}=$ the period for $n$-th horizontal translational mode of the building in the direction of interest, such as $T_{I b l d g}, T_{2 b l d g}$. Note that $T_{1 b l d g}$ is the same as $T_{\text {bldg }}$ 


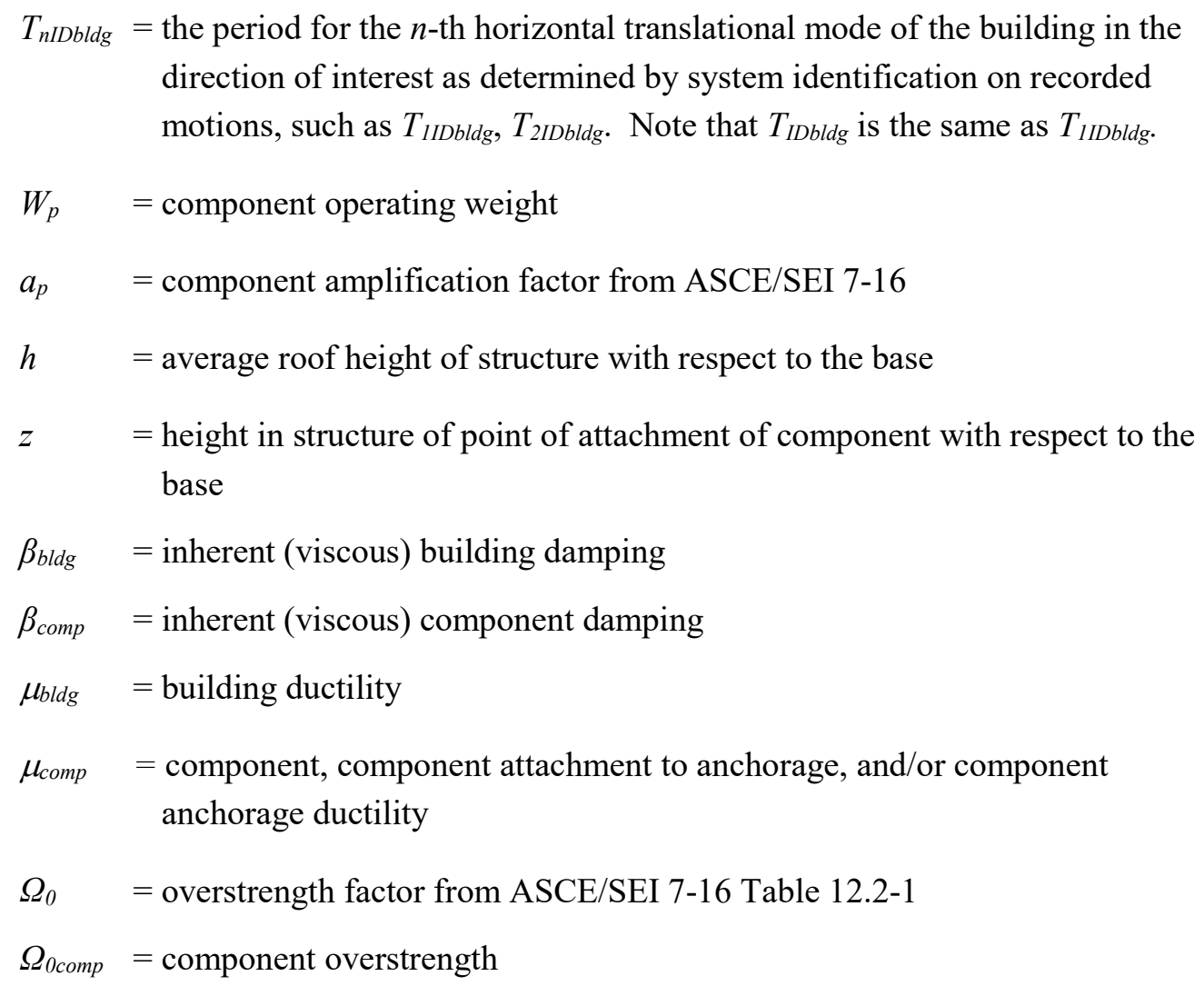




\section{References}

ACI, 2007, Qualification of Post-Installed Mechanical Anchors in Concrete and Commentary, ACI 355.2, American Concrete Institute, Farmington Hills, Michigan.

ACI, 2011, Building Code Requirements for Structural Concrete and Commentary, ACI 318-11, American Concrete Institute, Farmington Hills, Michigan.

ACI, 2014, Building Code Requirements for Structural Concrete and Commentary, ACI 318-14, American Concrete Institute, Farmington Hills, Michigan.

Adam, C., and Furtmüller T., 2008, "Response of nonstructural components in ductile load-bearing structures subjected to ordinary ground motions," Proceedings of the 14th World Conference on Earthquake Engineering, Beijing, China.

Adam, C., Furtmüller, T., and Moschen, L., 2013, "Floor response spectra for moderately heavy nonstructural elements attached to ductile frame structures," Computational Methods in Earthquake Engineering, pp. 69-89.

AISC, 1997, Seismic Provisions for Structural Steel Buildings, AISC 341, American Institute of Steel Construction, Chicago, Illinois.

AISC, 2016, Seismic Provisions for Structural Steel Buildings, AISC 341, American Institute of Steel Construction, Chicago, Illinois.

Al Atik, L., and Abrahamson, N., 2010, “An improved method for nonstationary spectral matching," Earthquake Spectra, Vol. 26, No. 3, pp. 601-617.

Alonso-Rodríguez, A., and Miranda, E., 2016, "Dynamic behavior of buildings with non-uniform stiffness along their height assessed through coupled flexural and shear beams," Bulletin of Earthquake Engineering, Vol. 14, No. 12, pp. 3463-3483.

Anajafi, H., 2018, Improved Seismic Design of Non-structural Components (NSCs) and Development of Innovative Control Approaches to Enhance the Seismic Performance of Buildings and NSCs, Ph.D. Thesis, University of New Hampshire. 
Anajafi, H., and Medina, R., 2018a, "Lessons learned from evaluating the responses of instrumented buildings in the US: the effect of supporting building characteristics on floor response spectra," Earthquake Spectra, in press.

Anajafi, H., and Medina, R., 2018b, "Uncertainties in using the spectrum matching technique for generating synthetic ground motions," Proceedings of the 11th National Conference in Earthquake Engineering, Earthquake Engineering Research Institute, Los Angeles, California.

Anajafi, H., and Medina, R., 2018c, "Effects of supporting building characteristics on nonstructural component acceleration demands," Proceedings of the 11th National Conference in Earthquake Engineering, Earthquake Engineering Research Institute, Los Angeles, California.

Anajafi, H., and Medina, R., 2018d, "Evaluation of ASCE 7 equations for designing acceleration-sensitive nonstructural components using data from instrumented buildings," Earthquake Engineering and Structural Dynamics, Vol. 47, No. 4, pp. 1075-1094.

ANSI/AHRI, 2015, Requirements for Seismic Qualification of HVACR Equipment, Standards 1270 (I-P) and 1271 (SI), Air Conditioning, Heating, and Refrigeration Institute, Arlington, Virginia.

ASCE, 2002, Minimum Design Loads for Buildings and Other Structures, ASCE/SEI 7-02, Structural Engineering Institute of American Society of Civil Engineers, Reston, Virginia.

ASCE, 2005, Minimum Design Loads for Buildings and Other Structures, ASCE/SEI 7-05, Structural Engineering Institute of American Society of Civil Engineers, Reston, Virginia.

ASCE, 2010, Minimum Design Loads for Buildings and Other Structures, ASCE/SEI 7-10, Structural Engineering Institute of American Society of Civil Engineers, Reston, Virginia.

ASCE, 2013, Minimum Design Loads for Buildings and Other Structures, ASCE/SEI 7-10 including Supplement No. 1, Structural Engineering Institute of American Society of Civil Engineers, Reston, Virginia.

ASCE, 2014, Seismic Evaluation and Retrofit of Existing Buildings, ASCE/SEI

41-13, Structural Engineering Institute of American Society of Civil Engineers, Reston, Virginia.

ASCE, 2017a, Minimum Design Loads and Associated Criteria for Buildings and Other Structures, ASCE/SEI 7-16, Structural Engineering Institute of American Society of Civil Engineers, Reston, Virginia. 
ASCE, 2017b, Seismic Evaluation and Retrofit of Existing Buildings, ASCE/SEI

41-17, Structural Engineering Institute of American Society of Civil Engineers, Reston, Virginia.

ASME, 2007, Safety Code for Elevators and Escalators, ASME A17.1, American Society of Mechanical Engineers, New York, New York.

ASME, 2014, Standards for Pressure Piping, ASME B31, American Society of Mechanical Engineers, New York, New York.

ASME, 2015, Boiler and Pressure Vessel Code, ASME BPVC, American Society of Mechanical Engineers, New York, New York.

Astroza, R., Pantoli, E., Selva, F., Restrepo, J., Hutchinson, T., and Conte, J., 2015, "Experimental evaluation of the seismic response of a rooftop-mounted cooling tower," Earthquake Spectra, Vol. 31, No. 3, pp. 1567-1589.

ATC, 1978, Tentative Provisions for the Development of Seismic Regulations for Buildings, ATC-3-06, Applied Technology Council, Redwood City, California.

ATC, 1989, Procedures for Postearthquake Safety Evaluation of Buildings, ATC-20, Applied Technology Council, Redwood City, California.

Bachman, R. and Dowty, S., 2008, "Nonstructural components or nonbuilding structures?," Building Safety Journal, April-May.

Bernal, D., Dohler, M., Kojidi, S. M., Kwan, K., and Liu, Y., 2015, "First mode damping ratio for buildings," Earthquake Spectra, Vol. 31, No. 1, pp. 367-381.

Calvi, P., and Sullivan, T., 2014, "Estimating floor spectra in multiple degree of freedom systems," Earthquakes and Structures, Vol. 7, No. 1.

CEN, 2004, Eurocode 8 - Design Provisions for Earthquake Resistant Structures, EN-1998-1:2004, Comite Europeen de Normalization, Brussels, Belgium.

Chaudhuri, S. R., and Villaverde, R., 2008, "Effect of building nonlinearity on seismic response of nonstructural components: a parametric study," Journal of Structural Engineering, Vol. 134, No. 4, pp. 661-670.

Chopra, A., 2012, Dynamics of Structures: Theory and Applications to Earthquake Engineering, Fourth Edition, Prentice Hall.

Clough, R.W., and Johnston, S.B., 1966, "Effect of stiffness degradation on earthquake ductility requirements," Proceedings of the Second Japan National Conference on Earthquake Engineering, Japan. 
Cruz, C. and Miranda, E., 2016, "Evaluation of damping ratios for the seismic analysis of tall buildings," Journal of Structural Engineering, Vol. 143, No. 1 .

CSI, 2017, Integrated Finite Element Analysis and Design of Structures, SAP2000 v19.0, Computers and Structures, Inc., Berkeley, California.

Fathali, S., and Lizundia, B., 2011a, Evaluation of ASCE/SEI 7Equations for Seismic Design of Nonstructural Components Using Strong Motion Records, prepared for the California Strong Motion Instrumentation Program, California Geological Survey, California Department of Conservation, Data Interpretation Project Agreement 1008.

Fathali, S., and Lizundia, B., 2011b, "Evaluation of current seismic design equations for nonstructural components in tall buildings using strong motion records," The Structural Design of Tall and Special Buildings, Vol. 20, No. S1, pp. 30-46.

Filiatrault, A., and Sullivan, T., 2014, "Performance-based seismic design of nonstructural building components: The next frontier of earthquake engineering," Earthquake Engineering and Engineering Vibration, Vol. 13, No. 1, pp. 17-46.

FEMA, 1995, NEHRP Recommended Provisions for Seismic Regulations for New Buildings, FEMA 222A, 1994 Edition, prepared by the Building Seismic Safety Council for the Federal Emergency Management Agency, Washington, D.C.

FEMA, 1997, NEHRP Guidelines for the Seismic Rehabilitation of Buildings, FEMA 273, prepared by the Applied Technology Council for the Building Seismic Safety Council and the Federal Emergency Management Agency, Washington, D.C.

FEMA, 1998, NEHRP Recommended Provisions for Seismic Regulations for New Buildings and Other Structures, FEMA 302, 1997 Edition, prepared by the Building Seismic Safety Council for the Federal Emergency Management Agency, Washington, D.C.

FEMA, 2001, NEHRP Recommended Provisions for Seismic Regulations for New Buildings and Other Structures, FEMA 369, prepared by the Building Seismic Safety Council for the Federal Emergency Management Agency, Washington, D.C.

FEMA, 2004, NEHRP Recommended Provisions for Seismic Regulations for New Buildings and Other Structures, Part 2: Commentary, FEMA 450-2, prepared by the Building Seismic Safety Council for the Federal Emergency Management Agency, Washington, D.C. 
FEMA, 2009a, Quantification of Building Seismic Performance Factors, FEMA P695 Report, prepared by the Applied Technology Council for the Federal Emergency Management Agency, Washington, D.C.

FEMA, 2009b, NEHRP Recommended Seismic Provisions for New Buildings and Other Structures, FEMA P-750, 2009 Edition, prepared by the Building Seismic Safety Council of the National Institute of Building Sciences for the Federal Emergency Management Agency, Washington, D.C.

FEMA, 2015a, Performance of Buildings and Nonstructural Components in the 2014 South Napa Earthquake, FEMA P-1024, prepared by the Applied Technology Council for the Federal Emergency Management Agency, Washington, D.C.

FEMA, 2015b, NEHRP Recommended Seismic Provisions for New Buildings and Other Structures, Volume 1: Part 1 Provisions, Part 2 Commentary, FEMA P-1050-1, 2015 Edition, prepared by the Building Seismic Safety Council of the National Institute of Building Sciences for the Federal Emergency Management Agency, Washington, D.C.

FEMA, 2015c, NEHRP Recommended Seismic Provisions for New Buildings and Other Structures, Volume 2: Part 3 Resource Papers, FEMA P-1050-2, prepared by the Building Seismic Safety Council of the National Institute of Building Sciences for the Federal Emergency Management Agency, Washington, D.C.

Goel, R., and Chopra, A., 1997, "Period formulas for moment-resisting frame buildings," Journal of Structural Engineering, Vol. 123, No. 11, pp. 14541461, November.

Goel, R., and Chopra, A., 1998, "Period formulas for concrete shear wall buildings," Journal of Structural Engineering, Vol. 124, No. 4, pp. 426-433.

Gupta, A. and Krawinkler, H., 1999, Seismic Demands for Performance Evaluation of Steel Moment Resisting Frame Structures, Report No. 132, the John A. Blume Earthquake Engineering Center, Stanford University, Stanford, California.

ICBO, 1927, Uniform Building Code, International Conference of Building Officials, Long Beach, California.

ICBO, 1976, Uniform Building Code, International Conference of Building Officials, Whittier, California.

ICBO, 1988, Uniform Building Code, International Conference of Building Officials, Whittier, California. 
ICBO, 1991, Uniform Building Code, International Conference of Building Officials, Whittier, California.

ICBO, 1997, Uniform Building Code, International Conference of Building Officials, Whittier, California.

ICC, 2009, 2009 International Building Code, International Code Council, Washington, D.C.

ICC, 2012, 2012 International Building Code, International Code Council, Washington, D.C.

ICC, 2015a, 2015 International Building Code, International Code Council, Washington, D.C.

ICC, 2015b, 2015 International Fire Code, International Code Council, Washington, D.C.

ICC, 2018, 2018 International Building Code, International Code Council, Washington, D.C.

ICC-ES, 2015, Seismic Certification by Shake-Table Testing of Nonstructural Components, ICC-ES AC156, ICC Evaluation Service, Country Club Hills, Illinois.

Jiang, W., Li, B., Xie W-C., and Pandey, M., 2015, “Generate floor response spectra: Part 1. Direct spectra-to-spectra method," Nuclear Engineering and Design, Vol. 293, pp. 525-546.

Johnson, T., and Dowell, R., 2017, "Evaluation of the overstrength factor for nonstructural component anchorage into concrete via dynamic shaking table tests," Journal of Building Engineering, Vol. 11, pp. 205-215.

Johnson, T., Dowell, R., and Silva, J., 2018, "Recommendations for $\Omega_{0}$ for anchorage into concrete for floor-mounted nonstructural components," Journal of Structural Engineering, Vol. 144, No. 2.

Kazantzi, A., Vamvatsikos, D., and Miranda, E., 2018, "The effect of yielding on the seismic demands of nonstructural elements," Proceedings of the 16th European Conference on Earthquake Engineering, Thessaloniki, Greece.

Lus, H., Betti, R., Longman, R., 1999, "Identification of linear structural systems using earthquake-induced vibration data," Earthquake Engineering and Structural Dynamics, Vol. 28, No. 11, pp. 1449-1467.

Mander, J., Priestley, M, and Park, R., 1988, "Theoretical stress-strain model for confined concrete," ASCE Journal of Structural Engineering, Vol. 114, No. 8, pp. 1804-1826.

Mazzeo, S., 2018, Personal communication, May. 
Miranda, E., 1993, "Site-dependent strength reduction factors," Journal of Structural Engineering, American Society of Civil Engineers, Reston, Virginia, Vol. 119, No. 12, pp. 3503-3519.

Miranda, E., and Taghavi, S., 2009, “A comprehensive study of floor acceleration demands in multi-story buildings," ATC \& SEI 2009 Conference on Improving the Seismic Performance of Existing Buildings and Other Structures, San Francisco, California.

Miranda, E., Kazantzi, A., and Vamvatsikos, D., 2018, “Towards a new approach to design acceleration-sensitive non-structural components," Proceedings of the 11th National Conference in Earthquake Engineering, Earthquake Engineering Research Institute, Los Angeles, California.

Miranda, E., Kazantzi, A., and Vamvatsikos, D., 2018, "New approach to the design of acceleration-sensitive non-structural elements in buildings," Proceedings of the 16th European Conference on Earthquake Engineering, Thessaloniki, Greece.

MSS, 2002, Pipe Hangers and Supports - Materials, Design, and Manufacture, MSS SP-58, Manufacturers Standardization Society of the Valve and Fittings Industry, Vienna, Virginia.

Naeim, F., 2004, "Impact of the 1994 Northridge earthquake on the art and practice of structural engineering," The Structural Design of Tall and Special Buildings, Vol. 13, No. 5, pp. 373-389.

Nagae, T., Tahara, K., Taizo, M., Shiohara, H., Kabeyasawa, T., Kono, S., Nishiyama, M., Wallace, J. W., Ghannoum, W. M., Moehle, J. P., Sause, R., Keller, W., and Tuna, Z., 2011, Design and Instrumentation of the 2010 EDefense Four-Story Reinforced Concrete and Post-Tensioned Concrete Buildings, 2011/104, Pacific Earthquake Engineering Research Center (PEER), Berkeley, California.

NFPA, 2016, Standard for the Installation of Sprinkler Systems, NFPA 13, National Fire Protection Association, Quincy, Massachusetts.

NIST, 2013, Development of NIST Measurement Science R\&D Roadmap: Earthquake Risk Reduction in Buildings, NIST GCR 13-917-23, prepared by the Building Seismic Safety Council for the National Institute of Standards and Technology, Gaithersburg, Maryland.

NIST, 2016, Community Resilience Planning Guide for Buildings and Infrastructure Systems, NIST Special Publication 1190, National Institute of Standards and Technology, Gaithersburg, Maryland. 
NIST, 2017, Seismic Analysis, Design, and Installation of Nonstructural Components and Systems - Background and Recommendations for Future Work, NIST GCR 17-917-44, prepared by the Applied Technology Council for the National Institute of Standards and Technology, Gaithersburg, Maryland.

NIST, 2018, Research needs to Support Immediate Occupancy Building Performance Objective Following Natural Hazard Events, NIST Special Publication 1224, National Institute of Standards and Technology, Gaithersburg, Maryland.

NRC, 2015, National Building Code of Canada, National Research Council Canada. NZS, 2004a, Structural Design Actions Part 5: Earthquake Actions - New Zealand, prepared by Technical Committee BD-006-04-11, Earthquake Loadings in New Zealand under Joint Committee BD-006, General Design Requirements and Loadings on Structures, Standards New Zealand, Ministry of Business, Innovation \& Employment, Wellington.

NZS, 2004b, Structural Design Actions Part 5: Earthquake Actions - New Zealand Commentary, prepared by Technical Committee BD-006-04-11, Earthquake Loadings in New Zealand under Joint Committee BD-006, General Design Requirements and Loadings on Structures, Standards New Zealand, Ministry of Business, Innovation \& Employment, Wellington.

Obando, J., and Lopez-Garcia, D., 2016, "Inelastic displacement ratios for nonstructural components subjected to floor accelerations," Journal of Earthquake Engineering, Vol. 22, No. 4.

PCI, 2017, PCI Design Handbook, $8^{\text {th }}$ Edition, Precast/Prestressed Concrete Institute, Chicago, Illinois.

Perrone, D., and Filiatrault, A., 2017, "Use of building information modelling for the automated seismic design of non-structural elements," Journal of Automation in Construction, Vol. 84, pp. 166-175.

Ray-Chaudhuri, S., and Hutchinson, T., 2011, "Effect of nonlinearity of frame buildings on peak horizontal floor acceleration," Journal of Earthquake Engineering, Vol. 15, No. 1, pp. 124-142.

Reyes, J., Riaño, A., Kalkan, E., Quintero, O., and Arango, C., 2014, “Assessment of spectrum matching procedure for nonlinear analysis of symmetric-and asymmetric-plan buildings," Engineering Structures, Vol. 72, pp. 171-181.

Ryan, K., Soroushian, S., Maragakis, E., Sato, E., Sasaki, T., and Okazaki, T., 2016, "Seismic simulation of an integrated ceiling-partition wall-piping system at E-Defense. I: Three-dimensional structural response and base isolation," Journal of Structural Engineering, Vol. 142, No. 2. 
Sankaranarayanan, R., and Medina, R., 2007, “Acceleration response modification factors for nonstructural components attached to inelastic moment-resisting frame structures," Earthquake Engineering and Structural Dynamics, Vol. 36, No. 14, pp. 2189-2210.

Sankaranarayanan, R., and Medina, R., 2008, "Statistical models for a proposed acceleration-response modification factor for nonstructural components attached to inelastic structures," Proceedings of the 14th World Conference on Earthquake Engineering, 14WCEE, Beijing, China.

SEAOC, 1974, Recommended Lateral Force Requirements and Commentary, Fourth Edition with Partial Commentary, Seismology Committee of the Structural Engineers Association of California, Sacramento, California.

SEAOC, 1996, Vision 2000: Performance Based Seismic Engineering of Buildings, Structural Engineers Association of California, Sacramento, California.

SEAOC, 1999, Recommended Lateral Force Requirements and Commentary, Seismology Committee of the Structural Engineers Association of California, Sacramento, California.

Seifried A., and Baker, J., 2016, "Spectral variability and its relationship to structural response estimated from scaled and spectrum-matched ground motions," Earthquake Spectra, Vol. 32, No. 4, pp. 2191-2205.

Sewell, R., Cornell, C., Toro, G., and McGuire, R., 1986, Study of Factors Influencing Floor Response Spectra in Nonlinear Multi-degree-of-freedom Structures, Technical Report 82, John A. Blume Earthquake Engineering Center, Stanford University.

Soroushian, S., Maragakis, E., Zaghi, A.E., Echevarria, A., Tian, Y., and Filiatrault, A., 2014, Comprehensive Analytical Seismic Fragility of Fire Sprinkler Piping Systems, Technical Report MCEER-14-0002, Multidisciplinary Center for Earthquake Engineering Research, University at Buffalo, New York.

SPUR, 2009, The Resilient City: Defining What San Francisco Needs from Its Seismic Mitigation Policies, San Francisco, California. Available at: https://www.spur.org/featured-project/resilient-city, last accessed July 12, 2018.

Sullivan, T., Calvi, P., and Nascimbene, R., 2013, "Towards improved floor spectra estimates for seismic design," Earthquakes and Structures, Vol. 1, pp. 109-132. 
Taghavi, S., and Miranda, E., 2005, Response assessment of nonstructural building elements, PEER Report 2003/05, Pacific Earthquake Engineering Research Center, College of Engineering, University of California Berkeley.

Taghavi, S., and Miranda, E., 2006, Probabilistic Seismic Assessment of Floor Acceleration Demands in Multi-Story Buildings, Technical Report 162, the John A. Blume Earthquake Engineering Center, Stanford University, Stanford, California.

Tian, Y., Filiatrault, A., and Mosqueda, G., 2013, Experimental Seismic Study of Pressurized Fire Sprinkler Piping Subsystems, Technical Report MCEER13-0001, Multidisciplinary Center for Earthquake Engineering Research, University at Buffalo, State University of New York, Buffalo.

TMS, 2011, Building Code Requirements and Specification for Masonry Structures and Related Commentaries, TMS 402-11/ACI 530-11/ASCE 5-11, Masonry Standards Joint Committee, American Concrete Institute, American Society of Civil Engineers, and The Masonry Society, Boulder, Colorado.

U.S. Department of Energy, 1997, Seismic Evaluation Procedure for Equipment in U.S. Department of Energy Facilities, DOE/EH-0545, Office of Defense Programs.

Vukobratović, V. and Fajfar, P., 2016, "A method for the direct estimation of floor acceleration spectra for elastic and inelastic MDOF structures," Earthquake Engineering \& Structural Dynamics, Vol. 45, pp. 2495-2511.

Vukobratović, V. and Fajfar, P., 2017, "Code-oriented floor acceleration spectra for building structures," Bulletin of Earthquake Engineering, Vol. 15, pp. 3013-3026.

Watkins, D., Chui, L., Hutchinson, T., and Hoehler M., 2010, Survey and Characterization of Floor and Wall Mounted Mechanical and Electrical Equipment in Buildings, Report No. SSRP-2009/11, Department of Structural Engineering, University of California, San Diego.

Welch, D., and Sullivan, T., 2017, "Illustrating a new possibility for the estimation of floor spectra in nonlinear multi-degree of freedom systems," Proceedings of the $16^{\text {th }}$ World Conference on Earthquake Engineering (16WCEE), Santiago, Chile, Paper Number 2632. 


\section{Project Participants}

National Institute of Standards and Technology

Steven L. McCabe

Engineering Laboratory (MS8604)

National Institute of Standards and Technology

100 Bureau Drive

Gaithersburg, Maryland 20899

\section{Applied Technology Council}

Jon A. Heintz (Program Manager)

Applied Technology Council

201 Redwood Shores Parkway, Suite 240

Redwood City, California 94065

\section{Program Committee on Seismic Engineering}

Jon A. Heintz (Chair)

Applied Technology Council

201 Redwood Shores Parkway, Suite 240

Redwood City, California 94065

Michael Cochran

Thornton Tomasetti

4551 Glencoe Avenue, Suite 350

Marina del Rey, California 90292

James R. Harris

J.R. Harris \& Company

1775 Sherman Street, Suite 1525

Denver, Colorado 80203

James Jirsa

Department of Civil, Architectural and

Environmental Engineering

University of Texas at Austin

301 E. Dean Keeton Street, Stop C1700

Austin, Texas 78712

Roberto Leon

Department of Civil and Environmental Engineering

Virginia Tech

102-D Patton Hall

Blacksburg, Virginia 24061
Matthew S. Hoehler

Engineering Laboratory (MS8662)

National Institute of Standards and Technology

100 Bureau Drive

Gaithersburg, Maryland 20899

Ayse Hortacsu (Associate Program Manager)

Applied Technology Council

201 Redwood Shores Parkway, Suite 240

Redwood City, California 94065

Stephen Mahin

Department of Civil and Environmental

Engineering

University of California, Berkeley

721 Davis Hall

Berkeley, California 94720

James O. Malley

Degenkolb Engineers

375 Beale Street, Suite 500

San Francisco, California 94105

Donald Scott

PCS Structural Solutions

811 First Avenue, Suite 620

Seattle, Washington 98104

Andrew Whittaker

Department of Civil, Structural and

Environmental Engineering

University at Buffalo

230 Ketter Hall

Buffalo, New York 14260 


\section{Project Technical Committee}

Maryann Phipps (Project Director)

Estructure

1144 65th Street, Suite A

Oakland, California 94608

John Gillengerten

Office of Statewide Health Planning and

Development (Retired)

1055 Rivermeade Drive

Hebron, Kentucky 41048

William T. Holmes

Consulting Structural Engineer

375 Beale St. Suite 310

San Francisco, California 94105

Bret Lizundia

Rutherford + Chekene

375 Beale St. Suite 310

San Francisco, California 94105

\section{Project Review Panel}

Robert Bachman (Chair)

R.E. Bachman Consulting

25152 La Estrada Drive

Laguna Niguel, California 92677

Andre Filiatrault

Department of Civil, Structural and Environmental Engineering

University at Buffalo

134 Ketter Hall

Buffalo, New York 14260

James R. Harris

J. R. Harris \& Company

1175 Sherman Street, Suite 2000

Denver, Colorado 80203

Michael Mahoney (ex officio)

Federal Emergency Management Agency

500 C Street, SW

Washington, DC 20472
Ricardo Medina

University of New Hampshire

33 Academic Way

Durham, New Hampshire 03824

Eduardo Miranda

Department of Civil and Environmental

Engineering

Stanford University

Yang and Yamazaki Energy and Environment

Bldg, Room 281

Stanford, California 94305

Robert Pekelnicky

Degenkolb Engineers

375 Beale St. Suite 500

San Francisco, California 94105

Shannon Rose

ISAT Seismic Bracing

42550 Albrae Street

Fremont, California 94538

Jeff Soulages

Intel Corporation

437 NE Hazelfern Place

Hillsboro, Oregon 97232

William Staehlin (ATC Board Contact)

14179 Copenhagen Drive

Truckee, California 96161

Chris Tokas

Office of Statewide Health Planning and

Development

400 R Street, Suite 200

Sacramento, California 95811 


\section{Working Group Members}

Hamidreza Anajafi

University of New Hampshire

33 Academic Way

Durham, New Hampshire 03824

Dago de la Rosa

Rutherford + Chekene

375 Beale St. Suite 310

San Francisco, California 94105

Athanasia Kazantzi

School of Civil Engineering; Metal Structures Laboratory

National Technical University of Athens

Athens, Greece 10682

David Lam

Degenkolb Engineers

375 Beale St. Suite 500

San Francisco, California 94105
Megan Leon

Estructure

1144 65th Street, Suite A

Oakland, California 94608

Matthew Namy

Degenkolb Engineers

375 Beale St. Suite 500

San Francisco, California 94105

Dimitrios Vamvatsikos

School of Civil Engineering; Metal Structures Laboratory

National Technical University of Athens

Athens, Greece 10682 